\title{
Ein Heer ist ein großes gefräßiges Tier
}

Soldaten in spanischen und kaiserlichen Diensten und die Bevölkerung der vom Krieg betroffenen Gebiete in Italien zwischen 1509 und 1530

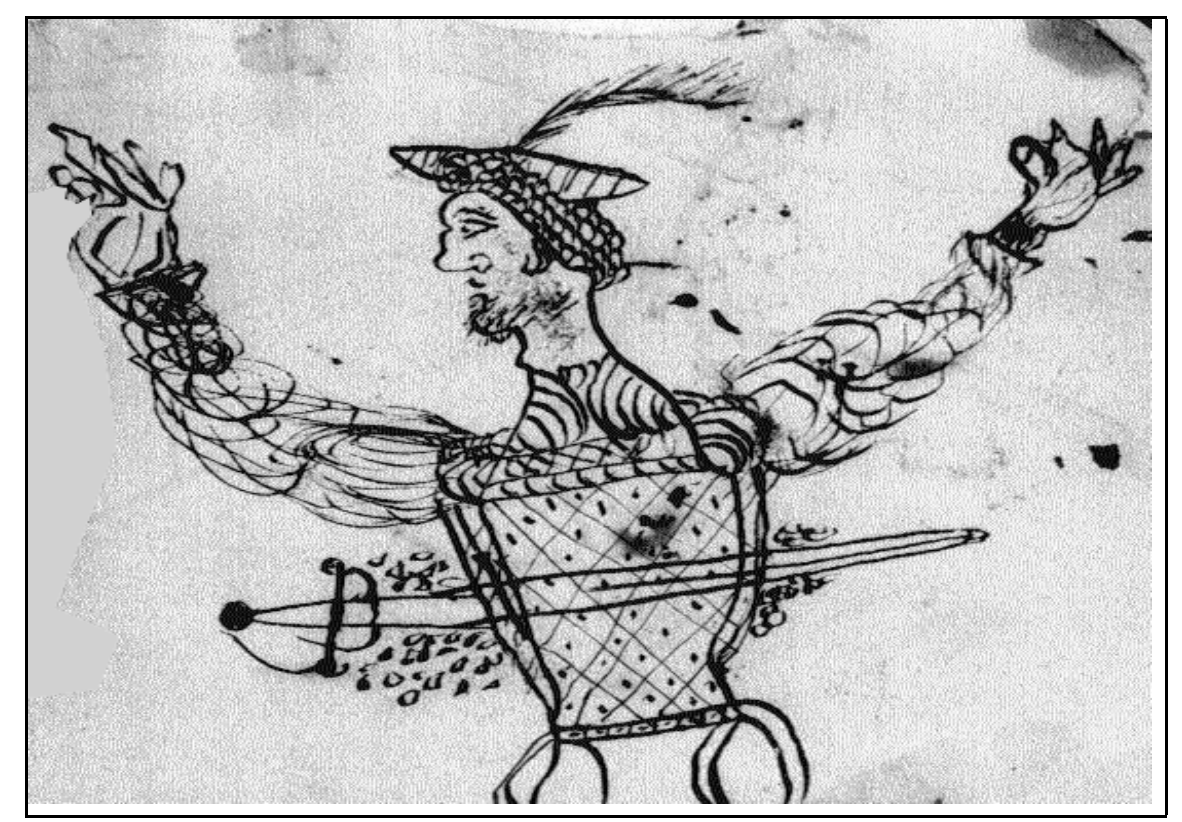

Dissertation zur Erlangung des Doktorgrades

der

philosophischen Fakultät

der

Georg-August-Universität Göttingen

\section{Michael Römling}


Diese Arbeit ist meinen Eltern gewidmet, in Dankbarkeit für die Kompromisslosigkeit ihrer Unterstützung, ihres Verständnisses und ihrer Liebe von Anfang an. 


\section{Inhalt}

Einleitung 5

Forschungsstand 9

Systematik der Quellen 13

I. Plünderung 20

A. Der Beutemarkt 23

\begin{tabular}{|lr}
1 1. Die Liste aus Pistoia & 25 \\
\hline 2. Ablufder Geschere & 28
\end{tabular}

\begin{tabular}{|rr}
\hline 2. Ablauf der Geschäfte & 28 \\
\hline
\end{tabular}

\begin{tabular}{|lr}
\hline 3. Ware & 32 \\
\hline . Preise & 36
\end{tabular}

\begin{tabular}{|lr}
\hline 4. Preise & 36 \\
\hline 5. Aunkăufer & 38 \\
\hline
\end{tabular}

\begin{tabular}{|lr}
\hline 5. Aufkäufer & 38 \\
\hline
\end{tabular}

B. Lösegelderpressung 41

\begin{tabular}{|lr}
\hline 1. Die Lösegelderklärungen aus Prato & 42 \\
\hline
\end{tabular}

\begin{tabular}{|lr}
\hline 2. Opfer und Täter & 46 \\
\hline
\end{tabular}

\begin{tabular}{|rr}
\hline 3. Gefangenschaft & 49 \\
\hline 4. Lösegelder & 52
\end{tabular}

\begin{tabular}{|lr}
\hline 4. Lösegelder & 52 \\
\hline
\end{tabular}

\begin{tabular}{lr}
\hline 5. Beschaffung und Bezahlung & 58 \\
\hline
\end{tabular}

\begin{tabular}{lr}
\hline C. Der Sacco di Roma & 63 \\
\hline l. Schurzmaßnamana
\end{tabular}

\begin{tabular}{|lc}
\hline 1. Schutzmaßnahmen & 66 \\
\hline 2. Die Plünderung & 68 \\
\hline
\end{tabular}

\begin{tabular}{|rr}
\hline 2. Die Plünderung & 68 \\
\hline 3. Beute und & 600 segelder \\
\hline
\end{tabular}

\begin{tabular}{|rr}
\hline 3. Beute und Lösegelder & 75 \\
\hline Besetzte Häuser & 83 \\
\hline
\end{tabular}

\begin{tabular}{|rr}
\hline 4. Besetzte Häuser & 83 \\
\hline
\end{tabular}

II. Charakteristik des Krieges 86

\begin{tabular}{lr}
\hline A. Demografische Auswirkungen & 87 \\
\hline
\end{tabular}

\begin{tabular}{lr}
\hline 1. Flucht und Abwanderung & 89 \\
\hline
\end{tabular}

\begin{tabular}{lr}
\hline 2. Maßnahmen der Militärs & 97 \\
\hline
\end{tabular}

\begin{tabular}{lr}
\hline B. Krieg auf dem Land & 100 \\
\hline l. Auf & $10 m$ Masch
\end{tabular}

\begin{tabular}{ll} 
1. Auf dem Marsch & 101 \\
\hline
\end{tabular}

\begin{tabular}{|rr}
\hline 2. Verteilung im Land & 107 \\
\hline
\end{tabular}

\begin{tabular}{|cc}
\hline 3. Auspressung der Bauern & 112 \\
\hline. & 118
\end{tabular}

\begin{tabular}{|rr}
\hline 4. Gegenwehr und Vergeltung & 118 \\
\hline
\end{tabular}

\begin{tabular}{lr}
\hline 5. Verbindungswege & 120 \\
\hline
\end{tabular} 


\begin{tabular}{lr|}
\hline C. Söldnerheere & 125 \\
\hline 1. Söldnerwesen & 126 \\
\hline 2. Auszahlung des Soldes & 128 \\
\hline 3. Deserteure, Uberläufer und Verräter & 139 \\
\hline 4. Ungehorsam, Anarchie und Meuterei & 146 \\
\hline 5. Wiederherstellung der Disziplin & 151 \\
\hline 6. Nationalitätenkonflikte & 155 \\
\hline
\end{tabular}

III. Besetzte Städte 159

\begin{tabular}{lr|}
\hline A. Einquartierungen in Mailand & 160 \\
\hline \begin{tabular}{lr} 
1. Organisation der Einquartierungen \\
\hline 2. Lebensmittelversorgung
\end{tabular} & 161 \\
\hline 3. Lebensmittelpreise & 176 \\
\hline 4. Belastung der Haushalte & 175 \\
\hline B. Leben mit der Besatzung & 184 \\
\hline 1. Sicherung der Herrschaft & 186 \\
\hline . Miliärische Erfordernisse & 189 \\
\hline 3. Alltag & 192 \\
\hline 4. Übergriffe & 199 \\
\hline 5. Persönliche Bindungen & 205 \\
\hline 6. Allgegenwart des Todes & 210 \\
\hline 7. Die Aufstände in Mailand & 213 \\
\hline & 219 \\
\hline Zusammenfassung & 226 \\
\hline Abkürzungen & 227 \\
\hline Bibliografie & \\
\hline
\end{tabular}

Anhänge

I. Nummerierung der Beuteliste 245

II. Kurzbiografien 246

III. Karten 252 


\section{Einleitung}

Als Spanien im Jahr 1509 der Liga von Cambrai beitrat, war damit neben Frankreich eine weitere außeritalienische Macht an diesem Bündnis beteiligt, mit deren Soldaten man in Italien in den Jahren zuvor bereits Bekanntschaft gemacht hatte: so wie Frankreich sich in Mailand etabliert hatte, herrschten die Spanier in Neapel. Gemeinsam mit Papst und Kaiser brachen sie nun zu einem Verwüstungsfeldzug gegen die Republik Venedig auf, der kurz darauf, als die Sieger ihrerseits übereinander herfielen, nach ganz Norditalien ausgriff. In der Folgezeit wurden vor allem die venezianische Terraferma und die Lombardei immer wieder von fremden Soldaten überschwemmt: Franzosen kamen von Westen, Spanier von Süden, Schweizer von Norden und Deutsche von Osten auf den Kriegsschauplatz. Die italienischen Staaten wurden mehr und mehr zu Statisten in den Konflikten, die die europäischen Mächte in ihrem Land austrugen; die diplomatischen Konstellationen und damit die Zusammensetzung der Heere wechselten häufig, während die Bevölkerung der vom Krieg heimgesuchten Gebiete wegen des akuten Geldmangels aller Beteiligten von feindlichen und verbündeten Soldaten gleichermaßen ausgepresst wurde. Schließlich trat 1516 mit dem Friedensschluss von Noyon vorübergehend Ruhe ein, aber als der spanische König drei Jahre später den deutschen Kaiserthron bestieg, bekam der Konflikt eine neue Dimension: Frankreich auf der einen Seite und der habsburgische Machtkomplex auf der anderen kristallisierten sich als Hauptgegner in einem bevorstehenden Kampf um die Vorherrschaft in Europa heraus, der wiederum vor allem in Italien ausgetragen werden sollte. Als der Krieg 1521 erneut ausbrach, konzentrierten sich die Anstrengungen beider Seiten fast ausschließlich auf das Herzogtum Mailand als Schlüssel zur Macht in Italien. Mailand und mehr noch die anderen Städte der Lombardei wechselten oft den Besitzer, die italienischen Potentaten und schließlich sogar der Papst kämpften als Anhängsel der einen oder der anderen Seite ums Überleben. Dazu kam es immer wieder auch zu Übergriffen auf benachbarte Gebiete, weil die durch Krieg, Hungersnot und Epidemie entvölkerte Lombardei die großen Heere kaum noch versorgen konnte. Eigenmächtige Plünderungen von marodierenden Soldaten waren überall an der Tagesordnung. Der chaotische Zug des kaiserlichen Heeres im Frühjahr 1527 nach Rom bezeichnet in zweierlei Hinsicht den dramatischen Höhepunkt dieser Entwicklung: noch zu Beginn des Krieges hatte der Kaiser die Unterstützung des Papstes in Italien mit der Verurteilung Luthers erkauft, nun erniedrigten protestantische Landsknechte in den Diensten desselben Kaisers einen Nachfolger desselben Papstes in für die Zeitgenossen unerhörter Weise, gleichzeitig kam es zu Gewaltexzessen gegen die Bevölkerung, die jedes bekannte Maß überschritten. In der Lombardei schleppte sich der Krieg noch einige Jahre dahin, bevor er schließlich mit dem Untergang des vorläufig letzten französischen Heeres unweit von Mailand im Sommer 1529 erlosch. Kurz darauf wurde, wiederum in 
Cambrai, ein Frieden geschlossen, durch den Spanien endgültig zur dominierenden Macht in Italien wurde, während die Lombardei und ihre Nachbargebiete nach mehr als zwanzig Jahren Krieg wirtschaftlich und moralisch am Boden lagen.

Den politischen und diplomatischen Hintergründen der Ereignisse dieser Zeit sowie den militärischen Aktionen und ihren Köpfen sind viele Studien gewidmet worden. Da die Korrespondenz der Herrscher und ihrer Diplomaten in zahllosen Dokumenten überliefert ist und der größte Teil der vielgestaltigen Masse an vor Ort entstandenen Quellen die Schilderung des Krieges in seinen militärischen Einzelheiten in den Vordergrund stellt, beschränken sich diese Studien zumeist auf die Nacherzählung von Ereignissen aus der Vogelperspektive und in sauberer chronologischer Reihung. Auf diese Weise lassen sich die einzelnen Kriegszüge mit den Zahlenstärken der Heere und den Aufenthaltsorten der Protagonisten bis auf den Tag genau rekonstruieren, darüber hinaus aber machen die meisten dieser Arbeiten kaum Aussagen. Dazu kommt die Begünstigung des Spektakulären. Schlachten und Eroberungen, Taten einzelner Persönlichkeiten, deren Schilderung in erster Linie den Ruhm des Betreffenden mehren soll, verstellen die Sicht auf die Masse der Beteiligten und verzerren das Bild schließlich auch wieder in chronologischer Hinsicht: wird der Schilderung einer eintägigen Schlacht mehr Platz eingeräumt als den vorangehenden und nachfolgenden Monaten relativer militärischer Tatenlosigkeit, so entsteht der Eindruck eines Ereignisvakuums vor und nach der Schlacht, das aber eben nur in militärischer Hinsicht ein solches ist. Diese Perspektive ist nicht nur durch das Interesse der Historiker vor allem des 19. Jahrhunderts begründet, sondern wird auch durch die erdrückende Überrepräsentation von Persönlichkeiten aus Politik, Diplomatie und Militär unter den Urhebern der Überlieferung begünstigt.

Da nun die Geschichte der Ereignisse in den italienischen Kriegen zwischen 1509 und 1530 aus dieser Perspektive seit beinahe einem Jahrhundert annähernd vollständig geschrieben ist, nimmt diese Arbeit eine andere, am entgegengesetzten Ende der sozialen und militärischen Hierarchie angesiedelte Perspektive ein: der Krieg soll aus der Sicht der breiten Masse seiner Beteiligten beschrieben werden, und zwar sowohl aus der Sicht der Soldaten, genauer gesagt, der Soldaten in den Diensten Spaniens und des Kaisers, als auch der Bevölkerung in den Gebieten, die jene durchzogen und in denen sie sich niederließen. Der Schwerpunkt liegt dabei auf den vielfältigen Berührungspunkten zwischen Soldaten und Bevölkerung, und nicht auf den Ursachen und Umständen militärischer Konfrontationen. Denn der Hunger war nicht weniger bohrend, nur weil die Saat im Zuge eines geschickten Manövers zertrampelt worden war, und für die Bewohner einer geplünderten Stadt war es zweitrangig, ob es Franzosen oder Spanier waren, die ihre Türen eintraten, die Truhen leerten und ihre Kinder als Geiseln verschleppten. Für die Handwerker und Kaufleute in Mailand machte es keinen Unterschied, wer die Schlacht von Pavia gewann, solange die Präsenz 
einer riesigen Masse von spanischen, deutschen, französischen, schweizerischen und italienischen Soldaten ihnen gleichermaßen das Geschäft ruinierte und manchmal auch belebte daher hat der Ausgang der Schlacht von Pavia für die Ergebnisse dieser Arbeit genausowenig Bedeutung wie die meisten der anderen hinreichend geschilderten Kriegstaten, die nur wieder politische, diplomatische und militärische, aber für die Masse der Beteiligten zunächst kaum gesellschaftliche Konsequenzen nach sich zogen. Diese Arbeit, so könnte man es auf den Punkt bringen, beschreibt die Phänomene, die den Alltag einer vom Krieg betroffenen Gesellschaft prägten, wobei mit Krieg in erster Linie allein die Anwesenheit der Soldaten im Land gemeint ist. Auch dieser Alltag konnte durchaus von spektakulären Ereignissen heimgesucht werden, die aber hier vor allem insoweit von Interesse sind, wie sie ihrerseits auf den Alltag zurückwirkten. Das folgende Schema gibt einen groben Überblick über alle Arten von Beziehungen zwischen den beteiligten Gruppen, die für diese Arbeit von Interesse sind:

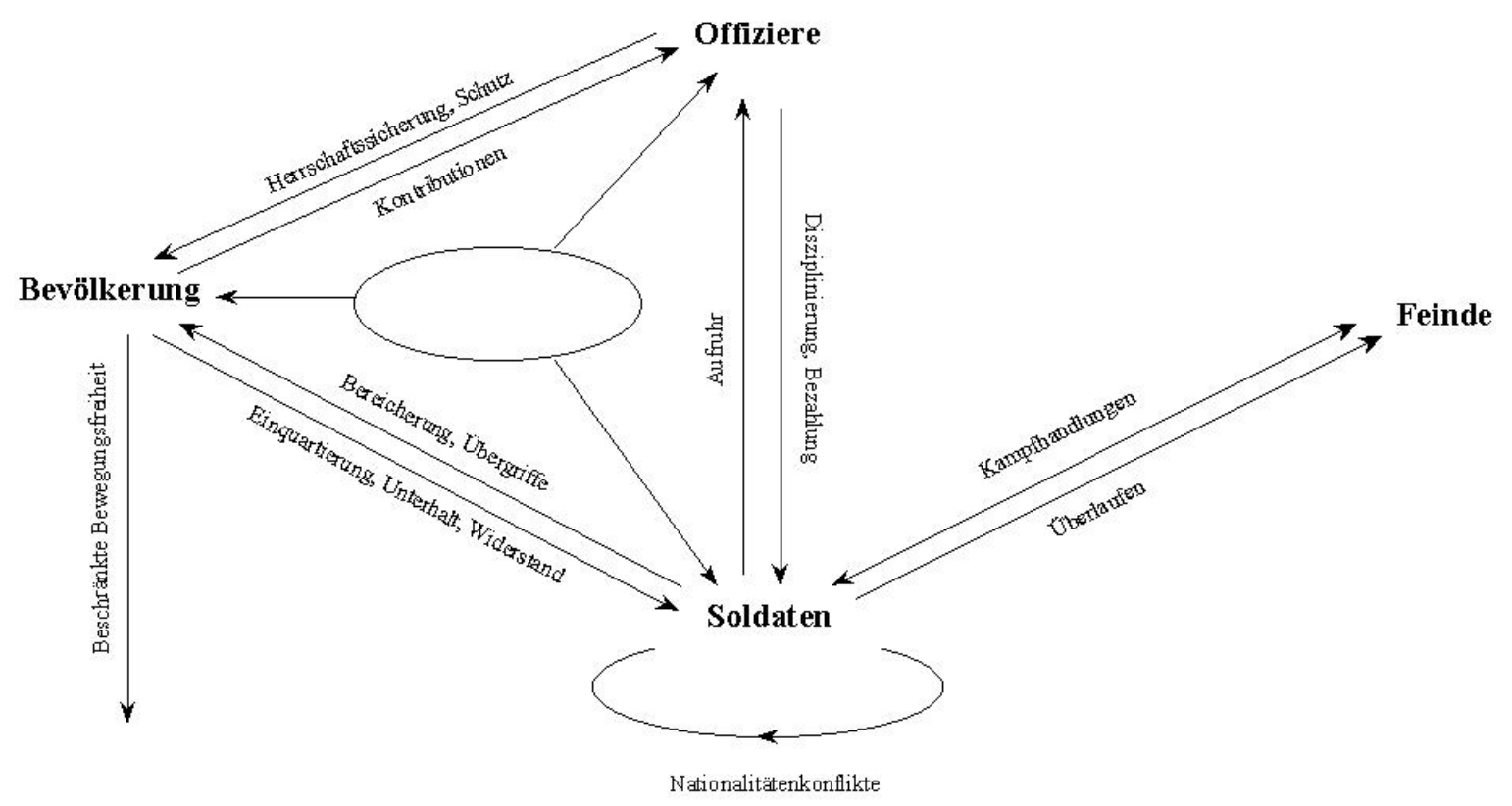

Für die Untersuchung wurden Quellen aus den Jahren 1509 bis 1530 von allen italienischen Kriegsschauplätzen herangezogen, auf denen spanische und kaiserliche Soldaten zu finden waren, mit Ausnahme des Königreichs Neapel, das zu dieser Zeit bereits nicht mehr als besetztes Gebiet, sondern als Bestandteil des spanischen Königreiches galt und von spanischen Vizekönigen regiert wurde. Die geografischen und chronologischen Schwerpunkte dieser Arbeit sind die Kriegsperiode von 1509 bis 1516 in der Terraferma und die von 1521 
bis 1529 in der Lombardei. Außerhalb dieses geografischen Rahmens liegen unter anderem die Plünderung von Prato im Jahr 1512 und der Sacco di Roma von 1527. Die Quellen, die beide Ereignisse hervorbrachten, sind von einmaliger Bedeutung für das Verständnis der Mechanismen von Plünderungen. Schließlich wurde auch die Belagerung von Florenz von 1529 bis 1530 berücksichtigt.

Die thematische Fokussierung auf spanische und kaiserliche Soldaten ist bedingt durch die Tatsache, dass diese beiden Gruppen den ganzen untersuchten Zeitraum hindurch kaum voneinander zu trennen sind. Die vertragliche Bindung von Spanien an das Reich in der ersten Kriegsperiode von 1509 bis 1516 brachte es mit sich, dass schon vor der Ankunft des ersten spanischen Heeres in Norditalien spanische Soldaten dort mit dem kaiserlichen Heer unterwegs waren, später operierten die kaiserlichen und spanischen Heere die meiste Zeit über gemeinsam. In der zweiten Kriegsperiode ab 1521 gab es wegen der Vereinigung der spanischen mit der Kaiserkrone dann nur noch ein Heer, in dem die Deutschen zahlenmäßig stärker vertreten waren als die Spanier. Abgesehen davon hatten sich auch zuvor schon zahlreiche italienische Soldaten in Begleitung der Spanier befunden, die entweder aus Neapel mit den spanischen Heeren nach Norden gespült worden waren oder sich diesen dort anschlossen, und zwar sowohl im Gefolge von verbündeten Potentaten, als auch aus eigenem Antrieb. So waren Spanier, Deutsche und Italiener die meiste Zeit über gemeinsam unterwegs.

Auch wenn einige der zu untersuchenden Beziehungen und Phänomene schwer in Zahlen zu fassen sind, soll dennoch so oft wie möglich versucht werden, eine Einschätzung ihrer Verbreitung zu geben. Die Quantifizierung auf Grund von Einzelaussagen ist in der Tat das quellenkritische Hauptproblem dieser Arbeit: immer wieder wird man mit Zahlen konfrontiert, die entweder übertrieben sind oder nur verstreut genannt werden und nicht freiwillig miteinander in Beziehung treten, vor allem in den Bereichen, in denen Zahlen eben eine zentrale Rolle spielen: bei den Lösegeldern und dem Verkauf von Plünderungsbeute, bei der Organisation der Einquartierungen, den Lebensmittelpreisen und den Soldrückständen. Solchen Verzerrungen soll in dieser Arbeit nach Möglichkeit entgegen getreten werden, wie auch der oben angesprochenen zeitlichen Verzerrung durch die Konzentration der Quellen und Darstellungen auf kurze, mit spektakulären Ereignissen angefüllte Perioden und auf zahlenmäßig kleine Gruppen, die die Spitze einer Gesellschaft darstellten, der der Krieg in ihren unteren Schichten auf viel breiterer Front seine Wunden schlug. 


\section{Forschungsstand}

Um die zweite Hälfte des 19. und zu Beginn des 20. Jahrhunderts erschien eine Reihe von Studien, die die Kriege der europäischen Staaten in Italien während des in dieser Arbeit behandelten Zeitraums zum Thema hatten, sowohl in Italien selbst, als auch in den Nachfolgestaaten der damals beteiligten Mächte - dort oft mit dem Ziel, die Taten der Vorfahren herauszustellen und die Ambitionen der jeweiligen Herrscher zu rechtfertigen und zu verteidigen. Neben einigen sehr umfangreichen Arbeiten, die sich mit der gesamten Epoche befassen, ${ }^{1}$ gibt es Einzeluntersuchungen in Hülle und Fülle über die militärischen Auseinandersetzungen. ${ }^{2}$ Am dichtesten konzentrieren sich die Arbeiten um die Schlacht von Pavia und den Sacco di Roma, und fast allen ist gemeinsam, dass sie sich vorwiegend politischen, diplomatischen und militärischen Fragen widmen und damit für die Zielsetzung dieser Arbeit weitgehend uninteressant sind. Die Arbeiten über den Sacco di Roma beschränken sich zumeist auf eine zusammenfassende Wiedergabe der bekanntesten Chroniken und der echten und vorgeblichen - Augenzeugenberichte. Die gründlichste Darstellung des Sacco und seiner Vorgeschichte aus der Sicht der Kaiserlichen liefert Schulz, ${ }^{3}$ solide ist ferner Gregorovius, ${ }^{4}$ der sich auf eine breite Quellenbasis stützt und durch sein geografisch eng begrenztes Interesse besser auf die betroffene Bevölkerung fokussieren kann als seine Kollegen, die mit dem Lichtkegel ihrer Untersuchungen den Heeren folgen.

1 Die wichtigsten unter ihnen: BALAN, PIETRO: Clemente VII e l'Italia dei suoi tempi. Mailand 1887. ClONARD, CONDE DE: Historia orgánica de las armas de infantería y caballería españolas, desde la creación del ejercito permanente hasta el día. Bd. 3. Madrid 1853. LEVA, GIUSEPPE DE: Storia documentata di Carlo V in correlazione all'Italia. Bd. 2. Venedig 1864. Mignet, M.: Rivalité de François $\mathrm{e}^{\mathrm{er}}$ et de Charles-Quint. Bd. 2. Paris 1875. MoIsè, FILIPPO: Storia dei dominii stranieri in Italia dalla caduta dell'Impero Romano in occidente fino ai nostri giorni. Bd. 4. Florenz 1843. Daneben zwei Werke, die sich mit mit den geistesgeschichtlichen und ansatzweise auch mit mentalitätsgeschichtlichen Fragestellungen des gesamten 16. Jahrhunderts befassen: Zum einen PICATOSTE, FELIPE: Estudios sobre la grandeza y decadencia de España. Los españoles en Italia. 2 Bde. Madrid 1887. Dieses Werk ist allerdings noch stark im Geist des 19. Jahrhunderts gefangen. Zum anderen CROCE, BENEDETTO: La Spagna nella vita italiana durante la Rinascenza. Bari 1917.

2 Um nur einige zu nennen: BARDI, AlESSANDro: Carlo V e l'assedio di Firenze. In: Archivio Storico Italiano. Serie 5, Bd. 11 (1893). S. 1-85. BerETtA, RinALDO: Gian Giacomo de' Medici in Brianza (15271531). In: Archivio Storico Lombardo 43 (1916). S. 53-120. RAVIOLI, CAMILLO: Le guerre dei sette anni sotto Clemente VII, assalto, presa e sacco di Roma, l'assedio e la perdita di Firenze dall'anno MDXXIII al MDXXXI sui documenti ufficiali. In: Archivio della Società romana di storia patria 6 (1883). SALVIOLI, GIUSEPPE: Nuovi studii sulla politica e le vicende dell' esercito imperiale in Italia nel 1526-27 e sul sacco di Roma da documenti inediti dell' Archivio di Stato di Modena. In: Archivio Veneto 9. (1879). S. 1-34. SCHÖNHERR, DAVID: Der Krieg Kaiser Maximilians I. mit Venedig 1509. Wien 1879. UlmanN, H.: Aus deutschen Feldlagern während der Liga von Cambrai. In: Deutsche Zeitschrift für Geschichtswissenschaft 2 (1889). S. 346-380. VIRgILI, A.: Dopo la battaglia di Pavia. In: Archivio Storico Italiano, Serie 5, Bd. 6. (1890) VIRGILI, A.: Otto giorni avanti alla battaglia di Pavia. In: Archivio Storico Italiano, Serie 5, Bd. 4 (1889). ZANETTI, PoLIBIO: L'assedio di Padova dell'anno 1509 in correlazione alla guerra combattuta nel Veneto dal maggio all'ottobre. Venedig 1891.

3 SchUlZ, Hans: Der Sacco di Roma. Karls V. Truppen in Rom 1527-1528. Halle 1894.

4 Gregorovius, FERDINAND: Storia della città di Roma nel Medio Evo. 6 Bde. Rom 1901. 
Die zahlreichen Arbeiten über Stadt und Herzogtum Mailand behandeln den hier interessanten Zeitraum von 1521 bis 1529 äußerst stiefmütterlich, weil er im epochemäßigen Niemandsland zwischen der Herrschaft der Sforza, der französischen Besatzung und der endgültigen Übernahme des Staates durch die Spanier angesiedelt ist: fast alle Studien über das Mailand der Sforza laufen in eine abschließende und zusammenfassende Beschreibung des Krieges und der Aktivitäten des glücklosen Herzogs Francesco II. in seinen letzten Jahren aus, während die Arbeiten über das Mailand der Spanier erst mit seinem Tod sechs Jahre nach dem Ende der hier behandelten Besatzungszeit einsetzen, so dass vor allem deren letzte Jahre von 1527 bis 1529 in der Geschichtsschreibung geradezu ein Schwarzes Loch darstellen. Indessen ist es gerade die Tatsache der ungeklärten Herrschaftsverhältnisse in Mailand, die diese Zeit so exemplarisch für das Leben einer Gesellschaft macht, die den Krieg fast täglich zu spüren bekam. Eine Ausnahme auf weiter Flur ist hier vor allem die gründliche Arbeit über das Herzogtum Mailand von Formentini. ${ }^{5}$ Vereinzelte Informationen vermitteln ferner einige der mehr oder weniger umfangreichen Studien über einzelne Städte in allen betroffenen Gebieten.

Da die mililtärgeschichtlichen Fragestellungen in den älteren Arbeiten fast vollständig abgegrast worden sind, werden solche Untersuchungen im 20. Jahrhundert seltener. Neuere umfangreiche Studien sind fast allen größeren und auch einigen kleineren Städten gewidmet, befassen sich aber vor allem mit strukturellen Fragen aus den Bereichen von Wirtschaft und Gesellschaft. Die Reihe der Arbeiten über den Sacco di Roma reißt nicht ab. Hook $^{6}$ bringt einige neue Quellen ins Spiel, Lenzi ${ }^{7}$ gibt verschiedene Deutungen der Geschichtsschreibung wieder, grundsätzlich bieten beide allerdings nichts Neues über die Beziehungen zwischen Bevölkerung und Soldaten, die hier von Interesse sind. Vollständig geistesgeschichtlich orientiert ist die Arbeit von Gouwens, ${ }^{8}$ der sich mit der Deutung der Plünderung Roms durch vier Humanisten befasst; Chastel $^{9}$ untersucht den Sacco vom Standpunkt des Kunsthistorikers aus. Dem von Orano ${ }^{10}$ schon vor 100 Jahren beklagten Fehlen der "storia interna" des Sacco di Roma und der sich anschließenden Besatzungszeit wird allerdings bald Abhilfe geschaffen werden, eine umfassende Arbeit dazu, die sich vor allem mit dem wirtschaftlichen und sozialen Leben der besetzten Stadt befasst, ist in Vorbereitung. ${ }^{11}$ Schon Cadenas y Vicent hat für die Plünderungen von Rom ${ }^{12}$ und Prato ${ }^{13}$ eini-

\footnotetext{
FORMENTINI, MARCO: Il ducato di Milano. Studi storici documentati. Mailand 1877.

HOOK, JUDITH: The Sack of Rome. London 1972.

LENZI, MARIA LUDOVICA: Il sacco di Roma del 1527. Florenz 1978.

Gouwens, KENNETH: Remembering the Renaissance. Humanist Narratives of the Sack of Rome. Brill's Studies in Intellectual History 85. Leiden 1998.

9 CHASTEL, ANDRÉ: The sack of Rome. Princeton 1983.

10 Orano, Domenico: Il Sacco di Roma del 1527. Studi e documenti. Bd. 1. Rom 1901. S. 10.

11 Wichtige Hinweise verdanke ich Anna Esposito und Manuel Vaquero Piñero, die seit Jahren auf diesem Gebiet arbeiten.

12 CADENAS Y Vicent, ViCEnTE DE: El saco de Roma de 1527 por el ejército de Carlos V. Madrid 1974.

13 CAdenas Y ViCENT, ViCEnTE DE: El saco de Prato, la primera reposición de los Medicis en Florencia y la
} 
ge interessante und wegweisende Fragen aufgeworfen, bleibt aber mit der Beantwortung zurück, und das obwohl ihm vor allem im Fall von Prato die einmaligen archivalischen Quellen bekannt waren, die eine systematische Untersuchung der Auswirkung von Plünderung und Lösegelderpressung auf das Leben der einfachen Einwohner gestatten. Untersuchungen über vom Krieg betroffene Städte sparen fast immer die Soldaten aus, während die Arbeiten über die Soldaten die Bewohner der von diesen heimgesuchten Länder vernachlässigen. Eine vorbildliche Ausnahme ist die Arbeit über den Krieg im Gebiet von Cremona von Bonetti. ${ }^{14}$ Daneben gibt es einige für das Verständnis des Verhaltens der Soldaten wichtige jüngere Studien, und zwar über die Landsknechte von Baumann, ${ }^{15}$ Möller ${ }^{16}$ und Burschel ${ }^{17}$ und über die Spanier von Quatrefages. ${ }^{18}$ In einem zeitlich sehr weit gefassten Rahmen befasst sich darüber hinaus Redlich ${ }^{19}$ mit dem Phänomen der Plünderung und Er$\operatorname{ler}^{20}$ mit der Lösegelderpressung.

Schließlich gibt es einige Untersuchungen aus jüngerer Zeit, die wegweisend für die vorliegende Arbeit sind: hier ist vor allem ein gerade erschienenes Werk von Wette über den dort so bezeichneten "Krieg des kleinen Mannes" zu nennen, das chronologisch zwar erst nach dem hier untersuchten Zeitraum einsetzt, aber einige beispielhafte Sudien über die gewöhnlichen Soldaten zusammenfasst. Wette postuliert eine "exemplarische Idividualisierung des 'kleinen Mannes' in der Uniform des Soldaten, der sich so oft ... in der Doppelrolle des Täters und Opfers befand" und stellt fest: "Wir leisten der konkreten Wahrheit über den Krieg einen Dienst, wenn wir dem unbekannten Soldaten sein Gesicht und seinen Namen wiedergeben." ${ }^{21}$ Einige allgemeinere Arbeiten über die Zusammenhänge zwischen Krieg und Gesellschaft waren vorausgegangen. ${ }^{22}$ Noch ein paar Jahre früher war eine in dieser Richtung vorbildliche Studie von $\operatorname{Esch}^{23}$ über die schweizerischen Söldner in der Lombar-

14 presencia de España en el Milanesado. Madrid 1982.

14 Bonetti, CARLO: Cremona durante le guerre di predominio straniero (1499-1526). Biblioteca Storica Cremonese 9. Cremona 1939.

15 BAUMANN, REINHARD: Das Söldnerwesen im 16. Jahrhundert im bayerischen und süddeutschen Beispiel. Eine gesellschaftsgeschichtliche Untersuchung. München 1978; BAUMANN, REINHARD: Landsknechte. Ihre Geschichte und Kultur vom späten Mittelalter bis zum Dreißigjährigen Krieg. München 1994.

16 MÖller, HANS-MichaEL: Das Regiment der Landsknechte. Untersuchung zu Verfassung, Recht und Selbstverständnis in deutschen Söldnerheeren des 16. Jahrhunderts. Wiesbaden 1976.

17 BURSCHEL, PETER: Söldner im Nordwestdeutschland des 16. und 17. Jahrhunderts. Sozialgeschichtliche Studien. Veröffentlichungen des Max-Planck-Instituts für Geschichte 113. Göttingen 1994.

18 QuATREFAGES, RENÉ: La Revolución militar moderna. El crisol español. Madrid 1996.

19 REDLICH, FRITZ: De praeda militari. Looting and booty 1500-1815. Beiheft 39 der Vierteljahresschrift für Sozial- und Wirtschaftsgeschichte. Wiesbaden 1956.

20 ERLER, ADALBERT: Der Loskauf Gefangener. Ein Rechtsproblem seit drei Jahrtausenden. Berlin 1978.

21 Wette, Wolfram: Militärgeschichte von unten. Die Perspektive des "kleinen Mannes". In: Der Krieg des kleinen Mannes. Eine Militärgeschichte von unten. Hrsg. v. Wolfram Wette. München 1999. S. 14.

22 Vor allem folgende: HALE, JOHN R.: War and Society in Renaissance Europe. London 1985. LENZI, MARIA LUDOVICA: La pace strega. Guerra e società in Italia dal XIII al XVI secolo. Montepulciano 1988. LENZI, MARIA LUDOVICA: L'Italia e l'Europa nella prima metà del Cinquecento. In: Storia della società italiana. Bd. 9: I secoli del primato italiano: il Cinquecento. Hrsg. v. Gianfranco Berardi u. a. Mailand 1989.

23 ESCH, ARNOLD: Mit Schweizer Söldnern auf dem Weg nach Italien. Das Erlebnis der Mailänderkriege 
dei zwischen 1510 und 1515 erschienen. Konsequent wird hier die "persönliche Perspektive gewöhnlicher Teilnehmer" ${ }^{24}$ eingenommen und alle Möglichkeiten der bezeichnenderweise als "Unnütze Papiere" katalogisierten Quellen ausgeschöpft, um ein Bild des Krieges in seinen Auswirkungen auf die einfachen Menschen nachzuzeichnen, die an ihm teilnahmen und unter ihm litten, und zwar sowohl exemplarisch an Hand von Einzelschicksalen als auch immer wieder quantifizierend. In dieser Untersuchung zeichnen sich darüber hinaus die quellenkritischen Probleme ab, die sich auch der vorliegenden Arbeit stellen, nämlich vor allem die Notwendigkeit einer sorgfältigen Gewichtung der einzelnen Aspekte unter Berücksichtigung des Quellenvorkommens, mit anderen Worten: die Bewusstmachung dessen, was Esch in einer anderen Arbeit die "Umverteilung der Wirklichkeit durch die Überlieferung" ${ }^{25}$ nennt.

1510-1515 nach bernischen Akten. In: Quellen und Forschungen aus italienischen Archiven und Bibliotheken 70 (1985). S. 348-440.

24 EsCH, Mit Schweizer Söldnern, S. 350.

25 EsCH, ARNOLD: Überlieferungs-Chance und Überlieferungs-Zufall als methodisches Problem des Historikers. In: Historische Zeitschrift 240 (1985). S. 529-570. S. 534. 


\section{Systematik der Quellen}

Für ein weit gefasstes Thema wie das vorliegende ist die Quellenbasis naturgemäß außerordentlich breit. Gleichzeitig aber sinkt durch die Wahl der Perspektive eine erste Gruppe von Dokumenten, denen lange Zeit vor allem im Hinblick auf ihre Edition die größte Wichtigkeit beigemessen wurde, zur Bedeutungslosigkeit herab, wie die Korrespondenz der Monarchen und ihrer Diplomaten, die Bündnisse und Friedensschlüsse, mit einem Wort: alle weit ab vom Geschehen entstandenen Dokumente, deren Beziehung zu den Ereignissen vor Ort eine sehr abstrakte ist.

Die zweite Gruppe der mit Vorliebe edierten Dokumente, die Schlachtberichte und die Briefe der Offiziere mit den detaillierten Angaben über militärische Aktionen, sind dagegen für diese Arbeit schon weniger uninteressant, da zwischen den Zeilen und im Kielwasser der militärischen Informationen bisweilen sehr aufschlussreiche Details über die Situation der Bevölkerung mitgeliefert werden. Wenn etwa ein venezianischer Offizier nach einem Erkundungsritt in der Umgebung von Mailand an seine Vorgesetzten berichtet, die Spanier ließen vor der Stadtmauer alle Häuser abreißen, dann bedeutet das für die venezianischen Militärs, dass ein Angriff auf die Stadt wegen der mangelnden Deckung schwieriger wird, dies und nichts anderes will der Informant mitteilen. Gleichzeitig aber erfährt man auf diese Weise, dass ein nicht geringer Teil der Bevölkerung durch militärische Maßnahmen der Besatzer über Nacht obdachlos werden konnte.

Neben einer solchen Auswertung der bekannten Dokumente kommen als dritte Gruppe bisher stark vernachlässigte Quellen vermehrt zu Wort, die sich direkt oder indirekt, absichtlich oder unfreiwillig mit dem Krieg von unten befassen, und die zumeist aus der Feder von Einwohnern betroffener Städte, mitunter auch von Soldaten stammen. Allgemein gilt: je weiter man in der sozialen und militärischen Hierarchie absteigt, desto dünner sind die Quellen gesät, desto zufälliger wird die Überlieferung. Um einen besseren Überblick über die Masse der Dokumente zu gewährleisten, sollen die wichtigsten Quellen nach den Erfordernissen dieser Arbeit klassifiziert und vorgestellt werden. Eine vollständige Auflistung aller ungedruckten wie gedruckten Quellen befindet sich im bibliografischen Anhang.

Die wichtigste Basis für alle späteren Darstellungen sind traditionell die Werke der zeitgenössischen Chronisten, die zumeist schon zu ihrer Zeit gedruckt erschienen. Bei den Berichterstattern handelt es sich in der Regel um gut informierte Personen aus Politik und Diplomatie, und in diesen Bereichen liegt auch der Schwerpunkt der Darstellungen: Francesco Guicciardini $^{26}$ und Giovio ${ }^{27}$ geben in ihren bekannten Geschichtswerken den detaillierte-

26 GuiCCIARDINI, FrAnCESCO: Storia d'Italia. Hrsg. v. Alessandro Gherardi. 4 Bde. Florenz 1919.

27 GIOvio, PAOLO: Istorie del suo tempo. Übersetzt v. Lodovico Domenichi. 2 Bde. Venedig 1555. 
sten Überblick für den gesamten Zeitraum, Mocenigo ${ }^{28}$ für das venezianische Gebiet in der Zeit von 1509 bis 1516 und Capella ${ }^{29}$ für die Lombardei zwischen 1521 und 1530. Die umfangreichste Darstellung des Sacco di Roma stammt von Francesco Guicciardinis Bruder Luigi. ${ }^{30}$ Fast allen ist eine Schilderung der Ereignisse aus kühler Distanz gemeinsam, einzig Capella erweist sich als aufmerksamer Beobachter des an der Bevölkerung verübten Unrechts. Diesen und zahlreichen anderen Berichterstattern ist gemeinsam, dass sie oftmals in weit verbreiteten, selten hinterfragten und bisweilen religiös motivierten Vorstellungen sowie persönlichen Sympathien und Antipathien gefangen waren, weshalb diametral entgegengesetzte Meinungen oft nebeneinander bestanden.

Um sich ein besseres Bild vom Geschehen in einer geplünderten oder besetzten Stadt machen zu können, sind Augenzeugenberichte daher zumeist wesentlich aufschlussreicher. Solche Berichte existieren in zwei verschiedenen Formen: entweder sie wurden aus einer Überlieferungsabsicht heraus verfasst, oder sie beschreiben das Geschehen für zeitgenössische Adressaten, also in der Regel in Form von Briefen. Wieder ist es vor allem der Sacco di Roma, der die meisten Berichte für sich verbuchen kann, das liegt zum einen an der hohen Dichte von schreibkundigen Personen in der Stadt, zum anderen daran, dass die Plünderung in ihrem Ausmaß und in ihrer Heftigkeit einen erschütternden Eindruck hinterließ. Dieser wurde noch um die geradezu eschatologische Dimension erweitert, dass es ausgerechnet protestantische Landsknechte waren, die den Papst demütigten und die Kirchen entweihten. Zu keinem anderen Ereignis dieser Zeit - mit Ausnahme der Schlacht von Pavia - gibt es so viele gedruckte und ungedruckte Berichte. Das quellenkritische Problem bei den vielen Zeugnissen zum Sacco di Roma ist daher oftmals auch ein philologisches: die Berichte überlagern sich gegenseitig in einzelnen Informationen und teilweise auch im Wortlaut so sehr, dass an der Authentizität vieler unter ihnen mit Recht zu zweifeln ist. Einige der bekanntesten Berichte, die auch durch die Fußnoten vieler gelehrter Darstellungen spuken, wurden so im Nachhinein als später entstandene Kompilationen anderer Quellen entlarvt. ${ }^{31}$ Mit Sicherheit authentisch sind die bekannten und facettenreichen Berichte in den Erinnerungen von Alberini, ${ }^{32}$ Cave $^{33}$ Gumpenberg $^{34}$ und Grollier. ${ }^{35}$ Cellini, ${ }^{36}$ prominenter

28 Mocenigo, ANDREA: La guerra di Cambrai, fatta a' tempi nostri in Italia tra gli illustrissimi signori venetiani con tutti i prencipi di Christianita. Venedig 1562.

29 CAPElla, Galeazzo: Beschreibung und Geschicht deß Meylandischen kriegß / der vom ein und zwentzigsten biß in das dryssigest fast by zechen Jar lang geweret hat / inn welcher schynbarlich ursach und ursprung / wie der Krieg entstanden / mit was anschlegen der selbig angehept / fürgenommen / verhandlet / und wie yedes geendet habe / erlütret wirt. Übers. v. Wenzelslaus Lincken. Bern 1539.

30 GUICCIARDINI, LUIGI: Il sacco di Roma. In: Il sacco di Roma del MDXXVII. Narrazioni di contemporanei. Hrsg. v. Carlo Milanesi. Florenz 1867. S. 1-244.

31 Die beiden bekanntesten unter ihnen sind: ROSSI, PATRIZIO DE': Memorie storiche dei principali avvenimenti politici d'Italia seguiti durante il Ponteficato di Clemente VII. Hrsg. v. G. T. Rom 1837; sowie BUONAPARTE, JACOPO: Ragguaglio storico. Köln 1756. Diesem Werk ist im übrigen eine eigene philologische Untersuchung gewidmet: BARDINI, MARCO: Borbone occiso. Studi sulle tradizioni storiografiche del sacco di Roma del 1527. Pisa 1991.

32 Alberini, Marcello: Ricordi. In: Domenico Orano (Hrsg.): Il Sacco di Roma del 1527. Studi e documenti, Bd. 1. Rom 1901. 
Augenzeuge der Ereignisse, stellt die Schilderung des Sacco vor allem in den Dienst seiner eigenen Heldenlegende und vermittelt glaubwürdige Informationen daher eher zwischen den Zeilen. Weitere kürzere Berichte gibt es - gedruckt und ungedruckt - in größerer Zahl bis hin zu Fragmenten, zum Teil als Randnotizen an zeitgenössischen Quellen ganz anderer Art, zum Teil eingebettet in Sammlungen von Berichten, deren größter Teil ediert ist. ${ }^{37}$ Überhaupt sind längere unedierte Schilderungen des Sacco di Roma wegen dessen ungebrochener Anziehungskraft auf weite Kreise und Generationen von Gelehrten sehr selten. ${ }^{38}$ Neben diesen Berichten gibt es eine Anzahl von sehr aufschlussreichen Briefen von Personen, die zur Zeit des Sacco in Rom anwesend waren. Der fleißigste Briefschreiber ist der kaiserliche Sekretär Juan Perez, der sich in Vertretung des abwesenden Botschafters während der ganzen Zeit der Besatzung in der Stadt befand und regelmäßig und ausgiebig Bericht erstattete. Seine Briefe sind zusammen mit denen einiger anderer in einer umfangreichen Edition erschienen. ${ }^{39}$ Bekannt sind daneben zwei lange Briefe, einer von Kardinal Trivulzio an seinen Sekretär ${ }^{40}$ und einer von Giovanni Bartolomeo Gattinara an den Kaiser. ${ }^{41}$ Kürzere Briefe finden sich in weiteren Editionen. ${ }^{42}$

Die Plünderung von Prato durch die Spanier im Jahr 1512, wenngleich weniger skandalös als der Sacco di Roma, brachte in viel engerem Rahmen die gleichen Phänomene hervor: eine Reihe von Augenzeugenberichten, die unter dem Eindruck der Vorkommnisse ent-

33 CaVe, Jean: Bellum Romanum. Hrsg. v. Léon Dorez. In: Mélanges d'archéologie et d'histoire. École Française de Rome. XVI ${ }^{\mathrm{e}}$ année, fasc. 5. Rom 1896. S. 355-407.

34 Gregorovius, FerdinAND (HRSG.): Ein deutscher Bericht über die Eroberung Roms. In: Sitzungsberichte der philosophisch-philologischen und historischen Classe der königlich bayerischen Akademie der Wissenschaften zu München. 1877, Heft 4, S. 329-397.

35 Grollier, CÉSAR: Historia expugnatae et direptae urbis Romae per exercitum Caroli V. Imp. die VI. Maii M. D. XXVII. Clemente VII. Pontifice. Paris 1637.

36 Cellini, Benvenuto: La vita. Hrsg. v. Giulio Davico Bonini. Turin 1973.

37 BAV, MS Urb. Lat. 850 und MS Urb. Lat. 1677, sowie BAR, MS 1002.

38 Ausnahme: BNM, MS 18730, Nr. 16, fol. $429^{\mathrm{r}}-431^{\mathrm{r}}$. Weniger interessant sind zwei Tagebücher in der BAV, nämlich MS Barb. Lat. 2799 (Biagio da Cesena) und MS Ottob. Lat. 2137 (Cornelius da Fine).

39 RodRiguez Villa, ANTONIO: Memorias para la historia del asalto y saqueo de Roma en 1527 por el ejército imperial formadas con documentos originales, cifrados é ineditos en su mayor parte. Madrid 1875.

40 Trivulzio, Scaramuccia: Copia d'una del cardinale di Como a uno suo segretario, data a Civitavecchia alli 24 di Maggio 1527. In: Carlo Milanesi (Hrsg.): Il sacco di Roma del MDXXVII. Narrazioni di contemporanei. Florenz 1867. S. 471-490.

41 GatTinARA, GiovanNi BARTOLOMEO: Lettera di ragguaglio di ciò che successe nel sacco di Roma, scritta da un offiziale dell'esercito di Borbone a Carlo V. In: Carlo Milanesi (Hrsg.): Il sacco di Roma del MDXXVII. Narrazioni di contemporanei. Florenz 1867. S. 493-530.

42 Die interessantesten unter ihnen: BICCI, UBALDO/COMBO, GIOVANNI: Notizia storica della famiglia Boccapaduli nobile romana. Rom 1761. GASPARONI, BENVENUTO (HRSG.): Arti e lettere. Bd. 2. Rom 1865. GAVARDO, ARRIVABENE: Copia d'una letra del successo et gran crudeltade fatta drento di Roma che non fu in Hierusalem o in Troia così grande. Hrsg. v. A. R. In: Archivio Storico Lombardo 4 (1877). LuzIO, AlessSANDRO (HrSG.): Fabrizio Maramaldo. Nuovi documenti. Ancona 1883. LuZIO, AleSSANDRO: Isabella d'Este e il sacco di Roma. Mailand 1908. MAYERHOFER, JOHANNES (HRSG.): Zwei Briefe aus Rom aus dem Jahre 1527. Ein Beitrag zur Geschichte des "Sacco di Roma". In: Historisches Jahrbuch 12 (1891). S. 747-756. 
standen, die wichtigsten von Modesti, ${ }^{43}$ Brami $^{44}$ und Bocchineri ${ }^{45}$ sowie einige kürzere, denen eine eigene Edition gewidmet ist, daneben einige Dutzend Briefe. ${ }^{46}$

Überhaupt sind Briefe für den gesamten Zeitraum aus der Sicht der Spanier die wichtigste Quelle: die ranghöchsten Offiziere und Beamten erstatteten regelmäßig Bericht bei Hof. Ab 1521 sind diese Briefe mehr oder weniger vollständig, zum Teil in mehreren Kopien und manchmal auch nur in Form von Zusammenfassungen für die Beantwortung durch die kaiserliche Kanzlei überliefert. Der mit Abstand größte Teil dieser Dokumente befand sich ursprünglich im Archiv von Simancas und wurde gegen Ende des 19. Jahrhunderts in die Real Academia de la Historia in Madrid überführt: die Briefe der Oberbefehlshaber sowie weiterer Offiziere, die Berichte der spanischen Botschafter in Genua, Rom und Venedig, der Generalkommissare beim Heer und einiger Sondergesandter, schließlich einige Memoranden. ${ }^{47}$ Ein paar verirrte Briefe derselben Personen befinden sich in Wien ${ }^{48}$ und in Mailand; ${ }^{49}$ ein Teil der Korrespondenz aus den letzten Jahren der Besatzung in der Lombardei ist aus ebenso unerfindlichen Gründen in Simancas verblieben, ${ }^{50}$ wie einige der Briefe aus der Academia später in die Bestände der Nationalbibliothek von Madrid übergingen. ${ }^{51}$ Alle diese Dokumente zusammen ergeben ein abgerundetes Bild des Krieges in Norditalien zwischen 1521 und 1529 aus der Sicht der Spanier. Verallgemeinernd lässt sich sagen, dass die zivilen Berichterstatter die für diese Arbeit interessanteren Informationen vermitteln, weil sie stärker als die Militärs auf die Situation der Bevölkerung eingehen. Kronzeugen sind in dieser Hinsicht vor allem der spanische Generalkommissar beim Heer, der Abt von Nájera Fernando de Marín, und der Botschafter in Genua, Lope de Soria. Die Korrespondenz von Nájera aus den Jahren 1521 bis 1524 liegt auch in gedruckter Form vor, eine vorgesehene Fortsetzung der Edition kam leider nicht zu Stande. ${ }^{52}$ Einige der wichtigsten Briefe aus Madrid und Wien sind ebenfalls herausgegeben worden, allerdings zumeist in gekürzter Form und in englischer Übersetzung. ${ }^{53}$ Weitere Editionen sind einigen ausgewählten Brie-

43 Modesti, JACOPO: Bericht über die Plünderung von Prato 1512. In: Documenti del Sacco dato a Prato dagli Spagnoli nel 1512. Hrsg. v. Atto Vannucci. Archivio Storico Italiano, Bd. 1 (1842).

44 BRAMi DA COLLE, Simone: Bericht über die Plünderung von Prato 1512. In: Documenti del Sacco dato a Prato dagli Spagnoli nel 1512. Hrsg. v. Atto Vannucci. Archivio Storico Italiano, Bd. 1 (1842).

45 BOCCHINERI, ANDREA: Ricordi. Hrsg. v. Cesare Guasti. In: Miscellanea pratese di cose inedite o rare antiche e moderne 8 (1872). S. 7-16.

46 Guasti, Cesare (HrsG.): Il sacco di Prato e il ritorno dei Medici a Firenze nel MDXII. Scelta di curiosità letterarie inedite o rare dal secolo XIII al XVII. Dispensa 177: Narrazioni in verso e in prosa. Bologna 1880. Dispensa 178: Documenti per la massima parte inediti. Bologna 1880.

47 RAH Salazar y Castro, A/21 bis A/45.

48 HHStA, Belgien PA 66 bis PA 67.

49 ASM Autografi, Cart. 195-196.

50 AGS Estado 1172.

51 BNM, MS 18690, MS 18697, MS 20210, MS 20212 und MS 20213.

52 PACHECO y DE LEYVA, ENRIQUe (HRSG.): La política española en Italia. Correspondencia de Don Fernando Marín, abad de Nájera, con Carlos I. Bd. 1 (1521-1524). Madrid 1919.

53 GAyAngOS, PASCUAL DE (HRSG.): Calendar of letters, despatches, and state papers, relating to the negociations between England and Spain, preserved in the archives at Simancas and elsewhere. Bd. 3, Teilbd. 1. Henry VIII. 1525-1526. London 1873. Bd. 3, Teilbd. 2. Henry VIII. 1527-1529. London 1877. Bd. 4. 
fen der kaiserlichen Militärs und Beamten zwischen der Schlacht von Pavia und dem Sacco di Roma, ${ }^{54}$ der Korrespondenz von Philibert von Oranges, ${ }^{55}$ einiger weiterer Offiziere ${ }^{56}$ und dem Gesandten des Herzogs von Ferrara beim spanischen Heer, Gerolamo Naselli, ${ }^{57}$ in lockerer und bisweilen ein wenig willkürlicher Zusammenstellung gewidmet.

Kommen wir zu den Gegnern der Spanier. Unermesslicher Reichtum an Quellen ist der Republik Venedig zu verdanken, deren weit verzweigtes System von Botschaftern und Spionen zu seiner Zeit einzigartig war. Die täglich in Venedig einlaufenden Berichte der Beamten aus den vom Krieg betroffenen Gebieten der Terraferma und später aus den Grenzstädten zum Herzogtum Mailand, die Briefe der venezianischen Offiziere, die Informationen aus abgefangenen Briefen der Gegner und die Berichte der Spione, die die Regierung in die von den Feinden besetzten Städte schickte, sind in den Tagebüchern des unermüdlichen Marino Sanuto überliefert, der bisweilen detailliertere Angaben macht als die Spanier selbst in ihrer eigenen Korrespondenz. ${ }^{58}$ Daneben gibt es einige andere militärische Berichte, die nur dann für diese Arbeit interessant werden, wenn es zum Kontakt mit den Spaniern oder den von diesen besetzten Orten kam, etwa in den Briefen der Offiziere des Herzogs Francesco Sforza aus dem Umland des von den Spaniern besetzten Mailand und anderen Städten seines Staates, ${ }^{59}$ den Berichten von dessen Gesandten beim venezianischen Heer vor Rom ${ }^{60}$ und denen des venezianischen Botschafters im belagerten Florenz. ${ }^{61}$

Neben den Briefen gibt es weitere Quellen, die den Krieg aus der Sicht der Soldaten schildern. Lebensbeschreibungen der berühmten Militärs erschienen schon früh, ${ }^{62}$ unendlich wertvoller sind allerdings die wenigen Zeugnisse in Form von persönlicher Korrespondenz oder Lebenserinnerungen beteiligter Soldaten. $\mathrm{Zu}$ nennen sind hier vor allem Reissner für

\section{Henry VIII. 1529-1530.}

54 RodRigueZ ViLla, ANTONIO: Italia desde la batalla de Pavia hasta el saco de Roma. Madrid 1885.

55 RoBerT, UlysSE: Philibert de Chalon, prince d'Orange. Lettres et documents. Boletín de la Real Academia de la Historia 39 (1901).

56 LANZ, KARL (HRSG.): Correspondenz des Kaisers Karl V. Aus dem königlichen Archiv und der Bibliothèque de Bourgogne zu Brüssel. Bd. 1. Leipzig 1844. HORMAYER (HRSG.): Carl V. und seine Helden. In: Archiv für Geographie, Historie, Staats- und Kriegskunst. Wien 1812. Verschiedene Editionen in Fortsetzung. GASSLER, FRANZ: Schilderungen aus Urschriften unserer Voreltern. Innsbruck 1789.

57 Balan, PIETRO (HrSG.): Monumenta saeculi XVI. Bd. 1: Clementis VII. epistolae per Sadoletum scriptae quibus accedunt variorum ad papam et ad alios epistolae. Önipons 1885.

58 SANUTO, Marino: Diarii. 58 Bde. Hrsg. v. Federico Stefani, Guglielmo Berchet, Nicolò Barozzi u. a. Venedig 1879-1903.

59 ASM Sforzesco, Cart. 1359-1361 (Mailand), Cart. 1375 (Lodi), Cart. 1386 (Pavia), Cart. 1394 (Tortona) und Cart. 1582 (gemischt).

60 ASM Sforzesco, Cart. 137.

61 Albèri, Eugenio (HrSG.): Relazioni degli ambasciatori Veneti al Senato. Serie 2, Bd. 3. Florenz 1846.

62 Giovio, PAolo: Le vite del Gran Capitano e del Marchese di Pescara, volgarizzate da Ludovico Domenichi. Hrsg. v. Costantino Panigada. Scrittori d'Italia 133. Bari 1931. VALLES, PEDRO: Historia del Fortissimo, y prudentissimo Capitan Don Hernando de Avalos Marques de Pescara, con los hechos memorables de otros siete excelentissimos Capitanes del Emperador Don Carlos V. Rey de España, que fueron en su tiempo, es a saber, el Prospero Coluna, el Duque de Borbon, Don Carlos Lanoy, Don Hugo de Moncada, Philiberto Principe de Orange, Antonio de Leyva, y el Marques del Guasto. Antwerpen 1558. Eine Lebensbeschreibung von Antonio de Leyva befindet sich in der BNM, MS 20476, fol. $188^{\mathrm{r}}-236^{\mathrm{V}}$. 
die Deutschen ${ }^{63}$ und Cerezeda für die Spanier. ${ }^{64}$ Eine Sonderstellung nimmt das sogenannte Journal von Philibert von Oranges ein, in dem die täglichen Ausgaben seines Gefolges und vor allem die Aufwendungen für das Privatvergnügen des Prinzen verzeichnet sind, und das so einige einzigartige Schlaglichter auf das Alltagsleben eines hohen Offiziers mitten im Krieg wirft. ${ }^{65}$ Was die einfachen Soldaten betrifft, sind die Quellen schon wegen der in der Regel mangelnden Schreibkundigkeit der Betreffenden äußerst selten und die Urheber bleiben namenlos. Das Tagebuch eines Landsknechts ${ }^{66}$ und die Erinnerungen eines Spaniers ${ }^{67}$ aus dem Krieg in der Terraferma sind Ausnahmen auf weiter Flur. Schließlich gibt es in Prato einige Briefentwürfe eines Soldaten nach der Plünderung der Stadt ${ }^{68}$ und ein für die Phantasie der Soldaten sehr aufschlussreiches Heft mit Zeichnungen und Kritzeleien aus der Zeit der Belagerung von Florenz. ${ }^{69}$

Aus der Sicht der Bevölkerung sind solche Zeugnisse des Alltags weniger selten. Aus den meisten betroffenen Städten sind lokale Chroniken oder Tagebücher überliefert, die über die Soldaten und ihr Verhalten berichten; die interessantesten aus Mailand, ${ }^{70}$ Pavia, ${ }^{71}$ Brescia, ${ }^{72}$ Verona $^{73}$ und Vicenza. ${ }^{74}$ Einige weitere aufschlussreiche Quellen lassen sich wegen der Zufälligkeit ihrer Überlieferung schwer in Kategorien fassen: eine Auflistung aller von verschiedenen durchziehenden Heeren erzwungenen Abgaben aus einem Dorf am Gardasee, ${ }^{75}$ der Bericht eines Reisenden im Umland des besetzten Rom, ${ }^{76}$ die Klagen der Abge-

63 ReISSNER, ADAM: Historia Herrn Georgen unnd Herrn Casparn von Frundsberg, Vatters und Sons / beyder Herrn zu Mündelheym / etc. Keyserlicher Oberster Feldt Herrn. Frankfurt 1572.

64 Cerezeda, MARTín GaRCÍA: Tratado de las campañas y otros acontecimientos de los ejércitos del emperador Carlos V en Italia, Francia, Austria, Berbería y Grecia, desde 1521 hasta 1545. Hrsg. v. der Sociedad de bibliófilos españoles. Bd. 1. Madrid 1873.

65 ADD, 7 E 1289. Einzelne Stellen ediert bei: Pierrugues, Antoine DominiQue (HrsG.): Giornali del Principe d'Oranges nelle guerre d'Italia dal 1526 al 1530. Florenz 1897.

66 JoPPI, VINCENZO (HRSG.): Diario del campo tedesco nella guerra veneta dal 1512 al 1516 di un contemporaneo. In: Archivio Veneto. Teil 1: Bd. 34 (1887). S. 133-152. Teil 2: Bd. 35 (1888). S. 83-116.

67 ANONYM: Relación de los sucesos de las armas de España en Italia en los años de 1511 y 1512, con la jornada de Ravenna. In: Colecciòn de documentos inéditos para la historia de España 79 (1882). S. 233298.

68 ASP Ceppi 96 , fol. $26^{\mathrm{r}}, 87^{\mathrm{v}}$ und $88^{\mathrm{r}}$.

${ }^{69}$ ASP Ceppi 728.

70 Burigozzo, Giovanni Marco: Cronaca di Milano dall' anno 1500 sino al 1544. Hrsg. v. Cesare Cantù. In: Archivio Storico Italiano, Bd. 3 (1842). S. 419-552.

71 Grumello, Antonio: Cronaca di Antonio Grumello pavese dal MCCCCLXVII al MDXXIX. Hrsg. v. Giuseppe Müller. Mailand 1856; VERRI, MARTINO: Relazione delle cose successe in Pavia dal MDXXIV al MDXXVIII. Hrsg. v. Giuseppe Müller. In: Raccolta di cronisti e documenti storici lombardi inediti. Bd. 2. Mailand 1857. BonardI, ANTONIO (HrSG.): L'assedio e la battaglia di Pavia. Diario inedito. Pavia 1895. Auch in: Memorie e Documenti per la Storia di Pavia e suo Principato. Jg. 1 (1894-1895).

72 Palazzo, Bartolomeo: Diario. In: Paolo Guerrini (Hrsg.): Le cronache bresciane inedite dei secoli XVXIX. Bd. 1. Brescia 1922. S. 256-386.

73 Zagata, Pier (HrSG.): Cronica della città di Verona colla continuazione di Jacopo Rizzoni, ampliata e supplicata da Giambattista Biancolini. 3 Bde. Verona 1745-49.

74 PORTO, LuIGI DA: Lettere storiche di Luigi da Porto vicentino dall'anno 1509 al 1528. Hrsg. v. Bartolomeo Bressan. Florenz 1857. GUERIN-DALLE MESE, JEANNINE (HRSG.): Una cronaca vicentina del cinquecento. Vicenza 1983.

75 Marchesini, G. B.: La lega di Cambray e le spese di guerra di un comune della Riviera Benacense. In: Archivio Veneto. Jg. 5 (1875). S. 126-154. 
sandten der Stadt Mailand vor dem Kaiser, ${ }^{77}$ Beschwerdebriefe der Regierung in Siena über marodierende Soldaten ${ }^{78}$ und eine einzigartige Sammlung von abgefangenen Briefen einiger Mailänder an Soldaten des abziehenden spanischen Besatzungsheeres. ${ }^{79}$

Schließlich sind einige Akten zu erwähnen, die vor allem für die zahlenmäßige Erfassung von Plünderungsschäden von unschätzbarem Wert sind. Es sind dies die in Prato im Zug einer Entschädigungskampagne entstandenen detaillierten Listen mit den von Kriegsgewinnlern aus Pistoia und Firenzuola aufgekauften Beutestücken ${ }^{80}$ und eine Sammlung von Erklärungen der Einwohner aus Prato über Lösegelder, die an spanische Soldaten gezahlt worden waren. ${ }^{81}$ Was den Sacco di Roma betrifft, so sind einige Aktenstücke ediert, die sich mit der Plünderung befassen, vor allem Notarsakten über Lösegelder. ${ }^{82}$ Die Masse der Verträge über die Lösegelder schlummert aber noch in den Archiven. Aus Mailand sind, für das Alltagsleben unter der Besatzung hochinteressant, Hunderte von öffentlichen Ausrufen der spanischen Besatzer aus den Jahren 1525 bis 1529 überliefert. ${ }^{83}$ Sehr aufschlussreich für das Verhalten der Soldaten sind schließlich die Akten eines in Mailand einige Jahre nach dem Abzug der Soldaten geführten Zivilprozesses um Schadensersatz für von den einquartierten Spaniern konsumierte Lebensmittel und gestohlene Waren. ${ }^{84}$ So unerwartet wie einige dieser Quellen - begraben unter Bergen von Dokumenten ganz anderer Art - zum Vorschein kamen, so wahrscheinlich ist es, dass weiteres und möglicherweise höchst aufschlussreiches Material über ganz Europa verstreut eben wegen seiner scheinbaren Bedeutungslosigkeit in den Archiven auf seine Entdeckung wartet.

76 LANCIANI, RODOLFO: Storia degli scavi di Roma e notizie intorno le collezioni romane di antichità. Bd. 1 (1000-1530). Rom 1902. S. 243-244.

77 SAlOMONi, Angiolo (HrSG.): Memorie storico-diplomatiche degli Ambasciatori, Incaricati d'affari, Corrispondenti, e Delegati, che la città di Milano inviò a diversi suoi principi dal 1500 al 1796. Mailand 1806.

78 RAH Lope de Soria 197-198.

79 ASM Sforzesco, Cart. 1424.

80 ASP Comune 2549, fol. $1^{\mathrm{r}}-53^{\mathrm{r}}$ (Pistoia) und fol. $198^{\mathrm{r}}-205^{\mathrm{r}}$ (Firenzuola).

81 ASP Comune 2549 , fol. $55^{\mathrm{r}}-197^{\mathrm{r}}$.

82 Cavalletti-Rondinini, G. (HrSG.): Nuovi documenti sul sacco di Roma del MDXXVII. Rom 1884. Auch in: Studi e documenti di storia e diritto 5 (1884). S. 221-246. CorVISIERI, AlESSANDRO (HRSG.): Documenti inediti sul sacco di Roma nel MDXXVII. Rom 1873. MAZIO, PAOLO: Storia della guerra fra Clemente VII e gli imperiali e documenti inediti in proposito. In: Il Saggiatore Romano 10-11 (1844). Teil 1: S. 305-316. Teil 2: S. 337-347. Einige Stücke finden sich zusammengefasst und in französischer Übersetzung bei RoDOCANACHI, E.: La première Renaissance. Rome au temps de Jules II et de Léon X. La cour pontificale, les artistes et les gens de lettres, la ville et le peuple, le sac de Rome en 1527. Paris 1912.

83 ASM Sforzesco, Cart. 1504 (1525), Cart. 1505 (1526), Cart. 1506 (1527-1528) und Cart. 1507 (1529). Ferner ACM Registri di lettere ducali, Bd. 19-20.

84 IIPPAB Comuni 182. 


\section{Plünderung}

Ein Heer ist ein großes gefräßiges Tier - so fasst ein Chronist aus Bergamo seinen Eindruck von den spanischen Soldaten in seiner Stadt zusammen, und ähnlich formulieren es fast alle Berichterstatter, die Zeugen des Durchzugs der spanischen, deutschen und italienischen Truppen wurden - ein ausgehungertes und zugleich unersättliches Tier mit Tausenden von Mäulern, das alles verschlang, was es auf seinem Weg antraf, vor allem aber Geld und immer wieder Geld. ${ }^{85}$

In diesem ersten Teil geht es um die Mechanismen der Plünderung von Städten. Plünderungen waren eine Begleiterscheinung des Krieges zu allen Zeiten, sie spielten sich in der Regel ab im Spannungsfeld zwischen der entfesselten Beutegier der Soldaten und den Versuchen der Autoritäten, diese wenigstens ansatzweise in geregelte Bahnen zu lenken, sei es, um die Bevölkerung zu schonen, sei es, um zu verhindern, dass man vollständig die Kontrolle über das Heer verlor und damit auch die militärischen Aktionen in Gefahr brachte. So befassen sich auch eine Reihe von militärtheoretischen und völkerrechtlichen Schriften mit dem Phänomen der Plünderung. Diese Werke versuchen zumeist, aus der Antike überlieferte Regelungen und kirchenrechtliche Bestimmungen mit den Erfahrungen ihrer Epoche in Einklang zu bringen und auf diese anzuwenden. Das wichtigste Moment ist dabei die Unterscheidung zwischen gerechtem und ungerechtem Krieg, eine Unterscheidung, die zur Grundlage aller weiteren Ausführungen gemacht wird und diese damit von vornherein unanwendbar macht, da in der Regel alle Parteien den gerechten Krieg für sich beanspruchten, wenn sie sich überhaupt die Zeit nahmen, sich juristische Gedankengebäude zu eigen zu machen, die der Wirklichkeit ohnehin in keiner Weise gewachsen waren.

Der italienische Militärtheoretiker Pierino Belli postuliert, dass Städte nur dann geplündert werden dürfen, wenn die ganze Bevölkerung sich eines Verbrechens schuldig gemacht hat. ${ }^{86}$ Diese Bestimmung ist an sich schon auslegbar genug, der spanische Völkerrechtler Francisco de Victoria geht indes noch weiter: auch Unschuldige dürfen ausgeplündert werden, da sie die Feinde stärken könnten, und sogar Frauen und Kinder dürfen zur Erpressung von Lösegeldern als Geiseln genommen werden, wenn das der Fortführung des Krieges dient. ${ }^{87}$ Aus demselben Grund dürfen Städte nach der Plünderung sogar angesteckt werden,

\footnotetext{
85 "Un esercito è come un grande animale che vive in continua voracità, ond'è necessario un grand'alimento ancora per mantenerlo nel vigor che bisogna." RONCHETTI, GIUSEPPE: Memorie istoriche della città e chiesa di Bergamo dal principio del V. secolo di nostra Salute sino all'anno MCCCCCXXVIII. Bd. 7. Bergamo 1839. S. 125.

86 BELLI, PIERINO: De Re militari \& Bello tractatus divisus in partes XI. Venedig 1563. Neudruck mit Einleitung v. Arrigo Cavalieri und englischer Übersetzung v. Herbert C. Nutting. The Classics of International Law 18. Washington 1936. Fol. 60r.

87 VICTORIA, FRANCISCO DE: De Indis recenter inventis et de iure belli Hispanorum in Barbaros relectiones. Vorlesungen über die kürzlich entdeckten Inder und das Recht der Spanier zum Kriege gegen die Barbaren. 1539. Hrsg. u. übers. v. Walter Schätzel. Tübingen 1952. S. $155 \mathrm{ff}$.
} 
immer unter der Voraussetzung, dass es sich um einen gerechten Krieg handelt. ${ }^{88}$ Die Idee, die Plünderungsbeute zusammenzutragen und wenigstens teilweise der Kriegskasse zuzuführen, trägt der weit verbreiteten Zahlungsunfähigkeit der Kriegsherren Rechnung, sie wurde aber so gut wie nie in die Tat umgesetzt und wäre den Soldaten wahrscheinlich geradezu lächerlich vorgekommen. ${ }^{89}$ Vor Ort zeigte sich immer wieder, wie weit die Theorien der Studierstuben sich von der Wirklichkeit der Kriegsschauplätze unterschieden.

In den folgenden beiden Abschnitten sollen an einem überschaubareren Beispielfall, der Plünderung von Prato durch die Spanier im Jahr 1512, die Mechanismen des Verkaufs der Beute und der Erpressung von Lösegeldern dargestellt werden, die durch einige außergewöhnliche Quellen besser dokumentiert sind, als eine noch so große Zahl von Augenzeugenberichten das leisten könnte. Und hier liegt bereits ein fundamentaler Mangel fast aller bisher erschienenen Arbeiten vor: bei den Schilderungen berüchtigter Plünderungen - allen voran des Sacco di Roma - werden fast ausschließlich die Verluste genannt, die einige wenige Personen des öffentlichen Lebens erlitten. Dass kleinere Haushalte durch eine Plünderung in der Regel stärker in Mitleidenschaft gezogen wurden als die Paläste von Bankiers und Kardinälen, wird meistens nur lustlos und floskelhaft erwähnt, da entsprechendes Zahlenmaterial schwer zugänglich ist und darüber hinaus kaum Aussagekraft besitzt, solange die Summen von Lösegeldern oder geplünderten Werten isoliert genannt und nicht zum Einkommen und den Lebenshaltungskosten der Opfer in Beziehung gesetzt werden. Es zeigt sich aber bei näherer Betrachtung eindringlich, wie sehr eine Plünderung sich für die Mehrheit der Geschädigten zu einer Bedrohung der Lebensgrundlage auswachsen konnte, da ihr die gesellschaftlichen Möglichkeiten fehlten, sich mit höherrangigen Soldaten zu arrangieren und die materiellen Möglichkeiten, aus der Plünderung entstandenen Verpflichtungen etwa durch die Verpfändung eines Landgutes nachzukommen, weil sie ein solches schlicht und einfach nicht besaß und deshalb gezwungen war, ihren geringen Besitz bis hin zu Kleidung und Kochgeschirr herzugeben oder sich auf lange Zeit hinaus zu verschulden. Vom Standpunkt der Soldaten aus zeigt sich parallel dazu, dass den Offizieren, die in den Palästen das große Geld eintrieben, eine weitaus größere Zahl von Soldaten gegenüber stand, die den ausbleibenden Sold durch den Verkauf von geplünderten Kleidungsstücken und Einrichtungsgegenständen ausglichen und die Städte keineswegs mit Gold beladen verließen, wie man angesichts vieler Aussagen vermuten könnte. Eine nähere Untersuchung solcher Verkäufe wird in dieser Hinsicht vieles erhellen.

Anschließend soll an Hand des Sacco di Roma der Ablauf einer Plünderung aus der Sicht der Opfer nachgezeichnet werden. Die Plünderung der Ewigen Stadt im Mai 1527 durch Landsknechte und Spanier bietet sich deshalb für ein solches Unterfangen an, weil durch die Masse an schreibkundigen Augenzeugen, die dem Geschehen unfreiwillig beiwohnten,

88 VICTORIA, De Indis recenter inventis, S. 165.

89 BELLI, De Re militari, fol. $45^{\mathrm{V}}$. 
eine große Zahl von unmittelbaren Zeugnissen existiert, die den Sacco di Roma aus dieser Sicht zur am besten dokumentierten Plünderung des gesamten untersuchten Zeitraums machen.

Bevor die Mechanismen der Plünderung im Detail beschrieben werden, soll noch einmal auf die schon in der Einleitung angesprochene Verzerrung des Bildes zu Gunsten von spektakulären Ereignissen hingewiesen werden: den Aufsehen erregenden Plünderungen der großen Städte steht eine ungleich größere Zahl kleinerer Plünderungen gegenüber, von denen man in den Chroniken in der Regel nichts erfährt, weil die betroffenen Orte keine eigene Überlieferung hervorgebracht haben. Im Krieg in der Terraferma wurden unzählige Städte und Dörfer geplündert, viele davon über die Jahre hinweg mehrmals. Solche Szenerien wiederholten sich später in der Lombardei und ihren Nachbargebieten und vor allem auf dem Zug nach Rom: kaum in päpstliches Gebiet eingetreten, plünderte das Heer von Charles de Bourbon Anfang April 1527 innerhalb von weniger als zwei Wochen 22 Orte. ${ }^{90}$ Rechts und links des Weges taten getrennt marschierende Kompanien und marodierende Pulks ein übriges. Die Grenzen zwischen Plünderung durch ein Heer, Raubzügen versprengter Gruppen desselben und mehr oder weniger offenem Diebstahl durch einzelne Soldaten bei allen Gelegenheiten waren fließend.

Wenn ein feindliches Heer vor einer Stadt auftauchte, wurden vor dem Angriff in der Regel Herolde vor die Tore geschickt, die um die Übergabe verhandelten. Wenn man sich einigte, wurde die Stadt gegen die Zahlung einer bei den Verhandlungen festgelegten Abgabe von der Plünderung verschont. Diese Summe richtete sich in erster Linie nach Größe und Reichtum der Stadt, aber auch nach dem Grad der Bedrohung: als der Herzog von Braunschweig im Juni 1528 mit seinen unbezahlten Landsknechten vor Bergamo ankam, verlangte er 50.000 Dukaten von der Stadt. ${ }^{91}$ Auf dem Weg des kaiserlichen Heeres nach Florenz im September 1529 wurden Arezzo für 10.000 und Cortona für 6.000 Scudi übergeben. $^{92}$ Kleinere Städte wie Montagnana ergaben sich für 2.000 Dukaten, ${ }^{93}$ Kastelle wie Breno für 500 Dukaten $^{94}$ und selbst Dörfer kauften sich bisweilen frei wie etwa Lavagna, das gegen 200 Dukaten durch einen Schutzbrief von der Plünderung befreit wurde. ${ }^{95}$ Städte, die sich ergeben hatten, durften nicht geplündert werden. ${ }^{96}$ Die Verteidiger befanden sich bei den Verhandlungen allerdings in einer gefährlichen Position: wenn sie die Übergabe

\footnotetext{
90 HHStA, Registratur Karls V., Belgien PA 66, fol. 204 . Quiñonez an den Kaiser, Mai 1527.

91 BNM, MS 20476, fol. 231 $\mathrm{V}$.

92 ALBÈRI, Relazioni degli ambasciatori veneti, Serie 2, Bd. 1, S. 221.

93 ZANETTI, L'assedio di Padova, S. 106.

94 Putelli, Romolo: Intorno al castello di Breno. Storia di Valcamonica, Lago d'Iseo e vicinanze. Breno 1915. S. 515.

95 SANUTO, Diarii, Bd. 15, Sp. 580.

96 So steht es unter anderem in der Kriegsordnung, die Erzherzog Ferdinand 1527 für die Landsknechte ausarbeiten ließ. Hale, JoHn R.: Armies, Navies and the Art of War. In: The New Cambridge Modern History. Bd. 2: The Reformation 1520-1559. Hrsg. v. G. R. Elton. Cambridge 1990. S. 560.
} 
ablehnten, war die Plünderung im Fall der Einnahme der Stadt sicher. Da die Angreifer aber in der Regel auch Zutritt zur Stadt verlangten, bestand die Gefahr, dass es nach der Kapitulation trotz der Absprachen zur Plünderung kam. Solche Befürchtungen waren nur zu berechtigt, da die Soldaten die Übergabeverhandlungen mit äußerstem Argwohn verfolgten. Sie fürchteten, um die Beute betrogen zu werden, von der sie nur eine Stadtmauer trennte, und manchmal noch nicht einmal das: während die spanischen Offiziere im November 1521 in Como nach einleitender Beschießung um die Übergabe der Stadt verhandelten, postierten sie Wachen in den Breschen der Stadtmauer, die ein Eindringen der beutegierigen Soldaten verhindern sollten. Diese aber waren nicht zu halten, stürmten auf die Breschen los und überrannten einige der Wachen, während andere ihnen sogar beim Überklettern der Trümmer behilflich waren und sich gern bei der anschließenden Plünderung anschlossen. ${ }^{97}$ Mit zunehmendem Verfall der Disziplin häuften sich dann Vorkommnisse wie in Como: im Juli 1525 ergab sich Saluzzo den aus Mailand ausquartierten Landsknechten, diese plünderten, kaum dass sie die Stadt betreten hatten. ${ }^{98}$ Drei Jahre später, als der Herzog von Braunschweig mit seinen Landsknechten nach Mailand zog, war ein derartiger Bruch mit den Gepflogenheiten kein Zwischenfall mehr: systematisch wurden die Städte, die auf seinem Weg lagen, zunächst zur Kapitulation gezwungen und nach Zahlung der vereinbarten Summe geplündert. ${ }^{99}$ Vor allem solche Erfahrungen waren es, die die Angst vor den Soldaten und das Misstrauen in das von den Offizieren gegebene Wort im Lauf der Jahre immer weiter verstärkten.

Wenn eine Kapitulation nicht zu Stande gekommen war, wurde der Angriff vorbereitet. Auf welche Weise die Städte im Einzelnen erobert wurden, ist für diese Arbeit unerheblich; ob die Soldaten, wie in Prato, durch Breschen stürmten, die sie in die Mauer geschossen hatten oder ob sie diese, wie in Rom, aus Mangel an Artillerie mit Leitern überstiegen: während die letzten Verteidiger kopflos durch die Straßen flohen, begann die Jagd nach der Beute.

\section{A. Der Beutemarkt}

Nachdem die Soldaten die Haustüren eingeschlagen hatten, begann eine fieberhafte Suche nach Geld, die in der Regel erfolglos blieb, weil Geld und Wertgegenstände beim Herannahen des Heeres von den Bewohnern aus der Stadt geschafft oder wenigstens versteckt worden waren. Das nützte diesen allerdings wenig, wenn sie selbst ihre Häuser nicht verlassen hatten, da die Soldaten keinen Augenblick zögerten, sie mit Gewalt zur Preisgabe der Ver-

\footnotetext{
97 GiOvio, Le vite del Gran Capitano e del Marchese di Pescara, S. 273.

98 Saluzzo di Castellar, Giovanni Andrea: Memoriale. Hrsg. v. V. Promis. Miscellanea di Storia Italiana 8. Turin 1869. S. 600.

99 RAH Salazar y Castro, A/43, fol. 113 ${ }^{r}$. Lope de Soria an den Kaiser, 2. 8. 1528.
} 
stecke und zur Beschaffung des Geldes zu zwingen. Die Mehrheit der Bewohner indes verfügte über wenig Geld und kaum über Möglichkeiten der Beschaffung. Soldaten, denen es nicht gelungen war, reiche Geiseln in ihre Gewalt zu bringen, mussten sich am oftmals kargen Besitz der großen Mehrheit ihrer Opfer schadlos halten. Mit diesem Besitz aber konnten sie in der Regel nichts anfangen, daher versuchten sie nach Kräften, alles zu Geld zu machen, was ihnen in den Häusern in die Hände fiel. So etablierten sich in geplünderten Städten und sogar auf dem Land regelrechte Märkte, auf denen Beute angeboten und gern gekauft wurde. Neben den Marketendern beteiligten sich auch einheimische Händler an diesem Geschäft, einige von ihnen folgten den Heeren über längere Zeiträume in der ständigen Hoffnung auf einträgliche Plünderungen. Auf diese Weise ging die Beute durch zahlreiche Hände, wurde dabei immer mehr zu einer gewöhnlichen Ware und verteilte sich unwiederbringlich im Land.

Unwiederbringlich - mit einer Ausnahme. Im September 1512, einen Monat nach der Plünderung von Prato durch das Heer des spanischen Vizekönigs von Neapel Ramón de Cardona, wurde in Florenz ein bemerkenswerter Befehl erlassen: die Verwaltungsbeamten in der Umgebung von Prato und auf dem Abmarschweg des Heeres wurden aufgefordert, Kommissare einzusetzen, die den Verbleib der Beute aus Prato erhellen und dafür sorgen sollten, dass die Ware ihren ursprünglichen Besitzern zurückgegeben würde. Dieser Befehl war der Auftakt für eine einmalige Entschädigungskampagne, mit der die Medici davon abzulenken versuchten, dass sie selbst Prato einen Monat zuvor den Spaniern geopfert hatten, um mit deren Hilfe in Florenz einen reibungslosen und gewaltfreien Staatsstreich zu inszenieren. So hatten sie die Macht übernehmen können, ohne dass die spanische Soldateska in die Hauptstadt einmarschieren musste. Prato indes blieb geplündert und teilweise zerstört zurück. Kaum an der Macht, begann man mit der Wiedergutmachung des Schadens durch die Nachforschungen zur Erstellung der Listen. Gleichzeitig wurden Besitzungen der Kirche veräußert, um den Rückkauf der Beute zu finanzieren.

Von den Listen, die die Kommissare der Regierung in der Umgebung von Prato anfertigten, haben nur zwei die Jahrhunderte überdauert: eine für Stadt und Contado von Pistoia und eine für das Vikariat Firenzuola. ${ }^{100}$ Beide enthalten die Namen der Einwohner der entsprechenden Gebiete, die Beute aus Prato gekauft hatten. Unter jedem einzelnen Namen sind minutiös alle Beutestücke aufgeführt, die von der betreffenden Person gekauft worden waren. Die Liste aus Firenzuola führt lediglich 56 Namen auf, die aus Pistoia dagegen 578, darüber hinaus ist sie aussagekräftiger, weil sie mehr Detailinformationen auch über die Umstände der Käufe und die Personen liefert, die in die Transaktionen verwickelt waren. Das macht die Beuteliste aus Pistoia zu einer einmaligen und bisher dennoch völlig ver-

100 ASP Comune 2549, fol. $1^{\mathrm{r}}-53^{\mathrm{r}}$ (Pistoia) und fol. $198^{\mathrm{r}}-205^{\mathrm{r}}$ (Firenzuola). Es ist überdies nicht sicher, ob weitere Listen überhaupt existiert haben, denn Modesti erinnert sich, dass von allen aufgeforderten Orten nur Pistoia und Firenzuola etwas herausgaben. ModEsti, Bericht, S. 245f. 
nachlässigten Quelle für das Verständnis der Mechanismen von Plünderungen: sie bildet den Kontrast zu den Augenzeugenberichten, die nur von mit Reichtümern beladenen Soldaten und den Verlusten der Prominenz sprechen und ermöglicht die Betrachtung einer Plünderung sozusagen unter der Lupe. Daneben ist sie vor allem deshalb wertvoll, weil sie wegen ihres Anspruchs auf Vollständigkeit eine Quantifizierung der Verluste - und bis zu einem gewissen Grad auch der Gewinne - erlaubt. Noch nicht einmal der Sacco di Roma, der eine Unzahl von Quellen aus erster und zweiter Hand hervorbrachte, ist in dieser Hinsicht annähernd so gut dokumentiert. Zum einen fehlen hier eben die Quellen, die systematischen Zugriff auf die Verluste der Bewohner aus den unteren sozialen Schichten gestatten, weil diese von den Augenzeugen in der Regel ignoriert oder nur am Rand erwähnt werden, zum anderen - und hier haben die Berichte bei allem Hang zur Übertreibung am Ende Recht - war die Beute aus Rom in der Tat immens: erstens weil die Stadt durch die Anwesenheit des päpstlichen Hofes, der Kardinäle und Bankiers nun einmal immens reich war, zweitens weil im Gegensatz zu fast allen anderen Plünderungen auf Grund eines päpstlichen Verbotes fast niemand dazu kam, seinen Besitz in Sicherheit zu bringen, und drittens weil die völlige Abwesenheit von Autorität den Sacco di Roma viel länger andauern ließ als das für eine Plünderung üblich war. Zum Vergleich: die Plünderung Genuas durch die Spanier im Mai 1522, neben dem Sacco di Roma übrigens die einzige gestattete Plünderung einer Hauptstadt im ganzen untersuchten Zeitraum, konnte schon nach einem Tag unter Kontrolle gebracht werden, in Prato waren es kaum drei Tage, und länger wurde die Plünderung einer Stadt in der Regel auch nicht gestattet. ${ }^{101}$ Der Sacco di Prato war also eine sozusagen schulbuchmäßige Plünderung und gibt auch wegen der überschaubaren Größe der Stadt ein Beispiel ab, das für die vielen anderen Städte steht, die von den Heeren auf ihrem Weg mit oder ohne Genehmigung, meistens aber mit Duldung und durchaus auch unter Teilnahme der Offiziere geplündert wurden. Die Ergebnisse der folgenden Untersuchung können daher im Hinblick auf den Ablauf der Geschäfte, die Beschaffenheit der Beute und die Identität der Aufkäufer als repräsentativ für andere Plünderungen der untersuchten Epoche gelten.

\section{Die Liste aus Pistoia}

Der Hintergrund der Erstellung der Beuteliste aus Pistoia wird auch durch andere Quellen erhellt. Aus einem Schreiben des Kommissars in Prato, Gherardo de Gherardis, an die Signoria in Florenz geht hervor, dass die Entschädigungsaktion bereits am 21. September,

101 CAdenas y Vincent, El saco de Prato, S. 95. 
also zwei Tage nach dem Abzug der Spanier angelaufen war. ${ }^{102}$ Um die Ware zurückzugeben, arbeitete man mit Strafe und Belohnung gleichzeitig: zwar waren die Aufkäufer verpflichtet, die Beute herauszugeben, es entstand ihnen aber kein finanzieller Verlust, im Gegenteil: sie bekamen das Geld erstattet und konnten an der Rückgabe noch geringfügig verdienen, weil dem von ihnen angegebenen Kaufpreis ein kleiner Aufschlag hinzuaddiert wurde. Das führte zu erheblichen Schwierigkeiten, weil viele überhöhte Preise angaben, um sich an der Differenz zu bereichern. Schließlich wurden die Kommissare autorisiert, die Preise durch Vergleiche selbst festzulegen. ${ }^{103}$ Andere weigerten sich einfach, die Ware herzugeben, obwohl die Kommissare die Aufkäufer zur Herausgabe zwingen und sie zur Not nach Florenz vor die Signoria zitieren konnten. ${ }^{104}$

Trotz ihres Umfangs gibt die Liste aus Pistoia nur einen Bruchteil dessen wieder, was von der Beute aus Prato durch die Hände der Aufkäufer ging, denn Pistoia war nur einer unter vielen möglichen Märkten. Der größte Anteil der Beute wird in Florenz verkauft worden sein. Die Stadt war zwar zunächst für die Soldaten gesperrt, aber schon drei Tage nach der Eroberung von Prato schrieb Jacopo Salviati an die Regierung in Florenz, die Herren täten gut daran, den Soldaten den Zutritt nicht länger zu verwehren, diese seien ungeduldig, die Beute zu verkaufen, und man könne nicht dafür garantieren, dass sie nicht aus Ungeduld die Ware und schlimmstenfalls die ganze Stadt in Flammen aufgehen ließen. ${ }^{105}$ Die Erlaubnis wurde gegeben, und schon bald strömten die Spanier, beladen mit Beute, nach Florenz und verkauften sie auf dem Domplatz und anderswo. ${ }^{106}$ Neben Florenz und Pistoia waren auch Empoli und San Miniato wichtige Umschlagplätze, sowie kleinere Orte östlich von Prato im Mugello. ${ }^{107}$ Und schließlich waren es sogar die unmittelbaren Nachbarn der Geschädigten selbst, die sich am Handel mit der Beute beteiligten: die Regierung in Florenz schrieb zwei Tage nach dem Abzug der Spanier an Gherardis in Prato und beglückwünschte ihn zum erfolgreichen Beginn der Entschädigungsaktion; das wichtigste sei dabei, dass die Geschäfte annulliert würden, in die die Einwohner aus Prato selbst verwickelt gewesen seien. ${ }^{108}$ Deren Beteiligung war offenbar von beträchtlichem Ausmaß gewesen, denn Gherardis hatte bei seinem Eintreffen in Prato unmittelbar nach dem Abzug der Spanier ein heilloses Durcheinander vorgefunden, in dem jeder versuchte, sich alles anzueignen, was er nur in die Hände bekommen konnte. Viele sträubten sich darüber hinaus gegen die Rückgabe der Beute mit der Begründung, diese als Entschädigung für ihre eigenen Verluste behalten $\mathrm{zu}$ wollen. ${ }^{109}$

102 GUASTI, Il sacco di Prato, Dispensa 178, S. 199.

103 GUASTI, Il sacco di Prato, Dispensa 178, S. 232f.

104 GUASTI, Il sacco di Prato, Dispensa 178, S. 226.

105 GUASTI, Il sacco di Prato, Dispensa 178, S. 158.

106 MODESTI, Bericht, S. 245.

107 MODESTI, Bericht, S. 245f.

108 Guasti, Il sacco di Prato, Dispensa 178, S. 197.

109 GuASTI, Il sacco di Prato, Dispensa 178, S. $198 f$. 
In Pistoia und Umgebung begannen die Nachforschungen am 28. September - mit diesem Datum ist der erste Eintrag überschrieben - und zogen sich dann über mehrere Tage hin, wie sich aus weiteren Überschriften ersehen lässt. Die letzten drei Einträge datieren vom 30. Oktober, es scheint sich auf Grund der starken zeitlichen Verschiebung gegen die anderen Daten und inhaltlicher Merkmale bei diesen allerdings um Nachträge zu handeln. Offenbar gingen die Kommissare von Haus zu Haus und befragten die Bewohner, wobei sie mit den von der Regierung ausgesetzten Strafen drohten, ferner wurde den Befragten ein Schwur abverlangt. So heißt es bei Raffaello di Piero am Ende seiner Aussage: "... e cosi giuro tochando la scriptura." (576) ${ }^{110}$ Die meisten gaben die Ware an, die sie selbst gekauft hatten, einige betätigten sich auch als Denunzianten, die andere beim Aufkauf der Beute beobachtet hatten, wie der Müller Francesco di Bastiano (575), der Mehl ins Haus des in Pistoia wohnhaften Mailänder Kaufmanns Vittorio lieferte und dabei zufällig ein Verkaufsgespräch aufschnappte, das dieser mit zwei Händlern aus Bologna um einige Textilien führte, die offenbar aus Prato stammten. Er wisse nicht, so der Zeuge weiter, ob das Geschäft zu Stande gekommen sei, da er das Haus nach Ablieferung seiner eigenen Ware wieder verlassen habe. Trotz dieser scheinbaren Bereitschaft zur Kooperation mit den Kommissaren kann kaum von einer Vollständigkeit der Listen ausgegangen werden, da viele wohl doch einen Teil der Ware unterschlugen. Unter einigen der Posten stehen Bemerkungen, die darauf hinweisen, dass die Ware tatsächlich den ursprünglichen Besitzern in Prato zurückgegeben wurde, diese datieren alle aus dem Zeitraum zwischen dem 6. und dem 31. Oktober, woraus sich schließen lässt, dass die Rückerstattung etwa einen Monat nach Beginn der Untersuchung abgeschlossen war.

Die 578 Personen der Liste aus Pistoia werden ohne erkennbare Ordnung geführt, lediglich bestimmte Herkunftsorte - neben Pistoia selbst vor allem die größeren Gemeinden in der unmittelbaren Umgebung - tauchen bisweilen gehäuft auf, was darauf hindeutet, dass mehrere Kommissare in mehreren Orten gleichzeitig von Haus zu Haus gingen und ihre Aufzeichnungen später zusammenfassten. Auf diese 578 Personen verteilen sich etwa 2.320 Posten $^{111}$ mit einem angegebenen Gesamtwert von annähernd 2.500 Florin, dazu kommen noch einige größere Posten mit Getreide, für die keine Summe angegeben ist, deren Wert sich aber auf etwa 500 Florin beläuft. Daraus ergibt sich, dass jeder Aufkäufer im Durchschnitt Ware für 5 Florin kaufte, die Streuung ist allerdings beträchtlich und reicht von einigen Soldi bis zu 61 Florin. (67) Jeder der Befragten wird mit Namen und Vaternamen, manchmal auch mit Familiennamen angeführt. Es schließt sich zumeist eine Herkunfts- und

110 Um allzu viele Fußnoten zu vermeiden, sind die Belegstellen für die Liste aus Pistoia in Form von Zahlen angegeben, die einer durchlaufenden Numerierung der aufgelisteten Personen entsprechen. Im Anhang I findet sich eine Tabelle, die für die einzelnen Zahlen das entsprechende Blatt im Manuskript angibt.

111 Die ganz genaue Zahl der Posten lässt sich nicht bestimmen, da einige wenige Angaben nicht als Punkt in der Liste erscheinen, sondern in die Aussage von Denunzianten eingebaut sind, die sich nicht immer genau erinnern. 
Wohnortsbezeichnung an, manchmal auch eine Berufsbezeichnung, bisweilen gefolgt von einer Formulierung, die die anschließende Auflistung der von dem Betreffenden gekauften Ware einleitet: "Filippo di Tommaso purgatore da Pistoia disse havere havuto da Astore Astesi ..." (21) Die dieser ersten Zeile folgende Auflistung besteht aus den einzelnen Posten, die kürzesten Auflistungen enthalten nur einen Posten, die längsten mehrere Dutzend, der Durchschnitt liegt bei 4 Posten pro Aufkäufer. Ein Posten setzt sich aus einem oder mehreren Einzelstücken der gleichen Ware zusammen oder aus einer bestimmten Menge von gemessener oder gewogener Ware. Hinter jedem Posten ist der Kaufpreis der Ware angegeben. Normalerweise sind die Erklärungen schematisch aufgebaut und enthalten wenig Text. Lediglich im Fall von Denunziationen finden sich auch längere Passagen, in denen die Zeugenaussagen von den Kommissaren genau wiedergegeben werden.

\section{Ablauf der Geschäfte}

Aus den Angaben der Kommissare lassen sich an einigen Stellen Rückschlüsse auf den Ablauf der Geschäfte mit der Beute aus Prato unmittelbar nach der Plünderung ziehen. Da die meisten der Befragten aber nur Art und Menge der von ihnen gekauften Ware angeben, ohne auf die näheren Umstände des Erwerbs einzugehen, müssen zumeist willkürlich eingestreute Informationsbruchteile zusammengesetzt werden. Die einfachsten solcher Informationen finden sich mehr zufällig und formelhaft in die Einleitungssätze eingestreut, etwa bei Giovanni Battista Vitale: "... disse havere comperato da uno spagniuolo ..." (1) Hier kaufte der Befragte die Ware also direkt bei dem spanischen Soldaten, der sie seinem Opfer abgenommen hatte. Manchmal brachten die Soldaten die Ware sogar selbst nach Pistoia. Raffaello di Piero (576) kaufte eine Wagenladung Stoff von den Spaniern, und zwar, wie er präzisiert, unterhalb der Brücke zur Zitadelle; Piermaria di Gabriele (438) beobachtete, wie die Soldaten 8 Wagenladungen auf einmal nach Pistoia fuhren, um sie dort an den Mann zu bringen. Aus den wenigen und verstreuten Informationen geht allerdings hervor, dass das der seltenere Fall war. In der Regel holten die Aufkäufer die Beute in Prato ab, wo die Spanier offensichtlich eine Art Markt eröffnet hatten. Matteo di Baldo (194) kaufte seine Ware "in sulla piazza di Prato", einiges wurde auch direkt in den ausgeplünderten Häusern angeboten: Lazzere di Nanni (578) ging mit einem Freund ganz ungeniert ins Haus eines Barbiers aus Prato, lud seinen Wagen voll mit Textilien und anderen Dingen, bezahlte bei den Spaniern und brachte alles nach Pistoia. Wer nicht wusste, wie er die Ware nach Hause schaffen sollte, kaufte die Transportmittel gleich mit ein: Raffaele di Pandragone (67) erstand einen Posten mit 1.100 Pfund $^{112}$ Wolle, einen Transportkarren und einen roten Och-

1121 libbra $=336 \mathrm{~g}$. 
sen. So lassen sich einige Informationen über die Umstände des Aufkaufs schon aus der Zusammenstellung der Posten schließen. Viele kauften die Ware auch bei Zwischenhändlern aus Pistoia, die sich in Prato mit größeren Mengen eindeckten und in Pistoia für ihre Verteilung sorgten. Wie viele der Endabnehmer sich wirklich selbst auf den Weg nach Prato machten und unter den Augen der Opfer deren Habe aufkauften, lässt sich nicht mehr feststellen, weil in der Liste eben nur die erfasst sind, die in Pistoia im Besitz der Ware angetroffen wurden. Oft wird diese schon durch verschiedene Hände gegangen sein, als die Kommissare mit der Befragung begannen.

Nicht alle Posten sind einzeln mit einer Summe ausgewiesen, manchmal werden mehrere $\mathrm{zu}$ einem Preis zusammengefasst, was darauf hindeutet, dass der Aufkäufer die Ware in diesem Fall als Gesamtpaket erstand, ohne dass um den Preis für jeden einzelnen Artikel verhandelt wurde. Insgesamt lassen sich die Aufkäufer nach der Menge der Ware und dem daraus ableitbaren Zweck des Geschäfts in drei Kategorien einteilen: zunächst die Masse derer, die für den unmittelbaren Eigenbedarf kauften, sodann einige, die die Ware offenbar auf Vorrat für eventuelle Gelegenheitsverkäufe erwarben, ohne dass der Handel ihre Haupterwerbstätigkeit darstellte, und schließlich eine Gruppe von Personen, deren Einkauf ganz offensichtlich die Absicht einer hauptsächlich kommerziellen Nutzung zu Grunde lag: die Weiterverarbeitung oder der Verkauf der Ware im großen Stil. ${ }^{113}$ Auf diese Kategorien verteilen sich die 569 Befragten, die selbst etwas kauften, ${ }^{114}$ folgendermaßen: 471 von ihnen kauften ausschließlich für den Eigenbedarf, 53 für Gelegenheitsverkäufe und 45 zum Zweck der kommerziellen Nutzung; diese letzte Gruppe grenzt sich zumeist klar von den anderen beiden ab, wie ein paar Beispiele zeigen: Francesco di Possente (143) kaufte 179 Artikel, hauptsächlich Wäsche, dazu 6 Rollen Leintuch und 89 Pfund Hanf; Mazzone di Cabello (197) erwarb einen Posten mit 110 Baretten und Bartolomeo di Zanobi (46) einen mit 500 Stücken Leder zur Herstellung von Taschen. Viele der größeren Transaktionen vor allem von Getreide kamen nicht durch die Erklärungen der Aufkäufer selbst ans Licht, sondern durch Denunziation von Personen, die in deren Auftrag den Abtransport erledigten: "Chino di Piero di Chino da Campale disse havere recato lui o suoi compagni per uno spagniuolo a Pistoia e scharico al podere di Vincente Collesi e consegnate a Mariotto Cellise 9 carrate di grano." (557) Die meisten scheinen sich unter dem Druck des Verhörs durch den Verweis auf Dritte selbst zu entlasten versucht haben. Die Tatsache, dass für diese Wagenladungen fast nie Preise genannt werden, deutet in der Tat darauf hin, dass die Denunzian-

113 Natürlich ist diese Einteilung etwas willkürlich, da die Grenzen zwischen den Kategorien nicht scharf zu ziehen sind, sie dient mehr als Arbeitshypothese: Eigenbedarf wird unterstellt bei Warenmengen bis 50 Pfund Tuch, Wolle oder Rohstoffen oder 10 Ellen Tuch, bei Getreide bis 20 staia und anderen Lebensmitteln bis 10 staia oder 4 barili; Gelegenheitsverkäufe bei darüber hinausgehenden Mengen bis zu folgender Grenze: 150 Pfund Tuch, Wolle oder Rohstoffe oder 30 Ellen Tuch, Getreide über 60 staia. Kommerzielle Nutzung beginnt bei darüber hinausgehenden Mengen sowie bei ganzen Wagenladungen und schließlich bei Posten mit 20 oder mehr Einzelstücken derselben Ware.

1149 Personen treten ausschließlich als Denunzianten in Erscheinung. 
ten lediglich als Lieferanten fungierten und mit dem Verkauf selbst nichts zu tun hatten. Von den insgesamt etwa 2.500 Florin des Warenwertes der ausgewiesenen Posten verteilt sich mehr als ein Viertel auf die Großeinkäufer. Andere wiederum organisierten sich selbst in Gruppen, so etwa fünf Personen aus Agliana (489), die zusammen aufbrachen und insgesamt 6 Wagenladungen Stoffe und Getreide mitbrachten, die sie über einen Dritten als Mittelsmann im Haus eines Vierten in Pistoia zwischenlagerten - dieser war übrigens nicht etwa Kaufmann, sondern Fassbinder von Beruf. Daneben bediente sich jeder der Lieferanten auch selbst.

Auch der weitere Umschlag der Ware in der Stadt und im Umland von Pistoia lässt sich mit Hilfe der Liste verfolgen. Einige der erwähnten Personen können über die Angaben der Befragten miteinander verknüpft werden. Gerolamo del Bati (20) kaufte ein Tuch bei Filippo di Tommaso, einem Tuchfärber, der seinerseits in der Liste auftaucht (21), und zwar als Aufkäufer von drei Posten Tuch, die er von drei verschiedenen Personen erwarb. Einer dieser drei ist Astore Astesi, selbst kein unbeschriebenes Blatt in der Liste: zwar gehört er, obwohl aus Pistoia, nicht zu den Befragten, aber mehrere andere erwähnen ihn als Verkäufer der Ware, die sie selbst erstanden hatten. Bei den anderen beiden handelte es sich ganz offensichtlich um Gelegenheitsverkäufer. Dass viele dieser Zwischenhändler und Lieferanten semiprofessionell arbeiteten, wird auch daran deutlich, dass sie einen Teil der Ware zum Verkauf lagerten und einen anderen für sich selbst behielten. Desiderio Giaconelli (559) zog nach Prato, lud Getreide auf und brachte einen Teil davon zum Verkauf nach Pistoia und den Rest zu seinem Haus in Preciana, wie übrigens nicht er, sondern sein Bruder aussagt. Giovanni di Marietto (558), der im Auftrag Dritter eine Wagenladung mit Bettwäsche von Prato nach Pistoia schaffte, nutzte die Gelegenheit, einige ausgewählte Stücke für sich selbst abzuzweigen. In einigen Fällen waren sogar Einwohner aus Prato selbst in die Geschäfte verwickelt: Lapo Giribelli (443) jedenfalls kaufte seine Ware bei seinem Cousin Biagio aus Prato, und auch Bello Bellieri (386) fand einen Anbieter direkt vor Ort.

Für die Beute aus Prato interessierte man sich nicht nur in Pistoia: der oben schon erwähnte Francesco di Bastiano (575) beobachtete den Mailänder Kaufmann Vittorio bei seinen Verhandlungen mit den beiden Geschäftsleuten aus Bologna. Vittorio selbst gehörte ebenfalls zu den Befragten, und seine Erklärung bestätigt in etwa die Beobachtungen des Denunzianten, auch wenn von den Händlern aus Bologna bei ihm kein Wort fällt. (100) In der Erklärung von Giovanni di Marietto (558) findet man sie möglicherweise wieder, dieser brachte eine ganze Wagenladung mit Tuchwaren zu einem Haus, in dem nach seiner Aussage einige Herren aus Bologna residierten, und lud sie dort ab. Ein anderer kaufte ein Priestergewand von einem Händler aus Lucca, der sich vorübergehend in der Stadt aufhielt. (12) 
Beim Getreide lassen sich solche Geschäfte und die Verflechtungen, die sich aus ihnen ergaben, etwas besser verfolgen. Offenbar fragten die Kommissare bei größeren Mengen Getreide - die in der Tat bis auf wenige Ausnahmen die bedeutendsten Posten in der Liste ausmachen - genauer nach der Herkunft. Hier sind die befragten Personen zumeist nicht nur Aufkäufer, sondern vor allem Denunzianten wie Francesco di Giorgio (248), der zunächst acht Abnehmer von größeren Getreidemengen namentlich nennt und einige Bauern aus der Umgebung als Käufer kleinerer Mengen erwähnt, bevor er zugibt, selbst auch etwas gekauft zu haben, allerdings kein Getreide, sondern eine Jacke. Da die Mengen von Getreide zumeist ziemlich groß sind, nämlich im Durchschnitt etwa $600 \mathrm{~kg}$ pro Posten, wurde es wohl von vornherein mit dem Ziel des Weiterverkaufs aus Prato geholt. In der Tat sind bei den meisten dieser Posten mehrere Namen angegeben, durch deren Hände die Ware ging. Einige dieser Namen wiederholen sich, wie etwa Antonio Tartaglia, der von zwei Zeugen $(55,248)$ als Aufkäufer einer großen Menge von Getreide denunziert wurde, bei seiner eigenen Befragung (139) aber den größten Teil davon unterschlug. Nanni Tinghi, der von drei Zeugen als Aufkäufer genannt wird (275, 314, 569), versuchte den Kommissaren offenbar weiszumachen, die Spanier hätten sein Haus geradezu gegen seinen Willen als Zwischenlager für das Getreide benutzt, um es an jemand anders weiterzuverkaufen: "... 98 staia di grano gli furono messe in casa da spagniuoli el quale grano compero da decti spagniuoli Francesco Damideo ..." (492) In Wahrheit aber hat man es bei den meisten vor allem im Zusammenhang mit Getreideverkäufen mehrmals erscheinenden Personen ganz offensichtlich mit Händlern zu tun, die den Ausverkauf der Beute nutzten, um im großen Stil daran zu verdienen. Die vielfältigen Verstrickungen einzelner Personen in die Geschäfte mit der Beute ergeben ein eindrucksvolles Bild von dem Verteilernetz, das sich nach kurzer Zeit im Umland einer geplünderten Stadt etablierte. Es gab keine klare Trennung zwischen Anbietern und Abnehmern, abgesehen von den zahlreichen Händlern fand sich eine nicht geringere Zahl von Privatleuten, die auf dem Beutemarkt ihr kaufmännisches Talent entdeckten. Wieder andere verdienten sich ein Zubrot durch die Organisation und Abwicklung der Transporte.

Aufschlussreich für die Praxis des Abtransportes der Beute ist in diesem Zusammenhang auch ein Seitenblick auf die Liste aus Firenzuola. Hier spielte der Weiterverkauf der Beute offenbar eine viel geringere Rolle als in Pistoia. Die Liste enthält nur 56 Namen und 196 Posten im Gesamtwert von lediglich 85 Florin. Die einzelnen Posten sind viel weniger umfangreich und solche mit Getreide fehlen fast ganz. Nun sind es von Prato nach Pistoia nur etwa $20 \mathrm{~km}$ durch relativ flaches Gelände, nach Firenzuola aber mehr als $40 \mathrm{~km}$ durchs Gebirge. Offenbar wollte niemand den ansteigenden Rückweg mit allzu schwerer Ladung auf sich nehmen, darüber hinaus ließ sich die Ware in Pistoia besser weiterverkaufen, weshalb die Einkäufer aus Firenzuola eher für den Eigenbedarf kauften als die aus Pistoia. Die- 
se beiden Umstände führten dazu, dass der Wert des durchschnittlichen Warenkorbes aus Pistoia den aus Firenzuola immerhin um das Dreifache überstieg.

\section{Ware}

Die aufgekaufte Ware in der Liste aus Pistoia lässt sich in 7 Kategorien unterteilen. Dazu kommen noch einige andere Artikel, die sich keiner der Kategorien zuordnen lassen, wie einige Waffen und Rüstungen, die man offenbar gefangenen Verteidigern abgenommen hatte und Beute, die aus Kirchen stammte, bezeichnenderweise aber keine wertvollen Messgeräte. Bei einigen wenigen Artikeln lässt sich auch nicht mehr feststellen, um was es sich handelt. Die prozentuale Verteilung der 2.211 Posten, die zugeordnet werden können, auf die einzelnen Kategorien sieht folgendermaßen aus:

\begin{tabular}{|l|c|c|c|}
\hline Warenkategorie & Posten & Anteil & Stückzahl \\
\hline Hausrat & 765 & $34,6 \%$ & 1.147 \\
\hline Kleidung & 568 & $25,7 \%$ & 1.093 \\
\hline Tuchwaren & 492 & $22,3 \%$ & 1.063 \\
\hline Stoff und Leder & 186 & $8,4 \%$ & - \\
\hline Lebensmittel & 98 & $4,4 \%$ & - \\
\hline Transportmittel & 71 & $3,2 \%$ & 74 \\
\hline Rohstoffe & 31 & $1,4 \%$ & - \\
\hline
\end{tabular}

Die meisten der verkauften Artikel fallen in die Kategorie Hausrat, in der sich gleichzeitig die größte Heterogenität feststellen lässt. Die Sortierung der einzelnen Artikel gleicht dem Rundgang durch einen durchschnittlichen Haushalt in Prato vom Schlafzimmer bis in den Werkzeugschuppen. Die gefragtesten Artikel dienten dem Schlafkomfort: nicht weniger als 134 Matratzen fanden den Weg nach Pistoia, gefolgt von 108 Federbetten, 24 Kissen und 18 Bettwärmern aus Metall. Die größte Auswahl bot sich den Plünderern - und später den Aufkäufern - allerdings in der Küche: die Liste führt alle Arten von größeren und kleineren Küchengeräten - von Kochkesseln über Töpfe, Pfannen, Krüge und Kannen bis hinunter zu Reiben und Suppenkellen. Teller und Besteck dagegen finden sich weitaus weniger als man erwarten möchte. Insgesamt 255 Küchenartikel führt die Liste. Meistens wird das Material angegeben, aus dem die Ware gefertigt ist, vor allem Kupfer und Zinn. Die Tendenz zur Angabe des Materials setzt sich auch außerhalb der Küche bei fast allen Artikeln fort, die aus Metall bestehen: an Kerzenleuchtern - zumeist aus Messing - wurden immerhin 93 nach Pistoia verkauft und an eisernen Kaminrosten 41, bei diesen wird ebenso wie bei den 28 Waagen bisweilen auch das Gewicht angegeben. Das Vorkommen von Waagen überhaupt und vor allem deren aus den Gewichtsangaben ablesbare Größe - die schwerste (440) wiegt 
320 Pfund - deuten schon darauf hin, dass die Beute nicht nur aus privaten Haushalten, sondern auch aus Gewerbebetrieben und Läden stammte. Die Kategorie Hausrat ist notgedrungen sehr weit gefasst, da der Hausrat im eigentlichen Sinn auf Grund der ungenauen Angaben in der Liste oft schwer zu trennen ist von Artikeln, die zur Ausrüstung von Gewerbetreibenden gehörten. Das trifft des weiteren auch auf alle Arten von Werkzeugen zu: solche für alltägliche Arbeiten in Haus und Garten, nämlich Zangen und Scheren, Sägen, Hacken, Äxte und Mistforken, darüber hinaus aber eben auch immer wieder solche, die eine berufliche Spezialisierung der ehemaligen Besitzer zumindest vermuten lassen - ganze Pflüge und einzelne Pflugscharen, auch diese manchmal mit Gewichtsangabe, Ambosse, Mörser, Backformen und Wollkämme. Bei einigen Artikeln wird deren professionelle Bestimmung auch durch einen erklärenden Zusatz deutlich, wie bei zwei "barini da barbiere" (17) oder einem "coltello da calzolaro" (5). Dass nicht alle Beute aus privaten Haushalten stammte, zeigt sich schließlich manchmal auch an der Menge: ein Posten mit 250 Pfund Seife (72) gehörte mit Sicherheit zu den Lagerbeständen eines Händlers oder wurde direkt aus der Siederei geholt. Insgesamt 119 Werkzeuge wurden in Pistoia verkauft, daneben waren auch vielseitig verwendbare Behälter beliebt, im einzelnen 48 Körbe, 43 Kübel, 41 Fässer und 36 Eimer. Weitere weniger zahlreich vertretene Einrichtungsgegenstände finden sich in bunter Mischung: Teppiche, Öllampen, Spiegel, sogar ein Schachspiel und ein Tintenfass werden einzeln verzeichnet. Dazu kommen einige vereinzelte Bücher und einmal eine ganze Bibliothek, die ziemlich achtlos verpackt in fünf Säcken zu ihrem neuen Besitzer fand. (339)

Die Kategorie Kleidung ist viel klarer strukturiert. Hier überwiegt Oberbekleidung verschiedenen Zuschnitts: 138 Roben, 134 Hemden und 93 Mäntel führen die Liste der Beliebtheit bei größeren Kleidungsstücken an, zahlenmäßig bedeutend sind weiterhin 163 Tücher und 197 Kopfbedeckungen, diese allerdings kommen vor allem durch zwei große Posten $(97,265)$ zu Stande, die wahrscheinlich wieder aus Läden oder Manufakturen stammten. Des weiteren finden sich 40 Jacken, 34 Hosen, 23 Kittel und 23 Umhänge. Die geringere Vielfalt der Bezeichnungen und vor allem die große Menge der Ware brachte die Notwendigkeit mit sich, die einzelnen Kleidungsstücke näher zu beschreiben. Auf diese Weise geben die Kommissare ganz nebenbei und unfreiwillig einen Einblick sowohl in die profane als auch in die sakrale Kleidermode ihrer Zeit: Bastiano di Piero (146) kaufte eine "cappa cum capperuccia alla spagnuola con mostra di velluto nero", Lazzero di Jacopo (15) eine "cioppetta monachina buona con velluto damaso da capo". Daneben werden ab und zu Farben genannt und Angaben über den Zustand gemacht. Nur wenn es sich um äußerst wertlose Artikel handelte, wird zusammengefasst, etwa bei einem von Vangiolista Fachetti (377) gekauften Posten von "23 capi di pannacci da contadini singoli." In der Regel ließ man Sorgfalt walten und führte selbst Unterwäsche gesondert auf, wie bei Alberto Collesi (532), der "camice sei da huomo e una da donna da contadini e un paio di mutande" kaufte. 
Die Tendenz der Soldaten, auch die unbedeutendsten Sachwerte zu Geld zu machen, setzt sich auch in den anderen Kategorien fort. Laken sind nicht nur in der Kategorie der Tuchwaren, sondern mit 247 Nennungen insgesamt der beliebteste größere Artikel überhaupt, daneben finden sich vor allem Taschentücher, Handtücher, Bettdecken und Tischdecken.

Die Kategorie Stoff und Leder umfasst die wichtigsten Materialien zur Herstellung von Textilien und Lederwaren aller Art. Am häufigsten sind Wolle und Leinen vertreten, aber auch eine ganze Reihe anderer und zumeist teurerer Stoffe in geringeren Mengen, sowie offenbar unbrauchbare Kleidungsstücke, die einfach abgewogen wurden. Neuer Stoff dagegen wurde nach Länge gemessen oder in ganzen Rollen verkauft. Leder wird wie auch einige Stoffe in der Regel in Stückzahlen angegeben, bisweilen erfährt man auch, ob die Ware schon gegerbt ist und was aus ihr hergestellt werden soll. Da die Verarbeitung von Stoff und Leder ein Mindestmaß an beruflicher Ausbildung verlangte, manifestiert sich in dieser Kategorie eine starke Überrepräsentation von Aufkäufern mit kommerziellem Interesse, wie aus den Mengenangaben ersichtlich ist.

Bei den Lebensmitteln überwiegt Getreide, das, wie erwähnt, fast immer in relativ großen Mengen und damit wohl oft für den Weiterverkauf erworben wurde. Erwiesenermaßen für den Eigenbedarf hatte der Schmied Bastiano di Salvatore (168) aus Pistoia gekauft, der zwar den Erwerb von 6 staia $^{115}$ Getreide zugab, die Ware aber nicht mehr herausgeben konnte, weil er bereits alles aufgegessen hatte: "6 staria di grano il quale sa mangiato." Neben dem Getreide kommen kaum andere Lebensmittel in der Liste vor, die einzigen Posten von einiger Bedeutung betreffen Bohnen und Öl.

Die Kategorie der Transportmittel lässt sich in Wagen und Tiere einteilen. 44 Karren kommen in der Liste vor, an Tieren vor allem Esel, daneben ein paar Ochsen und Pferde. Interessanterweise wurden ausgerechnet die Esel von den Kommissaren auf das Sorgfältigste mit Attributen zur Wiedererkennung versehen: unter den 23 Eseln der Liste befinden sich 15 Weibchen und 8 Männchen, die meisten sind grau, einige auch schwarz oder weiß. Insgesamt 9 von ihnen haben einen Tragsattel aufgeschnallt, eine Eselin ist lahm und eine schließlich wird geradezu liebevoll als "pulchera asinina con pelo nero" bezeichnet. (117) Unter den Rohstoffen schließlich findet sich fast ausschließlich Eisen und Zinn. Vor allem das Eisen scheint zur Wiederverwendung und Weiterverarbeitung bestimmt gewesen zu sein, beim Zinn hingegen wird oft genauer angegeben, aus was sich der entsprechende Posten zusammensetzt. Dabei handelt es sich vor allem um Teller, Schüsseln und Besteck. Offenbar ging man bei aller Gewissenhaftigkeit nicht davon aus, derart nichtssagende Artikel noch ihren ursprünglichen Besitzern zuordnen zu können und fasste sie in Posten zusammen, deren Wert nach dem Gewicht bestimmt wurde. Das erklärt auch, warum unter der Kategorie Hausrat solche Artikel nur in wenigen Ausnahmefällen figurieren.

115 Nach Florentiner Maß: 1 staro $=24,3631$. 
Zusammenfassend lässt sich sagen, dass die Liste einen fast vollständigen Überblick über die Ausstattung zumeist einfacher Haushalte und Läden der Epoche gibt, wobei die Überrepräsentation von Kleidung, Bettwäsche und Stoffen aller Art dem Umstand Rechnung trägt, dass in Prato vor allem Textilmanufaktur ansässig war. Ein Blick auf den Hausrat zeigt, bis zu welchem Grad einfache Familien durch die Plünderung ruiniert wurden. In vielen Häusern blieb scheinbar fast nichts zurück, und während viele noch überlegten, wie sie Kinder auslösen konnten, die noch nach Wochen als Geiseln von den Soldaten gefangen gehalten wurden, verteilte sich ihr Besitz bereits im ganzen Land.

Das Fehlen von Wertgegenständen verwundert nicht, sondern passt vielmehr zu den Aussagen anderer Quellen. Es genügt ein Blick zurück auf das Bild, das sich einige Tage vor der Ankunft der Spanier vor den Toren von Florenz bot: die Wagenkolonnen aus Prato und dem gesamten Umland stauten sich eine Meile lang vor der Stadt, die Wachen waren mit dem Ansturm derart überfordert, dass man die Wagen passieren ließ, ohne die Ladung zu kontrollieren. ${ }^{116}$ Dass in Prato nicht viel verblieb, wird von Bewohnern und Soldaten gleichermaßen bestätigt: Bonaventura Pistolfilo, Augenzeuge der Plünderung, schrieb schon am 29. August an Kardinal Hippolito d'Este, die Spanier seien unzufrieden mit der Beute, weil alle Wertgegenstände nach Florenz geschafft worden seien, ${ }^{117}$ und einer von Cardonas Soldaten, der einige linkische Briefentwürfe in Prato zurückließ, machte seiner Enttäuschung über die seiner Ansicht nach offenbar viel zu mager ausgefallene Beute Luft: "... secundo agio visto delo sacco non fu molto grandi che le citati ricchi se erano partiti et andati in Fiorenza et alcuni mandati illa la roba." ${ }^{118}$ Die Tatsache, dass noch nicht einmal ein einziger Trauring oder ähnlich alltägliche Schmuckstücke in der Liste auftauchen, befremdet indes schon. Hier bieten sich verschiedene Vermutungen zur Erklärung an: einige Wertgegenstände, die nicht in Sicherheit gebracht worden waren, werden auch von den Bewohnern selbst versetzt worden sein, um die Lösegelder zu bezahlen, einige wurden sicherlich von den Soldaten behalten, und schließlich darf man die Marketender nicht vergessen, die das Heer begleiteten und daher im Gegensatz zu auswärtigen Aufkäufern sofort vor Ort waren, so dass sie die attraktivsten Beutestücke möglicherweise schon aufgekauft hatten, bevor die Nachricht von der Plünderung in den Nachbarstädten angekommen war. Allein die Tatsache, dass die Soldaten gebrauchte Kleidung und Altmetall anboten, ist indes Beweis genug dafür, dass die Beute für die meisten von ihnen alles andere als spektakulär ausfiel. Das gilt im übrigen für alle anderen Plünderungen des untersuchten Zeitraums. Von der Plünderung von Vicenza im Mai 1510 wird berichtet, dass die offensichtlich zu spät gekommenen Landsknechte die Eisengitter von den Kellerfenstern rissen, um sie zu ver-

\footnotetext{
116 LANDUCCI, LUCA: Diario fiorentino dal 1450 al 1516 continuato da un anonimo fino al 1542 . Hrsg. v. Iodoco del Badia. Florenz 1883. S. 321.

117 GUASTI, Il sacco di Prato, Dispensa 178, S. 121.

118 ASP Ceppi 96, fol. $87^{\mathrm{V}}$.
} 
kaufen. ${ }^{119}$ Auf diese Weise relativieren sich die Zeugen in ihrem Hang zur Polarisierung unfreiwillig selbst: während die Verluste der Opfer in ihrer dramatischen Vollständigkeit zum Ausdruck kommen, wird gleichzeitig eindrucksvoll belegt, dass die Beute sich am Ende immer sehr ungleichmäßig verteilte.

\section{Preise}

Die Warenmengen, die nach einer Plünderung in Umlauf gerieten, waren ungeachtet des Fehlens von Wertgegenständen beachtlich, da den interessierten Aufkäufern neben der Ware der geplünderten Läden und Gewerbebetriebe, wie oben gesehen, auch noch der Privatbesitz der Einwohner angeboten wurde. Dabei dürfte es nicht allzu schwer gewesen sein, mit den Soldaten handelseinig zu werden, da diesen meistens in absehbarer Zeit der Abzug bevorstand und sie daher ein Interesse hatten, einen möglichst großen Teil der Beute loszuwerden. Dieses Überangebot und die Tatsache, dass es sich zu einem guten Teil um gebrauchte Ware handelte, lässt einen erheblichen Preisunterschied zwischen dem Beutemarkt und dem normalen Markt vermuten. In der Tat sprechen Augenzeugen zumeist von einer regelrechten Verschleuderung der Ware. Wieder soll kurz das Beispiel des Sacco di Roma bemüht werden, hier war die Situation geradezu paradox: dem Überfluss an Reichtümern, die den Soldaten in die Hände fielen, stand ein bedrohlicher Mangel an Lebensmitteln gegenüber, der darauf zurückzuführen war, dass kaum ein Händler es wagte, die verseuchte und von immer neuen Ausschreitungen heimgesuchte Stadt zu betreten. Die Abwesenheit von auswärtigen Händlern führte dazu, dass die Lebensmittelpreise sprunghaft anstiegen, während die Situation auf dem Beutemarkt den Augenzeugen wegen der Missachtung einst hoch geschätzter Werte durch Soldaten wie Aufkäufer zusätzliche Äußerungen des Entsetzens entlockte. Und diese Missachtung äußerte sich eben auch in den Preisen. Systematisch auswertbare Quellen sind dazu nicht bekannt und existieren aller Wahrscheinlichkeit nach auch nicht; die berichtenden Quellen sind wegen der Neigung der Zeitgenossen zur Übertreibung mit Vorsicht zu genießen. In einem anonymen Bericht heißt es, dass Edelsteine teilweise für ein Fünfzigstel ihres Wertes verkauft wurden und silberner Schmuck aus Kirchen für die Hälfte des Wertes der Münzen, die man daraus hätte prägen können. Das sei zum einen auf die Ignoranz der Soldaten zurückzuführen, zum anderen darauf, dass man wegen der Nähe des Heeres der Liga den baldigen Auszug erwartete. Als das Ligaheer unverrichteter Dinge abzog und die Lage sich vorübergehend entspannte, kamen auch Händler in die Stadt und die Preise auf dem Beutemarkt zogen an. ${ }^{120}$ Dass die Wertgegenstände zu

119 PORTO, Lettere storiche, S. 200.

120 Rodriguez ViLlA, Memorias, S. 139. Es heißt, ein Pfund Silber sei für 4 oder 5 Dukaten verkauft worden. Ein Pfund nach römischem Maß entspricht $339 \mathrm{~g}$ und damit dem Silbergehalt von etwa 93 Giulii, die 
diesem Zeitpunkt schon nicht mehr auf der Straße herumlagen, wird auch daran deutlich, dass die Gelegenheitshändler am Ufer des Tiber das aus den Häusern gerissene Metall zum Kauf anboten. ${ }^{121}$ Erst als die Besatzung sich hinzog und eine Epidemie in der Stadt ausbrach, verfielen die Preise erneut: ein zuverlässiger Zeuge, der spanische Botschaftssekretär Perez, berichtete zwei Monate nach dem Beginn der Plünderung und unmittelbar nach dem vorläufigen Abzug des Heeres an den Kaiser, dass die Landsknechte kurz vor dem Aufbruch alles verkauft hätten, was sie nicht hatten mitschleppen können, die Ware sei für ein Fünftel ihres Wertes abgegeben worden. Was nicht verkauft werden konnte, wurde einfach auf die Straße geworfen. ${ }^{122}$

Zurück nach Prato. Hier gab es von Anfang an keine Erschwernisse für den Handel mit der Beute: die Soldaten konnten schnell unter Kontrolle gebracht werden und es kam nicht zu Ausschreitungen wie in Rom, auch eine Epidemie blieb aus trotz der vielen Toten, die nach den Aussagen mehrerer Zeugen in den Brunnen lagen. ${ }^{123}$ Und so strömten nach kürzester Zeit die Aufkäufer in die Stadt. Jacopo Salviati schrieb schon am 1. September an die Signoria in Florenz, wegen des Ansturms der Nachbarn sei die Demontage der gesamten Stadt zu erwarten, und was jetzt noch für einen Dukaten zu haben sei, werde bald das Zehnfache kosten. ${ }^{124}$ Auch hier scheinen die Preise also nach Angebot und Nachfrage erheblichen Schwankungen unterworfen gewesen zu sein. Leider kann man diesen Anzug der Preise an der Beuteliste aus Pistoia nicht festmachen, da fast nie angegeben ist, wann die Ware von den Befragten gekauft wurde.

Es soll nun ein kurzer Blick darauf geworfen werden, in welchem Verhältnis die Preise des Beutemarktes zu denen des normalen Marktes standen, wie bedeutend also der Preisnachlass auf dem Beutemarkt gegenüber dem Neupreis der entsprechenden Ware war. Bei den meisten Waren, vor allem aber bei den Textilien zeigt sich auf dem Beutemarkt eine so weite Preisspanne, dass ein ermittelter Durchschnittspreis an Aussagekraft stark einbüßt und kaum zur Grundlage einer These gemacht werden kann. Lediglich bei den Hemden schwanken die Preise viel weniger und gruppieren sich relativ dicht um einen Bereich von etwa 20 bis 30 Soldi. Das erlaubt auch eher einen Vergleich mit dem ungefähren Preis für ein Hemd, wie er etwa zur gleichen Zeit in Florenz gezahlt wurde, nämlich etwa 60 Soldi. ${ }^{125}$ Daraus ergibt sich, dass Hemden auf dem Beutemarkt im Schnitt für ein Drittel bis die Hälfte des Neupreises angeboten wurden, was angesichts der Tatsache, dass es sich zu-

wiederum knapp zehn Dukaten entsprechen.

121 GuAlderonico, T.: Gli orrori del saccheggio di Roma l'anno 1527 descritti da un cittadino romano di quel tempo. Hrsg. v. M. Armellini. In: Cronachetta mensuale di scienze naturali e d'Archeologia. Jg. 20, Fasc. 6 (1886). S. 92.

122 RodrigueZ Villa, Memorias, S. 247.

123 Modesti, Bericht, S. 239. Ferner GuASTI, Il sacco di Prato, Dispensa 178, S. 231.

124 GUASTI, Il sacco di Prato, Dispensa 178, S. 161.

125 FAnfani, Amintore: Storia del lavoro in Italia. Bd. 3: Dalla fine del secolo XV agli inizi del XVIII. Mailand 1959. S. 352. 
meist um gebrauchte und zum völligen Ausverkauf bestimmte Ware handelte, immer noch ziemlich hoch erscheint. Bei Bettlaken ergibt sich eine ähnliche Relation, hier schwankt der Preis auf dem Beutemarkt zwischen 40 und 110 Soldi, während ein neues Laken für etwa 200 Soldi zu haben war. ${ }^{126}$ Hemden und Laken bieten sich für derartige Vergleiche an, da es sich um simple Stücke handelt, die nicht durch allzu große Unterschiede in der Ausführung einen unsicheren Durchschnittswert hervorbringen wie die meisten anderen Artikel. Bei den Lebensmitteln sind die Preise ähnlich stabil. Getreide schwankt zwischen 18 und 25 Soldi pro staro, bei einem stabilen Durchschnittswert von 20 Soldi. Auch dies entspricht in etwa der Hälfte des Marktpreises zur untersuchten Zeit. Die Behauptung eines Chronisten aus Prato, Getreide werde für 4 Soldi pro staro verkauft, lässt sich durch die Liste aus Pistoia nicht stützen. ${ }^{127}$

Als Bilanz aus solchen - wegen des Mangels an Zahlenmaterial leider sehr knappen - Vergleichen muss man feststellen, dass die Preise auf dem Beutemarkt in Prato vor allem für gebrauchte Kleidung doch nicht so niedrig waren, wie man auf Grund der Umstände vermuten möchte. Es bedurfte offenbar keines sensationellen preislichen Anreizes für die Aufkäufer, um sich die Garderobe auf Kosten der Opfer der Plünderung aufzustocken. Der große Zustrom lässt sich nur verstehen, wenn man bedenkt, dass es sich bei der Mehrheit der Endabnehmer um Personen mit geringen finanziellen Mitteln handelte, die den größten Teil ihrer Einkünfte für die Befriedigung der Grundbedürfnisse aufbrauchten. Kleidung und Bettwäsche waren für die meisten von ihnen zusätzliche Ausgaben, die sie sich selten leisteten: ein Maurer aus Florenz hätte für ein Hemd vier Tage und für ein Paar Bettlaken mehr als drei Wochen arbeiten müssen. ${ }^{128}$ So stellten die auf den ersten Blick geringen Beträge, die die meisten der Befragten aufbrachten, nicht selten den Gegenwert von mehreren Wochen Arbeit dar. Vor allem dieser Umstand schuf eine Gesellschaft, in der kaum etwas weggeworfen und fast alles entweder wiederverwendet oder weiterverarbeitet wurde. Das zeigt vor allem die große Beliebtheit von Rohstoffen und eben von gebrauchter Kleidung, die sich aus der Liste ergibt: es ist durchaus vorstellbar, dass viele der Aufkäufer in Pistoia die Kommissare in der Kleidung der Geschädigten an der Tür empfingen.

\section{Aufkäufer}

Über die Aufkäufer selbst sind nur wenige Informationen in der Liste verstreut. Der Wohnort ist die einzige Angabe, die von fast allen gemacht wird, daneben erfährt man manchmal

126 FAnfani, Storia del lavoro, Bd. 3, S. 352. Fanfani spricht von 19 Lire, also 380 Soldi als Preis für ein Paar Laken, während in der Beuteliste von Einzelstücken die Rede ist.

127 BRP, MS 72, S. 369.

128 FANFANI, Storia del lavoro, Bd. 3, S. 352f. 
die Herkunft und den Beruf. Die Berufsangabe ist von allen die wertvollste, weil sie etwas über den sozialen Status und die finanziellen Möglichkeiten der Befragten aussagt und dementsprechend, zu den Angaben über die gekaufte Ware in Beziehung gesetzt, immerhin einige Schlüsse über die Motive des Kaufs ermöglicht. Nur sehr selten schimmert auch eine persönliche Note der Befragten durch.

Von den insgesamt 578 Befragten machen 516 eine brauchbare Angabe des Wohnortes. Von diesen lebten 275 oder $53 \%$ in der Stadt Pistoia, die restlichen 241 nennen einen anderen Wohnort: 175 oder 34 \% von ihnen lebten demnach in kleineren Orten des Contado von Pistoia. In Stadt und Umland von Pistoia lebten also etwa $87 \%$ aller Befragten. Bei den restlichen $13 \%$ handelte es sich zum Teil um Besucher, was durch den Zusatz "sta in Pistoia" deutlich wird, oder um Personen, die bei Nachforschungen in außerhalb des Contado von Pistoia gelegenen Orten erfasst wurden. ${ }^{129}$ Betrachtet man die von den Aufkäufern angegebenen Wohnorte auf der Landkarte im einzelnen, so stellt sich heraus, dass die meisten von ihnen, vor allem die, aus denen eine große Zahl von Aufkäufern kam, südöstlich von Pistoia und damit in Richtung Prato gelegen sind. Das lässt darauf schließen, dass das Einzugsgebiet des Beutemarktes in der geplünderten Stadt zumindest für private Aufkäufer sich jenseits einer gewissen Grenze schnell verlief. Wer von weiter her kam, deckte sich offenbar in Pistoia bei den Zwischenhändlern ein. Die folgende Karte gibt einen Überblick über die Wohnorte der Aufkäufer und die Häufigkeit ihrer Erwähnung:

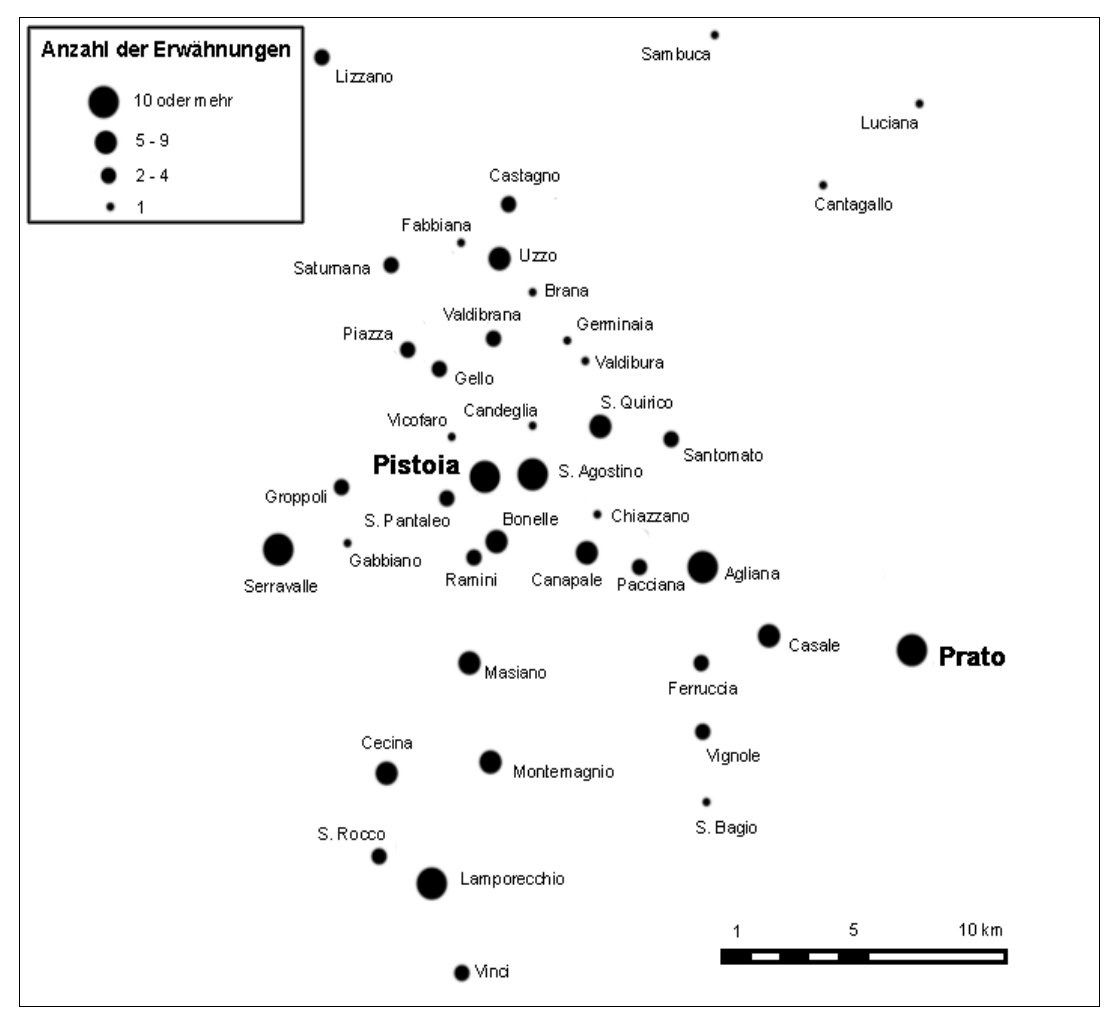

129 Warum die Kommissare in einigen wenigen Fällen außerhalb des Contado nachforschten, ist rätselhaft. 
Die wichtigste Information, die die Liste darüber hinaus über die Aufkäufer vermittelt, ist, wie gesagt, deren Beruf. Insgesamt 80 Personen geben ihren Beruf an, es handelt sich dabei fast ausschließlich um typische städtische Gewerbetreibende: angeführt wird die Liste von 7 Schuhmachern, es folgen 6 Barbiere, jeweils 5 Schmiede und Müller, 4 Schneider und Herolde, daneben mehrere Angehörige weiterer Handwerksberufe wie Wollweber, Tuchfärber, Bäcker, Weber, Maler, Maurer, Kübelmacher, Wollschläger und vereinzelte weitere Berufe, schließlich einige Geistliche. Die Vielfalt der Berufe an sich zeigt bereits die Selbstverständlichkeit, mit der sich breite Bevölkerungsschichten am Aufkauf der Beute beteiligten.

Die Zusammenhänge zwischen den Berufen der Aufkäufer und der Art und der Menge der Ware bestätigen die oben aufgestellte Einteilung der Aufkäufer in drei Kategorien. Dass die Ware teilweise zum Zweck einer hauptberuflich ausgeübten kommerziellen Nutzung gekauft wurde, zeigt sich neben dem Umfang der Posten nämlich oft auch an den Berufen der Befragten: so ist es kein Zufall, dass ausgerechnet ein Kürschner, Francesco Cinghi (71) einen Posten mit 180 Stücken unbearbeitetem Leder kaufte, und der Schmied Piero di Goro (501) gedachte die von ihm gekauften 750 Pfund Alteisen mit Sicherheit in seiner eigenen Werkstatt weiterzuverarbeiten. Bezeichnender noch als ein Zusammenhang zwischen Ware und Beruf ist es aber, wenn ein solcher Zusammenhang eben nicht besteht, die Menge der aufgekauften Ware aber darauf hindeutet, dass sie mit dem Zweck des Weiterverkaufs erworben worden war. Dieser Umstand zeigt ein weiteres Mal, dass findige Einwohner aus Pistoia sich durch die Beteiligung am Ausverkauf der Beute aus Prato einen Nebenverdienst erhofften, der mit ihrer eigentlichen Tätigkeit nichts zu tun hatte. Vor allem für Stoff gab es offenbar einen guten Markt in Pistoia. So kaufte der Müller Giuliano di Francesco (289) insgesamt 114 Ellen Tuch für fast 10 Florin. Neben ihm betätigten sich viele andere auf ähnliche Weise als Gelegenheitskaufleute.

Es ist schwer zu sagen, wie die moralische Beurteilung eines solchen Handelns bei den Zeitgenossen ausfiel. Verurteilungen finden sich natürlich vor allem von Seiten der Opfer. In der oben schon erwähnten Chronik aus Prato heißt es: "Non si tacera l'innumanita de vicini et altri soldati et Fiorentini che con le carre in quantita venivano a Prato a comprare i grani, olii, biade d'ogni sorte ..." ${ }^{130}$ Die weite Verbreitung des Phänomens, die sich aus der Liste aus Pistoia ergibt, widerspricht allerdings einer tief verwurzelten Einsicht in die Verwerflichkeit des Aufkaufs von Beute an sich, als die dieser von den Opfern empfunden wurde. Pistoia zählte zu jener Zeit weniger als 6.000 Einwohner. ${ }^{131}$ Bedenkt man, dass in der Liste 275 Einwohner von Pistoia als Aufkäufer figurieren und geht man weiterhin da-

130 BRP, MS 72, S. 369.

131 BELOCH, KARL JuLIUS: Bevölkerungsgeschichte Italiens. Bd. 2: Die Bevölkerung des Kirchenstaates, Toskanas und der Herzogtümer am Po. Berlin 1961. S. 169. Dort ist für das Jahr 1551 die Zahl von 6.000 Einwohnern angegeben, sie wird knapp 40 Jahre davor nach der allgemeinen demografischen Tendenz knapp darunter gelegen haben. 
von aus, dass an jedem Haushaltsvorstand im Durchschnitt fünf bis sechs Personen hingen, so ergibt sich, dass mindestens ein Viertel aller Einwohner von Pistoia in die Geschäfte mit der Beute aus Prato verwickelt war, wahrscheinlich aber noch mehr, wenn man unterstellt, dass es einigen gelang, sich dem Zugriff der Kommissare zu entziehen. Nicht weniger als die Verbreitung des Phänomens verblüfft auch die ganz selbstverständliche Verstrickung der Kirche in die Transaktionen, und zwar in allen möglichen Rollen: Cristofano di Mariotto (58) spendete ein aus der Beute gekauftes Altartuch an eine fromme Stiftung, und selbst ein Hospital aus Pistoia erscheint als Aufkäufer in der Liste. (155) Filippo di Tommaso (21) kaufte ein Tuch von einer gewissen Schwester Lorenza, Klosterfrau in Pistoia. Die Beteiligung von Geistlichen, die als Privatpersonen auftraten, ist durch weitere Mönche, Priester und einen Domkanoniker belegt. Aus all diesen Umständen lässt sich schließen, dass die Beteiligung am Handel mit Plünderungsbeute für die meisten Zeitgenossen durchaus nichts Anrüchiges war, selbst wenn die eigenen Nachbarn betroffen waren. Man kann sogar annehmen, dass viele sich insgeheim durch die Entschädigungsaktion um ihnen rechtmäßig zustehenden Besitz geprellt fühlten und daher den Kommissaren gegenüber bewusst falsche oder unvollständige Angaben machten. Lazzero di Nanni immerhin verleiht im Nachhinein, und vielleicht eher eingeschüchtert durch die angedrohte Strafe als getrieben von ehrlicher Reue und Einsicht in die sozusagen rückwirkend dekretierte Unrechtmäßigkeit seines Handelns, seinem schlechten Gewissen Ausdruck. Der Kommissar hielt in der Einleitung fest: "... volendo fuggire la pena del bando ... e per scharico di sua conscienza ..." (578) In der Regel aber wird durch die weite Verbreitung des Phänomens und durch die Tatsache, dass viele bereits aus zweiter und dritter Hand kauften, der Zusammenhang zwischen der Ware und dem Gedanken an die Plünderung immer indirekter und abstrakter geworden und damit das Gewissen der Aufkäufer immer weniger angesprochen worden sein.

\section{B. Lösegelderpressung}

Die Schätzung von gefangenen Feinden, mit anderen Worten: ihre Freilassung gegen Zahlung von Lösegeldern, war gängiger Brauch im Krieg, vor allem unter Adligen. Sieger und Besiegte beugten sich gleichermaßen einem Kanon von ritualisierten Spielregeln, durch die sowohl die Angemessenheit des Lösegeldes, als auch die Bedingungen der Gefangenschaft bestimmt wurden. Feilschen galt als stillos. ${ }^{132}$ Bald wurden auch einfache Soldaten um Lösegeld geschätzt, und zu Beginn des hier untersuchten Zeitraums hatten sich Konventionen für die Lösegelder etabliert, die sich nach dem Rang des Gefangenen richteten: für einfache

132 ERLER, Der Loskauf Gefangener, S. 43. 
Soldaten war der Sold eines Monats üblich, für Hauptleute der von sechs Monaten. Von Hauptleuten der schweren Kavallerie konnte man die Einnahmen eines ganzen Jahres fordern. $^{133}$

Durch die Verrohung der Soldaten, die im Verlauf der Kriege in Italien immer weiter fortschritt, verkam die Schätzung, die nun auch bei gefangenen Zivilpersonen angewandt wurde, mehr und mehr zu einer Form der erpresserischen Bereicherung um jeden Preis, die von allen Soldaten gegen alle Schichten der betroffenen Bevölkerung angewandt wurde. In Rom erreichten diese Auswüchse dramatische Höhepunkte, als Angehörige der höchsten gesellschaftlichen Schichten sich in der Gewalt von Soldaten wiederfanden, die bisweilen nicht davor zurückschreckten, ihren Forderungen nach astronomischen Lösegeldern durch Erniedrigungen und Misshandlungen Nachdruck zu verleihen. Im Unterschied zur Plünderung, bei der die Soldaten sich alles aneigneten, was ihnen gefiel, lag der Sinn des Lösegeldes darin, an Werte zu gelangen, die sich diesem direkten Zugriff entzogen.

Wie sich die Mechanismen der Lösegelderpressung vor allem an der breiten Masse der betroffenen Bevölkerung manifestierten, soll wieder am Beispiel von Prato dokumentiert werden. Hier schlug die Plünderung sich in den Akten der Notare im Gegensatz zu Rom fast gar nicht nieder. Die Reihe der Dokumente setzt bei den meisten von ihnen kurz vor der Ankunft des Heeres aus, offenbar hatten viele die Stadt verlassen und sich in Sicherheit gebracht. Erst nach dem Abzug der Soldaten nahmen sie die Arbeit wieder auf. Es existiert aus Prato allerdings eine Quelle, die die fehlenden Notarsakten mehr als ergänzt. Die im vorigen Abschnitt besprochene Entschädigungskampagne der Medici erstreckte sich neben der Rückerstattung des geplünderten Besitzes nämlich auch auf die Lösegelder. Um festzustellen, wie hoch die an die Spanier gezahlten Summen im einzelnen waren, wurden alle geschädigten Einwohner der Stadt aufgefordert, eine Erklärung abzugeben, die zur Grundlage einer Entschädigung gemacht werden konnte. Auf Grund der Tatsache, dass in diesen Erklärungen - zumindest war das die Absicht der Kampagne - alle geschädigten Bewohner eine Stimme bekamen, wird durch sie ein repräsentativer Teil der gesamten Bevölkerung erfasst.

\section{Die Lösegelderklärungen aus Prato}

Insgesamt 143 dieser Erklärungen haben sich in einer geschlossenen Sammlung erhalten. Der erste Eindruck dieser Schriftstücke gibt bereits ein Bild von ihrer Individualität: von Blatt zu Blatt wechseln Tinte und Handschrift, beim genaueren Durchsehen erkennt man,

133 Heros, Martin de los: Historia del conde Pedro Navarro, general de infantería, marina é ingeniero, en los reinados de Fernando y Isabel, y de doña Juana y su hijo don Carlos. In: Colección de documentos inéditos para la historia de España 25 (1854). S. 218. 
dass einige Hände in unregelmäßigen Abständen immer wieder auftauchen, viele aber auch nur einmal. Wie die Handschriften, so variiert auch die Erscheinung des Textes: einige Blätter sind von oben bis unten vollgeschrieben, andere enthalten nur wenige Zeilen. Eine Reihenfolge, die Rückschlüsse auf den Grund der Zusammenstellung gerade dieser 143 Erklärungen zulässt, ist nicht erkennbar. Es ist aber offensichtlich, dass es sich um einen Ausschnitt aus einer viel größeren Menge von Dokumenten handelt.

In den offiziellen Quellen sind im Gegensatz zu den Anstrengungen zur Rückerstattung der verkauften Beute keine Informationen darüber enthalten, in welchem Rahmen und unter welchen Umständen die Entschädigung für die Lösegelder stattfinden sollte. ${ }^{134}$ Aus einigen Wendungen in den Erklärungen geht aber klar hervor, dass man sich eine Erstattung des Geldes erhoffte: in einigen Erklärungen wird eine Anrede gebraucht, mit der die Regierung in Florenz oder deren verlängerter Arm in Prato gemeint ist. So erwähnt Francesco Fozzari $(137)^{135}$ in seiner förmlichen Anrede ausdrücklich eine Anweisung der Signoria: "Per cagione delli bandi mandati si notifica mandarsi alle spetabilita e prudensie vostre honorandi huomini di Balia della terra di Prato ..." Filippo di Piero (134) spricht eben diese Herren in seiner devoten Schlussformel an: "Rachomandomi alle vostre lemosine e quanto istando tacito e contento ogni vostra determinazione." Wie es scheint, hatte die Regierung tatsächlich eine Art Entschädigung in Aussicht gestellt, sich aber noch nicht endgültig dazu geäuBert.

Die Aufforderung zur Ausfertigung der Erklärungen wird Anfang Oktober ergangen sein, denn von den 40 datierten Erklärungen der Sammlung sind 28 zwischen dem 14. und dem 29. Oktober entstanden, nur einige Nachzügler datieren im November. Die meisten erklären in eigener Sache, geschrieben wurden die Dokumente aber wohl in der Regel von bezahlten Schreibern oder Notaren, die nach einem bestimmten Muster arbeiteten, darauf deuten nicht nur die teilweise identischen Handschriften hin, sondern auch Formulierungsähnlichkeiten und immer wiederkehrende Elemente. Dennoch werden die Schreiber nur in sechs Fällen namentlich genannt, wie etwa in der Erklärung von Fano di Giovanni: "E io Bernaba di Giovanni mi ho facto questa fede di mia mano a preghi del decto Fano dice non sapere scrivere." (74) Nur noch bei einer weiteren Person (136) wird Analphabetismus als Grund für die Ausfertigung der Erklärung durch eine dritte Person angeführt, und auch hier ist es wieder Bernaba di Giovanni, der die Aufgabe übernommen hat. Schließlich gibt es noch Lodovico Guilizoni (121), der auf Grund einer Krankheit vorübergehend nicht zu schreiben

134 Es gibt allerdings eine Namensliste mit den Empfängern von Entschädigungszahlungen aus dem Erlös verkaufter Kirchengüter, die möglicherweise auf der Grundlage der Erklärungen erarbeitet wurde, auch wenn es so gut wie keine namentlichen Übereinstimmungen gibt. Sie enthält 350 Namen von Nutznießern und knapp 33.000 Florin. ASP Buonamici 2, Fasc. 18.

135 Die Nummern in Klammern entsprechen den Seiten im Manuskript ASP, MS 2549. Die Erklärungen befinden sich auf fol. $55^{\mathrm{r}}$ bis $197^{\mathrm{r}}$, jeweils auf der Vorderseite; fol. 61 ist unbeschrieben. Bis auf eine Ausnahme (66) befindet sich auf jedem Blatt eine Erklärung. 
im Stande ist und von einem gewissen Raffaello vertreten wird: "E io Raffaello ho fatto questo in nome di detto Lodovicho perche e malatto e no puo schrivere." Lediglich zwölf Personen versichern am Ende, die Erklärung von eigener Hand verfasst zu haben.

Um der folgenden Auswertung allgemein verbindliche Aussagekraft zu verleihen, müssen noch einige Worte über das Verhältnis zwischen diesem überlieferten Material und dem möglicherweise nicht überlieferten Material verloren werden. Wenn man davon ausgeht, dass man die Erklärenden als Haushaltsvorstände ansprechen kann, die - ob sie dies nun ausdrücklich erklären oder nicht - für ihre ganze Familie stehen, kann man demnach von 143 Haushalten sprechen, die durch die hier behandelten Erklärungen erfasst werden, was bei einem ungefähren Durchschnitt von fünf Personen pro Haushalt etwa 750 Personen in den Einzugsbereich dieser Untersuchung bringt. Prato hatte zur Zeit der Plünderung vielleicht 7.000 Einwohner ${ }^{136}$ in 1.400 Haushalten, viele von ihnen aber waren beim Anmarsch des Heeres nach Florenz geflohen. Wie viele sich am Ende noch in Prato befanden, als die Soldaten sich in die Stadt ergossen, ist unmöglich zu sagen; Augenzeugen aus Florenz sprechen zwar von einer menschenleeren Umgebung und endlosen Flüchtlingskolonnen vor der Stadt, ${ }^{137}$ diese Angabe ist aber so ungenau, dass sich nicht annähernd sagen lässt, wie hoch der Anteil der Bevölkerung aus Prato war, der sich tatsächlich zur Flucht entschloss, schließlich machen 200 bepackte Wagen für einen zur Übertreibung neigenden Beobachter unter Umständen eine genauso ansehnliche Schlange aus wie 2.000 für einen anderen. Im Archiv selbst lässt sich keine Angabe darüber finden, wie die 143 Einzelstücke ihren Weg in das Manuskript fanden. Was die Repräsentativität betrifft, kann man allerdings im Vorgriff auf die folgende Analyse sagen, dass die Sammlung einen Querschnitt durch die Bevölkerung gibt: die Erklärenden gehören den unterschiedlichsten Berufsgruppen an, und die Lösegeldsummen differieren teilweise um dreistellige Faktoren. In den berichtenden Quellen sind die genannten Lösegeldsummen im Vergleich zu den von den Erklärenden genannten Beträgen unangemessen hoch. Bei näherer Betrachtung relativieren sich diese Zahlen allerdings beträchtlich: derselbe Jacopo Modesti, der zur Pointierung der Katastrophe behauptet, 100 Dukaten schienen ein erbärmliches Lösegeld, gibt die Gesamtsumme aller Lösegelder mit 60.000 Dukaten an, ${ }^{138}$ was bei 1.400 Haushalten einen Durchschnitt von lediglich 43 Dukaten pro Haushalt ausmacht.

Der Grundstock an Informationen, der in allen Erklärungen enthalten ist, wird gebildet durch den Namen des Erklärenden, in der Regel der Vorname mit Vaternamen und vereinzelt auch einem Familiennamen, die zweite Basisinformation ist die an die Soldaten ge-

136 FIUMI, ENRICO: Demografia, movimento urbanistico e classi sociali in Prato dall'età comunale ai tempi moderni. Florenz 1968. S. 150f. Fiumi stützt sich auf eine Zählung aus dem Jahr 1551, die 6.845 Einwohner ergab. Verluste durch die Plünderung und durch die Epidemien der 20-er Jahre werden bis zu diesem Zeitpunkt wieder ausgeglichen worden sein.

137 LANDUCCI, Diario fiorentino, S. 321; CoRAZZINI, GiusepPe OdOARDO (HrSG.): Ricordanze di Bartolomeo Masi calderaio fiorentino dal 1478 al 1526. Florenz 1906. S. 97.

138 MODESTI, Bericht, S. 245. 
zahlte Summe. Am Ende des Textes folgt oft noch eine formelhafte Wahrheitserklärung. Wenn die Umstände der Schätzung oder Bezahlung komplizierter sind, werden weitere Angaben möglich. Auch sie werden zumeist formelhaft mit sehr ähnlichen Wendungen angegeben. Da sind als wichtigster Bestandteil die Namen der Verwandten zu nennen, für die jemand mitbezahlt. Ein weiterer wichtiger Punkt ist die Unterscheidung zwischen ursprünglich vorgesehenem und tatsächlich gezahltem Lösegeld. Eine ganze Reihe von Personen hatte nämlich Lösegelder auferlegt bekommen, die am Ende aus verschiedenen Gründen nicht voll bezahlt wurden. In diesem Fall nennen sie neben dem tatsächlich gezahlten Lösegeld auch noch den Betrag, um den man sie bei ihrer Gefangennahme geschätzt hatte. Daneben bezahlten bei weitem nicht alle das Lösegeld einfach aus der eigenen Tasche. Den meisten war schon bei der Plünderung alles weggenommen worden, und einer der Zwecke der Lösegelder bestand ja darin, an Gelder heranzukommen, die man sich nicht einfach nehmen konnte. In vielen Erklärungen finden sich daher Angaben über Kreditgeber und die Rückzahlungsbedingungen für das geliehene Geld. Neben diesen Informationen, die immer in direktem Zusammenhang mit den Lösegeldern und ihrer Beschaffung stehen, liefern einige der Erklärenden, vielleicht aus einem anderen Verständnis von Vollständigkeit heraus, vielleicht aus Mitteilsamkeit, weitere Informationen. Da wäre das schon angesprochene Datum der Erklärung, von einigen auch einfach "al tempo delli spagniuoli" (90) oder "in tempo degli spagnuoli" (73) genannt, als müsste jeder zukünftige Leser nur zu gut wissen, was damit gemeint ist. Eine weitere Datumsangabe betrifft den Tag der Bezahlung, den Tag also, an dem sie sich aus den Händen der Soldaten freikauften. Ein solches Datum nennen 12 der Erklärenden. Interessanter und wichtiger ist die Angabe des Berufes. Dieser Information fällt eine wichtige Rolle bei der Kategorisierung der Lösegelder zu, denn sie wirft ein Schlaglicht auf den sozialen Status einzelner Opfer. Daneben machen einige flüchtige Angaben über ihre Peiniger. Insgesamt erwähnen 55 der Erklärenden die Soldaten, manche nur einen, andere mehrere, von denen sie zumeist nur die Namen, manchmal den Rang und noch seltener die Kompanie nennen. Ferner gibt es 16 Angaben über den Ort der Gefangennahme, zwei davon nennen ihr eigenes Haus, die übrigen den Namen einer dritten Person, in deren Haus sie offenbar Zuflucht gesucht hatten. Einige nennen neben den Beglaubigungsformeln auch noch Zeugen, die bei der Bezahlung des Lösegeldes zugegen waren und für die Wahrheit der Erklärung bürgen konnten. Solche Zeugen treten meistens dann auf, wenn das Geld geliehen worden war. Als weiteres Beglaubigungsmittel erwähnen manche sogar ein Schriftstück von Hand der Spanier. Man kann nicht sagen, wie selbstverständlich die Ausfertigung eines solchen Dokuments durch die Spanier an die Opfer gewesen ist, da es in den meisten Erklärungen nicht erwähnt wird, in einem Fall aber ausdrücklich darauf hingewiesen wird, dass es fehlt. (195) Schließlich geben einige der Opfer noch Kurzberichte, die mit dem Lösegeld nichts zu tun haben, an den wenigen Stellen ihres Vorkommens aber eine Menge über die Nöte der Geiseln aussa- 
gen. So gibt es Berichte über gescheiterte Fluchtversuche, Verschleppung in andere Städte, Aufenthaltsorte während der Gefangenschaft und besondere Umstände der Lösegeldbeschaffung. Diese Informationen sollen nun so miteinander in Verbindung gebracht werden, dass sinnvolle Aussagen über die Mechanismen der Lösegelderpressung gemacht werden können. Dabei muss immer im Hinterkopf behalten werden, dass eine Quantifizierung in einigen Fällen problematisch ist, da bei weitem nicht alle außer ihrem Namen und dem gezahlten Gesamtbetrag weitere Angaben machen. Diese sind zu sehr von der Willkür der einzelnen Erklärenden abhängig, als dass man ihr Vorhandensein oder ihr Fehlen allein zur Grundlage einer These machen könnte.

\section{Opfer und Täter}

Personen können in den Erklärungen in fünf verschiedenen Funktionen auftauchen: als Erklärende oder deren Angehörige, also als Opfer, daneben als Zeugen, als Kreditgeber, als Hausbesitzer, unter deren Dach sich die beschriebenen Vorgänge abspielten, oder als Soldaten, die die Lösegelder eintrieben.

Die wichtigste und am besten dokumentierte Gruppe sind die Opfer: bei den Erklärenden handelt es sich ausschließlich um Männer, und auch unter den Angehörigen werden nur zwei Frauen genannt. Die Erklärenden nennen ihren Vornamen und einen oder mehrere Vaternamen, einige noch den Nachnamen. Familiennamen geben mindestens 35 der Erklärenden an, wobei diese Zahl auf Grund von möglichen Verwechslungen mit Vaternamen, Herkunft und Berufsbezeichnung im Zusammenhang mit unleserlichen Schriften nicht ganz gesichert ist. Ferner nennen zwei noch einen Beinamen, nämlich "Bartolomeo vochato Tosino" (171) und "Albertino dito Fano". (147)

Aussagekräftiger sind natürlich die Berufsbezeichnungen, von denen es insgesamt 44 gibt. Die am stärksten vertretene Gruppe sind die Geistlichen, die sich in der Regel gemäß ihrem Status als Kanoniker, Prediger, Priester oder Erzpriester bezeichnen. Insgesamt neun der 44 Opfer, die ihren Beruf nennen, gehören dem geistlichen Stand an. Es folgen fast ausschließlich handwerkliche Berufe, davon zwölf aus dem Textil- und Ledergewerbe, nämlich drei Hutmacher, drei Schuhmacher, zwei Leinenweber, zwei Schneider, ein Kürschner und ein Tuchscherer, weitere 13 aus anderen Handwerkszweigen, im einzelnen fünf Müller, drei Bäcker, ein Kübelmacher, ein Glaser, ein Tischler, ein Maurer und ein Spengler. Die übrigen zehn gehören verschiedenen Berufszweigen an, es sind zwei Winzer, zwei Gärtner, zwei Apotheker, ein Krämer, ein Gastwirt, ein Barbier und ein Trödelhändler. So unvollständig diese Angaben leider auch sind, sie geben dennoch einen kleinen Querschnitt durch die handwerklich geprägte Gesellschaft in Prato zu jener Zeit. Mit Ausnahme der Geistli- 
chen sind keine Angehörigen höherer Schichten wie Akademiker oder Kaufleute genannt, man darf aber nicht vergessen, dass zwei Drittel der Erklärenden ihren Beruf verschweigen, und dass unter diesen die höchstdotierten Geiseln figurieren.

Neben den Berufen machen einige noch eine Ortsangabe. In aller Regel kann man davon ausgehen, dass fast alle Erklärenden direkt aus Prato stammten oder zumindest dauerhaft dort wohnten, auch wenn dies nur 59 von ihnen ausdrücklich angeben. In der Regel wird diese Information durch ein simples "da Prato" nach dem Namen vermittelt, einige schreiben auch "in Prato" nach dem Beruf. Einige scheinen nicht immer in Prato zu wohnen, es gibt einen "Giuliano prete di Santa Maria avencianese ${ }^{139}$ abitante al presente in Prato" (128), ferner, anscheinend schon lange in der Stadt, einen "Giovanfrancesco d'Antonio pugliese da Prato" (97). Ein gewisser Tiziano (69) stammt aus Ponzano, einem Dorf vor den Toren Pratos, wie auch Raffaello, "oggi habitante in Pinzano"140 (78). Bis auf diese beiden gibt niemand einen anderen Wohnort als Prato an. Das hilft zwar bei der Ermittlung des Anteils der geflohenen Stadtbewohner immer noch nicht weiter, lässt aber immerhin den Schluss zu, dass die meisten der Bauern aus der Umgebung nicht in Prato Zuflucht suchten, sondern gleich in Florenz, wodurch der dort beobachtete Strom der - vor allem wohlhabenden - Flüchtlinge offenbar erheblich anschwoll.

Neben den konkreten Informationen sagt bisweilen der Schreibstil einiges über die Aussteller der Erklärungen aus, die rührende Umständlichkeit, mit der manche versuchten, die Glaubwürdigkeit ihrer Erklärungen zu versichern. Bertoldo Guazalotti schreibt: "... Et cosi e la propria verita offerendomi bisogniando farne fare piu apparente fede veramente giustificare esser cosi. Et per fede della verita o fatto la presente di mia propria mano di 24 d'ottobre 1512 ..." (117) Einige geraten bei der Formulierung komplizierter Zusammenhänge ins Stolpern und stiften am Ende eher Verwirrung, wie Nicola Manucci: "... io pagai per Metto mio fratello fiorini quindici larggi d'oro in oro e quali furono per taglia sua e quali danari ebbi da Bruno e detti danari pagai in chasa di Ser Jachopo suo fratello e quali danari ebbe detto padrone di Metto che stava in chasa detto Ser Jachopo et aveva nome Meri e per fede di cio io Ser Nicholao Chlodovicho Manucci in Prato - Fiorini XV larggi." (110)

Zeugen werden selten genannt, und wenn, dann wird meistens nichts als ihr Name angegeben. Spanische Zeugen lassen sich wegen der Italianisierung der Namen nicht identifizieren, und selbst wenn sie ausdrücklich als solche angesprochen werden, ist Vorsicht geboten. Dennoch geht aus einigen Erklärungen eindeutig hervor, dass nicht nur andere Einwohner aus Prato, sondern auch Soldaten zur Bezeugung der Lösegeldübergabe herangezogen wurden. Lorenzo di Giuliani (111) nennt einen Herold als Zeugen, ebenso Vittorio Nigalozzi (103) und präzisiert, es handle sich um einen Herold von Herrn Simonetto da Cortona.

\footnotetext{
139 Meint wohl Avezzano in den Abruzzen.

140 Auch wenn Raffaello Pinzano schreibt, meint er wohl Ponzano und nicht Pinzano bei Mailand.
} 
Die Kreditgeber für die Lösegelder werden weiter unten noch behandelt, über die Hausbesitzer schließlich ist außer ihren Namen gar nichts zu erfahren. Interessant ist eher ihre Erwähnung an sich, die zeigt, dass viele der Einwohner vor dem Einfall der Spanier in die Häuser anderer Personen flüchteten. Wie weit dieses Phänomen verbreitet war, lässt sich wiederum nicht aus der Quelle schließen. Nichts spricht allerdings dagegen, dass es sich in Prato damit anders verhielt als in Rom, wo augenscheinlich eine Mehrheit der Bevölkerung das eigene Haus verließ.

Über die Soldaten gibt es weit mehr Informationen: 55 der 143 Erklärenden machen Angaben dazu, einige nennen mehrere Soldaten. So kommen 72 Nennungen zusammen, wobei drei jeweils doppelt genannt werden, so dass insgesamt 69 verschiedene Soldaten als Geiselnehmer erwähnt werden, unter diesen auch sechs Hauptleute. Es ist allerdings nicht sicher, ob es sich bei allen wirklich um Hauptleute handelte, oder ob die Opfer sie nur als solche bezeichneten, weil das der Erklärung in ihren Augen mehr Gewicht verlieh. Im gesamten untersuchten Zeitraum lässt sich die Tendenz der Zeugen feststellen, die Soldaten in den Berichten aus Unkenntnis im Zweifelsfall zu Hauptleuten zu befördern.

Wenn auch die Soldaten fast immer als Spanier angesehen und bezeichnet werden, so darf man doch nicht vergessen, dass fast die Hälfte des Heeres von päpstlichen Truppen gestellt wurde. In den Erklärungen sind diese schwer von den Spaniern zu unterscheiden, denn die Vornamen der Spanier werden durchweg italianisiert. Von den 69 Genannten werden allein 38 ausdrücklich als Spanier bezeichnet, dazu kommen noch weitere, die an Hand ihres Namens als Spanier identifiziert werden können, so etwa Juan de Urbina (81) oder Männer mit typisch spanischen Nachnamen wie Muñoz - vom Aussteller (103) "Mugnos" transkribiert oder Ruiz. (114) Die Tatsache, dass daneben Träger italienischer Namen wie Pontecomo (67) oder Gomberini (153) als Spanier bezeichnet werden, zeigt, dass in den spanischen Kompanien viele italienische Soldaten dienten, die zumeist zusammen mit den Spaniern in Neapel angeworben worden waren. ${ }^{141}$

Daneben finden sich noch einige fragmentarische Informationen in die Erklärungen eingestreut, die die Soldaten betreffen, wie Namen von Hausbesitzern, bei denen sie einquartiert waren oder andere Örtlichkeiten. Bartolomeo Micolucci (169) ist hierbei besonders mitteilsam: er selbst zahlte an einen "Messer Lugi ispagnolo istava nel Cepo Vechio di Prato e nelle mani di Messer Alfonso napoletano erano chompangni sotto lan bandiera di Don Ferante istava nella istessa"; ein goldener Ring für die Auslösung seiner Frau ging an "uno spangnolo istava in chasa di Lucha Tronboni nela Via Nuova".

141 Vor allem auf dem Weg nach Prato war das der Fall, da Cardona seine durch die Niederlage von Ravenna und eine Flut von Desertionen dezimierten spanischen Kompanien während eines kurzen Aufenthaltes im Königreich Neapel im Mai und Juni 1512 in aller Eile mit Italienern aufzufüllen gezwungen gewesen war. ANONYM: Relación de los sucesos, S. 266. 


\section{Gefangenschaft}

Es sieht auf den ersten Blick so aus, als sei in den meisten Fällen ein Erklärender einem Soldaten verpflichtet gewesen. Dieses Verhältnis steht allerdings im Widerspruch zu der Relation zwischen der Gesamtzahl der Soldaten und der Anzahl der Haushalte in Prato, bei der etwa acht Soldaten auf einen Haushalt kommen. Daraus lässt sich schließen, dass entweder die Mehrheit der Soldaten keine Lösegelder erpresste, oder die Opfer einen ihrer Geiselnehmer sozusagen zum Hauptempfänger des Lösegeldes erklärten und die anderen schweigend übergingen. Das Zahlenverhältnis zwischen Geiseln und Geiselnehmern verschiebt sich noch weiter zu Ungunsten der Soldaten, wenn man berücksichtigt, dass einzelne Soldaten - vor allem aber die Offiziere - bisweilen Lösegelder von mehreren Familien einnahmen, nämlich immer dann, wenn ihnen ein Gebäude in die Hände fiel, in dem neben der Familie des Hausherren auch andere Personen untergekommen waren. Solche Mechanismen lassen sich in den Erklärungen nur an einer Stelle nachweisen, nämlich in der Erklärung von Taldo di Guasparri (66), unter der sich eine zweite Erklärung befindet, in der ganz offensichtlich immer noch von Taldo - bekundet wird, dass ein gewisser Domenico in seinem Haus gefangen wurde, für den er das Lösegeld vorläufig bezahlt hat - und zwar an denselben spanischen Offizier, der schon in seiner eigenen Erklärung auftaucht. Da sonst fast nie mehrere Erklärungen auf einem Blatt stehen, kann man nicht sagen, in wie vielen Fällen die Sache so ablief, dass der Hausbesitzer und weitere Personen unter dessen Dach von denselben Spaniern gefangen wurden. Immerhin geben einige in ihrer Erklärung Personen an, mit denen sie offensichtlich nicht verwandt sind, daneben finden sich drei Namen von Soldaten, die in mehreren Erklärungen auftauchen, was auf den ersten Blick enttäuschend wenig erscheint, aber durch die Tatsache relativiert wird, dass mit den 143 Erklärungen nur ein Bruchteil dessen erfasst ist, was einmal existiert hat, und, da auch von diesen weniger als die Hälfte die Namen der Soldaten nennt, ein noch geringerer Bruchteil dessen dokumentiert ist, was da alles als Geiselnehmer auftrat. Doppelt genannt sind Hauptmann Carans aus der Erklärung von Taldo (66), Hauptmann Graziano, der bei Jacopo di Diuccio (116) und bei Antonio di Matteo (193) Lösegeld eintrieb, und schließlich Hauptmann Pedro Navarro, erwähnt von den Brüdern Tomaso ${ }^{142}$ und Nicolao di Buonavida (65) sowie von einem weiteren Opfer, dessen Name nicht mehr zu entziffern ist. (85)

Meistens werden die Familien zusammen in Gefangenschaft geraten sein, entweder zu Hause oder an ihren Zufluchtsstätten. Getrennt wurden sie wohl vor allem dann, wenn der Vater bei der Stadtverteidigung half und im Augenblick des Einbruchs mit den Fliehenden durch die Straßen gespült wurde. Wem es nicht gelang, im letzten Augenblick die Stadt zu verlassen, der flüchtete sich in eins der Häuser, wie Marsilio Pucetti (93), der mit seiner

142 Vielleicht identisch mit Tommaso di Buonaguida, in dessen Haus Filippo di Piero (134) gefangen gehalten wurde. 
ganzen Schar - "io e tutta la mia brigata" - im Haus von Betto della Pergola gefangen wurde. So konnte es vorkommen, dass die Lösegelder für mehrere Familienmitglieder nicht an dieselben Soldaten gezahlt wurden, wie im Fall von Giovanni Battista Ronconi (84), dessen Sohn von einem anderen Spanier gefangen gehalten wurde als er selbst, oder bei Jacopo Bisconti (159), der für sich, seinen Sohn und seinen Schwiegersohn an drei verschiedene Gruppen von Spaniern zahlte.

Daneben suchten viele Zuflucht in Gotteshäusern, vor allem Frauen wurden in den Schutz von Kirchen und Klöstern gebracht, was ihnen allerdings nicht viel nützte, weil die Spanier auch die Kirchenschätze plünderten und selbst das Leben von Geistlichen nicht schonten. In immerhin vier der Erklärungen ist von Kirchen oder Klöstern als Zufluchtsstätte die Rede: Biagio di Piero (68) wurde in Santa Maria Nuova gefangen, Raffaello Saracini (70) in San Domenico, Battista di Nardo (144) in einer Kapelle und Raffaello Casini (152) in der Abtei von Grignano, zusammen mit sechs anderen Männern und zwei Kindern.

Vom Ort der Gefangennahme wurden viele auch in andere Häuser gebracht oder mit anderen Gefangenen zusammengelegt. Michele Nomi (105) verbrachte von den elf Tagen seiner Gefangenschaft neun in einem Frauenkloster und die restlichen zwei im Haus eines Piero di Nicola. Damit liegt er auch für die Dauer seiner Gefangenschaft im Durchschnitt: zwölf der Erklärenden geben auch das Datum der Bezahlung des Lösegeldes, also den Tag ihrer Befreiung an. Diese Daten sind gleichmäßig über den Monat September verteilt, die Dauer der Gefangenschaft reicht bei diesen zwölf Opfern von fünf Tagen bis zu vier Wochen. Das Heer blieb aber nur drei Wochen in der Stadt, und aus den Erklärungen der beiden Einwohner, die für ihre Bezahlung ein Datum nach dem 20. September angeben, geht denn auch hervor, dass sie von den Soldaten verschleppt wurden. Dieses Schicksal widerfuhr nach anderen Berichten etwa 200 Gefangenen. ${ }^{143}$ Unter ihnen war der Kanoniker Andrea Luschini (81), der nach Bologna gebracht wurde, wo er dann sein Lösegeld bezahlte. Wie ihm scheint es noch einigen anderen der hier erwähnten Opfer ergangen zu sein, jedenfalls geht aus drei weiteren Erklärungen hervor, dass das Lösegeld in Bologna durch Dritte bezahlt wurde. Das passt zu anderen Berichten, nach denen Bologna der Ort war, an dem sich die Spanier der meisten ihrer Geiseln entledigten. Einige scheinen beim Weitermarsch des Heeres noch bis Modena gekommen zu sein; Girolamo di Domenico (130) schließlich dürfte einer der letzten gewesen sein, die freigelassen wurden, er berichtet in seiner Erklärung, bis nach Verona entführt worden zu sein. Von dort aus ging der Krieg weiter: in Verona rüstete Cardona sein Heer mit Artillerie für die Belagerung von Brescia aus, spätestens beim Aufbruch von dort werden die letzten Gefangenen aus Prato aus seinem Lager verschwunden sein. Das bedeutete aber keineswegs das Ende des Leidensweges für alle Geiseln: schließlich waren die Lösegelder noch nicht bezahlt, und die Spanier setzten alles daran, soviel

143 Wohl die zuverlässigste Angabe vom florentinischen Kommissar in Prato, Gherardo de Gherardis, aus einem Brief an die Signoria vom 21. September. GUASTI, Il sacco di Prato, Dispensa 178, S. 199. 
Geld wie eben möglich an ihren Gefangenen zu verdienen. Wem es auch in Bologna nicht gelang, über eigene Beziehungen oder solche seiner Familie an die nötigen Gelder zu gelangen, der wurde wie eine Kapitalanlage an findige Menschenhändler verkauft, die sich vor Ort um die Eintreibung kümmerten. Vor allem Francesco Frescobaldi, der päpstliche Gouverneur in Bologna, führte solche Aufkäufe im großen Stil durch und erzielte beachtliche Gewinne. ${ }^{144}$ Dabei waren die Geiseln bei ihm keineswegs besser aufgehoben als bei den Spaniern. Der Bericht von Andrea Bocchineri gibt eine Vorstellung von dem, was die Geiseln in Frescobaldis Kerker an Entbehrungen und Erniedrigungen erleiden mussten: "... morivamo di fame e di freddo, e non ci potevamo difendere dalle pulci e pidocchi, che ne eramo pieni ... ci furono messi i piedi ne' ceppi, che dove noi mangiavamo e dormivamo, bisognava noi cacassimo e pisciassimo." ${ }^{145}$ Nicht genug damit: Ende Dezember kauften spanische Soldaten ihn und seinen Cousin Piero von Frescobaldi zurück. Als sein Vater kurz darauf mit einer Anzahlung auf das Lösegeld eintraf, wurde er selbst gefangen genommen, Piero indes wurde freigelassen, weil er schwer erkrankt war und man befürchtete, dass er vor der Bezahlung der vollen Summe sterben und dadurch wertlos werden könnte. Andrea und sein Vater wurden nach Castelnuovo gebracht und dort in einen Turm gesperrt, aus dem sie nach einem Monat entkamen, nachdem sie mit dem Mut der Verzweiflung in einem wilden Kampf ihren Bewacher erschlagen hatten. ${ }^{146}$

Zurück nach Prato. Über ihre Behandlung sagen die Geiseln in den Erklärungen fast nichts. Einige Berichte erwähnen, dass viele Gefangene gefoltert wurden, um sie zur Annahme einer höheren Lösegeldsumme zu zwingen, aber das scheint nicht die Regel gewesen zu sein. Bisweilen wird zwar behauptet, dass viele Spanier die Geiseln umbrachten, die ihr Lösegeld nicht bezahlen konnten, aber auch dabei handelt es sich um Ausnahmefälle, schließlich stellten die Geiseln lebendes Kapital dar, abgesehen davon, dass ja immer die Möglichkeit bestand, den Betrag zu senken. Angedroht wurde die Ermordung im Fall des Ausbleibens der Bezahlung allerdings vielen. ${ }^{147}$ Andrea Luschini (81) ist der einzige, der in seiner Erklärung angibt, misshandelt worden zu sein. Auch andere Methoden wurden angewandt, um die Bezahlung zu beschleunigen. Meistens setzten die Soldaten bei der Schätzung eine Frist, vor deren Ablauf das Geld beschafft sein musste. Einigen drohte man damit, ihre Häuser abzubrennen, wenn die Bezahlung des Lösegeldes nicht zum festgelegten Zeitpunkt erfolgt war. ${ }^{148}$

Nicht alle wurden die ganze Zeit über gefangen gehalten, es scheint eher so gewesen sein, dass ein oder mehrere Kinder als Garantie für die Bezahlung unter Bewachung der Soldaten gelassen wurden, während sich die Väter auf den Weg machten, um das geforderte Geld zu

144 CADENAS, El saco de Prato, S. 119.

145 BOCCHINERI, Ricordi, S. 8.

146 BOCCHINERI, Ricordi, S. 12.

147 GUASTI, Il sacco di Prato, Dispensa 178, S. 156.

148 Modesti, Bericht, S. 243f., Anm. 26. 
besorgen. Solche Besorgungen führten viele - wohl zumeist nach vorangegangenen vergeblichen Versuchen der Geldbeschaffung vor Ort - in andere Städte, vor allem nach Florenz, wo das Wirtschaftsleben keinen Schaden genommen hatte und wo man daher leichter Bargeld bei Banken oder Privatpersonen bekommen konnte. So ging Tato di Tato (60) nach Florenz, "avendo io in Prato per mio ischambio Filippo mio figluolo", ganz so als ob immer nur einer der beiden unter Aufsicht gestanden hätte. Der Winzer Raffaelo di Buoso (87) ließ seinen Neffen bei den Spaniern, während er selbst - ebenfalls in Florenz und scheinbar vergeblich - das Geld aufzutreiben versuchte. Wer allein in Gefangenschaft war und somit keine Verantwortung für andere zu tragen hatte, der wagte bisweilen einen Fluchtversuch. Drei solcher Fluchtversuche sind in den Erklärungen geschildert, zwei davon scheitern am Ende und bescheren den Opfern dennoch Glück im Unglück: Fano di Matteo (73) wurde in seinem eigenen Haus gefangen gehalten und sollte 100 Dukaten ${ }^{149}$ Lösegeld bezahlen. Er floh, ohne sich in seiner Erklärung weiter über die Umstände auszulassen, wurde an der Stadtmauer von einem anderen Soldaten wieder aufgegriffen und auf 10 Dukaten geschätzt, von denen er am Ende nur 8 bezahlte. Lodovico Guilizoni (121) widerfuhr Ähnliches, er berichtet immerhin ein wenig ausführlicher: "... fui prigone delli spagnuolli in chasa mia e puosonmi di taglia duchatti cinquanta d'oro in oro e tenedomi legato. Una sera io mi colsi e gittami a terra delle finestre e scholami tutte dua e piedi in modo che io no potevi chorere pero fui ripreso d'alltri ispagnuolli e rachomandandomi mi ferano pagare duchatti tre d'oro in oro." So hatte der Fluchtversuch sich auch für ihn trotz seiner verstauchten Gelenke wenigstens finanziell gelohnt. Der dritte Fluchtversuch wird nur angedeutet und betrifft Simone, den Bruder von Battista di Piero. (182) In seiner Erklärung gibt dieser 10 Dukaten für Simone an, aber nicht als Lösegeldzahlung an einen Spanier, sondern an einen gewissen Francesco di Gorigi aus Bologna, und zwar "perche gli fece i spalle affugirsi." Offensichtlich hatte dieser für seine Fluchthilfe das Geld verlangt.

\section{Lösegelder}

Die Gesamtsumme der genannten Lösegelder beläuft sich auf knapp 5.700 Dukaten. Wenn man annimmt, dass die Erklärungen vom Schnitt der in ihnen erfassten Beträge als repräsentativ gelten können, lässt sich unter Einbeziehung der in anderen Quellen angegebenen Gesamtsumme der Lösegelder die Zahl der von der Lösegeldzahlung betroffenen Haushalte errechnen, aus der sich durch den Vergleich mit der Gesamtzahl der Haushalte in Prato der Anteil der geflohenen Einwohner ergibt. Eine solche Rechnung steht allerdings auf sehr

149 Dukaten und Florin, auf dem Papier annährend gleichwertig, werden in den Erklärungen nebeneinander genannt. Im Zweifelsfall ist in der Folge von Dukaten die Rede, auch wenn sich die genannten Beträge unter Umständen aus beiden Währungen zusammensetzen. 
dünnen Beinen, zum einen, weil die zahlenmäßige Repräsentativität der Angaben in den Erklärungen trotz der breiten Streuung der Summen eben doch nicht ganz gewährleistet ist, zum anderen, weil es zwei unterschiedliche Angaben über die Gesamtsumme der Lösegelder gibt, die beide aus gut informierten Kreisen stammen. Sie soll hier nur kurz vorgeführt werden, um einen ungefähren Eindruck von der möglichen Größenordnung des Phänomens zu geben und zu zeigen, was eine Quelle wie die Sammlung der Lösegelderklärungen unter anderen Umständen leisten könnte. Der Diurno der Stadt gibt als Gesamtsumme der Lösegelder - wahrscheinlich sogar auf der Basis aller eingereichten Erklärungen - 30.000 Dukaten an. ${ }^{150}$ Jacopo Modesti nennt in seiner Beschreibung der Plünderung dagegen 60.000 Dukaten. ${ }^{151}$ Der erste Wert führt durch die Hochrechnung auf 750 betroffene Haushalte, was bei einer Gesamtzahl von 1.400 Haushalten in Prato zu dem durchaus plausiblen Ergebnis führt, dass nicht ganz die Hälfte der Einwohner die Stadt verließ, der zweite Wert allerdings müsste zu der Annahme verleiten, dass niemand die Stadt verlassen hatte, was angesichts der Beobachtungen aus Florenz nicht der Wahrheit entsprechen kann. Entweder ist die von Modesti angegebene Zahl zu hoch, oder unter den nicht überlieferten Erklärungen befinden sich Beträge, die die von den 143 hier erfassten Betroffenen angegebenen bei weitem übersteigen.

Zurück zu den gesicherten Fakten. Jede Erklärung repräsentiert einen Haushalt. Da Frauen so gut wie gar nicht und Kinder nur als Geiseln erwähnt werden, kann man davon ausgehen, dass sie bei Nichterwähnung stillschweigend im Lösegeld des Haushaltsvorstandes enthalten sind. Anders ließe es sich nicht erklären, dass 105 der 143 Erklärenden niemanden außer sich selbst erwähnen, denn es ist kaum anzunehmen, dass zwei Drittel der Männer allein zu Hause saßen, als die Stadt gestürmt wurde.

Die Gesamtsumme der Lösegelder aus den Erklärungen, geteilt durch deren Anzahl, ergibt einen Durchschnitt von 37 Dukaten pro Haushalt. Damit ist allerdings wegen der weiten Streuung der Lösegelder noch nicht viel ausgesagt: es ist beeindruckend und fast befremdlich, wie sich die Formulare ähneln, mit denen einige einen oder eineinhalb Dukaten bezahlt zu haben bezeugen, andere bis zu 300. Eine solche Vielfalt bestätigt von den Augenzeugen nur Simone Brami, der mit einer Abteilung Soldaten aus Colle von der Signoria zur Verteidigung von Prato beordert worden war: seinem Bericht zufolge gab es in Prato Lösegelder zwischen 5 und 300 Dukaten, ${ }^{152}$ aus seiner Kompanie wurden einige sogar nur für 3 , andere wieder für 100 Dukaten geschätzt. ${ }^{153}$ Dass diese Darstellung eher den Tatsachen entspricht als die spektakulären Zahlen von Modesti, wird sich im weiteren Verlauf der Auswertung zeigen. Von den 143 Erklärenden liegen 18 bei 100 Dukaten und darüber, also etwas mehr als ein Achtel, auf dieses Achtel aber entfällt die Hälfte der Gesamtsumme von

150 GUASTI, Il sacco di Prato, Dispensa 178, S. 231.

151 MODESTI, Bericht, S. 245.

152 BRAMI DA COLLE, Bericht, S. $257 \mathrm{f}$.

153 BRAMi DA COLle, Bericht, S. 260. 
5.700 Dukaten. Der Übersichtlichkeit halber wurden die Lösegelder nach ihrer Größenordnung in sechs Bereiche eingeteilt. Die folgende Tabelle gibt einen Überblick: in der ersten Spalte sind die einzelnen Bereiche - immer in Dukaten - umgrenzt, die zweite Spalte nennt die Häufigkeit der Einzelsummen in den 143 Erklärungen für jeden der Bereiche, die dritte deren prozentuale Verteilung, die vierte die Gesamtsummen der sechs Bereiche und die fünfte den Anteil, den jede dieser Gesamtsummen an den insgessamt 5.700 Dukaten aller Erklärungen ausmacht:

\begin{tabular}{|c|c|c|c|c|}
\hline Bereich & Häufigkeit & Anteil & Gesamtsumme & Anteil \\
\hline $1-4$ & 24 & $16,8 \%$ & 46 & $0,8 \%$ \\
\hline $5-9$ & 22 & $15,4 \%$ & 150 & $2,6 \%$ \\
\hline $10-19$ & 36 & $25,2 \%$ & 486 & $8,6 \%$ \\
\hline $20-49$ & 26 & $18,2 \%$ & 809 & $14,2 \%$ \\
\hline $50-99$ & 17 & $11,9 \%$ & 1.017 & $17,9 \%$ \\
\hline $100-300$ & 18 & $12,5 \%$ & 3.174 & $55,9 \%$ \\
\hline
\end{tabular}

Der am dichtesten besetzte Bereich liegt zwischen 10 und 19 Dukaten. Am aufschlussreichsten ist jedoch die Kombination der Lösegelder mit den Berufen der Betroffenen. Um den Zahlen ein wenig Leben einzuhauchen, sollen zunächst noch einige Worte über den Hintergrund verloren werden. Um 1520 verdiente ein Tagelöhner auf dem Feld bei Florenz etwas mehr als 11 Soldi am Tag, ${ }^{154}$ das ergibt auf den Monat hochgerechnet bei 25 Arbeitstagen genau 2 Florin. Ein Maurer kam auf 16 Soldi am Tag, ${ }^{155}$ also 3 Florin im Monat. Der Familienbetrieb des Kesselmachers Gerolamo Masi brachte um 1515 immerhin 190 Florin im Jahr ein, ${ }^{156}$ was auf den Monat herunter gerechnet 16 Florin ausmacht und darauf schließen lässt, dass das Geschäft gut lief.

Aus den Erklärungen ergibt sich nun, dass innerhalb einer Berufsgruppe die Lösegelder bisweilen unerwartet weit gestreut waren. Das hat seine Ursache neben der Willkür der Soldaten wohl auch darin, dass bei der Angabe des Berufes kein Unterschied zwischen einem einfachen Gesellen oder Gehilfen und dem Eigentümer eines Betriebes gemacht wird, was ja, wie bei Masi gesehen, offenbar einen erheblichen Unterschied ausmachen konnte. Anders lässt es sich nicht erklären, dass der Müller Fano di Giovanni (74) nur 2 Dukaten, Mariotto di Calendi (106), ebenfalls Müller, dagegen 14 Dukaten Lösegeld bezahlte. Zur Unterstützung dieser Annahme tut uns ersterer den Gefallen, nach seinem Beruf anzugeben, dass er in der Mühle eines gewissen Zanobi beschäftigt ist, während Mariotto zusätzlich zu seinen 14 Dukaten noch einmal 3 für seinen Bruder, auch Müller, bezahlte, was zumindest die Vermutung zulässt, dass die Mühle als Familienunternehmen betrieben wurde, wobei Mariotto der Eigentümer war. Ähnliche Unterschiede sind bei den beiden Gärtnern und den

154 FANFANI, Storia del lavoro, Bd. 3, S. 329.

155 FANFANI, Storia del lavoro, Bd. 3, S. 340.

156 FAnFAnI, Storia del lavoro, Bd. 3, S. 317. 
drei Schuhmachern festzustellen, bei denen die Differenz der Lösegelder immerhin den Faktor 13 erreicht. Bei den Geistlichen, der am häufigsten vertretenen Berufsgruppe, sind solche Unterschiede aus ihrem jeweiligen Rang heraus erklärbar. Die einfachen Priester oder Prediger liegen bei Lösegeldern zwischen 10 und 30 Dukaten und kommen auf einen Durchschnitt von genau 15 Dukaten; immerhin 50 Dukaten bezahlt jeder der beiden Kanoniker, und an der Spitze steht der Erzpriester Bertoldo Guazzalotti (117) mit 150 Dukaten. Die Betrachtung von Durchschnittswerten ist für die anderen Berufe bei der spärlichen Zahl der Überschneidungen heikel, wenn man die oben angeführten Gründe für die Schwankungen bedenkt. Dennoch sollen hier die einzelnen Berufsgruppen in Bezug auf die Lösegelder verglichen werden, um einen plastischeren Eindruck von der finanziellen Belastung der kleinen Leute zu bekommen. Die Apotheker hatten demnach den höchsten Schnitt von 45 Dukaten, gefolgt von den Hutmachern mit 31 Dukaten, ein Wert, der allerdings durch Battista di Piero (182), der für sich und seine beiden Brüder insgesamt 70 Dukaten bezahlte, unnatürlich angehoben wirkt. Für die gängigen Handwerksberufe ergibt sich ein Schnitt von etwas weniger als 10 Dukaten: der Maurer, der Tischler und der Glaser - jeweils nur einmal genannt und daher leider wenig repräsentativ - führen die Liste mit 12 Dukaten an, es folgen die Winzer mit einem Durchschnitt von 11/1/2 Dukaten, dann die Schneider mit 101/2, die Gärtner mit 91/2, die Schuhmacher mit 81/2, die Müller mit 7 und die Bäcker mit 51/2 Dukaten. Wiederum nur einmal genannt sind der Gastwirt mit seinen 8, der Kübelmacher mit 7 und der Kürschner mit 6 Dukaten. Ganz unten auf der Leiter finden sich die beiden Leinenweber mit einem Schnitt von 2⿺辶⿸厃㔾 Dukaten.

Es soll nicht verschwiegen werden, dass einige der genannten Beträge in diesem Zusammenhang völlig aus dem Rahmen des Erwartbaren fallen. Auffällig ist dabei, dass diese überraschenden Werte fast immer zu hoch erscheinen. So sieht man einen Barbier (134) für sich und seinen Sohn stolze 146 Dukaten bezahlen; ein Krämer (189) wurde für sich, seine zwei Söhne und einen Unbekannten auf 145 und schließlich ein Trödelhändler (70) immerhin auf 47 Dukaten geschätzt. Bei allen Schwierigkeiten und Vorbehalten kann man dennoch sagen, dass sich inmitten der augenfälligen Schwankungen und Widersprüche eine Kerngruppe von Handwerkern und kleinen Gewerbetreibenden herauskristallisieren lässt, deren Lösegelder sich locker um einen Betrag zwischen 5 und 15 Dukaten gruppieren.

Für einige wenige Berufe lässt sich so ein einigermaßen gesichertes Verhältnis zwischen dem Einkommen des Erklärenden und seinem Lösegeld formulieren. Der Maurer zahlte demnach, geht man von den oben angeführten Zahlen aus, immerhin vier Monatslöhne an Lösegeld, die Gärtner vielleicht drei und die Leineweber einen, immer ausgehend von der Annahme, dass bei diesen Berufen eine Selbständigkeit, die eine größere Verdienstspanne und damit weniger Repräsentativität mit sich gebracht hätte, eher unwahrscheinlich ist. Bei den anderen kann man unter allen Vorbehalten Lösegelder in der Größenordnung von einem bis drei Monatseinkommen annehmen. In einer Gesellschaft, in der die Angehörigen 
der unteren sozialen Schichten den größten Anteil ihres Einkommens für den Lebensunterhalt ausgaben, konnte ein Lösegeld in dieser Größenordnung durchaus eine Belastung darstellen, die nur über einen längeren Zeitraum hinweg abgetragen werden konnte.

Die einzelnen Summen können noch zu weiteren Informationen in Beziehung gesetzt werden. Nicht immer lassen sich dabei allerdings Gesetzmäßigkeiten feststellen. So steht die Höhe der Lösegelder in keinem ersichtlichen Zusammenhang mit der Beschaffungsmethode, sowohl der höchste als auch der niedrigste Betrag werden durch Dritte bezahlt, mit anderen Worten vom Erklärenden geliehen, dazwischen treten solche Kreditgeber ohne jeden Bezug zur Höhe der Lösegelder manchmal auf und manchmal eben nicht.

Interessanter dagegen ist der Aspekt der Lösegeldsenkung. Viele der Erklärenden geben neben den am Ende gezahlten Lösegeldern auch noch die Summe an, die sie ursprünglich bei der ersten Schätzung bezahlen sollten. Man kann sich vorstellen, dass die Spanier, bestrebt, ein Maximum an Gewinn mit ihren Geiseln zu erwirtschaften, das Lösegeld im Zweifelsfall zu hoch veranschlagten. Wenn sich aber dann herausstellte, dass das Opfer den geforderten Betrag nicht aufbringen konnte, musste dieser gesenkt werden. Aus immerhin 32 der 143 Erklärungen geht eine solche Senkung hervor. Die typischen Formulierungen hören sich etwa so an: "... ebi di taglia venti duchati a di 20 di settembre ne pagai otto duchati" (86), oder: "... ebi di taglia Ducati 150 dagli spagniuolli e pagai della detta taglia Fiorini ${ }^{157}$ cinquantadue". (122) Die Hintergründe solcher Lösegeldsenkungen waren ein Problem, das weite Kreise zog und sich keineswegs nur zwischen Opfern und Tätern abspielte. Einige der Geschätzten - wahrscheinlich waren sie unterwegs, um das Lösegeld zu besorgen und hatten ihre Kinder als Geiseln bei den Soldaten zurückgelassen - beschwerten sich nämlich bei der Signoria in Florenz über die unmenschlich hohen Summen, die man ihnen auferlegt hatte. Diese schickte daraufhin am 1. September Botschafter an den Vizekönig, die diesen dazu bringen sollten, bei den Soldaten für eine Senkung der Lösegelder oder wenigstens für eine Verlängerung der Zahlungsfristen einzutreten. Vergeblich: zwar sähen auch andere Offiziere ein, dass die Lösegelder aus überzogenen Vorstellungen erwuchsen, gegen den Willen der Soldaten könne man aber nichts ausrichten, und schlimmer noch, man werde den Geiseln selbst durch ein allzu drängendes Auftreten in dieser Frage schaden. ${ }^{158}$ Am 6. September ließen die Botschafter des Vizekönigs in Florenz dennoch durchblicken, dass man wenigstens einige Hauptleute zur Senkung der Lösegelder habe bewegen können. ${ }^{159}$ Die Erlassung eines Teils der Lösegelder dürfte ihren Ursprung dabei weniger in der Nächstenliebe der Besatzer gehabt haben, oder, wie der fromme Girolamo di Domenico (130) es in seiner Erklärung ausdrückt, in der Liebe Gottes, als vielmehr in der Einsicht der Soldaten in die Zahlungsunfähigkeit ihrer Opfer. Einige, wie Taldo di Guas-

57 Auch hier wieder die Verwechslung der beiden Währungen.

158 GUASTI, Il sacco di Prato, Dispensa 178, S. 157.

159 GuASTI, Il sacco di Prato, Dispensa 178, S. $183 \mathrm{f}$. 
parri (66), ließen wohl auch ihre Beziehungen spielen: zu seinen Gunsten intervenierte ein Verwandter des Notars, der den ersten Vertrag zwischen Taldo und dem Hauptmann aufgesetzt hatte, der diesen geschätzt hatte.

Interessant ist auch hier wieder ein Vergleich der Durchschnittswerte: die tatsächlich gezahlten Lösegelder der 32 Personen, denen man das Lösegeld gesenkt hatte, liegen im Schnitt bei 49 Dukaten, die ursprünglich verlangten Summen sogar bei 108 Dukaten. Daraus folgt zunächst, dass die Soldaten eher bei besser gestellten Opfern dazu neigten, überhöhte Lösegelder zu fordern, man könnte daneben allerdings auch vermuten, dass diese es besser verstanden, eine Minderung zu erwirken. Chaotisch wird es wieder bei einem Vergleich des Größenverhältnisses zwischen geforderter und gezahlter Summe in den Einzelfällen. Wie die Gegenüberstellung der genannten Durchschnittswerte von 108 geforderten zu 49 tatsächlich gezahlten Dukaten ergibt, wurden die geforderten Lösegelder, wenn sie gesenkt wurden, im Schnitt um etwa die Hälfte gesenkt. Aber auch hier ist eine erhebliche Streuung festzustellen: 11 der 32 gesenkten Summen sind geringfügig gesenkt worden, nämlich um ein Drittel oder weniger, 14 in einem Bereich zwischen einem und zwei Drittel und 7 um mehr als zwei Drittel. So schaffte es Antonio Bizocchi (162), von den ursprünglich verlangten 200 Dukaten nur 40 zu zahlen, und Raffaele Damodar (184) zahlte von 500 Dukaten sogar nur 64. In seiner Erklärung nehmen sich die 500 allerdings astronomisch aus, denn für seinen Bruder und einen gewissen Andrea di Giovanni, die ebenfalls dort figurieren, betragen die Summen von vornherein nur 7 beziehungsweise 10 Dukaten. Offenbar hatten die Spanier ihn bei seiner Schätzung für wesentlich reicher gehalten, als er eigentlich war. Manchmal tauchen auch Minderungen in ganz unterschiedlicher Größenordnung in einer Erklärung auf und stiften zusätzliche Verwirrung, wie bei Marsilio Pucetti (93), dessen Lösegeld von 5 auf 4 Dukaten moderat gesenkt wurde, während das seines Sohnes von ursprünglich 12 auf einen Dukaten geradezu abstürzte. Ein solches Phänomen könnte sich so erklären, dass der Vater zunächst sein eigenes Lösegeld besorgte, während sein Sohn noch für ihn als Geisel festsaß. Die Beschaffung zog sich hin, und als Pucetti das Geld für seine Auslösung schließlich aufgetrieben hatte, waren seine Geldquellen völlig erschöpft, so dass die Spanier sich notgedrungen mit dem letzten Dukaten zufriedengeben mussten, den Pucetti ihnen noch anbieten konnte.

Zur Einschätzung der Besitzverschiebungen, die sich aus der Plünderung ergaben, muss schließlich noch ein anderer wichtiger Faktor berücksichtigt werden: das Verhältnis zwischen den geplünderten Geldbeträgen und Sachwerten und den bei der Lösegelderpressung verloren gegangenen Summen. Die Gesamtverluste können natürlich nur geschätzt werden, nach einer solchen Schätzung belaufen sie sich auf 200.000 Dukaten ${ }^{160}$ und sind damit mindestens dreimal so hoch wie die Verluste durch die Lösegelder. Das erklärt sich aus

160 CADENAS, El saco de Prato, S. 118. 
dem wichtigsten Mechanismus der Ausplünderung: die Erpressung von Lösegeldern ersetzte ja nicht die Plünderung, sondern sie schloss sich an diese an und hatte das Ziel, Werte in den Besitz der Plünderer zu bringen, an die man eben nur deshalb durch Erpressung gelangen konnte, weil sie sich in der Regel noch nicht im unmittelbaren Besitz der Opfer befanden, zumindest nicht in Form des von den Soldaten bevorzugten Bargeldes. Man kann also davon ausgehen, dass auch im Fall von Prato die Opfer vor der Schätzung völlig ausgeplündert worden waren. Das scheint von diesen auch als ganz selbstverständlich hingenommen worden zu sein, denn kaum einer erwähnt die Plünderung auch nur mit einem Wort. Eine der Ausnahmen ist Raffaello d'Antonio (79): "... fuimo presi mio fratello ed io dagli spagnoli e tolsaci la roba che noi avamo e denari contati e dipoi ci puosano ducati cento d'oro in oro ...". Dasselbe bemerkt der Kanoniker Giovanni (195), und Raffaello Casini (152) präzisiert: "E presente tutti mi tolsano Ducati 215 che io avevo adosso e Ducati 40 di taglia altra questo." Hier zeigt sich schon die Relation: das Lösegeld beläuft sich nur auf ein Fünftel des gesamten Bargeldes, das er bei seiner Gefangennahme im Glockenturm des Klosters von Grignano bei sich trug. Bezeichnend ist, dass er als Einziger auch die unmittelbare Plünderungsbeute, nämlich die 215 Dukaten, die man ihm wegnahm, zu der Endsumme der Lösegelder für sich und seinen Sohn addiert, was diese scheinbar versechsfacht.

Daraus ergibt sich folgendes: die Plünderung selbst fügte den Opfern zunächst größeren Schaden zu als die Erpressung von Lösegeldern. Die zum Teil lebensbedrohliche Bedrükkung, die diese nach allen Zeugenaussagen darstellte, ergab sich aus der Tatsache, dass man den Opfern bereits vor der Schätzung Bargeld und Wertgegenstände abgenommen hatte und sie sich unter großem Druck nach Mitteln zur Beschaffung des Lösegeldes umsehen mussten.

\section{Beschaffung und Bezahlung}

Neben zahlreichen Immobilienverkäufen zur Beschaffung des Lösegeldes, die nachweislich stattfanden, ${ }^{161}$ von denen in den Erklärungen aber nicht die Rede ist, erwähnen 65 der 143 Erklärenden weitere Personen, die ihnen das Lösegeld ganz oder teilweise zur Verfügung stellten, in der Regel also liehen. Die Formulierung dafür ist äußerst schwammig: "... e quali danari mi presto Antonio Dandria" (98) oder: "... e quali danari o ne olatato da Domenicho di Meo fornaro" (120) oder, am weitesten verbreitet: "... e quali pagho per me Lorenzo di Lionardo di Giovani da Prato" (157). Wie viele von diesen Geldgebern dafür Zinsen nahmen, also zum eigenen Vorteil handelten, ist schwer zu bestimmen. Sicher ist aller-

161 ModESTI, Bericht, S. 243. 
dings, dass nicht jeder, der in seiner Erklärung keine Kreditgeber erwähnt, das Geld auch zwangsläufig aus der eigenen Tasche bezahlte. So geht aus der Erklärung von Francesco Fozzari (137) nur aus einer anklagenden Bemerkung hervor, dass dieser das Lösegeld bei einem - wohl professionellen - Geldverleiher borgte, ohne dass er diesen namentlich nennt: "... a paghato Fiorini cento d'oro in oro larghi sensa lo rischatto della casa e sensa lo interesse a costo di quelli che gli achato a usura." Das Problem ist, dass all die anderen, die Kreditgeber erwähnen, kein Wort über die eventuellen Zinsen verlieren und damit diese Kreditgeber wie Privatpersonen wirken. Man kann daher nicht ausschließen, dass es sich um Freunde des Erklärenden handelt. Da die meisten Erklärungen keine Rückzahlungsbedingungen oder Zinsen nennen, ist es schwer, eine zahlenmäßige Gewichtung zwischen den beiden Phänomen Freundschaftsdienst und Kreditgeschäft vorzunehmen. Festzuhalten ist, dass mindestens an der Hälfte der Transaktionen zur Bezahlung der Lösegelder Dritte beteiligt waren.

6 der 65 ausgeschriebenen Kreditnehmer bekamen das Geld direkt von einem Verwandten. In weiteren 10 Erklärungen stellen Geistliche das Geld zur Verfügung, in diesen Fällen kann man ein Zinsgeschäft wohl ausschließen. Interessant ist auch hier wieder ein Blick auf die Einzelsummen: von den geringsten bis zu den höchsten Beträgen ist die gesamte Palette der Lösegelder vertreten. Die Kirche scheint also keineswegs nur den Bedürftigen geholfen haben, oder anders gesagt: die Lösegelder stellten die höheren Gesellschaftsschichten vor das gleiche Problem wie die unteren, nämlich das der Zahlungsunfähigkeit mit allen aus ihr resultierenden Gefahren für das Leben der Geiseln. Einer der Geistlichen, Bruder Benedetto aus dem Konvent von San Domenico, lässt sich sogar in drei der überlieferten Erklärungen ausfindig machen. Er zahlte sowohl die 2 Dukaten für Fano Baldinucci (174), als auch die 8 Dukaten für den Winzer Bartolomeo di Stefano (86), und schließlich auch den ganzen Batzen von 200 für Francesco di Santi. (160) Aus irgendeinem Grund muss der Konvent von San Domenico von der Plünderung verschont geblieben sein, denn bei Bernardo di Stefano (177) ist es dessen Prior, der als Geldgeber in Erscheinung tritt, wenn auch nur für 2 Dukaten. So verbreitet wie das Phänomen der Geldverleihung allgemein war, so schichtenübergreifend war die Hilfe, die die Kirche zur Verfügung stellte. Die Gemeinde Colle verkaufte sogar Land aus dem Besitz des Hospitals, um Gelder für die Bezahlung der Lösegelder ihrer Einwohner nach Prato zu schicken, die bei der Verteidigung in Gefangenschaft geraten waren. $^{162}$

Es bleibt eine Mehrheit von Schuldnern zurück, für die weder Verwandte noch die Kirche einsprangen. In ihren Fällen wird niemals eine Institution genannt, so dass die Vermutung gestattet ist, dass normale Zeitgenossen sich als Gelegenheitsbankiers versuchten. Zwar wird nur von drei Geldgebern in den Erklärungen der Beruf genannt, aber in allen drei Fäl-

162 BRAMi DA COLLE, Bericht, S. 258. 
len hat dieser nicht im entferntesten etwas mit dem Kreditwesen zu tun: einer ist Bäcker, ein anderer Schmied und der dritte Buchbinder. Wie schon bei den Ausführungen über den Beutemarkt gesehen, schalteten sich findige Zeitgenossen offenbar auch hier gern zwischen die einzelnen Parteien in der Hoffnung auf Profit.

An die Geldverleihung waren, wenn diese kommerziell betrieben wurde, Rückzahlungsbedingungen geknüpft. Wieder können Einzelheiten nur aus scheinbar zufällig und aus einer Laune des Schreibenden heraus hinzugefügten Randinformationen geschöpft werden. In der Regel werden die Geldgeber Zinsen verlangt haben, die aber in der Endsumme nicht zu dem Lösegeld dazugerechnet werden. Lediglich der Priester Meo di Lodovico (107) erwähnt Zinsen und addiert diese zum eigentlichen Lösegeld, dabei handelt es sich bei den vermeintlichen Zinsen aber eben aus diesem Grund eher um eine Schikane der Besatzer, die das Lösegeld selbst wegen einer Verzögerung bei der Bezahlung heraufgesetzt hatten. Immerhin waren seine sogenannten Zinsen fast genauso hoch wie der Betrag, den er eigentlich bezahlen soll.

Zurück zu den Geldverleihern. Neben den Zinsen, über deren Höhe uns die Erklärungen im Unklaren lassen, von denen Modesti aber schreibt, ihre Auswirkungen kämen einer zweiten Plünderung der Stadt gleich, ${ }^{163}$ wurden den Geldgebern bisweilen auch Sicherheiten überschrieben: so hielt es Geri d'Antonio (168) mit seinem Gläubiger Pellegrino di Simone, dem er ein Stück Land überschrieb, das zunächst von einem Notar treuhänderisch verwaltet werden sollte. Die Verhältnisse konnten beliebig kompliziert gelagert sein, wenn zwischen Schuldnern und Gläubigern noch weitere Personen auftraten, die den Kredit offenbar vermittelten, wie das bei Lodovico Guiziloni (121) der Fall war, dem sein Schwager den sienesischen Botschafter in Florenz als Kreditgeber vermittelte, oder Piero d'Antonio (94), für dessen Lösegeld anscheinend ein gewisser Bartolomeo del Bastiano ein Haus an einen weiteren Gläubiger aus San Miniato verpfändete. Immer undurchsichtiger wird es, wenn die Summe dann auch noch unter mehreren Kreditgebern aufgespalten wird, die nacheinander an verschiedenen Orten in Aktion treten, wie etwa bei dem Glaser Michele Nomi (105), der von seinen 50 Dukaten zunächst 4 selbst bezahlte, 16 bei einem gewissen Matteo Manucci und die restlichen 30 bei dem spanischen Händler Andrea di Palanchole in Florenz lieh.

Mit dem Stichwort Florenz ist ein wichtiger Aspekt der Lösegeldbeschaffung angesprochen. Bisher war die Rede von verschiedenen Personengruppen, die sich als Geldgeber zwischen Opfer und Soldaten schalteten und scheinbar direkt an letztere bezahlten. Bei diesen Geldgebern wurde unterschieden zwischen uneigennützigen und eigennützigen, wobei die uneigennützigen keine Zinsen nahmen und in der Regel Verwandte oder Freunde der Opfer waren oder im Auftrag einer kirchlichen Institution handelten. Die Erklärungen sind

163 MODESTI, Bericht, S. 245. 
für diese Aussagen zwar eine dünne Beweisgrundlage, aber die wenigen Argumente, die sie liefern, fügen sich gut ineinander. Über den konkreten Ablauf der Transaktionen sind ihre Informationen allerdings dürftig. In der Folge soll dennoch eine kurze Rekonstruktion dieses Ablaufs versucht werden. Dazu ist die Feststellung von erheblicher Bedeutung, dass ein Teil der Geldgeber - insgesamt 12 werden ausdrücklich genannt - nicht in Prato auftrat, sondern in Florenz. Das erscheint einleuchtend, denn in Prato war ja kaum jemand von Plünderung und Schätzung verschont worden. Das schließt nicht aus, dass viele Geldgeber aus Prato stammten und sich für ihre Kreditgeschäfte bei florentinischen Banken mit Bargeld versorgten. Konkret sah das so aus, dass die Opfer zunächst in Prato entweder aus eigenen Reserven schöpften oder sich nach Geldgebern umsahen. Wenn das nichts half, schickten sie Botschaften an Freunde oder Verwandte in Florenz oder begaben sich selbst dorthin, wenn sie Angehörige hatten, die sie als Geiseln zurücklassen konnten. Dort versuchten sie, gegen Wechsel, Schuldscheine und Verpfändung von Besitz an Bargeld zu kommen. ${ }^{164}$ Die wenigen Notarsakten, die sich mit den Lösegeldern beschäftigen, ergänzen die Erklärungen in diesem Punkt. So wurde Gerio di Buonristori von dem spanischen Soldaten, der ihn gefangen hielt, nach Florenz geschickt, um die 50 Florin zu besorgen, um die er geschätzt worden war. Wenn er sich nicht an die Absprachen halte, so steht es im Vertrag, werde das Lösegeld verdoppelt. ${ }^{165}$ Ebenfalls 50 Florin bekamen Benedetto Marmeggia und Simone Lombardi aus Casale Marittimo. Und während Benedetto in Prato im Gewahrsam der Soldaten blieb, musste Simone den Weg nach Casale Marittimo antreten und das Geld beschaffen. Zu diesem Zweck bekam er von Benedetto eine Vollmacht zum Verkauf seiner Besitzungen dort. Wenn Simone nicht innerhalb von 6 Tagen zurückkehrte - und das ist angesichts der Distanz von $80 \mathrm{~km}$ zwischen den beiden Orten nicht gerade großzügig bemessen - und das Geld aushändigte, sollte Benedetto für den gesamten Betrag verantwortlich gemacht werden. ${ }^{166}$

Es scheint darüber hinaus, als seien die Soldaten manchmal mitgegangen, sei es weil sich niemand als Geisel fand, sei es weil sie die Opfer bei der Besorgung des Lösegeldes unter Druck setzen wollten, um sich nicht mit weniger abspeisen zu lassen, als diese wirklich aufbringen konnten. Ein Indiz dafür ist die Tatsache, dass ab und zu Spanier als Mittelsmänner bei den Transaktionen auftraten, und zwar solche, die allem Anschein nach in Florenz tätig waren wie der schon genannte Andrea di Palanchole, der das Geld für Michele Nomi (102) bereitstellte. An anderer Stelle findet sich ein als Spanier bezeichneter Herr mit dem sehr italienischen Nachnamen della Rovere, an den der Kanoniker Giovanni (195) in Florenz seine 50 Dukaten auszahlte, und zwar "per hordine di chi m'aveva prigione" - ganz

\footnotetext{
164 CADENAS, El saco de Prato, S. 99.

165 ASF Notarile Antecosimiano 19970, fol. $157^{\mathrm{r}} \mathrm{f}$.

166 ASF Notarile Antecosimiano 2238, fol. $70^{r_{f}}$.
} 
so, als hätte dieser Pedro della Rovere eine Art Bankiersfunktion für die Soldaten in Florenz ausgeübt.

Verfolgen wir den Gang der Dinge noch ein Stück weiter. Wenn die ersten Bemühungen in Florenz - dreimal wird auch Pistoia genannt - nicht das gesamte Lösegeld hatten einbringen können, dürften sich Verhandlungen mit den Soldaten um eine Minderung angeschlossen haben, und, im Fall von Unnachgiebigkeit von Seiten der Soldaten, weitere ähnliche Versuche, an Bargeld zu kommen. Wenn einzelne Teilbeträge aufgebracht waren, wurden vielleicht als Geiseln festgehaltene Kinder freigekauft wie von Tato di Tato (60), der seine Söhne nacheinander auslöste. Und Giovanni Novellucci schrieb zwei Wochen nach der Plünderung an Pandolfo de Bardi in Florenz, er habe sein Lösegeld bezahlt und müsse jetzt noch seine Kinder auslösen, weshalb er Pandolfo bat, ihm 6 Dukaten zu leihen. ${ }^{167}$

Wer Pech hatte, hatte das Geld bis zum Abzug des Heeres immer noch nicht zusammen und wurde verschleppt wie Andrea Luschini (81). Der hatte zwar schon 30 der 50 Dukaten seines Lösegeldes angezahlt, aber die Spanier wollten sich damit nicht zufrieden geben und schleppten ihn nach Bologna, wo er die fehlenden 20 Dukaten von einem Geldverleiher namens Raffaello Parigi bekam - dieser wahrscheinlich selbst aus Prato und identisch mit Raffaello Giacomo Parigi (71), der 170 Dukaten Lösegeld für sich und seinen Vater bezahlt hatte. Schließlich schalteten sich bisweilen auch Angehörige der italienischen Abteilungen des Heeres in die Transaktionen um die Lösegelder ein. Ab und zu traten sie wie die Spanier als Geiselnehmer auf, aber auf Grund der lückenhaften Überlieferung und der unsicheren Unterscheidung zwischen Spaniern und Italienern in den Erklärungen lassen sich keine Unterschiede im Verhalten der Italiener zu dem der Spanier festmachen. Interessanter ist das Auftreten einiger Italiener aus dem Heer als Vermittler oder direkt auch als Geldgeber. Wer nämlich Glück hatte, verfügte über ein wirksames Mittel gegen Zahlungsschwierigkeiten beim Lösegeld: Beziehungen. Es ist sicher kein Zufall, dass Vittorio Nigalozzi (103) seine 50 Dukaten Lösegeld vom Kämmerer des Kardinals Giovanni de' Medici vorgestreckt bekam, wie auch für Pavolo Bisconti (172) die gesamten 150 Dukaten seiner Schätzung von einem Bediensteten des Kardinals direkt an den spanischen Hauptmann Ortega ausgezahlt wurden; für Bertoldo Guazalotti (117) bezahlte der Kardinal immerhin die Hälfte. Nicht nur die hohen Summen deuten bei diesen dreien auf einflussreiche Persönlichkeiten hin, und die Tatsache, dass der Kardinal ihnen helfen ließ, lässt natürlich vermuten, dass es sich um treue Parteigänger der Medici handelte, deren Loyalität nach dem Machtwechsel in der Republik nun endlich wieder begann, sich auszuzahlen. Auch die Signoria in Florenz selbst ließ ihre Günstlinge nicht verkommen: ihre Botschafter beim spanischen Heer in Prato, die in regem Briefverkehr mit der Regierung standen, empfahlen dieser wohl regelmäßig bestimmte Geiseln an, die sich unter der Aufsicht spanischer Soldaten auf dem Weg

167 GUASTI, Il sacco di Prato, Dispensa 178, S. 192. 
nach Florenz befanden, mit der Bitte, für deren Auslösung zu sorgen. ${ }^{168}$ Hier wie auch am Verhalten des Kardinals, der ja beachtliche Summen zum Loskauf von Geiseln aufbrachte, lässt sich darüber hinaus eindrucksvoll belegen, wie wenig die Autoritäten gegen den Willen der Soldaten ausrichten konnten. Man bezahlte stillschweigend die Lösegelder, ganz offensichtlich war gar nicht daran zu denken, die Freilassung der Geiseln zu befehlen.

Wenn die Lösegelder schließlich zur Zufriedenheit der Soldaten gezahlt waren, was, wie oben gesagt, im Durchschnitt vielleicht zwei Wochen dauerte, wurden die Geiseln freigelassen. Sie bekamen einen Schutzbrief, der sie davor bewahren sollte, aufs Neue gefangen genommen zu werden. Wahrscheinlich meinen 14 der 143 Erklärenden diesen Schutzbrief, wenn sie von einer "polizia di loro mano" sprechen wie Zanobi di Jacopo. (55)

Diese skizzierten Möglichkeiten konnten in allen beliebigen Kombinationen auftreten. Dadurch werden einige der Erklärungen sehr undurchsichtig, aber eben diese Verworrenheit zeigt, dass die Schwierigkeiten bei der Beschaffung des Lösegeldes zu einem guten Teil dem Chaos entwuchsen, das die Soldaten selbst angerichtet hatten, indem sie Familien auseinanderrissen, ihre Opfer durch Todesdrohungen in Panik versetzten und willkürliche Lösegelder festlegten, die den einen in den Ruin trieben und dem anderen die Möglichkeit ließen, seine Reserven eigennützig oder uneigennützig anderen zur Verfügung zu stellen. Auf welche Ideen man dabei verfallen konnte, das soll zum Abschluss Lorenzo Ferini (113) berichten, der 65 Lire und 2 Soldi, also 9 Florin und 42 Soldi bezahlen sollte: "Lorenzo di Pietro Ferini ista in Prato pagho di taglia Fiorini 9 e sei Grosoni e Fiorini furono larghi d'oro in oro fune mezano Federico di Nardo lavoratore di Piero Tomaso di Lardena chontado di Prato che fu uno bue avevo e la choline di Ghiavelo tenevalo dito Federico a foco era graso e amazoralo e vendero la charne Soldi 2 la libra el deto bue teneva detto Federico in foco e avevalo per istima di dicti Fiorini 9, -, 6 Grosoni cioe - Lire 65 Soldi 2."

\section{Der Sacco di Roma}

Über die legendäre Plünderung Roms im Mai 1527 ist viel geschrieben worden - so viel, dass eine erneute Untersuchung, die sich nicht schwerpunktmäßig auf unbekannte oder noch nicht ausgewertete Quellen stützt, Gefahr läuft, sich in Wiederholungen festzufahren. Zwar wurden auch für den folgenden Abschnitt einige unbekannte Quellen ans Licht geholt, sie gehören jedoch in der Regel denselben Gattungen an wie die schon bekannten und sind daher nicht geeignet, einen völlig neuen Zugang zu den Geschehnissen zu öffnen. Die Ausführungen des folgenden Abschnittes sind indes geprägt durch den Blickwinkel dieser

168 Wie in einem Empfehlungsschreiben des Kanzlers der Botschafter vom 1. September, das sicher nicht das einzige seiner Art sein dürfte. GUASTI, Il sacco di Prato, Dispensa 178, S. 163. 
Arbeit - die Hervorhebung dessen, was Chronisten und Historikern vergangener Generationen zu banal erschien, die Ausblendung dessen, was den Sonderfall Rom ausmacht, und dementsprechend die Fokussierung auf das Exemplarische: das Verhalten von Soldaten und ihren Opfern in einer eroberten und zur Plünderung freigegebenen Stadt, die in diesem Fall nur deshalb Rom heißt, weil die große Zahl von Zeugnissen es ermöglicht, die Filter auszumachen und zu eliminieren, die die beobachteten Ereignisse in den Köpfen der Augenzeugen passierten, bevor sie ihren Ausdruck auf dem Papier fanden. Daher sind zunächst einige quellenkritische Anmerkungen unerlässlich.

Um eine wirklichkeitsgetreue Vorstellung vom Geschehen in den ersten Tagen und Wochen nach der Eroberung Roms zu gewinnen, muss man sich einige Faktoren vergegenwärtigen, die bei der Interpretation der Quellen von Bedeutung sind. Zunächst ist zu beachten, dass die meisten der berichtenden Quellen ihre Entstehung dem tiefen Eindruck verdanken, den die Greueltaten der Soldateska hinterließen. Dieser Eindruck ist bestimmt durch eine Reihe von starken Gegensätzen: die in kultureller Blüte stehende Renaissancemetropole war einem Haufen von Soldaten in die Hände gefallen, wie er verwilderter kaum vorstellbar war. Diese Soldaten waren seit Monaten nicht bezahlt worden, nun fielen einigen von ihnen von einem Tag auf den anderen Reichtümer in die Hände, deren Wert sie oft noch nicht einmal schätzen konnten. Die physische Wehrlosigkeit der gebildeten Berichterstatter steht in scharfem Kontrast zur Rücksichtslosigkeit der Soldaten. Erschwerend kommt hinzu, dass sich in den Ausschreitungen der zum größten Teil lutherisch gesinnten Landsknechte gegen die vielen hohen und niedrigen Geistlichen in den Augen der meisten Chronisten ein geradezu apokalyptisches Aufeinanderprallen von Ketzerei und Rechtgläubigkeit manifestierte. Diese Faktoren mussten der Plünderung Roms in den ersten Tagen nach der Eroberung in den Augen der Berichterstatter ihre einmalige Wucht verleihen. Außerdem traf das Chaos, das der Erstürmung folgte, die Bevölkerung in unterschiedlichem Grad, je nachdem in welchem Teil der Stadt die Opfer wohnten, ob es ihnen gelang, Offiziere bei sich einzuquartieren, welche soziale Stellung sie innehatten, ob sie über Beziehungen verfügten und ob sie geforderte Lösegeldsummen sofort aufbringen konnten oder nicht. Dennoch neigen die Zeugen dazu, das ihnen persönlich und ihrer engsten Umgebung widerfahrene Unrecht zum Maßstab zu erklären, der auf das gesamte Geschehen übertragen wird. So liegt der Akzent der Berichte zumeist auf den Phänomenen des Sacco di Roma, die das persönliche Schicksal des Berichterstatters bestimmten.

Ein weiterer zu beachtender Faktor für die Beurteilung der Quellen ist die Tatsache, dass es offenbar unterschiedliche Vorstellungen von dem gab, was man sich unter einer Plünderung vorzustellen hatte. In den Quellen werden mit den Begriffen "sacco" und "saccheggio" nämlich sowohl die religiös motivierten und nicht unmittelbar der Bereicherung dienenden Untaten der Landsknechte, als auch die systematischen Geiselnahmen der Spanier erfasst, die Vergewaltigungen ebenso wie der Ausverkauf der Beute. Das Unrecht schmilzt zu ei- 
nem Komplex zusammen, der durch die Begriffe "sacco" und "saccheggio" für die Zeitgenossen offensichtlich hinreichend erfasst ist. So erklärt es sich zum Beispiel, dass die Aussagen der Quellen weit auseinanderdriften, was die Dauer der Plünderung angeht. Viel interessanter als deren tatsächliche Dauer ist aber eben die Tatsache, dass man diese so schlecht bestimmen kann. Die Angaben schwanken zwischen 9 und 20 Tagen. ${ }^{169}$ Diese Uneinigkeit deutet darauf hin, dass die Plünderung an einigen Stellen der Stadt länger fortgesetzt wurde als an anderen oder später wieder aufflammte, vor allem aber ist sie ein Indiz dafür, dass sie nicht von einem Tag auf dem anderen aussetzte, sondern langsam abebbte und in andere Formen der Bereicherung überging, die von einigen noch als Plünderung empfunden wurden und von anderen nicht. Immer wieder lässt sich beobachten, dass das Nachlassen der Brutalität von den Opfern in viel geringerem Maß für festhaltenswert befunden wurde als ihre Entladung. Angesichts der fortgesetzten Übergriffe der Soldaten während der folgenden Besatzungszeit ist auch der Standpunkt des Notars Gualderonico verständlich, der die Dauer der Plünderung Roms mit neun Monaten angibt: von der Eroberung durch das kaiserliche Heer bis zu dessen endgültigem Abzug. ${ }^{170}$ Daher müssen bei der Auswertung der Quellen eine Reihe von Entzerrungen vorgenommen werden:

1. Die Berichte müssen auf eventuelle Tendenzen ihrer Verfasser abgeklopft werden, das Geschehen aus einer vorgefassten Meinung heraus zu schildern und zu interpretieren.

2. Die Schlaglichter auf die prominenten Opfer müssen gedämpft werden, es sei denn, deren Schicksal kann als exemplarisch für die Gesamtsituation gelten, oder in dem sie umgebenden Halbschatten sind weitere und bisher vernachlässigte Details erkennbar.

3. Mehr als die erneute Wiedergabe der die Plünderung begleitenden Phänomene in allen ihren Einzelheiten interessiert hier eine Einschätzung ihrer tatsächlichen Verbreitung.

4. Oft sind zwischen den Zeilen gegebene Informationen wertvoller als solche, deren Vermittlung in der Absicht des Berichterstatters liegt, weil das Aussparen und Übergehen von Einzelheiten darauf hindeutet, dass es sich für die Zeitgenossen um Selbstverständlichkeiten handelt - um das, was auch inmitten einer ungewöhnlichen Situation zum Gewöhnlichen geworden war.

169 Cave, Bellum Romanum, S. 402: 9 Tage; Trivulzio, Copia, S. 471: 12 Tage; Gregorovius, Ein deutscher Bericht, S. 358: 13 Tage; MAYERHOFER, Zwei Briefe, S. 751: 14 Tage; SinIBALDI DA MONTELUPO, RAFFAello Di BartolomeO: Autobiografie. Hrsg. v. Giovanni Gaye. In: Carteggio inedito d'artisti dei secoli XIV, XV, XVI. Bd. 3 (1501-1672). Florenz 1840. S. 593: 15 oder 20 Tage.

170 GUALDERONICO, Gli orrori del saccheggio, S. 92. 
Unter diesen Voraussetzungen soll nun also der Sacco di Roma, chronologisch begradigt und von Übertreibungen möglichst bereinigt, an einigen Stellen zurechtgestutzt, an anderen aufgefächert, einer neuerlichen Betrachtung unterzogen werden.

\section{Schutzmaßnahmen}

In der Regel wandte sich die Bevölkerung von Städten, denen eine Plünderung drohte, mit einem möglichst großen Teil ihrer Habe zur Flucht. In Rom dagegen wurde drei Tage vor der Ankunft des Heeres das Verlassen der Stadt vom Papst verboten, so dass man innerhalb der Mauern nach anderen Mitteln suchte, um Leben und Besitz zu schützen.

Viele brachten ihr Geld und ihre Wertsachen in die Häuser von Personen, die als Anhänger des Kaisers bekannt waren, oder zu Spaniern und Deutschen, in der Annahme, dass die Soldaten ihre eigenen Landsleute schonen würden. ${ }^{171}$ Die Anhänger der Colonna brachten Zeichen an ihren Häusern an, um auf ihre Zugehörigkeit zur kaiserlichen Partei hinzuweisen und auf diese Weise bei der Plünderung ausgespart zu werden. ${ }^{172}$ Römische Banken brachten ihre Einlagen in die Engelsburg. ${ }^{173}$ Einige versteckten die Wertsachen im Haus, eingemauert in Wänden oder vergraben im Keller, wieder andere gruben ihr Geld in abgelegenen Weinbergen ein und einige sogar auf Friedhöfen. ${ }^{174}$ Manche, die bei der Plünderung umkamen, nahmen ihr Geheimnis mit ins Grab - wenn sie ein solches fanden. ${ }^{175} \mathrm{Da}$ neben waren einige entschlossen, ihr Haus zu verteidigen. Die Markgräfin von Mantua, Isabella Gonzaga, ließ im Palast der Colonna im unteren Stockwerk alle Fenster und Türen zumauern. ${ }^{176}$ Wer es sich leisten konnte, heuerte darüber hinaus Wachen an: Alessandro del Bene stationierte 50 Privatsöldner in seinem Haus; ${ }^{177}$ Kardinal Cesarini ließ seinen Palast von 200 Bewaffneten verteidigen. ${ }^{178}$ Einige versahen ihre Häuser sogar mit Artillerie. ${ }^{179}$

Da nun die Stadt nicht verlassen werden durfte, geriet die Bevölkerung kurz vor der Ankunft des Heeres innerhalb der Mauern in Bewegung. Angesichts der drohenden Gefahr der Plünderung blieb kaum jemand gern allein zu Hause: die Bewohner zogen sich in einzelnen

171 CAVE, Bellum Romanum, S. 394.

172 Hagen, A. (HrsG.): Die Eroberung Roms im Jahre 1527. Eine Beschreibung in der Beler-Platnerschen Chronik von Königsberg. In: Neue Preußische Provinzial-Blätter 8 (1849). S. 147-157 u. 179-191. S. 154.

173 ASM Sforzesco, Cart. 137. Scipione Atellaro an Francesco Sforza, 13. 5. 1527.

174 BAR, MS 1002, S. 249.

175 Fast 200 Jahre nach dem Sacco di Roma kam im Palazzo Verospi ein Vermögen von 70.000 Scudi ans Licht, das offenbar vor der Ankunft der Plünderer dort versteckt und nicht wieder hervorgeholt worden war. LANCIANI, Storia degli scavi, Bd. 1, S. $239 \mathrm{f}$.

176 ARCO, CARlo DE (HrSG.): Notizie di Isabella Estense, moglie a Francesco Gonzaga. In: Archivio Storico Italiano, App. 11 (1844). S. 236.

177 Cellini, La vita, S. 76.

178 HoOK, The sack of Rome, S. 160.

179 CAVE, Bellum Romanum, S. 395. 
Gebäuden zusammen, in denen sie sich sicherer fühlten. Viele Familienväter schickten ihre Frauen und Kinder in die Klöster und Paläste von Anhängern des Kaisers oder begaben sich mit ihnen dorthin, wenn sie nicht auf der Stadtmauer bei der Verteidigung halfen. ${ }^{180}$ Natürlich hatten die wenigsten Beziehungen, die ihnen den Zutritt zu den Palästen der Reichen ermöglichten, viele scheinen aber auch aus Mitleid eingelassen worden zu sein. Einige Mütter gingen mit ihren Kindern zu den Palästen der Kardinäle und baten um Aufnahme. ${ }^{181}$ Auch andere wohlhabende Familien öffneten verängstigten Nachbarn ohne Ansehen der Person ihre Türen, wie die Palombara, in deren Palast die ärmeren Familien aus der Nachbarschaft Zuflucht fanden. ${ }^{182}$ Die meisten der Häuser, die Flüchtlinge aufgenommen hatten, waren völlig überfüllt: im Palast der Colonna waren schließlich über 2.000 Menschen zusammengepfercht, ${ }^{183}$ beim Kardinal della Valle waren 700 Personen, ${ }^{184}$ zum Bischof von Cosenza, einem Spanier, hatten sich 500 seiner Landsleute geflüchtet, ${ }^{185}$ im Haus des spanischen Botschafters ${ }^{186}$ waren 200 und beim Bischof Cassador 100 Flüchtlinge. ${ }^{187}$ In anderen Palästen sah es ähnlich aus, so dass in den meisten Häusern nur einige Bedienstete zurückblieben, wenn man sie nicht ganz aufgab.

Die Überfüllung der Zufluchtsorte und die Kopflosigkeit, in der man sie aufgesucht hatte, brachten es mit sich, dass der größte Teil der Habe in den Häusern zurückgelassen werden musste. Marcello Alberini floh mit seiner Mutter wie viele andere in den Palast der päpstlichen Kanzlei; sie konnten nur eine Kiste mitnehmen, in der sich nichts als Kleidung befand, während sie wichtige Schriftstücke zu Hause liegen ließen. ${ }^{188}$ Raffaello da Montelupo hatte gerade noch Zeit, sich seinen Mantel überzuwerfen, ein paar Kleidungsstücke zusammenzuraffen und sich zu bewaffnen, dann eilte er in die Engelsburg, während in den Straßen schon geschossen wurde. ${ }^{189}$

180 ASV Pio 53, Nr. 6, fol. $123^{\mathrm{V}}$. Sanga an die Kurie, 27. 6. 1527; VITELLI, Vitello: Lettere di diversi illustrissimi signori, et repubbliche scritte all' Illustrissimo Signore il Signor Vitello Vitelli. Anonymer Hrsg. Florenz 1551. S. 144.

181 CAVE, Bellum Romanum, S. 395.

182 BAV, MS Urb. Lat. 1677. Fol. $197^{\mathrm{r}}$.

183 TRIVULZIO, Copia, S. 479.

184 CoRvisIERI, Documenti inediti. In einer Liste auf S. 23-31 figurieren 563 Flüchtlinge. Der Kardinalshaushalt umfasste 130 Personen. LeE, Egmont (HrSG.): Descriptio Urbis. The Roman Census of 1527. Rom 1985. S. 101, Nr. 6544.

185 SANUTO, Diarii, Bd. 45, Sp. 187.

186 RodrigUEZ Villa, Memorias, S. 163.

187 GROLLIER, Historia, S. 88.

188 ALBERINI, Ricordi, S. 321.

189 Sinibaldi da MonTELUPO, Autobiografie, S. 591. 


\section{Die Plünderung}

Der Gedanke daran, dass nun in kurzer Zeit möglicherweise ein Vermögen zu gewinnen war, entfachte in den Soldaten beim Anblick der zumeist schutzlos daliegenden Häuser eine maßlose Gier, in die sich die Sorge mischte, von anderen übervorteilt zu werden. Nichts beschreibt diese Gier treffender als der Bericht des in Rom lebenden Deutschen Ambrosius von Gumpenberg, der sah, wie die ausgehungerten Landsknechte in die Stadt stürmten: "... und da der Exercitus in Rom kam, wiettet, dobt, und hette in der gerechten Handt sein wehr, in der anderen ein stuck Brott, das sie vor den Beckerleden oder in Iren häussern im einfall genomben hetten, das assen sie im Lauffen, wie das wiettig, hungerig gestorben Vich ..."190 Jeder hatte Angst, andere könnten ihm zuvorkommen, noch in der Nacht stürmte man in Rom mit Fackeln von Haus zu Haus. ${ }^{191}$ Die sich nähernden Schreie und Schüsse und das Krachen der eingeschlagenen Türen schüchterten die Bevölkerung so sehr ein, dass kaum jemand sich am Fenster zu zeigen wagte, ohnehin waren die Fenster in der Regel verriegelt, so dass die Bewohner im Dunkeln saßen. ${ }^{192}$ Die meisten der Häuser fanden die Soldaten indes verlassen vor. ${ }^{193}$

Nur wenige sahen von mehr oder weniger sicheren Beobachtungsposten aus, was sich draußen abspielte, wie Alberini, der das Geschehen vom Balkon des Kanzleipalastes aus verfolgte. ${ }^{194}$ In den Straßen vor allem in der Nähe der Einbruchstelle bot sich überall das gleiche Bild von Flucht und Verfolgung der geschlagenen Verteidiger: Sinibaldi da Montelupo beobachtete, wie seiner Einschätzung nach 4.000 bis 5.000 Flüchtlinge versuchten, sich Zutritt zur Engelsburg zu verschaffen, während sie von nur 50 Landsknechten wie im Rausch verfolgt und vor den Toren zusammengedrängt und niedergemetzelt wurden, ohne dass man vom Kastell aus etwas dagegen unternehmen konnte: "Stavamo a vedere questa cosa come stare a vedere una festa, perché non posevamo tirare che non amazasimo de' nostri asai magior numero che de' nimici." ${ }^{195}$ Arrivabene Gavardo sah, wie viele auf der Flucht in die am Ufer des Tiber liegenden Boote sprangen; etliche der Flüchtlinge ertranken, weil die überladenen Boote sanken, bevor man sich in Sicherheit gebracht hatte. ${ }^{196}$ Wer Zuflucht in einem Haus gefunden hatte, versuchte in der Regel, sich möglichst nicht bemerkbar zu machen. Im Palast der Palombara verhielten sich die Flüchtlinge so still, dass die Landsknechte, denen es nach einigen vergeblichen Versuchen schließlich gelungen war

\footnotetext{
190 Gregorovius, Ein deutscher Bericht, S. 373.

191 PASTOR, LUDWIG VON: Geschichte der Päpste seit dem Ausgang des Mittelalters. Bd. 4: Geschichte der Päpste im Zeitalter der Renaissance und der Glaubensspaltung von der Wahl Leos X. bis zum Tode Klemens' VII. (1513-1534). Teilbd. 2: Adrian VI. und Klemens VII. Freiburg 1907. S. 275.

192 BNM, MS 10773, fol. 95 ${ }^{\mathrm{r}}$.

193 BAV, MS Urb. Lat. 1677, fol. 197V.

194 ALBERINI, Ricordi, S. 263.

195 SiniBAldi DA MonTEluPO, Autobiografie, S. 592f.

196 Gavardo, Copia d'una letra, S. 629.
} 
die Tür aufzubrechen, in den Räumen herumzustöbern begannen ohne zu bemerken, dass sich dort Menschen aufhielten. ${ }^{197}$ Die Einsicht in die Vergeblichkeit der Hoffnung, von den Soldaten übersehen zu werden, führte bei einigen allerdings dazu, dass sie die Initiative übernahmen; angesichts der Gefahr waren sich viele nicht zu schade, sich bei den Soldaten anzubiedern. Da sich in der Stadt zahlreiche Anhänger des Kaisers befanden, fehlte es nicht an Rufen wie "Imperio! Hispania!"; einige versuchten darüber hinaus, die Soldaten zu besänftigen, indem sie sie in ihre Häuser einluden, bevor sie sich mit Gewalt Zutritt verschafften. ${ }^{198}$ Das machte auf die Soldaten allerdings keinen Eindruck, wie Gumpenberg berichtet: "... da saget das Kriegsvolk, du falscher Laur, gib gellt her, oder wir wollen dich bey den Hoden aufhengen, es ist erlogen das du guett Kayserisch bist, dan werst du's so wehrtest du dich nit uns seiner Maj. gethreuen Dienern so vill Monat soldt darzuleihen ..."199

Es gab grundsätzlich zwei verschiedene Möglichkeiten, den Soldaten in die Hände zu fallen: wer Glück hatte, geriet an Offiziere, die zumeist mit kühler Berechnung ans Werk gingen und gegen Bezahlung von beträchtlichen Lösegeldern bereit waren, die Einrichtung der Häuser zu verschonen und die Bewohner vor den Übergriffen anderer Plünderer zu beschützen. Über das Schicksal der Häuser und ihrer Einwohner entschieden so unter Umständen wenige Augenblicke, wie der Bericht von Grollier zeigt: während die Soldaten in der unmittelbaren Nachbarschaft des Palastes von Bischof Cassador die Türen einschlugen, gelang es den Flüchtlingen dort, einen Fähnrich auf sich aufmerksam zu machen, der, offenbar selbst auf der Suche nach Beute, auf der Straße unterwegs war. Dieser versprach schließlich Hilfe und holte seinen Hauptmann, der eingelassen wurde, seine Forderungen nannte und nach Bezahlung des Geldes den Palast mit seinem Gefolge besetzte. Mehrmals mussten Eindringlinge abgewehrt werden, Leben und Gesundheit der Flüchtlinge aber blieben immerhin verschont. ${ }^{200}$ Ähnlich verhielt es sich im Palast der Colonna, in dem sich Isabella Gonzaga mit den über 2.000 Flüchtlingen aufhielt. Dort hoffte man auf eine Schonung des Palastes, weil der Sohn der Markgräfin, Ferrante Gonzaga, einen der höchsten Posten im Heer bekleidete. Vergeblich: während auf dem Platz vor dem Palast die ersten Schüsse fielen und Gruppen von Landsknechten in der unmittelbaren Umgebung ihr Unwesen zu treiben begannen, erschien der Hauptmann Alessandro Nuvolara, ließ sich mit einem Seil an den zugemauerten Fenstern vorbei nach oben ziehen und bot den Schutz des Palastes gegen Lösegeld an. ${ }^{201}$ Er und der spanische Hauptmann Alonso de Córdoba ließen den Palast besetzen, und als Ferrante, der bei der Einschließung der Engelsburg unabkömmlich gewesen war, schließlich nach vier Stunden beim Palast ankam, war das Geschäft schon

197 BAV, MS Urb. Lat. 1677, fol. 198

198 CAVE, Bellum Romanum, S. 399.

199 GrEgOrOviUs, Ein deutscher Bericht, S. 374.

200 Grollier, Historia, S. 86.

201 ARCO, Notizie di Isabella Estense, S. 236. 
abgeschlossen. Nuvolara und Córdoba gewährten ihm Zutritt nur unter der Bedingung, dass er sich nicht in ihre Angelegenheiten einmischte. Es gelang ihm lediglich, seine Mutter von der Schätzung auszunehmen. ${ }^{202}$ Das Geld wurde unter schwerer Bewachung im Palast zusammengetragen, weil in der Zwischenzeit eine Gruppe von Landsknechten versucht hatte, sich Zutritt zu verschaffen. ${ }^{203}$

Selbst wenn man sich nicht auf Lösegelder einigen konnte, lief eine Plünderung, wenn sie unter der Aufsicht von Offizieren durchgeführt wurde, zumeist geschäftsmäßig und nüchtern ab. Ein Beispiel dafür ist die von einem anonymen Berichterstatter geschilderte Plünderung des Kanzleipalastes, der immerhin zwei Wochen lang verschont geblieben war. Am Abend des 20. Mai jedoch versammelten sich einige Hauptleute vor dem Tor und gaben einen Schuss zur Warnung ab. Als man das Tor nicht öffnete, wurde es eingeschlagen. Die anwesenden Kardinäle boten den Hauptleuten sofort die Summe von 50.000 Dukaten für die Auslösung des Inventars an. Diese aber schlugen das Angebot aus, das von den verzweifelten Unterhändlern schließlich bis auf 120.000 Dukaten erhöht wurde. Dennoch schien man sich von einer Plünderung des Palastes mehr zu versprechen: auch das letzte Angebot wurde zurückgewiesen, und noch am Abend desselben Tages zog eine Besatzung ein, die den Palast zu durchsuchen begann, während angeblich nicht weniger als 600 Soldaten zur Bewachung abgestellt wurden. Während Wachen auf allen Treppenaufgängen darauf achteten, dass niemand durch die Maschen schlüpfte, durchstreiften andere den Palast von oben bis unten, gingen mit Lampen in den Keller und trieben alle Flüchtlinge, die sie fanden, im Innenhof zusammen. Es folgte eine gewissenhafte Plünderung des Palastes, bei der sich die Offiziere den wertvollsten Teil der Beute sicherten. Alles wurde demontiert und schließlich zusammen mit den Lebensmitteln, dem Schmuck und den wertvollen Kleidern, die man den Bewohnern abgenommen hatte, verpackt und im Innenhof zum Abtransport auf 38 Tragtiere verladen. ${ }^{204}$ Auch hier nahmen die Opfer keinen Schaden an Leib und Leben.

Die meisten vor allem kleineren Haushalte hatten ein solches Glück aber nicht. Sie wurden von den Soldaten heimgesucht, bevor Abmachungen getroffen werden konnten, ganz abgesehen davon, dass sich die Offiziere ohnehin nur für die vielversprechenden Objekte interessierten. Die von den Soldaten aufgebrochenen Häuser wurden zuerst nach Geld und Wertgegenständen durchsucht. Da aber kaum jemand sein Geld im Haus liegen gelassen hatte, versuchten die Plünderer, die Hausbesitzer, wenn sie sie antrafen, zur Preisgabe der Geldverstecke zu zwingen. Die beiden Hauptmerkmale der eigentlichen Plünderung lassen sich mit den Begriffen Vandalismus und Brutalität zusammenfassen. Das ist nun nicht gerade eine atemberaubend neue These, daher soll auf die Wiedergabe der Einzelheiten, wie

202 LUZIO, Fabrizio Maramaldo, S. 82.

203 LUZIO, Fabrizio Maramaldo, S. 80.

204 Der gesamte Bericht in: BAV, MS Urb. Lat. 1677, fol. $115^{\mathrm{V}}-119^{\mathrm{V}}$. 
sie sich vor allem aus den Augenzeugenberichten ergeben, an dieser Stelle weitgehend verzichtet werden. Tatsache ist, dass bei der Durchsuchung der Häuser viel zu Bruch ging, zum einen weil die Soldaten aus Angst vor Übervorteilung in höchster Eile zu Werk gingen, zum anderen weil durch die Habgier und das rauschartige Gefühl, sich alles erlauben zu können, der Vandalismus teilweise zum Selbstzweck geriet: in den Läden und Wohnungen wurden auf der Suche nach Beute die Gefäße zertrümmert und ausgekippt, Möbel umgerissen und die Einrichtung auf dem Boden verstreut. ${ }^{205}$ Durch die Überrepräsentation von Gelehrten unter den Berichterstattern bekommt der Schmerz über den Verlust von Büchern, potenziert durch den empörenden Kontrast zwischen der eigenen Kultiviertheit und der Verrohung der Soldaten, in den Quellen einen besonders gewichtigen Ausdruck. Bücher wurden nicht selten und zum Teil aus bewusster Missachtung dessen, was sie repräsentierten, zerstört. So fand Pietro Melini, als er Anfang März nach Rom zurückkehrte, viele seiner Bücher zerrissen vor, ${ }^{206}$ und Jacopo Sadoleto klagte über die Verwüstung seines Besitzes, wobei ihn der Verlust seiner Bücher den tiefsten Schmerz verursachte. ${ }^{207}$

Vor allem aber die Grausamkeit der Soldaten gegenüber ihren Opfern wird von den Zeugen und Chronisten in allen Einzelheiten geschildert. Zwar versuchen diese in der Regel, vom Verdacht der Sensationslust abzulenken, diese aber scheint dann doch immer wieder durch. Auf die Versicherung, eigentlich nicht über die schrecklichen Vorkommnisse schreiben zu können, folgt zumeist eine detailfreudige Schilderung der größten Abscheulichkeiten: "L'animo tutto mi si raccapriccia à volere raccontare le miserie e' tormenti de' Barbari ..." schreibt Giovio, selbst Augenzeuge der Ereignisse, ${ }^{208}$ und Giraldi Cinthio zitterte angeblich die Hand: "... oime che mi trema la mano a scrivere cosa si horibile ..."209 Es folgen die Schreckensszenarien von Folterungen, die vor allem das Ziel verfolgten, den Opfern die Geldverstecke zu entreißen oder die Bezahlung der Lösegelder zu beschleunigen. ${ }^{210}$ Manchmal jedoch diente die Brutalität noch nicht einmal dem Zweck der Bereicherung, wie bei dem von mehreren Berichterstattern erwähnten Massaker an den Kranken im Hospital von Santo Spirito. ${ }^{211}$ Wie viele Menschen der Plünderung zum Opfer fielen, lässt sich unmöglich bestimmen, weil in den Aussagen der Zeugen - die sich im übrigen nie auf gesicherte Informationen stützen, weil es solche gar nicht gab - deren Neigung, dem erlebten

205 Trivulzio, Copia, S. 487.

206 GASPARONI, Arti e lettere, S. 120.

207 ASV AA. Arm. I-XVIII 6522, fol. 104 ${ }^{\mathrm{r}}$. Jacopo Sadoleto an den Bischof von Verona, 3. 11. 1527.

208 GIOVIO, Istorie del suo tempo, Bd. 2, S. 16.

209 GiRALDI CINTHIO, GIOVANNI BATTISTA: Hecatommithi, overo cento novelle, nelle quali non solo s'impara, \& si esercita il vero parlar Toscano; ma ancora vengono rappresentate, come in vaghissima Scena, \& in lucidissimo Spechio, le varie maniere del viver Humano. Venedig 1608. S. 8.

210 Die schauderhaften Einelheiten bei LuIGI GUICCIARDINI, Il sacco di Roma, S. 225ff; TrIVULZIO, Copia, S. 484ff.; GregoroviUs, Ein deutscher Bericht, S. 374; MAYERHOFER, Zwei Briefe, S. 752.

211 CAVE, Bellum Romanum, S. 398; BerthIER, JOACHIM JOSEPH (HrSG.): Chroniques du monastère de San Sisto et de San Domenico e Sisto à Rome écrites par trois religieuses du même monastère et traduites par un religieux dominicain. Levanto 1919. S. 277. 
Schrecken in astronomischen Zahlen Ausdruck zu verleihen, zu Angaben führt, die die tatsächlichen Zahlen um ein Vielfaches übersteigen. So berichtet Gumpenberg von 15.000 bis 20.000 Toten allein in der ersten Nacht. ${ }^{212}$ Daneben beziehen viele der im Nachhinein entstandenen Berichte offenbar die Opfer der Epidemie, die kurz nach der Eroberung in der Stadt ausbrach, in die Zahlenangaben der Opfer der Plünderung ein. Vettori, einer der wenigen besonnenen Chronisten, weist ohne eine eigene Zahl zu nennen darauf hin, dass die Zahl der Opfer von den Zeitgenossen fast immer übertrieben wurde und dass die Soldaten am Ende doch selten solche Einwohner töteten, die sich nicht wehrten. ${ }^{213}$

Da die Bankiers und Kardinäle - mit einigen von den Zeugen um so ausgiebiger geschilderten Ausnahmen - sich in der Regel mit den Offizieren in beiderseitigem Interesse auf Lösegelder einigen konnten, wurden vor allem einfache Leute zu Opfern der Brutalität. Eindringlicher und unmittelbarer als die barocken Schilderungen der Chronisten ist etwa der Brief von Giovanni Barotio an seinen Bruder Antonio in Venedig: er sollte 140 Dukaten Lösegeld bezahlen, konnte die Summe aber nicht auftreiben und bat Antonio voller Verzweiflung, ihm auszuhelfen. In dem Schreiben vom 12. Mai berichtet er, dass man ihn bereits auf der Streckbank gefoltert und ihm die Füße verbrannt habe. Seit 6 Tagen hatte er nur Wasser und Brot bekommen, aus seinen Worten spricht die nackte Todesangst: "Io ho perso il tutto, ma di questo non me curo. Io non voria morir si presto ... el mio caro fradelo Antonio, a tu mi ricomando, non mi lassar morir sì miseramente ... se non pago i me farano in pezi, sì che el mio fradelo, aiutame per l'amor de Dio, aiutame per l'amor de la Nostra Donna più tosto è possibile, perchè vedendo loro una parte del danaro, forsi se placerano. Tutti romani et done et puti sono presoni, et chi non paga amazano ... Aiutame el mio Antonio, aiutame per l'amor de Dio et presto." ${ }^{214}$ Neben solchen und anderen Misshandlungen kam es häufig zu Vergewaltigungen, an denen sich auch einige Offiziere beteiligten, die sich angeblich die schönsten Frauen vorbehielten. ${ }^{215}$ Nicht selten mussten die Ehemänner der Opfer dabei zusehen. ${ }^{216}$ Gumpenberg umschreibt die furchtbaren Vorgänge mit ausgewählt vorsichtigen Worten: "Aber der Spagnol ... namb her des Romaner weib, kinder und töchter, und wolt ain weil seines gefallens auf den weissen untergelegten Leilachen mit Inen scherzen und kurzwillen." ${ }^{217}$ Das Phänomen war so verbreitet, dass zahlreiche Frauen, die man aus Klöstern entführt hatte, von Soldaten an andere Soldaten verkauft wurden. ${ }^{218}$ Wieder andere wurden aus der Stadt verschleppt. ${ }^{219}$

212 GregoroviUs, Ein deutscher Bericht, S. 379.

213 VetTORI, FRANCESCO: Sommario della storia d'Italia dal 1511 al 1527. Hrsg. v. Alfred v. Reumont. In: Archivio Storico Italiano, App. 22 (1849). S. 380.

214 SANUTO, Diarii, Bd. 45, Sp. 237f.

215 BAV, MS Urb. Lat. 1677, fol. 198v.

216 Grollier, Historia, S. 72; CAVE, Bellum Romanum, S. 400.

217 GREgOROVIUS, Ein deutscher Bericht, S. 373.

218 ASV Pio 53, Nr. 6, fol. 122 . Sanga an die Kurie, 27. 6. 1527; Rodriguez Villa, Memorias, S. 137.

219 SANUTO, Diarii, Bd. 45, Sp. 133. 
Ein weiteres Phänomen ist im Verlauf der Plünderung die immer weitere Zerstreuung der Soldaten, denen es nicht gelungen war, sich ein Vermögen zu sichern, für das es sich lohnte, auf weitere Beutezüge innerhalb der Stadt zu verzichten. Wenn die Häuser nicht von Soldaten besetzt wurden, die anderen Gruppen von Plünderern den Zutritt verwehrten, wurden die meisten von ihnen innerhalb von kurzer Zeit mehrmals durchstöbert, dabei wurden die Gruppen der Soldaten immer kleiner. Cave spricht von Gruppen von 10 bis 20 Soldaten, die in den Straßen ihre zerstörerischen Runden machten, ${ }^{220}$ die Größe dieser Gruppen richtete sich wohl in erster Linie nach der erwarteten Beute: je vielversprechender die Häuser waren, desto zahlreicher waren auch die Soldaten, die sich Zutritt zu verschaffen versuchten. Da die größeren Haushalte ein verheißungsvolleres Ziel waren als die kleinen, wurden sie - mit einigen Ausnahmen - wohl auch zuerst von den Plünderern heimgesucht, während die zu spät Gekommenen auf weniger aussichtsreiche Objekte ausweichen mussten. Im selben Maß schrumpfte auch die Beute: während spanische Offiziere in den Palästen der Kardinäle Verträge über fünfstellige Lösegeldsummen abschlossen und einige Landsknechte mit den Perlenketten der Kurtisanen behängt durch die Straßen ritten, blieb den Soldaten, die mit Kardinal Pompeo Colonna drei Tage nach der Eroberung in die Stadt gekommen waren, nichts anderes übrig als die von anderen weggeworfenen Beutestücke von der Straße aufzusammeln und in den leergeräumten Häusern die Nägel aus den Wänden zu ziehen. ${ }^{221}$ Das gleiche Bild bot sich dann einige Tage später in den von den Kardinälen verlassenen Palästen. Ein anonymer Zeuge, der bei Kardinal Cesarini untergekommen war, berichtet, wie die Landsknechte in der Morgendämmerung des 12. Mai in den Palast kamen und alles auf den Kopf stellten. Da der Kardinal aber bereits Lösegeld an die spanischen Offiziere gezahlt und sich mit seinem Besitz in den Kanzleipalast abgesetzt hatte, fanden sie nicht mehr viel vor und mussten sich damit begnügen, den verbliebenen Flüchtlingen ihre letzten Habseligkeiten abzunehmen; dem Berichterstatter selbst blieben nach eigener Angabe noch eine Jacke und ein Paar Strümpfe. ${ }^{222}$ Bei vielen Soldaten hat man in der Tat den Eindruck, dass sie die Plünderung mit einer gewissen Orientierungslosigkeit betrieben. Sie irrten mitunter Tage lang durch die Stadt, ohne ein rechtes Ziel vor Augen zu haben. Das Kloster San Sisto wurde in wenigen Tagen mehrmals von betrunkenen Gruppen von Soldaten heimgesucht, die die Herausgabe des Klosterschatzes verlangten, vergeblich versuchten, sich Zutritt zu verschaffen und es nach einiger Zeit offenbar wieder aufgaben. ${ }^{223}$

Die Kirchen gehörten überall zu den ersten Zielen, die die Plünderer ansteuerten. Mit Schaudern beschreiben die Chronisten Sakrilegien wie die Schändung von Reliquien, die

\footnotetext{
220 CAVE, Bellum Romanum, S. 402.

221 TrivulzIO, Copia, S. 487; Grollier, Historia, S. 80.

222 BNM, MS 18730, Nr. 16, fol. 430 r.

223 BERTHIER, Chroniques du monastère, S. 282.
} 
aus ihren kostbaren Behältnissen gerissen wurden, um diese einzuschmelzen oder zu verkaufen und die Plünderung von Tabernakeln, Messgeräten und anderem. ${ }^{224}$ Solcherlei Scheußlichkeiten wurden nach weit verbreiteter Meinung vor allem von den Landsknechten begangen, die zur Zeit des Sacco di Roma bereits überall in dem Ruf standen, allesamt Anhänger der Lehren Luthers zu sein. ${ }^{225}$ Zwar taten sich Spanier und Italiener bei der Plünderung der Kirchen durch dieselbe Ungeniertheit hervor wie die Deutschen, was deren Verhalten von dem der anderen Soldaten im Hinblick auf die Kirchen eher unterschied, war ihre Neigung zur Demütigung der Geistlichen und zur Zerstörung der Gotteshäuser, die in der Tat nicht dem Zweck der Bereicherung, sondern einer religiösen Motivation folgte. Die meisten Berichterstatter sahen in den Deutschen vor allem die Häretiker, eine abendländische Version der Türken, ${ }^{226}$ die nach Rom gekommen waren, um den Papst zu erniedrigen und die schlimmsten Sakrilegien zu begehen. Ihr Verhalten wurde immer an diesem Umstand gemessen: so konnte Giovanni Bartolomeo Gattinara, Augenzeuge der Plünderung und selbst Funktionsträger im kaiserlichen Heer, feststellen, die Deutschen hätten sich verhalten "come veri luterani". ${ }^{22}$ Und Grollier stellte die rhetorische Frage: "Qui enim aliter fieri potuit ab impuris haereticis atque schismaticis?"228

Die Bewegungsfreiheit innerhalb der Stadt blieb auch dann noch stark eingeschränkt, als die Plünderung schon abebbte. Viele wussten Tage lang nicht, ob ihr Haus überhaupt noch stand. Zwar hatten die meisten der wohlhabenderen Römer Bedienstete zurückgelassen, diese aber lebten selbst oft nicht mehr oder waren ihrerseits geflohen. Während Alberini mit seiner Mutter im Kanzleipalast ausharrte, wagte sich ein Freund der Familie zu deren Haus, um wichtige Dokumente zu bergen. ${ }^{229}$ Ein Sekretär des venezianischen Botschafters schlich sich in der ersten Nacht nach der Einnahme Roms in derselben Absicht noch einmal zum Palast des Botschafters, dieser aber war bereits aufgebrochen worden und die Soldaten damit beschäftigt, die Dokumente zu verbrennen. ${ }^{230}$ Wie gefährlich es war, die Häuser zu verlassen, zeigt vor allem wieder der Bericht von Alberini, der von einem Fenster des Kanzleipalastes aus eine Leiche auf der Straße sah, die seinem Vater ähnelte. Trotz der drängenden Ungewissheit wagten weder er noch seine Mutter, den schrecklichen Verdacht

224 TrivulzIO, Copia, S. 484; BAV, MS Vat. Lat. 7933, fol. 59 ${ }^{\text {ff; }}$ CAVE, Bellum Romanum, S. 400.

225 In den Tagebüchern Sanutos lässt sich verfolgen, wie seit den 20-er Jahren Begriffe wie "Luterani" oder "Eretici" mehr und mehr zu Synonymen für deutsche Söldner werden.

226 Der Vergleich mit diesen war landläufig, immer wieder findet sich der Hinweis, dass die Türken es nicht schlimmer hätten treiben können: ASV Pio 53, Nr. 6, fol. 122V. Sanga an die Kurie, 27. 6. 1527. Sanuto, Diarii, Bd. 45, Sp. 187. Und das nicht nur in Rom: BuRIgOzzo, Cronaca di Milano, S. 464.

227 GATTINARA, Lettera di ragguaglio, S. 504.

228 GROLLIER, Historia, S. 85.

229 ALBERINI, Ricordi, S. 321.

230 ANONYM: Copia d'una letra del successo et gran crudeltade fatta drento di Roma che non fu in Hierusalem o in Troia così grande. Gedruckter Brief eines Sekretärs des venezianischen Botschafters in Rom vom 20. Mai 1527 aus Civitavecchia, ohne Datum und Erscheinungsort. Das hier verwendete Exemplar befindet sich in Brescia, Biblioteca Queriniana, C. I. 15, S. 42. 
zu überprüfen. Mehrere Tage verbrachten sie so im Zweifel, bis sich die Vermutung als falsch erwies. ${ }^{231}$ Auch die Flüchtlinge, die mit Grollier im Palast von Bischof Cassador ausharrten, wurden von diesem eindringlich vor dem Verlassen des Hauses gewarnt. Trotz dieser Warnung begab sich Grollier einmal ins Freie und machte einen Rundgang, von dem er entsetzt über die Verwüstungen und die überall in der Stadt verstreut liegenden Leichen zurückkehrte. ${ }^{232}$

\section{Beute und Lösegelder}

Mit dem Geld, das den Soldaten in die Hände fiel, konnten sie zunächst gar nicht viel anfangen, da das Wirtschaftsleben durch die Plünderung von einem Tag auf den anderen zusammengebrochen war und man sich abgesehen davon ohnehin alles nehmen konnte, was einem gefiel. Grundsätzlich boten sich vier Möglichkeiten: man verschleuderte das Geld bei Glücksspielen, man hortete es für den späteren Abtransport, man versuchte es aus der Stadt zu schicken oder man machte sich selbst damit davon und wurde so zum Deserteur. Dasselbe gilt für die wertvollen Beutestücke, die darüber hinaus auch verkauft werden konnten. Der Erlös aus diesen Verkäufen musste dann seinerseits wieder verspielt, gehortet, verschickt oder abtransportiert werden. Nachdem das Chaos der ersten Wochen sich beruhigt hatte, konnte man es auch auf mehr oder weniger normale Weise ausgeben.

Viele Augenzeugen erwähnen die Spieltische in den Straßen, an denen um riesige Beträge und teure Beutestücke gewürfelt wurde. ${ }^{233}$ Das Spielen um Geld scheint seinen Reiz nicht allein aus der Aussicht gewonnen zu haben, eventuell noch mehr davon zu besitzen, da es sich für die meisten Soldaten ohnehin um Beträge handelte, die sie nie zuvor besessen, meistens noch nicht einmal gesehen hatten. Ein genauso wichtiger Faktor war offenbar die Prasserei mit der Beute an sich. Es muss für die Soldaten ein unwiderstehlicher Reiz darin gelegen haben, Vermögen, die sie sonst in ihrem ganzen Leben nicht verdient hätten, innerhalb von Stunden zu gewinnen und wieder zu verlieren, wie um sich einmal im Leben von dem Gefühl mitreißen zu lassen, selbst ein großer Herr zu sein und gleichzeitig die, die es waren, durch die Missachtung ihres oft mühselig erworbenen Vermögens zu demütigen.

Nachdem die Soldaten sich alles angeeignet hatten was ihnen gefiel, mussten vor allem das Geld und die wertvollen Beutestücke - wenn man sie nicht sofort wieder verloren hatte zuerst gesichert und dann abtransportiert werden. Die Mechanismen von Sicherung und Abtransport der Beute sind durch die Quellen recht gut, wenn auch nicht systematisch dokumentiert. Da viele ausschließlich der persönlichen Bereicherung wegen nach Rom ge-

\footnotetext{
231 ALBERINI, Ricordi, S. 282f.

232 Grollier, Historia, S. 88.

233 CAVE, Bellum Romanum, S. 404f.
} 
kommen waren, hätten sie sich am liebsten sofort mit ihrem Gewinn auf den Heimweg aus der mehr und mehr verseuchten und von immer neuen Ausschreitungen heimgesuchten Stadt gemacht. Schon am ersten Tag, nachdem das Heer den Borgo gestürmt hatte, begannen einige Soldaten, die Lasttiere zu töten, weil sie Angst hatten, die Trossknechte könnten die wertvollsten Beutestücke schon wegschaffen, während sie sich noch zum Sturm auf Trastevere sammelten. ${ }^{234}$

Wenn die Soldaten in den Häusern blieben, in denen sie die Beute gemacht hatten, etwa weil sie Geiseln zu bewachen hatten, blieb die Ware zunächst dort. Schon nach einigen Tagen ging in Rom unter den Landsknechten das Gerücht um, dass die Spanier vor allem im Palast des Kardinals della Valle ungeheure Reichtümer gehortet hatten, was nicht ganz falsch sein konnte, da in den Palästen ja neben der Beute auch die Lösegelder zusammenflossen. ${ }^{235}$ Bevor aber die Deutschen die Kardinalspaläste einnahmen, transportierten die Spanier den größten Teil der Beute ab. Da sie sich mit einiger Verspätung gemäß einem schon drei Tage nach der Eroberung ergangenen Befehl in den Borgo zurückzogen, ${ }^{236}$ wurde ein großer Teil der Beute in den dort bezogenen Häusern aufbewahrt. Die beinahe täglichen Zusammenstöße zwischen einzelnen Gruppen von Soldaten und die Tatsache, dass der Beuteneid dabei eine der Hauptursachen war, führten dazu, dass vor lauter Argwohn kaum jemand vor die Tür ging, der in seiner Unterkunft Geld und erbeutete Wertgegenstände gehortet hatte. ${ }^{237}$ Einige befestigten sogar die belegten Häuser, um sie im Fall eines Angriffs anderer Soldaten besser verteidigen zu können. ${ }^{238}$ Auch Kirchen wurden neben anderen Zweckentfremdungen als Lagerstätten für Beute benutzt, jedenfalls erfuhr Antonio Tebaldeo im November von den Nachbarn des Herrn Benedetto da Porto, dass dessen Besitz inzwischen in der Kirche von Santi Apostoli aufbewahrt werde. ${ }^{239}$ Viele Beutestücke, vor allem Dinge, die für die Soldaten keine größeren Werte darstellten und die überdies schwer zu transportieren waren, standen offenbar lange Zeit in den verlassenen Gebäuden herum. So ließ Sigismondo Fanzino einige Statuen, die er erbeutet hatte, von Landsknechten aus der Kompanie von Hauptmann Lodron in ein Privathaus bringen. Als er sie zum Abtransport verpacken lassen wollte, war Lodron bereits abgereist, und die Soldaten, die das Haus bewachen sollten, waren an der Pest gestorben. Das Haus aber fand Fanzino abgeschlossen vor und er kam nicht mehr an seine Statuen heran. ${ }^{240}$

Ein Teil der Beute wurde von Rom aus verschickt, ohne dass die Plünderer sich selbst auf den Weg machten. Als sich die Nachricht vom Sacco di Roma in Italien verbreitete, besan-

\footnotetext{
234 Hormayer, Carl V. und seine Helden, Bd. 109/110. S. 438.

235 REISSNER, Historia, fol. $122^{\mathrm{r}}$.

236 LuZIO, Fabrizio Maramaldo, S. 80.

237 GrolliER, Historia, S. 98f.

238 SANUTO, Diarii, Bd. 45, Sp. 166f.

239 BAV, MS Vat. Lat. 4104. Fol. 79r r.

240 LUZIO, Fabrizio Maramaldo, S. 29.
} 
nen sich einige offenbar ihrer Kontakte zum Heer, vor allem zu den Offizieren der italienischen Abteilungen. Der Briefwechsel zwischen Federico Gonzaga, dem Markgrafen von Mantua und seinen Kontaktleuten in Rom ist charakteristisch und soll hier kurz wiedergegeben werden: schon am 22. Mai 1527 schrieb Gonzaga an Fabrizio Maramaldo, zwei befreundete Edelmänner, Marmirolo und Te, hätten ihn gebeten, sich bei Maramaldo für die Beschaffung antiker Kunstschätze zu verwenden. Er, Gonzaga, habe den beiden das Gewünschte zugesagt und bat Maramaldo, ihn nicht zu enttäuschen, da er sonst seine beiden Freunde nicht daran hindern könne, schlecht über ihn, Maramaldo, zu reden. ${ }^{241}$ Am 5. Juni schrieb wiederum Sigismondo Fanzino an den Markgrafen, Maramaldo habe ihm bereits fünf Köpfe und eine große Statue vorgezeigt. Er selbst habe einen gewissen Herrn Giangiacomo beauftragt, sich umzusehen und weitere Kunstschätze zu organisieren, dieser habe auch schon sechs oder sieben der schönsten Stücke beiseite geschafft. ${ }^{242}$ Am 20. Juni aber stieß Fanzino, wie aus einem weiteren Brief hervorgeht, an die Grenzen seiner Mittel: weiteres Material sei nur gegen Bargeld zu besorgen, ließ er verlauten, die Banken aber seien zahlungsunfähig und die Zeit laufe ihm davon, da die Anhänger der Colonna und zahlreiche deutsche Offiziere selbst unzählige Schätze zum Abtransport bereit machen ließen. Vieles andere falle der Zerstörung anheim oder werde eingeschmolzen. ${ }^{243}$ Ob Gonzaga seine Statuen am Ende noch bekam, ist unklar, sicher ist indes, dass es viele gab, die wie er ihre Beziehungen spielen ließen, um Profit aus dem Schicksal Roms zu schlagen. Wenn man sein Schreiben näher betrachtet, entdeckt man sogar einen mehr oder weniger geistreichen kleinen Scherz: bei Marmirolo und Te handelt es sich nicht etwa um Edelleute, sondern um zwei Schlösser des Markgrafen. ${ }^{244}$

Schließlich ist eine außergewöhnliche Quelle überliefert, die von der elegantesten Möglichkeit zeugt, erbeutetes Geld in Sicherheit zu bringen: die Bilanz der Fuggerbank für das Jahr 1527, in der unter anderem Gelder aufgelistet werden, die Angehörige des kaiserlichen Heeres, ganz offensichtlich aus der Plünderungsbeute, in Rom eingezahlt und bei einer der Filialen in Deutschland später wieder abgehoben hatten. ${ }^{245}$ Nicht immer geht aus den Posten eindeutig hervor, dass es sich um Soldaten handelt, vieles deutet aber darauf hin, dass diese eine Mehrheit unter den Einzahlern ausmachten, ganz abgesehen davon, dass sich die Namen von bekannten Hauptleuten wie Sebastian Schertlin von Burtenbach und Konrad von Glürns unter ihnen befinden. Das Dokument verzeichnet insgesamt 42 Posten, die als Beutegelder in Frage kommen, es ist aber anzunehmen, dass weitaus mehr Soldaten solche Transaktionen vornahmen, denn die Bilanz - auch wenn sie später aufgestellt wurde -

241 LuZIO, Fabrizio Maramaldo, S. 26f.

242 LUZIO, Fabrizio Maramaldo, S. 27.

243 LUZIO, Fabrizio Maramaldo, S. 28.

244 CHASTEL, The sack of Rome, S. 99.

245 Schulte, Aloys: Die Fugger in Rom 1495-1523. Mit Studien zur Geschichte des kirchlichen Finanzwesens jener Zeit. Bd. 1: Darstellung. Bd. 2: Dokumente. Leipzig 1904. Bd. 2, S. 221-228. 
schließt mit dem 31. Dezember 1527. Zu diesem Zeitpunkt waren die meisten Soldaten noch in Italien, und sicherlich nicht alle hatten Bevollmächtigte geschickt, um das Geld abzuheben, wie Schertlin und Glürns das offensichtlich getan hatten - übrigens in Augsburg wie die große Mehrheit der aufgeführten Soldaten, nur zwei ließen sich das Geld bei der Nürnberger Filiale auszahlen und einer in Antwerpen. Neben den Hauptleuten und einfachen Soldaten figurieren sogar einige Frauen unter den Einzahlern, bei denen man es aller Wahrscheinlichkeit nach mit Marketenderinnen zu tun hat oder mit Begleiterinnen der Soldaten, die von diesen an der Beute beteiligt wurden, wie Elisabeth von Günzburg, die immerhin 450 Dukaten einzahlte. Auch bei den anderen Posten handelt es sich zumeist um Beträge in der Größenordnung von mehreren Hundert Dukaten, was jeweils dem Sold von mehreren Jahren entspricht. Den mit 3.000 Dukaten höchsten Betrag zahlte Schertlin ein. Ungeachtet der einmaligen und möglicherweise exemplarischen Aussagekraft dieses Dokuments verteilte sich der weitaus größte Teil der Beutegelder dennoch vor Ort in Italien. Schließlich desertierten viele Soldaten schon in der ersten Zeit mit der Beute - wie viele, ist schwer zu bestimmen; umgekehrt gab es auch reichlich Zulauf aus den Reihen des für kurze Zeit in der Nähe der Stadt lagernden Ligaheeres, weil dort viele Appetit auf die sagenhafte Beute bekommen hatten. Am 10. Mai waren angeblich schon 2.500 Soldaten desertiert, vor allem Spanier, die sich ins Königreich Neapel abgesetzt hatten. ${ }^{246}$ Neapel scheint das gelobte Land für alle gewesen zu sein, die viel zu transportieren hatten, wahrscheinlich weil dort kein Krieg herrschte und die Wege daher sicherer waren. Viele versuchten, sich von dort aus nach Spanien einzuschiffen, immerhin so viele, dass man Befehle nach Gaeta und Neapel ergehen ließ, um die Häfen für die Deserteure sperren zu lassen. ${ }^{247} \mathrm{Um}$ mit der Beute sicher auch durch das vom Heer der Liga kontrollierte Gebiet reisen zu können, fälschte ein deutscher Offizier sogar Geleitbriefe von hohen Offizieren der Liga. ${ }^{248}$

Auch in Rom etablierte sich nach der Plünderung ein Beutemarkt, allerdings mit einiger Verspätung und mit erheblichen Risiken für die Händler, weil die Situation zumindest in der ersten Woche noch viel zu unübersichtlich war und niemand die Stadt zu betreten wagte. Kaum hatte sich die Lage beruhigt, da brach die Epidemie aus und behinderte die Entfaltung der Transaktionen auf ihre Art. Die typischen Mechanismen des Beutemarktes wurden bereits am Beispiel von Prato beschrieben, aus Rom ist leider kein Material überliefert, das eine systematische Auswertung ermöglicht. Eine solche wäre sicherlich auch des Vergleichs wegen lohnend, da in Rom vor der Plünderung kaum Wertgegenstände aus der Stadt geschafft wurden und das Angebot auf dem Beutemarkt daher überwältigend gewesen sein muss: von den schon erwähnten aus der Wand gerissenen Nägeln bis zu den Wandteppichen der Sixtinischen Kapelle ${ }^{249}$ war dort alles zu finden. Die in der Bilanz der Fugger-

246 SANUTO, Diarii, Bd. 45, Sp. 133 u. 218.

247 SANUTO, Diarii, Bd. 46, Sp. 300.

248 SANUTO, Diarii, Bd. 46, Sp. 191.

249 Chastel, The sack of Rome, S. 97. 
bank erwähnten deutschen Marketenderinnen wurden übrigens auch von dem Augenzeugen Gualderonico beim Verkauf der Beute beobachtet: "Donne tedesche havevano le scoccie piene ad vendere et li se vendevano de tucte cose per un mercato grande, et poi la resachegiavano de nuovo." 250

Auch den Lösegeldern wurde bereits ein eigener Abschnitt gewidmet. Im Unterschied zum Beutemarkt jedoch bietet sich auch in Rom eine breite Quellenbasis für die Lösegelder. Viele Soldaten zwangen nämlich - zumindest im Fall von größeren Beträgen - ihre Geiseln, die Verpflichtungen durch Notare rechtskräftig zu machen, so dass die Gelder auch nach dem Abzug des Heeres noch einklagbar waren. In der Tat beschwerten sich einige römische Adlige noch im Mai 1530 bei der Kapitolinischen Kammer, dass spanische Soldaten die Zahlung der vor drei Jahren vertraglich festgelegten Lösegelder forderten. ${ }^{251}$ Die Akten der Notare, bei denen die Verträge abgeschlossen wurden, sind zum großen Teil überliefert, einige ausgewählte Dokumente sind sogar ediert worden. Das Material ist schwer zugänglich und weit verstreut, abgesehen davon ist eine umfassende Arbeit darüber in Vorbereitung, so dass hier auf eine systematische Auswertung verzichtet wird. Einige Bemerkungen, die die Ausführungen über Prato ergänzen, sollen dennoch gemacht werden. Die Verhältnisse bei der Beschaffung und Bezahlung der Lösegelder waren in Rom ähnlich gelagert wie in Prato, wenn auch in größerem finanziellen Rahmen: so war Ostilio Savelli von einigen Soldaten gefangen genommen und um 800 Scudi geschätzt worden. Camillo Colonna hatte das Geld vorgestreckt, und im Juni waren davon 417 Scudi durch den Bruder des Opfers zurückgezahlt worden. Bis Oktober sollte eine zweite Rate von 200 Scudi erstattet werden, für die restlichen 187 Scudi war Schmuck aus dem Besitz von Savelli bei einer dritten Person in Zahlung gegeben worden, der im Fall der Säumigkeit von Savelli nach Ablauf einer 15-tätigen Frist versetzt werden sollte. ${ }^{252}$

Bei 9.000 Haushalten in Rom und vielleicht 24.000 Soldaten kann nicht jeder Soldat eine eigene Familie in seiner Gewalt gehabt haben. Dazu kommt die Fluchtbewegung innerhalb der Stadt, die einen großen Teil der Bevölkerung an wenigen Punkten konzentrierte und sie im Fall der kollektiven Gefangennahme durch Offiziere dem Zugriff anderer potentieller Geiselnehmer entzog. Wie am Beispiel von Nuvolara und Córdoba gesehen, konnten zwei Hauptleuten und ihrem Gefolge mehr als 2.000 Geiseln auf einen Schlag in die Hände fallen. Um so mehr andere Soldaten gingen dafür leer aus oder mussten das Lösegeld aus einer Familie unter sich aufteilen. Bei Alberini platzten beispielsweise acht Soldaten herein und nahmen seinen Vater gefangen. ${ }^{253}$ Wenn bei der Gefangennahme nicht um ein Löse-

\footnotetext{
250 GUALDERONICO, Gli orrori del saccheggio, S. 93.

251 ASCR Camera Capitolina I, 16, fol. $5^{\mathrm{r}} \mathrm{ff}$.

252 ASR Sforza-Cesarini parte I, 17, Nr. 40.

253 ALBERINI, Ricordi, S. 198.
} 
geld für die Rettung der Einrichtung verhandelt wurde, wie das in den großen Palästen der Fall war, ging zumeist eine Plünderung voraus. ${ }^{254}$

Zur Festsetzung der Lösegelder mussten die Soldaten versuchen, die finanziellen Möglichkeiten der Geiseln einzuschätzen. Das war nicht immer ganz einfach, da viele ja nicht zu Hause angetroffen wurden und daher wenige Anhaltspunkte vorlagen. Wer vermögend war, tat gut daran, das möglichst nicht zu erkennen zu geben. Um bei der Schätzung im Palast der Colonna nicht als wohlhabender Mann erkannt zu werden, verkleidete sich Arrivabene Gavardo flugs als Stallbursche. ${ }^{255}$ Wie sachlich es bei der Schätzung dort dann zuging, zeigt ein Brief des venezianischen Botschafters Venier an seine Regierung: Nuvolara, der sich die Schätzung der Flüchtlinge mit Córdoba teilte, hatte ihm in aller Ruhe auseinandergesetzt, dass er bei ihm als Geisel sicherlich besser aufgehoben sei als bei Córdoba und empfahl ihm, sich in seine Hände zu begeben, bevor dieser bei ihm angelangt sei. ${ }^{256}$ Die Namen der Geschätzten wurden anschließend schriftlich festgehalten. ${ }^{257}$

Weniger zimperlich waren wiederum die Soldaten bei der Ermittlung des Wertes ihrer Geiseln. Die Chronik des Klosters von San Sisto berichtet, dass die Plünderer eine der Schwestern an einen Baum banden und versuchten, die Identität der Tochter des Kurators Mario Peruschi aus ihr herauszupressen, was aber nicht gelang, da Ferrante Gonzaga - von den Schwestern zunächst für den Heiligen Sebastian gehalten - im letzten Augenblick als Retter in der Not erschien. ${ }^{258}$ Anna Fornetti wurde in einem Kloster gefangen und anschließend durch die Straßen geschleift, um sie dazu zu zwingen, ihre Adresse anzugeben. Da sie sich weigerte, ließ man sie schließlich schwer verletzt auf der Straße liegen. ${ }^{259}$

Wenn die Lösegelder festgesetzt waren, begann für die Opfer die Suche nach dem Geld. Wie in Prato wurden auch in Rom oft Fristen gesetzt, ebenso kann man die Tendenz der Soldaten feststellen, unangemessen hohe Lösegelder zu veranschlagen. Was deren tatsächliche Höhe betrifft, so sind die Informationen aus Rom weniger repräsentativ als die aus Prato. Von vier Kardinälen sind auch durch berichtende Quellen gesicherte Beträge überliefert, sie liegen zwischen 35.000 und 45.000 Dukaten, schließen allerdings die Lösegelder für die Flüchtlinge in den jeweiligen Palästen ein. Das war auch in anderen Fällen bei kollektiver Geiselnahme üblich. ${ }^{260}$ Oft sahen sich die Hausherren dabei genötigt, den Flüchtlingen das Geld vorzustrecken. ${ }^{261}$

Daneben gibt es zahlreiche weitere und weit verstreute Zahlenangaben über die Spitze der römischen Gesellschaft. Weder durch berichtende Quellen, noch in den edierten Akten der

\footnotetext{
254 GuALDERONICO, Gli orrori del saccheggio, S. 93.

255 GaVARDO, Copia d'una letra, S. 630.

256 SANUTO, Diarii, Bd. 45, Sp. 215.

57 GAVARDO, Copia d'una letra, S. 630.

258 BERTHIER, Chroniques du monastère, S. 283.

259 BAV, MS Urb. Lat. 1677, fol. 166 ${ }^{\mathrm{r}}$.

260 Rodriguez Villa, Memorias, S. 144.

261 MAZIO, Storia della guerra, Bd. 11, S. 342ff.
} 
Notare sind - mit ganz wenigen Ausnahmen - Lösegelder von weniger als 50 Dukaten überliefert. An die unteren Schichten der Bevölkerung kommt man daher über diese Dokumente kaum heran. Einzig eine Liste aus dem Palast des Kardinals della Valle ist in dieser Hinsicht bemerkenswert, weil sie eine Streuung der Lösegelder wiedergibt, die beinahe in den Größenordnungen der Erklärungen aus Prato liegt. Diese Liste erfasst alle Personen, die mit dem Kardinal zusammen von Fabrizio Maramaldo geschätzt wurden und sich an der Gesamtsumme von 35.000 Dukaten beteiligen mussten. Insgesamt sind 120 Namen direkt mit einer Summe verbunden. ${ }^{262}$ Die 7.000 Dukaten des Kardinals sind mit Abstand der höchste Betrag, es folgen 7 Personen, die bei 1.000 oder knapp darüber liegen. 40 Personen wurden zwischen 100 und 200 Dukaten geschätzt, dieser Bereich ist damit am dichtesten besetzt. Es gibt daneben aber auch Beträge, die noch weit darunter liegen, der um die geringste Summe Geschätzte, Serafino de Gragniano, liegt bei 10 Dukaten. Die durchschnittlichen Beträge übersteigen die entsprechenden Werte aus Prato allerdings immer noch um den Faktor 5. So muss die scheinbare Repräsentativität der Liste durch praktische Überlegungen relativiert werden: selbst wenn der Kardinal seinen Palast den verängstigten Nachbarn geöffnet hatte, so waren unter diesen Flüchtlingen wohl immer noch solche Personen überrepräsentiert, die direkt oder indirekt berufliche oder private Beziehungen zum Kardinalshaushalt hatten. Nähere Aussagen dazu sollen der bald erscheinenden Arbeit überlassen werden.

Über das Leben der Geiseln in Rom gibt es wegen der vielen Augenzeugenberichte wieder mehr Informationen. Ein großer Teil der Geiseln wurde offenbar verlegt, um sie an einzelnen Punkten zu konzentrieren und so die Bewachung zu vereinfachen. Alberini beschreibt, wie er sich jeden Morgen zu seinem Vater aufmachte, der im Palast des Kardinals Cibo gefangen gehalten wurde. Während der Vater dann in der Stadt Verkäufe tätigte und bei Freunden und Bekannten das Geld zusammenborgte, verbrachte der Sohn den Tag unter der Aufsicht von spanischen Soldaten. ${ }^{263}$ Nach der zwischenzeitlichen Freilassung und dem Tod des Vaters im August wurde er im Dezember dann wieder in Gewahrsam genommen und anschließend sogar nach Velletri verschleppt, weil die Zahlung des Lösegeldes auf sich warten ließ. ${ }^{264}$

Die Geiseln wurden bewacht wie wertvolle Beutestücke; dass sie entfliehen könnten, war dementsprechend nicht die einzige Sorge, die die Soldaten umtrieb: als Kardinal Numatii bei seiner Schätzung mit Hinweis auf seinen Gesundheitszustand den Wunsch äußerte, unter Bewachung im Bett zu bleiben, erklärten ihm die Spanier, dort sei er nicht sicher genug vor anderen Soldaten, bei denen es ihm unter Umständen wesentlich schlechter erginge. ${ }^{265}$

262 CORVISIERI, Documenti inediti, S. 33-36. Es gibt allerdings eine Kopie dieser Liste in der BAR, MS 1002, S. 393-401, die für einige der aufgeführten Personen teilweise ganz andere Beträge wiedergibt.

263 ALBERINI, Ricordi, S. 302f.

264 ALBERINI, Ricordi, S. 343.

265 SANUTO, Diarii, Bd. 45, Sp. 145. 
Manche wurden aus diesem Grund ungeachtet ihres Standes einfach in Gefängnissen zusammengepfercht, ${ }^{266}$ andere wurden in Klöster gebracht. ${ }^{267}$ Für die Behandlung der Geiseln dürfte gelten, was schon bei der Plünderung gesagt wurde: wer in der Lage war, ein eben gefangenes Opfer zu foltern, damit es Geldverstecke verriet oder eine möglichst hohe Lösegeldsumme anzunehmen, der tat das möglicherweise auch später, um die Beschaffung des Geldes zu beschleunigen. Der Fall von Giovanni Barotio wurde bereits erwähnt. Römische Adlige in einem Gefängnis des Borgo wurden geschlagen, oder man verweigerte ihnen die Nahrung. ${ }^{268}$ Einem Edelmann, den man in den Schlafsaal des Klosters von San Cosimato in Mica Aurea gesperrt hatte, drohte man an, ihn zu steinigen, wenn das Lösegeld nicht bald käme. ${ }^{269}$ Andere wurden wie Tiere durch die Straßen geführt und verkauft. ${ }^{270}$ Wieder werden die Geiseln, die in den Palästen in die Hände der Offiziere fielen, unter erheblich besseren Bedingungen gelebt haben, bei ihnen verwies man wohl eher auf die notariell festgelegten Verpflichtungen.

Diese Verpflichtungen wurden allerdings nicht von beiden Seiten gleich ernst genommen. Berichte über die mehrfache Zahlung von Lösegeldern sind so häufig, dass eine erhebliche Verbreitung dieses Phänomens zu vermuten ist. ${ }^{271}$ Selbst die Offiziere, die mit ihrem Gefolge die Paläste der Kardinäle besetzt hatten, hielten sich nicht an ihren Teil der Abmachungen, denn kaum machten die Deutschen Anstalten, die Paläste zu stürmen, da verabschiedeten sich die Spanier und Italiener mit der Begründung, die Abmachungen seien unter Ausschluss der Deutschen getroffen worden, und sie könnten diesen nicht verwehren, nun ihren Teil zu verlangen. ${ }^{272}$ Im Palast von Kardinal Cesarini waren zu diesem Zeitpunkt noch nicht alle Lösegelder eingetrieben, und so stellten die Spanier die Flüchtlinge kurzerhand vor die Wahl, entweder den an der vollen Summe fehlenden Betrag sofort aufzubringen oder der Palast werde geplündert. Nachdem die Geiseln die Zahlungsverpflichtungen unterschrieben hatten, räumten die Offiziere den Palast und überließen die Opfer der Willkür der Landsknechte. ${ }^{273}$ In anderen Fällen vergriffen sich die Soldaten nach erfolgter Zahlung an genau den Gütern, die sie sich durch die Zahlung zu schonen verpflichtet hatten. Gavardo berichtet, dass einige nach der Schätzung im Weggehen die Wohnung ausräumten und andere, die sie auf der Straße trafen, einluden, sich das Haus noch einmal vor-

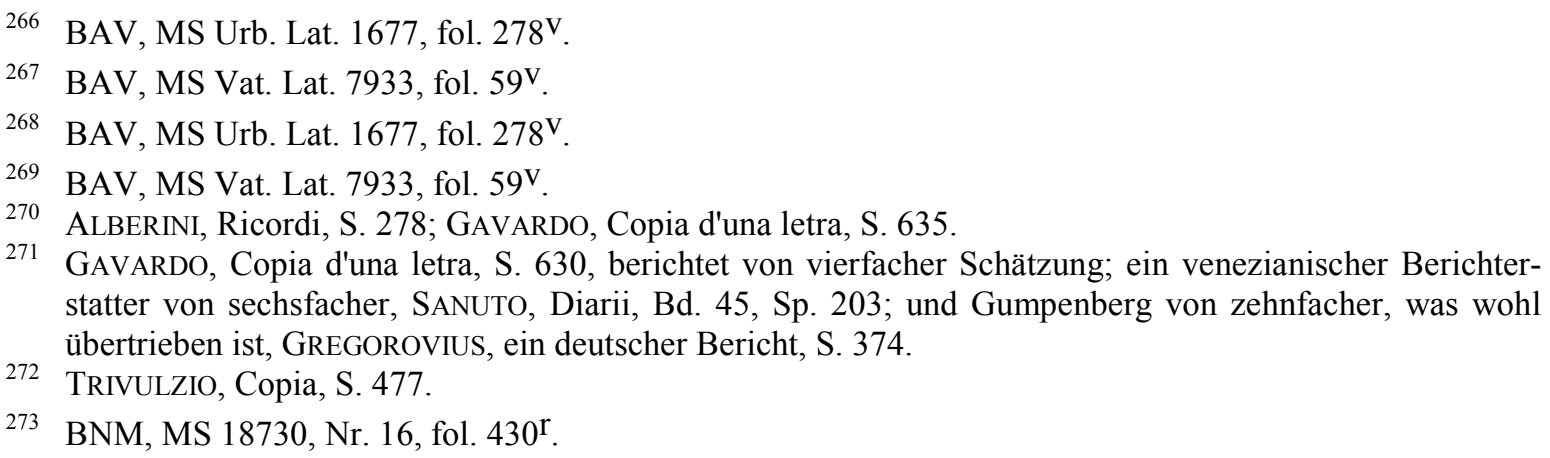


zunehmen. ${ }^{274}$ Wieder andere ließen die Geiseln nach der Zahlung der Lösegelder nicht frei, sondern verlangten noch mehr Geld. ${ }^{275}$ So wurden viele auf die eine oder andere Art mehrmals Opfer der Plünderung.

\section{Besetzte Häuser}

Nach dem Verbot der Plünderung versuchte man die Soldaten auf das rechte Tiberufer zurückzuziehen, ${ }^{276}$ um sie besser unter Kontrolle zu haben. Die Italiener und die Landsknechte wurden in Trastevere untergebracht und die Spanier im Borgo. Ein kurzer Blick auf die Zahlenverhältnisse zeigt, dass diese Regelung vor allem in Trastevere ein unerträgliches Chaos verursacht haben muss, da auf 5.000 Einwohner des Stadtteils viermal so viele Soldaten kamen, oder anders gesagt, auf jeden Haushalt mehr als zwanzig. ${ }^{277}$ Ein solcher Zustand kann kaum lange aufrecht erhalten worden sein, und in der Tat finden sich die Soldaten kurz darauf ganz selbstverständlich über die ganze Stadt verteilt: Alberini hatte vier Soldaten als ungebetene Dauergäste bei sich zu Hause im Stadtteil Monti, weit im Osten des damals bewohnten Teils der Innenstadt. ${ }^{278}$ Bei Francesco Calvo im zentral gelegenen Stadtteil Parione waren zwei oder drei Landsknechte einquartiert. ${ }^{279}$ Dieser Widerspruch zwischen den Befehlen der ersten Tage und der durch viele Zeugnisse belegten Präsenz der Soldaten im gesamten Stadtgebiet von Rom erklärt sich wohl aus den anarchischen Zuständen, die hier schon bald nach dem Sacco herrschten. Abgesehen davon scheinen auch viele Soldaten allein in den Häusern gelebt zu haben, die ihnen von den Einwohnern überlassen worden waren. Wenn diese sich noch in der Stadt aufhielten, dann wohnten sie oft bei Freunden oder Verwandten, um den täglichen Drangsalierungen zu entgehen. Als die Plünderung abebbte, wurde darüber hinaus der Palast der päpstlichen Kanzlei, die dem Kardinal Pompeo Colonna unterstand, der wichtigste Zufluchtsort. Dieser war drei Tage nach der Einnahme der Stadt mit seinen eigenen Truppen in Rom angekommen und öffnete die Tore des Palastes nicht nur den anderen Kardinälen, nachdem die Situation in deren eigenen Palästen trotz der Zahlung der Lösegelder an die Offiziere wegen der Bedrohung durch die

274 Gavardo, Copia d'una letra, S. 630.

275 MAZIO, Storia della guerra, Bd. 11, S. 337.

276 BAV, MS Ottob. Lat. 2137, S. 156.

277 Trastevere hatte nach einer kurz vor der Plünderung entstandenen Schätzung der Einwohner, dem sogenannten Censimento, knapp 5.000 Einwohner, verteilt auf 824 Haushalte, der Borgo ebensoviele in 563 Haushalten. LEE, Descriptio Urbis, S. 20.

278 AlberinI, Ricordi, S. 327. Alberinis Vater Giovanni Battista findet sich im Censimento als im Stadtteil Monti wohnhaft wieder. LEE, Descriptio Urbis, S. 33, Nr. 76.

279 OMONT, H. (HRSG.): Les suites du sac de Rome par les impériaux et la campagne de Lautrec en Italie. Journal d'un scrittore de la pénitencerie apostolique (Décembre 1527 - Avril 1528). In: Mélanges d'archéologie et d'histoire. École Française de Rome. Jg. 16, Fasc. 1-2. (1896). S. 24. Auch Calvo findet sich im Censimento. LEE, Descriptio Urbis, S. 85, Nr. 5114. 
Landsknechte unhaltbar geworden war, sondern auch allen anderen, die durch die Zerstörungen obdachlos geworden waren und nicht wussten, wohin sie sich wenden sollten, weil sie keine Verwandten außerhalb Roms hatten, die ihnen Unterschlupf boten. ${ }^{280}$ Kaum hatte sich die Nachricht von der Ankunft des Kardinals verbreitet, sah man Mütter mit ihren Kindern in Scharen zur Kanzlei fliehen. ${ }^{281}$ Aus Angst vor den Soldaten nahm man Zustände in Kauf, die zu einer Potenzierung der Seuchengefahr führten: im Palast der Kanzlei waren Hunderte von Personen in einzelnen Sälen untergebracht und verrichteten ihre Notdurft auf demselben Fußboden, auf dem sie auch schliefen. ${ }^{282}$ Schließlich wurde auch dieser Palast, wie geschildert, mit einiger Verspätung geplündert, obwohl das zu diesem Zeitpunkt schon gar nicht mehr gestattet war.

Auch nach dem Übergang zur Besatzung manifestierte sich dieses Phänomen wegen der unkontrollierbaren Situation und der Epidemie weiterhin. Der Notar Jacob Apocellus mied noch im Dezember 1527 sein eigenes Haus. ${ }^{283}$ Die Tendenz der verbliebenen Bewohner, sich aus Angst vor den Soldaten an Zufluchtsorten innerhalb der Stadt zusammenzuballen, setzte sich die ganze Zeit der Besatzung über auch im kleinen Rahmen fort. Bei Alberini hatte sich die ganze Nachbarschaft versammelt: "Di che ne possano far fede, oltra a tutto il vicinato, madona Menica Albanese, Cola suo figlio et l'altre sue figliole, Hippolita zoppa, Vincentino Roscio, Iaconitto pescivendolo et Hieronima sua moglie, Bernardo chiavaro et Prudentia sua moglie, mastro Antonio calzolaro et la moglie alla Pastina, quali se ritirono in casa per compagnia et fugir ancho tanto dispendio delle case loro, delli quali ho fatto mentione acciocchè, bisognando, si potesse verificare." ${ }^{284}$ Wieder andere wechselten rastlos die Unterkünfte, weil sie nirgendwo für längere Zeit Zuflucht fanden, vor allem aber weil sie Angst vor Ansteckung hatten, wie Gavardo: "Io per mi so che mi son fugito in otto giorni in quattro diverse stantie ne mai potei star doi giorni in in un loco che non si scoprisse qualche male tra quelli che stavano con mecho ..." ${ }^{285}$ Die verlassenen Häuser zu betreten konnte überdies gefährlich werden: Antonio Tebaldeo, der im November 1527 im Haus des geflohenen Römers Angelo Colotio nach dem Rechten sah, wurde von einem Spanier überrascht und scheinbar grundlos verprügelt. ${ }^{286}$

Wie angedeutet, verließen viele Einwohner die Stadt, nachdem sie ihr Lösegeld bezahlt hatten. Wie viele, ist unmöglich in Zahlen $\mathrm{zu}$ fassen, es wird überdies eine erhebliche Fluktuation zwischen dem Umland und der Stadt gegeben haben, als Reaktion auf drei Faktoren: die Gegenwart der Soldaten, die Versorgungssituation und die Epidemie. Als die

BAV, MS Ottob. Lat. 2137, S. 157.

CAVE, Bellum Romanum, S. 401.

CAVE, Bellum Romanum, S. 401.

83 MAYERHOFER, Zwei Briefe, S. 754.

284 ALBERINI, Ricordi, S. $327 \mathrm{f}$.

285 Gavardo, Copia d'una letra, S. 631.

286 BAV, MS Vat. Lat. 4104, fol. 79r. 
Plünderung abebbte, zeichnete sich zunächst eine Entspannung der Lage ab, die dann aber durch den Ausbruch der Epidemie und der Hungersnot wieder zunichte gemacht wurde. Im Juli besserte sich die Situation langsam, weil der größte Teil des Heeres abgezogen war, im September brach dann kurz vor dem erneuten Einzug eine Panik aus, die zu einer Massenflucht führte. Bis zum endgültigen Abzug des Heeres im Februar war der Alltag in der Stadt von weit verbreiteter Lethargie und Abwesenheit eines beträchtlichen Teils der Bevölkerung geprägt. Durch welche Phänomene er darüber hinaus gekennzeichnet war, darauf wird im Abschnitt über das Leben mit der Besatzung näher eingegangen. 


\section{Charakteristik des Krieges}

Der als Krieg bezeichnete Konflikt zwischen verfeindeten Mächten ruft immer wieder die Vorstellung von militärischen Zusammenstößen hervor, von Schlachten und Belagerungen, von Ereignissen also, die über Sieg und Niederlage entschieden und daher für die Geschichtsschreibung der vergangenen Jahrhunderte von vorrangiger Bedeutung waren. Krieg bestand aber nur zu seinem geringsten Teil aus militärischen Konfrontationen, im Gegenteil: im hier untersuchten Zeitraum wurden sie vermieden, wo sie nur vermieden werden konnten. Die Heere waren entweder unterwegs oder lagen als Besatzung auf Städte und Dörfer verteilt im Land. Krieg war damit für die Bevölkerung gleichbedeutend mit einer vorübergehenden oder dauerhaften Präsenz von Soldaten. Was sich auf den Schlachtfeldern abspielte, kursierte in Form von Berichten und beeinflusste den Alltag nur für kurze Zeit und in einem sehr eng gesteckten geografischen Rahmen, da sich die Sieger im eroberten Land selten anders verhielten als die Besiegten und der Übergang von einer Herrschaft zur anderen - vor allem wenn in beiden Fällen ausländische Mächte die Fäden in der Hand hielten - kaum Auswirkungen auf das Leben in Stadt und Land hatten.

In diesem Teil der Arbeit sollen die grundlegenden Phänomene beschrieben werden, die den Krieg in den beobachteten Gebieten, vor allem in der Terraferma und in der Lombardei charakterisierten. Im ersten Abschnitt werden seine demografischen Auswirkungen beschrieben und in Zahlen gefasst. Sie sind für das Verständnis der gesamten Situation grundlegend, da der starke Rückgang der Bevölkerung vor allem durch massenhafte Abwanderung nicht nur die in letzter Konsequenz schwerwiegendste Folge des Krieges war, sondern gleichzeitig Ursache und Rahmenbedingung einer Reihe von weiteren Phänomenen: geflohene Bauern konnten die Felder nicht bestellen und abwesende Stadtbewohner die Kontributionen nicht bezahlen, so dass sowohl in der Stadt als auch auf dem Land die Entvölkerung die Lage der Zurückgebliebenen eher verschlimmerte als erleichterte.

Durch solche entvölkerten Landschaften zogen die Heere auf verschlungenen und zerfaserten Wegen. Auf dem Land zeigte der Krieg ein grundsätzlich anderes Gesicht als in der Stadt. Er war von größerer Mobilität der Soldaten wie der Bevölkerung geprägt. Die Soldaten hielten sich nie lange an einem Ort auf und nahmen noch weniger Rücksicht auf die Bevölkerung als in der Stadt. Ihre Spuren verwischten um so schneller, als kaum jemand festhielt, welche Kompanie sich zu welchem Zeitpunkt an welchem Ort aufhielt. Aus diesem Grund manifestierte sich auch bei der Bevölkerung eine größere Beweglichkeit, die durch die Tatsache verstärkt wurde, dass die Bauern in der Regel materiell gesehen weniger $\mathrm{zu}$ verlieren hatten und sich auf der Flucht in ländlichen Gegenden besser zurechtfanden. Gleichzeitig waren sie eher bereit, sich gegen die Übergriffe der Soldaten gewaltsam zu wehren. Die Züge der Heere durch das Land, ihre Verteilung auf die Dörfer und die Last, 
die sie für die Bevölkerung darstellten, waren das am weitesten verbreitete und grundlegendste Gesicht des Krieges, gleichzeitig aber auch das am schlechtesten dokumentierte. Der zweite Abschnitt dieses Teils der Arbeit bemüht sich um eine möglichst alle Facetten dieser täglichen Wirklichkeit erfassende Schilderung des Krieges auf dem Land und seiner Auswirkungen auf die Bevölkerung.

Im dritten Abschnitt geht es dann ausschließlich um die Soldaten. Das Söldnerwesen brachte eine Reihe von Phänomenen hervor, die das Verhalten der Soldaten grundlegend beeinflussten und daher für das Verständnis von deren Auftreten gegenüber der Bevölkerung unerlässlich sind. Die Grundlage des gesamten Mechanismus war die Bezahlung der Soldaten; deren regelmäßiges und immer selbstverständlicheres Ausbleiben aber führte dazu, dass das System innerhalb von kurzer Zeit zu einem theoretischen Gebäude wurde, das auf den Schauplätzen, auf denen es zur Anwendung kam, einer Reihe von anderen Regeln folgte. Deren Auswirkungen hatte wiederum vor allem die Bevölkerung der betroffenen Gebiete zu tragen, am Ende aber auch die Soldaten selbst.

\section{A. Demografische Auswirkungen}

Der Krieg hatte wie zu allen Zeiten tiefgreifende demografische Folgen in den Städten wie auf dem Land. Die Bevölkerung der betroffenen Gebiete ging stark zurück, und zwar in erster Linie durch Migrationsbewegungen, deren Auswirkungen kurzfristig oder langfristig sein konnten, je nachdem ob ein Heer das Land nur passierte oder ob sich eine Besatzung etablierte. Vorübergehende Flucht und dauerhafte Abwanderung sind allerdings oft schwer voneinander abzugrenzen, vor allem wenn ein Heer das Land über längere Zeit auf und ab durchzog und die Gefahr des Einzugs von Soldaten zu einer täglichen Bedrohung wurde. Das war in der venezianischen Terraferma durch die Anwesenheit der kaiserlichen und spanischen Heere zwischen 1509 und 1516 der Fall und später in der Lombardei von 1521 bis 1529. In beiden Fällen wurde die Situation so untragbar, dass ein großer Teil der Bevölkerung für einige Zeit von der Bildfläche verschwand.

Bevölkerungsrückgänge durch Flucht und Abwanderung wurden nach dem Abzug der Soldaten in der Regel relativ schnell wieder ausgeglichen, da die meisten der Flüchtlinge nach Hause zurückkehrten. Daneben dezimierten aber auch Epidemien und Hungersnöte als Folgen des Krieges die Bevölkerung. Hunger, Krankheit und Entvölkerung waren ohnehin eng miteinander verflochtene Phänomene: Mangelernährung führte zu einer gesteigerten Anfälligkeit für Krankheiten, und sobald diese sich zu Epidemien auswuchsen, brach durch die Angst der Lieferanten, die Nahrungsmittel vom Produzenten zum Verbraucher zu transportieren, wenn damit das Betreten verseuchter Städte und Landstriche verbunden war, das 
Versorgungssystem zusammen, was wiederum der Hungersnot Vorschub leistete. Die Entvölkerung war ihrerseits eine Folge von Hunger und Epidemie, denn wer nicht an einem der beiden Übel starb, wanderte in besser versorgte und weniger verseuchte Gegenden ab. Diese Abwanderung wiederum wirkte zumindest auf eine ihrer eigenen Ursachen zurück, nämlich dann, wenn die Landbevölkerung betroffen war, da die Felder nicht mehr bestellt wurden und das Vieh auf der Flucht zumeist mitgenommen wurde, wodurch die nächste Hungersnot bereits vorprogrammiert war. Der Krieg und oft allein die Anwesenheit von Soldaten wirkte indes wie ein Katalysator dieser wechselseitigen Kausalitäten, führte dazu, dass sie sich gegenseitig schneller und stärker beeinflussten und konnte schließlich als Ursache jeder einzelnen von ihnen auch zur Ursache der anderen werden. Er wirkte in alle drei Richtungen: Produzenten flohen aus Angst vor Übergriffen der Soldaten, aus demselben Grund blieben Lieferanten besetzten Städten fern, wenn die Situation dort zu unruhig war. Die katastrophalen hygienischen Verhältnisse im Heer, die sich natürlich auch auf besetzte Städte übertrugen, potenzierten die Seuchengefahr. Und schließlich trieb nicht nur das Verhalten der Soldaten, sondern auch das Kontributionssystem der Besatzungsmacht einen mehr oder weniger bedeutenden Anteil der Bevölkerung von selbst in die Flucht. Das folgende Schema gibt einen Überblick über diese Zusammenhänge:

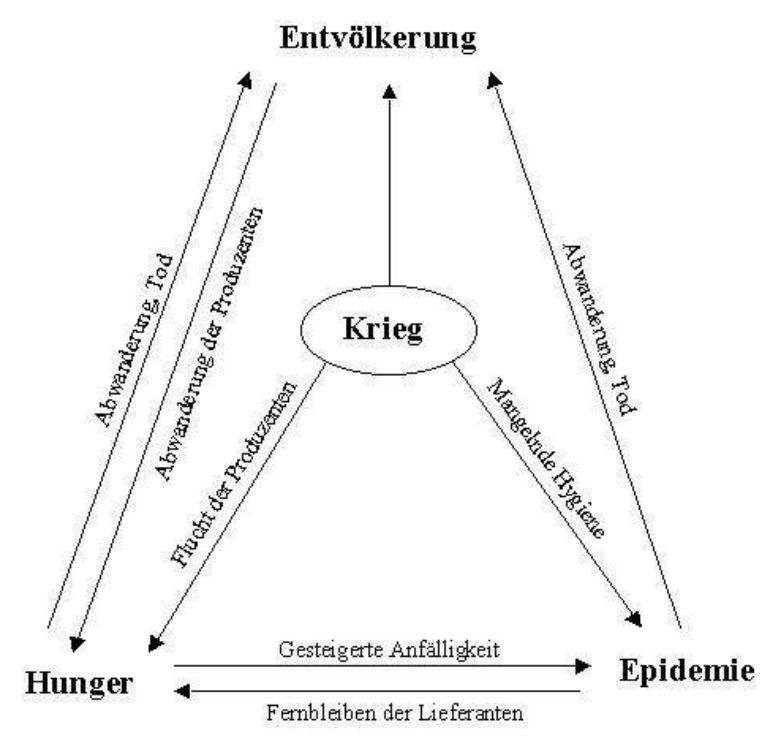

Auch wenn die Zeugenaussagen aus geplünderten Städten immer wieder die hohe Zahl der Opfer betonen, die durch die Greueltaten der Soldaten ums Leben kamen, nimmt deren Anteil am Bevölkerungsrückgang sich im Vergleich zu den oben genannten Phänomenen eher gering aus. ${ }^{287}$ In welchen Größenordnungen die in Form von Gerüchten verbreiteten

287 Reinhard, Marcel R./ARMEngaud, ANDrÉ: Histoire générale de la population mondiale. Paris 1961. 
Zahlen von den tatsächlichen Verhältnissen abwichen, zeigen die Bemerkungen von zwei besonnenen Berichterstattern für die Beschießung von Pavia und die Plünderung von Prato: so schrieb der Abt von Nájera im Oktober 1524 an den Kaiser, bei der Beschießung von Pavia durch die Franzosen seien 300 bis 400 Menschen ums Leben gekommen, auch wenn der Volksmund von bis zu 5.000 Toten spreche. ${ }^{288}$ Im Fall von Prato geistert durch fast alle Berichte eine Zahl von mindestens 5.000 Toten, Francesco Vettori indes nennt, auch er unter Hinweis auf die weit verbreiteten Übertreibungen, 500 Opfer. ${ }^{289}$ Bei diesen handelte es sich überdies vor allem um Soldaten, die bei der Verteidigung der Stadt umgekommen waren. Bei aller bisweilen aufflammenden Grausamkeit war das willkürliche Abschlachten der Bevölkerung den meisten Gemütern auch der übelsten Grobiane am Ende zuwider, vor allem aber hätte man sich dadurch ins eigene Fleisch geschnitten, da die Anwesenheit einer erwerbsfähigen Bevölkerung ein grundlegender Faktor für die Finanzierung der Fortführung des Krieges war. Wie die Soldaten auf die Versorgung mit Lebensmitteln angewiesen waren und sich darüber hinaus durch vielerlei Spielarten der Auspressung zu bereichern hofften, so brauchten die Offiziere ein einigermaßen funktionierendes Wirtschaftssystem zur Gewährleistung der Kontributionszahlungen, für das der Verbleib eines möglichst großen Teiles der Bevölkerung im Land - und vor allem in den Städten - eine Grundvoraussetzung war. In besetzten Städten sind daher vielerlei Maßnahmen zur Verhinderung der Abwanderung zu beobachten, die nichtsdestoweniger selten von Erfolg gekrönt waren.

\section{Flucht und Abwanderung}

Vor allem die Angst vor der Plünderung ergriff das Land, wann immer sich ein mehr oder weniger feindlich gesinntes Heer näherte. Die Bewohner fürchteten um Besitz und Leben und entfalteten eine fieberhafte Betriebsamkeit, um möglichst beides zu retten. Das Vertrauen in die Verteidigung der Städte scheint nicht besonders groß gewesen zu sein, denn die meisten versuchten, sich mit einem möglichst großen Teil ihrer Habe in Sicherheit zu bringen. Als sich im Juni 1510 das Heer der Liga von Cambrai in Richtung Vicenza in Bewegung setzte, bot die Stadt ein chaotisches Bild: alle packten in höchster Eile ihren Besitz zusammen, die Straßen lagen voll mit Hausrat, den man zum Abtransport aus den Häusern geschleppt hatte. Die nach Padua ablegenden Boote waren dermaßen überbesetzt, dass einige mit Gewalt davon abgehalten werden mussten, im letzten Moment noch aufzuspringen. ${ }^{290}$ Die Straße nach Padua war Tag und Nacht voll mit Flüchtlingen. ${ }^{291}$ Die nächstgele-

\section{S. 91.}

288 BNM, MS 2021321, Nr. 57. Nájera an den Kaiser, Soncino, 20. 11. 1524.

289 VeTTORI, Sommario della Storia d'Italia, S. 291.

290 PORTO, Lettere storiche, S. 198 f. 
genen größeren Städte waren überall die gesuchtesten Ziele: als das spanische Heer sich im August 1512 Prato näherte, fluteten die Bewohner aus der Stadt und dem gesamten Umland nach Florenz. ${ }^{292}$ Dort gab es kaum ein Haus, in dem keine Flüchtlinge untergebracht waren, die ganze Gegend war wie leergefegt. ${ }^{293}$ Im Juni 1513 ergriff die Fluchtwelle Brescia, hier befürchtete man beim Herannahen der Spanier schwere Vergeltungsmaßnahmen, weil die Stadt sich kurz zuvor den Venezianern in die Hände gegeben hatte. Nachdem die venezianischen Truppen die Stadt wieder aufgegeben hatten, floh der größte Teil der Einwohner nach Padua oder Venedig, während die spanische Kastellbesatzung in die ausgestorbene Stadt hinabstieg und die Tore von innen verschloss. Antonio da Martinengo, der mit einer großen Gruppe von Flüchtlingen in Venedig eintraf, berichtete Marino Sanuto dort vom Ausmaß des Exodus: " ... et disse in Brexa non li resta quasi niuno, non homo, no femina, no puto, nì galo, nì galina, imo non è in Brexa 200 persone." ${ }^{294}$ Und als Spanier und Deutsche im August 1513 Padua belagerten, fanden in Vicenza einquartierte Einheiten dort vielleicht 50 Einwohner vor, wie ein italienischer Soldat in den Diensten der kaiserlichen Artillerie berichtet. ${ }^{295}$ Solche Zahlen deuten darauf hin, dass die Erfahrungen der vorangegangenen Kriegsjahre in der Terraferma tiefe Eindrücke hinterlassen hatten. Hier wütete der Krieg in der Tat mit noch größerer Heftigkeit als später in der Lombardei, weil die Offiziere kaum versuchten, die Soldaten von Übergriffen gegen die Bevölkerung abzuhalten, sondern im Gegenteil bisweilen die systematische Zerstörung ganzer Ortschaften befahlen, um die Gegner zu demoralisieren und die Versorgung der Hauptstadt und der venezianischen Heere durch die Produktion der Terraferma nach Kräften zu schädigen. Bauern, die keine Gelegenheit hatten, in der Stadt unterzukommen, suchten oft Zuflucht in schwer zugänglichem Gelände: im Oktober 1513 floh die Landbevölkerung der Gegend um Mestre vor den Spaniern in die nah gelegenen Sümpfe, ${ }^{296}$ die Bauern, durch deren Dörfer Bourbons Heer im April 1527 kam, zogen sich ins Gebirge zurück. ${ }^{297}$ Schon beim Anmarsch der Landsknechte hatten Gerüchte genügt, um ein Massenflucht auszulösen: am 22. November 1526 schrieb Antonio Petra an Francesco Sforza, die Deutschen seien in Castiglione delle Stiviere angekommen, "et per questo cadauno se pone in fuga." ${ }^{298}$ Am selben Tag schrieb Baptista Pusterla, es gehe das Gerücht, sie wollten sich nach Cremona wenden, weshalb sich auf der entsprechenden Straße sofort das gleiche Bild bot: "... fugeno tutti e con tutte le robbe." ${ }^{299}$ So spülten die Heere auf ihrem Weg die meiste Zeit über eine Bugwelle von

291 GuERIN-DALle MeSE, Una cronaca vicentina, S. 194.

292 CORAZZINI, Ricordanze di Bartolomeo Masi, S. 97.

293 CORAZZINI, Ricordanze di Bartolomeo Masi, S. 97.

294 SANUTO, Diarii, Bd. 16, Sp. 376.

295 JOPPI, Diario del campo tedesco, Bd. 36, S. 96.

296 BARTHOLD, F. W.: George von Frundsberg oder das deutsche Kriegshandwerk zur Zeit der Reformation. Hamburg 1833. S. 151.

297 BALAN, Monumenta saeculi XVI, Bd. 1, S. 431.

298 ASM Sforzesco, Cart. 1359. Antonio Petra an Francesco Sforza, Casalmaggiore, 22. 11. 1526.

299 ASM Sforzesco, Cart. 1359. Baptista Pusterla an Francesco Sforza, Casalmaggiore, 22. 11. 1526. 
Flüchtlingen vor sich her, die hinter ihnen wieder zusammenschlug: die Menschen verteilten sich in panischer Hast und oft schon auf Gerüchte vom Herannahen eines Heeres hin in der Umgebung und kehrten nach Hause zurück, sobald die Gefahr vorüber war.

Nach schweren Plünderungen oder einer sich lange hinziehenden Besatzung konnte die Rückkehr allerdings auf sich warten lassen, denn manche Städte waren durch die Zerstörungen nahezu unbewohnbar geworden. Nach der Plünderung von Rom verließen noch im Mai 1527 nach der Schätzung eines Augenzeugen drei Viertel der Bevölkerung die Stadt, ${ }^{300}$ und als kurz darauf eine Epidemie ausbrach, blieb fast niemand mehr da. Im Juli schrieb Gerolamo Naselli, Botschafter des Herzogs von Ferrara beim kaiserlichen Heer: "... in questa terra è pochissima robba, nè vi sono Romani o altre persone forestiere, perchè tutti sono partiti chi per carestia, chi per la peste et chi per evitare tali pericoli." ${ }^{301}$ Der spanische Botschafter Perez meinte zwar, dass nach dem Auszug des Heeres die meisten Römer zurückkehren und das wirtschaftliche Leben wieder in Gang kommen würde, aber diese Hoffnung erfüllte sich nicht oder wurde spätestens beim erneuten Einzug des Heeres im September zunichte gemacht. ${ }^{302}$ Noch im Oktober 1528, acht Monate nach dem endgültigen Abzug der Soldaten, schrieb Francesco Gonzaga an seinen Bruder Federico, den Markgrafen von Mantua, die Stadt sei wie ausgestorben. ${ }^{303}$ Narni, das von dem aus Rom ausgelagerten Heer im Juli 1527 verwüstet worden war, blieb danach mehrere Monate lang vollständig unbewohnt. $^{304}$

Auch in der besetzten Lombardei wurden verlassene Städte ein vertrautes Bild. Hier waren es vor allem die Übergriffe der Besatzungstruppen, die die Bevölkerung in die Abwanderung trieben. Wohl keine Stadt der Lombardei war so stark in Mitleidenschaft gezogen worden wie Pavia: seit 1521 durch den Krieg um Mailand, vor allem durch die Belagerung der Franzosen und die Anwesenheit der Heere im Umland, und ab 1525 durch die Einquartierung aus Mailand ausgelagerter Kompanien. Schließlich wurde die Stadt innerhalb eines Jahres von den Franzosen erobert und geplündert, von den Spaniern zurückerobert und wieder geplündert und kurz darauf ein letztes Mal von den Franzosen eingenommen - eine Plünderung fand zwar statt, verdiente aber kaum noch den Namen, weil es nichts mehr zu plündern gab. Was von Pavia noch übrig war, wurde im Oktober 1529 den Spaniern übergeben. Durch den Dauerbeschuss der französischen Artillerie lag ein großer Teil der Stadt in Trümmern, ${ }^{305}$ und von den 16.000 Einwohnern vor dem Krieg waren nach dem Abzug der Spanier noch 5.000 übrig, was einem Rückgang um fast $70 \%$ entspricht. ${ }^{306}$ Schon im

300 BNM, MS 18730, Nr. 16, fol. 431 ${ }^{\mathrm{r}}$.

301 BALAN, Monumenta saeculi XVI, S. 442.

302 RodrigueZ Villa, Memorias, S. 247.

303 PASTOR, Geschichte der Päpste, Bd. 4, Teilbd. 2, Anhang 120, S. 753.

304 VARCHI, BenEDETTO: Storia Fiorentina. Hrsg. v. Gaetano Milanesi. 3 Bde. Florenz 1857-1858. Bd. 1, S. 210.

305 BNM, MS 20476, fol. 234r.

306 ALEATI, GIUSEPPE: La popolazione di Pavia durante il dominio spagnolo. Mailand 1957. S. 13. 
März 1525 hatte ein Informant der Venezianer geschrieben, Pavia und Lodi seien zur Hälfte zerstört und in Tortona seien noch ganze sieben Häuser bewohnt. ${ }^{307}$

In Mailand lässt sich die demografische Entwicklung detaillierter verfolgen. Bei der Angabe von Zahlen durch Augenzeugen müssen immer zwei Umstände bedacht werden: zum einen ist den Aussagen grundsätzlich mit größtem Misstrauen zu begegnen, da sie nicht nur zu ständiger Übertreibung neigen, sondern auch wenig Gespür für große Zahlen und daneben kaum Möglichkeiten besitzen, diese zu überprüfen. Zum anderen stellen solche Angaben, selbst wenn sie zuverlässig sind, immer nur eine Momentaufnahme dar, und da die Entvölkerung vor allem auf Abwanderung in benachbarte Gebiete zurückzuführen war, konnten in relativ kurzer Zeit relativ große Schwankungen auftreten. Es liegen allerdings zur Ergänzung der Berichte auch statistische Quellen vor: um Seuchen schneller ausmachen und Gegenmaßnahmen einleiten zu können, wurde in Mailand nämlich über alle Sterbefälle in der Stadt Buch geführt. Die Gesamtzahlen der Toten für jedes Jahr und deren Schwankungen über die Jahre hinweg spiegeln die Ursachen der Entvölkerung wider, je nachdem in welche Richtung sie ausschlagen. Als Basiswert müssen dazu die Jahre mit den niedrigsten Zahlen herangezogen werden: durch sie ist - zumindest annähernd - nur der Anteil der Einwohner repräsentiert, der jedes Jahr eines für jene Zeit natürlichen Todes starb. Das waren in Mailand in den Jahren vor dem Krieg etwa 3.000 Personen im Jahr. Zahlen, die über diesem Basiswert liegen, sind immer auf mehr oder weniger schwerwiegende Störungen von außen zurückzuführen, wie sie eben vor allem durch Epidemien und Hungersnöte verursacht wurden. Umgekehrt bedeutet ein Abfallen der Zahlen unter den Basiswert, dass sich ein zu diesem Rückgang proportionaler Anteil der durch den Basiswert repräsentierten Bevölkerung nicht mehr in der Stadt befand, also entweder gestorben oder abgewandert war. Für kurze Zeiträume ist eine solche Aussage allerdings schwer zu treffen, da eine Zahl im Bereich des Basiswertes ja auch durch eine Kombination aus hohem Entvölkerungsgrad und hoher Sterblichkeit zu Stande kommen und dennoch zu der in diesem Fall irrigen Annahme verleiten kann, dass die Verhältnisse sich normalisiert hatten. Solche Effekte lassen sich mit Hilfe der Werte der folgenden Zeit nur dann entlarven, wenn diese abstürzen und sich über mehrere Jahre hinweg auf niedrigem Niveau halten, was darauf hindeutet, dass ein großer Teil der Bevölkerung der Stadt tatsächlich verloren gegangen war. In der Regel tendierten Flüchtlinge dazu, in die Stadt zurückzukehren, sobald sich die Lage entspannt hatte.

Wenn sie sich entspannte. Zu Beginn des Krieges im Jahr 1521 lebten in Mailand noch etwa 60.000 Menschen. ${ }^{308}$ In den folgenden Jahren - für 1521 selbst sind keine Daten überliefert - war die Sterblichkeit als Folge des Krieges und der daraus resultierenden Überteue-

307 SANUTO, Diarii, Bd. 38, Sp. 96.

308 ZANETTI, DANTE E.: A Milano nel 1524. I sospetti del Gentilino. In: Fatti e idee di storia economica nei secoli XII-XX. Festschrift für Franco Borlandi. Hrsg. v. Carlo M. Cipolla, Domenico Demarco und Federigo Melis. Bologna 1977. S. 314. 
rung der Lebensmittel überdurchschnittlich hoch, für das Jahr 1522 sind fast 7.000 und für 1523 über 5.000 Tote verzeichnet. ${ }^{309}$ Daneben werden viele Einwohner die Stadt aus eben diesem Grund verlassen haben. Schon im April 1522 schilderten die Hauptleute die Lage in einem Brief an den Kaiser, ohne dabei die eigene Mitschuld an den Zuständen zu unterschlagen: Mailand und die anderen Städte der Lombardei seien völlig ausgelaugt, "de fuera de los enemigos, y de dentro de nosotros." ${ }^{310}$ Im Jahr 1524 kam die Pest nach Mailand. In der Liste sind lediglich knapp über 5.000 Tote verzeichnet, aber diese Zahl ist ganz offensichtlich viel zu niedrig, denn nach einer sehr hohen Anzahl der Toten im Mai - über 1.200 - sind in den Monaten danach nur noch verschwindend geringe Zahlen verzeichnet, obwohl die Seuche erst im Juni voll zum Ausbruch kam. ${ }^{311}$ Offenbar war die Situation so chaotisch, dass die Totenlisten zwischenzeitlich nicht mehr geführt wurden. Insgesamt betrug die Zahl der Todesopfer vielleicht 20.000. ${ }^{312}$ Als Franzosen und Spanier unmittelbar nach dem Ende der Epidemie im Oktober 1524 zum Wettlauf auf Mailand antraten, verließen noch einmal 7.000 Personen die Stadt. Zu diesem Zeitpunkt waren dort kaum noch Bewohner anzutreffen. ${ }^{313}$ Die Lage besserte sich nach der Niederlage der Franzosen bei Pavia im Februar 1525 und dem Abzug der Spanier in weiter entfernte Gebiete zwar vorübergehend, aber schon beim Einzug des Markgrafen von Pescara mit dem spanischen Heer im November 1525 löste die Angst vor Plünderungen und Vandalismus eine neue Fluchtwelle aus. ${ }^{314}$ In den folgenden Jahren wurde es nicht mehr besser: eine weitere Welle von Flüchtlingen flutete schon im Juni 1526 aus der Stadt, als es in Folge der Niederschlagung des zweiten Aufstandes der Bevölkerung zu schweren Repressalien und Plünderungen kam. Marino Caracciolo forderte den Kaiser zu dieser Zeit in einem Brief auf, dringend für eine Eindämmung der Übergriffe zu sorgen und kündigte Zustände an, die schon längst zur Wirklichkeit in der besetzten Stadt geworden waren: "Altramenti se sarra señor de le mure et case ruinate et de la campagna senza populi." ${ }^{315}$ Die Zahl der Toten lag für das Jahr 1526 in der Tat trotz der Unruhen nur noch bei etwa 1.200. Weitere Engpässe bei der Lebensmittelversorgung sorgten Hand in Hand mit den alltäglichen und immer ungenierteren Übergriffen der Soldaten und der Eintreibung von Kontributionen durch die Besatzungsmacht in der

\footnotetext{
309 Die im Folgenden genannten Zahlen entstammen alle der Tabelle bei FERRARIO, GIUSEPPE: Statistica medica di Milano dal secolo XV fino ai nostri giorni. Bd. 2. Mailand 1840. S. 374f.

310 RAH Salazar y Castro, A/45, fol. 100r. Hauptleute an den Kaiser, Binasco, 19. 4. 1522.

311 ZANETTI, A Milano nel 1524, S. 324.

312 Besta geht von einem Rückgang um ein Drittel aus. BESTA, BEATRICE: La popolazione di Milano nel periodo della dominazione Spagnola. In: Atti del congresso internazionale per gli studi sulla popolazione. (Roma, 7-10 settembre 1931). Hrsg. v. Corrado Gini. Bd. 1. Rom 1933. S. 594; ZANETTI, A Milano nel 1524, S. 331, spricht von höchstens 25.000 Toten bei einer angenommenen Einwohnerzahl von 50.000 zur Zeit des Ausbruchs der Pest. Ein venezianischer Informant spricht in ungefährer Übereinstimmung damit von einer Halbierung der Bevölkerung bis zum März 1525. SANUTO, Diarii, Bd. 38, Sp. 96.

313 BNM, MS 2021321, Nr. 55. Nájera an den Kaiser, Lodi, 26. 10. 1524.

314 ACM Registri di lettere ducali 19 , fol. $56^{\mathrm{V}}$.

315 RAH Salazar y Castro, A/37, fol. 456 ${ }^{\mathrm{r}}$. Caracciolo an den Kaiser, Mailand, 22. 6. 1526.
} 
folgenden Zeit zu einem weiteren Rückgang der Bevölkerung. Vor allem im September 1527 führte die Ausweisung aller Bewohner Mailands, die auch den niedrigsten Satz der Kontributionsleistungen nicht aufbringen konnten, zu einer Auswanderung, die einen Beobachter, der sich mit dem venezianischen Heer in Melegnano aufhielt, unwillkürlich an das Treiben zu besten Jahrmarktszeiten denken ließ: "Da do dì in qua la strada de Milano pare una fiera, per la gran gente che vien fuora de ogni sorta de Milano." ${ }^{316}$ Ein anderer Informant der Venezianer meldete im August 1528, es befänden sich noch 20.000 Personen in der Stadt. ${ }^{317}$ Schon einen Monat später muss die Einwohnerzahl wegen der im September eingeführten Besteuerung des Getreides noch weiter gefallen sein.

Die Zahlen aus der Totenliste für die Jahre nach der Besatzung - für 1527 bis 1529 sind sie leider verloren - bestätigen die Dauerhaftigkeit der Entvölkerung gegen Ende der Besatzungszeit trotz der Tatsache, dass die meisten Flüchtlinge bisher immer recht schnell wiedergekommen waren: für 1530 bis 1534 bleiben sie konstant knapp unter 1.000, es folgte ein langsamer, aber kontinuierlicher Aufstieg, der die Mailänder Bevölkerung nach den Totenlisten erst um 1560 auf den Stand von vor dem Krieg brachte. Als Folge des Krieges und der Besatzung kann man demnach in Mailand einen Rückgang der Bevölkerung um etwa $70 \%$ annehmen, ein Wert, der den Verlusten von Pavia und wahrscheinlich vielen anderen Städten der Lombardei entspricht. Das Ausmaß dieses Rückgangs wird parallel dazu in den untersuchten Jahren durch die stetige Abnahme der Staatseinnahmen aus der Lombardei, die sich vor allem aus den Einfuhrzöllen ergaben, in etwa bestätigt. Diese beliefen sich im Jahr 1515 noch auf 600.000 Dukaten im Jahr. ${ }^{318}$ Zu Beginn des Krieges im Jahr 1521 waren sie nach den Informationen des venezianischen Botschafters in Mailand schon auf einen Wert von 385.000 Dukaten abgesunken. ${ }^{319}$ Der Krieg brachte einen weiteren Rückgang mit sich: beim Einmarsch der Spanier im November 1525 wurden die Einnahmen für das auslaufende Jahr in einem Memorandum nur noch auf 300.000 Dukaten beziffert, bei einer gleichzeitigen Prognose von lediglich 225.000 Dukaten für das kommende Jahr. ${ }^{320}$ Nach dem Ende der Besatzungszeit, im Jahr 1530, waren sie auf 170.000 Dukaten gefallen, ${ }^{321}$ und noch für das Jahr 1536 waren etwa 200.000 Dukaten vorgesehen. ${ }^{322}$

Es ist eine eigene Untersuchung wert, wie viele der Flüchtlinge am Ende in der Fremde blieben und wo sie blieben. Die Tatsache, dass Mailand sich von der Besatzungszeit so schlecht erholte, spricht vor allem angesichts der geringen Zahl der Toten in den Totenli-

\footnotetext{
316 SANUTO, Diarii, Bd. 46, Sp. 92.

317 SANUTO, Diarii, Bd. 48, Sp. 398.

318 SANTORO, CATERINA: Gli Sforza. Mailand 1968. S. 389.

319 SegarizZI, ARNALdo (HrSG.): Relazioni degli ambasciatori veneti al Senato. Bd. 2: Milano - Urbino. Bari 1913. S. 42.

320 RAH Salazar y Castro, A/36, fol. $273^{\mathrm{r}} \mathrm{f}$. Der venezianische Botschafter in Mailand bezifferte die Einnahmen im Dezember 1525 in ziemlicher Übereinstimmung mit den Zahlen der Spanier auf 320.000 Dukaten. SANUTO, Diarii, Bd. 40, Sp. 423.

321 SANTORO, Gli Sforza, S. 389.

322 Chabod, FEDERICO: Lo stato e la vita religiosa a Milando nell'epoca di Carlo V. Turin 1971. S. $106 f$.
} 
sten dafür, dass ein befremdlich hoher Anteil der Bevölkerung durch den Krieg offenbar zu der Überzeugung getrieben wurde, dass in der Heimat kein Auskommen mehr zu finden war. Aus einem Dekret des Gouverneurs Antonio de Leyva aus dem Dezember 1528 geht hervor, dass sich viele Mailänder schon seit drei Jahren nicht mehr in der Stadt hatten blikken lassen. ${ }^{323}$ Der Wechsel zwischen Flucht und Rückkehr als schnelle Reaktion auf die Verhältnisse in der Stadt scheint gegen Ende der Besatzungszeit in Mailand mehr und mehr erstarrt zu sein.

Schließlich soll noch ein vergleichender Blick auf die Situation in der Terraferma zwischen 1509 und 1516 geworfen werden. Wie festgestellt, ergriffen die Fluchtwellen beim Anmarsch der Heere eine frappierende Mehrheit der Bevölkerung. Für die längerfristigen Auswirkungen der Entvölkerung existieren auch hier Quellen, die eine systematische Untersuchung erlauben, nämlich die Steuerlisten der venezianischen Beamten für die Besteuerung von Salz in den Städten der Terraferma. Da Salz ein unverzichtbarer Bestandteil der Ernährung und der Konservierung von Lebensmitteln war und gleichmäßig verbraucht wurde, kann sein Konsum als Indikator für die demografische Entwicklung angesehen werden. Den Listen ist bereits eine Untersuchung gewidmet worden, was ihre Auswertung für die Zwecke dieser Arbeit erheblich erleichtert. ${ }^{324}$ Sie existieren für alle Jahre, in denen die betreffenden Städte der Republik Venedig unterworfen waren, für die Kriegsjahre weisen sie daher entsprechende Lücken von mehreren Jahren auf. Hier ist aber vor allem der Vergleich zwischen der Zeit vor und der Zeit nach dem Krieg, genauer gesagt zwischen den Jahren 1508 und 1516 von Bedeutung. Demnach lassen sich folgende Beobachtungen anstellen: die Einbrüche und damit die Bevölkerungsverluste sind im Verlauf der betrachteten Jahre durchweg geringer als man angesichts der Heftigkeit des Krieges und nach den oben geschilderten Ausmaßen der dauerhaften Entvölkerung der Lombardei im darauffolgenden Jahrzehnt annehmen möchte. In Bergamo blieben die Einnahmen trotz zwischenzeitlicher spanischer Besatzung stabil, in Crema ist ein Rückgang um $19 \%$ zu verzeichnen, der allerdings schon zwei Jahre später vollständig ausgeglichen war. Vicenza, das mehrmals geplündert wurde, daneben in unmittelbarer Nähe des zweimal belagerten Padua lag und zwischenzeitlich, wie gesehen, völlig menschenleer war, erlebte einen Einbruch um immerhin $37 \%$ und brauchte etwas länger, nämlich bis 1521, um den Vorkriegsstand wieder zu erreichen. Aus Padua selbst sind für fast alle Jahre die Werte überliefert, da die Stadt nie erobert wurde. Demnach betrug der Rückgang zwischen 1508 und 1510 - die erste Belagerung fand im Jahr 1509 statt - immerhin 34 \% und blieb wegen der zweiten Belagerung im Jahr 1513, die eine Erholung zunächst verhinderte, für ein paar Jahre auf diesem Stand. Auch hier dauerte es nach dem Krieg bis 1521, bis der Vorkriegswert erreicht wurde. Der Rückgang

323 Formentini, Il ducato di Milano, Nr. 82, S. 488.

324 Torre, GiUSEPPE DEL: Venezia e la Terraferma dopo la guerra di Cambrai (1516-1530) Vicenza 1986. Die Listen, denen das zitierte Zahlenmaterial entstammt, finden sich im Anhang auf S. 133-137. 
für die gesamte Terraferma zwischen 1508 und 1516 betrug $22 \%$ und wurde bis 1523 vollständig ausgeglichen.

Die Dynamik der demografischen Schwankungen für dieses Gebiet lässt sich am besten an einer Gegenüberstellung der Größenordnungen von kurzfristigen und langfristigen Abwanderungsbewegungen ablesen. Für die Stadt Verona liegt für beide Phänomene gesichertes Zahlenmaterial vor, zum einen die oben genannten Zahlen über die Salzsteuer, zum anderen die Ergebnisse einer Zählung der Bevölkerung, die die genaue Zahl der Einwohner zu einem bestimmten Zeitpunkt wiedergibt. Nach dieser Zählung hatte Verona im April 1515 noch 27.000 Einwohner, was einem Rückgang um 10.000 oder $27 \%$ gegenüber dem Stand von vor dem Krieg entsprach. ${ }^{325}$ Der Rückgang auf Grund der Salzsteuer zwischen 1508 und 1516 betrug aber nur $14 \%$, woraus sich schließen lässt, dass die Hälfte der Verluste innerhalb eines Jahres schon wieder ausgeglichen worden war - immer vorausgesetzt, dass man die Salzsteuer als Indikator für die demografische Entwicklung betrachtet. Stellt man in Rechnung, dass auch in Verona in der Zwischenzeit eine schwere Epidemie wütete, so lässt sich die Behauptung aufstellen, dass fast alle abgewanderten Einwohner unmittelbar nach dem Ende des Krieges nach Verona zurückkehrten. Der Bevölkerungsrückgang in der Terraferma war also weniger langfristig als ein Jahrzehnt später in der Lombardei, mit anderen Worten: in der Terraferma war der Krieg von einer höheren Mobilität der Bevölkerung begleitet, durch die ein größerer Teil der Einwohner die gefährdeten Gebiete verließ, bevor er an einer Seuche starb oder durch die Plünderungen seiner Lebensgrundlage beraubt wurde. Das scheint paradoxerweise unter anderem eine Folge der gesteigerten Rücksichtslosigkeit der Soldaten gewesen zu sein, durch die ein größerer Teil der Bevölkerung motiviert wurde, sich den Folgen eben dieser Rücksichtslosigkeit zu entziehen. Vor allem aber waren die Aussichten, trotz Flucht und Abwanderung ein Auskommen zu finden, im venezianischen Gebiet weitaus besser als in der Lombardei, da Venedig als Hauptstadt und Zufluchtsort vom Krieg unversehrt geblieben war. Auch einige andere Städte der Terraferma boten trotz der selbst erlittenen Schäden immerhin einige Sicherheit, solange sie unter dem Schutz venezianischer Truppen standen. Diese behandelten die Untertanen der Republik nämlich wesentlich rücksichtsvoller als die spanischen, deutschen und italienischen Soldaten die Bevölkerung der Lombardei, deren Möglichkeiten zu Flucht und Abwanderung daneben stärker eingeschränkt waren, weil man kaum wusste, wohin man sich wenden sollte, ohne vom Regen in die Traufe zu kommen: in der Hauptstadt selbst herrschten durch die Besatzung unerträgliche Zustände, und die Nachbarregionen waren entweder wenig gastfreundlich wie die Schweiz und die venezianischen und päpstlichen Gebiete oder selbst durch den Krieg stark in Mitleidenschaft gezogen wie die Gebiete von Genua, Savoyen,

325 BELOCH, KARL Julius: Bevölkerungsgeschichte Italiens. Bd. 3: Die Bevölkerung der Republik Venedig, des Herzogtums Mailand, Piemonts, Genuas, Corsicas und Sardiniens. Die Gesamtbevölkerung Italiens. Berlin 1961. ZaGatA, Cronica della città di Verona, Bd. 2, S. 165, nennt die falsche Zahl von 20.000 der Stadt verloren gegangenen Einwohnern. 
Montferrat und Saluzzo. Nach dem Abzug der Kaiserlichen fehlte in der Lombardei ein intaktes Wirtschaftszentrum wie Venedig, das die finanziellen Mittel für den Wiederaufbau bereitstellen und einen Anreiz für die Rückkehr Flüchtlinge darstellen konnte. Mit der Wirtschaft erholte sich daher in der Lombardei auch die Bevölkerung langsamer von den Folgen des Krieges als die der Terraferma.

\section{Maßnahmen der Militärs}

Die Besatzungsmacht hatte ein lebhaftes Interesse daran, dass die Bevölkerung in der Stadt und im Land blieb, um die Lebensmittelproduktion aufrecht zu erhalten und die Kontributionszahlungen zu gewährleisten. Genauer gesagt: der Teil der Bevölkerung, der sich bei der Lebensmittelproduktion nützlich machte und zu einer Beteiligung an den Kontributionen herangezogen werden konnte. Genau unter diesen aber fand sich der größte Teil der Abwanderer wieder, da vor allem die wohlhabenderen Einwohner über die Mittel und die Beziehungen verfügten, sich in der Fremde niederzulassen. Schon unter den 7.000 Mailändern, die im Oktober 1524 die Stadt fluchtartig verließen, befanden sich nach einer Angabe Nájeras 3.000 der reichsten Einwohner, in der Stadt blieben fast nur die Armen zurück. ${ }^{326}$ Aus diesem Grund fiel die Wirtschaftskraft einer Stadt mit jeder Fluchtwelle in einem unverhältnismäßig hohen Maß ab. Maßnahmen der Besatzer zur Verhinderung der Abwanderung ließen nicht auf sich warten: kurz vor dem Einzug des Heeres im November 1525 ließ Pescara in der Stadt ausrufen, dass alle Ausgezogenen zurückzukehren hätten. ${ }^{327}$ Die Aufforderung wurde im Juni 1526 wegen des Massenauszugs nach den Aufständen wiederholt, wobei den Flüchtigen eine Frist von 6 Tagen gesetzt wurde. ${ }^{328}$ Kurz darauf wurden die Pfarreivorsteher aufgefordert, Listen mit den Namen der Flüchtigen einzureichen. ${ }^{329} \mathrm{Ab}$ August 1526 häufen sich die Anordnungen zur Rückkehr der Abwanderer, und im September 1527 ging man in den öffentlich ausgerufenen Dekreten dazu über, die Abwesenden namentlich zum Erscheinen in der Stadt aufzufordern. Ein Blick auf die Namen lohnt sich, denn er zeigt zweierlei: zum einen die weite Verbreitung des Phänomens, zum anderen das vorrangige Interesse der Besatzer an den zahlungskräftigeren Mailändern. In einem Dekret vom 7. September finden sich 14 Namen aus verschiedenen Pfarreien wieder, 6 von ihnen sind eindeutig in einer Schätzung der Einwohner, die 1524 in Mailand durchgeführt wurde, auszumachen. ${ }^{330}$ Unter ihnen figuriert unter anderem Paolo Paganino, mit 40.000 Dukaten

326 BNM, MS 2021321, Nr. 55. Nájera an den Kaiser, Lodi, 26. 10. 1524.

327 ACM Registri di lettere ducali 19 , fol. $56^{\mathrm{v}} \mathrm{f}$.

328 ASM Sforzesco, Cart. 1505, Dekret vom 20. 6. 1526.

329 ASM Sforzesco, Cart. 1505, Dekret vom 30. 6. 1526.

330 Eine Kopie dieser Schätzung befindet sich im ACM Famiglie, Cart. 1629, eine weitere im ASM Censo 
geschätztem Jahreseinkommen einer der reichsten Einwohner, ferner Gerolamo Casato mit 16.000 Dukaten, keiner der anderen Genannten liegt unter 1.000 Dukaten. ${ }^{331}$ Eine Woche später wurden 19 Personen aus der Pfarrei von San Martino Nosigia zur Rückkehr aufgefordert. 13 von ihnen sind in der Schätzung zu finden, die für diese Pfarrei insgesamt nur 30 Namen aufführt. Die Summe der Jahreseinkommen der Aufgerufenen allein dieses einen Dekrets macht 32.000 Dukaten aus, rund ein Drittel des in der Schätzung angegebenen Gesamteinkommens der erfassten Bewohner der Pfarrei. ${ }^{332}$

In der Regel wurde als Strafe für die Abwanderung die Konfiskation der Besitzungen angedroht. Da das offenbar zu nichts führte, wurde im Dezember 1526 zwischenzeitlich eine Amnestie für die Rückkehrer verkündet, ${ }^{333}$ doch schon bald darauf wurde wieder mit den Strafen Güterkonfiskation, Vogelfreiheit und Geldbuße und mit Kombinationen aus diesen gearbeitet. ${ }^{334}$ Im September 1527 ordnete Antonio de Leyva in Mailand die Zerstörung der Häuser der Ausgezogenen an, ${ }^{335}$ und in Como wurden kurz darauf die Güter der Abwanderer öffentlich zum Kauf angeboten. ${ }^{336}$

Nicht alle wurden um jeden Preis in der Stadt gehalten. In Cremona gestatte man im Dezember 1525, dass die Frauen in Sicherheit gebracht wurden, aber nur um eine Massenflucht zu verhindern, weil die Grenzen des Gebietes von spanischen Soldaten wimmelten, die offenbar die Absicht hegten, sich im Umland der Stadt einzunisten. ${ }^{337}$ Was scheinbar ein Zugeständnis war, kündigte in Wahrheit eine weitere Spielart der bevölkerungspolitischen Maßnahmen an: die Ausweisung aller überflüssigen Esser am karg gedeckten Mailänder Tisch. Zur gleichen Zeit wurden dort alle auswärtigen Bettler, Gauner und Bedürfti-

1520. Es sind alle Einwohner erfasst, die auf Jahreseinnahmen von mehr als 100 Dukaten geschätzt wurden. FANFANI, Storia del lavoro, S. 362. Insgesamt sind 3.229 Namen verzeichnet, was nur etwa ein Fünftel der Haushalte in Mailand ausmacht. Die Liste wurde immer wieder auf 1529 datiert, weil die letzten Nachträge aus diesem Jahr stammen, in Wahrheit aber wurde sie fast vollständig im Jahr 1524 erstellt. Das geht nicht nur aus der Datierung der im Staatsarchiv befindlichen Kopie hervor, sondern vor allem aus CAPELLA, Beschreibung und Geschicht, fol. $18^{r}$, der präzisiert, dass die Schätzung vor dem Ausbruch der Pest, also wohl im Mai 1524 abgeschlossen war. Da die von Capella angegebene Gesamtsumme mit der in den Manuskripten übereinstimmt, kann man davon ausgehen, dass es sich um dieselbe Schätzung handelt. Die einzelnen Summen hat bereits ausgezählt: FORMENTINI, MARCO: La dominazione spagnola in Lombardia. Mailand 1881. S. 38f. Eine umfangreichere Auswertung findet sich bei BARBIERI, GINO: I redditi dei Milanesi all'inizio della dominazione spagnuola. In: Rivista internazionale di Scienze Sociali (1937). S. 759-781.

331 ASM Sforzesco, Cart. 1506, Dekret vom 7. 9. 1527.

332 Die Gesamtsumme für San Martino Nosigia beträgt 120.000 Dukaten, davon müssen die 32.000 für Gerolamo Morone angegebenen Dukaten abgezogen werden, da dieser zu jenem Zeitpunkt den Posten des Generalkommissars im kaiserlichen Heer in Rom bekleidete und daher wohl kaum mit Kontributionszahlungen aus seinem Privatvermögen an die Besatzer in Mailand behelligt worden ist. Das Dekret in ASM Sforzesco, Cart. 1506, Dekret vom 14. 9. 1527. Die Namen der Personen finden sich in den Akten der Schätzung: ASM Sforzesco, Cart. 1520, fol. 104 V - 107V (S. Andrea); fol. 115V - 117V (S. Fedele); fol. $117^{\mathrm{r}}-119^{\mathrm{V}}$ (S. Martino Nosigia); fol. $119^{\mathrm{r}}-125^{\mathrm{V}}$ (S. Bartolomeo); fol. $131^{\mathrm{r}}-132^{\mathrm{r}}$ (S. Silvestro).

333 SANUTO, Diarii, Bd. 43, Sp. 452.

334 Formentini, Il ducato di Milano, S. 349 und 361.

335 SANUTO, Diarii, Bd. 46, Sp. 51.

336 Rovelli, GiUSEPPE: Storia di Como. Bd. 3. Como 1802. S. 462.

337 Bonetti, Cremona, S. 227. 
gen - "mendici, farfanti, carritoni" - aus der Stadt gejagt ${ }^{338}$ und im Juli 1526 traf es auch die einheimischen Armen sowie alle nicht arbeitsfähigen Einwohner. Das Dekret spricht eine deutliche Sprache: die Stadt sollte von den Armen befreit werden, "per lassarla piu libera alle persone utile, quale non havessero ad patire penuria del vivere per esse inutile." ${ }^{339}$ Zwei Jahre später erfolgte eine ähnliche Vertreibung immerhin mit dem Ziel, die Lebensmittelversorgung zu verbessern: alle Personen, die sich in Mailand ohne feste Beschäftigung aufhielten, wurden aufs Land geschickt, um bei der Einbringung der Ernte zu helfen, die durch die Abwesenheit von Bauern und Landarbeitern - ihrerseits eine Folge des Krieges - vom Ausfall bedroht war. ${ }^{340}$

An die ersten Ausweisungen schloss sich ein immer kopfloser wirkender Wechsel zwischen Auszugsverboten und Massenvertreibungen an. Im September 1527 erfolgte ein Rundumschlag gegen alle Einwohner Mailands, die nicht unmittelbar zur Geldbeschaffung für die Besatzungsmacht gebraucht wurden: wer nicht an den Kontributionen und Einquartierungen beteiligt war, musste die Stadt genauso verlassen wie die Geistlichen die Klöster. Wer wollte, konnte ferner seine Familie aus der Stadt schicken. Die Auswanderer wurden von der Verwaltung registriert, Lebensmittelvorräte durften nicht mitgenommen werden. Armen, die nach Ablauf eines Tages noch in der Stadt angetroffen wurden, drohte die Auspeitschung. ${ }^{341}$ Die aus dem akuten Geldmangel resultierende Kurzsichtigkeit dieser Maßnahme zeigt sich vor allem daran, dass alle, die nicht zum Verlassen der Stadt gezwungen wurden, sich das Recht zum Auszug durch die Vorauszahlung von zwei Monatsraten der Kontribution erkaufen konnten. ${ }^{342}$ Dass dadurch die wenigen verbliebenen zahlungskräftigen Mailänder zum Verlassen der Stadt geradezu eingeladen wurden, ging dem Gouverneur offenbar schon nach kurzer Zeit auf, denn weniger als einen Monat später wurde mit sofortiger Wirkung ein erneutes Auszugsverbot verhängt. ${ }^{343}$ Wer die Flüchtigen versteckte, machte sich ebenfalls strafbar. ${ }^{344}$ Die Auszugsverbote und die Aufforderungen zur Rückkehr der Abwanderer wurden in der folgenden Zeit mehrmals wiederholt, was darauf hindeutet, dass der Exodus weiterging. Im Dezember 1528 durfte man Mailand ohne Erlaubnis noch nicht einmal mehr verlassen, um außerhalb der Stadt gelegene Besitzungen zu besuchen. ${ }^{345}$ Im August 1528 hatte man ein erstes Mal versucht, den Flüchtigen durch das Versprechen der Aussetzung der Kontributionen die Rückkehr schmackhaft zu machen ${ }^{346}$ und

\footnotetext{
338 ASM Sforzesco, Cart. 1504, Dekret vom 20. 12. 1525.

339 ASM Sforzesco, Cart. 1505, Dekret vom 28. 7. 1526.

340 ASM Sforzesco, Cart. 1506, Dekret vom 3. 6. 1528.

341 Formentini, Il ducato di Milano, Nr. 73, S. $476 \mathrm{f}$.

342 CAPELla, Beschreibung und Geschicht, fol. 37V; ferner Burigozzo, Cronaca di Milano, S. 473.

343 FORMENTINI, Il ducato di Milano, Nr. 76, S. 479.

344 ASM Sforzesco, Cart. 1506, Dekret vom 29. 8. 1528.

345 Formentini, Il ducato di Milano, Nr. 80, S. 486.

346 ASM Sforzesco, Cart. 1506, Dekret vom 2. 8. 1528.
} 
im Dezember 1528 wurde eine Amnestie verkündet, mit der die Rückkehr erleichtert werden sollte. $^{347}$

Verbote allein halfen indes nicht viel. Neben der Verhaftung betuchter Mailänder zur Erpressung der Kontributionen wurden auch Frauen und Kinder als Geiseln genommen, um die Väter zum Verbleib in der Stadt zu zwingen. ${ }^{348}$ Solche Methoden wandten die Soldaten auch eigenmächtig an, um sich ihr Auskommen in den besetzten Häusern zu sichern. ${ }^{349}$ Auszüge des Besatzungsheeres für militärische Operationen wurden von der Bevölkerung daher als dankbare Gelegenheit zur Flucht wahrgenommen. ${ }^{350}$ Dabei war es angeraten, beim Verlassen der Stadt nicht als wohlhabend erkannt zu werden: einige reiche Mailänder wurden dabei beobachtet, wie sie sich bei Bauern mit ärmlicher Kleidung eindeckten, um nicht ausgeraubt oder aufgehalten zu werden. ${ }^{351}$ Den Aufrufen der letzten Jahre leistete allerdings kaum noch jemand Folge: die Situation im Staat hatte sich trotz aller Ankündigungen nicht verbessert und die Strafen konnten niemanden mehr schrecken, da die zurückgelassenen Güter ohnehin längst zerstört, beschlagnahmt oder von den Soldaten in Folge der ausbleibenden Bestrafung geplündert worden waren.

\section{B. Krieg auf dem Land}

Wie einleitend mehrfach betont wurde, muss diese Arbeit, die sich eine möglichst umfassende Schilderung der Kriegswirklichkeit zum Ziel gesetzt hat, einer Reihe von Verzerrungen entgegen treten, die durch die Blickrichtung der Quellen bedingt sind. Neben der Konzentration des Überlieferungsinteresses auf Personen von hohem gesellschaftlichen Rang und Ereignisse von politischer und militärischer Bedeutung oder emotionaler Tiefenwirkung ist es auch das Quellenaufkommen selbst, das zu einer anderen, nämlich demografisch bedingten Form der Verzerrung beiträgt: der weitaus umfangreichste Teil der Überlieferung hat die Städte zum Schauplatz. Das entspricht aber nicht der Gewichtung der Wirklichkeit, und zwar weder in Bezug auf die Zeit, die man in der Stadt verbrachte, noch auf den Anteil der Soldaten, die tatsächlich die Städte betraten und sich länger dort aufhielten. Mit anderen Worten: ein Heer, das zwei Monate lang in einer Stadt hauste und täglich neue Ausrufe des Entsetzens in Chroniken und Briefen provozierte, konnte zuvor zwei Monate lang sengend und brennend durch das Umland gezogen sein, ohne dass sich mehr als ein paar Bemerkungen von Militärs und örtlichen Beamten fanden, die dieses für die Bewohner der geschä-

\footnotetext{
347 ASM Sforzesco, Cart. 1506, Dekret vom 1. 12. 1528.

348 FORMENTINI, Il ducato di Milano, S. 346.

349 CAPELLA, Beschreibung und Geschicht, fol. $30^{\mathrm{V}}$.

350 RodriguEZ VILLA, Italia desde la batalla de Pavia, S. 179.

351 SANUTO, Diarii, Bd. 41, Sp. 684.
} 
digten Gebiete nicht weniger gravierende Verhalten der Soldaten zum Thema machten. Einer Kompanie, die in der Stadt einquartiert war, stand eine andere gegenüber, die während der ganzen Zeit zwischen verschiedenen Ortschaften hin und her geschoben wurde, ganz abgesehen davon, dass ein größerer Anteil der Bevölkerung auf dem Land lebte und die Auswirkungen des Krieges dort zu spüren bekam und nicht in der Stadt. Den wenigen, aber Aufsehen erregenden Plünderungen größerer Städte stehen eine Unzahl von kleineren und kleinsten Plünderungen auf dem Land gegenüber, die im einzelnen gar nicht mehr zu rekonstruieren sind. Die Städte stellen sozusagen den Wasserkopf der Überlieferung dar, wann immer die Soldaten dort einzogen, traten sie ein in den Lichtkegel der Berichterstattung, der um so heller war, je bedeutender die Städte waren, je höher die Schriftlichkeit von Wirtschaft und Verwaltung, denen die Zeugen zumeist entstammten. Das gilt auch von der Seite der Soldaten aus betrachtet, da die höchsten Offiziere zumeist in der Stadt residierten und von dort aus ihre Briefe schrieben, und das wiederum brachte auch die Spione in die Städte, deren Berichten ein guter Teil der Informationen zu verdanken ist. Die Tatsache, dass die Soldaten sich auf dem Land in der Regel selten lange an einem Ort aufhielten, trägt ihren Teil dazu bei, dass die Beschreibung der Zustände sich zumeist auf die Oberfläche des unmittelbar Beobachtbaren reduziert. Verwaltungsaufwand für Einquartierung und Versorgung fiel kaum an, Beziehungen wie in einer länger besetzten Stadt, die dem Bild, das die Soldaten hinterließen, einige Kontur gegeben hätten, konnten sich selten etablieren. Des weiteren schlägt durch den Mangel an parallelen Quellen, die eine Relativierung ermöglichen, die Bevorzugung des Empörenden noch stärker durch als in der Stadt: die Geschichte des Krieges und der Besatzung ist auf dem Land mehr als irgendwo sonst eine Geschichte von Übergriffen, Ausplünderung und Gewalttätigkeit. Die Häufung der Klagen aus der Feder nicht nur der Opfer, sondern auch der Offiziere lässt den Schluss zu, dass solche Zustände auf dem Land tatsächlich in einem beängstigenden Grad zur Normalität geworden waren. Um der erdrückenden Überrepräsentation der städtischen Berichterstattung ein Gegengewicht aufzuhängen, soll dieser Abschnitt ausschließlich den Auswirkungen des Krieges auf dem Land gewidmet sein.

\section{Auf dem Marsch}

Im Sommer war der größte Teil der Heere unterwegs. ${ }^{352}$ Dabei suchte man in der Regel keineswegs die Schlacht mit dem Feind, sondern vielmehr dessen Übervorteilung durch Manöver, die in erster Linie die Versorgung mit Lebensmitteln und anderen Ressourcen

352 Auf den Karten im Anhang III sind die Bewegungen der Heere für den gesamten untersuchten Zeitraum nachgezeichnet. 
abschneiden sollten. Vor allem italienische Condottieri der alten Schule wie Prospero Colonna taten sich in dieser Kunst hervor. Massive Zusammenstöße mit dem Gegner wurden traditionell in voller Absicht vermieden, die bedeutenden Schlachten des untersuchten Zeitraums lassen sich an einer Hand abzählen. Auch größere Belagerungen waren selten und erregten entsprechendes Aufsehen. Wenn zahlreiche vor allem kleinere Städte und Festungen innerhalb weniger Jahre so oft den Besitzer wechselten, so lag das vor allem daran, dass es in der Regel genügte, die Artillerie vor den Mauern in Stellung zu bringen, um die Verteidiger zu Übergabeverhandlungen zu zwingen. Dabei ging es dann weniger um die Frage, ob die Stadt kapitulieren sollte oder nicht, sondern um den Preis, um den sie sich von der Plünderung freikaufen musste. Anschließend wurde eine Besatzung in der Stadt gelassen, die ihrerseits vor dem nächsten anrückenden Feind kapitulierte, und das Heer zog weiter. Wenn eine Besatzung zu stark war, umging man die Stadt, ohne allzu spürbare Beeinträchtigungen dafür in Kauf nehmen zu müssen, da sich die Heere ohnehin direkt aus dem sie umgebenden Land ernährten. Die beiden hier untersuchten Kriegsperioden von 1509 bis 1516 in der Terraferma und von 1521 bis 1529 in der Lombardei waren jeweils zu Beginn von größerer Dynamik geprägt als gegen Ende, offensichtlich wurde der Krieg mit fortschreitender Dauer träger. Das ist vor allem auf die schwieriger werdende Versorgungslage und die daraus resultierende weitere Verteilung der Soldaten im Land zurückzuführen, die den Heeren einen erheblichen Teil ihrer Schlagkraft nahm. Genauer gesagt: die Dynamik, die einst in gezielten Manövern des ganzen Heeres bestanden hatte, verselbständigte sich in Richtung auf eine geografisch immer weiter gestreute Bewegung einzelner Bruchstücke dieses Heeres, beschleunigt durch den Verfall der Disziplin wegen der ausbleibenden Soldzahlungen. Die italienischen Condottieri, die sich den Heeren der großen Mächte anschlossen, betrachteten den Krieg ohnehin in erster Linie als Mittel zur persönlichen Bereicherung und zogen mit ihren Kompanien auf der Suche nach einträglichen Plünderungen und der Einbringung von Gefangenen durchs Land. Der Krieg wurde so militärisch gesehen zwischenzeitlich zu einer regelrechten Farce, die darin bestand, dass man bei der Führung nicht etwa auf einen Sieg, sondern auf den Zerfall des jeweils gegnerischen Heeres hoffte. Schon im April 1524 schrieb Nájera aus Novara in einem Brief an den Kaiser den bezeichnenden Satz: "Toda la esperança que los enemigos tienen es que por falta de dineros este exercito se ha de deshazer, plaçera Dios que ellos se desharan primero." ${ }^{353}$ Auf dem Marsch zogen die Heere einen immensen Schwanz von Trossknechten, Prostituierten, Händlern und Glücksrittern hinter sich her. Militärische Quellen indes schweigen sich über den Tross in der Regel aus, da seine Anwesenheit für den Fortgang des Krieges erst dann von Bedeutung war, wenn er wirklich aus allen Nähten platzte und die militärischen Operationen hemmte. Die Kolonne der Trosswagen wuchs vor allem nach Plünde-

353 BNM, MS 20213²1, Nr. 45. Nájera an den Kaiser, Novara, 9. 4. 1524. 
rungen zu einer Länge an, die von den Offizieren nicht gern gesehen wurde, weil sie die Bewegung des Heeres verlangsamte und den Feinden zusätzliche Angriffsfläche bot. Zum Transport von Ausrüstung und Lebensmitteln genügte ein Trosswagen für etwa 10 Soldaten, ${ }^{354}$ vor allem nach Plünderungen aber gab es weit mehr zu transportieren. Giovio berichtet, dass man nach der Plünderung von Genua im Juni 1522 wegen der vielen Packpferde den Eindruck hatte, das ganze kaiserliche Heer sei beritten gewesen. ${ }^{355}$ Auf dem Rückweg von dem Zug in die Provence im Oktober 1524 wurde dasselbe Heer von nicht weniger als 14.000 Trosswagen begleitet, die insgesamt eine Woche brauchten, um den Po zu überqueren. ${ }^{356}$ Neben Waffen, Vorräten, Beute und Besitz der Soldaten sowie der Ware der Marketender wurden auch die Kranken, Frauen und Kinder meistens auf Wagen transportiert. Bei den Frauen handelte es sich um Prostituierte und Soldatenliebchen, oft war ihr Status auch in einer Grauzone zwischen beidem angesiedelt und manchmal waren sie sogar mit den Soldaten verheiratet - von den Zeugen werden sie nichtsdestoweniger in der Regel als Prostituierte angesprochen. Über ihre Herkunft ist leider kaum etwas zu erfahren. Die meisten von ihnen hatten sich dem Heer erst im Land angeschlossen, es scheint, dass sich bei den Landsknechten ein größerer Anteil von Frauen befand, die diesen aus der Heimat gefolgt waren, als bei den Spaniern. In unregelmäßigen Abständen versuchten die Offiziere, die Zahl zumindest der einheimischen Prostituierten mit drastischen Methoden zu reduzieren, um die Versorgungslage zu verbessern und die Konzentration der Soldaten wieder den militärischen Aufgaben zuzuwenden. Bei der Belagerung von Padua im August 1513 befanden sich nach den Informationen der Belagerten etwa 3.000 Frauen beim spanischen Heer. ${ }^{357}$ Einen Monat später wurden alle italienischen Prostituierten unter Androhung der Todesstrafe aus dem Lager verwiesen, ${ }^{358}$ was dazu führte, dass nur etwa 15 Frauen pro Kompanie beim Heer verblieben. ${ }^{359}$ Als das kaiserliche Heer im März 1527 in der Nähe von Bologna lagerte, ließ man zur schnelleren Durchsetzung solcher Maßnahmen kurzerhand ein unmenschliches Exempel statuieren. Scipione Attelaro, Informant des Herzogs von Mailand beim Heer, berichtet ungerührt, dass zur Einschüchterung der Prostituierten "per intemorire queste puttane" - drei von ihnen ohne weiteren ersichtlichen Grund aufgehängt worden seien, was die italienischen Soldaten mit erheblicher Verstimmung quittiert hätten, da alle drei Italienerinnen und eine von ihnen überdies schwanger gewesen sei. Um den Tross abspecken zu lassen, wurde ferner bestimmt, dass vier Soldaten sich einen Trosswagen und einen Bediensteten zu teilen hatten und kein schwerer Reiter mehr als vier

\footnotetext{
354 FIEDLER, SIEGFRIED: Kriegswesen und Kriegführung im Zeitalter der Landsknechte. Abt. 1, Bd. 2 von: Heerwesen der Neuzeit. Hrsg. v. Georg Ortenburg. Koblenz 1985. S. 83.

355 GIOVIO, Le vite del Gran Capitano e del Marchese di Pescara, S. 313.

356 BNM, MS 2021321, Nr. 55. Nájera an den Kaiser, Lodi, 26. 10. 1524.

357 SANUTO, Diarii, Bd. 16, Sp. 603.

358 SANUTO, Diarii, Bd. 17, Sp. 63.

359 SANUTO, Diarii, Bd. 17, Sp. 126.
} 
Pferde mit sich führen durfte. ${ }^{360}$ Zumindest die Maßnahmen zur Vertreibung der Prostituierten aber schienen nicht zu fruchten, denn einen Monat später waren diese entweder immer noch oder schon wieder da. Antonio Petra, ein weiterer Informant des Herzogs, schickte im April einen Bericht über die Mannschaftsstärke des Heeres nach Cremona, in dem er neben 18.000 Fußsoldaten und 900 Reitern in aller Beiläufigkeit 12.000 Prostituierte und 6.000 Trossknechte aufzählt. ${ }^{361}$

So zog man im Land auf und ab. Und wie die meisten Dörfer im Lauf der Jahre mehr als einmal von durchziehenden Soldaten heimgesucht wurden, so kamen einzelne Soldaten im Lauf eines Feldzugs durch zahllose verschiedene Ortschaften. Das Allägliche dieses Wechsels lässt sich aus der Sicht der Soldaten wie auch aus der Sicht der Bevölkerung an Hand zweier außergewöhnlicher Quellen nachvollziehen, die zur Zeit des Krieges in der Terraferma entstanden. Es handelt sich auf der einen Seite um das Tagebuch eines italienischen Soldaten in kaiserlichen Diensten, dessen erhaltener Teil von November 1512 bis Januar 1514 reicht, ${ }^{362}$ und auf der anderen um eine Auflistung aller Kriegsereignisse zwischen Februar 1509 und April 1517, die für die Bewohner des Dorfes Polpenazze westlich des Gardasees mit Ausgaben verbunden waren, möglicherweise als Grundlage einer Entschädigungsforderung. ${ }^{363}$ Das Tagebuch ist einer der ganz wenigen detaillierten Berichte aus der Sicht der Soldaten. Es handelte sich offenbar um einen Offizier, der für den Transport der Artillerie zuständig war, mithin um einen Angehörigen des langsamsten und unbeweglichsten Teils des Heeres, dennoch sind die zurückgelegten Strecken bisweilen beeindruckend. Das Tagebuch setzt kurz nach dem Einmarsch der Spanier in Brescia im November 1512 ein. Nach einem kurzen Aufenthalt in der Stadt trennte sich das kaiserliche Heer von den Spaniern, schlug einen südlichen Bogen, hielt sich eine Weile in der Gegend von Desenzano am Gardasee auf, setzte dann über und zog in Verona ein. Ein paar Monate blieb man dort liegen, im Mai 1513 begann dann eine rastlose Betriebsamkeit, die das Heer zwischen Verona, Vicenza, Padua und der Etsch kreuz und quer durch das Herz der Terraferma führte. In keinem Ort hielt man sich lange auf, ab und zu wurden kleinere Festungen erobert, in erster Linie aber beschränkte sich die Aktivität auf die Plünderung der durchzogenen Dörfer. Oft machten einzelne Abteilungen auch Abstecher, um Ortschaften zu plündern, die abseits des Weges lagen. Überfälle venezianischer Kavallerie auf versprengte Gruppen waren an der Tagesordnung und endeten zumeist damit, dass die Überfallenen im Hemd zurückblieben oder als Gefangene nach Venedig gebracht wurden, wo man sie gegen Lösegeld freiließ oder gegen Gefangene der Gegenseite austauschen ließ. Im Juli vereinigte sich das kaiserliche Heer erneut mit den Spaniern, mit denen man im August vor Padua zog und die Stadt einschloss. Nach dem Abbruch der Belagerung stieß man im

360 ASM Sforzesco, Cart. 1360. Scipione Attelaro an Francesco Sforza, 9. 3. 1527.

361 ASM Sforzesco, Cart. 1361. Antonio Petra an Francesco Sforza, 15. 4. 1527.

362 JOPPI, Diario del campo tedesco.

363 MARCHESINI, La lega di Cambray. 
September bis an die Lagune von Venedig vor und von dort aus in einem nördlichen Bogen wieder in das Gebiet zwischen Vicenza und Verona, wo die Praxis des scheinbar ziellosen Umherziehens aufs Neue einsetzte. Auch wenn das Tagebuch nur einen kleinen Ausschnitt des ganzen Krieges wiedergibt, so ist der Eindruck des Wechsels zwischen Aufenthalten in der Stadt und Perioden hoher Beweglichkeit auf dem Land repräsentativ nicht nur für den Krieg in der Terraferma, sondern auch für die anderen Kriegszüge der Epoche. Diese hohe Beweglichkeit schließlich war nicht zuletzt deshalb unverzichtbar, weil die einzelnen Orte stark in Mitleidenschaft gezogen wurden und die Last der Versorgung und Unterbringung der Soldaten nicht lange tragen konnten.

Wie sich nun durch die Aufzeichnungen des anonymen Soldaten die Charakteristik der Bewegungen des Heeres in allen Details verfolgen lässt, so bietet die Liste aus Polpenazze einen lückenlosen chronologischen Schnelldurchlauf durch die Kriegsereignisse im kleinsten geografischen Rahmen. Wie in Zeitraffer passieren die venezianischen, französischen, deutschen und spanischen Truppen den kleinen Ort, den der anonyme Schreiber des Tagebuches im übrigen nur knapp verpasste: während er in Desenzano einquartiert war, lagen andere Soldaten seines Heeres über einen Monat lang nebenan in Polpenazze. Die Liste umfasst insgesamt nicht weniger als 129 Posten. Von diesen betreffen 46 die Lieferung von Ressourcen an das Heer, vor allem Wagen und Zugochsen für den Transport von Munition und Brennholz, aber auch Heu für die Pferde und Lebensmittel für in benachbarten Ortschaften einquartierte Kompanien. Erst die 39 Posten, die sich mit der Einquartierung von Soldaten befassen, machen jedoch das Ausmaß der Belastung des Ortes durch den Krieg deutlich. Während dessen aktivster Phase gaben sich Soldaten aller Nationen und Waffengattungen in Polpenazze die Klinke in die Hand. Schon seit Mai 1509 wechselten sich Venezianer und Franzosen im Besitz des Ortes ab, mit der Ausweitung des Krieges machte man in Polpenazze dann auch mit den Soldaten der anderen Mächte Bekanntschaft: nachdem sich Mitte November 1512 schon 415 Soldaten des venezianischen Heeres in Polpenazze aufgehalten hatten, kamen dann Anfang Dezember 302 Deutsche, die über einen Monat blieben, und nur sechs Tage nach deren Abzug rückten 54 Spanier ein, die drei Tage blieben, dann kurz auszogen, nach vier Tagen aber schon wieder da waren und noch einmal drei Wochen verweilten. Schon einen Monat später besetzten die Venezianer den Ort erneut. In den folgenden Jahren beruhigte sich die Lage dann, weil der Krieg sich weiter nach Osten verlagerte, erst im Oktober 1515 begann eine erneute Phase der Belastung, verursacht durch das Tauziehen zwischen Spaniern und Venezianern um die Stadt Brescia. Von Dezember 1515 bis März 1516 war venezianische Kavallerie in großer Zahl in Polpenazze einquartiert, die Kosten allein dieser drei Monate - über 30.000 Lire - machen mehr als die Hälfte der in den acht aufgeführten Jahren aufgewendeten Gesamtsumme aus. Im ganzen machte Polpenazze während des Krieges, wie gesagt, 39 Belegungsperioden durch, von denen mehr als die Hälfte allerdings nur einen Tag dauerte, weil sich das Heer ganz offen- 
sichtlich auf dem Durchzug befand. Nur zwölf Aufenthalte dauerten eine Woche oder länger, und von diesen wiederum zogen sich fünf über einen Monat oder länger hin. Die oben erwähnten venezianischen Reiter verbrachten mit drei Monaten den längsten verzeichneten Aufenthalt in Polpenazze. Wie die Dauer der Besetzung, so schwankte auch die Zahl der einquartierten Soldaten von einem halben Dutzend bis zu mehreren Hundert. Hier sind 556 Gascogner aus dem französischen Heer, die sich im August 1511 drei Tage lang in Polpenazze aufhielten, der größte Posten, dicht gefolgt von 552 Venezianern, die im Dezember 1515 zwar nur zwei Tage blieben, aber nicht weniger als 413 Pferde zu versorgen hatten und darüber hinaus viel stahlen. Neben den Materiallieferungen und der Einquartierung und Verpflegung der Soldaten verlangten die Militärs schließlich auch die Arbeitskraft der Bewohner: 18 Posten sind dem Unterhalt von Bauern aus Polpenazze gewidmet, die zu Befestigungsarbeiten in benachbarten Städten - vor allem in Brescia und Peschiera - herangezogen wurden. Die größte Gruppe umfasst 17 Personen, die sechs Wochen lang wegblieben. Im Durchschnitt dauerten solche Arbeiten etwa zwei Wochen. Daneben verlangten die Venezianer insgesamt 14-mal die Stellung von Bewaffneten zur Verstärkung ihrer Truppen, diese Gruppen waren größer und umfassten im Durchschnitt mehr als 30 Personen. Im Februar 1512 wurden in Polpenazze 93 Hilfssoldaten für den Angriff auf Brescia rekrutiert. Schließlich wurden einzelne Einwohner bisweilen als Boten und Geländeführer eingesetzt. Die Verteilung der Posten und der aufgewendeten Gelder sieht im Überblick folgendermaBen aus, die Summen sind in Lire angegeben:

\begin{tabular}{|l|c|c|}
\hline \multicolumn{1}{|c|}{ Leistung } & Posten & Kosten \\
\hline Einquartierung von Soldaten & 39 & 56.650 \\
\hline Lieferungen ans Heer & 46 & 850 \\
\hline Stellung von Arbeitern & 18 & 530 \\
\hline Stellung von Soldaten & 14 & 430 \\
\hline Sonstiges & 11 & 260 \\
\hline
\end{tabular}

Die Gesamtkosten des Krieges für Polpenazze beliefen sich nach den Angaben der Liste auf knapp 60.000 Lire oder etwa 8.000 Dukaten. Die Einquartierung und Verpflegung der Soldaten war, wie man sieht, mit Abstand die kostspieligste Angelegenheit, sie verschlang $96 \%$ der Ausgaben.

Da die einzelnen Posten meistens die genaue Zahl der einquartierten Soldaten und die Dauer des Aufenthaltes auflisten, lassen sich die Kosten für die Verpflegung eines Soldaten errechnen. Der kostete demnach im Durchschnitt etwa 15 Soldi am Tag, es gab allerdings erhebliche Schwankungen: die bescheidensten Soldaten waren die oben erwähnten Gascogner, von denen jeder lediglich 7 Soldi am Tag kostete, das ist wohl zum Teil auf die Tatsache zurückzuführen, dass sie sehr wenige Pferde mit sich führten. Die venezianischen Reiter, die zwischen Dezember 1515 und März 1516 in Polpenazze lagerten, kosteten am 
Tag etwa 25 Soldi pro Mann. Der Durchschnitt liegt, wie gesagt, bei etwa 15 Soldi pro Soldat, bezeichnenderweise lagen die Ausgaben für Spanier und Deutsche deutlich höher bei etwa 20 bis 22 Soldi. Angesichts des zerstörerischen Verhaltens der kaiserlichen und spanischen Heere während des ganzen Krieges in der Terraferma verwundert dieser Umstand nicht: offenbar stellte man neben allen anderen angerichteten Schäden auch bei der Verpflegung höhere Forderungen.

\section{Verteilung im Land}

Wenn keine militärischen Aktivitäten auf dem Programm standen, verteilte sich das Heer schnell im Land, zum Teil auf Befehl der militärischen Führung, die ungern viele Soldaten in der Stadt sah und darüber hinaus dem Umstand Rechnung tragen musste, dass weite Teile des Landes gar keine Soldaten mehr versorgen konnten, zum Teil aus Eigeninitiative der Hauptleute, die ihre Kompanien gern in abgelegene Gebiete führten, wo sie ungestört allen Arten von erpresserischen Aktivitäten nachgehen konnten. Im Januar 1526 schrieb Lope Hurtado de Mendoza an den Kaiser, die Soldaten würden in die wenigen Gebiete der Lombardei geschickt, die noch nicht völlig zerstört seien. ${ }^{364}$ Solche Gebiete aber fanden sich schließlich innerhalb des Staates kaum noch und mussten jenseits der Grenzen gesucht werden. Schon im November 1522 hatte es Beschwerden gehagelt, weil spanische Kompanien ohne Genehmigung des Papstes in die Gebiete von Parma, Piacenza und Reggio abgeschoben worden waren; in einem Brief an den Kaiser schrieb Nájera, der Papst habe ultimativ den Abzug der Spanier innerhalb von zwei Tagen gefordert, das sei aber unmöglich, weil man nicht wisse, wo man sie sonst unterbringen sollte, und für die vom Papst geforderten Entschädigungszahlungen sei kein Geld da. ${ }^{365}$ Offenbar wurden sie dann doch abgezogen, waren aber im folgenden Jahr schon wieder da, ohne dass man wusste, ob sie die Grenze eigenmächtig oder auf Befehl überschritten hatten. ${ }^{366}$ Mehr oder weniger zurückhaltende Beschwerden kamen von allen Grenzen. Manchmal behauptete man auf spanischer Seite einfach, die Soldaten wären sich der Grenzverletzung gar nicht bewusst gewesen, wie der Markgraf von Guasto, der sich im Januar 1526 bei den venezianischen Beamten in Crema entschuldigen musste, nachdem seine Soldaten von der Lombardei aus im Gebiet der Grenzstadt zu Requirierungen ausgezogen waren. Da die Bauern dort bereits zur Gegenwehr geschritten waren und ihrerseits die Soldaten ausgeraubt hatten, schlug er vor, den Vorfall auf sich beruhen zu lassen. ${ }^{367}$ In anderen Fällen wurde die Schuld auf andere

364 Gayangos, Calendar, Bd. 3, Teilbd. 1, S. 556.

365 BNM, MS 18690, Nr. 120. Nájera an den Kaiser, Genua, 11. 11. 1522.

366 Poggial, Cristoforo: Memorie storiche di Piacenza. Bd. 8. Piacenza 1760. S. 345f.

367 SANUTO, Diarii, Bd. 40, Sp. 762. 
Verbündete geschoben. Als im Dezember 1523 wieder einmal Klagen der venezianischen Beamten über Grenzverletzungen der kaiserlichen Soldaten einliefen, behauptete Prospero Colonna in einem Antwortschreiben, das seien Soldaten des Papstes gewesen und fügte trotzig hinzu, die venezianischen Truppen benähmen sich in ihrem eigenen Gebiet doch selbst wie die Axt im Wald. ${ }^{368}$

Die am schwersten und dauerhaftesten heimgesuchten Nachbargebiete lagen im Westen der Lombardei: das Herzogtum Savoyen und die Markgrafschaften Saluzzo und Montferrat. Im Juni 1524 forderte die Herzogin von Savoyen in einer Instruktion an ihren Botschafter beim kaiserlichen Heer den sofortigen Abzug der Soldaten aus ihrem Land und war sich nicht zu schade, deren Einquartierung in Saluzzo und Montferrat vorzuschlagen. ${ }^{369}$ Die Zustände besserten sich aber nicht, sondern verschlimmerten sich im folgenden Jahr noch. Schließlich wurde Lope Hurtado de Mendoza im Dezember 1525 als Sondergesandter nach Savoyen geschickt, um sich über die angerichteten Schäden zu informieren. Am Ergebnis gab es wenig zu beschönigen: in einem ersten Brief räumte er schwere Verwüstungen ein, bemerkte allerdings, eine genaue Untersuchung sei sinnlos, weil ohnehin kein Geld zur Behebung da sei. Die aufgebrachten Soldaten könne man aus Angst vor Meuterei und Massendesertion nicht zur Rechenschaft ziehen, und aus Geldmangel könne eine Entschädigung höchstens in guten Worten bestehen. ${ }^{370}$ Die detaillierte Untersuchung wurde dann aber doch weiter getrieben. Im April 1526 schrieb Hurtado de Mendoza, es sei geraten, eine Person von guter Kenntnis - etwa Nájera - mit der Erstellung eines Katalogs von Schandtaten zu beauftragen, die von der Bevölkerung von Savoyen an kaiserlichen Soldaten begangen worden waren, um ein Gegengewicht zur offenbar erdrückend langen Liste von Übergriffen der Soldaten gegen die Bevölkerung an der Hand zu haben. ${ }^{371}$ In Mailand scherte man sich indessen offenbar wenig um die Schadensbegrenzung, die Hurtado de Mendoza in Turin betrieb, denn schon im Mai 1526 ließ ausgerechnet Nájera weitere Soldaten in Richtung Savoyen marschieren. Der Herzog tobte vor Wut, so Hurtado de Mendoza, und seine Untertanen wollten eher zum Islam übertreten als weiterhin Soldaten in ihrem Land zu dulden. ${ }^{372}$ Ein solcher Schritt wurde am Ende aber nicht erforderlich, da die Spanier bereits zwei Wochen später wieder abgezogen waren. ${ }^{373}$ Kurz darauf lag das Ergebnis der Untersu-

368 BNM, MS $18690^{36}$, Nr. 6. Die Zuordnung des Schreibens ist nicht ganz klar, da das Faszikel laut Aufschrift Briefe von Prospero Colonna enthält und der Brief mit dem 29. Dezember 1524 datiert ist. Prospero Colonna aber war am 31. Dezember 1523 verstorben, so dass der Brief entweder nicht von ihm stammt, oder, was wahrscheinlicher ist, durch die Verwendung des Weihnachtsstils bei der Datierung ins Jahr 1524 gerutscht ist, obwohl er nach dem Circumcisionsstil ins Jahr 1523 gehört. Demnach wäre er zwei Tage vor Colonnas Tod entstanden.

369 Segre, ARtUro (HrSG.): Documenti di storia sabauda dal 1510 al 1536 preceduti da una introduzione. Turin 1902. S. 168f.

370 Gayangos, Calendar, Bd. 3, Teilbd. 1, S. $506 f$.

371 Gayangos, Calendar, Bd. 3, Teilbd. 1, S. 631.

372 Gayangos, Calendar, Bd. 3, Teilbd. 1, S. 687.

373 Gayangos, Calendar, Bd. 3, Teilbd. 1, S. 704. 
chung zur Ermittlung des Schadens vor: seit dem Beginn des Krieges war durch den Aufenthalt der kaiserlichen Soldaten ein Schaden von 11/2 Millionen Dukaten entstanden. Zur gleichen Zeit befand sich schon wieder italienische Kavallerie in Savoyen, die so schlimme Ausschreitungen beging, dass die Bevölkerung sich zur Gegenwehr organisiert, eine ganze Kompanie aufgerieben und einige weitere bis aufs Hemd ausgeraubt hatte. Und während eine Welle von Vergeltungsmaßnahmen das Land überrollte, hatte man sich mit dem Herzog über eine Entschädigungszahlung von 8.000 Dukaten geeinigt, für die man von kaiserlicher Seite aus bereit war, die Vorfälle zu vergessen. ${ }^{374}$

Die Unterbringung und Verpflegung der Soldaten war um so schwieriger, als der Tross, der mit den Heeren durch das Land gespült wurde, in der Regel größer war als das Heer selbst und ebenfalls ernährt werden musste. Welche zusätzliche Belastung das für die Einwohner bedeutete, belegen die Zahlen aus einer Liste, die von Vertretern der örtlichen Verwaltung im Januar 1526 als Grundlage einer Beschwerde angefertigt wurde und alle im Gebiet von Cremona - mit Ausnahme der Stadt - einquartierten kaiserlichen Truppen aufführt. Diese Liste stellt für jeden einzelnen Ort die genaue Zahl der Soldaten der genauen Zahl der mit diesen einquartierten zusätzlichen Personen gegenüber. Deren Anzahl war danach so groß, dass die Soldaten zur Minderheit wurden: schon bei der Infanterie stehen 2.400 Soldaten 4.600 weiteren Personen gegenüber, bei der Kavallerie sind es 800 Soldaten gegen 5.300 weitere Personen. ${ }^{375}$ Insgesamt handelt es sich also um 13.100 Personen, davon nur 3.200 Soldaten. Die in der Liste aufgeführten 19 Orte sind relativ gleichmäßig über das ganze Gebiet von Cremona verstreut.

Von den größeren Orten aus wurden die Soldaten weiter verteilt. Ein einzelnes Dorf wird kaum mehr als eine Kompanie beherbergt haben; die schwere Kavallerie, die nach der Schlacht von Pavia im Gebiet von Savoyen untergebracht wurde, bekam pro Kompanie 5 bis 6 Dörfer zugeteilt, die Hauptleute hielten sich aber nicht an diese Regelung, sondern konzentrierten die Soldaten jeweils in zwei Dörfern, um aus den anderen auf eigene Rechnung Gelder zu erpressen. ${ }^{376}$

Die Verteilung auf die Dörfer wurde von den Quartiermeistern organisiert. Auch die Liste aus Polpenazze erwähnt diese hin und wieder, wenn sie einen Tag vor dem Einrücken ganzer Einheiten im Dorf ankamen und sich beköstigen ließen. Ganz am Schluss der Liste findet sich übrigens ein Posten mit über 100 Lire, die im Lauf der Zeit an französische und spanische Quartiermeister gezahlt worden waren, ohne dass genauer präzisiert wird, worin die Leistung genau bestand, da die Versorgung der Quartiermeister in eigenen Posten aufgeführt wird. Man könnte spekulieren, dass durch Zahlungen oder besondere Leistungen an die Quartiermeister versucht worden war, diese zu bestechen und eine Einquartierung von

\footnotetext{
374 Gayangos, Calendar, Bd. 3, Teilbd. 1, S. 724.

375 BonetTi, Cremona, S. 228.

376 BNM, MS 20476, fol. 208r.
} 
Soldaten zu verhindern. Manchmal ist immerhin der Aufenthalt eines Quartiermeisters verzeichnet, ohne dass diesem die Einquartierung von Soldaten folgte.

Grundsätzlich galt, dass ein Ort, der keine Einquartierung bekam, sich durch Geldzahlungen oder Naturallieferungen an der Belastung beteiligen musste. Aus Cremona ist eine weitere Liste aus der Zeit der oben beschriebenen Anwesenheit der Soldaten im Gebiet überliefert, die für 10 Dörfer in der unmittelbaren Umgebung der Stadt Geldsummen aufführt, die für die Beteiligung an den Einquartierungen bestimmt waren. ${ }^{377}$ Offenbar mussten die Orte selbst erklären, wieviel sie abgeben konnten, denn neben dem Dorf Grontorto steht die Bemerkung "Mi pare non esser vera confessione". Die Beträge reichen von 3 bis 150 Lire und sind wahrscheinlich tägliche Abgaben. Die Gesamtsumme beträgt 622 Lire, was auf den Monat hochgerechnet für den Sold von knapp 600 Soldaten reichen würde. Unter den Beträgen steht die Bemerkung, dass Santo Bassano und Grumello bereits früher Einquartierungen gehabt hätten, dadurch stark in Mitleidenschaft gezogen worden seien und deshalb dieses Mal von der Beteiligung ausgenommen werden sollten. Offenbar gab es einen Turnus, durch den man versuchte, den betroffenen Orten Gelegenheit zu geben, sich zu erholen. Die meisten Orte waren bestrebt, durch solche Zahlungen einen Schutzbrief zu bekommen, der die Soldaten von ihrem Gebiet fernhielt, denn die Einquartierung konnte durch die zusätzlich angerichteten Schäden wesentlich teurer werden: in einem Schreiben des Botschafters von Siena beim kaiserlichen Heer während der Belagerung von Florenz aus dem September 1529 heißt es, wenn die Herren von der Regierung in Siena wüssten, wie sich die Soldaten des Kaisers in ihrem Gebiet benähmen, würden sie lieber für drei Monate deren Verpflegung bezahlen, als sie auch nur einen Abend lang im Gebiet von Siena unterzubringen. ${ }^{378}$

Die Zusammenarbeit mit der Verwaltung auf dem Land war üblich, wenn eine solche existierte. Kurz nach dem Einmarsch der Spanier in Brescia im November 1512 stellte sich das Problem, die aus der Stadt ausgelagerten Kompanien im umliegenden venezianischen Gebiet unterzubringen. Zu diesem Zweck musste man sich auf die venezianische Verwaltung stützen. Die Situation war angespannt, denn Cardona hatte seine venezianischen Verbündeten bei der gemeinsam geplanten Einnahme von Brescia übervorteilt, verwehrte deren Truppen den Zutritt zur Stadt und ließ sie unter Feuer nehmen, sobald sie sich der Mauer näherten. Als kurz darauf die Pest in Brescia ausbrach, wurden die Spanier aus der Stadt ins Umland verlegt. Wie schnell den Autoritäten in solchen Fällen die Kontrolle über die Situation entgleiten konnte, das zeigt deutlich die Korrespondenz der venezianischen Beamten in den betroffenen Gebieten mit der Regierung. Es begann damit, dass Cardona den venezianischen Provveditore in Urzinuovi Niccolò Michiel durch die Übersendung einer

377 ASM Sforzesco, Cart. 1422.

378 Falletti, Pio Carlo (HrsG.): Assedio di Firenze. Contributo. Parte II: Documenti. Palermo 1885. Nr. 12, S. 28. 
Einquartierungsliste vor vollendete Tatsachen stellte. Dieser konnte es gerade noch verhüten, dass Antonio de Leyva, damals noch Kommandant einer Kompanie spanischer Kavallerie, sich in Urzinuovi selbst einrichtete, weil dort bereits die Flüchtlinge aus Brescia untergebracht waren. In der Liste kommt übrigens auch Quinzano als Einquartierungsort für einen Teil der kaiserlichen Landsknechte und die Artillerie vor, unter denen sich der anonyme Tagebuchschreiber befunden haben muss. Einige Orte, in denen die Pest grassierte, wurden ausgenommen. ${ }^{379}$ Die Klagen ließen nicht auf sich warten: wenige Tage nach dem Einrücken der Spanier ins Gebiet von Chiari wurde die Verpflegung schon nicht mehr bezahlt. ${ }^{380}$ Die folgende Zeit ist geprägt von reger Betriebsamkeit der venezianischen Beamten, die den Schaden, den die ungeliebten Verbündeten anrichteten, möglichst gering halten sollte. Einen Bevollmächtigten des spanischen Gouverneurs von Brescia, der durch das Land reiste und zur Vorbereitung von Requirierungen die Vorräte inspizierte, konnte Michiel abwimmeln, gleichzeitig schrieb er einen Brief an Cardona, um für Urzinuovi eine Ausnahmeregelung zu erwirken. ${ }^{381}$ Von der Partnerschaft zwischen Spanien und Venedig war bald nicht mehr viel zu spüren: in der Gegend von Salò wurden spanische und venezianische Soldaten schon gegen Ende November 1512 miteinander handgemein. ${ }^{382}$ Der venezianische Provveditore dort, Daniele Dandolo, schrieb im Dezember an seine Regierung, spanische und deutsche Kompanien zögen am Ufer des Gardasees hinunter und plünderten die Ortschaften. Es dauerte nicht lange, da standen die spanischen Quartiermeister auch bei Dandolo vor der Tür und verlangten die Vorbereitung der Einquartierung von Soldaten. Es gelang ihm schließlich, die Einquartierung gegen die Zahlung von 500 Dukaten abzuwenden. ${ }^{383}$ Die Lage war brenzlig, denn schon wenige Tage später plünderten die Spanier das unmittelbar benachbarte Riviera und forderten allen Ernstes die Bereitstellung von 500 Wagen zum Abtransport der Beute. ${ }^{384}$ Weil die Deutschen im Januar 1513 auch mit der Plünderung von Salò drohten, ließ Dandolo Soldaten zum Schutz der Stadt anwerben, was wiederum die Spanier in Harnisch brachte: Dandolo musste sich von dem spanischen Hauptmann Carvajal belehren lassen, dass sie, die Spanier, dafür zuständig seien, die Bevölkerung vor den Deutschen zu schützen, wenn es angelegen sei. ${ }^{385} \mathrm{Im}$ Februar zog das Heer endlich $\mathrm{ab}$, und bald darauf befanden sich Spanien und Venedig auch offiziell wieder im Krieg miteinander.

Auf dem Land kam es daneben immer wieder zu Zusammenstößen mit dem Gegner. Vor allem die Reiterei der Spanier um Mailand lieferte sich ständig Gefechte mit den Venezianern und Franzosen. Dabei ging es um die Sicherung der Versorgungswege, vor allem aber

\footnotetext{
379 SANUTO, Diarii, Bd. 15, Sp. 324.

380 SANUTO, Diarii, Bd. 15, Sp. 342.

381 SANUTO, Diarii, Bd. 15, Sp. 370.

382 SANUTO, Diarii, Bd. 15, Sp. 373.

383 SANUTO, Diarii, Bd. 15, Sp. 396.

384 SANUTO, Diarii, Bd. 15, Sp. 402.

385 SANUTO, Diarii, Bd. 15, Sp. 455.
} 
um die Einbringung von Gefangenen, von denen man Lösegeld eintreiben konnte. Reiter waren dabei willkommener als einfache Soldaten, weil es bei ihnen mehr zu holen gab: schon im Dezember 1521 schrieb der Condottiere Gianni Maria Fregoso nach einem erfolgreichen Überfall, bei dem ihm 153 Pferde in die Hände gefallen waren, voller Zufriedenheit an die Regierung in Venedig, die spanischen Reiter würden durch solche Aktivitäten zu Fußsoldaten gemacht. ${ }^{386}$ Diese wiederum ließ man meistens sofort wieder frei, nachdem sie geschworen hatten, nach Hause zu gehen und eine bestimmte Zeit lang nicht am Krieg teilzunehmen. Nicht immer hielten sich die Soldaten an die Abmachungen: als die kaiserliche Besatzung von Cremona im September 1526 kapitulierte, bekamen die Soldaten freien Abzug unter der Bedingung, dass sie nach Hause zögen. Den Spaniern, die sich zunächst nach Neapel auf den Weg machen wollten, verweigerte der Herzog von Urbino die Geleitbriefe, und so zogen sie direkt in die Lombardei. Die Deutschen kehrten zwar nach Hause zurück, ließen sich dort aber sofort von Georg von Frundsberg für einen neuen Zug nach Italien anwerben. ${ }^{387}$ Genau aus diesem Grund hatte Guicciardini einige Monate zuvor in einem Brief geschrieben, die berittenen Patrouillen sollten die Gefangenen nicht laufen lassen, sondern sie umbringen oder wenigstens einkerkern. ${ }^{388}$

So war das Land die meiste Zeit über voll von Soldaten, die mit oder ohne Hauptleute, in Kompanien oder verwildert in Gruppen, auf Befehl oder trotz ausdrücklicher Verbote auf und ab zogen. Auf diesen Zügen kam es zu allen Arten von Auswüchsen gegen die Bevölkerung. Diese wurden um so schlimmer, je mehr die Situation sich verselbständigte und die Soldaten eigenmächtig umherzogen. In der Folge soll auf die verschiedenen Formen von Übergriffen gegen die Landbevölkerung näher eingegangen werden.

\section{Auspressung der Bauern}

Die Verpflegung der durchziehenden Soldaten war, wie am Beispiel von Polpenazze gesehen, selbstverständlich. Sie trat in verschiedenen Varianten auf: entweder man verlangte Kontributionen, mit denen die Verpflegung dann bezahlt wurde, oder man ließ die Soldaten direkt beköstigen. Daneben wurden Lebensmittel auch immer wieder requiriert. Selbst bei diesen organisierten Formen der Versorgung aus dem Land wurde die Grenze zur Erpressung oft überschritten. So schrieb Rudolf von Anhalt im Mai 1510 nach Marostica bei Bassano, er habe mit den Hauptleuten entschieden, den Ort zur Plünderung freizugeben, sich

386 SANUTO, Diarii, Bd. 32, Sp. 258.

387 Gayangos, Calendar, Bd. 3, Teilbd. 1, S. 1001.

388 BERNARDI, GIOACCHINO (HRSG.): L'assedio di Milano del 1526 dappresso una corrispondenza inedita di Francesco Guicciardini, commissario generale del papa nell'esercito dei collegati. In: Archivio Storico Lombardo 23 (1896). S. 340. 
auf Bitten der Einwohner aber bereit erklärt, gegen die Zahlung von 3.000 Dukaten von diesem Vorhaben Abstand zu nehmen. Einen Monat später bedankte er sich in einem weiteren Schreiben für den Erhalt des Geldes und stellte dem Ort einen Schutzbrief aus. ${ }^{389}$

Was auf höchster Ebene recht war, konnte den Soldaten nur billig sein: in feindlichem Gebiet war das Plündern auf dem Marsch selbstverständlich, so selbstverständlich, dass der Chronist Leonardo Amaseo im August 1509 fast verwundert in seinem Tagebuch festhielt, die Landsknechte hätten auf ihrem Zug an diesem Tag nichts abgebrannt. ${ }^{390}$ Der anonyme Soldat aus dem kaiserlichen Heer berichtet von einem alläglichen Auszug aus Verona nach Montagnana im Juni 1513 in seinem Tagebuch in aller Beiläufigkeit, dass auf dem Weg wohl innerhalb eines Tages - 10 bis 12 Dörfer geplündert wurden. ${ }^{391}$ Neben den Plünderungen kam es auch zu mutwilligen Zerstörungen, und zwar nicht nur aus Vandalismus, sondern direkt auf Anordnung von oben, wie im September 1513, als in Bovolenta und Pieve di Sacco die Landhäuser der reichen Venezianer der Reihe nach in Flammen aufgingen. ${ }^{392}$ Damit nicht genug: in Sichtweite der Hauptstadt angekommen, begann man neben weiteren Plünderungen auch mit Massakern an der Bevölkerung, bei denen die Venezianer von den Glockentürmen der Stadt aus in ohnmächtiger Wut zusehen mussten. ${ }^{393}$ Der Tagebuchschreiber dagegen berichtet ungerührt, wie die Entscheidung im Kriegsrat fiel: "... feceno consejo li Signori la sera che fossi arso e brusato Mestre tutto e non far più presoni e menar a fil di spada. E nota che se levassimo la domenega da mattina da Mestre che fo adi 2 ottobrio e vegnissimo amazzando e brusando tutte ville ..." ${ }^{394}$ Auch im Krieg gegen Florenz wurden solche Methoden angewandt: Oranges schrieb vor dem Beginn der Belagerung an den Kaiser und schlug ihm drei Lösungen vor: die Belagerung der Hauptstadt, die Eroberung der anderen toskanischen Städte oder die Verwüstung des gesamten Umlandes. Der Vorteil der dritten Lösung, so Oranges, seien die geringen Kosten. ${ }^{395}$

In der besetzten Lombardei sah der Fall anders aus, das Plündern war hier grundsätzlich nicht gestattet. Dennoch gingen auch hier die Autoritäten nicht gerade mit gutem Beispiel voran: schon im November 1521 hatte man die Stadt Bergamo mit der größten Selbstverständlichkeit aufgefordert, Lebensmittel an das Heer zu liefern, andernfalls werde man einige Dörfer in deren Gebiet plündern und abbrennen. ${ }^{396}$ Die Übergriffe gegen die Landbe-

389 MANTESe, G. (HRSG.): La guerra di Cambrai a Marostica e nel Vicentino negli anni 1510-1512, secondo nuovi documenti ed una cronaca inedita del notaio Paolo Bellodo. In: Archivio Veneto, Serie 5, Bd. 78 (1966). S. 49ff.

390 CerUTI, ANTONIO (HRSG): Diarii Udinesi dall'anno 1508 al 1541 di Leonardo e Gregorio Amaseo e Gio. Antonio Azio. Monumenti Storici publicati dalla R. Deputazione Veneta di Storia Patria, Bd. 11. Serie 3, Cronache e Diarii, Bd. 2. Venedig 1884. S. 117.

391 JOPPI, Diario del campo tedesco, Bd. 35, S. 89.

392 Ballesteros-Gaibrois, ManUel: Ramón de Cardona. Colaborador del Rey Catolico en Italia. Madrid 1953. S. 58.

393 SANUTO, Diarii, Bd. 17, Sp. 118.

394 JOPPI, Diario del campo tedesco, Bd. 35, S. 101.

395 BARDI, Carlo V e l'assedio di Firenze, S. 61.

396 RAH Salazar y Castro, A/28, fol. $277^{\mathrm{r}}$. Sekretär des Markgrafen von Mantua an dessen Frau, 17. 11. 
völkerung von Seiten der Soldaten waren ansonsten vor allem eine Folge des Mangels an Disziplin und Zusammenhalt im Heer. Es begann damit, dass die im Land einquartierten Kompanien nicht in den Orten blieben, die ihnen von den Quartiermeistern zugewiesen worden waren. In den schlimmsten Fällen waren diese selbst in Übergriffe und Grenzverletzungen verwickelt. In einem Brief des genuesischen Dogen Antoniotto Adorno an den spanischen Botschafter Lope de Soria ist von 5 oder 6 spanischen Kompanien die Rede, die sich unter der Führung des Generalquartiermeisters Vargas und unter einem Vorwand $\mathrm{Zu}$ tritt zu genuesischem Gebiet verschafft hatten und dort die schlimmsten Ausschreitungen begingen. ${ }^{397}$ Das unkontrollierte Vagabundieren im Land war gängige Praxis. Im Juni 1523 zog eine Horde von 1.000 meuternden Soldaten durch die Markgrafschaft Montferrat. ${ }^{398}$ In dem Beschwerdeschreiben, das die Herzogin von Savoyen ihrem Botschafter im Juni 1524 mitgab, heißt es am Ende, wenn die Soldaten schon nicht aus ihrem Land abgezogen würden, so sollte wenigstens dafür gesorgt werden, dass sie nicht auf eigene Faust umherzögen. ${ }^{399}$ Und Antonio de Leyva selbst kamen gegen Ende der Besatzungszeit in der Lombardei 300 marodierende Spanier entgegen, die weiterzogen, ohne ihn auch nur anzuhören. Gleichzeitig verschwanden die Soldaten aus der Stadt, als würde die Erde sie verschlukken. ${ }^{400}$ Solche Züge dienten in der Regel nur einem Ziel: so viel Beute wie möglich zu machen. Wie wenig die umherziehenden Einheiten sich um die militärischen Notwendigkeiten kümmerten, zeigt am besten die Aussage eines venezianischen Informanten, der im April 1524 schrieb, die Spanier im Umland von Mailand ließen die Ausrüstung so weit im Land liegen, dass jeder sie mitnehmen könnte. ${ }^{401}$

Dass der Mangel an Disziplin zu gesteigerter Rücksichtslosigkeit gegen die Bevölkerung führte, war eine Regel, die keineswegs nur auf der untersten Stufe der militärischen Hierarchie galt: es waren immer wieder die Hauptleute, die Übergriffe nicht nur nicht verhindern, sondern selbst gezielt als Mittel zur Erpressung kleiner Ortschaften zur eigenen Bereicherung einsetzten. Die Schutzbriefe, die man gegen die Zahlung von Kontributionen erlangt hatte, waren in diesem Fall nicht das Papier wert, auf dem sie geschrieben standen. Im Mai 1527 beschwerten sich die Einwohner des Dorfes Casal della Rosetta über den kaiserlichen Hauptmann Matteo Beccaria, der seine Soldaten nicht nur trotz des Schutzbriefes dort einquartiert hatte, sondern auch ganz selbstverständlich Plünderung und Geiselnahme gestattet hatte. $^{402}$ Und Fabrizio Maramaldo - ein Name, der im Zusammenhang mit Raub und Erpressung im Verlauf des Krieges immer wieder fällt - kam im April 1526 mit drei Kompa-

1521.

397 RAH Salazar y Castro, A/35, fol. 266r ${ }^{\mathrm{r}}$. Antoniotto Adorno an Lope de Soria, Genua, 13. 9. 1525.

398 RAH Salazar y Castro, A/28, fol. 242r . Lope de Soria an den Kaiser, Genua, 13. 6. 1523. Ferner fol.

$296^{\mathrm{r}} \mathrm{f}$. Charles de Lannoy an den Kaiser, Neapel, 5. 7. 1523.

399 SEGRE, Documenti di storia sabauda, S. 169.

400 AGS Estado 1172, fol. 25. Antonio de Leyva an den Kaiser, ohne Datum.

401 SANUTO, Diarii, Bd. 36, Sp. 189.

402 ASM Sforzesco, Cart. 1424. 
nien italienischer Infanterie nach Castillole und kündigte die Einquartierung an. Als die Einwohner antworteten, sie seien als Untertanen des Herzogs von Savoyen von der Einquartierung ausgenommen, wurde Maramaldo wütend und drohte mit der Beschießung des Ortes. Schließlich musste Castillole sich für 1.000 Dukaten freikaufen. Maramaldo behauptete hinterher, er habe gar nicht gewusst, dass der Ort zum Herzogtum Savoyen gehörte. Hurtado de Mendoza, der von dem Zwischenfall berichtete, bemerkte am Schluss resignierend, dass man gegen solche Auswüchse kaum etwas unternehmen könne, da die Hauptleute selbst die schlimmsten Halunken seien. ${ }^{403}$ Zur gleichen Zeit waren weitere Kompanien in Piemont unterwegs, deren Hauptleute es noch nicht einmal für nötig hielten, Hurtado de Mendoza auf seine Aufforderung zu antworten, das Gebiet sofort zu verlassen. Zwar wurde dieser offensichtlich angewiesen, die Namen der Hauptleute festzustellen und sie verhaften $\mathrm{zu}$ lassen, ob das aber tatsächlich geschah, ist nicht bekannt. ${ }^{404}$ Maramaldo jedenfalls trieb weiter sein Unwesen. Im Juni 1526 fand er sich mit 800 Soldaten in Casalmaggiore wieder, die der Bevölkerung wie 10.000 vorkamen. ${ }^{405}$ Zuvor schon hatte er das Umland von Alessandria heimgesucht, dort wurde er zunächst von Pietro da Pusterla und dann von Ascanio Gonzaga abgelöst, der angeblich 160 Einwohner der Gegend zur Beschleunigung der Bezahlung von widerrechtlichen Abgaben ermorden ließ. ${ }^{406}$

Vor allem die italienischen Condottieri der leichten Kavallerie entzogen sich der Kontrolle der Autoritäten weitgehend, so sehr, dass die venezianischen Beamten aus Bergamo im April 1526 an die Regierung schrieben: "Cerca il numero de li cavalli non se intende per certo, perchè vanno et vengono, nè stanno mai fermi ad un loco." ${ }^{407}$ Auf dem Zug nach Rom wusste man noch nicht einmal bei der Führung, wie viele Reiter das Heer eigentlich zählte. ${ }^{408}$ Vor allem im Krieg um Florenz strömten solche Condottieri aus allen Ecken Italiens in der Toskana zusammen und begannen, das Land rücksichtslos auszupressen, ohne an der Belagerung der Hauptstadt überhaupt teilzunehmen. Auch Maramaldo war mit 3.000 Soldaten wieder mit von der Partie. ${ }^{409}$ Wie die Gegend nur ein Jahr darauf aussah, das schildert Benedetto Varchi mit folgenden Worten: "... non fu nè città nè castello nè borgo $o$ villaggio nessuno, nè così grande nè così piccolo e povero, il quale non fosse, e bene spesso più volte, o saccheggiato $\mathrm{o}$ in altri diversi modi crudelissimamente dannificato, e nessuna casa, non che palagio, rimasero o usci o finestre, portandosene via ora i nimici e quando gli

\footnotetext{
403 Gayangos, Calendar, Bd. 3, Teilbd. 1, S. 631.

404 RAH Salazar y Castro, A/39, fol. $220^{\mathrm{r}}$.

405 BONETTI, Cremona, S. 235.

406 Ghilini, GiROLAMO: Annali di Alessandria, overo le cose accadute in essa città, nel suo, e circonvicino territorio dall'anno dell'origine sua sino al M.DC.LIX. Mailand 1666. S. 134f.

407 SANUTO, Diarii, Bd. 42, Sp. 8f.

408 BALAN, Monumenta saeculi XVI, S. 424.

409 CAPPONI, GINO: Storia della Repubblica di Firenze. Bd. 2. Florenz 1875. S. 412.
} 
amici, non che altro gli arpioni e le campanelle confitte ne' muri, come infino a questo dì presente in moltissimi luoghi si può vedere." ${ }^{410}$

Neben den Übergriffen marschierender oder im Land einquartierter Heere gehörten Auszüge aus den besetzten Städten zum Alltag. Solche Auszüge waren bis zu einem gewissen Grad nötig, um Ressourcen zu beschaffen, die man in der Stadt nicht bekam, wie etwa Pferdefutter oder Brennholz. Sie arteten aber immer wieder in Plünderungen aus. Im besetzten Verona war es üblich, dass die Soldaten einmal in der Woche auszogen, um Heu und Stroh zu besorgen, was trotz eines ausdrücklichen Verbotes von den Soldaten zur Plünderung genutzt wurde, die Beute wurde danach ganz offen in der Stadt auf dem Markt verkauft. ${ }^{411}$ Im Mai 1513 brachte ein solcher Auszug ans Ufer des Gardasees angeblich 50.000 Dukaten ein, weil man den Montag abgepasst hatte, an dem der wöchentliche Markt abgehalten wurde. 100 Personen wurden dabei erschlagen oder ertranken im See, wie der Tagebuchschreiber nebenbei erwähnt. ${ }^{412}$ Das Land scheint zu dieser Zeit voll von umherziehenden und gut organisierten Gruppen von Plünderern gewesen sein, die nach einem gründlichen System vorgingen: der Tagebuchschreiber selbst zog im August 1513 aus Vicenza aus und erbeutete in Lonigo 500 Wagenladungen Getreide, die er noch am selben Tag nach Vicenza brachte. Zwei Tage später zog er abermals nach Lonigo und brachte noch einmal 300 Ladungen mit. Als er weitere zwei Tage später ein drittes Mal nach Lonigo aufbrechen wollte, erfuhr er, dass die Venezianer ihm zuvorgekommen waren und den Rest aufluden. Drei Plünderungen eines Ortes schienen seinen Vorgesetzten aber immer noch nicht zu genügen: weitere zwei Tage darauf schickten sie ihn ein viertes Mal nach Lonigo, er aber leitete den Zug nach Montecchio um, wo er 2.000 Säcke Getreide in einem zugeschütteten Graben fand. ${ }^{413}$ Gegen Ende der Besatzungszeit in Verona hatte die Situation sich so weit verselbständigt, dass die Auszüge täglich stattfanden. ${ }^{414}$

Daneben kam es auch auf dem Land zu Geiselnahmen wie bei normalen Plünderungen. Im September 1509 kamen zwei Spanier mit einem Ochsenkarren nach Vicenza, auf dem gefesselt fünf junge Frauen saßen, die auf dem Markt zum Verkauf angeboten und schließlich von einem frommen Mann aus Mitleid für 7 Dukaten gekauft und freigelassen wurden. ${ }^{415}$ Im Mai 1515 platzten spanische Soldaten in ein Tanzfest in Castelbaldo und verschleppten alle Mädchen. ${ }^{416}$ Im Jahr 1528 war es so weit, dass zwei Botschafter, die von der Stadt Como zu Antonio de Leyva geschickt worden waren, auf dem Weg von verwilderten Sol-

\footnotetext{
410 VARCHI, Storia Fiorentina, Bd. 2, S. 370.

411 ZAGATA, Cronica della città di Verona, Bd. 2, S. 127.

412 JOPPI, Diario del campo tedesco, Bd. 34, S. 151.

413 JopPI, Diario del campo tedesco, Bd. 35, S. 96 f.

414 ZaGATA, Cronica della città di Verona, Bd. 2, S. 186.

415 PORTO, Lettere storiche, S. 120.

416 SANUTO, Diarii, Bd. 20, Sp. 237.
} 
daten überfallen und nach Lodi verschleppt wurden. Der Stadt blieb nichts anderes übrig, als das Lösegeld zu bezahlen. ${ }^{417}$

Im Umland des besetzten Mailand sah es ganz ähnlich aus. Im November 1525 war den Soldaten das Verlassen der Stadt zur Beschaffung von Brennholz erlaubt worden, weil man die Vorräte der Hausbesitzer - und auch das Inventar der Häuser - schonen wollte. ${ }^{418}$ Diese Auszüge wurden von den Soldaten aber zu ausgedehnten Plünderungen missbraucht, so dass im April 1526 ein Verbot erlassen wurde, aus dem sich bezeichnende Einzelheiten über die Art solcher Raubzüge ergeben: unter Androhung der Todesstrafe wurde es den Soldaten untersagt, aus der Stadt auszuziehen, um im Umland Getreide zu ernten, Gras abzumähen, Zaunpfähle auszureißen, die Gatter der Weiden zu zerstören oder andere Schäden anzurichten. ${ }^{419}$ Da die Auszüge aber weitergingen und offenbar zu einer regelrechten kommerziellen Aktivität führten, wurde es den Mailändern im Juni 1526 verboten, von Soldaten Heu, Stroh oder Pferdefutter zu kaufen. ${ }^{420}$ Das Verbot - wenn es beachtet wurde - brachte es aber mit sich, dass die Soldaten sich wieder an den Vorräten der Hausbesitzer in der Stadt bedienten, so dass es bereits im August wieder außer Kraft gesetzt wurde. ${ }^{421}$

Lukrativer als Heu und Stroh war ohne Zweifel der Raub von Vieh. Um das Plünderungsverbot auf dem Land zu umgehen, gingen die Soldaten dazu über, von Bauern gestohlenes Vieh in der Stadt zu verkaufen und zu behaupten, sie hätten es den Feinden abgenommen. Dieses Verfahren riss offenbar derart ein, dass im August 1526 in Mailand ein Dekret erlassen wurde, das die Soldaten verpflichtete, beim Verkauf von Vieh in der Stadt zwei Zeugen für dessen Herkunft anzuführen. Vieh unbekannter Herkunft durfte von niemandem gekauft werden. ${ }^{422}$ Solche Verbote wurden aber schon bald gar nicht mehr beachtet, und de Leyva musste die Soldaten gewähren lassen, weil er nicht wusste, wie er sie sonst beim Heer halten konnte. ${ }^{423}$ So wurden Übergriffe aller Art gegen die Landbevölkerung immer mehr zu einer Selbstverständlichkeit, zu einem immer schwerer rückgängig zu machenden Schritt in Richtung auf eine Verselbständigung der Situation in besetzten und durchzogenen Gebieten. Schon im April 1524 lag der Staat Mailand wegen der ständigen Plünderungen da wie ein Kadaver: "Questo stato et per li varii pagamenti facti et per le ruine de le guerre durante tanto tempo et per le graveze quale sole portare lo exercito sustenute et che hora susteneno et per la crudelissima peste e como un corpo quasi morto et extincto et e grandissima compassione a vederlo et questo e la verita a la quale volendo satisfare et a la conscientia loro so certo che farrano et per lettere et a bocca ogniuno el medesimo testimonio."

417 Rovelli, Storia di Como, S. 464.

418 ASM Sforzesco, Cart. 1504, Dekret vom 20. 11. 1525.

419 ACM Registri di lettere ducali 19 , fol. $73^{r_{f}}$.

420 ASM Sforzesco, Cart. 1505, Dekret vom 30. 6. 1526.

421 ASM Sforzesco, Cart. 1505, Dekret vom 12. 8. 1526.

422 ASM Sforzesco, Cart. 1505, Dekret vom 23. 8. 1526.

423 CAPELla, Beschreibung und Geschicht, fol. $42^{\mathrm{r}}$.

424 RAH Salazar y Castro, A/34, fol. 254r ${ }^{\mathrm{r}}$. Caracciolo an den Kaiser, Mailand, 26. 4. 1524. 


\section{Gegenwehr und Vergeltung}

Die Übergriffe der Soldaten auf die Bauern blieben nicht unbeantwortet. Im Gegensatz zur Stadt, wo die Bevölkerung leichter zu kontrollieren war und sich gleichzeitig eine größere Zahl von Soldaten auf engem Raum konzentrierte, die bei Unruhen sofort einschreiten konnte, waren die Soldaten auf dem Land nicht selten der Gefahr von Überfällen durch bewaffnete Bauern ausgesetzt, wenn sie sich in zu kleine Gruppen aufspalteten. Nach solchen Überfällen kamen die Bauern zumeist ungestraft davon, weil sie das Gelände kannten und sich in alle Richtungen frei bewegen konnten. Und da es aussichtslos war, die Schuldigen einzeln zu verfolgen, schlossen sich an solche Überfälle häufig kollektive Vergeltungsmaßnahmen gegen Bewohner einzelner Dörfer an, die mit den Überfällen gar nichts zu tun hatten. Diese Vergeltungsmaßnahmen steigerten wiederum den Hass auf die Soldaten und die Bereitschaft zu weiteren Überfällen. Die Brutalität beider Seiten schaukelte sich immer weiter hoch und konnte in kurzer Zeit zu vollständiger Verrohung führen. Schon im August 1509 waren die kaiserlichen Soldaten und die Bauern der Gegend um Treviso und Mestre dazu übergegangen, sich gegenseitig die Geschlechtsteile abzuschneiden: "... alguni vilani del Tarvisano et Mistrino avevino per disprezo tajati li coglioni ad alguni Todeschi, et de qui è nasuda la crudeltà deli Todeschi, in modo che quanti vilani che capitano in man de Todeschi, li gli taglia lo cazo et li coioni ..." ${ }^{425}$ Als zur gleichen Zeit bei Vicenza zwei Landsknechte überfallen und ausgeraubt wurden, verschleppten die Soldaten die Einwohner von vier benachbarten Dörfern ins Lager bei Padua. ${ }^{426}$ Überfälle und Vergeltungsmaßnahmen häuften sich auch, als der Krieg die Terraferma vorübergehend verließ. Als Cardona nach der Niederlage von Ravenna den langen Rückweg nach Neapel antrat, folgten Schwärme von Bauern seinem Heer und stürzten sich auf versprengte Gruppen. Das Ziel war dabei weniger Vergeltung für begangene Untaten, als vielmehr die Ausplünderung der Soldaten. Pedro de Paz, der zu dieser Zeit mit seinen Begleitern bei Rimini eine Rast einlegte, wurde dabei Zeuge, wie einige Bauern einen anderen Spanier ausraubten. Als er einschreiten wollte, wurde er selbst angegriffen und schwer verletzt liegen gelassen. ${ }^{427}$ Und Antonio de Leyva schrieb im Juli 1512, schon auf dem Rückweg nach Norden, er habe alle Hände voll zu tun, seine Soldaten von Vergeltungsmaßnahmen gegen die Bewohner der durchzogenen Gebiete abzuhalten, weil diese nicht von den Überfällen abließen. ${ }^{428}$

So wie die Soldaten im Krieg gegen Venedig aufgefordert waren, das Land möglichst zu schädigen, so versuchten ihrerseits auch die Regierungen der durchzogenen Gebiete, die Bauern für militärische Zwecke einzuspannen: als Cardona im August 1512 in die Toskana eingefallen war, wurden die Bauern in der Umgebung von Prato durch einen Befehl der

25 CERUTI, Diarii Udinesi, S. 120.

426 GUERIN-DALLE MESE, Una cronaca vicentina, S. 171f.

427 ANONYM, Relación de los sucesos, S. 294f.

428 BNM, MS 18690, Nr. 33. Antonio de Leyva an Miguel Perez de Almaza, Pesaro, 25. 7. 1512. 
Regierung in Florenz aufgefordert, die Soldaten auszurauben und umzubringen, wo sie sie nur anträfen, die Beute sollten sie behalten dürfen. ${ }^{429}$ Kaum war Prato geplündert und die Regierung in Florenz ausgetauscht, stand man vor dem Problem, die Überfälle gegen die nunmehr verbündeten Spanier wieder einzudämmen. Diese waren nämlich ihrerseits schon dazu übergegangen, die Umgebung von Prato aus Rache für die Überfälle zu verwüsten. ${ }^{430}$ Einige Bauern vergifteten den Wein, bevor sie ihre Häuser verließen, so dass die Spanier gefangene Frauen zwangen, den Wein vorzukosten, den sie auf ihrem Weg durch das Land vorfanden. ${ }^{431}$ Die Überfälle gingen indes weiter. Am 4. September schrieb die neue Regierung an die Kommandanten der Festungen im Umland von Prato, es solle sofort mit den Angriffen auf umherstreifende Spanier aufgehört werden, da daraus nur noch mehr Gewalttätigkeiten resultierten. ${ }^{432}$ Nur eine Stunde später erging bereits das nächste Schreiben. Kaum hatte nämlich der erste Brief Florenz verlassen, da erfuhr man dort - ausgerechnet durch die Botschafter des Vizekönigs - dass ein weiterer Überfall stattgefunden hatte, dem 12 spanische Reiter zum Opfer gefallen waren. Solche Angriffe müssten sofort eingestellt werden, sonst drohten größte Schwierigkeiten. ${ }^{433}$ Doch noch am selben Tag wurde ein Spanier in Florenz selbst ausgeraubt, durch die ganze Stadt geschleift und in den Arno geworfen. ${ }^{434}$ Die Regierung hatte schließlich auch ein materielles Interesse an der Einstellung solcher Überfälle, denn Cardona richtete seine Schadensersatzforderungen direkt an sie. ${ }^{435}$ Mit dem Wiedereinzug in die Terraferma setzten sich die Überfälle genau wie die Vergeltungsmaßnahmen fort. Im August 1513 bedauerte Cardona in einem Brief an die venezianischen Militärs die Brandstiftungen und Morde, die seine Soldaten unter der Bevölkerung begangen hatten, betonte aber, dies sei nur eine Reaktion auf die ständigen Überfälle der Bauern. ${ }^{436}$ Einen Monat später drangen diese Bauern sogar in Vicenza ein und erschlugen die kranken Soldaten, Spanier und Deutsche, die dort gepflegt wurden. ${ }^{437}$ In erster Linie aber hatten sie es auch dort wieder auf Beute abgesehen. ${ }^{438}$

In der Lombardei waren solche Überfälle seltener. Das scheint unter anderem darauf zurückzuführen zu sein, dass die Spanier sich hier als neue Herren zu etablieren gedachten und daher viele Orte dauerhaft besetzt hielten, was die Bevölkerung besser unter Kontrolle hielt. Da die Übergriffe von Seiten der Soldaten auf dem Land aber nicht weniger häufig vorkamen, waren die Bauern um so eingeschüchterter. Auch in der ansonsten sehr ausführlichen Korrespondenz der Offiziere ist selten von diesem Problem die Rede. Allenfalls au-

\footnotetext{
429 GUASTI, Il sacco di Prato, Dispensa 178, S. $17 \mathrm{f}$.

430 LANDUCCI, Diario fiorentino, S. 326.

431 CADENAS Y Vicent, El saco de Prato, S. 61f.

432 GuASTI, Il sacco di Prato, Dispensa 178, S. $177 \mathrm{f}$.

433 GuASTI, Il sacco di Prato, Dispensa 178, S. 178.

434 LANDUCCI, Diario fiorentino, S. 326.

435 GUASTI, Il sacco di Prato, Dispensa 178, S. 185f., ferner S. 196.

436 SANUTO, Diarii, Bd. 16, Sp. 653.

437 SANUTO, Diarii, Bd. 18, Sp. 16.

438 SANUTO, Diarii, Bd. 18, Sp. 19.
} 
Berhalb des Staates, wie in Savoyen, oder in Zeiten, in denen den Spaniern die Kontrolle über den ganzen Staat zu entgleiten drohte, wurde es für die Soldaten wieder gefährlich: während der Aufstände in Mailand im April und im Juni 1526 begann um die Stadt eine regelrechte Menschenjagd. Im April waren die Bauern in Scharen von mehreren Hundert unterwegs, ${ }^{439}$ und als sich das Spektakel im Juni wiederholte, fielen ihnen innerhalb von drei Tagen 50 Soldaten zum Opfer, wie Hurtado de Mendoza berichtet. ${ }^{440}$ Die Vergeltungsmaßnahmen wurden mit aller Härte durchgeführt, wie etwa in Pau, einem kleinen Ort bei Lodi, in dem einige Spanier umgebracht wurden, woraufhin vier spanische Kompanien in das Dorf einrückten und alle Einwohner töteten, auch die Kinder. ${ }^{441}$ Derartige Gewaltexzesse und die Resignation über die Fortdauer des Krieges und die eigene Machtlosigkeit führten in den folgenden Jahren in der Lombardei dazu, dass die Landbevölkerung sich den Soldaten immer seltener entgegen stellte und immer öfter das Heil in der Flucht suchte.

\section{Verbindungswege}

Neben den vielen Gefahren für die Bewohner der betroffenen Gebiete führte der Krieg auch zu einer allgemeinen Einschränkung der Nachrichtenverbindungen und des Verkehrs überhaupt. Die Gefahr kam dabei von zwei Seiten: zum einen von den Soldaten, die abseits der Einquartierungsorte in Gruppen auf der Suche nach Beute umherstreiften, zum anderen von Wegelagerern, die von der unsicheren Gesamtlage und dem Verfall der zivilen Verwaltung profitierten. Dieser führte Hand in Hand mit der allgemeinen Verarmung viele Bauern in die Versuchung, sich als Straßenräuber zu versuchen. Capella berichtet von der immer weiteren Verbreitung des Wegelagerertums in der Lombardei im Verlauf des Krieges. ${ }^{42}$ So wurden die Wege immer unsicherer und viele Briefe endeten in den Straßengräben.

Der Nachrichtenverkehr war vor allem um Mailand eingeschränkt, weil die Spanier Angst vor Spionen hatten, die Nachrichten mit militärischem Inhalt zu ihren Gegnern bringen konnten. Wahrscheinlich aus diesem Grund musste der venezianische Botschafter im November 1525 die Stadt verlassen. ${ }^{443}$ In den Briefen der Offiziere wurden militärische Details fast immer verschlüsselt. Dennoch machten beide Seiten Jagd auf die Boten des Gegners, und so landete vor dem Rat in Venedig mancher Brief von Antonio de Leyva. Dieser versuchte natürlich, die Venezianer über seine wahre Stärke zu täuschen: im Beisein eines

439 SANUTO, Diarii, Bd. 41, Sp. 243.

440 RoDrigUeZ VILLA, Italia desde la battaglia di Pavia, S. 150.

441 SANUTO, Diarii, Bd. 41, Sp. 670.

442 CAPELLA, Beschreibung und Geschicht, fol. 39 .

443 Am 4. Dezember legte er in Venedig eine Art Abschlussbericht über die Einnahmen des Staates Mailand und die Zahl der gegnerischen Soldaten sowie eine kurze Charakterisierung ihrer Anführer vor. SANUTO, Diarii, Bd. 40, Sp. $422 \mathrm{f}$. 
abgefangenen venezianischen Kuriers ließ er im Juni 1529 die diesem abgenommenen Briefe verlesen, und als da an einer Stelle behauptet wurde, die Spanier verfügten in Mailand nur über 4.000 Soldaten, warf der Gouverneur ein, er habe das Dreifache, was maßlos übertrieben war. ${ }^{444}$ Die meisten der Boten versuchten, sich der Briefe im letzten Augenblick zu entledigen, wenn sie aufgegriffen wurden. Das gelang nicht immer: ein Kurier, der mit Briefen aus Mailand kam und diese beim Anblick der Spanier fortgeworfen hatte, wurde von ihnen in die Stadt verschleppt und so lange gefoltert, bis er die Stelle verriet, an der die Briefe lagen. ${ }^{445}$ Wieder ein anderer wurde von den Spaniern durchsucht, aber offenbar nicht als Kurier erkannt, denn nach seiner Freilassung barg er die Briefe und lieferte sie am Bestimmungsort ab. ${ }^{446}$

In Rom konnten die Kaiserlichen in den ersten Wochen kein Interesse an einer Unterbindung der Nachrichtenübermittlung haben, denn viele der Geiseln mussten an Verwandte und Freunde außerhalb schreiben, um die Lösegelder zusammenzubringen. In der Not der Gefangenschaft konnte ein solches Vorhaben allerdings sogar an so vordergründigen Dingen wie Papiermangel scheitern. ${ }^{447}$ Es sind zahlreiche Briefe von Opfern überliefert, die Übermittlung dauerte allerdings wegen der unsicheren Wege länger als gewöhnlich. Ein Brief von Antonio Tebaldeo an Pietro Bembo brauchte einen ganzen Monat von Rom nach Padua, ${ }^{448}$ und Marino Caracciolo klagte noch am 20. Juni in Mailand, es gebe seit der Eroberung von Rom keine gesicherten Nachrichten, sondern nur Gerüchte. ${ }^{449}$ Das Interesse an den Ereignissen in Rom war überall sehr hoch, nicht nur weil die Eroberung der Heiligen Stadt durch lutherische Soldbanden für die Zeitgenossen etwas Ungeheuerliches war, sondern auch, weil nicht wenige Verwandte und Freunde in Rom hatten, um deren Verbleib in den ersten Wochen viele Gerüchte kursierten. In Modena wurden einige totgesagt, von denen sich hinterher herausstellte, dass sie in der Engelsburg Zuflucht gefunden hatten und von dort aus zunächst nicht hatten schreiben können. ${ }^{450}$ Die vielen Berichte aus zweiter Hand sind daher vor allem interessant, was die Verbreitung der Nachrichten aus den besetzten Städten angeht und oft weniger wegen der Nachrichten selbst. Vieles wird zuerst gerüchteweise und oft völlig verdreht wiedergegeben, erfährt dann - wenn die Dichte der Nachrichten hoch genug ist - tägliche Korrekturen, um sich schließlich ungefähr bei den Tatsachen einzupendeln. In Rom ist den Nachrichten allerdings immer ein höherer Grad an Unzuverlässigkeit gemein, weil die spektakuläre Einnahme der Stadt und das Schicksal des Papstes und des illustren Kreises von Prälaten, Künstlern und Gelehrten dort von viel grö-

\footnotetext{
444 SANUTO, Diarii, Bd. 50, Sp. 435.

445 SANUTO, Diarii, Bd. 41, Sp. 62.

446 SANUTO, Diarii, Bd. 49, Sp. 452.

447 SANUTO, Diarii, Bd. 45, Sp. 238.

448 BemBO, PIETRO: Opere in volgare. Hrsg. v. Mario Marti. Florenz 1961. S. 797.

449 RAH Salazar y Castro, A/40, fol. 486V . Caracciolo an den Kaiser, Mailand, 20. 6. 1527.

450 BAnChi DetTo DE' Lancellotti, Tommasino DE': Cronaca Modenese. Parma 1862-1884. 12 Bde. Bd. 1-8 hrsg. v. C. Borghi. Bd. 9-12 hrsg. v. T. Lodi. Eintrag vom 5. Juni 1527.
} 
Berem öffentlichen Interesse war und daher mehr Spielraum und Anreiz zu Übertreibungen bot. Da die Nachrichten oft von Mund zu Mund gingen, kamen am Ende bisweilen haarsträubende Berichte heraus, die in ganz Europa kursierten und zum Teil in gedruckter Form verbreitet wurden. Ein glänzendes Beispiel für solche Missverständnisse liefert der Mailänder Chronist Burigozzo, als er kurz auf die Geschehnisse in Rom eingeht und berichtet, dort habe nun Prinz Angelo aus Bologna das Sagen. ${ }^{451}$ Ganz offensichtlich hatte er oder jemand anders in seiner Informationskette den Namen des Prinzen Philibert von Oranges dahingehend falsch verstanden, dass er aus "Oranges" den Vornamen "Angelo" gemacht hatte und aus der italienischen Bezeichnung für Burgund - Borgogna - die Stadt Bologna.

In Mailand schuf der andauernde Kriegszustand in der Lombardei eine andere Situation, zum einen wegen der oben angesprochenen militärischen Aktivitäten im Umland, zum anderen, weil es eben ein militärisches Interesse der Venezianer und Franzosen an der Situation in der Stadt gab. So schickten die Statthalter der venezianischen Regierung in den Grenzstädten Bergamo und Crema vor allem in den Jahren 1525 bis 1527 regelmäßig Spione in die Stadt, die sich dort umsahen und Bericht erstatteten. Danach trat das Interesse Venedigs an Mailand augenscheinlich immer weiter vor den Ereignissen in Rom und an der Türkengrenze in den Hintergrund. Aus der Zeit der regen Berichterstattung sind viele Hinweise über das Vorgehen der Spione in der Stadt überliefert. Da die Spanier sehr misstrauisch waren, musste man vorsichtig zu Werke gehen. Es gab regelrechte Doppelagententätigkeit: Spione betraten die Stadt unter dem Vorwand, Informationen über die Feinde zu bringen, sahen sich um und erstatteten ihren Auftraggebern Bericht. Manchmal kehrten sie auch unverrichteter Dinge zurück, wie ein Kundschafter des venezianischen Statthalters in Crema, der im Juli 1526 nicht mit seinem Kontaktmann sprechen konnte, weil dieser das ganze Haus voll mit spanischen Soldaten hatte. ${ }^{452}$

Die Spione waren oft einfache Leute, die sich mit ihrer Kundschaftertätigkeit ein Zubrot verdienten und im übrigen auch weniger Verdacht erregten. Der Statthalter in Crema schickte im Juli 1526 eine Bäuerin als Spionin nach Mailand, die sich dort unter dem Vorwand umsah, Lebensmittel in die Stadt zu bringen. ${ }^{453}$ Im März 1527 gelang es ihm dann, einen ehemaligen Hausverwalter des Palastes anzuwerben, in dem nun Antonio de Leyva residierte. ${ }^{454}$ Überhaupt war es immer am besten, wenn die Kundschafter in der Stadt Beziehungen hatten. Einem Offizier in venezianischen Diensten glückte es im September 1527, einen Spion im Haus eines Mailänders zu platzieren, der seinerseits mit einem Hauptmann der Landsknechte befreundet war und versprach, Informationen aus dem Kriegsrat der Kaiserlichen weiterzugeben. ${ }^{455}$ Die Spione lebten gefährlich, weil ihnen bei

451 Burigozzo, Cronaca di Milano, S. 469.

452 SANUTO, Diarii, Bd. 42, Sp. 21.

453 SANUTO, Diarii, Bd. 42, Sp. $166 \mathrm{f}$.

454 SANUTO, Diarii, Bd. 44, Sp. 226.

455 SANUTO, Diarii, Bd. 46, Sp. 41. 
Entdeckung die Todesstrafe drohte. So bemerkte wieder einmal der Statthalter in Crema, der in dieser Hinsicht aktivste Beamte der venezianischen Regierung, im Juli 1526 in einem Brief an diese lakonisch, er erwarte noch einen seiner Spione aus Mailand, und wenn dieser heute nicht mehr käme, werde man ihn wohl aufgehängt haben. ${ }^{456}$

So lange die Soldaten nicht vollständig verwildert waren, boten Geleitbriefe einen gewissen Schutz für alle, die auf dem Land unterwegs waren. Im Herzogtum Mailand florierte trotz der Feindschaft zwischen den Spaniern und dem Herzog Francesco Sforza der Kuhhandel um die Geleitbriefe, mit denen die Begünstigten - theoretisch - das von der Gegenseite kontrollierte Gebiet passieren konnten, ohne von deren Truppen behelligt zu werden. Geleitbriefe wurden förmlich mit Begründung beantragt und in der Regel - oft wohl gegen Zuwendungen - bewilligt. So stellte Antonio de Leyva im April 1527 einem gewissen Francesco Marescoto einen Geleitbrief für einen Kuraufenthalt in Bormio aus, ${ }^{457}$ und drei Tage später beantragte Jacopo Robio beim Sekretär des Herzogs Francesco Sforza einen Geleitbrief für eine Geschäftsreise, der sich auf ihn, einen Geschäftsfreund und zwei Diener für das von den Truppen des Herzogs kontrollierte Gebiet von Lodi erstrecken sollte. Gleichzeitig verkündete er, ohne einen solchen Geleitbrief die Reise nicht antreten zu können. ${ }^{458}$ Die Gefahr von Überfällen durch marodierende Soldaten und Wegelagerer konnte durch Geleitbriefe indes nicht gebannt werden.

In der Umgebung des besetzten Rom waren die Zustände noch schlimmer: wie gefährlich die Straßen waren, zeigt am besten die Geschichte von Dionysius de Jugurgonibus, der Ende November mit einigen Begleitern von Florenz aus aufbrach, um wichtige Briefe nach Rom zu bringen. In Civita Castellana warteten sie auf die angeforderten Geleitbriefe aus Rom, da rückten plötzlich spanische Kompanien an, um die Stadt zu besetzen. In der allgemeinen Aufregung wurden sie wohl von den Einwohnern für Feinde gehalten und eingekerkert, einer von ihnen wurde dabei misshandelt. Als sie wieder frei waren, schickten sie von Civita Castellana aus einen Boten mit den Briefen nach Rom, der aber kam schon bald wieder zurück, weil er von spanischen Soldaten überfallen und ausgeraubt worden war. Es wurde ein zweiter Bote geschickt, der ebenfalls ausgeraubt wurde. Ein dritter, dem sie das Doppelte geboten hatten, kam schließlich mit dem Antwortschreiben zurück. Als sie erfuhren, dass der Papst inzwischen nach Viterbo entkommen war, beschlossen sie, sich ebenfalls dorthin zu begeben und mieteten wegen der gefährlichen Straßen eine bewaffnete Begleitung bis nach Orte. Kaum hatten sie die Eskorte entlassen, da wurden sie von den Reitern eines Burgherren überfallen und in einen Turm verschleppt. Als sie ein Lösegeld von insgesamt über 300 Dukaten bezahlt hatten, wurden sie schließlich freigelassen, nachdem einer von ihnen geflohen war und ihre Peiniger es offensichtlich mit der Angst zu tun be-

456 SANUTO, Diarii, Bd. 42, Sp. 85 .

457 CANETTA, CARLO: I bagni di Bormio. In: Archivio Storico Lombardo 9 (1882). S. 723.

458 ASM Sforzesco 1424. Jacopo Robio an Francesco Sforza, Mailand, 9. 4. 1527. 
kommen hatten. ${ }^{459}$ Ähnliches erlebte der englische Sonderbotschafter William Knight. Er war unterwegs nach Rom, um für seinen König den Dispens für dessen Ehescheidung beim Papst zu erwirken. Aus Knights Briefen klingt heraus, dass die Reise immer gefährlicher wurde, je näher er der Stadt kam. In Monterotondo wurden er und seine Begleiter überfallen und um ein Haar erschlagen. In ihrer Unterkunft in Rom wimmelte es von spanischen Soldaten. Da es ihm nicht möglich war, den Papst zu treffen, ließ er ihm sein Anliegen schriftlich zukommen, in der Antwort riet ihm der Papst dringend, die Stadt zu verlassen, weil die Spanier von seiner Anwesenheit erfahren hätten. ${ }^{460}$ Später erfuhr Knight, dass das Haus, in dem er untergekommen war, nur einen Tag nach seiner Abreise bei einer Razzia von 200 Spaniern auf den Kopf gestellt worden war. ${ }^{461}$

Es gibt viele weitere Zeugnisse darüber, wie unsicher die Straßen zu dieser Zeit waren. Wer Rom verließ, wurde von Banden aus Bauern überfallen. ${ }^{462}$ Das widerfuhr unter anderem niemand Geringerem als Giovanni Bartolomeo Gattinara, der im Juli 1527 nach Parma und Piacenza unterwegs war, um die Städte zur Übergabe im Namen des Kaisers aufzufordern. ${ }^{463}$ Und Francesco Palmieri, Philosoph an der Sapienza, verschwand auf einer Reise zwischen Orvieto und Rom mit seinen Begleitern spurlos. ${ }^{464}$ Während die Straßen in der Umgebung von Rom vor allem eine Massenbewegung von der Stadt weg sahen, wurden in einigen Städten Gesandtschaften ausgerüstet, um das Schicksal der in Rom verschollenen Angehörigen zu erhellen. So machte sich keine zwei Wochen nach der Eroberung in Modena, offenbar im Auftrag der Angehörigen der Verschollenen, Agostino Scazera auf den Weg, um herauszufinden ob die Vermissten noch lebten. ${ }^{465}$ Einer von diesen, Antonin Colombo, schlug sich im Herbst von Rom aus in 30 Tagen nach Modena durch, wobei er die Nächte aus Angst im Freien verbrachte. Trotzdem wurde er überfallen. ${ }^{466}$

Um solchen Überfällen zu entgehen, reiste man nachts und auf abgelegenen Straßen, was die Reisezeiten natürlich erheblich verlängerte. So hielt es selbst der anonyme Tagebuchschreiber aus dem Krieg gegen Venedig im November 1512, als er in der Gegend von Brescia unterwegs war. ${ }^{467}$ Und ein Bote der Regierung in Siena kam im März 1527 als Bauer verkleidet im Lager des kaiserlichen Heeres vor Florenz an. ${ }^{468}$

459 LANCIANI, Storia degli scavi, S. 243f.

460 BREWER, J. S. (HRSG.): Letters and papers, foreign and domestic, of the reign of Henry VIII. preserved in the public record office, the British Museum and elsewhere in England. Bd. 4, Teilbd. 2. London 1872. Nr. 3638, S. 1633.

461 BREWER, Letters and papers, Nr. 3749, S. 1672.

462 BAV, MS Barb. Lat. 2799, fol. 129r.

463 RAH Salazar y Castro, A/43, fol. 25ํ. Lope de Soria an den Kaiser, Genua, 17. 7. 1527.

464 RENAZZI, Storia dell'università degli Studi di Roma, detta comunemente la Sapienza che contiene anche un saggio storico della letteratura romana dal principio del secolo XIII sino al declinare del secolo XVIII. Bd. 2. Rom 1804. S. 50.

465 BANCHI DETTO DE' LANCELLOTTI, Cronaca modenese, Eintrag vom 21. Mai 1527.

466 BANCHI DETTO DE' LANCELLOTTI, Cronaca modenese, Eintrag vom 15. Oktober 1527.

467 JOPPI, Diario del campo tedesco, Bd. 34, S. 138.

468 BALAN, Monumenta saeculi XVI, Bd. 1, S. 409. 


\section{Söldnerheere}

Das Leben der Soldaten war im Alltag geprägt von der Interaktion mit zwei verschiedenen Gruppen: mit der Bevölkerung der besetzten Orte und mit Angehörigen des Heeres aus der unmittelbaren Umgebung, also vor allem anderen Soldaten, aber auch Trossknechten, Frauen und Kindern. Dieser Alltag spielte sich zunächst in den engen Grenzen ab, die durch die Einquartierung in einem bestimmten Haushalt mit einer begrenzten Zahl von anderen Personen oder die langen Märsche auf dem Land vorgegeben waren, er war in der Regel hinreichend ausgefüllt mit der Befriedigung der Grundbedürfnisse, der Verrichtung der militärischen Pflichten und der mehr oder weniger derben Freizeitgestaltung. Die Gewichtung zwischen diesen drei Bereichen richtete sich nach der Versorgungslage und der militärischen Situation, zwei Faktoren, die sich ihrerseits gegenseitig beeinflussten.

Gleichzeitig waren die Soldaten Teil eines Apparates, der nach bestimmten Regeln funktionierte, Regeln, denen im Idealfall jeder der drei genannten Bereiche unterworfen war: für die Befriedigung der Grundbedürfnisse war die Soldzahlung oder das Abgabensystem vorgesehen, die militärischen Pflichten wurden von den Offizieren nach der aktuellen Notwendigkeit bestimmt und die Freizeitgestaltung blieb den Soldaten überlassen, war aber in zwei Richtungen eingeschränkt: die Erfüllung der militärischen Aufgaben durfte nicht gefährdet und die Bevölkerung nicht über das zumutbare Maß hinaus drangsaliert werden.

Tatsächlich aber geriet dieses System, 7das auf dem Grundprinzip allen Söldnerwesens Gehorsam gegen Bezahlung - beruhte, immer wieder aus dem Gleichgewicht. Übergriffe gegen die Bevölkerung häuften sich zu bestimmten Zeiten, gleichzeitig verweigerten die Soldaten den Weitermarsch, liefen kompanienweise zum Feind über oder desertierten mehr oder weniger offen. Mitunter kam es zu Ausschreitungen gegen die Offiziere, bei denen diese um Haaresbreite mit dem Leben davonkamen. Solche Zustände waren in Italien aus vergangenen Zeiten völlig unbekannt und wurden von den Zeitgenossen immer wieder als Beweis für den barbarischen Charakter der fremden Besatzer angeführt. Im Widerspruch dazu steht die Tatsache, dass das Verhalten der italienischen Kompanien, die den spanischen Heeren angegliedert waren, sich kaum von dem der Spanier und Deutschen unterschied. Die Ursache für die Störung des Gleichgewichts aus Gehorsam und Bezahlung lag vielmehr darin begründet, dass die Bezahlung als Bedingung des Gehorsams fast nie im versprochenen Maß geleistet wurde und mithin die Voraussetzungen für jede Form der Gehorsamsverweigerung die meiste Zeit über erfüllt waren: das Verhalten der Soldaten stellt in aller Regel eine Reaktion auf den ausbleibenden Sold dar. Die Systematik der Zusammenhänge zwischen den Soldrückständen und dem Stand der Disziplin wird im Folgenden beschrieben. 


\section{Söldnerwesen}

Mit dem Krieg bestritten die Soldaten ihren Lebensunterhalt. Wenn der Sold nicht gezahlt wurde, waren sie gezwungen, sich aus dem Land und damit auf Kosten der Bevölkerung zu ernähren. Es blieb aber in der Regel nicht dabei, dass man sich nur das Lebensnotwendige nahm: die Bereicherung durch Plünderung wurde zum obersten Ziel der meisten Soldaten, da es auf diese Weise unter Umständen wesentlich mehr zu verdienen gab als durch den abgemachten Sold. Der Traum, als reicher Mann nach Hause zurückzukehren, begleitete viele vom Augenblick der Anwerbung an auf ihrem Weg nach Italien, wenngleich er sich für die meisten nicht erfüllte. Die Hoffnung auf reiche Beute war für viele ein wichtigeres Motiv für den Aufbruch in den Krieg als der Sold. Es kam so weit, dass in den Heeren zahlreiche Soldaten und oft ganze Einheiten dienten, die in keiner Soldliste auftauchten und ausschließlich von der Plünderung lebten. Als der Herzog von Braunschweig im Mai 1528 nach Norditalien zog, folgten seinen 14.000 Landsknechten nicht weniger als 6.000 solcher Abenteurer. ${ }^{469}$ Dementsprechend benahmen sie sich auch: im August schrieb Lope de Soria an den Kaiser, Braunschweigs Soldaten seien das Schlimmste, was Italien je gesehen habe. Sie seien ausschließlich gekommen, um die Lombardei zu plündern und dächten gar nicht daran, nach Neapel gegen die Franzosen zu marschieren. ${ }^{470}$ Über die Italiener, die dem kaiserlichen Heer 1527 nach Rom gefolgt waren, schrieb Hernando de Alarcon, die meisten von ihnen seien nur wegen der Plünderung gekommen, denn sie profitierten ja kaum von den Soldzahlungen. ${ }^{471}$ Bei der Belagerung von Florenz im Jahr 1530 verweigerten acht spanische Kompanien, die nach Ungarn verlegt werden sollten, rundheraus den Abzug, weil der Fall der Stadt unmittelbar bevorstand und sie auf eine Plünderung spekulierten. ${ }^{472}$ Noch unverblümter und geradezu geschäftsmäßig taten die Spanier im Mai 1522 bei der Ankunft des Heeres vor Genua ihre Absichten kund: sie boten den Offizieren 50.000 Dukaten, wenn diese nicht um eine Übergabe verhandelten, sondern die Stadt stürmen ließen. ${ }^{473}$ Aus diesen Gründen war das Söldnerwesen an sich in Italien durchaus umstritten. Machiavelli fällte ein vernichtendes Urteil über die Söldnerheere, in denen sich seiner Meinung nach der Abschaum aller europäischen Gesellschaften wiederfand: "Se alcuni vi sono scandalosi, oziosi, senza freno, senza religione, fuggitisi dallo imperio del padre, bestemmiatori, giuocatori, in ogni parte male nutriti, sono quelli che vogliono militare." 474

War die Gier nach Beute an sich schon ein Grund für die instabile Disziplin, so wurde die Hemmschwelle für alle Spielarten von Gehorsamsverweigerung durch weitere Faktoren

\footnotetext{
469 Gayangos, Calendar, Bd. 3, Teilbd. 2, S. 686.

470 Gayangos, Calendar, Bd. 3, Teilbd. 2, S. 761.

471 RodrigueZ Villa, Memorias, S. 232.

472 CEREZEDA, Tratado, Bd. 1, S. 259.

473 PACHECO Y DE LEYVA, La política española, S. 301.

474 MACHIAVELLI, NiCCOLÒ: L'arte della guerra. Mailand 1928. S. 30.
} 
herabgesetzt, die mit dem Wesen der Söldnerheere zusammenhingen. Der Kriegsdienst gegen Bezahlung brachte es mit sich, dass die einzelnen Soldaten - vor allem die Deutschen und noch weniger die Italiener - sich kaum mit den Kriegszielen identifizierten, zu deren Erreichung man sie angeworben hatte. Verbündete des eigenen Kriegsherrn wurden in der Regel nicht geschont. Nach der Plünderung von Prato im Jahr 1512 musste Kardinal Giovanni de' Medici mit seinem Privatvermögen Parteigänger seiner Familie aus der Gewalt seiner eigenen Soldaten loskaufen. ${ }^{475}$ Die Auswüchse gegen die Anhänger des Kaisers bei der Plünderung von Rom sind hinreichend bekannt. Und im Umland der Stadt plünderten ausgelagerte Einheiten kurz darauf ungeniert die Besitzungen der Colonna, was die Beziehungen zwischen diesen und dem Kaiser zu belasten drohte. ${ }^{476}$ Das mangelnde Verständnis für die Winkelzüge der Diplomatie bewirkte eine zusätzliche Entfremdung von den Autoritäten, die es den Soldaten erleichterte, sich als Opfer blutleerer Mächte zu fühlen, denen man am Ende die Loyalität um so leichter entziehen konnte, als sie sich selbst niemals loyal erwiesen. Dem Deutschen Claus Seidensticker - immerhin selbst Hauptmann - legte Reissner einen bezeichnenden Satz in den Mund: "Die grossen Herren spielen underm Hütlin / machen Fried und Unfried wenn sie wöllen / und uns / die dem Keyser treuwlich gedienet / wil man all auff die Fleischbanck opffern." 477

Ausschreitungen der Soldaten wurden durch das Verhalten der Offiziere oft begünstigt. Zum einen fehlte es an Personen, die genügend Ansehen bei den Soldaten genossen, um die brüchige Disziplin auch dann noch wenigstens einigermaßen aufrecht zu erhalten, wenn über längere Zeiträume gar kein Geld mehr ausgezahlt werden konnte, zum anderen gingen viele Offiziere insoweit mit schlechtem Beispiel voran, als sie keinen Hehl daraus machten, dass auch sie in erster Linie an persönlicher Bereicherung interessiert waren. Vor allem in Rom hatte der Mangel an Personen mit Autorität geradezu groteske Auswirkungen. Nachdem Frundsberg durch einen Schlaganfall und Bourbon durch den tödlichen Schuss beim Angriff auf die Stadt ausgefallen waren, fühlte sich niemand den Soldaten gewachsen. Als der Kaiser vom Tod Bourbons erfuhr, ernannte er den Herzog von Ferrara zum Generalhauptmann, Philibert von Oranges sollte sein Stellvertreter sein. ${ }^{478}$ Dieser war zwar durch die Wahl der anderen Offiziere ohnehin zum Oberbefehlshaber in Rom aufgerückt, hatte aber Anfang Juli 1527 die Stadt verlassen, nachdem die Landsknechte seine Unterkunft geplündert hatten. Von Siena aus versuchte er, die Verantwortung abzuwälzen: er schrieb an den Herzog von Ferrara - der im übrigen im Begriff stand, ins Lager der Feinde des Kaisers zu wechseln - und forderte ihn auf, nach Rom zu kommen, um sein Amt wahrzunehmen, aber der Herzog antwortete mit einer Reihe von Ausflüchten. Gleichzeitig ließ Oran-

\footnotetext{
475 ASP, MS 2549, fol. 103, 117, 173.

476 OMONT, Les suites du sac de Rome, S. 30.

477 REISSNER, Historia, fol. 105V .

478 ROBERT, Philibert de Chalon, S. 93.
} 
ges den Kaiser durch einen Gesandten wissen, dass er das Kommando abgelehnt habe. ${ }^{479}$ Angeblich wurde der Vizekönig von Neapel Charles de Lannoy von den Soldaten favorisiert. In der Tat war dieser von Vertretern der Hauptleute und Soldaten im August mit der Bitte aufgesucht worden, das Kommando zu übernehmen, hatte sie aber zwei Wochen lang von Gaeta aus mit dem Vorwand hingehalten, er brauche zuerst genaue Aufstellungen über die Soldrückstände. Gleichzeitig bekniete er seinerseits Guasto, dieser aber lehnte mit der Begründung $\mathrm{ab}$, er habe eine solche Ehre nicht verdient. ${ }^{480}$ Hernando de Alarcon hatte schon vorher selbst an den Kaiser geschrieben, er sei zu alt und könne das Kommando aus gesundheitlichen Gründen nicht übernehmen. ${ }^{481}$ So blieb am Ende doch alles an Oranges hängen: noch im Dezember betonte er zwar die übergeordnete Stellung der anderen Offizie$\mathrm{re}^{482}$ und weigerte sich sogar, Befehle zu unterschreiben, ${ }^{483}$ doch am 18. Januar 1528, einen Monat vor dem Abzug aus Rom, schickte er dem Kaiser die Annahmeerklärung. ${ }^{484}$

Die Weigerung der Offiziere, Verantwortung zu übernehmen, war gleichzeitig eine Folge der mangelnden Disziplin im Heer wie auch eine ihrer Ursachen. Daneben trug das Verhalten vieler Offiziere nicht eben dazu bei, bei den Soldaten Verständnis für die Aussetzung der Soldzahlungen zu wecken. Die Liste der Verdächtigungen wegen Veruntreuung und ungebührlicher Bereicherung war lang und sorgte oft für eine Vergiftung des Klimas, die schizophrene Auswirkungen zeitigte: Empörung und Enttäuschung konnten sich gleichzeitig in einer Meuterei gegen die Offiziere und in einer Nachahmung von deren Verhalten bei der rücksichtslosen Ausplünderung der Bevölkerung entladen.

\section{Auszahlung des Soldes}

Der übliche Sold lag bei 3 Dukaten im Monat für die einfachen Soldaten, und zwar für Spanier, Deutsche und Italiener gleichermaßen. Die leichten Reiter bekamen 5 bis 6 Dukaten im Monat, die schweren 10 bis 12. Etwa einem Drittel der Infanterie standen Übersölde für besondere Ausrüstung - vor allem mit Feuerwaffen - oder für Ämter innerhalb der Kompanie zu, so dass diese Soldaten auf das Eineinhalbfache und manchmal sogar auf das Doppelte des Grundsoldes kamen. Je nach Rang vervielfachte sich der Sold dann um ein Beträchtliches, so bekamen die Fähnriche bei den Deutschen wie bei den Spaniern 15 und die Hauptleute 40 Dukaten im Monat. ${ }^{485}$ Der Grundsold der einfachen Soldaten von 3 Du-

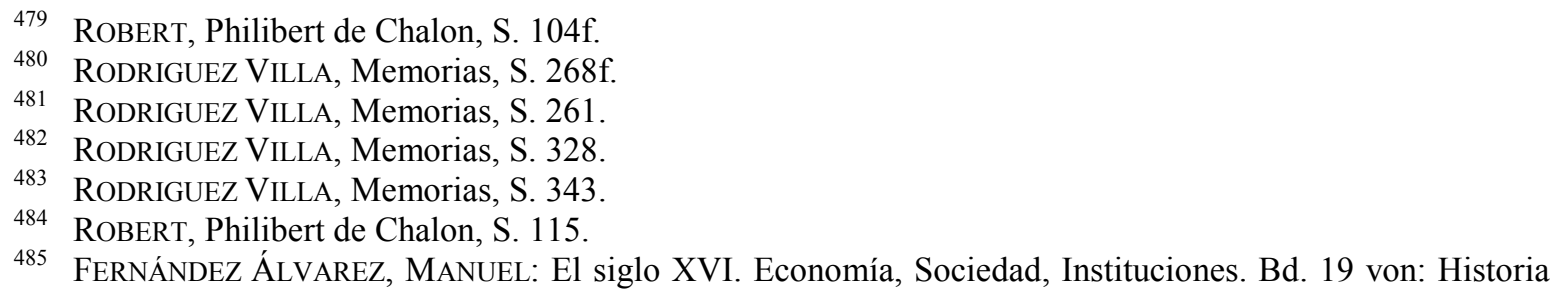


katen im Monat entsprach etwa dem Lohn eines Handwerksmeisters in Mailand, wie er im Juni 1525 von der zuständigen Behörde festgesetzt wurde, und immerhin dem Doppelten des Lohnes eines ungelernten Arbeiters ebendort. ${ }^{486}$ Um den Vergleich auf höherer Ebene fortzusetzen, könnte man etwa sagen, dass Hauptleute von ihren Einkünften her auf einer Stufe mit den bestbezahlten Professoren der Universität von Pavia standen. ${ }^{487}$

Es war üblich, einen Teil des Soldes in Ausrüstung, Lebensmitteln oder anderer Ware auszuzahlen. In der Lombardei griff man wegen der dort ansässigen Textilmanufaktur gern auf Stoffe zurück, worüber die Soldaten nicht immer erfreut waren. ${ }^{488}$ Frundsbergs Landsknechte wurden im Januar 1527 vor Parma mit einem Dukaten und einem Paar Schuhe zum Weitermarsch bewegt, ${ }^{489}$ und den Spaniern, die im April 1529 zur Verstärkung der Mailänder Besatzung in Genua eintrafen, zahlte man einen Monatssold in Kleidung und einen in Ausrüstung aus - und das war auch bitter nötig, wenn man den Zeugen glaubt, die fassungslos über den Zustand berichten, in dem diese Soldaten aus den Schiffen stolperten. ${ }^{490}$ Alle Übersölde eingerechnet, kostete ein Heer etwa fünf Dukaten pro Mann. Die Kosten des kaiserlichen Heeres in der Lombardei beliefen sich im Dezember 1523 mit den Besatzungen aller Städte und Festungen auf rund 87.000 Dukaten im Monat, ${ }^{491}$ kaum mehr als ein Jahr später, unmittelbar vor der Schlacht von Pavia, waren sie auf 130.000 Dukaten angewachsen. ${ }^{492}$ Das war eine enorme Summe, wenn man bedenkt, dass die Jahreseinkünfte des Herzogtums Mailand zu dieser Zeit vielleicht bei 350.000 Dukaten lagen. ${ }^{493}$ Mit anderen Worten: die gesamten Staatseinkünfte des Herzogtums aus einem Jahr hätten das kaiserliche Heer dort noch nicht einmal für drei Monate unterhalten können. Die Schulden den Kaisers in Spanien beliefen sich indes auf rund 2 Millionen Dukaten. ${ }^{494}$

Die Auswirkungen einer solchen Finanzlage werden nun am Beispiel des kaiserlichen Besatzungsheeres in Mailand und des Heeres von Bourbon und Frundsberg geschildert, das ja teilweise aus dem Mailänder Besatzungsheer hervorging und daher auch dessen Soldschulden partiell übernahm. Schon im Dezember 1524 erschien es Nájera, dem kaiserlichen Ge-

\footnotetext{
de España. Hrsg. v. José María Jover Zamora. Madrid 1989. S. 705.

486 ACM Dicasteri 221, fol. 54r .

487 SANTORO, CATERINA (HrSG.): Contributi alla storia dell'amministrazione sforzesca. In: Archivio Storico Lombardo, N. S. 4 (1939). Darin Dokument Nr. 4. Diese Zahlen sind zwar aus dem Jahr 1499, allerdings bemerkt die Autorin auf S. 37, dass sich an den Gehältern die ganze Zeit der Sforzaherzöge hindurch nichts änderte.

488 PACHECO Y DE LEYVA, La política española, S. 313; BNM, MS 20213²1, Nr. 45. Nájera an den Kaiser, Novara, 9. 4. 1524; SANUTO, Diarii, Bd. 39, Sp. 272.

489 BALAN, Monumenta saeculi XVI, S. 380.

490 SANUTO, Diarii, Bd. 50, Sp. 169. GaYANGOs, Calendar, Bd. 3, Teilbd. 2, S. 986.

491 PACHECO Y DE LEYVA, La política española, S. 487.

492 Baumgarten, HermanN: Geschichte Karls V. Bd. 2. Stuttgart 1888. S. 378.

4931521 lagen sie bei 385.000 Dukaten und fielen bis 1525 mehr oder weniger kontinuierlich auf etwa 300.000 Dukaten ab. SEGARIZZI, Relazioni, Bd. 2, S. 42; RAH Salazar y Castro, A/36, fol. 273 r $\mathrm{r}$; SANUTO, Diarii, Bd. 40, Sp. 423.

494 LEVA, Storia documentata, Bd. 2, S. 330.
} 
neralkommissar beim Heer, offenbar wahrscheinlicher, dass das Geld zur Bezahlung seiner Landsknechte vom Himmel regnete, als dass es denn vom Kaiser aus Spanien käme: wenn Gott kein Geld schicke, so der Abt, müsse man innerhalb weniger Wochen eine Entscheidung in der Schlacht suchen. ${ }^{495}$ In der Tat waren die Schulden bereits zu diesem Zeitpunkt erdrückend, wie aus einer detaillierten Aufstellung hervorgeht: demnach beliefen sich die Rückstände auf 970.000 Dukaten, wobei die Kavallerie die Liste mit bis zu 10 Monaten anführte, gefolgt von deutscher und spanischer Infanterie, denen man 6 Monate schuldete. Die italienische Infanterie schnitt am besten ab: ihr schuldete man lediglich 4 Monate. ${ }^{496}$ Doch trotz des Erfolges von Pavia am 24. Februar 1525 und der lukrativen Gefangennahme des französischen Königs und zahlreicher schwerreicher Adliger waren die kaiserlichen Offiziere nicht in der Lage, die Soldschulden zu begleichen, die sich über einen längeren Zeitraum hinweg angesammelt hatten. Vom Kaiser und den verbündeten Mächten kamen 400.000 Dukaten, danach stockten die Zahlungen aufs Neue. ${ }^{497}$ Einen Monat nach der Schlacht schrieb Lannoy folgerichtig, er schulde dem Heer 600.000 Dukaten. ${ }^{498}$ Das war in der Tat eine sehr schlechte Ausgangssituation, denn das Heer lag tatenlos im Land und die Schulden stauten sich weiter. Es ist mühselig, die Entwicklung der Soldrückstände in den folgenden Monaten zu verfolgen, da oft für mehrere Monate gar kein Material existiert und die Zahlen sich ansonsten ständig widersprechen. So schrieb der venezianische Botschafter in Mailand im Dezember 1525 an seine Regierung, die Landsknechte würden regelmäßig alle 30 Tage bezahlt, den schweren Reitern aber schulde man 18 Monate Sold. ${ }^{499}$ Dieser Rückstand wurde von Nájera drei Tage später auf lediglich 4 Monate beziffert. ${ }^{500}$ Von den Gründen für solche Diskrepanzen wird noch die Rede sein, zunächst zurück zu den Besatzern in Mailand.

Hier hatte der Einmarsch des Markgrafen von Pescara mit dem gesamten Heer im November 1525 eine neue Situation geschaffen, über die sich aus der Korrespondenz zwischen den Offizieren und dem Kaiser interessante Erkenntnisse ergeben. Der Konflikt mit dem Herzog Francesco Sforza hätte die finanzielle Lage eigentlich erheblich verbessern müssen, und das aus zwei Gründen: erstens konnte Pescara durch die Übernahme der Regierungsgewalt die Staatsfinanzen kontrollieren und direkt in die Kriegskasse umleiten, und zweitens hatte er durch die Besatzung die Möglichkeit, Kontributionen in beliebiger Höhe aus der Bevölkerung zu pressen, ohne Rücksicht auf den Verbündeten nehmen zu müssen. Dennoch trat eine Verbesserung der finanziellen Lage nicht ein, sondern das Gegenteil: die Kontributionen trafen auf den erbitterten Widerstand der Bevölkerung, konnten nur schlep-

\footnotetext{
495 BNM, MS 2021321, Nr. 59. Nájera an den Kaiser, Cremona, 23. 12. 1524.

496 QUATREFAGES, La Revolución militar moderna, S. 284ff.

497 QUATREFAGES, La Revolución militar moderna, S. 286.

498 HALKIN, LÉOn E./DANSAERT, GeORGES: Charles de Lannoy, Vice-Roi de Naples. Brüssel 1934. S. 78.

499 SANUTO, Diarii, Bd. 40, Sp. 423.

500 Gayangos, Calendar, Bd. 3, Teilbd. 1, S. 515.
} 
pend eingetrieben werden und brachten lediglich einen geringen Teil des erhofften Geldes ein, weil die meisten Bewohner die besetzten Städte verließen. Dadurch fiel die Wirtschaft auf einen Bruchteil ihrer eigentlichen Kapazitäten zurück, was wiederum die Staatseinnahmen verringerte - ohnehin hatte man vom Herzog einen Berg von Schulden bei verschiedenen Bankiers übernommen, die jedes Jahr mit 50.000 Dukaten allein an Zinsen zu Buch schlugen. ${ }^{501}$ Zusammenfassend lässt sich sagen, dass weder die Kontributionen noch die Staatseinnahmen die davongaloppierenden Soldrückstände auch nur annähernd ausgleichen konnten. So war man gezwungen, Schulden zu immer ungünstigeren Konditionen zu machen, bis auch diese Möglichkeit sich erschöpfte: schon Mitte Dezember 1525 schrieb Nájera, niemand gäbe ihm mehr Kredite, ${ }^{502}$ und als Hugo de Moncada einige Tage später mit 60.000 Dukaten in Mailand eintraf, waren 58.000 davon schon im Voraus ausgegeben. ${ }^{503}$ Die Lage wurde im Lauf des Jahres 1526 immer aussichtsloser. Der Kreditverkehr wurde vor allem über Genua abgewickelt, aber auch dort war bald nichts mehr zu holen, ebensowenig in Venedig. Im Januar 1526 versuchte Nájera ein weiteres Mal, 60.000 Dukaten in Genua aufzutreiben, aber die Bankiers verlangten die Tilgung der alten Schulden und boten schließlich noch einmal 10.000 an. ${ }^{504}$ So wurde um immer geringere Beträge gekämpft, während die Soldschulden trotz der Verkleinerung des Heeres immer noch bei 600.000 Dukaten lagen und jeden Monat allein für die Infanterie um 60.000 Dukaten anwuchsen. ${ }^{505}$ Sicherheiten gab es ohnehin keine mehr: die Einnahmen aus dem Herzogtum Mailand waren schon im November 1525 teilweise bis zum Jahr 1527 im Voraus verpfändet worden. Eine detaillierte Aufstellung aller Gelder, die man zwischen Mitte November 1525 und Ende Februar 1526 eingenommen hatte, spricht eine beredte Sprache über die Mühe, mit der das Geld zusammengekratzt wurde: kaum ein Posten beinhaltet reguläre Einnahmen, es handelt sich vor allem um Kredite und Vorschüsse, ferner um alte Steuerschulden und angeblich betrügerisch zurückgehaltene Einnahmen der Zollbehörden in Mailand, und schließlich um Gelder für die Aufhebung der Einquartierung von Soldaten. ${ }^{506}$ Die Zölle in Mailand waren derweil in der Hand von ortsansässigen Kaufleuten, die in Cremona hatte ein venezianischer Bankier gepachtet. ${ }^{507}$ Im Juni 1526 traten solche Probleme dann vorübergehend in den Hintergrund, da nach der Niederschlagung des zweiten Aufstandes in Mailand die Soldaten in der Stadt vollständig auf Kosten der Bevölkerung lebten. In den Briefen Nájeras und der anderen kaiserlichen Amtsträger ist vorübergehend kaum noch von Geldbeschaffungsproblemen die Rede, obwohl diese zweifellos bestanden. Als

501 RAH Salazar y Castro A/36, fol. 273 ${ }^{\mathrm{r}}$. Aufstellung über die Finanzlage im Herzogtum Mailand.

502 Gayangos, Calendar, Bd. 3, Teilbd. 1, S. 519.

503 GaYangos, Calendar, Bd. 3, Teilbd. 1, S. 534.

504 GaYAngos, Calendar, Bd. 3, Teilbd. 1, S. 557.

505 Gayangos, Calendar, Bd. 3, Teilbd. 1, S. 599.

506 RAH Salazar y Castro, A/36, fol. $276^{\mathrm{r}}-280^{\mathrm{V}}$. Es schließt sich eine Aufstellung der Ausgaben an.

507 Gayangos, Calendar, Bd. 3, Teilbd. 1, S. 570. 
Bourbon Anfang Juli in Mailand eintraf, brachte er Wechsel für 100.000 Dukaten mit, von denen 75.000 zur Tilgung von alten Schulden gleich in den Taschen der genuesischen Bankiers verblieben, bei denen das Geld angewiesen war. ${ }^{508}$

Die folgenden Monate sind gekennzeichnet von den Kriegsvorbereitungen gegen die im Mai geschlossene Liga von Cognac. Fast scheint es, als hätte man in der Frage der Bezahlung resigniert - die Folgen waren allerdings verheerend, denn je klarer den Soldaten wurde, dass sie das ihnen zustehende Geld niemals bekommen würden, desto weniger fühlten sie sich an die Regeln gebunden, die willkürliche Gewaltakte gegen die Bevölkerung und Revolten gegen ihre eigenen Autoritäten verboten. Die Kriegsmaschinerie lief indes auch ohne Bezahlung irgendwie weiter. Und in der Tat: parallel kann man die Entwicklung der Soldrückstände verfolgen, die zwar, wie gesagt, von stark abweichenden Zahlenangaben durchzogen ist, aber für die spanische und deutsche Infanterie immerhin einen roten Faden erkennen lässt. Die Widersprüche in den Quellen lassen sich aus vier Faktoren erklären:

1. Bisweilen werden Forderungen der Soldaten mit den tatsächlichen Rückständen verwechselt - sie lagen in der Regel allerdings nicht etwa über den korrekten Beträgen, sondern blieben hinter diesen zurück, was deutlich zeigt, dass die Soldaten sich von vorn herein über den Kompromisscharakter ihrer Forderungen und über die Unmöglichkeit, die vollen Rückstände auszuzahlen, im Klaren waren.

2. Es ist schwer zu sagen, wann ein Anspruch verfiel - womit nicht etwa gemeint ist, dass er rechtlich verfiel, sondern wann er so weit zurücklag, dass die Unmöglichkeit, ihn angesichts der in der Zwischenzeit hinzugekommenen Rückstände noch einzuklagen, offensichtlich geworden war.

3. Der Stand der Bezahlung konnte sich von einer Kompanie zur anderen unterscheiden, vor allem zwischen Kavallerie und Infanterie und zwischen den einzelnen Nationen waren die Unterschiede immens.

4. Man war sich uneinig darüber, wie die Zeit zu verrechnen war, in der die Soldaten auf Kosten der Bevölkerung gelebt hatten.

Es präsentiert sich nun folgendes Bild: die Rückstände bei der spanischen Infanterie in Mailand stauten sich auch in der zweiten Jahreshälfte 1526 weiter an, während man gleichzeitig die Deutschen besser und die Kavallerie schlechter bezahlte. Die Soldschulden bei den Spaniern beliefen sich nach den vorsichtigsten Schätzungen im Augenblick des Abzugs von Mailand im Frühjahr 1527 auf mindestens 7 Monate. ${ }^{509}$ Plausibler ist allerdings die krassere Variante: drei revoltierende spanische Kompanien in Monza bezifferten den ihnen

508 Bucholtz, Franz-Bernhard vOn: Geschichte der Regierung Ferdinand des Ersten. Bd. 3. Wien 1832. S. 37.

509 ASM Sforzesco, Cart. 1359. 
geschuldeten Sold schon im Juni 1526 auf 13 Monate, ${ }^{510}$ das deckt sich mit den Berichten des venezianischen Statthalters in Crema, der die Rückstände im Dezember mit 19 Monaten angab, von denen dann zwei ausgezahlt wurden, ${ }^{511}$ und weiterhin mit der Aussage des spanischen Botschafters in Venedig, Alonso Sanchez, der im März 1527 ganze 20 Monate Soldschulden nannte. ${ }^{512}$ Auf dem Weg nach Rom wurde dann fast gar nichts mehr ausgezahlt. Die Landsknechte Frundsbergs, die zu den Spaniern stießen, begannen den Weg im Januar mit zwei Monaten Rückstand. Vom Augenblick des Zusammentreffens an geraten die Zahlen deshalb wieder verstärkt in Widerspruch zueinander. Mehrere Angebote des Papstes, das Heer gegen die Zahlung eines Teils der Soldrückstände zur Umkehr in die Lombardei zu bewegen, wurden von Bourbon ausgeschlagen und mit höheren Forderungen beantwortet. Das ermüdende Spiel der wechselseitigen Forderungen und Angebote vor und nach der Eroberung Roms ist von vielen Autoren ausführlich beschrieben worden, ohne dass die zumeist zusammenhanglos wiedergegebenen Zahlen eine Aussage über den tatsächlichen Stand der Bezahlung machen könnten. Tatsache ist, dass die 400.000 Dukaten, die zu zahlen der Papst sich nach der Eroberung von Rom im ersten Vertrag vom 6. Juni 1527 verpflichtete, und die von allen Autoren mit einigem Recht als eine spektakulär hohe Summe angesehen wurden, dennoch nicht ausreichen konnten, um die Rückstände zu dekken. Das wird deutlich, wenn man sich die Mühe macht, die wenigen gesicherten Zahlen zusammenzurechnen: das Heer wird mindestens die 100.000 Dukaten im Monat gekostet haben $^{513}$ und war im Januar 1527 - zumindest aus der Sicht der Spanier - mit beträchtlichen Rückständen aufgebrochen. Natürlich hatte jeder einzelne Soldat bei der Plünderung dann hinreichend Gelegenheit gehabt, sich zu bereichern. Das stand bei den Verhandlungen um die Bezahlung aber nie zur Debatte. Es gibt Anzeichen, die darauf hindeuten, dass die Spanier auf dem Weg nach Rom auf einen Teil des ihnen geschuldeten Soldes verzichteten. Nájera - und er war der erste, der über den Stand der Bezahlung hätte informiert sein müssen - schrieb Ende März 1527 an den Kaiser, die Spanier hätten bei einem Aufruhr alle geschuldeten Gelder verlangt, nämlich 150.000 Dukaten. ${ }^{514}$ Geht man von 5.000 Spaniern aus, kommt man auf 25.000 Dukaten monatlich für die spanische Infanterie und damit auf einen Soldrückstand von nur 6 Monaten. Das wiederum deckt sich mit der Aussage Gumpenbergs, den Soldaten in Rom schulde man im Mai 9 Monate Zahlung ${ }^{515}$ - was 225.000 Dukaten entspräche. Zu diesem Zeitpunkt lagen die Soldschulden der Deutschen bei mindestens 5 Monaten oder 300.000 Dukaten. Wenn man noch 3.000 bezahlte Italiener dazu-

\footnotetext{
510 SANUTO, Diarii, Bd. 41, Sp. 617.

511 SANUTO, Diarii, Bd. 43, Sp. 556.

512 Rodriguez ViLla, Memorias, S. 74.

513 Nach der im Eingang des Kapitels beschriebenen Aufschlüsselung: 12.000 Landsknechte für 60.000 Dukaten, 5.000 Spanier für 25.000 Dukaten, mindestens 3.000 bezahlte Italiener für 15.000, dazu noch die Kavallerie und weitere Kosten für Artillerie und Munition.

514 Gayangos, Calendar, Bd. 3, Teilbd. 2, S. 132.

515 GregoroviUs, Ein deutscher Bericht, S. 360.
} 
rechnet und bei ihnen einen Rückstand von 5 Monaten, also 75.000 Dukaten annimmt, ergeben sich ohne die Kavallerie 600.000 Dukaten Soldrückstand für das gesamte Heer nach dem Einzug in Rom - oder, genauer gesagt, für den Teil des Heeres, der in den Soldlisten vermerkt war. Dazu kam noch, dass vor Ablauf des Monats ein weiteres Heer in Rom einrückte, nämlich die 10.000 Mann des Vizekönigs von Neapel, und schließlich noch die vorwiegend aus Bauern rekrutierten Soldaten der Colonna. Inwieweit das neapolitanische Heer bei den Forderungen an den Papst mit einbezogen wurde und ob die Soldaten der Colonna überhaupt Sold bezogen, ist nicht klar - mit Sicherheit aber verstärkten sie den Druck auf den Papst bei den Verhandlungen.

Clemens hatte sich im Vertrag verpflichtet, 100.000 Dukaten sofort, 50.000 innerhalb von 20 Tagen und die restlichen 250.000 in zwei Monaten zu bezahlen. ${ }^{516}$ Bis Ende Juni bezahlte er 80.000 statt der im Vertrag geforderten 150.000 Dukaten. ${ }^{517}$ Diese waren offenbar für die Deutschen vorgesehen und wurden auch an diese ausgezahlt; die Spanier gingen leer aus. ${ }^{518}$ Danach kam zunächst scheinbar fast nichts mehr vom Papst. Im Sommer zog das Heer aus der Stadt aus, und Anfang September forderten die Landsknechte vom Vizekönig immer noch den Rest der 150.000 Dukaten, die bis Ende Juni hätten bezahlt werden müssen, die restlichen 250.000, die Ende August fällig gewesen wären, fehlten ganz. ${ }^{519}$ Den Spaniern waren im August 50.000 Dukaten ausgezahlt worden, möglicherweise aus Geldern des Papstes. ${ }^{520}$ Dessen Bankiers waren indessen zahlungsunfähig, ${ }^{521}$ und von da an waren alle weiteren Verhandlungen nur noch Schadensbegrenzung. Anfang November war immer noch kein einziger Dukaten der 250.000 bezahlt. ${ }^{522}$ Die massive Bedrohung der päpstlichen Geiseln durch die Landsknechte führte zu einem neuen Vertrag mit dem Papst am 26. November 1527, in dem Clemens insgesamt 368.000 Dukaten zusagte, davon 73.000 innerhalb von 10 Tagen, woraufhin er laut Vertrag freigelassen werden sollte. ${ }^{523}$ Am Vorabend des zehnten Tages nach der Unterzeichnung aber floh der Papst verkleidet aus Rom und begab sich nach Orvieto.

Seit dem ersten Vertrag waren fast 6 Monate vergangen, und die Rückstände waren weiter angewachsen - wie weit, scheint schwierig zu errechnen, weil inzwischen viele Soldaten an

516 Vertrag in Latein und Deutsch bei REISSNER, Historia, fol. $132^{\mathrm{r}}-138^{\mathrm{r}}$.

517 ROBERT, Philibert de Chalon, S. 85.

518 GUICCIARDINI, FRANCESCO: Opere inedite. Bd. 9: La prigionia di Clemente VII, la caduta della Repubblica Fiorentina e la legazione di Bologna. Carteggio dal 1527 al 1534. Hrsg. v. Piero und Luigi Guicciardini. Florenz 1866. S. 107. Die ersten 100.000 Dukaten waren für die Deutschen vorgesehen und die folgenden 50.000 für die Spanier, was zumindest von der Relation her ja auch gerecht erscheint, da doppelt soviele Deutsche wie Spanier dabei waren. Als aber die ersten 80.000 an die Deutschen bezahlt waren, hatten die Spanier von ihren 50.000 noch nichts gesehen. LUZIO, Isabella d'Este, S. 132.

519 Gayangos, Calendar, Bd. 3, Teilbd. 2, S. 359.

520 RoDrigueZ Villa, Memorias, S. 272f.

521 Rodriguez ViLla, Memorias, S. 260.

522 RodrigueZ Villa, Memorias, S. 304.

523 Molini, GIUSEPPE (HrSG.): Documenti di storia italiana copiati su gli originali autentici e per lo più autografi esistenti in Parigi. 2 Bde. Florenz 1836-1837. Bd. 1, S. 273-278. 
der Epidemie gestorben oder desertiert waren. Indes gibt es präzise Hinweise: so berichtete Perez Ende November an den Kaiser, dass die Deutschen 21/2 Zahlungen, also 85.000 Dukaten verlangten. ${ }^{524}$ Demnach betrug eine Zahlung zu diesem Zeitpunkt 34.000 Dukaten, nach dem oben stehenden Schlüssel belief sich die Zahl der Deutschen also auf 6.800 Soldaten - vielleicht etwas mehr, denn die Offiziere werden zu diesem Zeitpunkt wegen der brenzligen Stimmung nicht allzu laut nach Sold verlangt haben, der Schnitt war also leicht gesenkt. Das passt wiederum verblüffend gut zu zwei weiteren Tatsachen:

1. Einem Bericht von Perez zufolge kam es einen Tag nach dem Vertragsabschluss zu schweren Ausschreitungen, weil statt der angeblich versprochenen 91/2 Dukaten pro Mann an die Deutschen nur 3 ausgezahlt worden waren, obwohl doch der Zahlungstermin noch gar nicht verstrichen war, wie Perez bemerkt. ${ }^{525}$ Teilt man die 73.000 am Vortag versprochenen Dukaten des Papstes durch die 91/2 Dukaten, ergibt sich ziemlich genau die Zahl der verbliebenen deutschen Soldaten. Bei dem noch nicht verstrichenen Termin kann es sich nur um den im Vertrag festgesetzten zehnten Tag nach der Unterzeichnung handeln. So liegt die Vermutung nahe, dass der Papst von den 368.000 Dukaten des zweiten Vertrages vor seiner Flucht nur wenig mehr als 20.000 bezahlte, was gerade einen Monatssold der zu dieser Zeit noch anwesenden Deutschen ausmachte. Und wieder einmal waren die Spanier offenbar leer ausgegangen.

2. Nach einem weiteren Bericht von Perez aus dem Januar 1528 bezifferten die Deutschen - auf einer Versammlung noch 6.000 Köpfe stark - ihre gesamten Rückstände auf 347.000 Dukaten. ${ }^{526}$ Das ergibt knapp zwölf Monate Zahlung und fügt sich in das Bild, nach dem seit dem Aufbruch im Januar 1527 - als man den Deutschen schon zwei Monate schuldete - kaum noch ein Monatssold vollständig ausgezahlt worden war.

Der Papst hatte also offenbar nur etwa 20.000 der im zweiten Vertrag verlangten 368.000 bezahlt. Für weitere 35.000, so stand es dort, hätte das Heer aus Rom abziehen müssen. Von einer weiteren Zahlung des Papstes ist aber in keinem der Dokumente die Rede. Als das Heer im Februar 1528 endlich die Stadt Rom verließ, geschah dies nur auf Grund der Tatsache, dass die Franzosen im Königreich Neapel eingerückt waren und es den Offizieren - wohl vor allem unter dem Druck dieses Umstandes - gelungen war, eben in Neapel die Gelder aufzutreiben, die die Soldaten schließlich zum Aufbruch bewegten.

$\begin{array}{ll}524 & \text { RODRIGUEZ ViLLA, Memorias, S. } 312 . \\ 525 & \text { RodRIGUEZ ViLLA, Memorias, S. } 317 . \\ 526 & \text { RodRIGUEZ ViLLA, Memorias, S. } 353 \mathrm{f} .\end{array}$ 
So ergibt sich ein recht klares Bild von der Entwicklung der Soldzahlungen in Rom: von den 400.000 Dukaten des ersten Vertrages zahlte der Papst noch nicht einmal 150.000. Die Rückstände der Soldaten beliefen sich zum Zeitpunkt des Vertragsabschlusses schon auf mindestens 600.000 Dukaten, wuchsen zunächst weiter an und verfielen dann scheinbar, allerdings nur absolut und nicht relativ, durch die schweren Verluste der Epidemie im Sommer 1527 und die Abgänge durch Desertion. Im zweiten Vertrag sicherte der Papst den Soldaten die Zahlung von 368.000 Dukaten zu, zahlte aber nur 20.000 davon. Alle weiteren Zahlungen ab dem November 1527 wurden von den Offizieren in kleinen Portionen in Neapel organisiert. Diese Zahlungen machten aber immer nur Bruchstücke von Monatssölden aus. So schuldete man den Landsknechten beim Abzug sicherlich 10 Monate Zahlung, den Spaniern noch mindestens drei Monate mehr. Auch das passt wieder zu einer anderen Aussage, nach der die Schulden bei den Spaniern, die inzwischen nach Neapel gezogen waren, bis zum Sommer 1528 auf 20 Monate angewachsen waren. ${ }^{527}$

Solche Rechnungen zeigen deutlich: die Vernachlässigung der Soldzahlungen waren so selbstverständlich, dass manche Soldaten Jahre lang nicht das ihnen zustehende Geld und oft Monate lang überhaupt nichts ausgezahlt bekamen. Dass es nicht möglich ist, solche Entwicklungen bis ins kleinste Detail nachzuvollziehen, zeigt am besten eine Anekdote aus der Epoche selbst: Anfang Januar 1528 beschwerten sich die Landsknechte in Rom, es habe einen Rechenfehler zu ihren Ungunsten gegeben, denn man schulde ihnen 18.000 Dukaten mehr als gedacht. ${ }^{528}$ Das war, wie gesagt, zu einem Zeitpunkt, als die Rückstände sich schon auf ein Jahr beliefen. All diese Rechnungen setzen voraus, dass kaum ein Monatssold vollständig gezahlt wurde. An Hand einiger Beispiele von Auszahlungen soll nun gezeigt werden, dass das tatsächlich so war.

Am 15. Januar 1525 hielt Pescara eine Ansprache vor den Spaniern und forderte sie auf, bis zum 10. Februar ohne Sold zu dienen, und sie erklärten sich dazu bereit. Die Deutschen schlossen sich immerhin für einen halben Monatssold an. ${ }^{529}$ Als zwei Tage vor der Schlacht von Pavia wieder zur Bezahlung gerufen wurde, erwartete schon niemand mehr Geld, sondern lediglich die üblichen Predigten Pescaras. ${ }^{530}$ Solche Versammlungen waren in der Folgezeit in Mailand wie in Rom fast immer dadurch gekennzeichnet, dass man, anstatt Sold auszuzahlen, erklärte, warum der Sold wieder einmal nicht ausgezahlt oder nur angezahlt werden konnte. Typisch für die Größenordnung, in denen sich solche Anzahlungen bewegten, sind etwa die 4.000 Dukaten, die Nájera im November 1525 statt der fälligen 19.000 an die Deutschen auszahlte - das machte kaum einen Dukaten pro Mann aus und wurde von den Soldaten gar nicht als Anzahlung verstanden, sondern eher als eine Investition in ihre Geduld, eine Art Beschwichtigungszahlung, die mit den Rückständen nicht ver-

527 CEREZEDA, Tratado, S. 219.

528 RODRIGUEZ VILLA, Memorias, S. 347f.

529 BAUMgarten, Geschichte Karls V., S. 378f.

530 VIRGILI, Otto giorni, S. 186f. 
rechnet wurde. ${ }^{531}$ Die folgende Zeit ist in Mailand nur bruchstückhaft beleuchtet. Es existiert eine Erklärung des Zahlmeisters der spanischen Besatzer dort, aus der hervorgeht, dass in acht Monaten zwischen Februar und Oktober 1527 insgesamt 132.000 Scudi ausgezahlt wurden. ${ }^{532}$ Das entspricht ziemlich genau der Hälfte der Kosten, die das Besatzungsheer bei einem monatlichen Aufwand von 33.000 Dukaten in diesem Zeitraum verursacht hätte. ${ }^{533}$ Zumindest für diesen etwa in der Mitte der Besatzungszeit liegenden Abschnitt lässt sich also sagen, dass die Soldaten immerhin die Hälfte des ihnen zustehenden Geldes ausgezahlt bekamen. Inwieweit die von den Bewohnern an die in Mailand einquartierten Soldaten gezahlten Tagesabgaben in diesen Beträgen enthalten sind, ist leider nicht mehr festzustellen. Da die Gesamtsituation sich nach 1527 erheblich verschlimmerte, ist anzunehmen, dass der ausgezahlte Anteil des den Soldaten zustehenden Geldes mit der Zeit noch geringer wurde. Dafür spricht einiges: wie schon auf dem Weg nach Rom versuchte man auch in Mailand, durch einmalige Abschlagszahlungen die Soldaten zum Verzicht auf einen Teil der Rückstände zu bewegen. Die Tatsache, dass die Soldaten sich darauf einließen, zeigt, wie unrealistisch die Hoffnung auf eine Begleichung der Soldschulden war: im Januar 1529 forderte de Leyva die Landsknechte in Mailand auf, ihm zusätzlich zu einem offenbar schon geleisteten Verzicht auf 80.000 Dukaten unbefristeten Aufschub für weitere $140.000 \mathrm{zu}$ geben. Gegen eine einmalige Zahlung von 25.000 Dukaten waren sie dazu bereit. Gleichzeitig verzichteten die Spanier gegen 15.000 Dukaten auf volle drei Jahre Soldrückstand. ${ }^{534}$ Die Forderungen, die damit verfielen, mussten also bis ins Jahr $1525 \mathrm{zu}-$ rückreichen, so dass an ihre Erfüllung in der Tat in keiner Weise mehr zu denken war. Die leeren Versprechungen der Offiziere wurden nicht nur von den Soldaten immer weniger geglaubt, sondern konnten ohnehin angesichts der finanziellen Situation unmöglich ernst gemeint sein. So wurde das Tauziehen um die Soldrückstände immer mehr zwischen Misstrauen und Unredlichkeit ausgetragen: als die Soldaten im November 1526 eine Abordnung an den Kaiser schickten und diese instruierten, alle Soldrückstände einzufordern, hatte Nájera nichts Eiligeres zu tun, als selbst an den Kaiser zu schreiben und ihm dringend zu raten, die Erfüllung aller Forderungen zu versprechen, denn wenn erst alles zugesagt sei und die Gemüter sich beruhigt hätten, werde es genügen, ein Viertel der versprochenen Gelder wirklich auszuzahlen. ${ }^{535}$

531 Gayangos, Calendar, Bd. 3, Teilbd. 1, S. 492.

532 RAH Salazar y Castro, A/41, fol. 263 ${ }^{\mathrm{r}}$. Bestätigung des Zahlmeisters Agocio Bostino, Mailand, 13.10. 1527. In einem Brief vom 7. 9. 1527 spricht de Leyva selbst von 160.000 Dukaten. BNM, MS 20212, 43, 12.

533 Gayangos, Calendar, Bd. 3, Teilbd. 2, S. 304.

534 Gayangos, Calendar, Bd. 3, Teilbd. 2. Gayangos datiert den Brief de Leyvas zunächst auf den 7. Januar 1528 (S. 530), dann tauchen dieselben Zahlen noch einmal in einem Brief vom 7. Januar 1529 auf (S. 871). Die plausibelste Erklärung ist, dass Gayangos den Brief zweimal ediert hat und ihm beim ersten Brief ein Datierungsfehler unterlaufen ist, da weitere Informationen in diesem Brief - etwa über die Brotsteuer - darauf hindeuten, dass 1529 das wahrscheinlichere Datum ist.

535 Gayangos, Calendar, Bd. 3, Teilbd.1, S. 1011. 
Oben ist schon angedeutet worden, dass die Rückstände bei verschiedenen Einheiten unterschiedlich hoch waren. Die Unterschiede klafften vor allem zwischen Kavallerie und Infanterie weit auseinander, aber auch zwischen den verschiedenen Nationen und schließlich sogar zwischen einzelnen Kompanien einer Nation. In Rom kam es vor, dass die deutschen Hauptleute darum losten, wer seine Soldaten als erster bezahlen durfte, weil zu wenig Geld für alle da war. ${ }^{536}$ In Mailand scheinen die ausgelagerten Kompanien schlechter bezahlt worden zu sein als die in der Stadt einquartierten, da die Offiziere den Unmut der Soldaten in Mailand selbst am eigenen Leib zu spüren bekamen, während er sich im Umland zwangsläufig an der Bevölkerung entlud. Wenn also Geld in Mailand ankam, wurde es zuerst an die Kompanien vor Ort verteilt. Genau das ist auch der Grund für die schlechte Bezahlung der Kavallerie: da die Pferde in der Stadt schlechter zu halten waren und die Reiter vor allem für Streifzüge im Umland eingesetzt wurden, befand sich die Kavallerie fast immer auf dem Land. Von diesen Reitern sind schon 1525 die höchsten Soldrückstände überliefert, gleichzeitig werden sie am seltensten erwähnt, wenn von Auszahlung die Rede ist. Da die Streifzüge der Reiter fast immer mit einer Plünderung der Landbevölkerung oder mit Überfällen auf feindliche Soldaten, aber durchaus auch auf Reisende einhergingen, hatten sie ganz andere Möglichkeiten der Bereicherung. Damit schienen sich die Offiziere in Mailand abgefunden zu haben: sie ließen der Kavallerie freie Hand und waren im Gegenzug wenigstens von dieser Seite nicht dem permanent aufstandsschwangeren Druck der Soldschulden ausgesetzt. In der Tat revoltierte die Kavallerie viel seltener als die Infanterie. $\mathrm{Zu}$ den Unterschieden bei der Bezahlung der verschiedenen Nationen lässt sich sagen, dass offenbar im Zweifelsfall immer die Deutschen bezahlt wurden. ${ }^{537}$ Schon während der Besatzung in Mailand gibt es mehrere Hinweise, dass zumindest in der ersten Zeit vor dem Aufstand im Juni versucht wurde, den Landsknechten regelmäßig Bezahlung zukommen zu lassen - natürlich vor allem auf Kosten der Spanier. Wenn schon die Deutschen unzufrieden seien, denen man jeden Monat wenigstens einen Teil des Soldes auszahlte, schrieb Nájera im März 1526 an den Kaiser, könne man sich wohl vorstellen, wie es um die Moral der anderen bestellt sei - die nämlich offenbar gar nichts bekamen. ${ }^{538}$ Auf dem Marsch nach Rom wurde diese Politik dann fortgesetzt: als Bourbon im März 1527 von Bankiers in Ferrara einen Kredit über 15.000 Dukaten bekam, brach ein Aufstand unter den Spaniern los, weil das Geld vollständig an die Deutschen verteilt wurde. ${ }^{539}$ In deren Taschen floss, wie beschrieben, auch der größte Teil des Geldes, das der Papst in Rom bezahlte, und als die Offiziere nach dessen Flucht gezwungen waren, in Neapel auf eigene Rechnung Gelder zu

\footnotetext{
536 REISSNER, Historia, fol. $141^{\mathrm{r}}$.

537 BAEÇA, GASPAR DE (HrSG.): Vida del famoso caballero Don Hugo de Moncada. Colección de documentos inéditos para la historia de España. Bd. 24. Madrid 1854. S. 469.

538 Gayangos, Calendar, Bd. 3, Teilbd. 1, S. 624.

539 Gayangos, Calendar, Bd. 3, Teilbd. 2, S. 131.
} 
besorgen, wurden auch damit als erstes die Deutschen ruhig gestellt. ${ }^{540}$ Ein anonymer Berichterstatter schrieb im Januar 1528 aus Rom, die Spanier und Italiener seien zwar mit weit weniger zufrieden als die Deutschen, aber auch sie würden bald deren Beispiel folgen und desertieren. $^{541}$

\section{Deserteure, Überläufer und Verräter}

Nicht nur durch Krieg und Seuchen nahm die Zahl der Soldaten ständig ab, viele verließen ihre Kompanien und machten sich einfach auf den Heimweg. Bei den oben beschriebenen Soldrückständen scheint das häufige Vorkommen der Desertion zunächst kein Wunder, zu dem Motiv des fehlenden Geldes gesellt sich aber noch ein anderes, nämlich dessen genaues Gegenteil: Desertion wurde immer dann zum Problem, wenn die Soldaten entweder gar kein Geld hatten oder aber zuviel davon.

Bei der schlechten Disziplin im Heer waren die Grenzen zwischen Entlassung aus dem Dienst und Desertion nicht immer ganz klar zu ziehen. Es kam vor, dass Soldaten um ihre vorzeitige Entlassung baten und diese gewährt bekamen. Andererseits wurden Deserteure oftmals nicht etwa bestraft, sondern geradezu hofiert, als gälte es, sie neu anzuwerben immer dann nämlich, wenn durch die allgemeine Unzufriedenheit die Soldaten in Massen desertierten und das Heer auseinanderzufallen drohte. So konnte die Drohung mit Desertion den Soldaten oftmals als wirksameres Mittel zur Erreichung ihrer Ziele erscheinen als die Bitte um Entlassung. Schon im Januar 1527 drohten die Landsknechte Frundsbergs, wenn sie ihre Bezahlung nicht bekämen, würden sie nach Hause gehen. ${ }^{542}$ Desertiert wurde dann ganz ungeniert: eine Woche vor der Schlacht von Pavia begegneten einem venezianischen Berichterstatter 200 Landsknechte mit Frauen und Gepäck, die das kaiserliche Heer wegen der ausbleibenden Bezahlung verlassen und sich auf den Heimweg gemacht hatten. ${ }^{543}$ In Rom desertierten vor allem die Spanier, wie gesehen, in solchen Massen in Richtung Neapel, dass dort die Häfen gesperrt wurden. ${ }^{544}$ Als sich Anfang November wieder eine Welle von Deserteuren auf den Weg machte, stürzte Juan de Urbina hinterher und es gelang ihm, die meisten von ihnen zur Umkehr zu bewegen. ${ }^{545}$ Gegen Ende des Monats waren es dann die im Umland stationierten schweren Reiter, die nach Neapel aufbrachen, und Guasto, der sie mit dem Versprechen baldiger Bezahlung zurückholte. ${ }^{546}$ Daneben sickerten aber immer

BAEÇA, Vida del famoso caballero, S. 469.

541 Gayangos, Calendar, Bd. 3, Teilbd. 2, S. 541.

542 BALAN, Monumenta saeculi XVI, S. 380.

543 SANUTO, Diarii, Bd. 37, Sp. 599.

544 SANUTO, Diarii, Bd. 46, Sp. 300.

545 Rodriguez Villa, Memorias, S. 305f.

546 BALAN, Monumenta saeculi XVI, S. 443. 
wieder Soldaten in kleinen Gruppen aus der Stadt. Kaum jemand ging wegen der gefährlichen Straßen allein. Gegen Ende des untersuchten Zeitraums war die Desertion dann so weit verbreitet, dass ganze Kompanien sich auflösten: im Februar 1530 schrieb Lope de Soria an den Kaiser, wenn nicht bald Geld zur Bezahlung der Kompanien der Hauptleute Mendoza und Vacca käme, würden diese auseinanderfallen. ${ }^{547}$

Natürlich fiel die Desertion denen am leichtesten, die keinen weiten Weg nach Hause hatten. Für einen Spanier war es einfacher, 1527 aus Rom ins Königreich Neapel zu desertieren, als 1515 aus Brescia. Kriegsherren taten gut daran, nicht durch verfrühte Zahlungsunfähigkeit den ganzen Kriegszug zu gefährden. Die Belagerung von Bergamo im Frühjahr 1528 durch das Heer des Herzogs von Braunschweig - das anschließend eigentlich noch bis nach Neapel marschieren sollte - musste abgebrochen werden, weil die Stadt nicht weit genug von den Heimatorten der Landsknechte entfernt lag und die Gefahr bestand, dass sie alle nach Hause liefen. ${ }^{548}$ Doch auch der Einzug in die Lombardei brachte keine Besserung: es kam kein Geld, und der Strom der Deserteure riss nicht ab. Schließlich musste die Belagerung von Lodi aufgegeben werden und das Heer fiel auseinander, nicht ohne zuvor noch einmal Zulauf aus den Reihen von de Leyvas Besatzungstruppen bekommen zu haben: einige der Landsknechte aus Mailand desertierten sozusagen intern, weil sie hofften, im Gefolge von Braunschweig und seiner marodierenden Soldateska einen besseren Schnitt zu machen als im ausgelaugten Herzogtum. ${ }^{549}$ Am leichtesten hatten es natürlich die Italiener. Schon während der ersten Aktion im Krieg um die Lombardei, der Belagerung von Parma im Spätsommer 1521, desertierten 3.000 von insgesamt 5.000 der italienischen Verteidiger, ${ }^{550}$ und de Leyva schrieb im Juli 1527 von Mailand aus an den Kaiser, die frisch vor Ort ausgehobenen Italiener müsse er auf jeden Fall bezahlen, da sie andernfalls sofort nach Hause gingen. ${ }^{551}$

Nach Plünderungen schnellte die Zahl der Deserteure ebenfalls in die Höhe. Als den Soldaten in Rom das Geld ausging und sie die Stadt wegen der ausbleibenden Bezahlung verließen, hatte die erste Welle von Deserteuren, schwer beladen mit Beute, der Stadt schon den Rücken gekehrt. ${ }^{552}$ Um die Beute sicher nach Hause zu bringen, schloss man sich erst recht zu Gruppen zusammen und nahm offenbar auch weitere Wege in Kauf: im Zusammenhang mit Plünderungen sah man Spanier auch aus Norditalien aufbrechen, so im Frühjahr 1513 nach Raubzügen in der Gegend von Piacenza ${ }^{553}$ oder im Mai 1522 nach der Plünderung von Genua, von wo aus die Deserteure sich bequem nach Neapel einschiffen

\footnotetext{
547 RAH, Archivo Lope de Soria, Nr. 176.

548 Gayangos, Calendar, Bd. 3, Teilbd. 2, 724.

549 Molini, Documenti, Bd. 2, S. 105.

550 OMAN, Charles: A History of the Art of War in the Sixteenth Century. London 1937. S. 37.

551 Gayangos, Calendar, Bd. 3, Teilbd. 2, S. 304.

552 ASM Sforzesco, Cart. 137.

553 SANUTO, Diarii, Bd. 16, Sp. $119 \mathrm{f}$.
} 
konnten. ${ }^{554}$ Nach der Schlacht von Pavia desertierten jeden Tag zahlreiche Soldaten, wer keine Beute gemacht hatte, blieb und wartete auf die Soldzahlungen. ${ }^{55}$ Selten wurden die Soldaten zur Rechenschaft gezogen, lediglich im Dezember 1526 wurden in Genua gleich 40 Spanier aufgehängt, die man mit der Beute aus verschiedenen Mailänder Klöstern dort aufgespürt hatte. ${ }^{556}$ Dass Soldaten, die durch eine Plünderung reich geworden waren, nach Hause gingen, galt als selbstverständlich. Nach dem zweiten Aufstand in Mailand im Juni 1526 verhinderten die Offiziere eine Plünderung, weil sie fürchteten, das Heer werde anschließend auseinanderfallen, obwohl sich alle darüber einig waren, dass es in Mailand kaum noch etwas zu holen gab. ${ }^{557}$ In Rom dagegen gab es etwas zu holen, und so war hier das Problem der Desertion in der ersten Zeit nach der Plünderung besonders bedrohlich, so sehr, dass ein anonymer Berichterstatter die Reichtümer Roms und die Pest als gleich schädlich für den Erhalt des Heeres nebeneinander stellte. ${ }^{558}$

Schlimmer als das Desertieren wurde das Überlaufen zum Feind angesehen. Für italienische Condottieri und ihre Soldaten war es von alters her ein normaler und wenig Anstoß erregender Vorgang, den Kriegsherrn zu wechseln, wenn der Dienst bei dessen Gegner lukrativer erschien. So waren es auch im hier untersuchten Zeitraum vor allem Italiener, die nicht nur häufiger, sondern auch in größerer Zahl, nämlich meistens in geschlossenen Einheiten überliefen. Pierino Belli drückte es blumiger aus: die Italiener wechselten häufiger zwischen den Kriegsparteien hin und her als die Bienen zwischen Blüte und Bienenstock. $^{559}$

Zu den Spaniern kamen immer dann Überläufer, wenn Aussicht auf Beute bestand. Schon auf dem Weg nach Rom schlossen sich Bourbon viele Glücksritter an. Ihre Zahl ist unmöglich zu bestimmen, denn sie bekamen keinen Sold, viele von ihnen unterstanden noch nicht einmal einem Hauptmann. Nach dem Einfall in Rom schoss die Zahl der Überläufer dann in die Höhe, weil sich das Heer der Liga unter dem Herzog von Urbino in den ersten Wochen noch in der Nähe befand. Die Gerüchte von der sagenhaften Beute in Rom sprachen sich herum und bald präsentierten sich bei den Stellvertretern Bourbons ganze Kompanien, die über Nacht bei Urbino desertiert waren und glichen so die Verluste, die den Kaiserlichen ihrerseits durch die Desertion entstanden waren, teilweise wieder aus. Die Offiziere wollten aber nicht alle Anwärter aufnehmen, weil sie der Ansicht waren, dass sich viel Gelichter darunter befand. ${ }^{560}$ In Urbinos Heer wurde derweil offenbar das Gerücht ausgestreut, die Kaiserlichen ermordeten die Überläufer, um ein weiteres Ausbluten zu verhindern. ${ }^{561}$

554 SANUTO, Diarii, Bd. 33, Sp. 288.

555 SANUTO, Diarii, Bd. 38, Sp. 60.

556 SANUTO, Diarii, Bd. 43, Sp. 557.

557 Guicciardini, Storia d'Italia, Buch 17, Kap. 4 (Bd. 4, S. 24f.).

558 RAH Salazar y Castro, A/40, fol. $455^{\mathrm{V}}$.

559 BELLI, De Re militari, fol. $101^{\mathrm{r}}$.

560 Rodriguez Villa, Memorias, S. 153.

561 ASM Sforzesco, Cart. 137. 
Vergeblich: Anfang Juni hatten bereits 3.000 Soldaten und 300 Reiter die Seite gewechselt. ${ }^{562}$ Schließlich zog Urbino unverrichteter Dinge ab. In Rom selbst liefen nach der Erstürmung auch Söldner des Papstes, die die Stadt noch verteidigt hatten, zu den Spaniern und Deutschen über, ${ }^{563}$ und nach dem Abschluss des ersten Vertrages mit dem Papst traten sogar 12 Angehörige der Schweizer Garde in die Dienste des Kaisers. ${ }^{564}$

Die Italiener kamen und gingen. Doch auch Spanier und Deutsche waren unter Umständen allzu bereit, zum Gegner überzulaufen. Deutsche Landsknechte kämpften üblicherweise in fast allen Heeren, die im hier untersuchten Zeitraum durch Italien zogen, auch wenn der Kaiser immer wieder versuchte, sie an das Reich zu binden und den Dienst bei seinen Feinden unter Strafe stellte. Spanier dagegen wurden in Spanien und im Königreich Neapel rekrutiert, ausgerüstet und dann nach Norditalien gebracht. ${ }^{565}$ Sie tauchen viel seltener in anderen als spanischen Heeren auf. Dennoch gibt es zahlreiche Beispiele dafür, dass Spanier genau wie Landsknechte in beträchtlicher Zahl zum Gegner überliefen, wenn auch ihre Gründe mitunter etwas anders gelagert waren. Einige Beispiele werden die Unterschiede verdeutlichen.

Im Juli 1513 präsentierte sich ein spanischer Hauptmann namens Peralta im Heer der Venezianer und bot an, mit 400 Soldaten in ihre Reihen überzutreten. Als Grund gab er an, er habe sich mit dem Vizekönig Ramón de Cardona überworfen, weil dieser ihm das Kommando hatte entziehen wollen. ${ }^{566}$ Im Frühjahr 1516 begannen einige der Deutschen und der Spanier der Besatzung in Brescia aus Ärger über den ausbleibenden Sold Verhandlungen mit den Venezianern anzuknüpfen. ${ }^{567}$ Man kam zu keinem Abschluss, aber nachdem die Stadt am 26. Mai übergeben war, traten offenbar mindestens 600 spanische Soldaten in die Dienste der Venezianer und wurden dort ordnungsgemäß besoldet. ${ }^{568}$ Insgesamt liefen zu dieser Zeit laut Francesco Guicciardini immerhin 3.000 Deutsche und Spanier zu den Venezianern und Franzosen über, allerdings war der Krieg kurz darauf zu Ende und sie kamen wohl nicht mehr zum Einsatz. ${ }^{569}$ Im Krieg um das Herzogtum Urbino, an dem keine außeritalienischen Mächte beteiligt waren, holte der Herzog Francesco Maria della Rovere im folgenden Jahr angeblich 5.000 beschäftigungslose Spanier in sein Heer. ${ }^{570} \mathrm{Ab} 1521 \mathrm{kam}$ es

562 Rodriguez Villa, Memorias, S. 214.

563 SANUTO, Diarii, Bd. 45, Sp. 187.

564 DURRER, ROBERT: Die Schweizergarde in Rom und die Schweizer in päpstlichen Diensten. Luzern 1927. S. 405.

565 RÜsTOW, W.: Geschichte der Infanterie. Bd. 1. Bis auf den Anfang des Siebenzehnten Jahrhunderts. Gotha 1857. S. 112; DELBRÜCK, HANS: Geschichte der Kriegskunst im Rahmen der politischen Geschichte. 7 Bde. Berlin 1920-1936. Bd. 4: Neuzeit (1920). S. 21.

566 SANUTO, Diarii, Bd. 16, Sp. 545.

567 Treccani Degli Alfieri, Giovanni, U. A. (HrSGg.): Storia di Brescia. Bd. 2: La dominazione veneta (1426-1575). Brescia 1963. S. 294.

568 SANUTO, Diarii, Bd. 22, Sp. 301; ZagATA, Cronica della città di Verona, Bd. 2, S. 180f.

569 GuicCiardini, Storia d'Italia, Buch 12, Kap. 20 (Bd. 3, S. 149).

570 HerrerA, ANTONIO DE: Commentarios de los hechos de los Españoles, Franceses, y Venecianos en Italia, y de otras Republicas, Potentados, Principes, y Capitanes famosos Italianos, desde el año de 1281. hasta el de 1559. Madrid 1624. S. 298. 
dann auch in der Lombardei immer wieder zu Übertritten kaiserlicher Soldaten in die Dienste der Venezianer und Franzosen, im April 1522 waren es einmal 1.500 Spanier auf einen Schlag, die wegen des ausbleibenden Soldes im eigenen Heer zu den Franzosen gingen. ${ }^{571}$ Im April 1523 sickerten sie in Gruppen zu 30 bis 50 Soldaten ins französische Heer, ${ }^{572}$ und im Mai 1523 bot ein spanischer Hauptmann, den Pescara entlassen hatte, den Venezianern mit 800 Soldaten seine Dienste an. ${ }^{573}$ Wenige Tage später klagte Nájera, es bestehe akute Gefahr, dass weitere Spanier überliefen. ${ }^{574}$ Im Oktober warb Pescara den Franzosen 200 Spanier wieder ab, mindestens 400 aber verblieben unter dem Hauptmann Iñigo de Mendoza bei den Gegnern. ${ }^{575}$ Gegen Ende des Jahres 1524 trat der spanische Hauptmann Guevara mit angeblich 1.000 Soldaten ebenfalls ins Heer der Franzosen ein, weil er mit Pescara im Hader lag - auch ihm hatte man das Kommando entziehen wollen. ${ }^{576}$ Im Januar 1525 lief dann - diesmal wieder wegen der Soldrückstände - die gesamte spanische Besatzung eines Kastells an der Adda von 300 Soldaten zu den Franzosen über. ${ }^{577}$

Nach der Schlacht von Pavia hatte sich das Überlaufen für einige Zeit erledigt. Auch während der Besatzungszeit in Mailand fand kein großer Austausch zwischen den Bruchstükken der Heere statt, die sich noch dort aufhielten, als habe die allgemeine Ermattung sich auch auf die Dynamik des Überlaufens gelegt, oder anders: als habe der chronisch gewordene Geldmangel, die allgemeine Verwüstung des Landes und die Desillusionierung in Bezug auf fabelhafte Beute die Hoffnung erstickt, beim Gegner bessere Zustände vorzufinden. Im Januar 1529 gab es noch einmal eine Reihe von vereinzelten Übertritten in die Reihen der Venezianer, ${ }^{578}$ doch erst mit dem Abmarsch aus der Lombardei kamen die Dinge wieder in Bewegung: den Abschluss für den untersuchten Zeitraum bildet die tollkühne Aktion eines spanischen Hauptmanns, der zum Belagerungsheer vor Florenz gehörte und es fertigbrachte, im Mai 1530 zu einem der Stadttore zu gehen und den Übertritt von 800 spanischen Soldaten von den Belagerern zu den Verteidigern anzubieten. ${ }^{579}$ Später stellte sich heraus, dass das Ganze eine Finte war: die Zustimmungsbriefe der Soldaten - interessant immerhin deren Erwähnung - waren gefälscht, der Hauptmann und einige seiner Spießgesellen hatten die Prämie für den Übertritt, die als Anzahlung auf den Sold gedacht war, kassieren und sich mit dem Geld aus dem Staub machen wollen. ${ }^{580}$

Diese Aufzählung soll zeigen, dass das Überlaufen zum Heer der Feinde ein Phänomen war, das unter den Soldaten aller Nationen gleichermaßen verbreitet war und mehrere Ursa-

\footnotetext{
571 SANUTO, Diarii, Bd. 33, Sp. 188.

572 RAH Salazar y Castro, A/27, fol. $365^{\mathrm{r}}$. Luiz Fernandez de Córdoba an den Kaiser, 16. 4. 1523.

573 SANUTO, Diarii, Bd. 34, Sp. 153.

574 PACHECO Y DE LEYVA, La política española, S. 408.

575 BNM, MS 18697, Nr. 46. Nájera an den Kaiser, Mailand, 2. 10. 1523.

576 CEREZEDA, Tratado, S. 96.

577 SANUTO, Diarii, Bd. 37, Sp. 442f.

578 SANUTO, Diarii, Bd. 49, Sp. 345.

579 FAlletti, Assedio di Firenze, Bd. 2, S. 206.

580 ALBĖRI, Relazioni degli ambasciatori veneti, Serie 2, Bd. 1, S. 292 f.
} 
chen hatte: in den meisten Fällen ging es um Geld, und die Initiative zum Überlaufen scheint zumindest bei den Deutschen eher von den Soldaten selbst ausgegangen zu sein. Das passt zur Organisationsstruktur der Landsknechtsheere, die den einzelnen Soldaten mehr Mündigkeit zugestand als das bei den Spaniern der Fall war, und auch zu der Tatsache, dass die Deutschen bei den Soldzahlungen insgesamt ungeduldiger waren. Daneben konnten auch persönliche Differenzen zwischen einzelnen Offizieren und ihren Vorgesetzten ausschlaggebend für den Übertritt zum Gegner sein. Es scheint, dass bei den Spaniern die Initiative eher von den Offizieren ausging. Dafür spricht, dass die Zeugen in der Regel bei übertretenden Deutschen einfach deren Zahl angeben, während sie bei den Spaniern eher dazu tendieren, den Namen eines Hauptmanns zu nennen, dem seine Männer dann folgten. Wie die Desertion, so wurde auch das Überlaufen von den Soldaten als Druckmittel gegen die Offiziere eingesetzt: Ende August 1527 schickten die aus Rom ausgelagerten Kompanien 100 Abgesandte in die Stadt zu Guasto und ließen ihm ausrichten, dass sie innerhalb von sechs Tagen zum Heer der Liga überlaufen würden, wenn sie kein Geld bekämen. ${ }^{581}$

Das Überlaufen zum Gegner scheint in der Praxis nicht als das schwere Verbrechen angesehen worden zu sein, zu dem es die Theorie gern machen wollte. Wie das Beispiel der 200 von Pescara den Franzosen abgeworbenen Spanier zeigt, wurden Überläufer nicht etwa bestraft, wenn sie zurückkamen, sondern wieder in die Reihen des Heeres eingegliedert. Das lag natürlich auch an der weiten Verbreitung des Phänomens im Zusammenhang mit der Tatsache, dass es ohnehin schwer genug war, angesichts einer katastrophalen Finanzlage ein Heer überhaupt zusammen zu halten. Das wussten selbstverständlich auch die Gegner: bei den Venezianern und Franzosen war die finanzielle Situation weit weniger angespannt als bei den Kaiserlichen, und so gingen sie bisweilen selbst zur Initiative über. Sie schickten Werber ins Lager der Kaiserlichen oder in von diesen besetzte Städte, um die Soldaten zum Übertritt zu bewegen. Das war allerdings eine gefährliche Tätigkeit. Kurz vor der Schlacht von Pavia wurde ein französischer Werber im Lager der Kaiserlichen entlarvt, gevierteilt und in Sichtweite der französischen Bastionen ausgestellt. ${ }^{582}$ Auch nach Rom streckten die Gegner der Kaiserlichen ihre Fühler aus: im Januar 1527 trat ein Römer an einige der deutschen Offiziere heran und schlug ihnen bei einer harmlosen Plauderei vor, in die Dienste der Liga zu treten. Man vermutete ein groß angelegtes Komplott, verhaftete und folterte ihn, weil man hoffte, er werde Verräter in den Reihen der Deutschen denunzieren, aber es kam nichts dabei heraus. ${ }^{583}$

Ein schlimmeres Verbrechen als der offene Übertritt war natürlich der Verrat. Die am häufigsten anzutreffende Form von Verrat war die Übergabe von Städten oder Kastellen an die

581 Rodriguez Villa, Memorias, S. 272.

582 CEREZEDA, Tratado, S. 120.

583 RodrigueZ Villa, Memorias, S. 353. 
Feinde oder geheime Abmachungen mit dem Ziel, diesen heimlich Zutritt zu verschaffen. In Brescia fanden sich 1515 einige Offiziere, die bereit waren, die Stadt den Venezianern zu übergeben. ${ }^{584}$ Im Oktober 1523 hatte eine Gruppe von italienischen Soldaten sich mit den im Umland von Mailand lagernden Franzosen abgesprochen, diese nachts in die Stadt einzulassen. Die Sache wurde den Vorgesetzten hinterbracht und unter der Folter gestanden die Verschwörer, man habe ihnen 5.000 Dukaten für ihren Verrat versprochen, sowie 500 Dukaten Pension für jeden von ihnen. Stattdessen endeten sie am Strick und ihre Leichen wurden, gut sichtbar für die Franzosen, auf der Stadtmauer aufgehängt. ${ }^{585}$ Dem Kastellan der Festung von Peschiera hatten die Venezianer im Mai 1513 sogar 8.000 Dukaten - sicherlich mehr als er in zehn Jahren verdient hätte - versprochen, ihm nach der Übergabe aber nur 500 gegeben. ${ }^{586}$ Direkt oder indirekt war Verrat immer mit Geld verbunden: als die Franzosen im September 1527 in Alessandria einmarschierten, unterstellte man dem Grafen von Lodron, er habe die Stadt auf Grund eines Kuhhandels mit dem französischen Kommandanten Lautrec übergeben, dem Lodrons Frau und Kinder kurz zuvor in die Hände gefallen waren, weil man diese verdächtigerweise ohne Lösegeldforderungen wieder freigelassen hatte. $^{587}$

Verbreitet waren auch verschiedene Formen von Sabotage, und mehr als alle anderen Gegner der Spanier setzten die Venezianer auf solche Mittel. Auf dem Weg nach Rom wurde in Bourbons Heer ein Soldat hingerichtet, der von den Venezianern zum wiederholten Mal dafür bezahlt worden war, Munition zur Explosion zu bringen. ${ }^{588}$ Ansonsten war die Aufwiegelung der Soldaten die beliebteste Form der Sabotage. Im Juli 1526 bezahlten die Venezianer zwei Deutsche, die in Cremona entweder den deutschen Hauptmann Konrad von Glürns zur Übergabe überreden oder dessen Soldaten zur Meuterei anstacheln sollten. ${ }^{589}$ Solche Provokateure wurden entweder von außen geschickt oder direkt im Heer angeheuert, was natürlich schwieriger war, aber weniger Misstrauen erregte: bei der Belagerung von Florenz gelang dem florentinischen Condottiere Stefano da Palestrina ein Überfall auf das Lager der Spanier und Deutschen, weil vier Landsknechte, die zu ihm übergelaufen waren, die Wachen in ein Gespräch verwickelten und anschließend überraschend ermordeten. ${ }^{590}$ In Bourbons Heer auf dem Marsch nach Rom 1527 betätigten sich die Venezianer ebenso $^{591}$ wie ein Jahr später im kaiserlichen Belagerungsheer vor Lodi, ${ }^{592}$ indem sie

\footnotetext{
584॰ CAVRIOLO, ELIA: Dell'istorie della città di Brescia libri XIV con diverse aggiunte di altri autori. Venedig 1744. S. 296f.

585 SANUTO, Diarii, Bd. 35, Sp. 156ff.

586 JOPPI, Diario del campo tedesco, Bd. 34, S. 84.

587 GayAngos, Calendar, Bd. 3, Teilbd. 2, S. 399.

588 BALAN, Monumenta saeculi XVI, S. 437.

589 BERNARDI, L'assedio di Milano, S. 294.

590 Ughi, GIULIANO: Cronica di Firenze o compendio delle cose di Firenze dall'anno MDI al MDXLVI. Hrsg. v. Francesco Frediani. In: Archivio Storico Italiano, Appendice 23. (Bd. 7) Florenz 1849. S. 97274. S. 155.

591 BALAN, Monumenta saeculi XVI, S. 412.
} 
Landsknechte als Aufwiegler schickten. Meistens sind solche Machenschaften nur überliefert, weil sie aufgedeckt wurden.

\section{Ungehorsam, Anarchie und Meuterei}

Immer wieder klang oben an, dass die Soldaten sich Säumigkeit bei der Auszahlung ihres Soldes nur begrenzt gefallen ließen. Die erste Stufe in einer Kette von möglichen Reaktionen war die Verweigerung des Weitermarsches oder des Abzugs aus einer Stadt, ein Problem, das alle Nationen gleichermaßen betraf, und mit dem die Offiziere immer wieder zu kämpfen hatten, weil es die militärischen Operationen lähmte. Im Mai 1523 schrieb Nájera entnervt an den Kaiser, spanische und italienische Infanterie widersetze sich dem Befehl zum Abzug aus Tortona. ${ }^{593}$ Nach der Schlacht von Pavia verweigerte die deutsche Besatzung den Abzug aus der Stadt, in der sie kurz zuvor noch von den Franzosen blockiert gewesen war. ${ }^{594}$ In Mailand waren es ab November 1526 dann wieder die Spanier, die Bourbon mehrere Monate lang Schwierigkeiten machten, weil sie nicht aus der Stadt ausziehen wollten. ${ }^{595}$ Das Problem war so landläufig, dass Gerolamo Morone im Herbst 1524 von einer Besetzung Mailands dringend abriet, mit der Begründung, die unbezahlten Spanier würden die Stadt anschließend nicht mehr verlassen. ${ }^{596}$

Die Verweigerung von Befehlen war allerdings noch die mildeste Form der Unmutsäußerungen, die sich schrittweise bis hin zur gewalttätigen Revolte steigerten. Die Anarchie erreichte immer wieder neue Höhepunkte, vor allem im geplünderten Rom war das Chaos vollständig. Es begann damit, dass zunächst niemand den Aufrufen zum Abbruch der Plünderung nachkam und sich bei den Kompanien einfand. ${ }^{597}$ In der Folgezeit verfiel der letzte Rest der Disziplin mit zunehmender Frustration über das Ausbleiben der vom Papst vertraglich versprochenen Bezahlung. Auf einer Versammlung Anfang November 1527 schlugen die Soldaten allen Ernstes vier Lösungen vor, von denen eine sich haarsträubender anhörte als die andere: die Verschleppung der sieben Geiseln des Papstes nach Deutschland, die Verwüstung Roms, ein Plünderungszug ins Königreich Neapel oder den geschlossenen Übertritt ins Heer der Liga. ${ }^{598}$ In Mailand sah die Lage zur gleichen Zeit kaum anders aus: im September 1527 revoltierten die Landsknechte nach einem Brief von de Leyva jede

592 Stolz, Oтто: Zum Verbot des Kriegsdienstes für fremde Mächte in Deutschland im sechzehnten Jahrhundert. In: Elsass-lothringisches Jahrbuch 21 (1943). S. 199f.

593 PACHECO Y DE LEYVA, La política española, S. 407.

594 VERRI, Relazione, S. 220.

595 REISSNER, Historia, fol. 95r.

596 CAPELLA, Beschreibung und Geschicht, fol. $22^{\mathrm{r}}$.

597 GUICCIARDINI, Storia d'Italia, Buch 18, Kapitel 8 (Bd. 4, S. 126).

598 SANUTO, Diarii, Bd. 46, Sp. 334. 
Woche, ${ }^{599}$ im Oktober dann schon beinahe täglich. ${ }^{600}$ Völlig aberwitzig wurde die Situation, als im Dezember 1529 revoltierende Banden von spanischen Soldaten auf Mailand zogen und der kaiserliche Gouverneur Ludovico di Belgioioso die Einwohner aufforderte, sich gegen die Soldaten zu bewaffnen. ${ }^{601}$

Solche Revolten waren durch eine Reihe von typischen Merkmalen gekennzeichnet. Zunächst rotteten sich die Soldaten zusammen. Vor allem die tumultuarischen Treffen der Landsknechte, die sich oft an von den Offizieren einberufene Versammlungen wegen des Soldes anschlossen, erregten großes Aufsehen. Die Soldaten traten dabei wie eine eigene Autorität auf und wählten Vertreter, die den Offizieren die Entscheidungen der Versammlung bisweilen förmlich mitteilten. Anfang Juni 1527, noch vor dem Vertragsabschluss mit dem Papst in Rom, klagte Perez, die Landsknechte hätten die Regie bei den Unterhandlungen an sich gerissen und die eigentlichen Verhandlungsführer zu Statisten degradiert. ${ }^{602}$ Als sich die aus Rom ausquartierten Deutschen nach dem Sommer wieder auf die Stadt zuwälzten, schickte Alarcon ihnen Vertreter entgegen, die anfragten, ob sie in friedlicher oder feindseliger Absicht kämen. Sie antworteten, sie kämen um der Bezahlung willen, woraufhin sich viele Spanier in der Engelsburg verbarrikadierten. ${ }^{603}$ Der zweite Vertrag mit dem Papst im November kam unter dem massiven Druck der Deutschen zu Stande, die kurz nach dem Einzug die Offiziere gezwungen hatten, ihnen die Geiseln des Papstes auszuliefern. Auch anderswo agierten die Soldaten unabhängig von den Offizieren auf eigene Verantwortung: in Brescia wurden ihnen 1515 zwei Einwohner der Stadt als Geiseln übergeben, um für die Bezahlung des Soldes zu garantieren. ${ }^{604}$ Vom Lager bei Melegnano aus schickten sie im Mai 1522 Vertreter zu den Offizieren, um ihre Forderungen mitzuteilen, weil diese es nicht wagten, sich ins Lager zu begeben. ${ }^{605}$ Ein Jahr später waren im Heer Zettel im Umlauf, die zu Versammlungen aufriefen, auf denen beraten werden sollte, was wegen der Soldrückstände zu tun sei. ${ }^{606}$ Und schließlich schickten sie von Mailand aus im November 1526 eine eigene Gesandtschaft an den Kaiser, um die volle Bezahlung zu verlangen, die Zeit, die man auf Kosten der Bevölkerung gelebt hatte, sollte dabei nicht abgezogen werden. ${ }^{607}$

Es kam auch vor, dass revoltierende Soldaten an bestimmte Treffpunkte auszogen und sich dort vorübergehend niederließen, um Angebote abzuwarten. Im Juni 1523 versammelten sich meuternde Spanier aus der Lombardei in Asti, um dort auf weiteren Zuzug zu war-

\footnotetext{
599 GayangOs, Calendar, Bd. 3, Teilbd. 2, S. 400.

600 Gayangos, Calendar, Bd. 3, Teilbd. 2, S. 420.

601 Rosmini, CARLo DE: Dell'istoria di Milano. 4 Bde. Mailand 1820. Bd. 3, S. 573.

602 RoDRiguEZ Villa, Memorias, S. 213.

603 Grollier, Historia, S. 108.

604 CAVRIOLO, Istorie, S. 298.

605 PACHECO Y DE LEYVA, La política española, S. 278.

606 PACHECO Y DE LEYVA, La política española, S. 403.

607 Gayangos, Calendar, Bd. 3, Teilbd. 1, S. 1011.
} 
ten. ${ }^{608} \mathrm{Im}$ Dezember 1525 rotteten sich 200 meuternde und hungernde Spanier in einem Kloster vor den Toren von Mailand zusammen. Es gelang Guasto mit Mühe, sie mit den üblichen Versprechungen von Bezahlung zur Rückkehr zu bewegen. ${ }^{609}$ Gleichzeitig zogen die Landsknechte in Gruppen zu 300 und 400 aus der Stadt aus und begannen, das Umland zu verwüsten. Auch ihnen musste Guasto hinterherreiten, um sie zu beschwichtigen. ${ }^{610}$ Überhaupt scheinen revoltierende Soldaten vor allem deshalb ausgezogen zu sein, um ihren Unmut an der Bevölkerung auszulassen. Die aus der Unzufriedenheit der Soldaten resultierenden Übergriffe hatten zwei Gesichter: zum einen war man wegen des unbezahlten Soldes manchmal sogar gezwungen, auf Kosten der Bevölkerung zu leben, zum anderen wurde diese Tatsache aber auch ausgenutzt, um sich weit über das Maß des Notwendigen zu bereichern, oder man übte durch die Drohung mit Gewalttaten gegen die Bevölkerung Druck auf die Offiziere aus. Schon bei der Plünderung von Prato im August 1512 wurde die Gewalt gegen die Bevölkerung nach dem Urteil von Jacopo Salviati von den Soldaten unter anderem auch als Mittel eingesetzt, um die Offiziere an das ihnen zustehende Geld zu erinnern. ${ }^{611}$ Im April 1516 kündigten die Spanier der Besatzung in Brescia aus Wut über die ausbleibende Bezahlung die Plünderung der Stadt an, der Gouverneur floh ins Kastell. ${ }^{612}$ Im Dezember 1526 drohten die Spanier in Mailand, die ohnehin seit einem Monat den Abzug verweigerten, die Stadt vollständig auseinanderzunehmen. ${ }^{613}$ Und selten konnten die Offiziere anders reagieren als auf die übliche Weise: sie beeilten sich, Anzahlungen zu versprechen und vertrösteten die Soldaten auf später.

Bei Revolten im Lager oder in Städten machten die Soldaten ihrem Ärger gern lautstark Luft. Nach der Schlacht von Pavia schrien die aufgebrachten Landsknechte so laut, dass die Offiziere kaum verstanden werden konnten. ${ }^{614}$ Das Geschrei der Deutschen wird von den Zeugen bisweilen ein wenig unbeholfen wiedergegeben; was die Soldaten da skandierten, das hörte sich in italienischen Ohren immer gleich an: " ... sopragiunsero li lancichnech quali con archibusi et in grosso numero gridando Ghelte, Ghelte ad alta voce e voleano ad ogni modo in le mani mons. ill. dicendo poltrone Borbone ..." ${ }^{615}$ Zusätzlich machten die

608 PACHECO Y DE LEYVA, La política española, S. 410.

609 GAYANGOS, Calendar, Bd. 3, Teilbd. 1, 539f.

610 SANUTO, Diarii, Bd. 40, Sp. 539.

611 GuASTI, Il sacco di Prato, S. 161.

612 PALAZZO, Diario, S. 299.

613 SANUTO, Diarii, Bd. 43, Sp. 477.

614 SANUTO, Diarii, Bd. 38, Sp. 60.

615 BALAN, Monumenta saeculi XVI, S. 412. Weitere Kostproben: "Et essendo già passati doi mesi doppo il detto assedio [auf Pavia im Oktober 1524] ritrovandosi i soldati alamanni, quali erano nella città, senza danari, si incominciorno a dolere grandemente verso il signor Antonio de Leva et dimandarli ghelteni, alla qual cossa non potendo remediare il detto signor Antonio da Leva per non havere danari ..." VERRI, Relazione, S. 209f. Nach Jacopo de Cappo weigerten sich die Deutschen in der Nacht vom 7. März 1526, in Mailand auf die Wache zu gehen und schrien stattdessen immer "Ghelten, Ghelten". SANUTO, Diarii, Bd. 41, Sp. 90. Im Februar 1527 fiel ein Auszug aus Mailand nach Monza ins Wasser: "Lanzchenech ... si amutinorno et cominciorno a gridar: Gelter, et sono ritornati dentro de Milano." SANUTO, Diarii, Bd. 44, Sp. 142. Und als Lope de Soria im August 1528 ins Lager des Herzogs von Braunschweig kam, wurde er 
Soldaten gern von der Schusswaffe Gebrauch, um den Forderungen Nachdruck zu verleihen. Immer wieder bemächtigten sich meuternde Soldaten zuerst der Artillerie, wie im Mai 1522 vor Melegnano, als die Landsknechte die Kanonen in ihre Gewalt brachten und nicht weniger als die Hälfte des gesamten Munitionsvorrats einfach in die Luft verschossen, wie Nájera anklagend bemerkte. ${ }^{616}$ Es scheint, dass solche Aktionen auch von einer guten Portion Übermut getragen wurden, denn trotz der vielen Schießereien kam selten jemand zu Schaden. Bei dem Aufstand im März 1527 auf dem Weg nach Rom schossen die Soldaten in Bourbons Quartier die Fenster ein, obwohl dieser schon längst geflüchtet war. ${ }^{617} \mathrm{Am}$ folgenden Tag wurde Bourbon erneut überfallen, von den 25 bis 30 Schüssen, die man ihm nach dem Bericht des ferraresischen Botschafters Gerolamo Naselli hinterher feuerte, traf keiner; Bourbon indes verbrachte die Nacht, angezogen schlafend, in Frundsbergs Quartier. ${ }^{618}$ In Mailand feuerten aufgebrachte Spanier im Sommer 1529 ihre Arkebusen sogar mitten im Dom ab. ${ }^{619}$

Noch gefährlicher wurde es, wenn die Soldaten tatsächlich handgreiflich gegen die Offiziere wurden. Bourbon floh im März 1527 wohl nicht ohne Grund vor seinen eigenen Soldaten aus dem Quartier. Übergriffe gegen die höchsten Offiziere hatte es in den vorangegangen Jahren immer wieder gegeben, zum Beispiel im März 1525 in Pavia, als es den Soldaten gelang, das Quartier von Pescara zu stürmen und niemand Geringeres als Lannoy in ihre Gewalt zu bringen. Sie schleppten ihn ins Kastell und berieten scheinbar ernsthaft, ob sie ihn umbringen sollten oder nicht. ${ }^{620}$ Schließlich wurde er freigelassen, als er aber einen Monat später in Mailand aus der Kirche kam, stellten sich ihm Hauptleute und Fähnriche aus Pavia in den Weg und verlangten Bezahlung für die Landsknechte dort, gaben aber gleichzeitig kleinlaut zu, sie seien von den Soldaten zu diesem Schritt gezwungen worden, die gedroht hatten, sie umzubringen, wenn sie ohne Geld nach Pavia zurückkehren sollten. ${ }^{621}$ Solche Vorfälle häuften sich in Mailand in der Folgezeit, immer wieder mussten sich die Offiziere in ihren Häusern verbarrikadieren oder ins Kastell fliehen. Und immer wieder war es Guasto, der schlichtete, offenbar genoss er besonderes Ansehen bei den Soldaten. Als er im Juni 1526 nach Monza kam, um dort zwischen revoltierenden Soldaten und ihren im Kastell eingeschlossenen Hauptleuten zu vermitteln, wurde er von den Soldaten angegriffen und verjagt, auf dem Rückweg nach Mailand holten ihn dann Boten der Soldaten ein, die sich entschuldigten und erklärten, man hätte ihn nicht erkannt. ${ }^{622}$ Bei den Aus-

\footnotetext{
von den Deutschen bedrängt: "... pasando yo por el quartel de los alemanes comencaron todos a gritar guelten guelten ...", RAH Salazar y Castro A/43, fol. $111^{\mathrm{r}}$.

616 PACHECO Y DE LEYVA, La política española, S. 277.

617 BALAN, Monumenta saeculi XVI, S. 411.

618 BALAN, Monumenta saeculi XVI, S. 414.

619 Burigozzo, Cronaca di Milano, S. 495.

620 SANUTO, Diarii, Bd. 38, Sp. 79.

621 SANUTO, Diarii, Bd. 38, Sp. 208.

622 SANUTO, Diarii, Bd. 41, Sp. 648.
} 
schreitungen gab es bisweilen auch Tote, es erscheint wie ein Wunder, dass nie höhere Offiziere darunter waren. Als Hernando de Alarcon während der Belagerung von Neapel durch die Franzosen von den Deutschen in seinem Quartier bestürmt wurde, kamen bei den Tumulten sieben seiner Bediensteten ums Leben, ihm selbst blieb nichts anderes übrig, als aus dem Fenster spanische Soldaten zu Hilfe zu rufen. ${ }^{623}$ Und Lope de Soria, der Braunschweigs Heer noch im Juni 1528 in den höchsten Tönen gelobt hatte, ${ }^{624}$ änderte seine Ansicht schon bald: drei Wochen später wäre er bei einem Besuch im Lager um ein Haar von den Soldaten als Geisel genommen worden. ${ }^{625}$ So leichtsinnig wie Soria war Braunschweig zu dieser Zeit schon nicht mehr: er hielt sich aus Angst um sein Leben von seinen eigenen Soldaten fern. ${ }^{626}$

Das bekannteste Opfer der Anarchie war Frundsberg. Wenige Tage nachdem er Bourbon in seiner Unterkunft Zuflucht gewährt hatte, erlitt er vor Aufregung einen Schlaganfall, als die Landsknechte die Piken gegen ihn senkten, während er versuchte, sie zu beschwichtigen. ${ }^{627}$ Auf dem Weg nach Rom kam es noch zu weiteren Zwischenfällen, und in Rom selbst spitzte sich die Lage weiter zu. Einer nach dem anderen verließen die Offiziere Rom und überließen die Stadt ihrem Schicksal. Als erster floh der leidgeprüfte Lannoy noch während den Verhandlungen mit dem Papst, er fürchtete um sein Leben, weil die Soldaten ihn verdächtigten, Clemens zu begünstigen. ${ }^{628}$ Oranges floh nach dem Überfall auf seine Unterkunft, die er schon zwei Stunden zuvor verlassen hatte, angesichts wilder Alkoholexzesse der Soldaten, die nichts Gutes verhießen. ${ }^{629}$ Frundsbergs Stellvertreter Konrad von Bemelberg hielt trotz mehrerer Überfälle in der Stadt aus. ${ }^{630}$ Seinen Mut bezahlte er beinahe mit dem Leben. Am 27. November 1527 ereigneten sich die bis dahin schwersten Zwischenfälle: Soldaten bliesen zur Menschenjagd auf die in Rom verbliebenen Hauptleute, brachen die Türen der Quartiere auf, zerrten Bemelberg und andere auf die Straße und verprügelten sie. Adam Reissner kommentiert: "Sie haben ... schier keinen Hauptmann on ein Schlappen auß dem Ring gelassen." ${ }^{631}$ Bemelberg bekam dabei einen Messerstich im Gesicht ab. ${ }^{632}$ Sebastian Schertlin von Burtenbach und Konrad von Glürns entschuldigten sich zu allem Überfluss noch hinterher bei den Soldaten. ${ }^{633}$ Nach diesem Vorfall verließen auch die letz-

623 SuARez de Alarcon, ANTONIO: Comentarios de los hechos del señor Alarcon, marques de la Valle Siciliana, y de Renda, y de las guerras en que se hallò por espacio de cinquenta y ocho años. Madrid 1665. S. 375.

624 RAH Salazar y Castro, A/42, fol. 417 r . Lope de Soria an den Kaiser, Reggio, 16. 6. 1528.

625 RAH Salazar y Castro, A/42, fol. 425 . Lope de Soria an den Kaiser, Reggio, 6. 7. 1528.

${ }^{626}$ RAH Salazar y Castro, A/43, fol. $15^{\mathrm{r}}$. Lope de Soria an den Kaiser, Reggio, 6. 7. 1528.

627 REISSNER, Historia, fol. $105^{\mathrm{r}}$.

628 HALKIN/DANSAERT, Charles de Lannoy, S. $116 \mathrm{f}$.

629 BALAN, Monumenta saeculi XVI, S. 442.

630 GREgOROVIUS, Bericht, S. 390.

631 REISSNER, Historia, fol. $162 \mathrm{~V}$.

632 RODRIGUEZ VILLA, Memorias, S. 317.

633 SCHERTLIN VON BURTENBACH, SEBASTIAN: Lebensbeschreibung des berühmten Ritters Sebastian Schärt- 
ten deutschen Hauptleute die Stadt, so dass in der Folge bei den Versammlungen die Fähnriche und deren Vertreter sich mit den Soldaten auseinandersetzen mussten. ${ }^{634}$

Solche Vorfälle resultierten nicht nur aus der Unzufriedenheit der Soldaten wegen des ausbleibenden Soldes, sondern auch aus einem tiefen Misstrauen gegen die Autoritäten, die man immer wieder - bisweilen immerhin mit einigem Recht - der Unredlichkeit beschuldigte. Vor allem die Deutschen in Rom waren misstrauisch. So behauptete man nach dem Wiedereinzug des Heeres, Alarcon und Morone hätten vom Papst 20.000 Dukaten dafür kassiert, dass sie die Auslieferung der Geiseln an die Landsknechte hintertrieben. ${ }^{635}$ Bei dem Überfall auf Bemelberg wurde dieser beschuldigt, mit den Geiseln des Papstes zu konspirieren, was nicht ganz falsch war, denn als diese einige Tage später durch eine List von Kardinal Pompeo Colonna aus dem Palast der Kanzlei befreit wurden, geschah dies mit Wissen und Billigung der Offiziere. ${ }^{636}$ Gleichzeitig beeilten sich die Hauptleute und sogar die Fähnriche zu erklären, dass sie von der nächsten Auszahlung nichts bekommen würden, um dem Verdacht der Bereicherung die Grundlage zu entziehen. Angestiftet zu dem Aufstand, der zum Anlass zur Befreiung der Geiseln geworden war, hatte die Soldaten nach dem Bericht von Grollier ein betrunkener Landsknecht, der in einer römischen Taverne eine einpeitscherische Rede gehalten hatte, in der er die Offiziere der Prasserei beschuldigte, während sie doch alles ihnen, den Soldaten verdankten. Am Ende hatte er seine Zuhörer zum gewaltsamen Vorgehen gegen die Offiziere und, falls das nichts helfe, zur Zerstörung der Stadt aufgefordert. ${ }^{637}$

\section{Wiederherstellung der Disziplin}

Das naheliegendste Mittel zur Wiederherstellung der Ordnung war natürlich die Bezahlung. Dass dazu aber das Geld fehlte, ist hinreichend ausgeführt worden. Kompromisshalber konnte man die Soldaten in Ware ausbezahlen, aber auch die war nicht immer zu bekommen, ohne dabei die Bevölkerung bewusst zu schädigen. Dasselbe gilt für die faktische Legalisierung von Raub, wie sie in Mailand unter dem Druck der Verhältnisse durch das System der Tagesabgaben praktiziert wurde. Die Beschwichtigung der Soldaten war immer eine Gratwanderung im Spannungsfeld zwischen Ausplünderung der Bevölkerung und dem Risiko von Revolten, die das Heer an den Rand des Zerfalls brachten. Man konnte natürlich

lins von Burtenbach. Aus dessen eigenen und Geschlechts-Nachrichten vollständig herausgegeben und mit Anmerkungen und Beylagen versehen. Hrsg. v. Christoph Sigmund von Holzschuher. Frankfurt und Leipzig 1777. S. 23f.

634 GROLLIER, Historia, S. 117.

635 REISSNER, Historia, fol. $148^{\mathrm{V}}$.

636 GREgOROVIUS, Bericht, S. 390.

637 GrolliER, Historia, S. 114-116. 
versuchen, andere Bedürfnisse als das nach Bargeld zu befriedigen, aber auch ein solches Vorgehen barg Gefahren. Frundsberg hatte den Soldaten bisweilen Wein verabreichen lassen, um sie zu besänftigen, ${ }^{638}$ dieser Schuss konnte aber leicht nach hinten losgehen: ohnehin waren die Deutschen - viel mehr als Spanier und Italiener - als wüste Trunkenbolde verschrien, und viele der Übergriffe resultierten aus übermäßigem Alkoholkonsum. In Mailand versuchte de Leyva im Februar 1527, die Landsknechte nach den Erfahrungen des Vorjahres neben einigermaßen pünktlicher Bezahlung vor allem mit bequemen Unterkünften und Betten ruhig zu stellen. ${ }^{639}$

Daneben gab es einige Offiziere, die offenbar auf Grund ihrer persönlichen Ausstrahlung von den Soldaten mehr respektiert wurden als andere. Einer von ihnen war sicherlich Guasto, dessen Name immer wieder im Zusammenhang mit Schlichtungen fällt - er verbrachte offenbar einen guten Teil seines Dienstes damit, desertierenden Kompanien hinterher zu laufen und sie zur Rückkehr zu bewegen oder disziplinarische Maßnahmen einzuleiten. Besonders entschlossene Offiziere griffen bisweilen auch selbst zu Mitteln der körperlichen Züchtigung. Nach einem eigenmächtig organisierten Überfall spanischer und italienischer Truppen auf den Ort Gottolengo im Oktober 1521 wurde Pescara zufällig Zeuge, wie einige seiner Soldaten einen Beamten der Republik Venedig misshandelten, der ihnen in die Hände gefallen war. Er wurde nackt und gefesselt ins Lager getrieben und musste dabei noch einige Gänse tragen, die die Soldaten erbeutet hatten. Als Pescara erfuhr, dass er eine Persönlichkeit von Rang vor sich hatte, verprügelte er kurzerhand den Soldaten, der den Mann gebunden hielt und ließ einen anderen aufhängen, der zufällig mit Beute aus Gottolengo beladen vorbeikam. ${ }^{640}$ Bei der Plünderung von Genua im Mai 1522 wurde er von einem Ehemann zu Hilfe gerufen, dessen Frau von zwei Soldaten vergewaltigt wurde; Pescara stürzte in dessen Haus und erschlug die beiden eigenhändig, woraufhin auch andere Soldaten von Vergewaltigungen Abstand nahmen. ${ }^{641}$ Als es zu einem späteren Zeitpunkt zu Unruhen im Lager kam, ließ er einen Aufwiegler, der sich mit einer eigenen Leibwache bei ihm präsentierte, während des Gesprächs auf ein Zeichen hin erstechen, die Leibwache vertrieb er selbst mit gezücktem Schwert. ${ }^{642}$ In Rom erschlug Juan de Urbina im Verlauf einer Meuterei im November 1527 einen Soldaten, der auf ihn angelegt hatte. ${ }^{643}$

Gewalttätig oder nicht: der Verlust solcher Persönlichkeiten machte sich bei den anderen Offizieren schmerzhaft bemerkbar. Im April 1523 schrieb Nájera an den Kaiser und bat ihn, Pescara wieder zum Heer zu schicken. ${ }^{644}$ Im Juli 1528 empfahl Antonio de Leyva dem Kaiser den durch seinen Schlaganfall gelähmten und todkranken Frundsberg an und bemerkte,

\footnotetext{
638 MitTermaier, KARL: Machiavelli. Moral und Politik zu Beginn der Neuzeit. Gernsbach 1990. S. 381.

639 Burigozzo, Cronaca di Milano, S. 465.

640 SANUTO, Diarii, Bd. 32, Sp. 71.

641 Giovio, Le vite del Gran Capitano e del Marchese di Pescara, S. $310 \mathrm{f}$.

642 Giovio, Le vite del Gran Capitano e del Marchese di Pescara, S. $314 f$.

643 Rodriguez Villa, Memorias, S. 307.

644 PACHECO Y DE LEYVA, La politica española, S. 390.
} 
dass dieser allein durch seine Persönlichkeit die Soldaten immer wieder vom Desertieren abgehalten hatte und mehr Einfluss auf sie ausüben konnte als alle anderen Offiziere zusammen. ${ }^{645}$ Und selbst den Soldaten wurde in einigen Momenten offenbar klar, dass sie sich nicht selbst aller ihrer Anführer berauben konnten. Als Bemelberg auf dem Marsch nach Rom nach einem Überfall der Soldaten auf sein Quartier in Orte drohte, sein Kommando niederzulegen, wurde er von Vertretern der Landsknechte bekniet, zurückzukommen. ${ }^{646}$

Theoretisch gab es natürlich eine Reihe von disziplinarischen Maßnahmen. Die übliche Strafe für Desertion ${ }^{647}$ und für Tätlichkeiten gegen die Offiziere ${ }^{648}$ - und darunter fiel auch die Gegenwehr, wenn man von einem Vorgesetzten geschlagen wurde - war eigentlich das Aufhängen, Verbrennen oder Vierteilen. Oben wurde gezeigt, dass solche Strafen fast nie zur Anwendung kamen, dasselbe gilt für die Bestrafung von Übergriffen gegen die Bevölkerung. In Mailand wurde sofort nach dem Einzug im November 1525 von Pescara durch einen Ausruf dekretiert, dass auf schon auf Vandalismus in den Unterkünften die Todesstrafe stand. Der Ausruf sollte in den Sprachen der Soldaten überall verkündet werden. ${ }^{649}$ Doch in den folgenden Jahren zeigte sich wie auch davor schon immer wieder, dass die Soldaten solche Verbote wie selbstverständlich ignorierten. Beisp7iele für eine Durchsetzung sind dünn gesät. Während die Spanier im Spätsommer 1512 die Kirchen und Klöster in Prato ausplünderten, wurde ein einzelner Soldat wegen der Schändung einer Hostie verbrannt. ${ }^{650}$ Auf dem Weg nach Rom wurde noch ein Landsknecht aufgehängt, weil man bei ihm einen gestohlenen Messkelch gefunden hatte, während sich 12.000 seiner Landsleute einige Wochen später in den Kirchen Roms ungestraft austobten und Sakrilegien ganz anderer Art begingen. ${ }^{651}$ Einige Soldaten, die das Plünderungsverbot ignoriert hatten, wurden auch in Rom exemplarisch aufgehängt, ${ }^{652}$ doch der Erfolg solcher Maßnahmen ist bekannt. Ebenso in Mailand: im November 1525 wurden noch zwei Landsknechte hingerichtet, die das Haus eines Adligen geplündert hatten. ${ }^{653}$ Im Januar 1526 schnitt man über 20 Landsknechten, die ihre Nachtwache vernachlässigt hatten, das erste Glied des Zeigefingers der rechten Hand ab, um sie dienstuntauglich zu machen. ${ }^{654}$ Im Mai 1526 ließ Guasto dann sogar zwei Offiziere enthaupten, die sich auf Kosten der Bevölkerung bereichert hatten, dazu bemerkte er aber selbst resignierend, wenn es nach den Beschwerden gegangen wäre,

645 Gayangos, Calendar, Bd. 3, Teilbd. 2, S. 753.

646 PASTOR, Geschichte der Päpste, S. 298.

647 BELLI, Re militari, fol. 103V .

648 BELLI, Re militari, fol. 105 $\mathrm{V}$.

${ }^{649}$ ACM Registri di lettere ducali 19 , fol. $62^{\mathrm{V}}$.

650 GUASTI, Il sacco di Prato, Dispensa 178, S. 176.

651 BALAN, Monumenta saeculi XVI, S. 436.

652 CAVE, Bellum Romanum, S. 404.

653 SANUTO, Diarii, Bd. 40, Sp. 382.

654 SANUTO, Diarii, Bd. 40, Sp. 737. 
hätte er gleich das ganze Heer köpfen lassen können. ${ }^{655}$ Bei der Belagerung von Florenz verfolgte man dann eine andere Strategie: offenbar um Aufsehen zu vermeiden, ließ Oranges im Mai 1530 einen der Rädelsführer eines Aufstands zum Schein zu Guasto zitieren und auf dem Weg hinterrücks erschlagen. ${ }^{656}$

Wenn die Situation besonders gefährlich war, setzte man auch einzelne Truppenteile gegen andere ein. Im Mai 1522 nannte Nájera als letztes Mittel gegen renitente Landsknechte die Mobilisierung von spanischen und italienischen Kompanien gegen diese, falls es ihnen in den Kopf kommen sollte, wegen der fehlenden Bezahlung zur Plünderung Mailands zu schreiten. ${ }^{657}$ Und als im November 1527 durch die meuternden Landsknechte in Rom die Gefahr, dass diese die Stadt abbrennen würden, akut geworden war, berieten die Offiziere darüber, die Spanier zu mobilisieren, um solche Auswüchse notfalls mit Waffengewalt zu verhindern. ${ }^{658}$

Schließlich bewirkten bisweilen auch militärische Herausforderungen eine Einkehr bei den Soldaten, die der Disziplinierung sehr zuträglich war. Aus Mailand schrieb Nájera im Februar 1522, die Soldaten seien so begierig, sich mit dem Gegner zu messen, dass ihnen eine Stunde wie ein Jahr vorkomme. ${ }^{659}$ In Rom scheint nicht zuletzt durch den Vorstoß der Franzosen ins Königreich Neapel die Einsicht schließlich Überhand gewonnen zu haben, dass man nicht länger bleiben konnte. Natürlich versuchten die Offiziere bei solchen Gelegenheiten, ihre Soldaten bei der Ehre zu packen und eventuell die eine Nation durch den Hinweis auf die Tapferkeit der anderen zusätzlich anzuspornen. So berichtet es Cerezeda von Frundsberg vor der Schlacht von Pavia: " ... Jorge de Freundsperg pasa por medio del escuadron, diciéndoles que los españoles eran deliberados de morir dos mil muertes ántes que perder ningun punto de la honra ganada, é que ansimismo confiaba que ellos harian ..." 660

Zusammenfassend kann man wohl sagen, dass jedes einzelne der hier beschriebenen Mittel zur Wiederherstellung der Disziplin nur in bestimmten Situationen, über eingeschränkte Zeiträume und durch fähige Personen zur Wirkung gebracht werden konnte. Langfristig lief es immer darauf hinaus, dass nur ein einziges Mittel den Gehorsam und die Loyalität der Soldaten gesichert hätte: pünktliche und vollständige Bezahlung des bei der anwerbung abgemachten Soldes.

\footnotetext{
655 GayangOs, Calendar, Bd. 3, Teilbd. 1, S. 699f.

656 FALlETTI, Assedio, S. 198.

657 PACHECO Y DE LEYVA, La politica española, S. 278.

658 Rodriguez Villa, Memorias, S. 318.

659 PACHECO Y DE LEYVA, La politica española, S. 224.

660 CEREZEDA, Tratado, S. 122.
} 


\section{Nationalitätenkonflikte}

Eine der wichtigsten Charakteristiken der Söldnerheere des untersuchten Zeitraums war deren internationale Zusammensetzung. Die Nationen bildeten innerhalb der Heere feste Körper, die nach Möglichkeit getrennt wurden. Das Lager war zumeist in Sektoren für Spanier, Deutsche und Italiener unterteilt, und in besetzten Städten fanden sich selten Angehörige verschiedener Nationen im selben Stadtviertel. Die angebliche nationale Geschlossenheit vor allem der spanischen Kompanien hält allerdings einem kritischen Blick nicht Stand, mit anderen Worten: nicht alles, was von den Zeugen vereinfachend als Spanier bezeichnet wurde, war auch tatsächlich Spanier. Das Rekrutierungssystem brachte es mit sich, dass spanische Kompanien keineswegs nur aus Spaniern zusammengesetzt waren. Im einzelnen funktionierte das folgendermaßen: die Soldaten wurden in der Regel im Königreich Neapel angeworben, das seit der Jahrhundertwende der spanischen Krone angegliedert war. Das Söldnerreservoir Neapel wurde seinerseits aus Spanien gespeist, und streng genommen wurden viele der neuen Soldaten erst in Italien zu Söldnern, da sie in Spanien zunächst zwangsrekrutiert worden waren. ${ }^{661}$ Etliche kehrten dennoch nach der Entlassung aus dem Dienst nicht nach Spanien zurück, sondern warteten in Neapel auf ihre erneute Rekrutierung. In den dortigen Tavernen mischten sich zahlreiche italienische Abenteurer unter die Soldaten und gingen bei der Anwerbung in den spanischen Kompanien auf. Die militärische Dominanz der Spanier führte offenbar dazu, dass die Italiener in den Heeren eher die Gebräuche der Spanier adaptierten als umgekehrt. Der Chronist Gregorio Amaseo bezeichnet sie dementsprechend als "Italianos hispagnolados", ${ }^{662}$ und Ramón de Cardona gab im Februar 1521 die Schuld für die chaotischen Zuständen im spanischen Heer, das sich in Neapel für den Zug nach Norditalien vorbereitete, den "Italianos españolados" und riet dem Kaiser, in Zukunft nur noch Spanier anzuwerben. ${ }^{663}$ Er selbst war schon 1512 gezwungen gewesen, einige seiner Kompanien nach Massendesertionen der Spanier so massiv mit Italienern aufzufüllen, dass praktisch nur noch die Offiziere Spanier waren. ${ }^{664}$ Als genau dieses Heer kurz darauf Prato plünderte, schlug sich dieses Phänomen auch in den dortigen Quellen nieder, in denen, wie im Abschnitt über die Lösegelder gesehen, viele als Spanier bezeichnete Personen mit italienischen Namen auftauchen. Die Tatsache, dass ein venezianischer Beamter im Dezember 1526 in einem Bericht über die Truppenstärke der Kaiserlichen in Mailand präzisiert, bei den Spaniern handele es sich mehrheitlich um Neapolitaner, Korsen und Sarden, zeigt deutlich, wie weit diese Gruppen innerhalb der Heere scheinbar mit den Spaniern verschmolzen waren. Für die Deutschen lässt sich eine solche Heterogenität - mit wenigen Ausnahmen - nicht nachweisen. Sie wurden in der Regel in

661 RÜstow, Geschichte der Infanteri, Bd. 1, S. 21; DeLBRÜCK, Geschichte der Kriegskunst, Bd. 4, S. 21.

662 Ceruti, Diarii Udinesi, Bd. 2, S. 299.

663 BN Madrid, MS 18690, Nr. 72. Brief von Cardona an den Kaiser, Neapel, 16. 2. 1521.

664 ANONYM: Relación de los sucesos, S. 266. 
den an Italien, genauer gesagt, an die Republik Venedig angrenzenden habsburgischen Erblanden rekrutiert. Mit Venedig aber lag man abgesehen von allen administrativen Barrieren die meiste Zeit über im Krieg.

$\mathrm{Ob}$ in besetzten Städten oder im Lager auf dem Land - immer wieder kam es zu Ausschreitungen unter den Soldaten. Solche Zusammenstöße fanden vor allem zwischen Angehörigen verschiedener Nationen statt, oder besser gesagt: Konflikte zwischen Angehörigen verschiedener Nationen zogen weitere Kreise, waren von größerer Brutalität geprägt und fanden daher eher einen Niederschlag in den Quellen. Die Trennung der Nationen im Lager und in Städten hatte gute Gründe: die ungleiche Bezahlung schuf eine Grundstimmung des Misstrauens vor allem zwischen Spaniern und Deutschen, in der jede Gruppe mit dem ständigen Argwohn lebte, von der anderen übervorteilt zu werden. So kam es immer wieder zu Tumulten um die Verteilung der Gelder. Im Februar 1525 revoltierten die Spanier vor Pavia, weil die Deutschen einen Dukaten pro Mann ausbezahlt bekommen hatten und sie selbst leer ausgegangen waren. ${ }^{65}$ Die Behauptung der Deutschen in Rom, die Spanier hätten mehr Sold bekommen als sie, entsprach keineswegs den Tatsachen und ist daher lediglich ein Zeichen für die allgemeine Unzufriedenheit wegen der ausbleibenden Zahlungen, die eine Zielscheibe suchte. ${ }^{666}$ Und Oranges klagte bei der Belagerung von Florenz im Dezember 1530, wenn er eine Nation bezahle, revoltiere die andere, und wenn er das Geld unter allen verteile, sei niemand zufrieden. ${ }^{667}$ Neben der Bezahlung lieferte auch die Zuteilung der Unterkünfte Anlässe für Neid und Misstrauen. Als das kaiserliche Heer im Juli 1527 aus Rom auszog, kommentierte Reissner: "Die Hispanier sich in die besten Flecken und Häuser gelegt / da sie umb sonst essen und trincken fanden. Die Teutschen musten im Feld ligen / und alles theuwer bezalen." ${ }^{668}$ Und in Pavia kam es im Dezember $1523 \mathrm{zu}$ Schießereien zwischen Spaniern und Italienern, weil diese beim Einzug in die von den Spaniern besetzte Stadt deren Unterkünfte mit der Begründung beanspruchten, sie seien zuvor dort einquartiert gewesen. ${ }^{669}$

Daneben kam es natürlich vor allem in Rom immer wieder zu Zusammenstößen um die Beute. Grollier berichtet von einer regelrechten Schlacht, die Spanier und Deutsche austrugen, und bei der die Italiener zunächst nur zuschauten, sich dann aber auf die Seite der Deutschen schlugen, weil die Spanier mehr Beute gemacht hatten und bei ihnen daher mehr zu holen war. ${ }^{670}$ Nicht selten wurden die Quartiere der Gegenseite gestürmt, wenn man vermutete, dass dort Beute gelagert war. ${ }^{671}$ Größere Ausschreitungen fanden fast aus-

\footnotetext{
665 SANUTO, Diarii, Bd. 37, Sp. 631.

666 GROLLIER, Historia, S. 107.

667 BARDI, Carlo V e l'assedio di Firenze, S. 79.

668 REISSNER, Historia, fol. $141^{\mathrm{V}}$.

669 RAH Salazar y Castro, A/29. Lope de Soria an den Kaiser, 2. 12. 1523, fol. 509r.

670 GROLLIER, Historia, S. 91.

671 BALAN, Monumenta saeculi XVI, S. 441.
} 
schließlich zwischen Angehörigen verschiedener Nationen statt, wobei keine von diesen hinter den anderen zurückstand: im Oktober 1521, auf dem Weg nach Mailand, plünderten die Italiener das Gepäck der Spanier, woraufhin eine wilde Lagerschlacht entbrannte. ${ }^{672}$ Nach der Plünderung von Genua im Mai 1522 waren es die Deutschen, die den Spaniern die Beute abjagten, ${ }^{673}$ und im Dezember 1526 machten sich die Spanier in Mailand über das Gepäck der Deutschen her. ${ }^{674}$

Konkrete Anlässe für Zusammenstöße boten sich auch im alltäglichen Umgang, vor allem beim Spiel. Reissner schildert eine in Rom scheinbar alltägliche Situation: "Ein Teutscher Knecht spielet auff dem Campoflor mit einem Hispanier / und durch ire Uneinigkeit erregt sich ein mercklicher zwytracht under beyden Nationen / darinn sind zu beyder theil viel erschossen / erstochen und beschädigt worden ..." ${ }^{675}$ Die Gefahr, dass Soldaten auf diese Weise aneinander gerieten, war so landläufig, dass in vielen Artikelsbriefen der Landsknechte das Spiel zwischen Angehörigen verschiedener Nationen verboten wurde. ${ }^{676}$ Bei einer anderen Schlacht zwischen Spaniern und Deutschen in Rom ging es angeblich um eine Frau. ${ }^{677}$ Solche Zwischenfälle wuchsen sich zu Massenschlägereien aus, weil die unterlegene Partei - und in der Folge wohl auch die andere - an die Solidarität der in Hörweite befindlichen Landsleute appellierte. Immer wieder hörte man in besetzten Orten Rufe wie "Spagna, Spagna!" oder "Italia, Italia!", wie im April 1517 in Mondolfo, als ein Deutscher und ein Italiener wegen eines halben Fasses Wein auf dem Marktplatz aneinander geraten waren und bald eine Massenschlägerei entstand, in die auch Franzosen und Spanier verwikkelt wurden. ${ }^{678}$ Man hat den Eindruck, dass sich die Hinzugerufenen nur zu gern ins Getümmel stürzten, dankbar für einen Anlass, der ihren eigenen Ressentiments ein Ventil gab. Abgesehen davon war es immer wieder der Alkohol, der zum Katalysator für die Eskalation von Schlägereien wurde. Die Ausmaße, die solche Zusammenstöße annehmen konnten, waren auch unter Berücksichtigung eventueller Übertreibungen der Zeugen bei den Zahlenangaben erschreckend: nach der Plünderung von Meldola auf dem Weg nach Rom kam es $\mathrm{zu}$ einer Massenschlägerei mit 200 Verletzten. ${ }^{679}$ Und das war noch glimpflich, denn wenn Schusswaffen zum Einsatz kamen, waren die Verluste weitaus schwerer: eine von Gerolamo Naselli geschilderte Schießerei auf dem Campo de' Fiori - möglicherweise dieselbe, von der auch Reissner spricht - forderte mehr als 20 Todesopfer, in Cremona entstand im Juni 1526 ein Tumult zwischen Spaniern und Deutschen bei der Wachablösung, der 30 Soldaten

672 CEREZEDA, Tratado, S. 12.

673 PACHECO Y DE LEYVA, La politica española, S. 301.

674 SANUTO, Diarii, Bd. 43, Sp. 566.

675 REISSNER, Historia, fol. 139V.

676 BARTHOLD, George von Frundsberg, S. 77.

677 GUICCIARDINI, Opere inedite, Bd. 9, S. 78.

678 BANDINI, ANGELO MARIA: Il Bibbiena o sia il ministro di stato delineato nella vita del cardinale Bernardo Dovizi da Bibbiena. Livorno 1758. S. 30.

679 REISSNER, Historia, fol. $107^{\mathrm{V}}$. 
das Leben kostete, ${ }^{680}$ und bei den Zusammenstößen in Pavia wegen der Quartiere gab es nach Informationen des Botschafters des Markgrafen von Mantua ebenfalls 30 Tote, ${ }^{681}$ nach Lope de Soria, dessen Angabe wohl stark übertrieben ist, waren es 240 Tote. $^{682}$

Gegen solche Gewaltausbrüche gab es kaum ein Mittel. Die oben erwähnte Lagerschlacht zwischen Spaniern und Italienern im Oktober 1521 wurde eingedämmt, indem sich Pescara und Kardinal Giulio de' Medici - der spätere Clemens VII. - unter Lebensgefahr zwischen die Fronten warfen. ${ }^{683}$ In Rom gingen nach den Ausschreitungen gemischte Patrouillen um, die die Aufgabe hatten, bei aufkommendem Zwietracht zwischen Spaniern und Deutschen zu vermitteln. ${ }^{684}$ Abgesehen davon bestand die einzige Möglichkeit zur Verhinderung von Ausschreitungen darin, die verschiedenen Nationen sowohl auf dem Marsch als auch in besetzten Städten so weit wie möglich voneinander zu trennen. Nach den Erfahrungen im Dezember 1523 in Pavia - kurz darauf war es auch in Mailand zu Ausschreitungen gekommen - wurde ein Austausch vorgenommen, dergestalt, dass die Spanier aus Pavia nach Mailand gingen und die Italiener aus Mailand nach Pavia, so dass nicht mehr beide Nationen zusammen in derselben Stadt lagen. ${ }^{685}$

680 BONETTI, Cremona, S. 236.

681 SANUTO, Diarii, Bd. 35, Sp. 255.

${ }^{682}$ RAH Salazar y Castro, A/29. Lope de Soria an den Kaiser, 2. 12. 1523, fol. $509^{\mathrm{r}}$.

683 VALLES, Historia, fol. $43^{\mathrm{r}}$.

684 REISSNER, Historia, fol. $139^{\mathrm{V}}$.

685 SANUTO, Diarii, Bd. 35, Sp. 286. 


\section{Besetzte Städte}

Wie im Abschnitt über den Krieg auf dem Land gesagt, sind in der Überlieferung die Ereignisse in den Städten im Gegensatz zu denen auf dem Land sowohl im Hinblick auf ihre Quantität, als auch auf ihre Qualität stark überrepräsentiert. Bei den bisherigen Schilderungen wurde immer dann auf beide Arten von Quellen zurückgegriffen, wenn die beschriebenen Phänomene sich parallel in der Stadt und auf dem Land manifestierten. Dennoch zeigt sich an allen Stellen die besagte Überrepräsentation. So wurde etwa im ersten Teil ausschließlich die Plünderung von Städten an den Beispielen von Prato und Rom beschrieben. In diesem dritten Teil der Arbeit sind die besetzten Städte sogar der ausschließliche Schauplatz. Zunächst wird am Beispiel von Mailand gezeigt, wie die Einquartierung von Soldaten in einer Stadt vorgenommen wurde und welche organisatorischen Probleme dabei auftraten. Diese und die daraus resultierenden Belastungen betrafen vor allem die Versorgung mit Lebensmitteln, die durch die chaotische Situation im Umland immer wieder erschwert wurde und zu einer Preissteigerung führte, die das Leben für einen immer größeren Anteil der Bewohner unbezahlbar machte. Der zweite und nicht weniger gravierende Aspekt der Belastung waren die Kontributionen, die von der Besatzungsmacht zur Bezahlung der Soldaten eingetrieben wurden.

Die dreifache Bedrückung durch die Gegenwart der Soldaten, die Teuerung der Lebensmittel und die finanzielle Auspressung der Haushalte gaben den Rahmen für das Zusammenleben vor. Auf die einzelnen Aspekte dieses Zusammenlebens, oder anders gesagt: auf die vielen Formen der Einschränkung des alltäglichen Lebens durch die Anwesenheit der Soldaten wird im zweiten Abschnitt fokussiert. Vor allem die gewaltsamen Übergriffe machten das Leben in den besetzten Städten über lange Zeiträume hinweg unerträglich. Trotz der allgemeinen Erschöpfung etablierten sich an einigen Stellen aber dennoch individuelle Beziehungen zwischen Soldaten und Bevölkerung, die leider nur äußerst selten Niederschlag in den Quellen fanden. Daneben formten sich auch kollektive Haltungen und daraus resultierende Verhaltensmuster, die ihrerseits eine über die weit verbreitete Lethargie hinausgehende Reaktion auf das Verhalten der Soldaten darstellten. Während es auf dem Land, wie gesehen, immer wieder zu vereinzelter Gegenwehr kam, war gewaltsamer Widerstand in den Städten sehr selten. Lediglich in Mailand kam es bei zwei Gelegenheiten zu Aufständen, deren Niederschlagung die Situation, die durch die Anwesenheit der Soldaten entstanden war, für den Rest der Besatzungszeit zementierte.

Auch in diesem Abschnitt sollen die beschriebenen Phänomene nach Möglichkeit quantifiziert werden, um ihnen ihre Widersprüchlichkeit zu nehmen. Das wird erschwert durch die Tatsache, dass kollektive Haltungen und individuelle Interessen oft in Konkurrenz zueinander traten und auf den ersten Blick gegensätzliche Phänomene hervorbrachten. Die Bre- 
chungen waren vielfältig: Einschüchterung, Kollaboration und Widerstand überlagerten sich zur gleichen Zeit und am gleichen Ort ebenso wie Brutalitäten von Seiten der Besatzer und Schutz der Bevölkerung durch einzelne - vor allem nationale - Gruppierungen derselben vor Übergriffen anderer Gruppierungen.

\section{A. Einquartierungen in Mailand}

Wenn ein Heer in eine Stadt einzog, stellten sich sofort zwei grundsätzliche und eng miteinander verknüpfte Probleme: die Unterbringung und die Versorgung einer großen Zahl von Personen auf engem Raum. Wenn der Aufenthalt sich hinzog, versuchte man die Soldaten so weit wie möglich auf das Umland zu verteilen und in der Stadt selbst nur eine Besatzung zu lassen. Diese allein reichte allerdings oft schon, um das städtische Leben vor allem in wirtschaftlicher Hinsicht auf eine harte Belastungsprobe zu stellen. Die Soldaten bewohnten die Häuser in der Regel zusammen mit den Familien und brachten ihre unfreiwilligen Gastgeber allein durch ihre Anwesenheit in finanzielle Schwierigkeiten: mit einem Mal saßen mitunter doppelt so viele Esser am Tisch, und obwohl die Soldaten eigentlich für ihre Verpflegung aufzukommen hatten, blieben die Bewohner zumeist mit der Belastung allein gelassen, sei es, weil die Soldaten auf Grund des ausbleibenden Soldes gar nicht bezahlen konnten, sei es, weil sie sich weigerten. Gegen ein solches Verhalten waren die Bewohner in der Regel völlig machtlos. In den schlimmsten Fällen wurden sie Monate lang von den bei ihnen einquartierten Soldaten drangsaliert und ausgepresst.

Am Beispiel der kaiserlichen Besatzung in Mailand soll hier gezeigt werden, wie die Organisation der Einquartierung und Verpflegung von Soldaten im Einzelnen funktionierte. Das kaiserliche Heer operierte seit dem November 1521 unter Prospero Colonna in der Lombardei, und zwar zunächst im Bündnis mit dem Herzog Francesco Sforza. Nach dem Tod von Colonna im Dezember 1523 übernahm Pescara das Kommando, und im November 1525 kam es zum Bruch mit Sforza, was den Einmarsch des gesamten Heeres in Mailand zur Folge hatte. Die Situation war chaotisch: während Sforza im Kastell belagert wurde, zogen die Soldaten zwischen der Stadt, den Vororten, den umliegenden Dörfern und anderen Städten der Lombardei hin und her. Im April und im Juni 1526 brachen zwei schwere Aufstände unter der Bevölkerung aus, kurz darauf tauchte das venezianische Heer vor den Toren von Mailand auf. Nachdem Sforza mit der Kastellbesatzung im Juli 1526 kapituliert hatte, beruhigte sich die Lage etwas, und im Februar 1527 zog der größte Teil der spanischen Soldaten aus Mailand ab, um sich mit den Landsknechten zu vereinigen, die mit Frundsberg nach Italien gekommen waren und bei Piacenza auf sie warteten. Es blieben vor allem Deutsche und einige Spanier unter dem Kommando des Gouverneurs Antonio de 
Leyva in der Stadt zurück, während sich verbündete italienische Condottieri mit ihren Kompanien im Umland aufhielten. Im Dezember 1529 kam es schließlich zur Aussöhnung zwischen dem Kaiser und Sforza, und einen Monat später verließen die letzten Reste des kaiserlichen Besatzungsheeres die Stadt.

Die Besatzung in Mailand ist neben vielen anderen Aspekten für das Verständnis der Organisation von Einquartierung und Versorgung von Soldaten in einer besetzten Stadt beispielhaft. Der ständige Wechsel der Quartiere, die Versuche der Autoritäten, die Belastung gleichmäßig auf die Haushalte zu verteilen und das Interesse der Soldaten an einer möglichst bequemen Unterbringung, die Eintreibung von Kontributionen, mit denen das Heer mehr schlecht als recht zusammen gehalten wurde, die schwankenden Lebensmittelpreise und das Tauziehen um die Bezahlung der Lebensmittel in den besetzten Haushalten: all das sind Phänomene, die sich auch in anderen besetzten Städten immer wieder beobachten lassen. Dabei ist die Unterscheidung zwischen Feinden und Verbündeten eher abstrakt, wie die Erfahrungen in Mailand zeigen - der Bruch mit dem Herzog änderte nichts am Verhalten der Soldaten in der Lombardei, die im übrigen rechtlich vom Land eines verbündeten Fürsten zu einem durch den Abfall des kaiserlichen Vasallen heimgefallenen Lehen wurde.

\section{Organisation der Einquartierungen}

Wenn ein Heer in eine Stadt einrückte, waren die Vorbereitungen für die Unterbringung der Soldaten in den meisten Fällen bereits abgeschlossen. Quartiermeister und manchmal die höchsten Offiziere ritten den Kompanien voran, um sich nach den Einquartierungsmöglichkeiten vor Ort umzusehen und darüber hinaus die Versorgung des Heeres in der Stadt zu gewährleisten. Den städtischen Autoritäten blieb nichts anderes übrig, als mit den Militärs zusammenzuarbeiten, um die Unordnung so gering wie möglich zu halten. In Cremona sprach im Juni 1526 ein spanischer Offizier beim Stadtrat vor und verlangte Unterkünfte für 200 Reiter und 2.000 Fußsoldaten sowie die Bereitstellung von Getreidevorräten für drei Monate. ${ }^{686}$ Im Februar 1527, als ein Teil der Landsknechte von Mailand nach Monza verlegt wurde, ließen die Quartiermeister dort nach der Vorbereitung der Einquartierungen kurzerhand die Stadt absperren, um den Abtransport von Lebensmitteln zu verhindern. ${ }^{687}$ In Mailand selbst erlauben die Quellen eine genauere Fokussierung auf den Ablauf der Quartierzuteilung. Hier wurde die Verwaltung bis zur untersten Instanz hinab in den Dienst der Wohnraumbeschaffung für die Besatzungsmacht gestellt. Die Offiziere stellten Papiere aus, mit denen die Quartiermeister bei den Pfarreivorstehern derjenigen der insgesamt 82

$\begin{array}{ll}686 & \text { SANUTO, Diarii, Bd. 41, Sp. } 519 . \\ 687 & \text { SANUTO, Diarii, Bd. 44, Sp. } 105 .\end{array}$ 
Pfarreien von Mailand vorstellig wurden, in denen Soldaten einquartiert werden sollten. Diese wiederum sorgten dafür, dass den Soldaten dort Häuser zugeteilt wurden. ${ }^{688}$ Einige Klöster wurden durch Schutzbriefe, die den Quartiermeistern den Zugriff verboten, von der Belegung ausgenommen. ${ }^{689}$ Die Zuteilung erfolgte nach den finanziellen Mitteln der Hausherren, wie sie sich aus der im Jahr 1524 durchgeführten Schätzung aller Einwohner von Mailand ergaben. Demnach musste man für 1.000 Dukaten geschätztes Jahreseinkommen für die Unterbringung und Verpflegung von zwei Soldaten aufkommen. ${ }^{690}$ Bedenkt man, dass die Summe der Einkommen nach der Schätzung über 10 Millionen Dukaten beträgt, dass aber unmittelbar nach ihrer Vollendung eine Epidemie in der Stadt ausbrach, ergibt sich nach diesem Verteilerschlüssel eine theoretische Gesamtkapazität von vielleicht 12.000 bis 15.000 Soldaten, was durchaus in der anfänglichen Größenordnung des Besatzungsheeres liegt. ${ }^{691}$ Die Zahl der Soldaten in der Stadt wurde durch die Ausquartierung der meisten Kompanien in der Folgezeit zwar drastisch gesenkt, im selben Maß aber fielen auch die Versorgungskapazitäten der Stadt durch die Abwanderung vor allem der zahlungskräftigen Einwohner.

Die Zuteilung der Quartiere an die Soldaten war verbindlich und genau. In der Praxis aber scherte man sich offensichtlich kaum um die Anweisungen der Quartiermeister. Schon im November 1525, also unmittelbar nach dem Einzug, wurde es den Soldaten ausdrücklich verboten, eigenmächtig die Unterkünfte zu wechseln. ${ }^{692}$ Dieses Verbot scheint aber trotz seiner häufigen Wiederholung kaum beachtet worden zu sein. Aus Mailand sind die Akten eines Schadensersatzprozesses überliefert, den Andrea Sormani nach dem Abzug der Spanier gegen zwei seiner Nachbarn führte, weil die Soldaten, die eigentlich eben diesen Nachbarn zugeteilt waren, sich unter Übergehung der Vorschriften stattdessen bei Sormani häuslich eingerichtet hatten. Die Aussagen der Zeugen in diesem Prozess sind sehr aufschlussreich für die Zustände, die im besetzten Mailand herrschten. In Zahlen ausgedrückt, sah der Fall folgendermaßen aus: Sormani hatte 6 Soldaten zugeteilt bekommen, in Wahrheit aber deren 15 beherbergt. Die zusätzlich angefallenen Kosten wollte er nun also von den Nachbarn erstattet bekommen, die zur Unterbringung der 9 überzähligen Soldaten verpflichtet gewesen waren. ${ }^{693}$ Aus den Aussagen der Zeugen geht hervor, dass das eigenmächtige Umziehen bei den Soldaten gängige Praxis war, vor allem wenn die Hausherren zumeist wegen der ständigen Übergriffe der Soldaten - die Stadt verlassen hatten, zogen die

\footnotetext{
688 Burigozzo, Cronaca di Milano, S. 472.

689 ASM Sforzesco, Cart. 1423. Schutzbrief von Guasto für das Frauenkloster Corpus Domini.

690 SALOMONI, Memorie, S. 62.

691 Auch wenn die Chronisten die Katastrophe in allen Farben ausmalen, werden die Verluste bei den in der Schätzung erfassten Einkünften nicht so hoch gewesen sein, da die Epidemie vor allem die unteren Bevölkerungsschichten heimsuchte, die weniger Möglichkeiten hatten, sich einer Ansteckung zu entziehen.

692 ACM Registri di lettere ducali 19, fol. $61^{\mathrm{V}}$.

693 IIPPAB Comuni 182, Punkt 3.
} 
Soldaten um und ließen sich anderswo bewirten. ${ }^{694}$ Bezeichnenderweise existiert ein Dekret von Charles de Bourbon aus dem September 1526, das den Einwohnern von Mailand das Abschließen der Türen gestattete. ${ }^{695}$ Wie aus dem Bericht des Chronisten Galeazzo Capella hervorgeht, nützte eine solche Maßnahme wenig, da die Soldaten ganz ungeniert Leitern anlegten und durch die Fenster oder über die Dächer einstiegen. ${ }^{696}$ Capellas Aussage ist keineswegs nur als Polemik zu verstehen, denn auch andere Quellen bestätigen diese Angewohnheit der Soldaten, die sich natürlich mit Vorliebe die Häuser der Reichen aussuchten, wo nicht nur die Räumlichkeiten komfortabler, sondern auch die Vorratskammern besser gefüllt waren. ${ }^{697}$ Wenn es in einem Quartier nichts mehr zu holen gab, zogen die Soldaten oft einfach ein paar Häuser weiter. Im Februar 1527 waren es die Reiter aus der Kompanie des Gouverneurs Antonio de Leyva selbst, die mit großem Spektakel in Mailand einzogen, die vielversprechendsten Häuser aussuchten und sie bezogen, indem sie die Türen eintraten. ${ }^{698}$ Danach entspannte sich die Lage vorübergehend, da ein großer Teil der Besatzer mit Bourbon abgezogen war. ${ }^{699}$ Das Problem des eigenmächtigen Umzugs indes blieb bestehen, wie einige Dekrete der Besatzungsmacht zeigen. Im September 1527 wurde Francesco Barbavaria aufgefordert, sich innerhalb eines Tages bei der Verwaltung zu melden, da die in seinem Haus einquartierten Landsknechte nach seiner Flucht unverzüglich zu den Nachbarn gezogen waren. ${ }^{700}$ Dieselbe Aufforderung erging im Januar 1528 an zwei Mailänder namens Alessandro Francesco und Giulio Antonio. Die Soldaten, die man ihnen zugeteilt hatte, lagen seit vier Monaten den Nachbarn auf der Tasche. ${ }^{701}$ Die Ursachen solcher Probleme lagen nicht allein bei den Soldaten: schon im Mai 1526 war es den Quartiermeistern verboten worden, Einquartierungen oder Verlegungen von Soldaten ohne die Zustimmung der örtlichen Behörden vorzunehmen. Soldaten, die keinen gültigen Quartierschein vorweisen konnten, durften die Hausherren den Zutritt verweigern. Das Dekret führt zur Begründung dieser Maßnahme aus, dass die Quartiermeister gegen Zahlung von Bestechungsgeldern den Soldaten die Unterkünfte ihrer Wahl zuteilten oder einem Soldaten mehrere Quartierscheine ausstellten, unter der Bedingung, dass ein Teil der von den Hausherren erpressten Gelder für sie abgezweigt wurde. ${ }^{702}$

Natürlich machte es für die Belastung der Bewohner einer Stadt einen großen Unterschied aus, ob ein ganzes Heer oder nur eine Besatzung zur Verteidigung der Stadt sich dort aufhielt. Und weil sich die Führung über diese Belastung und den Konfliktstoff im Klaren war,

\footnotetext{
694 IIPPAB Comuni 182, Punkt 17.

695 ACM Registri di lettere ducali 19, fol. 81 ${ }^{\mathrm{r}} \mathrm{f}$.

696 CAPELLA, Beschreibung und Geschicht, fol. $44^{\mathrm{r}}$.

697 Burigozzo, Cronaca Di Milano, S. 480.

698 SANUTO, Diarii, Bd. 44, Sp. 150.

699 IIPPAB Comuni 182, Punkt 3.

700 ASM Sforzesco, Cart. 1506, Dekret vom 3. 9. 1527.

701 ASM Sforzesco, Cart. 1506, Dekret vom 14. 1. 1528.

702 ASM Sforzesco, Cart. 1505, Dekret vom 11. 6. 1526.
} 
den die Einquartierungen auf so engem Raum auch für die Soldaten untereinander lieferten, bevorzugte sie eine Verlegung des Heeres in die Umgebung oder wenigstens in die Vororte. Wenn die Soldaten widersetzlich waren wie in Mailand, wo der Abzug im Januar 1527 rundheraus verweigert wurde, konnte man einzelne Abteilungen nur durch Anzahlungen auf den ohnehin längst überfälligen Sold zum Verlassen der Stadt bewegen. Solche Vorkommnisse lassen sich überall beobachten: entweder die Soldaten stellten als Bedingung für einen befohlenen Auszug die Bezahlung, oder die Hauptleute boten Bezahlung unter der Bedingung des Auszugs an. Die Abneigung der Soldaten ist nicht weiter verwunderlich, denn auf den Dörfern waren die Möglichkeiten der persönlichen Bereicherung stark eingeschränkt.

Daneben spielte die Furcht vor Plünderungen und Ausschreitungen eine Rolle. So schilderte Nájera dem Kaiser bereits im November 1521 die allgemein verbreitete Sorge, die Vororte von Mailand könnten beim Einzug des Heeres in Flammen aufgehen und sprach sich deshalb für eine Ausquartierung aufs Land aus. ${ }^{703}$ Aus den Briefen der Militärs spricht dabei in der Regel allerdings weniger die Sorge um das Wohl der Einwohner, als vielmehr wirtschaftliche Erwägungen, da von einer ausgeraubten und von unhaltbaren Zuständen in die Flucht getriebenen Bevölkerung keine Kontributionszahlungen zu erwarten waren. So wurde in der Folgezeit immer wieder darauf gedrängt, möglichst große Teile des Heeres aus der Stadt aufs Land zu verlegen. Dieses Bestreben setzte sich auch später fort, als die Spanier selbst die Herren im Staat waren. Die Präsenz von Soldaten in der Innenstadt wurde sehr ungern gesehen: unmittelbar nach dem Einzug des Heeres in Mailand im November 1525 brachte man die Soldaten in den Vororten unter und wenige Wochen später wurde ein Großteil des Heeres in die umliegenden Orte verlegt. Innenstadt, Vororte, Umland: diese drei ineinander liegenden Kreise waren überall wie eine Zielscheibe, auf der die Soldaten nach innen strebten und die Offiziere darauf bedacht waren, sie wieder nach außen zu drängen.

Charakteristisch für die folgenden Jahre ist in Mailand und Umgebung ein reges Kommen und Gehen, es war allerdings selten, dass das gesamte Heer sich über längere Zeit in der Stadt aufhielt. Der ständige und oft ohne das Wissen der Offiziere vollzogene Wechsel der Aufenthaltsorte der Soldaten macht es unmöglich, deren Zahl in der Stadt zu bestimmen. Es genügt ein Blick auf die Briefe der Informanten, die den abgesetzten Herzog mit Nachrichten aus der von seinen Feinden besetzten Hauptstadt versorgten: am 3. Januar 1527 schrieb Gerolamo Trivulzio, nach den Informationen eines seiner Spione habe eine Musterung in der Stadt 4.000 Soldaten ergeben, ${ }^{704}$ am 9. Januar korrigierte er die Zahl nach dem Bericht eines anderen Spions auf lediglich 1.500 Soldaten, ${ }^{705}$ einen Tag später schrieb Andrea Lo-

703 PACHECO Y DE LEYVA, La politica española, S. 162.
704 ASM Sforzesco, Cart. 1360. Gerolamo Trivulzio an Francesco Sforza, 3. 1. 1527.
705 ASM Sforzesco, Cart. 1360. Gerolamo Trivulzio an Francesco Sforza, 9. 1. 1527. 
redan, es blieben 2.500 Soldaten in der $\mathrm{Stadt}^{706}$ und in einem Brief vom 31. Januar war dann wieder von 5.000 die Rede. ${ }^{707}$ Die Verwirrung ist keineswegs verwunderlich, denn offenbar wussten noch nicht einmal die Offiziere so genau, wer gerade in Mailand untergebracht war und wer nicht: schon im März 1526 wurde in der Stadt ein Dekret ausgerufen, nach dem alle Soldaten, die in keiner Musterliste verzeichnet und nicht an der Belagerung des Kastells beteiligt waren, die Stadt sofort zu verlassen hatten. ${ }^{708}$ Solche Anordnungen verpufften zumeist wirkungslos, sie wurden offenbar noch nicht einmal von den regulären Soldaten beachtet, das zeigt allein ihre gebetsmühlenartige Wiederholung vor allem in den Jahren 1528 und 1529. Anfang März 1528 zog de Leyva das Heer in Pioltello zusammen, um sich mit den Landsknechten des Herzogs von Braunschweig zu vereinigen. Alle Soldaten in Mailand wurden aufgefordert, sich unverzüglich bei ihren Kompanien einzufinden und die Stadt zu verlassen. ${ }^{709}$ Doch gegen die Dickfelligkeit der Söldner war kein Kraut gewachsen: obwohl der Befehl mehrmals wiederholt wurde, wartete de Leyva drei Wochen später immer noch in Pioltello auf die letzten Nachzügler. Schließlich wurden die Hausbesitzer, bei denen sich noch Soldaten befanden, aufgefordert, diese bei der Besatzungsmacht anzuzeigen. ${ }^{710}$ Von Mai bis September 1528 und von April bis Oktober 1529 gab es jeden Monat neue Aufrufe an die Soldaten, die Stadt zu verlassen - der Erfolg war äußerst zweifelhaft.

Insgesamt wird man es in Mailand die meiste Zeit über mit einer Präsenz von 2.000 bis 6.000 Soldaten zu tun gehabt haben, bei einer Einwohnerzahl, die zu Beginn des untersuchten Zeitraums etwa bei 60.000 gelegen haben wird, vorübergehend aber durch die Flucht eines großen Teils der Bevölkerung auf 20.000 und weniger abfiel. Grob geschätzt, kam so auf etwa 10 Einwohner ein Soldat, dieses Verhältnis konnte allerdings schnell zu Gunsten der Soldaten kippen, etwa wenn in unruhigen Zeiten das ganze Heer in die Stadt geholt wurde, da die Bevölkerung in Scharen floh, sobald sich nur ein entsprechendes Gerücht verbreitete. ${ }^{711}$ Mit Tränen in den Augen, so berichtete Marino Caracciolo im Juli 1527 an den Kaiser, seien Abgesandte der Mailänder bei ihm gewesen und hätten ihn bekniet, dem Einzug des Heeres entgegenzuarbeiten, nachdem de Leyva die Soldaten wegen gärender Unruhen in den Vororten von Mailand zusammengezogen hatte. ${ }^{712}$ Solche Manöver waren durchaus als Drohgebärde zu verstehen: als im März 1526 die Stimmung in der Bevölkerung gegen die Besatzer kurz vor dem Siedepunkt stand, hatte de Leyva die Einquartierung von 6.000 Soldaten in der Stadt angedroht. ${ }^{713}$ Zwei Monate später, einen Auf-

\footnotetext{
706 ASM Sforzesco, Cart. 1360. Andrea Loredan an Francesco Sforza, 10. 1. 1527.

707 ASM Sforzesco, Cart. 1424. Absender unleserlich, 31. 1. 1527.

708 ASM Sforzesco, Cart. 1505, Dekret vom 4. 3. 1526.

709 ASM Sforzesco, Cart. 1506, Dekret vom 2. 3. 1528.

710 ASM forzesco, Cart. 1506, Dekret vom 23. 3. 1528.

711 FORMENTINI, Il ducato di Milano, Nr. 80, S. 486.

712 RAH Salazar y Castro, A/41, fol. $60^{\mathrm{r}} \mathrm{f}$.

713 SANUTO, Diarii, Bd. 41, Sp. 27.
} 
stand hatte die Stadt in der Zwischenzeit erlebt und ein zweiter sollte bald folgen, ließ er spanische Kompanien aus den umliegenden Ortschaften auf die Stadt rücken und im letzten Augenblick wieder umkehren. ${ }^{714}$ Auch innerhalb der Stadt wurde die Einquartierung von Soldaten die ganze Zeit der Besatzung über als Repressalie gegen renitente Bevölkerungsgruppen benutzt. Schon im Januar 1526 waren die Soldaten mit Vorliebe in den Pfarreien untergebracht worden, in denen der Treueschwur an den Kaiser verweigert wurde. ${ }^{715}$ Mit zunehmendem Geldbedarf wurde die Einquartierung schließlich zu einem unter vielen anderen Mitteln der Erpressung von Kontributionen. Im Juli 1527 ließ de Leyva verkünden, dass jedem, der seinen festgeschriebenen Anteil an einer frisch erhobenen Kontributionsforderung nicht bezahle, noch am selben Tag ungebetener Besuch von Seiten der Landsknechte ins Haus stünde. ${ }^{716}$ Wenn das Heer erst in die Stadt einrücke, so hieß es in einer weiteren unheilsschwangeren Bekanntmachung, werde große Unruhe in Mailand einkehren und jeder könne sich dann nur bei sich selbst beschweren. ${ }^{717}$

\section{Lebensmittelversorgung}

Die Versorgung einer besetzten Stadt mit Lebensmitteln war die meiste Zeit über das drängendste Problem der Soldaten wie der Bevölkerung. Vier Faktoren waren es, die eine hinreichende Versorgung immer wieder erschwerten:

1. Der Einzug der Soldaten ließ die Zahl der Verbraucher ansteigen. Dazu kam, dass den Heeren ein Tross folgte, der für jeden Soldaten manchmal mehrere weitere Personen in die Städte spülte.

2. Im Zuge der Entvölkerung besetzter Städte und ganzer Gebiete hatten auch viele Produzenten die Gegend verlassen.

3. Lebensmitteltransporte fielen oft umherstreifenden Marodeuren oder feindlichen Einheiten in die Hände.

4. Lieferanten betraten die Städte nur ungern aus Angst vor Übergriffen der Soldaten und vor Ansteckung in Zeiten von Epidemien.

Die Tatsache, dass der Tross von den militärischen Quellen so selten erwähnt wird, änderte nichts daran, dass die Trossangehörigen beim Einzug in eine Stadt genauso untergebracht werden mussten wie die Soldaten. In besetzten Städten scheint die Zahl der Frauen biswei-

\footnotetext{
714 SANUTO, Diarii, Bd. 41, Sp. 581.

715 SANUTO, Diarii, Bd. 40, Sp. 725.

716 FORMENTINI, Il ducato di Milano, Nr. 68, S. 470.

717 Formentini, Il ducato di Milano, Nr. 69, S. 471.
} 
len sogar höher gewesen zu sein als die der Soldaten, da ausgelagerte Einheiten die Frauen offenbar lieber in der Stadt zurückließen: als die spanische Besatzung im Mai 1516 aus Brescia abzog, sah man zwischen den Soldaten so viele Frauen, einige davon zu Pferd, andere auf Wagen, viele überdies mit Kindern auf dem Arm, dass sich die Beobachter einig waren, doppelt so viele Frauen wie Soldaten gesehen zu haben. ${ }^{718}$ Im Herzogtum Mailand sah es kaum anders aus: 200 Landsknechte, die dem Grafen von Caiazzo im Dezember 1528 in einen Hinterhalt gingen und unter der Bedingung des sofortigen Abzugs aus dem Kriegsgebiet freigelassen werden sollten, lamentierten, dass sie nicht ohne ihre Frauen nach Deutschland ziehen könnten, die ahnungslos in Mailand auf ihre Rückkehr warteten. Schließlich hatte Caiazzo ein Einsehen und ließ die Landsknechte nach Mailand zurückkehren, um die Frauen abzuholen. ${ }^{719}$ Genaue Zahlen sind indes wegen der vielen Widersprüche in den Quellen schwer zu bestimmen. Der Sondergesandte Lope Hurtado de Mendoza schrieb im Juli 1526 an den Kaiser, in Cremona seien 3.000 Soldaten und 2.000 weitere Personen zu versorgen. ${ }^{720}$ Wenn diese Zahl im Vergleich zu denen aus Brescia und anderen Beobachtungen gering erscheint, so erklärt sich das möglicherweise dadurch, dass Hurtado de Mendoza nur die Trossangehörigen zählte, die separat einquartiert und versorgt werden mussten, also vor allem Händler und Prostituierte, nicht aber die Personen, die zwar im Tross mitzogen, ansonsten aber als Ehefrauen, Geliebte oder Bedienstete einzelner Soldaten mit diesen zusammen in deren Quartiere zogen und von diesen versorgt wurden, also der militärischen Verwaltung nur indirekt zur Last fielen, der Bevölkerung aber wiederum um so mehr. Dass das selbstverständlich war, darin sind sich auch die Zeugen einig, die in Mailand im Prozess von Sormani gegen seine Nachbarn aussagten: die eigentlichen Kosten der Einquartierung, so die Quintessenz der Angaben, seien viel höher gewesen als von der Besatzungsmacht veranschlagt, weil die Soldaten zusätzlich noch ihre Liebchen und Diener ins Haus gebracht hätten. ${ }^{721}$ Es ist sicherlich nicht zu hoch gegriffen, wenn man auch in Mailand für jeden Soldaten zwei weitere Personen veranschlagt, die von der Bevölkerung beköstigt werden mussten. In den offiziellen Festlegungen wurden diese Zahlen allerdings erheblich geschönt: im Mai 1526 wurde bestimmt, dass für drei Soldaten ein Bediensteter und für sechs Soldaten ein Pferd zu versorgen sei. ${ }^{722}$

Dem gesteigerten Bedarf in der Stadt stand ein reduziertes Angebot auf dem Land gegenüber, zwei Umstände, die sich auf fatale Weise gegenseitig verstärkten: die Fluchtwelle, die durch die Anwesenheit des Besatzungsheeres ausgelöst wurde, ergriff keineswegs nur die Stadtbewohner, sondern auch die Bauern des Umlands, die von den ausgelagerten Kompanien terrorisiert wurden. In einem Schreiben, das dem Kaiser im Juni 1526 von Gesandten

\footnotetext{
718 SANUTO, Diarii, Bd. 22, Sp. 249.

719 SANUTO, Diarii, Bd. 49, Sp. 292.

720 GaYAngos, Calendar, Bd. 3, Teilbd. 1, S. 788.

721 IIPPAB Comuni 182, Punkt 16.

722 ASM Sforzesco, Cart. 1505, Dekret vom 26. 5. 1526.
} 
der Stadt Mailand überbracht werden sollte, heißt es, die Bauern seien so verängstigt, dass sie die Ernte nicht mehr einbrächten. ${ }^{723}$ Ein Jahr später waren die meisten dieser Bauern bereits geflohen und das Vieh war mitgenommen oder von den Soldaten weggetrieben worden. ${ }^{724}$ Ein weiteres Jahr später stürzten sich die Spanier zusammen mit den Landsknechten des Herzogs von Braunschweig wie ein Heuschreckenschwarm auf die Getreidefelder im Umland von Lodi, während sie die Stadt belagerten. ${ }^{725}$ Wann immer Soldaten auf dem Land unterwegs waren, war an eine geregelte Ernte nicht zu denken. Das Problem dabei war, dass Lebensmittel nicht nur mitgenommen und verbraucht, sondern auch vernichtet wurden, um zu verhindern, dass sie den Feinden in die Hände fielen. Von solchen Methoden konnten vor allem die Gegner der Spanier Gebrauch machen, die zwischen den von diesen besetzten Städten in der Lombardei umherzogen; was man nicht abtransportieren konnte, wurde auf der Straße verschüttet. ${ }^{726}$ Solcherlei Störungen machten sich sofort bemerkbar: als die Franzosen unter Bonnivet im September 1523 vor den Toren von Mailand die Mühlen verbrannten, hungerte innerhalb von vier Tagen die ganze Stadt. ${ }^{727}$ Kurz darauf, nach dem Abzug der Franzosen aus Monza, öffnete sich ein Korridor für die Getreidelieferungen und die Lage besserte sich schlagartig. ${ }^{728}$ Solche Versorgungslinien wurden immer wichtiger, je mehr das Umland von Mailand durch den Krieg verwüstet wurde und keine Lebensmittel mehr produzieren konnte. In den folgenden Jahren kam das Getreide zunächst aus der Gegend von Novara ${ }^{729}$ und später vom Comer See. ${ }^{730}$ Dass die Soldaten bei der Versorgung Vorrang vor den Bewohnern hatten, zeigt ein Dekret aus dem Juli 1528, durch das der Verkauf von Getreide in den Vororten von Mailand ausschließlich an Soldaten gestattet wurde. ${ }^{731}$ Im September 1528, als die Lebensmittelknappheit wegen der teilweise ausgefallenen Ernte bedrohliche Ausmaße annahm, wurden die Orte im Umkreis von 20 Meilen um Mailand durch ein Dekret des Gouverneurs aufgefordert, alle Lebensmittelvorräte in die Stadt zu bringen. ${ }^{732}$ Praktisch sah das so aus, dass die Lieferungen die meiste Zeit über nur mit bewaffneter Eskorte transportiert werden konnten. Als der Herzog von Urbino im Juli 1526 mit dem venezianischen Heer vor Mailand erschien und den Naviglio abgraben ließ, um den Lebensmitteltransport auf dem Wasserweg zu unterbinden, rückten täglich spanische Kompanien aus, die den Händlern aus Novara Geleitschutz gaben. ${ }^{733}$

23 SALOMONI, Memorie, S. 47.

724 SALOMONI, Memorie, S. 55.

725 BRugazzI, Giovanni Stefano: Vicende di Lodi dal 1528 al 1542. Hrsg. v. Andrea Timolati. In: Archivio Storico Lombardo 2 (1875). S. 385.

726 SANUTO, Diarii. Bd. 47, Sp. 197.

727 CAPELLA, Beschreibung, fol. $14^{\mathrm{V}}$.

728 CAPELLA, Beschreibung, fol. $15^{\mathrm{r}}$.

729 BNM, MS 20212, 43, 12.

730 Beretta, Gian Giacomo de' Medici, S. 83.

731 ASM Sforzesco, Cart. 1506, Dekret vom 21. 7. 1528.

732 ASM Sforzesco, Cart. 1506, Dekret vom 24. 9. 1528.

733 BNM, MS 20476, fol. 212v. 
Obwohl solche Transporte in erster Linie den Bedürfnissen des Heeres dienten, kam es zu dieser Zeit auch vor, dass die militärischen Ressourcen den Bewohnern zur Verfügung gestellt wurden, die selbst mit Geleitschutz ausgeschickt wurden, um Getreide zu holen. Burigozzo schildert, wie Männer, Frauen und Kinder von Trosswagen des kaiserlichen Heeres begleitet nach Abbiategrasso zogen und schwer bepackt zurückkehrten. ${ }^{734}$ Solche Bilder wiederholten sich, wann immer Abteilungen der feindlichen Heere das Umland unsicher machten. Noch im Juni 1529 waren die Geleitzüge wegen der Venezianer vorwiegend nachts unterwegs. ${ }^{735}$ Diese aber hatten selbst an entscheidenden Stellen den Bock zum Gärtner gemacht: im Oktober 1528 lief ein Prozess gegen zwei Statthalter der venezianischen Regierung in der Grenzstadt Crema, die gegen Schmiergeld die Lebensmitteltransporte nach Mailand durchgelassen hatten. ${ }^{736}$ Und selbst Sforza hatte aus Geldnot einige Geleitbriefe für Lieferungen in die von seinen Feinden besetzte Stadt verkauft. Offenbar peinlich berührt dadurch, dass die venezianische Regierung diesen Umstand gegenüber seinem Botschafter zur Sprache gebracht hatte, wies er auf deren Statthalter in Crema und Bergamo hin und behauptete, diese würden die Transporte sogar durch venezianische Truppen bis nach Mailand geleiten lassen. ${ }^{737}$

Auch in der Stadt wurden Maßnahmen ergriffen, mit denen die Lebensmittelversorgung der Soldaten und der Bevölkerung verbessert werden sollte. Nach der oben erwähnten Zerstörung der Mühlen vor den Toren von Mailand im September 1523 durch die Franzosen bestand neben der Anlieferung von Getreide ein weiteres Problem: selbst wenn Getreide ankam oder man sich aus Vorräten in der Stadt bediente, konnte kein Mehl daraus gemahlen werden. Man behalf sich durch die Konstruktion von Mühlen, die von Hand betrieben wurden und innerhalb kürzester Zeit die gesamte Herstellung von Mehl in der Stadt besorgten. Ihre Zahl wuchs schnell auf 500 an. ${ }^{738}$ Auch in anderen Städten der Lombardei bot sich dieses Bild. Im belagerten Pavia wurden sogar Grabsteine vom Friedhof geholt und zu Mühlsteinen umfunktioniert. ${ }^{739}$ Ab Juli 1526 wiederholte sich dieses Szenario in Mailand, weil die Feinde erneut vor den Toren der Stadt auftauchten. In den öffentlich ausgerufenen Dekreten der Besatzungsmacht häufen sich zu dieser Zeit die Bestimmungen, die der Versorgung der Stadt mit Lebensmitteln dienten und denen der vorangegangenen Jahre ähneln: die Handmühlen mussten wieder betriebsbereit gemacht werden, ${ }^{740}$ jeder Einwohner, der über ein Jahreseinkommen von mehr als 1.000 Dukaten verfügte, musste eine eigene Mühle bauen $^{741}$ und die Zahl der Mühlen in den Pfarreien wurde verdoppelt. ${ }^{742}$

\footnotetext{
734 Burigozzo, Cronaca di Milano, S. 458.

735 SANUTO, Diarii, Bd. 50, S. 441.

736 SANUTO, Diarii. Bd. 49, Sp. $110 \mathrm{f}$.

737 SANUTO, Diarii. Bd. 49, Sp. 265.

738 BNM, MS 18697, 46.

739 BNM, MS 20212, 43, 8.

740 ASM Sforzesco, Cart. 1505, Dekret vom 28. 6. 1526.

741 ASM Sforzesco, Cart. 1505, Dekret vom 29. 6. 1526.
} 
Um die Lieferung von Lebensmitteln nach Mailand lukrativer zu machen, hatte Pescara im November 1525 deren zollfreien Verkauf in der Stadt erlaubt. ${ }^{743}$ Antonio de Leyva dagegen machte sich als Gouverneur in den Jahren darauf eher durch Maßnahmen unbeliebt, die die Nahrungsmittelproduktion in den Dienst der Geldbeschaffung zur Bezahlung seiner Söldner stellten: im Januar 1527 wurde der Zoll wieder eingeführt und niemand durfte mehr auf eigene Rechnung Brot backen. ${ }^{744}$ Die folgende Zeit ist gekennzeichnet durch einen ermüdenden Wechsel zwischen Einführung und Aufhebung von Maßnahmen, durch die man versuchte, die Balance zwischen Entvölkerung des Staates und Auflösung des Besatzungsheeres zu halten. Im Juni 1528 wurde ausgerufen, dass jeder wegen der Lebensmittelknappheit ohne Zahlung von Abgaben Brot backen und in der Stadt verkaufen dürfe. ${ }^{745}$ Schon im September trat dann allerdings eine Verordnung in Kraft, nach der nur noch in vier großen Bäckereien in Mailand Brot gebacken werden durfte. ${ }^{746}$ An den Verteilerstellen wurde der kaiserliche Adler angebracht. ${ }^{747}$ Einschränkungen für den Handel mit Lebensmitteln wurden immer wieder mit der Begründung verkündet, Preistreiberei bei den Händlern unterbinden zu wollen. Das war aber ganz offensichtlich nur ein Vorwand, um die Kontrolle über den Markt zu behalten, denn in Wahrheit wurden die Lebensmittel durch die Verordnungen de Leyvas nicht billiger, sondern wegen der erhobenen Abgaben sogar teurer. Als das Backmonopol eingeführt wurde, mussten die Bäcker für jedes moggio ${ }^{748}$ Mehl, das sie von den Großhändlern kauften, eine Abgabe von 15 Lire entrichten. ${ }^{749}$ Gleichzeitig wurde die Einfuhr und sogar der Besitz von Wein mit einer Steuer belegt und Kontrolleure durch die Stadt geschickt, die die Vorräte inspizierten. ${ }^{750}$ Eine Flut von Verordnungen unterwarf alle Lebensmittelvorräte der Meldepflicht. ${ }^{751}$ Auch als im Dezember 1528 das Bakken in privaten Haushalten kurzfristig wieder erlaubt wurde, gingen Kontrolleure um und maßen die Getreidevorräte nach, so dass die Abgabe nicht ausgesetzt, sondern lediglich von den Bäckern auf die privaten Haushalte umgewälzt wurde. ${ }^{752}$ Schon im Januar 1529 wurde auch diese Maßnahme außer Kraft gesetzt und das Backmonopol wieder eingeführt. ${ }^{753}$ Erst im Juli 1529 wurden die vorangegangenen Verbote für den Rest der Besatzungszeit wenigstens insoweit gelockert, als jeder für den Eigenbedarf Brot backen durfte. ${ }^{754}$ Die Ergebnis-

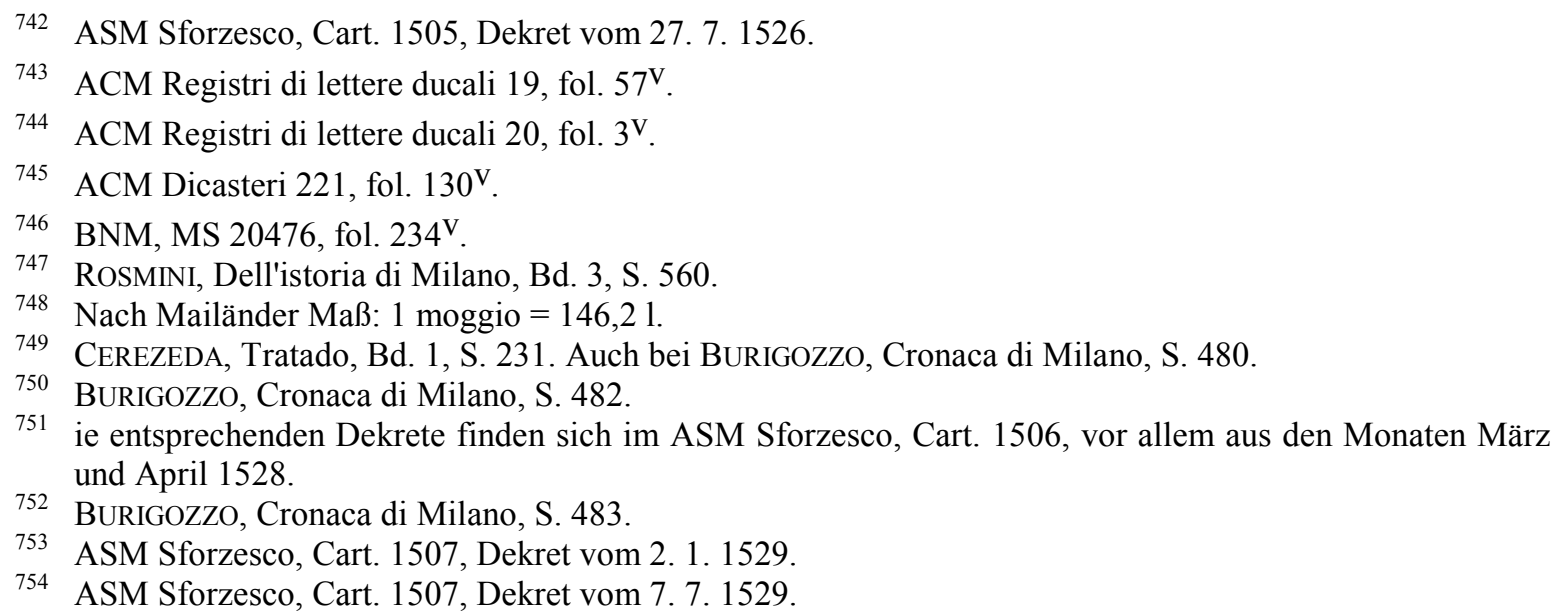


se dieser Politik schlugen sich in den Lebensmittelpreisen deutlich nieder, wie in der Folge gezeigt wird.

\section{Lebensmittelpreise}

Wie oben gesehen, beeinflusste nicht nur die Anwesenheit der Besatzungssoldaten, sondern auch die militärische Situation im Umland von Mailand die Versorgungslage in der Stadt. Deren Schwankungen drückten sich natürlich in erster Linie in den Lebensmittelpreisen aus. Da die Verpflegung von Einwohnern und Soldaten zumeist das drängendste Problem in einer besetzten Stadt war, lohnt sich ein Blick auf die Preise der wichtigsten Lebensmittel, um zu beurteilen, wie die Besatzung und die Aktionen im Umland sich auf diesen existentiell bedeutenden Bereich des Lebens in der Stadt auswirkten. Die Amplitude der Preisschwankungen, so könnte man es anders ausdrücken, ist ein Indikator für den Grad der Bedrohung der Lebensgrundlage, in diesem Fall durch den Krieg.

Zunächst ein paar grundsätzliche Anmerkungen. Ein durchschnittlicher Konsument verbrauchte am Tag etwa 600 bis 700 g Brot, was einem Jahresverbrauch von etwa 2 moggia Getreide nach Mailänder Maß entspricht. Soldaten verbrauchten etwa um die Hälfte mehr, wahrscheinlich, weil sich nur wenige Kinder beim Heer befanden, die den Schnitt drückten. Ein moggio Getreide wiederum kostete in den Jahren vor dem Krieg zwischen 6 und 10 Lire. Der Mehrpreis von Brot gegenüber der entsprechenden Menge Getreide betrug etwa $25 \%$, so dass sich insgesamt Ausgaben von etwa einem Soldo für eine Tagesration Brot oder 20 Unzen ergaben. ${ }^{755}$ Der Preis für Wein bewegte sich in den Jahren vor dem Krieg etwa zwischen 2 und 5 Lire pro brenta. ${ }^{756}$ Geht man von einem Tageskonsum von 11/2 1 aus, so ergeben sich hier tägliche Ausgaben von ein bis zwei Soldi pro Person. ${ }^{757}$ Um diesen

755 Die Zahlen aus Quellen und Studien fügen sich hier überraschend gut ineinander: FORMENTINI, Il ducato di Milano, S. 573 spricht von 500 g Mehl am Tag, was 650 g Getreide entspricht; ZANETTI, DANTE E.: Problemi alimentari di una economia preindustriale. Cereali a Pavia dal 1398 al 1700. Turin 1964. S. 60, von 700 g; FERRARIO, Statistica, S. 226 von 2 moggia im Jahr für Stadtbewohner und 3 moggia für Soldaten. In einem Dekret für die Versorgung der Soldaten wird die Tagesration Brot mit 28 Unzen oder 760 g angegeben. ASM Sforzesco, Cart. 1506, Dekret vom 26. 5. 1526. Nach Vigo, GiovanNi: Real Wages of the Working Class in Italy: Building Workers' Wages (14th to 18th Century). In: Journal of European Economic History 3 (1974). S. 395 und ZANETTI, Problemi, S. 61f. entsprechen 1001 Getreide $70 \mathrm{~kg}$ Brot bei einer Ergiebigkeit von etwa 90 \%. MAGALDI, V./FABRIS, R. (HRSG.): Notizie sui salari e sui prezzi di alcune derrate alimentari e prodotti industriali nelle città di Milano, Venezia, Genova, Firenze, Pisa, Mantova, Lucca e Forlì nei secoli XIII al XVIII. In: Annali di statistica. Serie 2a , Bd. 3 (1878). S. 9 geben den Mehrpreis von Brot gegenüber Getreide mit $23 \%$ an. Und schließlich FERRARIO, Statistica, S. 227 nennt die Preise für die Jahre vor dem Krieg, die zwischen 6 und 10 Lire pro moggio schwanken.

756 Nach Mailänder Maß: 1 brenta = 75,55 1 .

757 Die Preise für den Wein bei FERrARIO, Statistica, S. 254. Der überraschend hoch erscheinende Tageskonsum von Wein ergibt sich aus den präzisen Angaben über den Verbrauch der Stadt Florenz. Nach VARCHI, Storia Fiorentina, Bd. 2, S. 72 verbrauchten die 70.000 Einwohner von Florenz jährlich 840.000 barili Wein, also $1 \frac{1}{2} 1$ pro Kopf und Tag. Auch andere Quellen gehen von einem für heutige Zeiten unge- 
gering scheinenden Zahlen Leben einzuhauchen, sollte darauf hingewiesen werden, dass ein Handwerksmeister auf dem Bau in Mailand im Sommer 1525 nach den offiziellen Lohnfestschreibungen 15 Soldi am Tag verdiente, ein Erntearbeiter 10 Soldi und ein Tagelöhner in der Stadt 8 Soldi. Frauen verdienten überall die Hälfte. ${ }^{758}$ Einige erschwerende Umstände kommen noch hinzu: die Arbeit war oft Saisonarbeit und auch in der Saison wurde zwar jeden Tag gegessen, aber nicht jeden Tag gearbeitet, ferner fielen neben den Grundnahrungsmitteln Brot und Wein auch noch etliche andere Kosten an, und schließlich hatten die meisten eine Familie zu ernähren. Aus diesen Umständen ergibt sich, dass fast der gesamte Verdienst eines normalen Arbeiters für Lebensmittel aufgewendet wurde und daher eine Erhöhung der Lebensmittelpreise durchaus die Lebensgrundlage einer Mehrheit der Bevölkerung bedrohen konnte.

Es soll nun die Preisentwicklung einiger Grundnahrungsmittel in Mailand vom Zeitpunkt des Einmarsches der Spanier in der Lombardei im November 1521 bis zu deren Abzug im Dezember 1529 nachgezeichnet werden. Die angegebenen Werte können nur eine ungefähre Vorstellung von den Größenordnungen geben, innerhalb derer die Preise schwankten, da es sich um Angaben von Augenzeugen handelt, vor allem aus der Chronik von Burigozzo und aus den Berichten der venezianischen Spione an die Regierung, mithin um Beobachtungen, die bisweilen Verzerrungen unterworfen waren. Es wurden zwar auch die Akten des Tribunale della Provvisione berücksichtigt, der obersten Behörde in Mailand, die unter anderem auch für die Preisregulierung zuständig war, ${ }^{759}$ doch diese geben die Preisschwankungen nicht in ihrem vollen Ausmaß wieder, weil sie eben versuchten, selbige einzudämmen und daher eher die angestrebten als die herrschenden Zustände beschreiben. Akten, die eine lückenlose Nachvollziehung der tatsächlichen Preise erlauben, sind aus Mailand leider nicht überliefert.

Zunächst zu Getreide und Mehl. ${ }^{760}$ Zu Beginn des Krieges hielt sich der Preis noch im oben genannten Vorkriegsrahmen unter 10 Lire pro moggio. Bis zum September 1523 bezahlte man in Mailand für Mehl nicht mehr als 8 Lire, dieser Preis schoss mit der Ankunft des französischen Heeres vor der Stadt dann bis auf 28 Lire hoch. ${ }^{761}$ Der Markt reagierte nicht nur empfindlich, sondern auch schnell. Nach dem Abzug der Franzosen normalisierten sich die Preise wieder, die nächste Preisexplosion stand den Mailändern im Juli 1526 ins Haus, diesmal waren es die Venezianer, die vor den Toren der Stadt die Lebensmittellieferungen

\footnotetext{
wöhnlich hoch erscheinenden Pro-Kopf-Verbrauch aus.

758 ACM Dicasteri 221, fol. 54 ${ }^{\mathrm{r}}$.

759 Zu deren Kompetenzen: VisCONTI, AlessANDRO: Storia di Milano. Mailand 1952. S. 429; CAZZAMINI MUSSI, FRANCESCO: Milano durante la dominazione spagnola (1525-1706). Mailand 1947. S. 58.

760 Die Preisunterschiede zwischen Getreide und Mehl betragen, wie oben gesehen, nur etwa $25 \%$. Da die Berichte bei den Angaben willkürlich zwischen Getreide und Mehl wechseln und die Preise ohnehin Schwankungen im dreistelligen Prozentbereich unterworfen sind, werden hier in der Folge beide zusammen abgehandelt.

761 Burigozzo, Cronaca di Milano, S. 441.
} 
blockierten. Der Preis für Mehl ging diesmal bis auf 32 Lire hoch $^{762}$ und hielt sich offenbar lange auf diesem Niveau: noch im November gab es Beschwerden, dass die Bäcker das Brot immer noch zum Vierfachen des üblichen Preises verkauften, was zeigt, dass sich die Teuerung des Getreides proportional bis zum Endverbraucher auswirkte. Das Tribunale della Provvisione setzte den Preis zwar herab, er blieb aber auf dem Zweieinhalbfachen des Normalpreises. ${ }^{763}$ Mit der Verlagerung des Krieges nach Süden und wegen des Abzugs eines Teils des Besatzungsheeres aus Mailand im Februar 1527 fielen die Preise für Mehl wieder für kurze Zeit auf den Vorkriegsstand von 8 Lire, ${ }^{764}$ bevor sie abermals nach oben schnellten: im März zahlte man schon wieder 16 Lire, im April berichtet Burigozzo von 40 und im Mai von 52 Lire, ${ }^{765}$ und ein venezianischer Berichterstatter gab schließlich im Juni einen Spitzenwert von 60 Lire an. ${ }^{766}$ Für den Rest des Jahres pendelte sich der Preis bei etwa 30 Lire ein. ${ }^{767}$ Da zu dieser Zeit kaum militärische Aktionen im Umland stattfanden, hingen der Anstieg und die starken Schwankungen wohl vor allem mit den Maßnahmen des Gouverneurs zur Besteuerung zusammen. Schon im August des Jahres 1527 gab es in Mailand die ersten Hungertoten. ${ }^{768}$ Aus allen Berichten spricht das Entsetzen über die insgesamt katastrophale Versorgungslage. Die aber sollte im folgenden Jahr noch schlimmer werden: im März 1528 kletterte der Preis für Getreide auf 50 Lire $^{769}$ und hielt sich den ganzen Sommer über auf diesem Stand. ${ }^{770}$ Ursachen waren die fortschreitende Verwüstung des Landes vor allem durch das berüchtigte Heer des Herzogs von Braunschweig und eine Missernte. Beide suchten nicht nur Mailand, sondern die ganze Lombardei heim. Im September kam dann auch noch die Einführung des Backmonopols durch de Leyva hinzu, so dass man für Brot schließlich das Achtfache des üblichen Preises bezahlte. ${ }^{771}$ In der Folgezeit war der Preis starken Schwankungen ausgesetzt, fiel aber nicht mehr unter das Dreifache des Vorkriegswertes. ${ }^{772}$ Inzwischen hatte sich in Mailand offenbar ein Schwarzmarkt zur Umgehung der Abgaben etabliert, doch selbst hier lagen die Preise bei ungefähr 24 Lire für Mehl, wie aus einem Dekret hervorgeht, durch das dem Händler Pietro de Vigletio im August 1529 die Lizenz entzogen wurde, weil er einen Bäcker beliefert hatte, ohne die Wa-

\footnotetext{
762 Burigozzo, Cronaca di Milano, S. 458.

763 ACM Dicasteri 221, fol. 86V .

764 Burigozzo, Cronaca di Milano, S. 465.

765 Burigozzo, Cronaca di Milano, S. 469.

766 SANUTO, Diarii, Bd. 45, Sp. 344.

767 Burigozzo, Cronaca di Milano, S. 470 gibt für den Juli 32 Lire an; SANUTO, Diarii, Bd. 46, Sp. 92, nennt für den September zunächst 25 Lire, dann einen Anstieg auf 36; nach BURIGOZZO, Cronaca, S. 475 stand der Preis im November immer noch bei 32 Lire.

768 FORMENTINI, Il ducato di Milano, S. 362.

769 SANUTO, Diarii, Bd. 47, Sp. 202.

770 Im April waren es nach SANUTO, Diarii, Bd. 47, Sp. 267 für Mehl 52 Lire; kurz darauf, immer noch SANUTO, Diarii, Bd. 47, Sp. 333, sogar 55 Lire für Getreide; nach BURIGOZZO, Cronaca, S. 478 im Juni 48 Lire für Getreide.

771 BNM, MS 20476, fol. 234V.

772 Burigozzo, Cronaca di Milano, S. 482 nennt für den Dezember 28 Lire für Mehl.
} 
re zur Besteuerung zu deklarieren. ${ }^{773}$ Erst nach dem Abzug der letzen kaiserlichen Soldaten im Januar 1530 fiel der Getreidepreis auf einen halbwegs erträglichen Wert von 12 Lire. $^{774}$ Die Preise anderer Lebensmittel folgen denen des Getreides in ihren Schwankungen, allerdings in der Regel mit geringerer Amplitude. Kalbfleisch etwa wurde vor dem Einmarsch der Spanier für 4 Soldi pro Pfund verkauft. ${ }^{775}$ Im Juli 1526 zog der Preis dann kurzfristig sehr stark auf 22 Soldi an, ${ }^{776}$ lag im November aber wieder bei 10 Soldi. ${ }^{777}$ Kurz darauf wurde der Preis vom Tribunale della Provvisione auf 7 Soldi festgesetzt. Die militärischen Operationen im Umland hätten eine Zeit lang die Viehtransporte unmöglich gemacht und dadurch die Preise für Fleisch in astronomische Höhen getrieben, hieß es in der Bekanntmachung. Da nun die Gefahr gebannt sei, gebe es keinen Grund mehr, die alten Preise aufrecht zu erhalten. ${ }^{778}$ Ganz offensichtlich spekulierten viele Händler darauf, die unsichere Lage zu ihrem Vorteil auszunutzen. In der folgenden Zeit wurde der Preis zunächst noch weiter gesenkt, im Oktober 1529 aber auf einen offiziellen Höchststand von 10 Soldi gesetzt. ${ }^{779}$ Die häufige Wiederholung der Preisfestlegungen, die Eindringlichkeit der daran geknüpften Mahnungen und vor allem immer wieder die Aussagen der Zeugen belegen, dass Übertretungen eher die Regel als die Ausnahme waren. So blieb der Preis für Kalbfleisch bis zum Ende der Besatzung immer auf einem Stand, der mindestens dem Dreifachen des normalen Marktpreises entsprach.

Schließlich soll noch ein Blick auf den Wein geworfen werden. Der Preis lag hier, wie oben erwähnt, zwischen 2 und 5 Lire pro brenta. Die Anwesenheit des französischen Heeres hatte offenbar auf den Wein keinen Einfluss, denn dessen Preis blieb im September 1523 stabil bei 5 Lire. ${ }^{780}$ Im Juli 1527 machte er dann einen Sprung auf 15 Lire, weil das ausgelagerte Besatzungsheer im Anmarsch war. ${ }^{781}$ Die Hungersnot, die nun folgte, beeinflusste auch den Weinpreis, der in den folgenden Monaten noch weiter stieg, im April 1528 gleichzeitig mit dem Getreide - einen vorläufigen Höchststand von 24 Lire erreichte ${ }^{782}$ und dann zwar wieder abfiel, aber wie das Getreide nicht unter das Dreifache des Vorkriegswertes kam. Im Juni 1529 schoss der Preis noch einmal kurzfristig auf 50 Lire, dann fiel er steil ab und lag schon im Juli 1529 bei 8 Lire. ${ }^{783}$ Noch vor dem Abzug der Spanier hatte sich der Preis mit 6 Lire fast wieder normalisiert. ${ }^{784}$

\footnotetext{
773 ACM Dicasteri 221, fol. 161 V.

774 TreCCANi DEgLi AlFieri, Storia di Milano, S. 310.

775 ACM Dicasteri 221, fol. $41^{\mathrm{V}}$.

776 Burigozzo, Cronaca di Milano, S. 458.

777 SANUTO, Diarii, Bd. 43, Sp. 220.

778 ACM Dicasteri 221 , fol. $85^{\mathrm{V}_{\mathrm{f}}}$.

779 ASM Sforzesco, Cart. 1507, Dekret vom 27. 10. 1529.

780 SANUTO, Diarii, Bd. 34, Sp. 474.

781 Burigozzo, Cronaca di Milano, S. 470.

782 SANUTO, Diarii, Bd. 47, Sp. 333.

783 Burigozzo, Cronaca di Milano, S. 496.

784 Burigozzo, Cronaca di Milano, S. 498.
} 
Die Auswertung der Lebensmittelpreise lässt eine Reihe von Beobachtungen zu, die grundlegend für das Verständnis der alltäglichen Situation der besetzten Stadt Mailand sind. Zunächst einmal verblüfft die Heftigkeit der Preisschwankungen, und zwar sowohl in Bezug auf den Ausschlag, als auch auf die Schnelligkeit. Die Schwankungen sind ein Indikator sowohl für die Lage im Umland, als auch in der besetzten Stadt selbst. Die Gegenwart von Soldaten allein trieb die Preise allerdings nicht in die Höhe, so lange die Versorgungswege frei waren und die Situation in der Stadt nicht außer Kontrolle geriet. Tendenziell kann man den untersuchten Zeitraum in zwei Phasen einteilen: eine erste von 1521 bis 1526, in der die Lebensmittelpreise zwar starken Schwankungen unterlagen, aber zwischendurch immer wieder annähernd die Werte aus der Zeit vor dem Krieg erreichten, und eine zweite von 1527 bis 1529, in der die Preise durchweg mindestens das Dreifache des üblichen Preises ausmachten und in vergleichbarem Maß nur noch nach oben ausschlugen. Mit anderen Worten: für lange Zeit war das Leben im besetzten Mailand mindestens dreimal so teuer wie zuvor. Vor allem die demografischen Auswirkungen der Besatzung bestätigen diese Einteilung. Die Tatsache, dass die Lebenshaltungskosten sich innerhalb von kurzer Zeit fast verzehnfachen konnten, war an sich schon schlimm genug, als solche Verhältnisse dann ab 1527 zum Dauerzustand wurden, waren viele zur Auswanderung gezwungen, wenn sie dem Hungertod entgehen wollten.

Ein Seitenblick auf einige andere Fälle zeigt, dass eine Amplitude der Preisschwankungen von dieser Größenordnung unter dem Einfluss von Krieg und Besatzung keine Seltenheit war. In Pavia lag der Getreidepreis vor dem Krieg bei etwa 100 Soldi pro sacco. ${ }^{785}$ Bereits 1523 verdoppelte er sich, fiel dann 1525 noch einmal auf den Vorkriegswert ab und explodierte 1528 auf 450 Soldi, ein Wert, der auch im folgenden Jahr annähernd gehalten wurde. ${ }^{786}$ Diese im Vergleich zu Mailand noch stärkere Teuerung erklärt sich aus der Tatsache, dass Pavia durch den Krieg schwerer in Mitleidenschaft gezogen wurde als Mailand: 1528, im Jahr der heftigsten Preissteigerung, hatte die Stadt drei Plünderungen hinter sich und war zu weiten Teilen zerstört.

\section{Belastung der Haushalte}

Die Teuerung machte es den Einwohnern in Mailand schwer, die Soldaten zu beköstigen. Genau das aber wurde meistens von ihnen erwartet. Es ist leicht vorstellbar, dass drei oder vier Soldaten, die sich rücksichtslos an allen Vorräten bedienten, auch einer wohlhabenden Familie in Zeiten der Teuerung finanziell das Genick brechen konnten. Als das kaiserliche

\footnotetext{
785 Nach Paveser Maß: 1 sacco = 122,3 1.

786 ZANETTI, Problemi alimentari, S. 157.
} 
Heer im November 1525 in Mailand einzog, hatte Pescara versprochen, dass die Soldaten für ihren Verzehr aufkommen würden, bezeichnenderweise noch vor dem endgültigen Bruch mit dem Herzog, als sei die Partnerschaft mit diesem ohnehin nicht verbindlich für die Soldaten. ${ }^{787}$ Dass schon eine Woche später der venezianische Botschafter in Mailand an seine Regierung schrieb, die Ausgaben für die in seinem Haus einquartierten Soldaten würden ihn noch ruinieren, zeigt im Zusammenhang mit dem Versprechen Pescaras nur, dass die Offiziere ihre Soldaten nicht davon abhalten konnten, auf Kosten der Bevölkerung zu leben, solange der Sold nicht bezahlt war. ${ }^{788}$ Und der war zum Zeitpunkt des Einzugs in Mailand alles andere als bezahlt: allein der spanischen Infanterie schuldete man im November 1525 mindestens 5 Monate Sold. ${ }^{789}$ Die Briefe von Nájera sprechen eine deutliche Sprache, was die Zusammenhänge zwischen dem ausbleibenden Sold und der Verweigerung der Bezahlung durch die Soldaten betrifft. Auf dem Land, wo vor allem die Kavallerie der Kontrolle durch die Autoritäten weitgehend entzogen war, bestand das Problem schon seit dem Beginn des Krieges: "... este exército come sobre los pueblos: digo que ansi es, porque no avia dineros para les pagar ..."790 Die Tatsache, dass ein solches Verhalten - "vivere a discrezione" nennen es Vorgesetzte wie Opfer - auch von den Offizieren durchaus als Missstand angesehen wurde, berechtigt zu der Frage nach seiner Selbstverständlichkeit. Es gibt kaum Stellen in den Briefen und Berichten der Zeugen, die ausdrücklich von einer finanziellen Beteiligung der Soldaten an den täglichen Ausgaben sprechen, auch wenn eine solche eigentlich Vorschrift war und die Regel hätte sein müssen. ${ }^{791}$ Nach dem Bruch mit dem Herzog verschlimmerten sich die Zustände noch erheblich. Hurtado de Mendoza klagte schon im Dezember 1525, dass von 10.000 Soldaten des Heeres gerade 300 für ihre Verpflegung aufkämen. ${ }^{792}$ Gleichzeitig schwappte das Problem auf die Stadt über, im Januar 1526 schrieb Hurtado de Mendoza: "Los pobres labradores no tienen qué dalles, y no es maravilla, porque ha muchos días que lo dan sin discrecion á más de XV mil caballos y XX mil personas sobre todas las malas venturas pasadas, ya no pueden ni tienen con qué sufrir." ${ }^{793}$ Je weiter sich die Situation im besetzten Mailand verselbständigte, desto selbstverständlicher wurde das Leben "a discrezione" durch die Soldaten. Im Juli 1526 war es so weit, dass die Einwohner die Lebensmittel vor den Soldaten versteckten. ${ }^{794}$

Die Behauptung einiger Offiziere, den Soldaten bleibe oftmals keine Wahl, als auf Kosten der Bevölkerung zu leben, ist durchaus berechtigt angesichts des doppelten Geldproblems von Teuerung und ausbleibendem Sold. Andererseits muss jedoch gesagt werden, dass die

\footnotetext{
787 ACM Registri di lettere ducali 19, fol. $57^{\mathrm{r}}$.

788 SANUTO, Diarii, Bd. 40, Sp. 285.

789 SANUTO, Diarii, Bd. 40, Sp. 423.

790 PACHECO Y DE LEYVA, La politica española, S. 330.

791 BELLI, De Re militari, fol. 36V .

792 GaYAngOs, Calendar, Bd. 3, Teilbd. 1, S. 533.

793 RodrigueZ VILLA, Italia desde la batalla de Pavia, S. 110f.

794 RAH Salazar y Castro, A/38, fol. $61^{\mathrm{r}}$.
} 
Soldaten sich keine Mühe gaben, die Familien der belegten Haushalte zu schonen. Sie benahmen sich wie die großen Herren und stellten unentwegt Forderungen. Es ist schwer zu sagen, über welche Zeiträume die Bevölkerung eine solche Belastung aushalten musste, da die einzelnen Aussagen immer nur Schlaglichter auf die Zustände in den Städten werfen. Wenn neue Einheiten einzogen, häuften sich die Klagen; dass sie danach abebbten, ist eher ein Zeichen dafür, dass sich die Zeugen an den Zustand gewöhnten, als dafür, dass dieser Zustand sich besserte. Die meiste Zeit der Besatzung über wurde wohl tatsächlich "a discrezione" gelebt, ein Umstand, der auch als alltägliche Ausplünderung bezeichnet werden kann.

Die Offiziere standen dem Problem weitgehend machtlos gegenüber. Da kein Geld vorhanden war, um die enormen Soldrückstände auszugleichen, versuchten sie entweder durch kleinere Zahlungen die Soldaten dazu zu bringen, für ihre Verpflegung aufzukommen, oder sie legten eine Tagesabgabe fest, die die Bewohner an die Soldaten zu entrichten hatten, um die Übergriffe so in halbwegs kontrollierbarem Rahmen zu halten. In Mailand fügten diese Tagesabgaben dem Katalog der Beschwerden über die Besatzer eher einen Punkt hinzu, als dass sie dazu beigetragen hätten, die Aufwendungen der Bevölkerung für die Nahrungsmittelbeschaffung auf ein erträgliches $\mathrm{Maß}$ zu senken. Sie scheinen im Gegenteil oft als Einladung missverstanden worden zu sein, die von den Offizieren festgelegten Forderungen eigenmächtig in die Höhe zu schrauben. Das System der Tagesabgaben war schon zu Beginn des Krieges in der Lombardei eingeführt worden, zunächst auf dem Land. Die Festlegungen waren sehr genau, um Missbrauch zu vermeiden: im Oktober 1522 schrieb Nájera an den Kaiser, die Bauern, die man zur Unterbringung der schweren Kavallerie verpflichtet hatte, müssten jeweils einen Reiter mit vier Pferden beherbergen, diesem jeden Tag eineinhalb Reales - etwa 15 Soldi - auszahlen und ihm Kochgeschirr sowie Heu und Stroh für die Pferde zur Verfügung stellen. ${ }^{795}$ Im Dezember 1525 galten dieselben Bedingungen, die Abgabe aber war inzwischen auf einen halben Dukaten verdreifacht worden. ${ }^{796}$ Zur gleichen Zeit schlug Hurtado de Mendoza eine solche Regelung auch für die in Mailand einquartierte Infanterie vor. ${ }^{797}$ Wann seine Vorschläge zum ersten Mal zur Anwendung kamen, ist nicht ganz klar, die erste Nachricht darüber stammt von einem Informanten der venezianischen Regierung aus dem April 1526. Demnach gab es offenbar unterschiedliche Regelungen für Spanier und Deutsche: die Landsknechte bekamen Brennholz, Öl, Salz und Bettwäsche, die Spanier nur Bettwäsche und 10 Soldi am Tag. ${ }^{798}$ Abgesehen davon, dass die Soldaten sich ohnehin alles nahmen, was ihnen gefiel, schien diese Summe nicht zu genügen: im September 1526 erging ein Dekret von Bourbon, nach dem jeder Soldat 20 Soldi am

\footnotetext{
795 PACHECO Y DE LEYVA, La politica española, S. 330.

796 SANUTO, Diarii, Bd. 40, Sp. 500.

797 Gayangos, Calendar, Bd. 3, Teibd. 1, S. 533.

798 SANUTO, Diarii, Bd. 41, Sp. 170.
} 
Tag zu bekommen hatte und dafür seine gesamte Verpflegung selbst bezahlen musste. ${ }^{799}$ Auf den Monat hochgerechnet, ergibt sich die Summe von 6 Dukaten, das Doppelte des üblichen Soldes, eine Erhöhung, mit der man wohl der Steigerung der Lebensmittelpreise Rechnung tragen wollte. Für die folgende Zeit sind unterschiedliche Beträge für die Tagesabgaben überliefert, offenbar wurde das System immer wieder abgewandelt. Im Januar 1527 waren Landsknechte einquartiert, die 10 Soldi am Tag bekamen, ${ }^{800}$ Burigozzo berichtet im August desselben Jahres von 15 Soldi $^{801}$ und im September ist für einige frisch eingezogene Kompanien abermals von 20 Soldi die Rede. ${ }^{802}$ Aus einer Reihe von Dekreten aus dem Jahr 1528 geht hervor, dass die Abgaben jeweils für 5 Tage im Voraus geleistet wurden. ${ }^{803}$

Die Autoritäten versuchten, das Gewicht möglichst gleichmäßig zu verteilen, die Mailänder indes waren froh, wenn sie sich durch eine tägliche Abgabe die Soldaten vom Hals halten konnten. ${ }^{804}$ Neben den vielen anderen Unannehmlichkeiten, die eine Einquartierung mit sich brachte, konnte das nämlich auch teuer werden. Einer der Zeugen im Prozess von Sormani erinnert sich, dass der Verwalter, den Sormani für die Zeit seiner Abwesenheit bestellt hatte, nicht mit den Soldaten im Haus bleiben wollte, weil er fürchtete, dass diese über die üblichen Tagesabgaben hinaus weitere Zahlungen von ihm verlangen würden. Ein anderer Zeuge sagt aus, dass es wegen der großen Unordnung noch nicht einmal möglich war, Buch über die Ausgaben zu führen, oder besser gesagt: dass der Verwalter sich nicht traute, diese schriftlich festzuhalten, aus Angst, die Soldaten könnten seine Aufzeichnungen entdecken und ihn weiteren Drangsalierungen aussetzen. ${ }^{805}$ Diese Aussage deutet darauf hin, dass viele Soldaten die unübersichtliche Situation dazu nutzten, den Hausbesitzern höhere Abgaben abzupressen. Für die tatsächliche Höhe der Tagesabgaben geben die Zeugen Summen zwischen 26 und 32 Soldi an. ${ }^{806}$ Am Ende machte Sormani einen Betrag von 30 Soldi am Tag zur Grundlage seiner Schadensersatzforderung, die sich insgesamt auf 4.500 Lire belief. ${ }^{807}$ Nimmt man diese Zahl und setzt sie zu den oben genannten Kriterien für die Einquartierung der Soldaten nach der Schätzung von 1524 in Beziehung, so ergibt sich, dass für den Unterhalt der Soldaten ein Fünftel des geschätzten Einkommens aufgewendet werden musste. Dieses Einkommen aber dürfte in der Zwischenzeit wegen der Kriegsschäden und durch den Rückgang des Wirtschaftslebens bei den meisten Mailändern schwere

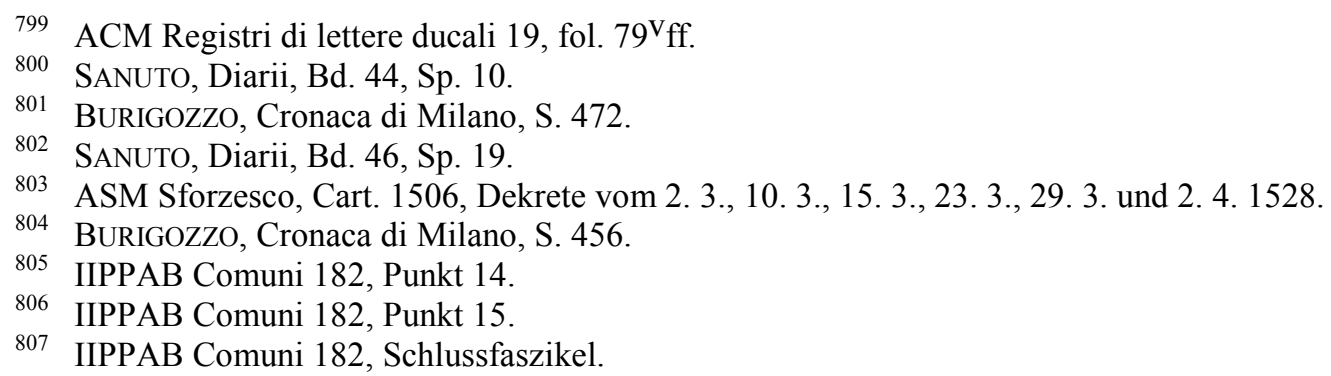


Einbrüche erlitten haben, so dass der für die Versorgung der Soldaten aufgewendete Anteil des Einkommens in Wahrheit höher war und vielleicht die Hälfte von diesem betrug.

Die Abgaben wurden nicht allein von den Hausbesitzern geleistet, bei denen die Soldaten einquartiert waren, sondern auch von allen anderen, bei denen noch etwas zu holen war. Die Last wurde nach den finanziellen Möglichkeiten der Einwohner auf deren Schultern verteilt: nach Burigozzo bezahlten einige bis zu 20 Dukaten am Tag, eine Summe, die nach dem oben berechneten Schlüssel ein geschätztes Jahreseinkommen von rund 35.000 Dukaten voraussetzte. ${ }^{808}$ Zwar gab es in Mailand einige Großverdiener, die tatsächlich ein solches Einkommen erreichten, doch erklären sich derart hohe Tagesabgaben wohl vor allem aus eigenmächtig erpressten Forderungen der Soldaten. Die Spanier gingen sehr gewissenhaft vor: wer neu in die Stadt kam, musste sich bei der Besatzungsmacht vorstellen, daneben wurden die Soldaten aufgefordert, die Hausherren, bei denen sie einquartiert waren, zu ihren Hauptleuten zu bringen, damit diese die Abgaben festlegen konnten. ${ }^{809}$ Wer kein Geld hatte, wurde schließlich zur unerwünschten Person: im September 1527 wurden durch ein Dekret de Leyvas alle Mailänder, die nicht mindestens 5 Soldi am Tag zahlen konnten, innerhalb eines Tages zum Verlassen der Stadt aufgefordert. ${ }^{810}$

Neben der Beköstigung und den Tagesabgaben gab es eine weitere Komponente der alltäglichen Belastung - die Beteiligung der Einwohner an den der Stadt auferlegten Kontributionen, oder besser gesagt: die Verteilung der Kontributionssumme auf die einzelnen Haushalte. Kontributionen wurden in unregelmäßigen Abständen von der Besatzungsmacht erhoben, in der Regel, indem man eine Summe angab, die innerhalb einer bestimmten Frist von der Stadt aufzubringen war. Die Forderungen bewegten sich zumeist in Größenordnungen zwischen 10.000 und 30.000 Dukaten. Die Umschichtung übernahmen entweder die Besatzer selbst oder sie überließen sie der örtlichen Verwaltung. In der Regel wurden dabei die unteren Schichten der Bevölkerung ausgespart: Einwohner, die man für reich hielt, bekamen Zahlungsaufforderungen über bestimmte Summen geschickt. So wurden bereits kurz nach dem Einmarsch von einigen Kaufleuten Beträge von bis zu 1.000 Dukaten verlangt. Als diese klagten, sie könnten das Geld nicht aufbringen, ließ de Leyva ungerührt antworten, es seien genug genuesische und florentinische Bankiers in der Stadt, bei denen sie Kredite bekommen könnten. ${ }^{811}$ Im April 1526 musste er dann eine weitere Forderung von 20.000 Dukaten wieder fallen lassen, weil die angeschriebenen Kaufleute offenbar tatsächlich kein Geld beschaffen konnten. ${ }^{812}$ Neben solchen willkürlich festgesetzten Anteilen gab es auch Kontributionen, die die Schätzung von 1524 zur Grundlage einer prozentual zum Einkommen erhobenen Abgabe machten, wie etwa eine Forderung aus dem Januar 1527,

\footnotetext{
808 Burigozzo, Cronaca di Milano, S. 459.

809 SANUTO, Diarii, Bd. 46, Sp. 67.

810 Formentini, Il ducato di Milano, Nr. 75, S. 479.

811 Burigozzo, Cronaca di Milano, S. 450f.

812 ASM Sforzesco, Cart. 1505, Dekret vom 27. 4. 1526.
} 
bei der es um zwei Promille des geschätzten Jahreseinkommens - insgesamt 18.000 Dukaten - ging. ${ }^{813}$ Und schließlich wurde manchmal eine feste Summe von allen Haushalten gefordert, wie im August 1527, als man einen Dukaten pro Haushalt und einen pro Laden verlangte. ${ }^{814}$ Die Berechnung der Abgaben auf der Grundlage der Schätzung von 1524 war wegen der Abwanderung und dem Niedergang des Wirtschaftslebens problematisch, und die geforderten Gelder konnten trotz der Konfiskationen - bei denen im übrigen wohl der größte Teil des Geldes in alle möglichen Taschen wanderte, nur nicht in die Kriegskasse der Besatzer - nicht annähernd aufgebracht werden. Eine Aufforderung aus dem August 1526, die geschuldeten Anteile an einer Forderung von 30.000 Dukaten bis zum folgenden Tag zu begleichen, wurde innerhalb eines Monats sechsmal wiederholt. ${ }^{815}$ Nach einem weiteren Monat war offenbar immer noch nicht alles bezahlt, denn die Pfarreivorsteher wurden angewiesen, mit Namenslisten der Säumigen beim Gouverneur zu erscheinen. ${ }^{816}$ Schon im Juli 1526 hatte es Beschwerden gegeben, die Schätzung von 1524 sei völlig unzureichend; de Leyva versprach eine neue Erhebung, aber es geschah nichts dergleichen. ${ }^{817}$ Zur Eintreibung der Kontributionen war jedes Mittel recht: oft wurden willkürlich Personen verhaftet und so lange in Gewahrsam behalten, bis sie die geforderte Summe aufgebracht hatten. Eine Liste aus dem Januar 1527 verzeichnet 56 Personen, die zu diesem Zeitpunkt wegen unbeglichener Kontributionsforderungen im Kastell von Mailand inhaftiert waren. ${ }^{818}$ Zur gleichen Zeit wurden in Monza wie selbstverständlich 25 Personen verhaftet, die für die Zahlung von 4.000 Dukaten garantieren sollten. ${ }^{819}$ Wenn jemand sich dem Zugriff der Besatzungsmacht entziehen wollte, nahm man Geiseln aus seiner Familie. ${ }^{820}$ Schon im August 1526 hatte Bourbon im Zuge einer Kontributionsforderung den Säumigen das Recht entzogen, Prozesse zu führen, Verträge zu schließen, Testamente aufzusetzen und Erbschaften anzutreten. ${ }^{821}$ Später gab es Geldstrafen, die das Achtzigfache der verlangten Abgabe betragen konnten. ${ }^{822}$ Daneben wurden alle Spielarten von Güterkonfiskation angewandt: im Oktober 1527 nahm man ausgewählten Kaufleuten die Schlüssel der Lagerhäuser ab und erklärte, sie gegen 18.000 Dukaten wieder auszuhändigen. Als das Geld nicht kam, wurden die Lagerhäuser geplündert. ${ }^{823}$ Im August 1528 schickte de Leyva Beamte durch die Häuser der Kaufleute und ließ Listen der Vorräte erstellen. Wer einer daraufhin geschickten Zahlungsaufforderung nicht nachkam, bekam bald ein zweites Mal Besuch,

\footnotetext{
FormentinI, Il ducato di Milano, Nr. 66, S. 467; ACM Registri di lettere ducali 19, fol. 85 ${ }^{\mathrm{r}} \mathrm{f}$.

14 Formentini, Il ducato di Milano, S. 362.

815 ASM Sforzesco, Cart. 1505, Dekrete vom 11. 8., 14. 8., 16. 8., 18. 8., 21. 8., 27. 8., 11. 9. 1526.

816 ASM Sforzesco, Cart. 1505, Dekret vom 9. 10. 1526.

817 ASM Sforzesco, Cart. 1505, Dekret vom 22. 7. 1526.

818 ASM Autografi 230.

819 ASM Sforzesco, Cart. 1360. Gerolamo Trivulzio an Francesco Sforza, 3. 1. 1527.

820 SANUTO, Diarii, Bd. 43, Sp. 503.

821 Formentini, Il ducato di Milano, S. 348.

822 FormentinI, Il ducato di Milano, Nr. 71, S. 473f.

823 SANUTO, Diarii, Bd. 46, Sp. 231.
} 
diesmal von Soldaten, die die Ware beschlagnahmten. ${ }^{824}$ Im Oktober 1528 mussten dann die Kaufleute ihre Kontenbücher zur Überprüfung abgeben. ${ }^{825}$

Schon im August 1527 ging es so weit, dass de Leyva eine für die Säumigkeit bei den Kontributionszahlungen erhobene Strafe von 400 Dukaten demjenigen versprach, der die Summe für den Betreffenden bezahlte. Der Bezahlende durfte sich an den Gütern des Säumigen bedienen und bekam die Besitzurkunde vom Gouverneur persönlich ausgestellt; wenn er darüber hinaus lieber Bargeld wünschte, konnte er den Schuldner verhaften lassen. ${ }^{826}$ Auf diese Weise wurden die zahlungsfähigen und die zahlungsunfähigen Einwohner gegeneinander ausgespielt. Zur gleichen Zeit kam es vor, dass Häuser verbrannt wurden, um den Forderungen Nachdruck zu verleihen, ${ }^{827}$ daneben wirkte auch immer wieder die oben schon erwähnte Drohung mit Einquartierung. Die Folgen dieser Maßnahmen waren zum Teil kontraproduktiv, weil viele der Stadt den Rücken kehrten, was die Last auf den Schultern der Zurückgebliebenen immer schwerer werden ließ. Im Oktober 1526 wurde daher verkündet, dass jeder, der die Stadt verlassen wollte, dafür zu sorgen hatte, dass die Bezahlung seines Anteils an den Kontributionen bei Strafe der Güterkonfiskation gewährleistet blieb. ${ }^{828}$ Dennoch waren viele Mailänder der Soldaten dermaßen überdrüssig, dass sie lieber 10 oder 15 Dukaten am Tag zahlten, als in der besetzten Stadt zu bleiben. ${ }^{829}$

Durch die Handhabung der Kontributionsforderungen etablierte sich ein dem Gemeinwesen höchst schädliches System von Willkür und Missbrauch. Als im Mai 1527 spanische Soldaten revoltierten, gab der Kastellan ihnen die Adressen einiger Mailänder und schickte sie in die Stadt, um bei den Genannten insgesamt 6.000 Dukaten einzutreiben. ${ }^{830}$ Die Grenzen zwischen offiziell erhobenen Kontributionen und der Bereicherung der Soldaten auf eigene Faust waren wie auch bei den Tagesabgaben fließend. Nichts macht das deutlicher als eine Bekanntmachung des neuen Gouverneurs Ludovico di Belgioioso aus dem Oktober 1529: er erinnerte daran, dass die Kontributionen ausgesetzt worden seien und forderte Offiziere und Soldaten auf, keine Gelder mehr einzutreiben. ${ }^{831}$ Offensichtlich hatten einfache Soldaten das bisher auch ohne ausdrückliche Autorisation von Vorgesetzten getan. Schon im November 1526 hieß es in einem anderen Dekret, dass die Soldaten oft willkürlich einzelne Hausbewohner zur Zahlung der Abgaben heranzogen, weil sie keine Lust hatten, sich mit dem von den Autoritäten bestimmten Verteilerschlüssel auseinanderzusetzen. ${ }^{832}$ Die Widersprüchlichkeit der von der Besatzungsmacht festgelegten Zahlungsmodalitäten begün-

\footnotetext{
824 Burigozzo, Cronaca di Milano, S. 479.

825 ASM Sforzesco, Cart. 1506, Dekret vom 15. 10. 1526.

826 FORMENTINI, Il ducato di Milano, Nr. 71, S. $473 \mathrm{f}$.

827 SANUTO, Diarii, Bd. 46, Sp. $21 \mathrm{f}$.

828 FORMENTINI, Il ducato di Milano, Nr. 65, S. 466.

829 GAYANGOS, Calendar, Bd. 2, S. 380.

830 ASM Sforzesco 1361. Anhang zu einem Brief von Paolo Antonio del Bene, 27. 5. 1527.

831 ACM Materie 11, 6, fol. $4^{\mathrm{r}}$.

832 ASM Sforzesco, Cart. 1505, Dekret vom 2. 11. 1526.
} 
stigte ein solches Verhalten: die Verantwortung für die ordnungsgemäße Einsammlung der Gelder wurde zunächst abwechselnd verschiedenen Funktionsträgern des Heeres und schließlich den Quartiermeistern zugesprochen. ${ }^{833}$ Daneben tauchen aber auch immer wieder die Pfarreivorsteher als Verantwortliche auf. Dass die Eintreibung der Kontributionen in den Händen der städtischen Beamten nicht unbedingt besser aufgehoben war als bei den Militärs, zeigt eine andere Bekanntmachung von Belgioioso aus dem Oktober 1529: es habe sehr viel Missbrauch auch von Seiten der Pfarreivorsteher gegeben, die trotz der Aussetzung der Kontributionen weiter Gelder eingetrieben hätten. ${ }^{834}$ Ein solches Verhalten wurde wahrscheinlich durch die Tatsache begünstigt, dass die Aussetzung der Kontributionen schon seit dem Mai 1528 versprochen, aber immer wieder aufgeschoben worden war. ${ }^{835}$ Und bereits im April 1528 hatte es Beschwerden gegeben, die Pfarreivorsteher leiteten die Gelder nicht weiter. ${ }^{836}$

Daneben fehlte es aber auch nicht an Klagen über das Verhalten der höchsten Offiziere selbst. Wie schwer solche Beschuldigungen wegen der Widersprüche in den Quellen nachzuweisen sind, soll hier kurz am Beispiel des Gouverneurs selbst verdeutlicht werden. Francesco Sforza, damals noch mit den Spaniern verbündet, schrieb bereits im März 1523 persönlich an den Kaiser und trat Behauptungen entgegen, Antonio de Leyva presse seine nämlich Sforzas - Untertanen in Novara aus. ${ }^{837}$ Im Oktober desselben Jahres war es Nájera, der de Leyva ein weiteres Mal in Schutz nahm und hinzufügte, dieser treibe sogar weniger Geld ein als seine Vorgänger. ${ }^{838} \mathrm{Ob}$ diese Abgaben für die Bezahlung der Soldaten bestimmt waren oder für de Leyvas private Bedürfnisse, geht aus den Schreiben nicht hervor, als dieser aber Gouverneur von Mailand geworden war, hagelte es weitere Klagen. Nach Informationen der venezianischen Beamten im Januar 1526 hatte er von einer Abgabe aus Cremona, die sich auf 10.000 Dukaten belief, den größten Teil für sich selbst kassiert, ${ }^{839}$ und in den folgenden Monaten liefen dann drei Berichte in Venedig ein, nach denen der Gouverneur aus Mailand zwischen 200 und 500 Dukaten am Tag für sich erpresste. ${ }^{840}$ Ähnlich massiv wie die Klagen waren die Bemühungen der Funktionsträger aus dem Umkreis des Gouverneurs, um diese bei Hof zu entkräften. Im Juni 1526 ging von Mailand aus eine Reihe von Briefen nach Spanien: Nájera versicherte da, de Leyva sei sehr betrübt über die Vorwürfe und er, Nájera, wolle sich den Kopf abhacken lassen, wenn die Beschuldigungen der Wahrheit entsprächen. ${ }^{841}$ Gleichzeitig bekundete Hurtado de Mendoza in einem

\footnotetext{
833 ASM Sforzesco, Cart. 1506, Dekret vom 29. 3. 1528.

834 ACM Materie 11, 6, fol. $2^{\mathrm{r}}$.

835 ASM Sforzesco, Cart. 1506, Dekrete vom 7. 5., 9. 5. und 16. 5. 1528.

836 ASM Sforzesco, Cart. 1506, Dekret vom 24. 4. 1528.

837 RAH Salazar y Castro, A/27, fol. 244r. Francesco Sforza an den Kaiser, Mailand, 28. 3. 1523.

838 RAH Salazar y Castro, A/45, fol. 82V . Francesco Sforza an den Kaiser, Mailand, 28. 3. 1523.

839 SANUTO, Diarii, Bd. 40, Sp. 655.

840 SANUTO, Diarii, Bd. 41, Sp. 26; Bd. 41, Sp. 148; Bd. 41, Sp. 327.

841 RodriguEZ VILLA, Italia desde la batalla de Pavia, S. 128.
} 
anderen Brief, er und der Schatzmeister könnten bezeugen, dass alle eingetriebenen Gelder in die Kriegskasse geflossen seien und dass jeder, der anderes behaupte, ein Verleumder sei. ${ }^{842}$ Miguel de Herrera versicherte in einem weiteren Brief dasselbe, ${ }^{843}$ und einen Monat später schrieb noch einmal Nájera, de Leyva und andere hätten sich nicht etwa bereichert, sondern ihr letztes Hemd für die Bezahlung der Soldaten hergegeben. ${ }^{844}$ Schon im Februar hatte er den Kaiser gebeten, 7.000 Dukaten an de Leyva zu schicken, die dieser aus der eigenen Tasche vorgestreckt hatte. ${ }^{845}$ Und der Gouverneur selbst erklärte im Juli 1527, er habe alle seine Besitzungen im Königreich Neapel verpfändet und noch nicht einmal seine Freunde wollten ihm nun mehr Geld leihen. ${ }^{846}$ Weitere drei Monate später klagte er theatralisch, ihm blieben eine Jacke, eine Hose und sein Pferd. ${ }^{847}$ In einer abschließenden Bilanz erklärte er im März 1530, man schulde ihm noch über 75.000 Scudi, die er während seiner Zeit als Gouverneur vorgschossen habe. ${ }^{848}$

An Stelle einer Zusammenfassung der hier beschriebenen Mechanismen soll schließlich noch ein anonymer Mailänder zu Wort kommen, der in einem einzigen Brief eindrucksvoll das Nebeneinander der verschiedenen Spielarten der Geldbeschaffung in einer besetzten Stadt aus der Perspektive der unmittelbar Betroffenen vorstellt. Der Brief datiert aus dem März 1527 und fiel auf seinem Weg von Mailand nach Finale wahrscheinlich den Reitern von Sforza in die Hände. Es handelt sich beim Absender ganz offensichtlich um einen der Pfarreivorsteher, der im Auftrag der Spanier für die Umschichtung und Eintreibung der Kontributionen zuständig war. ${ }^{849}$ Er war offenbar gerade dabei, seine Runde zu machen: die Pächter - von was, wird nicht gesagt - habe er keineswegs übergangen, offenbar hatte ihm das der Empfänger des Briefes, ein gewisser Felipe Pescatore, unterstellt. 150 Lire habe er dort schon eingesammelt. Pietro Paolo Chaimo dagegen sträube sich gegen die Zahlung, obwohl man aus sicherer Quelle wisse, dass er 200 brente Wein und viel Getreide verkauft habe. Man müsse seine Bücher einsehen, um Näheres sagen zu können. Filippo de Casate habe die Tagesabgaben von jeweils 20 Soldi für 8 Spanier aus dem Gefolge von Juan de Urbina bezahlt, die allerdings nicht bei ihm selbst, sondern bei seinem Nachbarn einquartiert seien. Von den Beamten des Stadtviertels Porta Tosa habe er eine Bestätigung, dass ein gewisser Monte zwar die Stadt verlassen, aber alles Notwendige zur Bezahlung seines Anteils an den Kontributionen geregelt hatte. Zwei andere seien geflohen, einem von ihnen

${ }^{842}$ GayangOs, Calendar, Bd. 3, Teilbd. 1, S. 724.

843 Gayangos, Calendar, Bd. 3, Teilbd. 1, S. 722.

844 RoDRIGUEZ VILLA, Italia desde la batalla de Pavia, S. 148.

845 Gayangos, Calendar, Bd. 3, Teilbd. 1, S. 584.

846 GaYAngos, Calendar, Bd. 3, Teilbd. 2, S. 305.

847 Gayangos, Calendar, Bd. 3, Teilbd. 2, S. 401.

848 CARANDE Y TOVAR, RAMÓN: Carlos V y sus banqueros. Bd. 3: Los caminos del oro y de la plata. Barcelona 1990. S. 77. Damit lag er übrigens ungefähr gleich auf mit Cardona, dessen Witwe im Juli 1525 an den Kaiser schrieb, ihr Mann habe zu Lebzeiten 71.000 Dukaten vorgestreckt und nichts davon wiedergesehen. RAH Salazar y Castro, A/34, fol. $376^{\mathrm{r}} \mathrm{f}$. Cardonas Witwe an den Kaiser, 16. 7. 1525.

849 ASM Sforzesco 1424. Giovanni Pietro V., 26. 3. 1527. 
hätten die Soldaten nach seiner Flucht das Haus verwüstet, ein anderer sei ordnungsgemäß zum Empörer erklärt worden, weil er die Kontribution nicht bezahlt habe. So ergehe es im übrigen allen, die den Anordnungen der Besatzungsmacht nicht Folge leisteten. Und schließlich erfährt man von ihm selbst, dass auch er einen Landsknecht in seinem Haus beherbergte.

\section{B. Leben mit der Besatzung}

Der Einzug der Soldaten in eine Stadt stellte das Leben der meisten Bewohner zunächst vollständig auf den Kopf. Neben den schon beschriebenen, die Existenz permanent und unmittelbar bedrohenden Faktoren - Teuerung der Lebensmittel und Eintreibung von Tagesabgaben und Kontributionen - hatte auch allein die Gegenwart der Soldaten Auswirkungen auf das Alltagsleben. Denn ein solches musste sich irgendwann wieder einstellen, und zwar sowohl für die Bewohner, als auch für die Soldaten. Das Leben in dieser sich anbahnenden Normalität wurde zunächst beeinflusst oder besser gesagt: eingeschränkt durch eine Reihe von Maßnahmen der Besatzungsmacht, deren erster Zweck die Sicherung der Herrschaft war, und zwar sowohl nach außen gegen die Feinde, als auch nach innen gegen umstürzlerische Neigungen einer Bevölkerung, die vor allem im dauerhaft besetzten Mailand immer weniger bereit war, die Auspressung durch die Kontributionen und die ständigen gewaltsamen Übergriffe der Soldaten hinzunehmen. Um zu verhindern, dass die gesamte Bevölkerung in die Flucht getrieben wurde, versuchte man daneben, deren Sicherheitsbedürfnis durch die Herstellung einer sehr rudimentären Form von öffentlicher Ordnung wenigstens ansatzweise zu befriedigen. Gleichzeitig wurde ein Teil der Bewohner zumeist gegen deren Willen für den militärischen Apparat eingespannt. Während nun die Beschaffung von Lebensmitteln in einer wirtschaftlich durch die Besatzung geschädigten Stadt für die Bewohner zu einem zentralen Problem aufrückte, gingen die Soldaten ihren in der Regel recht derben Vergnügungen nach. Ihr Treiben erregte nicht selten Anstoß, so dass Spannungen in den besetzten Haushalten vorprogrammiert waren. Vor allem aber war das Nebeneinander durch die Gefahr von Übergriffen der ungebetenen Gäste geprägt. Der Mangel an Disziplin in den Söldnerheeren begünstigte jede Art von Rechtsbruch, weil die Soldaten nur selten zur Rechenschaft gezogen wurden, auch wenn es an einigen Stellen augenscheinlich zu Ansätzen von Solidarität zwischen den einquartierten Soldaten und den Bewohnern der belegten Häuser kam. Die wirtschaftlichen Folgen der Bevölkerungsverminderung waren beträchtlich, dazu kam, dass viele Handwerker und Händler ihre Werkstätten und Läden über lange Zeiträume aus Angst vor Plünderungen geschlossen hielten. Dadurch war auch das öffentliche Leben starken Einschränkungen unterworfen, ganz abge- 
sehen davon, dass die schlechten hygienischen Verhältnisse, die überall in den Heeren herrschten, sich auf die besetzten Städte übertrugen und die Seuchengefahr dort potenzierten.

Die folgenden Ausführungen stützen sich auf unterschiedliche Quellen aus den besetzten Städten des untersuchten Zeitraums. Der mit Abstand am besten dokumentierte Fall ist wieder einmal die Stadt Mailand, aus der neben zahlreichen Briefen von Augenzeugen und den Berichten der venezianischen Informanten auch eine große Zahl von öffentlich ausgerufenen Dekreten überliefert ist, durch die die Besatzungsmacht das alltägliche Leben zu reglementieren versuchte. Die folgende Tabelle gibt einen Überblick über die am häufigsten genannten Bereiche in den insgesamt 446 Dekreten aus dem Zeitraum der spanischen Besatzung zwischen November 1525 und Dezember 1529, die in der umfangreichsten unter mehreren Sammlungen von Dekreten überliefert sind. ${ }^{850}$ Die Verteilung der Dekrete auf die einzelnen Bereiche des städtischen Lebens in der besetzten Stadt gibt eine ungefähre Vorstellung davon, auf welchen Gebieten die spanischen Autoritäten den größten Handlungsbedarf sahen:

\begin{tabular}{|l|c|c|}
\hline \multicolumn{1}{|c|}{ Bereich } & Anzahl & Anteil \\
\hline Lebensmittelversorgung & 101 & $22,6 \%$ \\
\hline Bekanntmachungen an die Soldaten & 58 & $13,0 \%$ \\
\hline Öffentliche Sicherheit & 47 & $10,5 \%$ \\
\hline Einquartierungen und Tagesabgaben & 43 & $9,6 \%$ \\
\hline Bevölkerungspolitik & 38 & $8,5 \%$ \\
\hline Arbeitsdienst und Belieferung des Heeres & 30 & $6,7 \%$ \\
\hline Handel und Wirtschaftsleben & 28 & $6,3 \%$ \\
\hline Kontributionszahlungen & 20 & $4,5 \%$ \\
\hline Verwaltungsfragen & 15 & $3,4 \%$ \\
\hline Verbannungen & 11 & $2,5 \%$ \\
\hline
\end{tabular}

Die unterschiedliche Ausgangssituation in den einzelnen Beispielfällen - vor allem im Fall von Mailand und Rom - lässt eine parallele Abhandlung auf den ersten Blick problematisch erscheinen. Eines der Ziele dieser Arbeit ist es jedoch, die übergreifenden Phänomene der Besatzung sowie bestimmte Verhaltensmuster der an dieser Beteiligten herauszuarbeiten. So lässt sich zeigen, dass die meisten der charakteristischen Erscheinungen und Mechanismen immer wieder auftraten. Das liegt ganz einfach daran, dass in Rom wie in Mailand und in allen anderen eroberten und besetzten Städten dieser Zeit dieselben Gruppen von Menschen beteiligt waren, die dieselben Interessen und Bedürfnisse hatten und sich nach einer

850 ASM Sforzesco, Cart. 1504 - 1507. Aus dem Inhalt zahlreicher Dekrete geht hervor, dass die überlieferten 446 Stücke nur einen Teil der Menge an Dekreten darstellen, die einmal existiert haben muss. Die Kopien einiger dieser Dekrete und einige weitere sind im ACM Registri di lettere ducali, Bd. 19 u. 20 überliefert, ferner, vor allem die Preisfestlegungen für Lebensmittel, in den Akten des Tribunale della Provvisione, ACM Dicasteri 221. Bei FormentinI, Il ducato di Milano, findet sich eine Auswahl von Dekreten verschiedener Provenienz in Edition. 
gewissen Zeit die Besonderheit ihrer Situation nicht mehr jeden Tag bewusst machten. Nichts zeigt dieses angesichts der endlosen Kette von Gewalttätigkeiten in gewisser Weise paradox erscheinende Phänomen deutlicher als der Bericht eines venezianischen Offiziers, der im Juni 1529 bei Antonio de Leyva in Mailand zu Besuch war. Der Gouverneur fragte ihn spöttisch, wo denn die Verbündeten blieben und führte ihn anschließend durch die arg mitgenommene Stadt. Verdutzt schrieb der Mann an seine Vorgesetzten, er habe an vielen Stellen gesehen, dass die Bewohner tanzten, so als sei gar kein Krieg. ${ }^{851}$

\section{Sicherung der Herrschaft}

Um die Kontrolle über eine besetzte Stadt auszuüben, war es geraten, sich den Verwaltungsapparat gefügig zu machen. In Rom blieben solche Maßnahmen in den Ansätzen stekken, da man nicht die Absicht hatte, sich lange dort aufzuhalten, vor allem aber, weil fast alle Offiziere schon nach kurzer Zeit die Stadt verlassen hatten. Die unübersichtliche Lage führte überdies dazu, dass die wenigen neu ernannten Amtsträger vor allem zum eigenen Vorteil arbeiteten: im August 1527 schrieb Perez an den Kaiser, die Männer, die man mit Posten ausgestattet habe, führten ihre Arbeit angesichts des in Bälde erwarteten Abzugs sehr nachlässig aus. ${ }^{852}$ So kam es, dass die Verwaltung die ganze Zeit der Besatzung über fast vollständig lahmgelegt war.

Anders in Mailand. Hier verfolgten die Spanier vom Augenblick des Einzugs an die Absicht, Stadt und Herzogtum dauerhaft unter ihre Kontrolle zu bringen. Noch bevor in Spanien das Verfahren gegen den Herzog Francesco Sforza eröffnet wurde, leitete man vor Ort die ersten Schritte ein: schon Anfang November wurden die Finanzbeamten in Mailand angewiesen, im Namen Pescaras als kaiserlichem Gouverneur zu siegeln. ${ }^{853}$ Die Einnahmen aus dem Staat mussten Nájera ausgehändigt werden, um den Geldbedarf des Heeres zu decken. ${ }^{854}$ Noch vor Ende des Monats waren alle hohen Beamten mit Ausnahme der Senatoren ausgetauscht. ${ }^{855}$ Diese sträubten sich zunächst gegen die Aufforderung, dem Kaiser die Treue zu schwören, solange die Schuld des Herzogs nicht bewiesen sei. Schließlich wurde es de Leyva zu bunt und er drohte nach einer weiteren fruchtlosen Unterredung mit Gewaltanwendung. ${ }^{856}$ Obwohl die Spanier am längeren Hebel saßen, war die Frage nach der Rechtmäßigkeit der spanischen Herrschaft für eine problemlose Übernahme des Staates nicht ganz unbedeutend: im Dezember 1525 riet Nájera dem Kaiser dringend davon ab, in

851 SANUTO, Diarii, Bd. 50, Sp. 425.

852 Gayangos, Calendar, Bd. 3, Teilbd. 2, S. 315f.

853 ASM Sforzesco, Cart. 1504, Dekret vom 2. 11. 1525.

854 ASM Sforzesco, Cart. 1504, Dekret vom 2. 11. 1525.

855 Gayangos, Calendar, Bd. 3, Teilbd. 1, S. 488.

856 SANUTO, Diarii, Bd. 40, Sp. 334f. 
seiner Korrespondenz den Titel eines Herzogs von Mailand zu führen, weil man das in der Stadt vor dem Ende des Prozesses gegen Sforza als anmaßend empfinde. ${ }^{857}$ Gleichzeitig begann auf der unteren Verwaltungsebene das Tauziehen um den von den Spaniern verlangten Treueschwur der Bevölkerung: während die Militärs diesen als Voraussetzung für den Abzug der Besatzungssoldaten forderten, verlangten die Mailänder deren Abzug als Bedingung für die Leistung des Eides. Ende Dezember wurden alle Pfarreien ultimativ aufgefordert, Bevollmächtigte zu benennen, dennoch kam die Sache nur sehr zögerlich in Gang. ${ }^{858}$ Im Januar 1526 hatten einige Pfarreien sich gebeugt, die anderen versuchte man mit der Einquartierung von Soldaten ${ }^{859}$ und kurz darauf durch die Verhaftung von 100 ausgewählten Personen gefügig zu machen. ${ }^{860}$ Nach dem zweiten Aufstand im Juni verlangte man einen zweiten Treueschwur, die Vertreter der Stadt gaben daraufhin die geistreiche Antwort, sie hätten doch nur eine Treue. ${ }^{861}$

Daneben wurde während der gesamten Besatzungszeit mit Verbannungen gearbeitet. Mailänder, die als Anhänger Sforzas bekannt waren, wurden zu Rebellen erklärt und der Stadt verwiesen. Viele folgten dieser Aufforderung nicht, sondern versteckten sich in der Stadt oder zogen, wie Pietro da Pusterla, durch ein Stadttor aus und durch ein anderes wieder ein. ${ }^{862}$ Daher forderte man im Juni 1526 von allen Verbannten, dass sie innerhalb von 10 Tagen nach der Ausweisung eine Bestätigung schickten, das Gebiet des Staates verlassen zu haben. ${ }^{863}$ Erst im September 1529 wurde für die Verbannten eine Amnestie vom Kaiser ausgesprochen. ${ }^{864}$

Neben solchen Anordnungen, die für die Mehrheit der Bevölkerung ohne Auswirkungen blieben, manifestierte sich die Angst der Militärs vor Unruhen auch in zahlreichen Maßnahmen, deren Auswirkungen in der Stadt selbst für alle sichtbar und spürbar waren. Sofort nach dem Einzug des Heeres in Mailand wurde der Dom besetzt, um zu verhindern, dass die Stadt durch Sturmläuten in Aufruhr versetzt wurde. Genau das geschah dann im April 1526 doch, als eine aufgebrachte Menge die Kathedrale stürmte. Nach den Erfahrungen des ersten Aufstandes wurden daher weitere Maßnahmen ergriffen: die Soldaten mauerten kurzerhand die Türen des Doms bis auf eine $\mathrm{zu}^{865}$ und trugen Bretter und Balken zusammen, um in kürzester Zeit Straßenbarrikaden errichten zu können. ${ }^{866}$ Dennoch kam es zu einem zweiten Aufstand im Juni. Was für ein wichtiger Faktor auch dieses Mal das Läuten der Glocken gewesen war, zeigt am besten ein Dekret der Spanier aus dem folgenden Monat,

857 GayangOs, Calendar, Bd. 3, Teilbd. 1, S. 514.

858 SANUTO, Diarii, Bd. 40, Sp. 572.

859 SANUTO, Diarii, Bd. 40, Sp. 725.

860 SANUTO, Diarii, Bd. 40, Sp. 738.

861 SANUTO, Diarii, Bd. 41, Sp. 734.

862 SANUTO, Diarii, Bd. 41, Sp. 583.

863 ASM Sforzesco, Cart. 1505, Dekret vom 28. 6. 1526.

864 Formentini, Il ducato di Milano, Nr. 85, S. 491f.

865 ASM Sforzesco, Cart. 1375. Gerolamo Maggiolino an Francesco Sforza, 11. 6. 1526.

866 SANUTO, Diarii, Bd. 41, Sp. 572. 
durch das allen Pfarrern und Äbten befohlen wurde, die Schwengel und Seile von den Glocken der Kirchen und Klöster abzumontieren. ${ }^{867}$ Pünktlich zu Weihnachten wurde das Glockenläuten dann wieder gestattet. ${ }^{868}$

Des weiteren reglementierte eine Flut von Dekreten auch das alltägliche Leben der Mailänder. Was die Besatzer zur Verhinderung von Aufständen zur öffentlichen Sicherheit erklärten, begann mit dem unermüdlich und mit Variationen ausgerufenen Verbot, Waffen zu tragen. Zunächst wurden nur Schusswaffen verboten, ${ }^{869}$ dann auch Rüstungen ${ }^{870}$ und alle anderen Arten von Waffen. ${ }^{871}$ Wer sich den Gräben näherte, mit denen die Spanier das Kastell umgeben hatten, durfte von den Wachen ohne Warnung erschossen werden. ${ }^{872}$ Nach dem zweiten Aufstand wurden alle Mailänder aufgefordert, die Waffen abzuliefern; die Waffenhändler mussten Listen mit allen vorrätigen Waffen einreichen. ${ }^{873}$ Obwohl in deren Läden anschließend Razzien durchgeführt wurden, wurde das Verbot nicht von allen befolgt, denn im September wurde eine allgemeine Meldepflicht für alle Arten von Waffen angeordnet. ${ }^{874}$ Nach dem zweiten Aufstand, bei dem offenbar im Schutz der Dunkelheit viele Soldaten umgebracht worden waren, erging das Gebot, bei Alarm Lichter in die Fenster zu stellen, ${ }^{875}$ und schon einen Monat später wurde angeordnet, dass diese Lichter die ganze Nacht über zu brennen hatten. ${ }^{876}$ Auch diese Dekrete wurden mehrmals wiederholt. Eine nächtliche Ausgangssperre ${ }^{877}$ galt ebenso wie ein allgemeines Versammlungsverbot. Schon im November 1525 war festgelegt worden, dass bereits mehr als 6 Personen als Versammlung angesehen wurden. ${ }^{878}$ Die Verbote gingen so weit, dass das öffentliche Anstellen von Spekulationen über die Absichten der Feinde unter Todesstrafe gestellt wurde. ${ }^{879}$

Besonderes Misstrauen brachte man Fremden entgegen. Schon im November 1525 wurden Reisende, die die Stadt betraten, von den Offizieren über ihre Absichten befragt. ${ }^{880} \mathrm{Im}$ März 1526 wurde für das Beherbergen von Fremden auch dann die Todesstrafe angedroht, wenn es sich um Freunde der Gastgeber handelte. ${ }^{881}$ Kurz darauf wurde diese Maßnahme dahin gehend gelockert, dass Fremde dann bleiben durften, wenn sie geschäftlich in Mailand zu tun hatten. ${ }^{882}$ Dennoch wurden vor den Häusern der Gastwirte Wachen postiert ${ }^{883}$

867 ASM Sforzesco, Cart. 1505, Dekret vom 20. 7. 1526.

868 ASM Sforzesco, Cart. 1505, Dekret vom 24. 12. 1526.

869 ASM Sforzesco, Cart. 1505, Dekret vom 30.1. 1526.

870 ASM Sforzesco, Cart. 1505, Dekret vom 2. 3. 1526.

871 ASM Sforzesco, Cart. 1505, Dekret vom 30. 4. 1526.

872 ASM Sforzesco, Cart. 1505, Dekret vom 9. 2. 1526.

873 ASM Sforzesco, Cart. 1505, Dekret vom 23. 6. 1526.

874 ASM Sforzesco, Cart. 1505, Dekret vom 28. 9. 1526.

875 ASM Sforzesco, Cart. 1505, Dekret vom 30. 6. 1526.

${ }^{876}$ ASM Sforzesco, Cart. 1505, Dekret vom 20. 7. 1526.

877 ASM Sforzesco, Cart. 1506, Dekret vom 19. 2. 1528.

878 ASM Sforzesco, Cart. 1504, Dekret vom 30. 11. 1525.

879 SANUTO, Diarii, Bd. 40, Sp. 786.

880 SANUTO, Diarii, Bd. 40, Sp. 359.

881 ASM Sforzesco, Cart. 1505, Dekret vom 6. 3. 1526.

882 ASM Sforzesco, Cart. 1505, Dekret vom 19. 3. 1526. 
und die Ankömmlinge nicht selten bis zu ihrer Unterkunft geleitet. ${ }^{884}$ Die Wirte mussten Listen mit den Namen der Gäste bei der Besatzungsmacht einreichen. ${ }^{885}$ Die Maßnahmen zur Einschüchterung der Fremden machten durchaus nicht vor den Türen der Herbergen halt: ein venezianischer Spion, der im Dezember 1525 in einem Gasthaus untergekommen war, wurde in seiner Kammer von einem halben Dutzend Soldaten überrascht, die ihm wortlos ins Gesicht blickten und wieder abzogen. Verängstigt wechselte er die Herberge, kam aber am nächsten Tag wieder, um seine zurückgelassenen Sachen abzuholen. Als der Wirt ihm berichtete, in der Nacht seien die Spanier gekommen und hätten alle seine Gäste aus den Betten geholt, verließ er unverrichteter Dinge die Stadt. ${ }^{886}$

Die Durchsetzung der Maßnahmen erfolgte unter Androhung von drakonischen Strafen, die weniger ein Anzeichen für die Schwere des Delikts an sich sind, als für die Tatsache, dass die Anordnungen nur sehr nachlässig befolgt wurden. Ähnliche Beobachtungen wurden schon bei den Kontributionen gemacht, und hier wie dort versuchte man, durch hohe Belohnungen Denunzianten zu gewinnen. Denen wurde auf einen Schwur hin geglaubt, selbst wenn es um Vergehen ging, auf die die Todesstrafe stand. ${ }^{887}$ Augenscheinlich wurden die Strafen die meiste Zeit über selten angewandt, auch wenn man mitunter Exempel statuierte wie im Mai 1527, als in Mailand ein Mann aufgehängt wurde, nur weil er das Gerücht verbreitet hatte, die Kaiserlichen seien aus dem eben eroberten Rom wieder vertrieben worden. $^{888}$

\section{Militärische Erfordernisse}

Bei allen Maßnahmen zur Sicherung der Herrschaft nach innen gegen Aufstände verloren die Besatzer auch die Verteidigung der Stadt gegen Feinde von außen nicht aus den Augen. Maßnahmen zum Schutz gegen Angriffe bestanden vor allem in der Ausbesserung und Erweiterung der Verteidigungsanlagen. Die Spanier hatten zur Organisation solcher Maßnahmen eigene Festungsingenieure. ${ }^{889}$ Für die Arbeiten selbst aber zogen sie nach Möglichkeit wieder die Bevölkerung heran. Obwohl die Besatzer immer wieder Entlohnung versprachen, deutet vieles darauf hin, dass die Einwohner fast immer zu den Arbeiten an den Befestigungen und Gräben gezwungen wurden. Daneben ist es fraglich, inwieweit die Zwangsverpflichtung von Arbeitskräften von oben angeordnet wurde: oft scheinen die Sol-

\footnotetext{
883 SANUTO, Diarii, Bd. 41, Sp. 208.

884 SANUTO, Diarii, Bd. 41, Sp. 74.

885 ASM Sforzesco, Cart. 1505, Dekret vom 19. 6. 1526.

886 SANUTO, Diarii, Bd. 40, Sp. 520.

887 ACM Registri di lettere ducali, Bd. 19, fol. $73^{\mathrm{V}}$.

888 ASM Sforzesco, Cart. 1361. Gerolamo Trivulzio, 31. 5. 1527.

889 SANUTO, Diarii, Bd. 39, Sp. $271 \mathrm{f}$.
} 
daten die Bevölkerung zum Graben und Mauern eingespannt zu haben, weil sie selbst nicht arbeiten wollten. Einige Beispiele sollen das verdeutlichen.

In Mailand gab es zwei Arten von Befestigungsarbeiten: die Ausbesserung der Stadtmauern und, vor allem zu Beginn und gegen Ende der Belagerung des Herzogs im November 1525 und im Juli 1526, die Arbeit an den Gräben, die man um das Kastell gezogen hatte. Wer diese Tätigkeit ausübte, lebte gefährlich: die Schanzgräber waren die meiste Zeit über der Festungsartillerie ausgesetzt und gerieten bei Ausfällen nicht selten zwischen die Mühlsteine oder wurden gefangen genommen. Das war wohl auch der Hauptgrund, warum die Soldaten nicht selbst graben wollten. Fast jeden Tag gab es Tote und Verletzte unter den Belagerern, wenn auch deren Zahl von den Berichterstattern der Gegenseite stark übertrieben wurde. Die Bewohner aus der Stadt und den umliegenden Dörfern kamen den Aufforderungen der Besatzer zur Arbeit alles andere als freiwillig nach: im November 1525 wurde im Umland von Mailand unter Androhung der Todesstrafe nach Schanzgräbern geschickt, ${ }^{890}$ angeblich wurden auf diese Weise 3.000 Personen zur Arbeit an den Gräben in die Stadt gebracht. Viele von ihnen flohen schon nach kurzer Zeit wieder, und zwar aus mehreren Gründen: ein Informant der Venezianer berichtete, dass die Spanier die Abwesenheit der Bewohner nutzten, um sich über deren Häuser herzumachen, ${ }^{891}$ ein anderer traf vor der Stadt eine Gruppe von zehn geflohenen Schanzgräbern, die erzählten, sie hätten trotz der harten Arbeit nichts zu essen und zu trinken bekommen. ${ }^{892}$ Ein dritter Beobachter berichtet von regelrechter Menschenjagd: "... spagnoli fanno gran guardia al castelo, et che retengono li vilani per la strada et li conducono ad lavorar al castelo. Et che lui relatore li ha veduti cazar da li soldati con la spada in più luochi ..." ${ }^{893}$ Viele trauten sich aus Angst, bei der Arbeit an den Gräben verheizt zu werden, nicht mehr aus dem Haus. ${ }^{894}$ Andere kauften sich von der Zwangsverpflichtung frei, was angesichts der vielerorts beobachteten Findigkeit der Soldaten in Bezug auf die Aufbesserung des Soldes die Vermutung zulässt, dass es sich bei diesem Verfahren am Ende um eine weitere Spielart der Erpressung von Lösegeldern handelte. ${ }^{895}$ Bauern, die zum Verkauf von Lebensmitteln in die Stadt gekommen waren, wurden bisweilen gleich dabehalten. ${ }^{896}$ Gegen Ende der Belagerung war der Bedarf an Arbeitskräften offenbar so dringend, dass jeder Haushalt in Mailand aufgefordert wurde, einen Schanzgräber zu stellen. ${ }^{897}$ Spaten und Spitzhacken mussten die Arbeiter selbst mitbringen. ${ }^{898}$ Aus Cremona ist der Lohn für die Schanzgräber übrigens auch in Zahlen über-

\footnotetext{
890 SANUTO, Diarii, Bd. 40, Sp. 300.

891 SANUTO, Diarii, Bd. 40, Sp. 427.

892 SANUTO, Diarii, Bd. 40, Sp. 326.

893 SANUTO, Diarii, Bd. 40, Sp. 450.

894 CAPELLA, Beschreibung und Geschicht, fol. $32^{\mathrm{V}}$.

895 SANUTO, Diarii, Bd. 40, Sp. 320.

896 SANUTO, Diarii, Bd. 42, Sp. 7.

897 ASM Sforzesco, Cart. 1505, Dekret vom 19. 7. 1526.

898 ASM Sforzesco, Cart. 1505, Dekret vom 1. 7. 1526.
} 
liefert: für die Ausbesserung der Stadtbefestigungen dort bot man im Mai 1526 immerhin 10 Soldi am Tag, eine Bezahlung, die in etwa der eines Tagelöhners auf dem Bau entsprach. Daneben wurde versprochen, dass die Arbeit ausschließlich an ungefährlichen Stellen ausgeführt werden würde. ${ }^{899}$ Die Tatsache, dass kurz darauf Landsknechte durch die umliegenden Dörfer zogen und Bauern einfingen, zeigt auch hier, dass das Versprechen der Entlohnung nicht gerade einen massenhaften und begeisterten Zulauf zur Folge hatte. ${ }^{900}$ Eine andere weit verbreitete Maßnahme zur Verteidigung der Städte war auf andere Weise nicht weniger gravierend: um das Schussfeld von der Stadtmauer aus frei zu halten, wurde im engeren Umkreis um die Stadt alles niedergerissen, was eventuellen Angreifern Dekkung bieten konnte. Schon im März 1522 waren vor Mailand aus diesem Grund zwei Wälder abgeholzt worden. ${ }^{901}$ Im August 1526 fällte man Bäume vor der Stadt und verbarrikadierte damit die Zufahrtsstraßen, auf denen die Venezianer ihr Unwesen trieben. ${ }^{902}$ Sogar ein Kloster war abgerissen worden, weil man fürchtete, die Venezianer könnten dort die Artillerie zur Beschießung der Stadtmauer platzieren. ${ }^{903} \mathrm{Im}$ folgenden Jahr drohte den Vororten von Mailand dann die vollständige Zerstörung: als im August die Franzosen in der Lombardei einmarschiert waren und die Hauptstadt bedrohten, ließ de Leyva anordnen, alle Häuser in Schussweite vor der Stadtmauer müssten abgerissen werden, die Hausbesitzer selbst waren für die Durchführung dieser Maßnahme verantwortlich. Einige Tage später wurde dieser Befehl dann aber wieder zurückgenommen, man begnügte sich mit dem Abholzen der Büsche. ${ }^{904}$ Einen Monat später schien der Gouverneur noch einmal seine Meinung geändert zu haben, er ließ nun Steinmetze aus der Stadt zur Zerstörung der Vororte antreten und Brennstoff zusammentragen, doch auch diese Maßnahme scheint am Ende nicht zur Ausführung gekommen zu sein. ${ }^{905}$ Ein solches Vorhaben war durchaus kein Einzelfall: im August 1509 wurden vor den Mauern von Vicenza alle Häuser und Kirchen und zum Zweck der Aushebung eines inneren Grabens sogar die von innen an die Stadtmauern grenzenden Häuser abgerissen, ${ }^{906}$ einen Monat später traf es die Vororte von Padua ${ }^{907}$ und im Juni 1513 die von Verona. ${ }^{908}$ Auch gegenüber anderen Städten der Lombardei kam Mailand am Ende gut davon: im Sommer 1526 waren sowohl die Vororte von Como ${ }^{909}$ als auch die von Cremona ${ }^{910}$ dem Erdboden gleich gemacht worden.

\footnotetext{
899 BONETTI, Cremona, S. 223f.

900 BONETTI, Cremona, S. 234.

901 SANUTO, Diarii, Bd. 33, Sp. 200.

902 SANUTO, Diarii, Bd. 42, Sp. 362.

903 BNM, MS 20476, fol. 213 ${ }^{\mathrm{V}}$.

904 Formentini, Il ducato di Milano, S. 360f.

905 SANUTO, Diarii, Bd. 46, Sp. 104.

906 PORTO, Lettere storiche, S. 110.

907 ZANETTI, L'assedio di Padova, S. 106.

908 ZAGATA, Cronica della città di Verona, Bd. 2, S. 155.

909 Rovelli, Storia di Como, Bd. 3, S. 461.

910 BonetTi, Cremona, S. 239.
} 
Neben der Arbeit an den Befestigungsanlagen war das Transportwesen ein weiterer Bereich, der für die Zwecke der Besatzungsmacht in Anspruch genommen wurde. Im Juli 1526 wurde in Mailand verkündet, dass Lastenträger sich jeden Tag bei den Beamten ihres Stadtviertels zu melden hatten. ${ }^{911}$ Kurz darauf wurden alle Besitzer von Tragtieren aufgefordert, sich mit den Tieren vorzustellen. ${ }^{912}$ Im Februar 1528 mussten die Tiere dann ganz abgegeben werden, wieder wurde eine Entschädigung versprochen. ${ }^{913}$ Die aber schien für die Betroffenen nicht gerade ein unwiderstehlicher Anreiz zu sein: im Sommer 1529 schrieb de Leyva selbst an den Kaiser, die Zugtiere für die Artillerie seien nur durch Gewaltanwendung zu bekommen. ${ }^{914}$

Wann immer das Besatzungsheer aus der Stadt auszog, ergingen verbindliche Weisungen an die Händler, täglich Lebensmittel für die Soldaten anzuliefern. Im August 1528 fanden sie jeden Tag in Mailand eine Eskorte vor, die sie ins Lager geleitete. ${ }^{915}$ Die Größenordnungen dieser Lieferungen waren beträchtlich und sind aus dem folgenden Jahr überliefert: die Bäcker hatten jeden Tag 40.000 Brote und die Weinhändler 100 brente Wein - über 7.5001 - zu den Soldaten zu befördern. ${ }^{916}$ In der Stadt selbst wurden neben den Lebensmitteln auch alle möglichen anderen Waren verlangt, im August 1526 waren es Betten für die Wachen, ${ }^{917}$ Stroh für die Matratzen ${ }^{918}$ und alle Arten von Zelten. Obwohl auch hier die Bezahlung der Ware angekündigt wurde, zeigt die völlig übertriebene Geldstrafe von 500 Scudi für die, die der Besatzungsmacht die Zelte vorenthielten, dass die Bevölkerung offenbar gute Gründe hatte, mit der Erfüllung der Forderungen zu zögern. ${ }^{919}$

\section{Alltag}

In den besetzten Häusern übten die Soldaten sich nicht in Zurückhaltung. Sie ließen sich ganz selbstverständlich von den Hausbesitzern bewirten ohne dafür zu bezahlen, obwohl das eigentlich Vorschrift war und immer wieder betont wurde. Dass sie wegen des ausbleibenden Soldes für die Bezahlung der Lebensmittel zumeist gar kein Geld hatten, kann ihnen nicht angelastet werden, ihre Ansprüche aber gingen in der Regel weit über das Lebensnotwendige hinaus: so behaupteten die Landsknechte, die im Sommer 1526 in Mailand

\footnotetext{
911 ASM Sforzesco, Cart. 1505, Dekret vom 2. 7. 1526.

912 ASM Sforzesco, Cart. 1505, Dekret vom 23. 7. 1526.

913 ASM Sforzesco, Cart. 1506, Dekret vom 29. 2. 1528.

914 AGS Estado 1172, fol. 25. Antonio de Leyva an den Kaiser, ohne Datum, der Kontext deutet aber auf den Sommer 1529 hin.

915 ASM Sforzesco, Cart. 1506, Dekret vom 24. 8. 1526.

916 ASM Sforzesco, Cart. 1507, Dekret vom 21. 8. 1529.

917 ASM Sforzesco, Cart. 1505, Dekret vom 4. 8. 1526.

918 ASM Sforzesco, Cart. 1505, Dekret vom 4. 8. 1526.

919 ASM Sforzesco, Cart. 1505, Dekret vom 9. 8. 1526.
} 
einzogen, den Spaniern seien Hühner und Kapaune aufgetischt worden und forderten eine ebenso fürstliche Bewirtung. Bis zu ihrem Auszug im Februar 1527 ließen sie sich bedienen und bezahlten nichts von allem. ${ }^{920}$ Die Hausherren taten im eigenen Interesse gut daran, den Soldaten jeden Wunsch von den Augen abzulesen, um nicht deren Unmut auf sich zu ziehen. Giovanni Antonio Visconti schrieb zur selben Zeit aus Mailand an einen Hauptmann im spanischen Heer: "Io anchora ho in casa li lanschenechi, et ... me convene pascerli da principe ..."921 Es wurde schon erwähnt, dass die Soldaten sich ohne Rücksicht auf die Befehle zur Einquartierung in den Häusern einnisteten, die ihnen am besten gefielen. Dass sie sich überall gleich wie zu Hause benahmen, zeigt ein Dekret aus dem Mai 1526, durch das ihnen verboten wurde, andere Soldaten zum Essen in ihre Quartiere einzuladen. ${ }^{922}$ Capella berichtet, dass sie zum Frühstück in einem Haus einkehrten, zum Mittagessen in einem anderen. ${ }^{923}$ Auch nach den Aussagen der Zeugen im Prozess von Sormani war das ganz selbstverständlich, Beschwerden bei den Offizieren führten zu nichts. ${ }^{924}$ Und nicht nur in den Vorratskammern, sondern sogar an den Kleidertruhen der Hausherren bedienten die Soldaten sich, wie mehrere Zeugen übereinstimmend festhalten. ${ }^{925}$ Die detaillierten Reglementierungen, was die Hausherren den Soldaten zur Verfügung zu stellen hatten und was nicht, wirken angesichts solcher Zustände völlig wirklichkeitsfremd: drei Soldaten sollten nach einem Dekret Bourbons in Mailand eine Matratze, zwei Laken, ein Kissen und eine Decke bekommen. ${ }^{926}$ In Cremona wurde sogar präzisiert, dass die Handtücher jede Woche und die Laken alle zwei Wochen zu waschen waren. ${ }^{927}$

Neben Bewirtung und Einkleidung verlangten die Soldaten auch andere Dienstleistungen. Capella berichtet, dass sie die Angstellten der Hausherren in Mailand wie Leibeigene behandelten. ${ }^{928}$ In den schlimmsten Fällen wurden diese selbst zu Dienern degradiert wie in Rom, wo Personen von Rang und Ansehen sich als Pferdeknechte, Küchengehilfen und Wasserträger der Soldaten wiederfanden. ${ }^{929}$

Das Benehmen der Soldaten war denkbar schlecht und fiel in den mit Vorliebe belegten Häusern der kultivierten Oberschichten um so unangenehmer auf. $\mathrm{Zu}$ den Zuständen, die in den von Landsknechten bezogenen Wohnungen im Mai 1510 in Vicenza herrschten, fiel einem anonymen Chronisten nichts anderes ein als der Vergleich mit Schweineställen: "... nelle camere netissime e pomposamente adornate et abbellite, tanto immonde erano che

\footnotetext{
920 Burigozzo, Cronaca di Milano, S. 464.

921 ASM Sforzesco, Cart. 1424. Giovanni Antonio Visconti an Alvisio Ciciliano, Mailand, 15. 2. 1527.

922 ASM Sforzesco, Cart. 1505, Dekret vom 26. 5. 1526.

923 CAPELLA, Beschreibung und Geschicht, fol. $44^{\mathrm{r}}$.

924 IIPPAB Comuni 182, Punkt 9.

925 CAPELlA, Beschreibung und Geschicht, fol. 31 ${ }^{\mathrm{r}}$; SANUTO, Diarii, Bd. 42, Sp. 25; VAlLES, Historia, $217^{\mathrm{V}}$.

926 ACM Registri di lettere ducali, Bd. 19, fol. $81^{\mathrm{V}}$.

927 BONETTI, Cremona, S. 153.

928 CAPELLA, Beschreibung und Geschicht, fol. $31^{\mathrm{V}}$.

929 GUICCIARDINI, Il sacco di Roma, S. 240.
} 
quelle non da huomini habitate parevano ma da porci et d'altri più immondi animali, se si ne ritrovano, et questo non in spatio di settimane ma di hore, in maniera che non era camera così rilucente et monda che al più in un giorno non havessero quelli animali imondissimi resa una fetida stalla." 930

Mit den Soldaten hielten Sitten Einzug, die auch die Bewohner zur Verzweiflung trieben, die keinen körperlichen oder materiellen Schaden erlitten. Perez schrieb aus Rom an den Kaiser, dass die Frommen sich wegen der vielen Lästerungen, die die Soldaten den ganzen Tag über ausstießen, wünschten, mit Taubheit geschlagen zu werden. ${ }^{931}$ Doch dieses Wunder blieb aus, und so mussten die Einwohner nicht nur die Flüche über sich ergehen lassen, sondern wurden auch täglich Zeugen des unsittlichen Treibens der Soldaten. Mit den Heeren kamen Scharen von Frauen in die Stadt, die mit den Soldaten zusammen die Quartiere bezogen. Viele von ihnen waren Prostituierte, die unter den Augen der Einwohner ihrem Lebensunterhalt nachgingen. In Rom ging das so weit, dass deutsche und spanische Dirnen in den Kirchen ihre Dienste anboten, wie Luigi Guicciardini angewidert berichtet. ${ }^{932}$

Die unhaltbaren Zustände führten neben den großen Abwanderungsbewegungen dazu, dass viele ihre Häuser verließen und innerhalb der Stadt eine andere Bleibe suchten. Im Januar 1527 wurde durch ein Dekret von Antonio de Leyva in Mailand verkündet, dass niemand die Adresse aufgeben durfte, unter der er in der Schätzung von 1524 registriert worden war. Das Phänomen war offenbar weit verbreitet: "... molti de li ditti habitatori per fuggir ditti carichi stano nascosti in diverse parti de la ditta Città et Borghi ..." Wer die Flüchtigen bei sich aufgenommen hatte und sie nach Bekanntmachung des Dekrets nicht sofort aus dem Haus warf, machte sich mitschuldig und musste deren Anteil an der Kontribution übernehmen. ${ }^{933}$ Da viele sich in den Schutz der Klöster geflüchtet hatten, wurden im Juni 1526 die Äbte angewiesen, die Flüchtlinge aus ihren Mauern zu verweisen. ${ }^{934}$ Ein ähnliches Dekret folgte im August 1527, die Geistlichkeit wurde darin aufgefordert, den Flüchtigen ihr gesellschaftsschädigendes Verhalten vor Augen zu führen. ${ }^{935}$ Dass neben den Kontributionen die Übergriffe der einquartierten Soldaten der zweite wichtige Grund für das Verlassen der Stadt war, ist oben schon erwähnt worden. Da nun innerhalb der Stadt die Soldaten nach Nationen auf die Viertel verteilt waren, zogen einige Mailänder, wenn sie die Stadt nicht ganz verlassen wollten, das von den offenbar weniger rabiaten Landsknechten belegte Viertel der Porta Cumana ${ }^{936}$ den von den Spaniern bewohnten Gegenden vor. Burigozzo berichtet, dass der Volksmund die Porta Cumana aus diesem Grund in Schlaraffenland cucagna - umtaufte: "Et per questa poca de amicizia et confidenzia che avevano con dicti

\footnotetext{
930 GUERIN-DALLE MESE, Una cronaca vicentina, S. 174.

931 Rodriguez ViLla, Memorias, S. 140.

932 GuICCIARDINI, Il sacco di Roma, S. $240 f$.

933 Formentini, Il ducato di Milano, Nr. 67, S. 469.

934 ASM Sforzesco, Cart. 1505, Dekret vom 27. 6. 1526.

935 FormentinI, Il ducato di Milano, Nr. 72, S. 475.

936 Eigentlich Porta Comasina.
} 
Lanzinechi, ognuno che fuggiva da Spagnoli se ne andava al quartero de Lanzinechi, et erano salvi ... perchè, come se diseva, avevano baptizato el quartero de Lanzinechi la cucagna, et tutto el resto de Milano la Spagna, perchè dappertutto erano Spagnoli." ${ }^{937}$ An jedem Festtag ging man in das Viertel der Deutschen, um die flüchtigen Verwandten - von Burigozzo sinnigerweise "li fore insciti" genannt - zu besuchen.

Die Angst vor Übergriffen führte neben den von der Besatzungsmacht verordneten Einschränkungen zu einer weiteren Lähmung des öffentlichen Lebens. In Rom wurden wegen der Plünderung, den Zerstörungen und auf Grund der Tatsache, dass viele Kirchen profanen Zwecken zugeführt worden waren, sieben Monate lang keine Messen gelesen, mit Ausnahme der spanischen Nationalkirche. ${ }^{938}$ In Mailand gingen die Priester aus Angst vor Überfällen verkleidet umher und vernachlässigten den Gottesdienst. ${ }^{939}$ Nach dem Aufstand im Juni 1526 hatten die Vergeltungsmaßnahmen der Besatzer die Mailänder darüber hinaus so sehr eingeschüchtert, dass die Spione in den Diensten Venedigs klagten, man könne kaum Informationen bekommen, weil die wenigen, die sich überhaupt auf die Straße trauten, mit niemandem zu reden wagten, noch nicht einmal mit ihren Freunden: "... et quelli di la terra non olsano parlar cum nissun et vanno soli, nè tra loro osano pur parlar andando per la terra dubitando de non esser amazati; et qual ha voluto parlar cum li sui amici, mai non se hanno voluto lassar parlar." ${ }^{140}$ Ein anderer Informant bemerkte, die Mailänder gingen nur noch zur Kirche aus dem Haus. ${ }^{941}$

Bei Unruhen wurden sofort die Läden geschlossen, ganz abgesehen davon, dass viele Geschäftsleute die Stadt verlassen hatten. Die Nervosität der Mailänder führte zu einer ständigen Schließung und Öffnung der Läden, die wie ein Indikator für die Angst vor Übergriffen wirkt, gleichzeitig aber auch Ausdruck einer Widerstandshaltung vor allem gegen die Kontributionsforderungen der Besatzer werden konnte. Im Frühjahr 1526 sperrten sich die Mailänder gegen die Zahlung einer geforderten Abgabe mit dem Argument, wegen der Verdienstausfälle durch die Schließung der Läden sei kein Geld vorhanden. ${ }^{942}$ Ein Jahr später wurden die Läden dann wiederum aus Protest gegen eine geplante Kontributionsforderung geschlossen. ${ }^{943}$ Um dieser doppelten Kausalität entgegen zu treten, wurde in unregelmäßigen Abständen die Öffnung der Geschäfte durch Dekrete vorgeschrieben, die entweder, wie nach dem ersten Aufstand im April 1526, die Rückkehr an die Arbeit als Voraussetzung für die Abstellung von umstürzlerischen Aktivitäten verordneten ${ }^{944}$ oder, wie im

937 Burigozzo, Cronaca di Milano, S. 459.

938 BAV, MS Ottob. Lat. 2137, S. 171; SANuTO, Diarii, Bd. 45, Sp. 436; ArMELlini, M. (HrSG.): Un documento del sacco di Roma nel 1527. In: Cronachetta mensuale di Archeologia e di scienze naturali. Jg. 25, Bd. 12 (1890). S. 93.

939 Burigozzo, Cronaca di Milano, S. 477.

940 SANUTO, Diarii, Bd. 42, Sp. 142.

941 SANuTO, Diarii, Bd. 42, Sp. 211.

942 Burigozzo, Cronaca di Milano, S. 451.

943 Burigozzo, Cronaca di Milano, S. 471.

944 ASM Sforzesco, Cart. 1505, Dekret vom 26. 4. 1526. 
Oktober 1528, die Gefahr von Übergriffen für beendet erklärten, weil die Soldaten - im übrigen wie immer sehr unvollständig - bezahlt worden seien. ${ }^{945}$ Dass eine solche Erklärung reine Schönfärberei war, zeigt am besten ein Brief, den der Gouverneur zur selben Zeit an den Kaiser schrieb und aus dem die tiefste Verzweiflung spricht: "Podeis considerar como me hallo, la tierra esta destruyda, los hombres consumidos, no ay vituallas ny una gota de vino. No ay soldado que mas me crea, e menos tengo de donde poder sacar un quatrino." ${ }^{946}$ Alle Zeugen sind sich darüber einig, dass Mailand wie ausgestorben dalag, aus den Ritzen im Pflaster wuchsen Brennnesseln. ${ }^{947}$

Inmitten dieser Szenerie vertrieben sich die Soldaten die Zeit mit Tätigkeiten, die den oben begonnenen Katalog der anstößigen Verhaltensweisen vervollständigten. Vor allem die Landsknechte waren als Trunkenbolde verschrien. Perez schrieb aus Rom, dass die Deutschen mehr als alles andere hinter dem Wein her seien, ${ }^{948}$ und selbst den Spaniern fiel die Trunksucht und Völlerei der Deutschen auf. ${ }^{949}$ Die Landsknechte betranken sich bei jeder Gelegenheit, nach der Plünderung des Palastes ihres Landsmanns, des Kardinals Wilhelm von Enckenvoirt im Mai 1527, wo aus der ganzen Nachbarschaft Tische für ein wildes Gelage zusammengetragen wurden, ${ }^{950}$ ebenso wie im Anschluss an ein Reiterturnier auf dem Campo de' Fiori im Januar 1528, bei dem niemand nach Hause ging, bevor er nicht vollständig betrunken war. Das berichtet das Tagebuch eines anonymen Franzosen, bei dem ein italienischer Soldat namens Gaspar Pisognius einquartiert war, der in einer Kompanie von Landsknechten diente. Auch unter dem folgenden Tag hatte der Zeuge von seinem italienischen Hausgenossen in deutschen Diensten nicht mehr zu berichten, als er in einem nüchternen Satz zusammenfasste: "Ebrius fuit Gaspar Pisognius hoc die." ${ }^{951}$ Es ging so weit, dass die Besatzung der Engelsburg zweimal ausgewechselt werden musste, weil die Soldaten keine Lust hatten, dort zu bleiben, wo sie nicht zechen konnten: "... Bembelberg verordnet den Haubtmann Corradin mit aim Vendle Landtsknecht, welche bestia sorg truegen, sie kundten nit frey und unflettig sein, das Irs gefallens stetigs zum wein gehn kundten, und wolten nit darin bleiben, da verordnete man den haubtman Georg Prantten mit sein fendlen Knecht, der war auch etwan ain vier oder fünf tag darin, da hat er des Castels auch genueg, und wolt auch nit mehr darinnen sein, sondern bei dem lieben vino greco an der stat ..."952 Dem weit verbreiteten Phänomen des übermäßigen Alkoholkonsums trug die Besatzungsmacht nicht etwa durch Einschränkungen Rechnung, sondern durch Maßnahmen, die ganz

945 ASM Sforzesco, Cart. 1506, Dekret vom 22. 10. 1528.

946 AGS Estado 1172, fol. 13. Antonio de Leyva an den Kaiser, 13. 10. 1528.

947 GuICCIARDINI, Storia d'Italia, Buch 18, Kap. 18 (Bd. 4, S. 173).

948 RoDRIGUEZ Villa: Memorias, S. 213.

949 BAV, MS Urb. Lat. 850, fol. $72 \mathrm{~V}$.

950 DROYSEN, Zeitgenössische Berichte, S. 49.

951 OMOnT, Les suites du sac de Rome, S. 27. Der Nachname des Soldaten ist merkwürdig. In seiner italienischen Form müsste er Bisogno lauten, das aber war der Spitzname der zumeist in Neapel rekrutierten Spanier.

952 GregOrOVIUS, Ein deutscher Bericht, S. 363. 
offensichtlich ein Heer von Trinkern bei Laune halten sollten: in Cremona wurde 1526 die Tagesration für Wein auf 4 bocali - mehr als 31 - festgeschrieben. ${ }^{953}$

Nachrichten über andere Formen der alltäglichen Beschäftigung sind wegen des Mangels an Außergewöhnlichkeit und Auffälligkeit aus der Sicht der Zeitgenossen sehr dünn gesät und sollen hier nur der Kuriosität halber erwähnt werden. Wer schreiben konnte - und das waren wohl die allerwenigsten - blieb in Kontakt mit der Heimat. Private Briefe von Soldaten, die die Zeit überdauert haben, sind eine Seltenheit. Aus Prato sind drei Entwürfe von Briefen überliefert, die ein namenloser Soldat aus dem Heer des Vizekönigs gegen Ende August oder Anfang September 1512 in holprigem Italienisch mit unüberhörbar spanischem Einschlag an seine Liebste daheim und zwei weitere Personen schrieb. Seine Liebesschwüre zeugen von der Mühe auf der Suche nach eleganten Formulierungen: "Unica mia in cui spero et la propria vita teni in soy mano quanto e el dispiacer esser assenti de vostra presencia dio lo sa supplicola me avvisa al spesso che certamente moro pensando in vuy et bene sapete che quando stava in vostra presencia non me potia partire de quel bel viso al presente asento et non lo haver visto a tanti jorni pensato uni como voglio far et con che modo et uno pensero sto." Des weiteren erfährt man, dass ihm der Militärdienst Freude bereitete: "... cum piacere me piglo le fatige militari non avendo ad nessuna cosa fastidio ..." Kein Wunder, denn die Plünderung der Stadt, von der er kurz berichtet, lag gerade zurück. Immerhin belegen die Briefe und einige Aufforderungen an die Empfänger, von sich hören zu lassen, dass auch ein privater Nachrichtenaustausch zwischen dem Heer und den Heimatorten der Soldaten stattfand. ${ }^{954}$ Ebenfalls aus Prato ist ein Heft überliefert, in dem einige spanische Soldaten sich offenbar aus Langeweile verewigten. Es handelt sich um Zeichnungen und Kritzeleien, die von mangelhaftem künstlerischen Talent und einer noch mangelhafteren Beherrschung der Schrift zeugen. Zeichnungen von Menschen und Tieren wechseln sich mit Schreibübungen ab, die darauf hindeuten, dass die Soldaten offenbar aus vorliegenden Briefen abschrieben. Dass es sich nicht um echte Entwürfe handelt, zeigt neben dem wüsten Durcheinander von Ansätzen und der selbst für jene Zeit haarsträubenden Rechtschreibung auch die Tatsache, dass einzelne Buchstaben spiegelverkehrt, also von einer des Schreibens unkundigen Person wiedergegeben wurden. Immerhin erfährt man aus Textstücken wie "yo dixo ansi ya Florencia se toma", dass es sich um Soldaten handelte, die zum Belagerungsheer vor Florenz gehörten, das im Januar 1530 Prato besetzte. ${ }^{955}$ So rudimentär wie die Kenntnisse der Schrift war offenbar auch die Beherrschung der Sprache des Landes, in dem man sich aufhielt: zusammenhanglos eingestreute Worte wie "cazzo"

\footnotetext{
953 BONETTI, Cremona, S. 226.

954 ASP Ceppi 96. Eingänge und Ausgänge des Ceppo Nuovo für das Jahr 1501. Offenbar war der Soldat in dem Gebäude einquartiert, in dem die Bücher aufbewahrt wurden. Die Briefentwürfe finden sich auf fol. $26^{\mathrm{r}}$, fol. $87^{\mathrm{V}}$ und fol. $88^{\mathrm{r}}$.

955 Falletti, Assedio, S. 109.
} 
nebst entsprechenden Zeichnungen zeigen, dass vor allem Vokabeln aus dem Bereich der Fäkalsprache Eingang in den Wortschatz der Soldaten fanden. ${ }^{956}$

Die Offiziere indes gingen weitaus distinguierteren Vergnügungen nach. Aus der Zeit der Besatzung in Rom ist das sogenannte Journal von Philibert von Oranges überliefert, das die Ausgaben für das Privatvergnügen des Prinzen aufführt. ${ }^{957}$ Auch bei ihm standen alle Arten von Spielen hoch im Kurs, die allerdings nur dann in den Aufzeichnungen auftauchen, wenn sie mit Ausgaben verbunden waren, mit anderen Worten: wenn Oranges verlor. Im Januar 1528 verlor er 2 Scudi beim Schachspiel an einen spanischen Hauptmann, ${ }^{958}$ ein paar Tage später 39 Scudi an den deutschen Hauptmann Konrad von Bemelberg. ${ }^{959}$ Noch ein paar Tage darauf wurde es dann teuer: Bemelberg und Urbina nahmen ihm beim Würfelspiel 515 Scudi ab. ${ }^{960}$ Weitere Partien mit den jeweiligen Verlusten sind über den dokumentierten Zeitraum verstreut, neben Schach und Würfeln vergnügte man sich bei verschiedenen Brettspielen und Kartenspielen. ${ }^{961}$ Daneben gab Oranges sich kulturellen Genüssen hin. Schon am 9. Mai 1527, während die Plünderer sich draußen mit ungebrochener Wucht austobten, ließ er sich im Papstpalast ein Trompetenkonzert 14 Dukaten kosten. ${ }^{962}$ Eine besondere Vorliebe hatte er offenbar für Oboenklänge, aber auch andere Instrumentalisten und ein gemischter Chor traten vor ihm auf. ${ }^{963}$ Insgesamt 14 Konzerte verzeichnet das Journal in den nicht ganz fünf Monaten, die Oranges in Rom weilte. Im Juni ließ er ein Porträt von sich anfertigen, was etwas seltsam anmutet, denn zu dieser Zeit muss er durch eine schwere Schussverletzung im Gesicht arg entstellt gewesen sein. ${ }^{964}$ Diese wiederum wurde zuerst von Chirurgen - deren Dienste für eine einzige Behandlung mit stolzen 20 Dukaten zu Buch schlugen ${ }^{965}$ - und dann von Frauen und Barbieren versorgt. ${ }^{966}$ Neben zahlreichen Anschaffungen für die alltäglichen Bedürfnisse seines Gefolges - von Küchengeräten über Tischtücher und Kerzen bis hin zur Ausstattung für seine Pagen - liebte Oranges selbst die Raffinesse: unter den Ausgaben finden sich eine Phiole mit Rosenwasser für seine Taschentücher, ${ }^{967}$ eine mit Goldfäden durchwirkte Satteldecke, ${ }^{968}$ ein Paar parfümierte Handschuhe ${ }^{969}$ und allerhand teure Stoffe, aus denen seine Schneider Kleidung für ihn fertigten. Neben einer Reihe von Reparaturen an seiner Ausrüstung kamen auch die

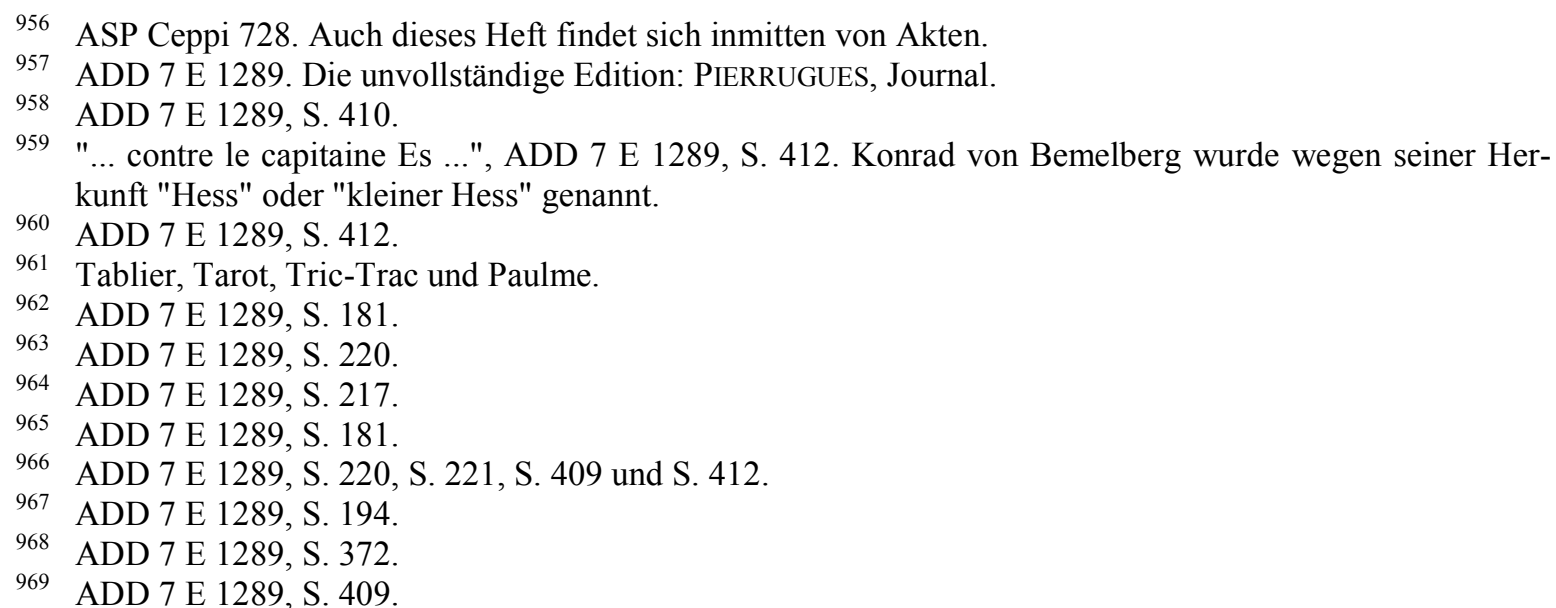


geistlichen Dienstleistungen nicht zu kurz: allein in den Monaten Mai und Juni des Jahres 1527 ließ er 75 Messen für sein Seelenheil lesen, und kurz nach Weihnachten führte ihn sein Beichtvater durch die sieben Hauptwallfahrtskirchen der Stadt. ${ }^{970}$ Einige weitere Eintragungen geben Momentaufnahmen des Lebens im geplünderten Rom wieder: im Mai 1527 löste er einen Gefangenen bei einem spanischen Soldaten für 110 Scudi aus, ${ }^{971}$ gleichzeitig kaufte er eine Uhr für 30 Scudi, die der Anbieter aller Wahrscheinlichkeit nach irgendwo erbeutet hatte. Einen Monat später bezahlte er die Beerdigung eines Toten, den man vor seiner Unterkunft gefunden hatte. ${ }^{972}$ Schließlich fand im Januar 1528 ein Maskenball mit Damen statt. ${ }^{973}$ Insgesamt gab er während der fünf Monate, die er in Rom verbrachte, für sich und sein Gefolge etwa 7.000 Scudi aus.

Galante Feste waren auch bei den Hauptleuten in der Lombardei beliebt. Guasto, der im Februar 1526 in Asti weilte, nahm dort ebenfalls an einem Maskenball teil, im Anschluss daran wurde er bei einem Kampfspiel an der Hand verletzt. Eigentlich war er von Mailand nach Asti gezogen, um wegen der Übergriffe dort ein Exempel an einigen Soldaten zu statuieren. ${ }^{974}$ Das hinderte ihn aber nicht daran, sich sogar seine Jagdhunde hinterherbringen zu lassen, von dem Maskenball berichtet nämlich sein Page, der für den Transport der Hunde verantwortlich war. ${ }^{975}$ Ansonsten sind die Berichte über die Vergnügungen der Offiziere wegen der Irrelevanz der Informationen für die militärischen Belange selten. Die Zeugnisse sind wie so oft in anderen Zusammenhängen überliefert, nämlich dann, wenn es aus scheinbar abwegigen Gründen doch eine Verbindung gab: aus dem März 1527 wird berichtet, dass die Venezianer sich die Karnevalszeit aussuchten, um Antonio de Leyva eine Feier zu verderben. Mitten in der Nacht schossen sie aus allen Rohren vor den Mauern von Mailand, so dass überall in der Stadt Alarm ausgelöst wurde und das Kostümfest sich auflöste. Einer der Beteiligten bemerkte dazu voller Schadenfreude: "Da poi se incominciò un gran remor et grossa allarma, et fu questo a hore 4 di notte et pensamo haverge disviato la festa, que non havea voglia più di ballare in quella nocte." 976

\section{4. Übergriffe}

Übergriffe gegen die Bevölkerung waren in besetzten Städten an der Tagesordnung. Dennoch finden sich entsprechende Berichte vor allem aus der Anfangszeit der jeweiligen Be-

\footnotetext{
970 ADD 7 E 1289, S. 373.

971 ADD 7 E 1289, S. 182.

972 ADD 7 E 1289, S. 220.

973 ADD 7 E 1289, S. 414.

974 SANUTO, Diarii, Bd. 40, Sp. 826.

975 SANUTO, Diarii, Bd. 40, Sp. 867.

976 SANUTO, Diarii, Bd. 44, Sp. 262.
} 
satzung. Die Tatsache, dass sie mit fortschreitender Dauer der Anwesenheit der Soldaten immer seltener explizit erwähnt und beschrieben werden, ist viel eher ein Zeichen für die zunehmende Lethargie und Abstumpfung der Opfer als für eine tatsächliche Abnahme der Übergriffe.

Diese häuften sich immer dann, wenn die Soldaten wegen der ausbleibenden Soldzahlungen in Wut gerieten. Zum einen holten sie sich durch Plünderungen bei der Bevölkerung das, was ihnen ihrer Meinung nach zustand, zum anderen versuchten sie, Druck auf die Offiziere auszuüben, um die Beschaffung des Geldes zu beschleunigen. Was in den meisten Fällen nach ziellosen Gewaltakten aussah, hatte bisweilen System: Burigozzo berichtet, dass die Soldaten im Herbst 1528 in Mailand die Läden um den Domplatz auseinandernahmen und ankündigten, die Plünderungen so lange fortzusetzen, bis die Bezahlung erfolgt sei. Dieses Spiel wiederholte sich alle zwei Wochen, nämlich immer dann, wenn eine halbe Monatszahlung ausstand. ${ }^{977}$ In Rom beschränkten sich solche Ausschreitungen nicht auf Plünderungen, sondern wurden zu einer Bedrohung für Leib und Leben der Bewohner, vor allem nach der Flucht der Geiseln des Papstes aus dem Palast der Kanzlei. Als die Landsknechte am Morgen des 1. Dezember 1527 die verwaisten Betten und eine Strickleiter im Kaminschacht vorfanden, gerieten sie in Raserei: "... und weren nur wildt, wolten nur wider anfangen Rom zu plündern, und das Kindt in Mutter laib erwürgen. Und stunden lenger dan 5 ganzer stundt bei einand versamblet, wie zue beratschlagen, und des mehren thails rath war erwürgen, plündern und alles übel zue thun, das möglich und menschlich were. ${ }^{978}$ Alarcon bezeugte in einem Brief an den Kaiser, dass solche Gewaltexzesse dann tatsächlich stattfanden. ${ }^{979}$

Vor Überfällen war man in Rom weder auf der Straße, noch im eigenen Haus sicher: Giulio Cardello, der an einem Abend im Januar 1528 zum Spielen zu Gast bei Giovanni Barotio der die Misshandlungen bei der Plünderung also offenbar überlebt hatte - im Palast des Kardinals Pisano weilte, traute sich am Ende der Partie nicht, den Weg nach Hause durch die nächtliche Stadt anzutreten, "ob militum periculum". ${ }^{980}$ Und Dionisio Boccapaduli bekam Ende Mai 1527 mitten in der Nacht Besuch von Soldaten, die sich unter einem Vorwand Zutritt zu seinem Haus verschafften, ihm den Schlüssel abnahmen, ihn in eine Latrine warfen und anschließend so lange misshandelten, bis er das Versteck seiner Wertgegenstände verriet. ${ }^{981}$

Nach dem vorübergehenden Abzug des Heeres aus Rom im Sommer 1527 gingen die Übergriffe im September weiter. Wie weit die Angst vor erneuten Plünderungen verbreitet war, zeigen die Schutzmaßnahmen, die man ergriff, als die Nachricht vom Herannahen der

977 Burigozzo, Cronaca di Milano, S. 481f.

978 GregOrOVIUS, Ein deutscher Bericht, S. 395.

979 Gayangos, Calendar, Bd. 3, Teilbd. 2, S. 493.

980 OMONT, Les suites du sac de Rome, S. 25.

981 BICCI/COMBO, Notizia storica, S. 74f. 
Soldaten die Stadt erreichte: im August 1527 hatte die Welserbank in Rom eine Reihe von Wertgegenständen bei der Fuggerbank deponiert. Viele der in einer überlieferten Liste verzeichneten Gegenstände gehörten Opfern der Plünderung und waren als Pfand gegen Bargeld für die Bezahlung der Lösegelder eingelagert worden. ${ }^{982}$ Am 24. September, einen Tag vor dem Einrücken des Heeres, gab die Fuggerbank die Einlagen dann plötzlich zurück. ${ }^{983}$ Auch aus dem Kloster San Silvestro e Martino wurden zur selben Zeit die wenigen noch verbliebenen Wertgegenstände in Sicherheit gebracht. ${ }^{984}$ In einem Brief an den Kaiser brachte Perez die Angst zum Ausdruck, die in diesen Tagen in Rom umging: "Si, lo que Dios no quiera, aquí volviesen los alemanes, sería de todo punto destruida Roma, porque sería forzado venir toda la otra gente, y no dexarían piedra sobre piedra." ${ }^{985}$ Er selbst hatte bereits vorher schlechte Erfahrungen gemacht: Anfang Juni waren ihm vier Fässer Wein aus dem Keller gestohlen worden - um sich Zutritt zu verschaffen, hatten die Soldaten kurzerhand eine Wand durchbrochen. Francisco de Salazar, der von dem Vorfall berichtete, schrieb, man lebe in ständiger Angst, dass solche Zwischenfälle sich wiederholten. ${ }^{986}$

Ausbrüche der Gewalt traten im Verlauf von immer wieder aufflammenden Plünderungen auf, aber auch aus verschiedenen anderen Gründen. In Mailand entfesselte die Niederschlagung der Aufstände eine Welle von Gewaltakten gegen die Bevölkerung, die einen guten Teil zur faktischen Bagatellisierung der Brutalität beitrugen. Dionisio Sesto, Mitkläger im Prozess von Sormani gegen seine Nachbarn, hatte sein Haus verlassen, weil er zur selben Zeit von einem bei ihm einquartierten Soldaten verprügelt worden war. ${ }^{987} \mathrm{Im}$ September 1527 stellte der Gouverneur den Soldaten durch ein Dekret dann praktisch einen Freischein für Übergriffe gegen die Bewohner der Stadt aus: neben den üblichen Strafen gegen die durch das Dekret zum Verlassen der Stadt aufgeforderten Personen - in diesem Fall diejenigen, die die Tagesabgaben nicht aufbringen konnten - wurde verkündet: "... che li soldati possano passato dicto giorno fare prigioni et fare ogni altro male contro dicti tali, tanto maschii, quanto femine a discretione di essi soldati ..."

Wie die Gewaltakte, so häuften sich auch die Plünderungen in Mailand zur Zeit der Aufstände. Deren Niederschlagung hatte nicht nur einige Hemmschwellen gesenkt, sondern auch dazu geführt, dass die Soldaten sich angesichts der Feindseligkeit der Bevölkerung zu Übergriffen geradezu berechtigt fühlten. Die Aktionen zur Entwaffnung der Bevölkerung arteten derart aus, dass Passanten Gefahr liefen, auf offener Straße und am hellichten Tag von vorübergehenden Soldaten ausgeraubt zu werden: "... et se l'aveva bona cappa adosso

\footnotetext{
982 Cavalletti-Rondinini, Nuovi documenti, S. 26-30.

983 SCHUlTE, Die Fugger in Rom, Bd. 2, S. 240.

984 ASR, Silvestro e Martino, Busta 8, fol. $11^{\mathrm{r}}$.

985 RoDrigueZ VILLA, Memorias, S. 283.

986 RodRIGUEZ VILLA, Memorias, S. 157.

987 IIPPAB Comuni 182, 3. Fasc.

988 FormentinI, Il ducato di Milano, Nr. 74, S. 478.
} 
et bona baretta, et anche bona borsa, tolevano quel che ghe piaseva: et non erano homeni de dir sua rasone." ${ }^{989}$ Gleichzeitig führte man Razzien in den Läden der Waffenhändler durch, ${ }^{990}$ die in Plünderungen ausarteten und dann offenbar eigenmächtig von den Soldaten auf die Juweliere und Goldschmiede ausgedehnt wurden, in deren Läden sie teilweise über die Dächer einstiegen. ${ }^{991}$ Auch die Klöster wurden nach Waffen durchsucht und unter diesem Vorwand geplündert. Nach dem Ende der Razzien wegen des zweiten Aufstands wurde den Soldaten aus diesem Grund der Zutritt zu den Klöstern verboten. ${ }^{992}$ Die Überfälle auf die Klöster wiederholten sich in der Folgezeit trotzdem immer wieder, im Dezember 1526 wurde auch das Hospital geplündert. ${ }^{993}$ Kurz darauf kam es zu einem unerhörten Zwischenfall, als die Soldaten das Haus von Ludovico da Corte, einem der höchsten Mailänder Beamten stürmten und bis ins Schlafzimmer seiner Frau vordrangen, wo sie die Schmuckschatulle plünderten. Als der Hausherr in Begleitung von Bourbon am Schauplatz des Geschehens eintraf, wurden die beiden von den Soldaten beschossen und mussten ins Kastell fliehen. Der Bruder von Corte wurde kurz darauf gefangen und erst gegen ein Lösegeld von 5.000 Dukaten freigelassen. ${ }^{994}$ Eine Reihe von Dekreten der Besatzungsmacht gegen willkürliche Geiselnahme durch die Soldaten belegen, dass eine solche Begebenheit kein Einzelfall war. Auch dieses Treiben scheint zur Zeit der Aufstände in Gebrauch gekommen zu sein, jedenfalls datiert das erste Verbot aus dem Juni 1526. ${ }^{995}$ Im September wurde dieses Verbot durch ein neues Dekret bekräftigt, aus dem hervorgeht, dass die Soldaten bisweilen auch städtische Beamten in ihre Gewalt brachten. ${ }^{996} \mathrm{Im}$ Zweifelsfall behaupteten sie offenbar, dass es sich um rechtmäßig eingebrachte Kriegsgefangene handelte. Obwohl die Verbote allein wenig halfen, machte man erst im Juni 1529 Anstalten, dem Problem der Lösegelderpressung durch Geiselnahme ernsthaft auf den Leib zu rücken: durch ein Dekret wurde den Soldaten befohlen, alle Gefangenen dem Justizhauptmann Juan de Sarmiento auszuliefern, damit dieser die Rechtmäßigkeit der Forderungen überprüfen, mit anderen Worten: feststellen konnte, ob die Gefangenen "de bona guerra" waren. Die Festungskommandanten im gesamten Staat wurden aufgefordert, Listen mit den Namen aller Gefangenen einzureichen, die bei ihnen inhaftiert waren. Neu eingebrachte Gefangene mussten sofort gemeldet werden. ${ }^{997}$

Aus Verona sind gegen Ende der spanischen Besatzungszeit ähnliche Zustände überliefert. Hier war die Bevölkerung so eingeschüchtert, dass die Soldaten es sich erlauben konnten,

\footnotetext{
989 Burigozzo, Cronaca di Milano, S. 456.

990 SANUTO, Diarii. Bd. 41, S. 677.

991 SANUTO, Diarii. Bd. 41, S. 721.

992 ASM Sforzesco, Cart. 1505, Dekret vom 2. 7. 1526.

993 ASM Sforzesco 1359, anonymer Bericht aus Mailand vom 22. 12. 1526.

994 SANUTO, Diarii. Bd. 43, S. 530.

995 ASM Sforzesco, Cart. 1505, Dekret vom 20. 6. 1526.

996 ASM Sforzesco, Cart. 1505, Dekret vom 3. 9. 1526.

997 ASM Sforzesco, Cart. 1507, Dekret vom 4. 6. 1529.
} 
die Läden zu betreten, sich mit der größten Selbstverständlichkeit alles zu nehmen was ihnen gefiel und die Läden wieder zu verlassen. ${ }^{998}$ Wenn es sich herumsprach, dass jemand noch Weinvorräte hatte, fielen sie in Horden von 50 oder 100 in seinem Haus ein. ${ }^{999}$ Eine weitere Variante der Plünderung hatten die Landsknechte dort entwickelt: sie brachen auf dem Markt zum Schein einen Streit vom Zaun und nutzten das sich anschließende Getümmel, um die Stände auszuräubern. ${ }^{1000}$

In Mailand war es daneben üblich, sich am Besitz der Ausgezogenen zu bereichern. Wer die Stadt verbotswidrig verlassen hatte, wurde zum Empörer erklärt und seine Habe verfiel der Konfiskation. Es ist schwierig zu beurteilen, in wessen Taschen der konfiszierte Besitz floss. Sicher ist indes, dass es für die Soldaten gängige Praxis war, die leerstehenden Häuser einfach aufzubrechen und alles herauszuschleppen, was ihnen gefiel. Die Abwesenheit der Hausherren genügte in diesem Fall auch ohne dass eine Konfiskation angeordnet worden war. ${ }^{1001}$ Auch in Rom gingen Soldaten in den verlassenen Häusern ein und aus, wie bei Angelo Colotio, wo Antonio Tebaldeo ein heilloses Durcheinander vorfand und schließlich, wie erwähnt, von einem Spanier überrascht und verprügelt wurde. ${ }^{1002}$ Der Notar Jakob Apocellus, der sein Haus verlassen hatte, kehrte zweimal dorthin zurück und fand es beide Male aufs Neue durchwühlt vor. ${ }^{1003}$

Auch in den Quartieren selbst kam es zu Übergriffen aller Art. Der Verwalter von Sormani musste bei den einquartierten Spaniern die im Haus gelagerte Ware auslösen, um zu verhindern, dass sie verkauft wurde. Dennoch wurden Kisten mit Waren im Wert von 150 Dukaten aus dem Haus geschleppt. ${ }^{1004}$ Einer der Zeugen erinnert sich an das Chaos, das die Soldaten im Haus von Sormani angerichtet hatten: Waren lagen überall auf dem Boden verstreut und die Bettlaken waren zu Pferdedecken zweckentfremdet worden. ${ }^{1005}$ Forderungen wurden mit Androhung von körperlicher Gewalt untermauert, zwischenzeitlich wurde der Verwalter von den Soldaten eingesperrt. ${ }^{1006}$ Überhaupt kam es nicht selten vor, dass die Familien der Hausbesitzer von den Soldaten gefesselt wurden, um zu verhindern, dass sie entflohen. $^{1007}$

\footnotetext{
998 ZAGATA, Cronica della città di Verona, Bd. 2, S. 184.

999 ZAGATA, Cronica della città di Verona, Bd. 2, S. 185.

1000 ZAGATA, Cronica della città di Verona, Bd. 2, S. 126.

${ }^{1001}$ BurigOzZO, Cronaca di Milano, S. 464; CAPELLA, Beschreibung und Geschicht, fol. 31r; IIPPAB Comuni 182, Punkt 22; ASM Sforzesco, Cart. 1424. Giovanni Antonio Visconti an Alvisio Ciciliano, Mailand, 15. 2. 1527.

1002 BAV, MS Vat. Lat. 4104, fol. 79r.

${ }^{1003}$ MAYERHOFER, Zwei Briefe, S. 754.

${ }^{1004}$ IIPPAB Comuni 182, Punkt 5.

1005 IIPPAB Comuni 182, Fasc. 3.

1006 IIPPAB Comuni 182, Punkt 20.

${ }^{1007}$ RAH, Salazar y Castro, A/42, fol. $117^{r}$ f.
} 
Darüber hinaus kam es in allen besetzten Städten gelegentlich zu Vergewaltigungen. In Verona vergewaltigten randalierende Spanier im Oktober zahlreiche Frauen, ${ }^{1008}$ in Cremona fanden schon zu Anfang der Besatzungzeit gegen Ende des Jahres 1525 Vergewaltigungen statt, ${ }^{1009}$ ebenso in Carpi. ${ }^{1010}$ In Mailand kam es dazu vor allem nach dem Aufstand im Juni 1526, wie Jacopo de Cappo bemerkt: "Per quanto ho inteso de molti lochi, godeno le done o per amor o per forza." ${ }^{1011}$ Ganz abgesehen von den Schreckensszenarien bei der Plünderung waren Vergewaltigungen in Rom auch zu fortgeschrittener Zeit an der Tagesordnung. Gumpenberg drückt vorsichtig aus, was im September 1527 nach dem erneuten Einzug des Heeres offenbar in den besetzten Häusern geschah: "... und namben alle heuser und pallaci ein ... und wolten darzue nit bei der magt, sonder bei der Patrona und Dochter schlaffen ..."1012

Neben der Ausplünderung und Misshandlung der Einwohner ist die mutwillige Zerstörung der Gebäude in den besetzten Städten ein drittes Phänomen, das zu den Übergriffen gezählt werden muss. Schon im November 1525 war es den eben in Mailand eingerückten Soldaten ausdrücklich verboten worden, Türen und Läden auszuhängen sowie Fensterrahmen und Treppen aus den Häusern zu reißen. ${ }^{1013}$ Dennoch schritt die Zerstörung vor allem wegen des einsetzenden Winters fort: Einrichtung und Bausubstanz aus Holz wurde kleingehackt und als Brennholz verwendet oder verkauft. Im September 1526 wurde eine Bestandsaufnahme des Schadens angeordnet. ${ }^{1014} \mathrm{Ob}$ die Begehung tatsächlich durchgeführt wurde, ist nicht bekannt, ein venezianischer Berichterstatter aber gab im Dezember an, ein Viertel der Häuser in Mailand sei durch die Zerstörung der Holzteile nahezu unbewohnbar gemacht worden. ${ }^{1015}$ In Pavia war dieses Ausmaß der Zerstörung bereits im Januar 1525 erreicht. ${ }^{1016}$ Brennholz sollte eigentlich auf dem Land geholt werden, aber die Soldaten hatten zumeist keine Lust, den Weg auf sich zu nehmen. ${ }^{1017}$ Wie sehr solche Verwüstungen offenbar von der täglichen Laune der Soldaten abhingen, zeigen zwei Briefe aus Mailand aus dem Februar 1527: Giovanni Antonio Visconti berichtet, die Landsknechte hätten im Haus einer jungen Frau, von der noch die Rede sein wird, die gesamte Einrichtung zerschlagen oder fortgeschleppt, kaum dass sie die Stadt verlassen hatte. ${ }^{1018}$ Unter demselben Tag schreibt Galeazzo Casato, die Landsknechte in seinem Haus benähmen sich gut. ${ }^{1019}$

\footnotetext{
1008 SANUTO, Diarii, Bd. 19, Sp. 184.

1009 BonetTI, Cremona, S. 225.

1010 ACC Guaitoli, Busta 83, fasc. 6.

1011 SANUTO, Diarii, Bd. 41, Sp. 709.

1012 GregOrOviUS, Ein deutscher Bericht, S. 382.

1013 ACM Registri di lettere ducali, Bd. 19, fol. $62^{\mathrm{r}} \mathrm{f}$.

1014 ACM Registri di lettere ducali, Bd. 19, fol. $81^{\mathrm{V}}$.

1015 SANUTO, Diarii, Bd. 43, Sp. 557.

1016 BONARDI, L'assedio e la battaglia di Pavia, S. 11.

1017 ZAGATA, Cronica della città di Verona, Bd. 2, S. 135.

1018 ASM Sforzesco, Cart. 1424. Giovanni Antonio Visconti an Alvisio Ciciliano, 15. 2. 1527.

1019 ASM Sforzesco, Cart. 1424. Galeazzo Casato an Jacopo Vulpo, 15. 2. 1527.
} 
So bot sich in allen über längere Zeit besetzten Städten das gleiche Bild der Verwüstung: herausgerissene Türen und Fenster, zerschlagene Einrichtungen bis hin zu abgedeckten Dächern. Dass selbst das Gefolge der Offiziere in dieser Hinsicht wenig zimperlich war, zeigt ein Schutzbrief aus Rom, durch den Juan de Urbina den Soldaten im August 1527 verbot, das Haus von Jacopo Cardello zu betreten. Das nämlich sei schon durch seine eigene Anwesenheit hinreichend in Mitleidenschaft gezogen worden: "... que nynguno sea osado de se venir a alojar en casa de monseñor Jacobo Cardelo asi por ser estançia mia como por estar destruyda a causa de los muchos dias que en ella soy estado alojado." ${ }^{1020}$ Bezeichnend für das ganze Ausmaß des Schadens in Rom ist darüber hinaus die Tatsache, dass der Papst im Januar 1528, also noch vor dem Abzug der Soldaten aus der Stadt, von Orvieto aus alle in Rom geschlossenen Mietverträge vom Tag der Eroberung an wegen der eventuellen Unbewohnbarkeit der Objekte für ungültig erklärte. ${ }^{1021}$

\section{Persönliche Bindungen}

Auch wenn das Miteinander zwischen Bevölkerung und Besatzern in erster Linie von Zwang und Einschüchterung geprägt war, lassen sich in einigen Fällen Bindungen zwischen Soldaten und Bewohnern der besetzten Städte ausmachen, die entweder beim Einzug schon bestanden oder sich während des alltäglichen Umgangs etablierten. In diesem zweiten Fall sind sie schwer nachzuweisen, da die Chroniken sich in der Regel darüber ausschweigen, was hinter verschlossenen Türen passierte und kein Aufsehen erregte. Über die Verbreitung des Phänomens kann nicht viel gesagt werden, weil das wenige überlieferte Material nur einige Momentaufnahmen liefert, die keine quantifizierenden Schlüsse zulassen. Es scheint aber einleuchtend, dass etwa in Mailand vier Jahre der Besatzung nicht verstreichen konnten, ohne dass sich Bekanntschaften ergaben, durch die die Mechanismen der Gewalttätigkeit ausgebremst wurden. Mit anderen Worten: Affekthandlungen aus Wut über unerfüllte Forderungen sowohl gegenüber den Offizieren, als auch gegenüber den Bewohnern der belegten Häuser konnten sich nicht jeden Tag an denselben Personen und in derselben Weise wiederholen. Selbst wer auf der Suche nach Brot bereit war, jeden Tag einen anderen Bäcker zu erschlagen, konnte dem Hunger der Kinder in den Quartieren nach Monaten des erzwungenen Zusammenlebens nicht ganz gleichgültig gegenüberstehen. Die Beziehungen, die aus dieser Art von täglichem Umgang erwuchsen, werden nichtsdestotrotz selten von gegenseitiger Zuneigung getragen worden sein - sie entwickelten sich eher im Spannungsfeld zwischen dem Wechselspiel von Angst und Drohung auf der einen Seite

\footnotetext{
1020 ASCR Cardelli, Div. I, Bd. 146.

${ }^{1021}$ COMUNE DI ROMA (HRSG.): Regesti di bandi, editti, notificazioni e provvedimenti diversi relativi alla città di Roma ed allo Stato Pontifico. Bd. 1 (1234-1605). Rom 1920. Nr. 53.
} 
und der Einsicht, dass man unter Umständen parallele Interessen hatte, auf der anderen. Auch relativiert diese Feststellung keineswegs die oben angestellten Beobachtungen über die weite Verbreitung der Übergriffe. Sie deutet aber darauf hin, dass die Soldaten die Einwohner in zwei Kategorien einteilten: solche, mit denen sie sich nach einer gemeinsam unter demselben Dach verbrachten Zeit oder durch alltägliche Begegnungen in gewisser Weise verbunden fühlten, und solche, denen sie gleichgültig gegenüberstanden und die daher jederzeit zur Zielscheibe der Entladung von Aggressionen werden konnten.

Wer Offiziere bei sich einquartiert hatte, kam nicht nur bei Plünderungen, sondern auch während längerer Besatzungsperioden besser davon: zum einen waren den Offizieren die guten Manieren weniger fremd als den Soldaten, zum anderen hatten sie keinen Grund, die Frustration über den ausbleibenden Sold an der Bevölkerung auszulassen, weil sie nicht von den Soldzahlungen abhängig waren. So traten sie immer wieder als Beschützer der Hausbesitzer auf, bei denen sie sich einquartiert hatten. Bei der Eroberung Genuas im Mai 1522 hatte der Herzog Francesco Sforza noch eigenhändig einige allzu vorwitzige Plünderer aus dem Haus von Giovanni Battista Sauli geprügelt, bei dem er abgestiegen war. ${ }^{1022}$ Und Giovanni Andrea Saluzzo di Castellar erwirkte im Juli 1522 von Pescara die Einquartierung eines jungen Hauptmanns aus Neapel, der sich offenbar ruhig verhielt und ihm durch seine Anwesenheit die anderen Soldaten vom Hals hielt. ${ }^{1023}$ Solche Schonung war allerdings in aller Regel den Reichen vorbehalten. Luigi da Porto aus Vicenza brachte diese einfache Logik auf den Punkt: weil ihm die schönsten Häuser in der Stadt gehörten, habe er auch die höchsten Herren bei sich einquartiert, was immerhin seinen Besitz schütze. ${ }^{1024}$ Das erzwungene Zusammenleben zwischen Besatzern und Bevölkerung war naturgemäß keine gute Voraussetzung für die Entwicklung von Freundschaften, die diese Bezeichnung verdienen. Dennoch etablierten sich eine Reihe von Beziehungen, die von Seiten der Bevölkerung nicht ohne Hintergedanken gepflegt wurden: man hoffte, durch die Bekanntschaft mit möglichst hochrangigen Soldaten die übelsten Begleiterscheinungen der Besatzung von seinem eigenen Haus abzuwenden. Die Beschaffenheit solcher Verhältnisse dokumentiert für Mailand ein kleines Bündel von privaten Briefen, die von Einwohnern der Stadt im Januar und Februar 1527 an Angehörige des mit Bourbon abrückenden Besatzungsheeres geschrieben wurden. Sie befinden sich inmitten einer großen Sammlung von Lageberichten der Kavallerieoffiziere des von den Spaniern abgesetzten Herzogs Francesco Sforza, die mit ihren Kompanien im Umland der Stadt auf und ab zogen. Ganz offensichtlich hatten die Reiter des Herzogs den Boten abgefangen, der die Briefe transportierte, und diese, vielleicht im Zweifel über ihre militärische Verwendbarkeit, an die herzogliche Kanzlei in Cremona geschickt, wo man offensichtlich einfach vergaß, sie wegzuwerfen. Es

\footnotetext{
1022 SANUTO, Diarii, Bd. 33, Sp. 284.

1023 SALUZzo Di CASTELlar, Memoriale, S. 575.

1024 PORTO, Lettere storiche, S. 108.
} 
handelt sich um nicht mehr als 10 Briefe, die nichtsdestoweniger einige grelle Schlaglichter auf die Beziehungen zwischen den angeschriebenen Soldaten und den Mailändern werfen. ${ }^{1025}$ Allen ist die Beflissenheit der Absender gemeinsam, mit der sie den Soldaten ihre Verbundenheit und ihre Bereitschaft signalisieren, deren zurückgelassene Angelegenheiten weiterzuführen. Da verspricht Galeazzo Casato dem Sekretär von Guasto, Jacopo Vulpo: "... debbe essere certa che le cose sue sono mie proprie ..." ${ }^{1026}$; Giovanni Antonio Visconti versichert dem Hauptmann Alvisio Ciciliano: "... non desidero sinon farli bona servitute ..." ${ }^{1027}$, und, in einem weiteren Brief: "Sempre saro servo a Vostra Signoria la quale io pregho che la se ricorda di me." ${ }^{1028}$ Der dezente Hinweis darauf, dass man sich für solche Dienste eine Gegenleistung erhoffte, lässt in keinem der Briefe auf sich warten: wenn das Anliegen nicht direkt formuliert wird, so deuten die Absender es doch durch bittere Klagen über die finanzielle Misere oder die aus den Einquartierungen erwachsenden Belastungen an. Von den Beziehungen versprach man sich offenbar viel: ein Herr Giovanni Francesco klagt, dass eine Bande von Soldaten sich vor den Toren der Stadt an seinem mit Heu beladenen Maulesel vergriffen habe und bittet den Adressaten, sich unter den anderen Soldaten umzuhören, ob das Tier - klein und mit langem Schwanz - irgendwo gesehen worden sei, und, wenn das der Fall sei, alles in seiner Macht Stehende zur Rückerstattung des Maulesels zu unternehmen. ${ }^{1029}$ Und Giovanni Antonio Visconti hatte den Hauptmann Ciciliano offenbar schon in einem vorangegangenen Brief darum gebeten, dafür zu sorgen, dass die Soldaten aus seinem Haus abgezogen würden: die Kosten für diese seien dabei, ihn zu ruinieren, der ersehnte Brief von Guasto, den Ciciliano ihm versprochen hatte und durch den dieser den Soldaten ein anderes Quartier hatte zuweisen wollen, sei immer noch nicht eingetroffen. Er schließt bei aller berechtigten Verzweiflung nicht ohne eine Portion Weinerlichkeit: "Quella non se maravelia se scrivo et dico male, perche sono desperato. Baso le mane a Vostra Signoria." ${ }^{1030}$ Dass es ein Mindestmaß an privater Vertraulichkeit gab, zeigt der Brief von Giovanni Francesco Gubernato an Giovanni Tommaso Tucca: er richtet die Grüße einer gewissen Francesca aus und teilt mit, dass sie und ihre Töchter gesund seien; dass es ihnen gut gehe, sei indes zuviel gesagt. ${ }^{1031}$ Schließlich warfen sich die einquartierten Soldaten bisweilen offenbar auch zu Beschützern der Hausherren auf, wie aus einem anderen Brief unbekannten Absenders hervorgeht. Ein spanischer Soldat hatte zu Gunsten des Mailänders, bei dem er einquartiert war, in einen Streit eingegriffen und dessen Kontrahenten - einen italienischen Soldaten - mit einem Schwerthieb schwer verletzt. ${ }^{1032}$

\footnotetext{
1025 ASM Sforzesco, Cart. 1424.

1026 ASM Sforzesco, Cart. 1424. Galeazzo Casato an Jacopo Vulpo, 15. 2. 1527.

1027 ASM Sforzesco, Cart. 1424. Giovanni Antonio Visconti an Alvisio Ciciliano, 15. 2. 1527.

1028 ASM Sforzesco, Cart. 1424. Giovanni Antonio Visconti an Alvisio Ciciliano, 17. 2. 1527.

1029 ASM Sforzesco, Cart. 1424. Giovanni Francesco Let. [Name abgekürzt] Gerolamo Fabio, 28.12. 1527.

1030 ASM Sforzesco, Cart. 1424. Giovanni Antonio Visconti an Alvisio Ciciliano, 15. 2. 1527.

1031 ASM Sforzesco, Cart. 1424. Giovanni Francesco Gubernato an Giovanni Tommaso Tucca, 17. 2. 1527.

1032 ASM Sforzesco, Cart. 1424. Unbekannter Absender an einen Hauptmann Berardo, 31. 1. 1527.
} 
Die zweite Form der Beziehungen zwischen Bevölkerung und Soldaten war ganz anderer Art: während der langen Monate der Besatzung in den Städten blieb es nicht aus, dass einige Soldaten den jungen Damen den Hof zu machen begannen, oder, wie Alberini es in einem anderen Zusammenhang ausdrückt, die Kriege des Amor denen des Mars vorzogen. ${ }^{1033}$ Das wichtigste Thema der beiden überlieferten Briefe von Giovanni Antonio Visconti ist dann auch die offenbar ernste Liaison des Hauptmanns Ciciliano mit einer gewissen Signora Cornelia. Visconti engagierte sich mit vollem Einsatz in der Angelegenheit und fungierte gleichzeitig als Heiratsvermittler und Sittenwächter in einem geradezu bühnenreifen Stück: während er bei Cornelias Familie die Hochzeit zwischen dieser und dem Hauptmann betrieb, musste er gleichzeitig einen hartnäckigen Nebenbuhler von ihr fernhalten. Ein Hauptmann der Landsknechte, die als Besatzung in der Stadt geblieben waren, hatte nämlich ebenfalls ein Auge auf sie geworfen. Zunächst nahm er sie in seinem Haus auf, "solamente perche io habia a fare testimonio dei suoi honesti modi ..." Doch auch dort war Cornelia offenbar nicht sicher vor den Zudringlichkeiten des deutschen Hauptmanns, und kurz darauf griff Visconti zu anderen Mitteln: er verkleidete sie als Bäuerin und schickte sie aufs Land, ihren Aufenthaltsort hielt er geheim. Das Tauziehen mit Cornelias Verwandten endete zunächst unentschieden. Bei einem Zusammentreffen mit diesen las Visconti ihnen die Leviten über ihr respektloses Verhalten einem Hauptmann des kaiserlichen Heeres gegenüber: "... ho trovatole tutte insieme questa sera, et li ho dicto alchune parole como loro fano male deportarse di questa sorte cum uno pare de Vostra Signoria." Diese redeten sich damit heraus, dass jemand gefälschte Briefe im Namen von Cornelia an Ciciliano geschrieben habe. Die Gefühle der jungen Dame indes waren über jeden Zweifel erhaben: "... sapra Vostra Signoria che la signora Cornelia vi ama ultra modo ..." ${ }^{1034}$ Als er ihr zwei Tage später die Grüße des Hauptmanns ausrichtete, fand er sie als die glücklichste Frau der Welt - "la piu felice dona del mondo" - vor. ${ }^{1035}$ Obwohl die Kuppelei eigentlich nicht sein Metier sei, wie er versichert, hatten ihn die Gefühle derart übermannt, dass er alle Zweifel vergaß: "Me incresce intrometterme in simile cose, ma lo grande amore de Vostra Signoria me fa trapassare." ${ }^{1036}$ Dass solche Verhältnisse in Mailand einige Verbreitung gefunden hatten, zeigt der Brief eines venezianischen Informanten aus dem Januar 1527: als die Spanier abziehen sollten, das Gepäck stand schon bereit, zögerten sie den Auszug immer weiter hinaus, weil sie sich angeblich nicht von ihren Herzensdamen trennen konnten. $^{1037}$

1033 ALBERINI, Ricordi, S. 237.

${ }^{1034}$ ASM Sforzesco, Cart. 1424. Giovanni Antonio Visconti an Alvisio Ciciliano, 15. 2. 1527.

1035 ASM Sforzesco, Cart. 1424. Giovanni Antonio Visconti an Alvisio Ciciliano, 17. 2. 1527.

1036 ASM Sforzesco, Cart. 1424. Giovanni Antonio Visconti an Alvisio Ciciliano, 15. 2. 1527.

1037 SANUTO, Diarii, Bd. 43, Sp. 764. Der eigentliche Grund für die Verweigerung des Abzugs war wohl eher das Ausbleiben der Bezahlung. Wie dem auch sei: die Anekdote ist bezeichnend für die Selbstverständlichkeit, mit der amouröse Beziehungen zwischen Soldaten und Frauen aus der besetzten Stadt abgehandelt werden. 
In Rom werden Liebschaften zwischen Soldaten und einheimischen Frauen eher selten gewesen sein. Das Tagebuch des anonymen Franzosen erzählt aber gleich von zwei derartigen Verhältnissen. Beim ersten handelt es sich um ein Eifersuchtsdrama, das sich im Januar 1528 im bereits erwähnten Palast des Kardinals Pisani zutrug. Ein gewisser Baptista bewohnte dort ein Zimmer und beherbergte bei sich eine Prostituierte namens Lucrezia. Im gleichen Palast war ein Hauptmann der Landsknechte mit seinem Gefolge einquartiert. Zwischen Baptista und den Deutschen herrschte ein familiäres Miteinander, und es blieb nicht aus, dass ein Soldat namens Augustin aus dem Gefolge des Hauptmanns sich in Lucrezia verliebte und auch erhört wurde. Die Sache blieb lange geheim, bis eines Abends Giulio Cardello zu Besuch kam und man sich bis spät in die Nacht am Spieltisch vergnügte. Der Besuch Cardellos und seine Angst, sich wegen umherstreifender Soldaten auf den Heimweg zu machen, wurde schon angesprochen, die Geschichte ging aber noch weiter: Baptista lud ihn ein, in seinem Zimmer zu übernachten. Nun war das Verhältnis zwischen Baptista und Lucrezia offensichtlich nicht nur von Wohltätigkeit geprägt, denn Cardello fand sich ganz selbstverständlich im Bett zwischen den beiden wieder. Von einem eifersüchtigen Bediensteten wurde diese Sache am nächsten Tag Augustin hinterbracht, der Lucrezia daraufhin wutschnaubend zu Baptista zerrte und Aufklärung über die Vorkommnisse der letzten Nacht verlangte. Die wurde ihm aber offenbar verweigert, denn er schleppte sie davon, und als Baptista ihnen folgen wollte, rückte Augustin ihm mit gezücktem Schwert auf den Leib. Es stellte sich heraus, dass er sich mit Heiratsplänen trug. ${ }^{1038}$

Dieser Bericht ist nicht nur wegen der Liebesgeschichte interessant, sondern auch weil er ein Schlaglicht auf das tägliche Miteinander in vielen Facetten wirft, zusammengefasst: auf die Existenz von normalem menschlichen Umgang inmitten eines ansonsten von Gewalt und Zwang dominierten Verkehrs. Ein anderer Fall wird vom gleichen Zeugen einige Tage später geschildert, allerdings weniger farbenreich, obwohl der beteiligte Soldat mit ihm unter einem Dach lebte. Caspar Pisognius, der trinkfreudige Italiener, entflammte für ein Mädchen, das nach kurzer Zeit sogar zu ihm in die Unterkunft zog. Deren Stiefmutter schien einer Verbindung nicht abgeneigt. ${ }^{1039}$ Bei der reichen Beute konnte es in der Tat lohnend sein, sich mit den Soldaten einzulassen. Von einem Spanier in Rom wird berichtet, dass er sich verliebte und seiner Angebeteten, die bei der Plünderung alles verloren hatte, 3.000 Dukaten schenkte. ${ }^{1040}$ In Carpi schließlich wurde im Oktober 1526 eine Verschwörung gegen die Spanier aufgedeckt, weil eine verheiratete Frau sich in einen in ihrem Haus einquartierten Spanier verliebt hatte und ihm den Plan hinterbrachte, aus Angst, ihr Geliebter könne bei dem geplanten Aufruhr ums Leben kommen. ${ }^{1041}$

\footnotetext{
1038 OMONT, Les suites du sac de Rom, S. 24f.

1039 OMONT, Les suites du sac de Rome, S. 29.

1040 SANUTO, Diarii, Bd. 46, Sp. 437.

1041 ACC Guatoli, Busta 83, fasc. 6.
} 


\section{Allgegenwart des Todes}

Die Ausschreitungen der Soldaten, die Nahrungsmittelknappheit und die zuweilen katastrophalen hygienischen Verhältnisse machten die Angst vor dem Tod zu einem ständigen Begleiter der Bewohner. Vor allem in Rom waren die Auswirkungen der Plünderungen verheerend: es folgte eine Epidemie, so dass das Sterben weiterging und diesmal Soldaten und Einwohner gleichermaßen traf. Selbst die vorsichtigsten Berichterstatter sprechen in den schlimmsten Zeiten von mehreren Hundert Todesopfern am Tag. ${ }^{1042}$ Wer nicht selbst betroffen war, der wurde auf Schritt und Tritt an die Gefahr erinnert: zunächst lagen die Toten von der Plünderung noch unbegraben herum, durch die Straßen zog ein widerwärtiger Gestank. Noch im Mai wurden dann die ersten begraben, allerdings so nachlässig, dass Körperteile aus dem Boden schauten, die von Raben und Hunden angenagt wurden. ${ }^{1043}$ Gegen Ende des Monats fiel den Venezianern der Mann in die Hände, der im Auftrag der Spanier für die Beseitigung der Leichen verantwortlich war. Er gab an, dass auf seine Veranlassung hin 9.800 Tote begraben und 2.000 in den Tiber geworfen worden waren. ${ }^{1044}$ Viele Zeugen berichten entsetzt, dass die Kranken durch die Straßen irrten, bis sie tot zusammenbrachen. ${ }^{1045}$ Auch im Juni wütete die Epidemie weiter und brachte eine regelrechte Endzeitstimmung hervor. Caspar Schwegler schrieb an den kranken Frundsberg: " ... knecht sterben hie, schmeckt in vil Orten ubel hie, ... werden unsinig in köpfen." ${ }^{1046}$ In den folgenden Jahren rollte eine Welle von Seuchen über ganz Italien, die mit dem Krieg in Zusammenhang standen. Eine schwere Pestepidemie hatte Mailand bereits im Sommer 1524 erlitten, die von den französischen Besatzungstruppen eingeschleppt worden war. Nach dem Einrücken der Spanier kam es zu einigen weiteren, wenn auch weniger ausgeprägten Krankheitswellen. Im Sommer 1527 kam eine Abordnung des Hospitals zu de Leyva und meldete, dass aus Mangel an Mitteln keine weiteren Soldaten aufgenommen werden könnten. ${ }^{1047}$ Aus dem Oktober 1528 ist eine weitere Krankheitswelle in Mailand überliefert, an der jeden Tag bis zu 20 Soldaten starben. ${ }^{1048}$ Dabei handelte es sich nicht immer um die Pest, auch wenn die Zeugen für Epidemien in aller Regel keine andere Bezeichnung kennen. Weit verbreitet waren Typhus und Ruhr, die vor allem durch verseuchtes Trinkwasser verursacht wurden. ${ }^{1049}$ Ein interessantes Detail ist in diesem Zusammenhang die Tatsache,

\footnotetext{
1042 Rodriguez Villa, Memorias, S. 138 u. 246.

1043 BERTHIER, Chroniques du monastère, S. 278.

1044 SANUTO, Diarii. Bd. 45, Sp. 210.

1045 Dieses Phänomen ist ein Indiz dafür, dass es sich bei der Epidemie um die Pest handelte, deren Krankheitsbild durch ein mehrere Tage dauerndes und von Rastlosigkeit begleitetes Delirium geprägt ist. WOEHLKENS, ERICH: Pest und Ruhr im 16. und 17. Jahrhundert. Hannover 1954. S. 22.

1046 GASSLER, Schilderungen, S. 116.

1047 GAYANGOS, Calendar, Bd. 2, S. 300.

1048 Molini, Documenti, Bd. 2, S. 105.

1049 CORRADI, ALFONSO: Annali delle epidemie occorse in Italia dalle prime memorie fino al 1850 compilati con varie note e dichiarazioni. Memorie della società medico-chirurgica di Bologna seguito agli opuscoli da essa pubblicati. Bologna 1865-1895. Bd. 6, S. 743, Anm. 1.
} 
dass die Pest unter den Deutschen die meisten Opfer forderte, weil diese sich weniger als etwa die Spanier an die Ratschläge zur Verbesserung der hygienischen Bedingungen hielten. ${ }^{1050}$ Nájera schrieb im Juli 1522 aus Pavia, unter den Spaniern gebe es keine Krankheitsfälle, unter den Deutschen aber um so mehr, weil diese es nicht lassen wollten, in den infizierten und von den Bewohnern aufgegebenen Orten Hühner zu stehlen. ${ }^{1051}$ Und der Chronist Saluzzo di Castellar berichtet zur selben Zeit, dass man in Carmagnola die Landsknechte einquartiert habe, weil dort die Pest herrschte und die Deutschen die einzigen seien, die davor nicht zurückschreckten, sondern im Gegenteil noch die auslachten, die sich vor der Ansteckung fürchteten. ${ }^{1052}$

Die Schutzmaßnahmen gegen die Krankheit waren ohnehin rudimentär. Die Bestattung der Toten war eine wichtige, aber während eines Massensterbens oft vernachlässigte Tätigkeit. Um eine Ansteckung zu vermeiden, blieb man nach Möglichkeit im Haus. Burigozzo verbarrikadierte sich mit seiner Familie im Sommer 1524 einen Monat lang zu Hause, während draußen die Totenkarren ihre Runde machten, dennoch starben zwei seiner Kinder. ${ }^{1053}$ Die Autoritäten indes waren bestrebt, nicht nur die Kranken, sondern auch alle, die mit diesen in Kontakt gekommen waren, zu isolieren. Die Mehrzahl der zu dieser Zeit in Mailand ins Hospital eingelieferten Personen waren selbst gar nicht krank, sondern hatten lediglich mit den Kranken unter einem Dach gelebt. ${ }^{1054}$ Die Quarantäne, während der auch die Gesunden in Gefahr gerieten, sich durch den Kontakt mit den Kranken anzustecken, dauerte 40 Tage. So verließen mehr als die Hälfte der Eingelieferten das Hospital nicht mehr lebend, wie eine exemplarische Untersuchung ergab. ${ }^{1055}$ Maßnahmen zum Schutz vor Epidemien sind aus der Zeit der spanischen Besatzung fast nicht überliefert. Lediglich aus dem Oktober 1526 findet sich eine Anweisung an die Beamten eines Stadtviertels, dafür zu sorgen, dass die dort in Quarantäne befindlichen 28 Personen nicht auf der Straße herumliefen, und aus der Zeit davor sind einige Anordnungen erhalten, die die Verbrennung von Gegenständen aus verseuchten Häusern betreffen. ${ }^{1056}$

Der Hunger hatte in der Lombardei schlimmere Auswirkungen. Im Januar 1525 schrieb Nájera an den Kaiser, im belagerten Pavia diskutiere man darüber, was besser schmecke: das Fleisch der Kavalleriepferde oder das der Maultiere. ${ }^{1057}$ Spätestens drei Jahre später waren solche Späße nicht mehr angebracht: die ganze Lombardei wurde von einer Hungersnot heimgesucht, zu den Zerstörungen des Krieges und der Vertreibung der Bauern kam 1528 auch noch eine Missernte, die dazu führte, dass in Lodi in jedem Haushalt an-

\footnotetext{
${ }^{1050}$ Grollier, Historia, S. 103; CAPELla, Beschreibung und Geschicht, fol. $41^{\mathrm{r}}$.

1051 BN Madrid, MS 18697, Nr. 18. Brief von Nájera an den Kaiser, Pavia, 24. 7. 1522.

1052 SAluZzo di CASTEllar, Memoriale, S. 573.

1053 Burigozzo, Cronaca di Milano, S. 445f.

1054 ZANETTI, A Milano nel 1524, S. 322.

1055 ZANETTI, A Milano nel 1524, S. $327 \mathrm{ff}$.

1056 ASM Sanità, Busta 38.

1057 Gayangos, Calendar, Bd. 3, Teilbd. 1, S. $691 \mathrm{f}$.
} 
geblich mindestens drei Personen starben. ${ }^{1058}$ In Mailand fand man jeden Morgen Tote auf der Straße. ${ }^{1059}$ Leute, die es gewohnt waren, in Luxus zu schwelgen, lebten von Wasser und Brot aus gestrecktem Mehl. Andere brachen mitten auf der Straße vor Entkräftung zusammen. ${ }^{1060}$ Auch viele Soldaten verhungerten. ${ }^{1061}$ Die anderen verwilderten unter dem Einfluss des Hungers mehr und mehr: im September 1528 wurden die Vorratskammern einiger Klöster ausgeräumt, so dass man die Nonnen auf der Suche nach Nahrung in der Stadt umherirren sah. ${ }^{1062}$ Burigozzo berichtet, dass man für den Gang zum Bäcker gut beraten war, sich Geleitschutz zu besorgen, weil ausgehungerte Soldaten an jeder Ecke lauerten. Einige, die ihr Brot mit dem Mut der Verzweiflung verteidigten, kamen dabei ums Leben. ${ }^{1063}$ In Rom herrschten ganz ähnliche Zustände. Hungernde Soldaten brachen auf der Suche nach Lebensmitteln in die Häuser ein und schlitzten am Ende ohne Rücksicht auf die Anstekkungsgefahr sogar die Matratzen der Betten auf, in denen die Kranken lagen. ${ }^{1064}$ Und während einige die Läden der Bäcker stürmten, ${ }^{1065}$ boten römische Prostituierte, deren Dienste sonst 10 Dukaten kosteten, sich für ein Brot an. ${ }^{1066}$

Die Angst vor dem Tod vor allem durch die Pest führte in Rom offenbar bei einigen Soldaten zu einem Gesinnungswandel. Von dem spanischen Soldaten Valentino Cyprian ist das Vermächtnis überliefert, das er auf dem Totenbett und in höchster Eile am 2. Juli 1527 in Rom diktierte, so überstürzt, dass sein Beichtvater die Testamentsaufnahme übernehmen musste, weil kein Notar zur Stelle war. Cyprian hatte nun offenbar wegen seiner Untaten ein schlechtes Gewissen und fürchtete um sein Seelenheil. So versuchte er neben den Bestimmungen für den Ort seines Begräbnisses, den Nachlass und die üblichen Totenmessen auch das Verhältnis zu seinem Opfer, dem florentinischen Bankier Bernardo Bracci, ins Reine zu bringen, indem er kleinlaut die Rückerstattung des von diesem erpressten Lösegeldes verfügte: "Item lego Bernardo bracio florentino tricentos ducatos auri quos michi pro talia fecit et illos quos magis michi fecit illum rogat quod sibi parcat illos et meo confessori committo quod in hoc intendat quod michi de residuo parcat ne anima mea patiatur."1067 Andere waren in ihrer Angst immer noch abgebrühter: ein anonymer Zeuge berichtete im August 1527, dass in Civitavecchia einige Spanier an einer unbekannten Krankheit gestorben waren und daraufhin einige andere ihre Gefangenen freigelassen, in ihr Testament aber

\footnotetext{
1058 BRUGAZZI, Vicende di Lodi, S. 385.

1059 CAPELLA, Beschreibung und Geschicht, fol. 40 $\mathrm{r}$.

1060 Gayangos, Calendar, Bd. 3, Teilbd. 2, S. 497.

1061 Gayangos, Calendar, Bd. 3, Teilbd. 2, S. 493.

1062 GayangOs, Calendar, Bd. 3, Teilbd. 2, S. 788.

1063 Burigozzo, Cronaca di Milano, S. 495.

1064 ALBERINI, Ricordi, S. 298.

1065 Grollier, Historia, S. 101.

1066 CAVE, Bellum Romanum, S. $401 \mathrm{f}$.

1067 Das ganze Testament findet sich bei CAVALLETTI-RondinINI, Nuovi documenti, S. 24-26.
} 
eine Klausel eingebaut hatten, dass diese im Fall ihrer Genesung wieder eingefangen werden sollten. ${ }^{1068}$

\section{Die Aufstände in Mailand}

In Mailand und der gesamten Lombardei lässt sich in der Zeit vom ersten zwischenzeitlichen Einmarsch der Spanier im November 1521 bis zur Übernahme des Staates vier Jahre später bei der Bevölkerung ein Umschlagen der Stimmung feststellen, durch das die Spanier in der öffentlichen Meinung von umjubelten Befreiern zu verhassten Besatzern wurden. In den Monaten, die der Übernahme des Staates im November 1525 folgten, heizte sich die Stimmung durch die ständigen Übergriffe der Soldaten und die Kontributionsforderungen immer weiter auf und entlud sich im April und im Juni 1526 in zwei Aufständen, deren brutale Niederschlagung eine vollständige Einschüchterung der Bevölkerung für die restlichen Jahre der Besatzung zur Folge hatte. Bevor auf die Aufstände näher eingegangen wird, soll kurz die Entwicklung der öffentlichen Meinung in der Lombardei an einigen Beispielen nachgezeichnet werden.

Da die Spanier unmittelbar nach der Einnahme von Mailand ins Umland abgezogen waren und die Stadt dem Herzog überlassen hatten, kostete es die Mailänder im März 1522 noch nicht viel, auf eine flammende Ansprache von Prospero Colonna und Pescara hin zu erklären, sie wollten eher ihre eigenen Kinder essen, als den kaiserlichen Truppen die Unterstützung zu versagen. ${ }^{1069}$ Hier war es wohl vor allem die Erinnerung an die erst kurz zurückliegende Herrschaft der Franzosen, die zur Favorisierung der Kaiserlichen führte. Das war besonders deutlich in Pavia zu spüren, als die Gefahr einer erneuten französischen Besatzung durch die Belagerung des französischen Heeres im Herbst 1524 akut geworden war. In Pavia scheint der Hass auf die Franzosen besonders ausgeprägt gewesen zu sein und schuf eine geradezu paradiesische Harmonie zwischen der kaiserlichen Besatzung und der Bevölkerung, die angesichts der Zustände, die wenig später in der Lombardei eintraten, fast unwirklich anmutet: nachts besserten Männer, Frauen und sogar die Geistlichen zusammen mit den Soldaten die Breschen in der Mauer aus. ${ }^{1070}$ Das Vertrauen war so groß, dass man ohne Losung die Bastionen betreten konnte, und sogar das Geld für die Bezahlung der Soldaten wurde von der Bevölkerung freiwillig aufgebracht, wenn auch nicht vollständig. ${ }^{1071}$ Nach dem Bruch mit dem Herzog und der Besetzung von Mailand und anderen lombardischen Städten durch die Spanier schlug die Stimmung im ganzen Staat um. Der veneziani-

\footnotetext{
1068 BREWER, Letters and papers, Nr. 3405, S. 1541.

1069 SANUTO, Diarii, Bd. 33, Sp. 32.

1070 BONARDI, L'assedio e la battaglia di Pavia, S. 5.

1071 VERRI, Relazione, S. $208 \mathrm{ff}$.
} 
sche Botschafter in Mailand hatte schon 1520 festgestellt, was nicht nur dort, sondern überall galt: "Del populo non è da far caso, quale va dietro el favor." 1072 Schon bald nach dem Einzug der Spanier wünschte sich eine Mehrheit der Bevölkerung wieder die Franzosen herbei, was ihr wohl auch um so leichter fiel, als Francesco Sforza, den die meisten nach wie vor als rechtmäßigen Herzog von Mailand betrachteten, inzwischen mit diesen verbündet war. Selbst in Pavia schien die Erinnerung an die gemeinsame Verteidigung gegen die Franzosen verblasst zu sein, denn als diese im Oktober 1527 die Stadt erneut belagerten, erhob sich die Bevölkerung gegen die kaiserliche Garnison, um deren Kommandanten Belgioioso zur Übergabe zu zwingen. ${ }^{1073}$

Die erste Reaktion auf die Unzufriedenheit aber waren Beschwerden. In Como wurden zu Beginn der spanischen Besatzung zwei Beamte ernannt, die die Beschwerden der Bevölkerung anhören und an den Gouverneur weiterleiten sollten. ${ }^{1074}$ Auch in Mailand häuften sich die Beschwerden, aber es wurde von Seiten der Offiziere nichts unternommen, um die beklagten Zustände abzumildern. Schon im November 1525 kamen Abgesandte kleinerer Orte des Herzogtums zu Pescara und verkündeten, dass die Einwohner die Belastung nicht länger aushalten könnten. ${ }^{1075}$ Eine andere Abordnung wurde im Dezember 1525 von einem Soldaten aus dem Gefolge von Antonio de Leyva beleidigt, woraufhin ein Tumult entstand. ${ }^{1076}$ Solche Zwischenfälle brachten die Bewohner weiter gegen die Spanier auf und führten zu ersten Handgreiflichkeiten: Ende Dezember wurde Juan de Urbina in der Nacht von Unbekannten angegriffen und musste in eine Kirche fliehen, ein paar Tage darauf widerfuhr dem von den Spaniern eingesetzten Polizeihauptmann ähnliches. ${ }^{1077}$ Eine weitere Gesandtschaft, diesmal bei Nájera, kündigte unheilvoll an, dass die Gewogenheit der Mailänder für den Kaiser bald ins Gegenteil umschlagen könnte, ${ }^{1078}$ und einen Monat später berichteten venezianische Spione, die Offiziere hätten sich eingeschlossen und gäben vor, krank zu sein, um keine weiteren Beschwerden entgegennehmen zu müssen. Gleichzeitig waren die Soldaten mit geladenen Waffen unterwegs, weil man mit einem Aufstand rechnete. ${ }^{1079}$ Dessen Ausbruch ließ zwar noch drei Monate auf sich warten, aber die Gewalt lag in der Luft. Ende Februar 1526 wurde ein Haus unter Beschuss genommen, in dem ein Karnevalsfest unter Beteiligung der Landsknechte stattfand. ${ }^{1080}$ Einige Tage darauf wurden in der Nacht Stimmen laut, die "Duca, Duca!" schrien, gleichzeitig kam es zu ersten Zusammenstößen zwischen Mailändern und den Soldaten. ${ }^{1081}$ Bereits zu dieser Zeit werden

\footnotetext{
1072 SegarizZI, Relazioni, Bd. 2, S. 22.

1073 Gayangos, Calendar, Bd. 3, Teilbd. 2, S. 419.

1074 Rovelli, Storia di Como, S. 457.

1075 SANUTO, Diarii, Bd. 40, Sp. 243.

1076 SANUTO, Diarii, Bd. 40, Sp. 463.

1077 SANUTO, Diarii, Bd. 40, Sp. 575.

1078 SANUTO, Diarii, Bd. 40, Sp. 567.

1079 SANUTO, Diarii, Bd. 40, Sp. 673.

1080 SANUTO, Diarii, Bd. 40, Sp. 867.

1081 Gayangos, Calendar, Bd. 3, Teilbd. 1, S. 585.
} 
die Nachrichten aus Mailand unsicher, die meisten Informationen stammen von den venezianischen Beamten in Crema und Bergamo, die die Ereignisse mit größter Aufmerksamkeit verfolgten. Fest steht, dass am Tag nach dem Zwischenfall mehrere Personen hingerichtet wurden, wie viele, darüber sind sich die Zeugen nicht einig. Burigozzo sah zwei Männer am Galgen mit Schildern auf dem Rücken, auf denen als unmissverständliche Warnung der Schlachtruf "Duca, Duca!" geschrieben stand. Nach Informationen der venezianischen Beamten in Bergamo waren 90 Personen verhaftet worden. Ein letztes Mal konnte die Situation durch einige Mailänder gerettet werden, die offenbar einen guten Draht zur Besatzungsmacht hatten: sie versicherten den Spaniern, das Geschrei habe nicht etwa die Entfachung eines Aufstandes zum Ziel gehabt, sondern sei durch von Kindern und einfachen Leuten unters Volk gebrachte Gerüchte zu Stande gekommen, nach denen der Herzog in seinem Amt bestätigt worden sei. Schließlich begnügten sich die Spanier mit Geldstrafen und dem Verbot, den Namen des immer noch im Kastell eingeschlossenen Herzogs überhaupt in den Mund zu nehmen. ${ }^{1082}$ Außerdem wurde eine Abgabe von 60.000 Dukaten verlangt, die durchaus als Strafe für die Zwischenfälle zu verstehen war. ${ }^{1083}$ Doch die Ruhe, die für einige Wochen einkehrte, war trügerisch. Die Beamten aus Crema schrieben Mitte April, wenn die Mailänder nur von irgendeiner Seite Unterstützung bekämen, würden sie sofort über die Soldaten herfallen. ${ }^{1084}$ Am 22. April trafen einige Soldaten, die ihre Runde zur Eintreibung von Kontributionen machten, bei einem reichen Mailänder - nach Informationen der Beamten aus Bergamo handelte es sich um Dionisio di Rosarii ${ }^{1085}$ - dann unerwartet auf Widerstand. Als sie nach einiger Zeit mit Verstärkung zurückkehrten, um die Tür aufzubrechen, eskalierte die Situation, weil sich auch die Nachbarschaft bewaffnet hatte und die Soldaten in einer wilden Schießerei in die Flucht schlug. ${ }^{1086}$

Drei Tage später explodierte in Mailand die Gewalt. Offenbar auf eine Absprache mit der Kastellbesatzung hin erhob sich die Bevölkerung gegen die Besatzer: während vom Kastell aus durch Ausfälle und Artilleriebeschuss die Soldaten der Wache abgelenkt wurden, bewaffnete sich die Bevölkerung und besetzte die Glockentürme der Kirchen und die Stadttore, um zu verhindern, dass im Umland einquartierte Kompanien zur Verstärkung in die Stadt geholt wurden. Andrea de Calusco, der an diesem Tag nach Mailand unterwegs war, fand die Stadttore verschlossen vor und musste unverrichteter Dinge wieder umkehren, während die Bewohner der Vororte in Scharen in die Berge flohen. In der Stadt läuteten alle Glocken Sturm. Nach der Besetzung der Kirchtürme wurde der von 200 Soldaten bewachte Sitz der kaiserlichen Militärverwaltung gestürmt. Am Ende des Tages befand sich die Stadt in den Händen der Aufständischen, die Soldaten waren in den Bastionen um das

\footnotetext{
1082 SANUTO, Diarii, Bd. 41, Sp. 26f.

1083 SANUTO, Diarii, Bd. 41, Sp. 31.

1084 SANUTO, Diarii, Bd. 41, Sp. 187.

1085 SANUTO, Diarii, Bd. 41, Sp. 231.

1086 BurigOzZO, Cronaca di Milano, S. 451.
} 
Kastell zusammengedrängt oder hatten sich in die Häuser der Anhänger der kaiserlichen Partei geflüchtet. Diese waren den ganzen Tag über durch die Stadt geritten und hatten versucht, die Bevölkerung - vor allem mit Hinweis auf die Gefahr des Einzugs der ausgelagerten Kompanien - zur Einstellung des Aufstandes zu bewegen. Die anfängliche Wirkung solcher Beschwichtigungen war aber verpufft, nachdem Antonio de Leyva von einem Balkon aus mit Steinen beworfen worden war und seine Leibwache daraufhin begonnen hatte, in die Menge zu schießen. ${ }^{1087}$ Bis zum nächsten Morgen wurde überall in der Stadt aus verbarrikadierten Häusern geschossen, die Unterkünfte der Offiziere wurden geplündert, die Gefängnisse aufgebrochen und die Gerichtsakten verbrannt. Dennoch bewirkte die Nähe der spanischen Verstärkungen, die in die umliegenden Ortschaften eingerückt waren, offenbar ein Einlenken bei der Bevölkerung. Es wurden Verhandlungen angeknüpft, deren Ergebnis keinen Zweifel daran lässt, dass die Herrschaft der Spanier in Mailand auf Messers Schneide gestanden hatte: die Kontributionsforderungen wurden fallen gelassen und man versprach, keine neuen Einquartierungen vorzunehmen. Um den Schein zu wahren, verkündeten de Leyva und Guasto am 27. April in einer Erklärung eine Amnestie für alle, die an dem Aufstand beteiligt gewesen waren. Die Auflistung der gegen die öffentliche Ordnung begangenen Verbrechen, die wohl vor allem deren Schwere und damit die Nachsicht der Besatzungsmacht beim Verzicht auf ihre Ahndung herausstellen soll, gibt unfreiwillig einen Eindruck von der Breitenwirkung des Aufstandes: "... sive fussero stato origine, autore, et principio di tal tumulto, seu fussero stati seductori, se havessero sonato, o facto sonare Campane a martello, seu fussero stati Capi ne le compagnie, seu accenditori de animi, et sive fussero stati depopulatori et incendiari de la Corte Regia, seu effractori de carcere, et congremattori de scripture publice seu havessero perpetrato qualche homicidii, sive havessero facto pregioni et captivi ancora officiali publici, sive fussero venuti ad assalire la guardia del Castello, et ad dicto Castello dato adiuto aut segni, sive fussero venuti ad assalire li lochi dove Noi allogiati stavamo ..."1088 Nach Schätzung von Jacopo de Cappo, einem Informanten der Venezianer und Augenzeugen des Aufstandes, waren insgesamt 500 Personen ums Leben gekommen. ${ }^{1089}$

Ein Blick auf die Korrespondenz der Offiziere in Mailand zeigt allerdings ein ganz anderes Bild. Diese waren scheinbar um jeden Preis darauf bedacht, die Bedeutung des Aufruhrs herunterzuspielen. Am 24. April berichtete Nájera in einem Brief an Lope de Soria von dem Zusammenstoß bei Rosarii. Die Sache sei unter Kontrolle, es habe auf beiden Seiten drei oder vier Verletzte gegeben, und wenn es den Mailändern noch einmal einfallen sollte, Widerstand zu leisten, werde es sie teuer zu stehen kommen. Anders lautenden Meinungen dürfe Soria keinen Glauben schenken. ${ }^{1090}$ Allein in dieser Bemerkung zeigt sich die Furcht,

\footnotetext{
1087 SANUTO, Diarii, Bd. 41, Sp. $231 \mathrm{f}$.

1088 Formentini, Il Il ducato di Milano di Milano, S. 343f.

1089 SANUTO, Diarii, Bd. 41, Sp. 280.

1090 RAH Salazar y Castro, A/37. Nájera an Lope de Soria, Mailand, 24. 4. 1526.
} 
solche anders lautenden Meinungen könnten beim Kaiser den Eindruck erwecken, die Offiziere in Mailand hätten die Lage dort nicht unter Kontrolle. Die aber war schon zwei Tage später alles andere als unter Kontrolle, dennoch fuhren die spanischen Militärs in Mailand mit ihrer Strategie der Verharmlosung fort. In einem Brief vom 26. April berichteten Guasto, de Leyva und Nájera von dem Aufstand an Lope de Soria: "... huvo una quistion en esta ciudad entre los alemanes questan a la guardia deste castillo y el pueblo como suele acaeçer adonde hay gente de guerra a la qual quistion acudimos a tiempo que facilmente se pudo remediar." ${ }^{1091}$ Soria aber hatte seine eigenen Quellen: am 28. April schrieb er an den Kaiser, die Offiziere in Mailand hätten ihm zwar geschrieben, sie hätten die Lage im Griff, er selbst aber habe gesicherte Berichte, nach denen die Kämpfe noch nicht beendet seien. Die Stadttore befänden sich noch in der Hand der Aufständischen, die Verbindungsstraßen seien blockiert und spanische Soldaten würden in den Quartieren ermordet. ${ }^{1092}$

Nach der vorläufigen Einigung blieb die Lage angespannt, denn während die Barrikaden abgebaut wurden und die Läden wieder öffneten, blieben die spanischen Kompanien, die man zur Verstärkung geholt hatte, in den umliegenden Ortschaften liegen und verunsicherten die Bevölkerung. ${ }^{1093}$ Und wie die Offiziere alle Hände voll zu tun hatten, die Soldaten von Übergriffen abzuhalten, so waren die einflussreichen Mailänder, die es mit den Spaniern hielten, vor allem damit beschäftigt, der Bevölkerung einen neuen Aufstand auszureden. Wie geladen die Luft war, das zeigt eine Episode aus dem Juni: es genügte, dass sich ein Pferd losriss und über den Markt galoppierte, und schon erhob sich ein Tumult, bei dem am Ende niemand mehr wusste, was die Ursache war, den aber alle offenbar für den Ausbruch eines neuen Aufstandes hielten. Läden wurden aus Angst vor Schießereien geschlossen. ${ }^{1094}$ Die Soldaten waren so nervös, dass sie noch nicht einmal mehr selbst zum Einkaufen gingen, sondern die Frauen oder ihre Bediensteten schickten. ${ }^{1095}$

Im Juni wurde dann gegen alle Abmachungen eine neue Kontributionsforderung vorgelegt. ${ }^{1096}$ Kurz darauf kam es zu einem Zwischenfall, der den zweiten Aufstand auslöste, und der von den Zeugen in verschiedenen Versionen wiedergegeben wird: sicher ist, dass Antonio de Leyva am 16. Juni mit seinem Gefolge in der Stadt unterwegs war, und dass es zum Zusammentreffen mit einem Mann kam, der sich ebenfalls in Begleitung befand. Einigen Aussagen zufolge handelte es sich um Alessandro Simonetta, der sich weigerte, seinen Hut vor dem Gouverneur zu ziehen, ${ }^{1097}$ nach der Version der Spanier hatte dieser in seinem Ge-

\footnotetext{
${ }^{1091}$ RAH Salazar y Castro, A/37. Guasto, de Leyva und Nájera an Lope de Soria an den Kaiser, Mailand, 26. 4. 1526 , fol. $201^{\mathrm{r}}$.

1092 RAH Salazar y Castro, A/37. Lope de Soria an den Kaiser, Genua, 28. 4. 1526.

1093 SANUTO, Diarii, Bd. 41, Sp. 281.

1094 SANUTO, Diarii, Bd. 41, Sp. 576.

1095 SANUTO, Diarii, Bd. 41, Sp. 632.

1096 SANUTO, Diarii, Bd. 41, Sp. 589.

1097 SANUTO, Diarii, Bd. 41, Sp. 665 und 684.
} 
genüber einen Spion erkannt, ${ }^{1098}$ jedenfalls kam es zu einer Schießerei zwischen der Leibwache des Gouverneurs und der Begleitung des Unbekannten, die zu einer Straßenschlacht ausartete und sich zu einem Aufstand auswuchs, der bald die ganze Stadt erfasste. Diesmal aber ließen sich die Spanier das Heft nicht aus der Hand nehmen. Es gelang ihnen, die Verstärkung aus den umliegenden Orten durch Feuerzeichen in die Stadt zu holen. Nach Angaben des kaiserlichen Postmeisters kamen 70 Soldaten ums Leben, bevor die Ordnung wiederhergestellt war, ${ }^{1099}$ nach den Informationen der Beamten in Bergamo gab es 100 Todesopfer unter den Mailändern und weit mehr unter den Soldaten. ${ }^{100}$ Wieder wurde um einen Waffenstillstand verhandelt, Caracciolo schildert, wie ihm auf dem Weg zu den Besprechungen die Kugeln um die Ohren pfiffen: "... andai con alchuni gentilhomini non senza gran pericolo de la vita in mezo de scoppettate et archibusate ..." ${ }^{1101}$ Diesmal waren es allerdings die Kaiserlichen, die die Forderungen stellten. Sie überreichten den Vertretern der Stadt eine Liste mit unerwünschten Personen, die aus der Stadt verbannt wurden. Die Anwesenheit des gesamten Heeres und die unübersichtliche Situation führten zu schweren Übergriffen gegen die Bevölkerung mit allen Begleiterscheinungen der Plünderung. Caracciolo schrieb an den Kaiser, die Soldaten seien von einer nie dagewesenen Brutalität, ${ }^{1102}$ und ein Informant der Venezianer bemerkte, es genüge ein falsches Wort auf der Straße und die Spanier griffen zur Waffe. ${ }^{103}$ Raub und Misshandlung wurden zumindest in der ersten Zeit nach dem Aufstand zu einem Teil des Alltags: "Vanno questi soldati per Milano et se ritrovano uno milanese cum arme ge le toliono, et la capa et la bereta se gli piace, a cui mostra dolersene, cum qualche coltellata è dato causa manifesta de dolerse." ${ }^{1104}$ Der Widerstandswille der Bevölkerung war so weit gebrochen, dass sie dazu überging, die Stadt in Scharen zu verlassen, anstatt sich weiter den Belastungen einer solchen Besatzung auszusetzen.

\footnotetext{
1098 Gayangos, Calendar, Bd. 3, Teilbd. 1, S. 757 und 772; RAH Salazar y Castro, A/37. Marino Caracciolo an den Kaiser, Mailand, 22. 6. 1526, fol. 454r.

1099 GAYANGOS, Calendar, Bd. 3, Teilbd. 1, S. 756f.

1100 SANUTO, Diarii, Bd. 41, Sp. 666.

1101 RAH Salazar y Castro, A/37. Caracciolo an den Kaiser, Mailand, 22. 6. 1526, fol. 455V .

1102 RAH, Salazar y Castro, A/37, fol. 436V .

1103 SANUTO, Diarii, Bd. 41, Sp. 692.

1104 SANUTO, Diarii, Bd. 41, Sp. 709.
} 


\section{Zusammenfassung}

In der vorliegenden Arbeit wurde versucht, ein möglichst vollständiges Bild des Krieges in Italien zwischen den Jahren 1509 und 1530 aus der Sicht der an ihm beteiligten spanischen und kaiserlichen Soldaten sowie der Bevölkerung zu zeichnen, die in ihn hineingezogen wurde. An Stelle einer Wiederholung der Ergebnisse der einzelnen Kapitel soll hier abschließend eine Quersumme dieser Ergebnisse gezogen werden, zum einen um einige scheinbare Widersprüche aufzulösen, die sich aus der Streuung der herangezogenen Beispielfälle, der Heterogenität der Quellen und der Einteilung des Stoffes ergeben, zum anderen um einige übergeordnete Phänomene hervortreten zu lassen, die sich nicht in die thematischen Kategorien dieser Arbeit fügen und daher nicht dem einen oder anderen Kapitel zugeordnet werden können, deshalb aber um so wichtiger für das Verständnis des Gesamtkomplexes sind, den der Krieg darstellte.

Das erste dieser Phänomene ist die Bereicherung der Soldaten, und zwar sowohl bei einer Plünderung, als auch während einer Besatzung. Hier manifestierte sich der Widerspruch vor allem in Klagen: kaum ein Chronist, der nicht in astronomischen Zahlen die Verluste der Opfer beklagte und vor allem bei der Beschreibung von Plünderungen das Bild von beutebeladenen Soldaten bemühte, kaum ein hoher Offizier, der nicht in seinen Briefen an König und Kaiser die ruinösen finanziellen Zustände im Heer und die eigenen Opfer herausstrich. In gewisser Weise haben beide Seiten auf ihre Weise recht: bei Plünderungen und während einer Besatzung wurden in der Tat immense Geldbeträge und Sachwerte umgeschichtet, sie flossen aber nicht gleichmäßig von einer Seite zur anderen, sondern verteilten sich in höchst unausgeglichener Weise. In welchen Dimensionen sie sich bewegten, ist schwer auch nur annähernd zu sagen. Bei der Schätzung der Mailänder Bevölkerung wurde kaum mehr als ein Jahr vor dem Einmarsch der Spanier festgestellt, dass die wohlhabenden Mailänder zusammen mehr als 10 Millionen Dukaten im Jahr verdienten, dennoch gelang es der Besatzungsmacht nur unter größten Schwierigkeiten, Beträge aus der Bevölkerung zu pressen, die kaum mehr als ein Promille dieser Summe ausmachten. Die Verluste bei der Plünderung von Rom werden auch in den vorsichtigsten Schätzungen mit mehreren Millionen Dukaten angegeben, und trotzdem befand sich bereits wenige Monate später das gesamte Heer in Aufruhr wegen der ausbleibenden Soldzahlungen, die wiederum nur einen Bruchteil dieser Beträge ausmachten. Daraus lässt sich schließen, dass es der großen Mehrheit vor allem der einfachen Soldaten noch nicht einmal bei Plünderungen gelang, sich in zufriedenstellender Weise zu bereichern. Das liegt vor allem an zwei Faktoren: zum einen wurde der wertvolle Besitz von den Opfern zumeist schon vor der Ankunft der Soldaten in Sicherheit gebracht, zum anderen wanderten die verbliebenen Wertgegenstände und Gelder in die Taschen vor allem der Offiziere und einiger weniger Soldaten, die es verstanden 
hatten, den anderen zuvorzukommen. Das wird neben den ständigen Revolten der Soldaten auch daran deutlich, dass in Prato und selbst in Rom schon kurz nach der Plünderung viele Soldaten damit beschäftigt waren, eine Beute zu verkaufen, wie sie wertloser kaum sein konnte. Auch die Lösegelderpressung brachte für die meisten Soldaten nicht den erhofften Gewinn, da die Masse der Soldaten sich eine relativ geringe Zahl von Geiseln teilen musste und viele gänzlich leer ausgingen. Wem es tatsächlich gelungen war, ein Vermögen zu gewinnen, der machte sich in der Regel so schnell wie möglich damit auf den Heimweg. Und selbst wenn jemand - wie etwa im besetzten Mailand - ein Vielfaches des ihm zustehenden Soldes aus dem Hausbesitzer presste, bei dem er einquartiert war, konnte die Preisexplosion dazu führen, dass auch dieses Vielfache ihm durch die Finger rann, ohne dass er damit mehr als seinen Lebensunterhalt bestritten hätte.

Dass Geld abgesehen vom individuellen Streben nach persönlicher Bereicherung der wichtigste Faktor zur Fortführung des Krieges war, ist keine überraschende Neuheit. Erst ein Blick auf die Vielfalt der Methoden zur Eintreibung der Gelder in Stadt und Land aber zeigt, wie tief die Auswirkungen dieser Notwendigkeit auf die Bevölkerung waren. Fast alle Maßnahmen, die von den Besatzern getroffen wurden, hatten direkt oder indirekt die Geldbeschaffung zum Ziel. Anordnungen zur Verhinderung der Abwanderung dienten der Sicherung der Kontributionen, bewirkten durch ihre Kopflosigkeit aber eine Verunsicherung der Bevölkerung: mal wurde das Verlassen der Städte bei drakonischen Strafen verboten, kurz darauf gegen eine einmalige Zahlung wieder gestattet, die zwar dazu führte, dass sich die Kriegskasse kurzfristig füllte, anschließend aber die Eintreibung von weiteren Geldern fast unmöglich machte. Zölle und Abgaben wurden eingeführt und wieder abgeschafft, was die Wirtschaft eher lähmte als anspornte. Alles ließ sich in Geld ausdrücken: sowohl von der Einquartierung von Soldaten als auch von der Heranziehung zu Zwangsarbeit konnte man sich freikaufen. Die Vielgestaltigkeit und Beliebigkeit dieses Systems aber führte dazu, dass die erhofften Gelder nicht dort ankamen, wo man sie hinzuleiten versuchte, weil bis auf die unterste Ebene sowohl der militärischen als auch der zivilen Hierarchie jeder versuchte, sich selbst zu bereichern: Quartiermeister und städtische Beamte kungelten um die Einquartierungen und die Soldaten trieben in den Häusern Abgaben ein, deren Widerrechtlichkeit zwar offensichtlich war, gegen die man aber dennoch kaum etwas unternehmen konnte, weil die Offiziere es angesichts ihrer eigenen Zahlungsunfähigkeit nicht wagten, die Missstände abzustellen. Auf dem Land zeigte sich dasselbe Phänomen in anderer Ausprägung: kleinere Staaten wurden durch die Drohung mit Einquartierung in ihrem Gebiet zur Beteiligung an den Kosten eines Krieges gezwungen, an dem sie eigentlich gar nicht teilnehmen wollten, Heere zogen über die Dörfer und drohten überall mit Plünderung, von der sich die Landbevölkerung dann durch Zahlung von einmaligen oder regelmäßigen Abgaben freikaufen konnte. Lebensmittel wurden ohnehin die ganze Zeit über requiriert. Die selbstverständliche Anwendung solcher erpresserischen Methoden 
durch die militärische Führung lud Hauptleute einzelner Kompanien und deren Soldaten geradezu ein, zum eigenen Vorteil mit immer rücksichtsloseren Methoden Gelder einzutreiben. Die Kontribution wurde so in ihrer verwilderten Form zur Lösegelderpressung, die Requirierung zur Plünderung.

Damit wäre ein grundsätzliches Phänomen des Krieges angesprochen: die zunehmende Usurpation von Kompetenzen durch Hauptleute und sogar Soldaten. Sie war eng mit dem Verfall der Disziplin wegen des ausbleibenden Soldes verbunden und manifestierte sich neben der beschriebenen Eintreibung von Geldern vor allem in einer immer weiteren Verstreuung und einem immer selbständigeren Agieren der einzelnen Kompanien. Wieder sind Parallelen zwischen Stadt und Land zu beobachten: auf dem Land entfernten sich einzelne Kompanien so weit von der Führung, dass man kaum noch von einem Heer sprechen konnte. Dessen Mobilität wurde durch die Verteilung seiner Bestandteile immer weiter eingeschränkt, während die Mobilität dieser Bestandteile im kleineren geografischen Rahmen ständig zunahm. Die Aufenthaltsorte der einzelnen Kompanien waren der Führung oft gar nicht bekannt. In der Stadt wurde der hohe Organisationsgrad der Einquartierungen durch den eigenmächtigen Wechsel der Quartiere durch die Soldaten und den ständigen Wechsel aus Einzug und Auszug ohne Wissen der Besatzungsmacht über lange Zeiträume ad absurdum geführt. Gegenmaßnahmen konnten kaum gegen den Willen der Soldaten eingeleitet werden, die gegenüber den Offizieren - vor allem bei den Deutschen war das der Fall - wie eine eigene Autorität auftraten und diesen ihre Forderungen durch Vertreter übermittelten. Massendesertion und das Überlaufen zum Feind wurden immer offener praktiziert, so dass an die Stelle der Bestrafung immer häufiger die Versuche der Offiziere traten, Deserteure und Überläufer durch Versprechungen zur Rückkehr zu ermuntern. Nachdem dieses Verhalten eingerissen war, konnten die Soldaten es sich erlauben, ganz offen mit Desertion und Überlaufen zu drohen, um ihren Forderungen Nachdruck zu verleihen.

Auch die Mobilität der Bevölkerung wurde vom Krieg beeinflusst: neben den Verlusten durch dessen direkte Auswirkungen und seine Begleiterscheinungen wie Hunger und Epidemie war es vor allem die Abwanderung der Bewohner, die zur Entvölkerung von ganzen Städten und Landstrichen führte. Die Trennung zwischen Flucht und Abwanderung ist wichtig, da die Flüchtlinge zumeist nach kurzer Zeit nach Hause zurückkehrten, während die Abwanderer ihren Heimatorten oft für mehrere Jahre oder für immer verloren gingen. Wann immer ein Heer sich näherte, setzte eine Fluchtwelle ein, die dazu führte, dass die Soldaten bei ihrer Ankunft nicht selten menschenleere Städte und Dörfer vorfanden. Wenn die Heere sich über längere Zeit in eng umgrenzten Gebieten aufhielten, hielt die Entvölkerung an. Auch dieses Phänomen lässt sich innerhalb der Städte beobachten, zwar in ganz anderem Rahmen, aber derselben Motivation folgend: die Angst vor Plünderungen und der alläglichen Gewalt führte zu einer Zusammenballung der Bevölkerung an bestimmten Punkten, mit anderen Worten: viele verließen das Haus, aber nicht die Stadt. Sie kamen bei 
Nachbarn, Freunden und Verwandten unter und riskierten zusätzlich zu allen Unbequemlichkeiten den Verlust ihres gesamten Besitzes.

Die Erfahrungen mit den Soldaten brachten es mit sich, dass die Bevölkerung bestimmte Haltungen annahm. Die Bandbreite dieser möglichen Haltungen reichte von einer Favorisierung der Plünderer und Besatzer aus der Hoffnung auf Gewinn heraus bis zu erbittertem Widerstand gegen diese. Die Mehrheit der Bevölkerung verbrachte die Zeit in weitgehender Passivität, die sich in den Quellen fast gar nicht manifestierte. Die Grenzen zwischen dieser Passivität und den beiden Polen waren fließend, da auf der einen Seite auch die behutsamsten Überlebensstrategien zumeist irgend eine Art von Arrangement mit einer Soldateska voraussetzten, die dem Gemeinwesen großen Schaden zufügte, und auf der anderen Seite das Vorenthalten von Geldzahlungen und Materiallieferungen von den Militärs auch dann schon als Ausdruck einer Widerstandshaltung angesehen wurde, wenn die Betroffenen diese Leistungen gar nicht erbringen konnten.

Widerstand indes fand seinen lebhaftesten Ausdruck in gewaltsamer Gegenwehr. Diese fand fast nur auf dem Land statt, in den Städten konnte sie sich kaum entfalten, weil die Soldaten durch ihre höhere Konzentration und die Besetzung von befestigten Gebäuden im Vorteil waren. Die Aufstände in Mailand zeigten die Aussichtslosigkeit von organisiertem Widerstand, während auf dem Land immer wieder Gruppen von Bauern über versprengte Soldaten herfielen und diese ausraubten und umbrachten, was wiederum zu harten Vergeltungsmaßnahmen und einem Aufschaukeln der Gewalt führte.

Das andere Ende der Skala von möglichen Haltungen, das Profiteurswesen, fand vielfältigere Ausprägungen. Es kam so weit, dass einzelne Bewohner geplünderter Städte sich unter die Soldaten mischten und an der Plünderung teilnahmen. Während es sich dabei um Einzelfälle handelte, war die Beteiligung am Handel mit der Plünderungsbeute geradezu ein Massenphänomen. Angehörige aller gesellschaftlichen Schichten waren in das Verteilernetz eingebunden, das im Umland geplünderter Städte entstand; aus der Beuteliste aus Pistoia lässt sich schließen, dass vielleicht die Hälfte aller Einwohner von Pistoia und den kleineren Orten zwischen Pistoia und dem geplünderten Prato in die Transaktionen mit der Beute aus Prato verwickelt waren. Zwischen den professionellen Händlern und den Endabnehmern gab es eine breite Grauzone von Personen, die den Aufkauf von Beute über den persönlichen Gebrauch hinaus als Investition handhabten: entweder sie beteiligten sich am Zwischenhandel, obwohl das mit ihren eigentlichen Berufen gar nichts zu tun hatte, oder sie verarbeiteten die Ware in eigenen Kleinbetrieben weiter. Auf Grund der weiten Verbreitung des Phänomens kann man davon ausgehen, dass die Beteiligung am Handel mit der Beute von einer Mehrheit nicht als anstößig angesehen wurde, ein Umstand, der durch die schnelle Verteilung der Ware im Land und die daraus resultierende Verblassung des Zusammenhangs mit der Plünderung begünstigt wurde. Im Zuge von Plünderungen fand das Profiteurswesen eine weitere Erscheinungsform in der Ausnutzung der drängenden 
Geldnot all derer, die ihre Lösegelder nicht bezahlen konnten. Vor allem in den Nachbarstädten fanden sich viele, die den Opfern gegen Zinsen Kredite zur Verfügung stellten oder ihnen Immobilien abkauften. In besetzten Städten gab es andere Arten von Kriegsgewinnlern, sie machten ihren Schnitt vor allem durch die Beteiligung an Beutezügen, die die Soldaten regelmäßig im Umland abhielten und durch die Spekulation mit den Lebensmittelpreisen in Zeiten der Teuerung. Beides wurde weder von den Soldaten, noch von der Besatzungsmacht gern gesehen.

Auf dem Land gab es kaum Möglichkeiten, vom Krieg zu profitieren, allerdings führte dessen Fortdauer zu einer Verwilderung der Bauern, die sich in zunehmendem Maß als Wegelagerer betätigten. In den Städten hielt die Besatzungsmacht immerhin noch eine öffentliche Ordnung aufrecht, auch wenn diese höchst einseitig war, da sie die Soldaten kaum von den Übergriffen abhielt. Auf dem Land hingegen brach diese Ordnung durch den Krieg zumeist zusammen, so dass Überfälle auf Reisende und Soldaten - die ihrerseits wiederum auch Ausdruck des Widerstandes sein konnten - nur selten geahndet werden konnten. Der Grund für diese Verwilderung war aber nicht nur die Aussicht auf ungestrafte Betätigung: vielen blieb kaum noch eine Alternative, da die schweren Verwüstungen durch den Krieg und die Schutzlosigkeit gegenüber den Soldaten es unmöglich machten, einer landwirtschaftlichen Tätigkeit weiterhin nachzugehen.

Diese Form des Profiteurswesens war darüber hinaus Ausdruck eines weiteren, noch abstrakteren und grundlegenderen Phänomens, das den Krieg kennzeichnete und zeigt, wie tief dieser in die Gesellschaft hineinwirkte. Es manifestierte sich auf dem Land wie in den Städten und kann mit dem Begriff der Fluktuation umrissen werden. Wie gesehen, nahm die Bevölkerung unter Umständen Verhaltensweisen an, die ihr ohne den Krieg fremd gewesen wären. Die spanischen und kaiserlichen Heere wurden ohnehin fast immer von italienischen Einheiten begleitet und vor allem in den spanischen Kompanien dienten viele Italiener, die mit den Spaniern aus Neapel gekommen waren. Das war so selbstverständlich, dass dieser Umstand aus den meisten Quellen nur dann hervorgeht, wenn es zu Verwechslungen kam. Es kam so weit, dass innerhalb der spanischen Kompanien zu manchen Zeiten die Zahl der Italiener die der Spanier überstieg. Nun sind italienische Soldaten im Gefolge spanischer Heere allein noch kein Indiz für die Auswirkungen des Krieges auf die Gesellschaft vor Ort, denn italienische Söldner hatte es immer gegeben. Das hier als Fluktuation bezeichnete Phänomen äußerte sich aber auf viel breiterer Front. Das begann mit der Parteinahme einzelner Gruppen in den Städten für oder gegen die Besatzer und führte bis zu bewaffneten Aktionen in deren Diensten oder gegen sie. Bauern wurden von den Regierungen gegen verfeindete Heere eingesetzt, die in das Land eingedrungen waren. So verwischte die von den Theoretikern so gern bemühte Unterscheidung zwischen Kombattanten und Nichtkombattanten, was Übergriffe gegen die Bevölkerung vor allem im Zug von Vergeltungsmaßnahmen noch erleichterte. Die alltägliche Konfrontation mit bewaffneter Ge- 
walt führte zu einer Gewöhnung an diese und ersetzte in gewisser Weise den Ausfall, der durch den Krieg unter den anderen Möglichkeiten entstanden war, ein Auskommen zu finden. Neben den Bauern, die sich organisierten und Jagd auf Soldaten machten, wobei sie deren Verhalten bei der Ausplünderung und sogar der Erpressung von Lösegeldern imitierten, fanden sich andere, die den Heeren aus der Not oder der Hoffnung auf Beute heraus folgten - und diese beiden Motive waren nicht klar voneinander abzugrenzen - und auch an der Plünderung von Städten oder kriegerischen Konfrontationen teilnahmen. Sie wurden so zeitweise zu aktiven Teilen des militärischen Apparates, und selbst unter der Stadtbevölkerung rekrutierten die Besatzer mit Hilfe des ihnen gewogenen Teils der örtlichen Autoritäten bisweilen Soldaten. Die chaotischen Zustände in den Söldnerheeren erleichterten das Unterschlüpfen in deren Reihen; die Soldaten trugen keinerlei Uniform, Waffen und Rüstungen aber hatten auch Stadtbewohner und selbst Bauern nicht selten im Haus. Schon außerhalb Italiens schlossen sich den Heeren viele Glücksritter an, deren Zahl stieg nun im Land selbst durch den Zulauf vor Ort weiter an, was von den Autoritäten mit gemischten Gefühlen gesehen wurde, aber kaum verhindert werden konnte. Da man das Heer jederzeit wieder verlassen konnte, waren mit dem Anschluss an dieses keinerlei Verpflichtungen verbunden, so dass diese Möglichkeit für viele, die im zivilen Leben nichts mehr zu verlieren hatten, nicht mehr als einen Versuch darstellte, das Überleben auf eine bisher unbekannte Weise zu sichern. Diese Fluktuation zwischen Heer und Umland erfasste auch die fremden Soldaten selbst, da die Desertion und das Überlaufen zum Feind eine Option darstellte, die oft in Anspruch genommen wurde. Die Tatsache, dass man sich auch im Heer aus dem Land ernährte, führte dazu, dass größere Gruppen von Deserteuren kaum ein anderes Dasein führten als ordnungsgemäß in den Soldlisten verzeichnete Kompanien. Viele von diesen bewegten sich so in einer Grauzone zwischen der Zugehörigkeit zu einem Heer und dem Status einer Räuberbande. Das zeigt unter anderem sehr deutlich die willkürliche Gefangennahme von Zivilpersonen durch Soldaten, die von diesen als Kriegsgefangene deklariert wurden, oder der Raub von Vieh, das man den Feinden abgenommen zu haben vorgab. Gewalt war kein Monopol der Soldaten, oder anders gesagt: Soldat zu sein war kein Monopol der Angehörigen eines Heeres.

Diese Fluktuation machte schließlich auch vor dem die Heere begleitenden Tross nicht halt. Dessen Zahlenstärke, die im übrigen die der Soldaten mitunter bei weitem überstieg, variierte stark durch Zulauf und Abgang aus dem Umland. Viele der Personen, die dem Tross folgten, stammten aus den vom Krieg betroffenen Gebieten selbst, und eine Verkleinerung des Trosses durch Anordnung der Autoritäten war oft nur von kurzer Dauer. Das galt auch für die Frauen, die den Heeren im Tross als Prostituierte folgten.

Soldaten, Bauern und Bürger: sie alle lebten mehr schlecht als recht mit dem Krieg, vom Krieg und trotz des Krieges, des großen gefräßigen Tieres, das sich immer schwerfälliger durchs Land schleppte und im Sommer 1530, als der letzte Wiederstand gegen eine spa- 
nisch dominierte Herrschaft in Italien vor den Toren von Florenz zertreten war, entkräftet zusammenbrach. 


\section{Abkürzungen}

ACM - Mailand, Archivio Civico

ADD - Besançon, Archives Départementales du Doubs

AGS - Simancas, Archivo General

ASCC - Carpi, Archivio Storico Comunale

ASCR - Rom, Archivio Storico Capitolino

ASF - Florenz, Archivio di Stato

ASM - Mailand, Archivio di Stato

ASP - Prato, Archivio di Stato

ASR - Rom, Archivio di Stato

ASV - Rom, Archivio Segreto Vaticano

BAR - Rom, Biblioteca Angelica

BAV - Rom, Biblioteca Apostolica Vaticana

BNM - Madrid, Biblioteca Nacional

BRP - Prato, Biblioteca Roncioniana

HHStA - Wien, Haus-, Hof- und Staatsarchiv

IIPPAB - Mailand, Archivio dell'amministrazione delle Istituzioni Pubbliche di Assistenza e Beneficenza (II. PP. A. B.)

RAH - Madrid, Real Academia de la Historia 


\section{Bibliografie}

\section{Archivalische Quellen:}

\section{Besançon, Archives Départementales du Doubs:}

7 E 1289. Journal von Philibert von Oranges mit täglichen Ausgaben und Einnahmen für ihn und sein Gefolge von Dez. 1526 - Okt. 1530.

7 E 1295. Kontenbuch des Schatzmeisters von Oranges, Odot Roy, mit den Einnahmen von Juni 1527 - Apr. 1528.

\section{Carpi, Archivio Storico Comunale:}

Archivio Guaitoli, Busta 107, Fasc. 7. Historische Nachrichten aus Carpi.

Archivio Guaitoli, Busta 83, Fasc. 6. Bericht über die Verschwörung gegen die Spanier in Carpi vom Oktober 1526.

\section{Florenz, Archivio di Stato:}

Notarile Antecosimiano, 2238. Akten des Notars Antonio Benamati.

Notarile Antecosimiano, 19970. Akten des Notars Lorenzo Tani.

\section{Madrid, Biblioteca Nacional:}

MS 10773. Auf fol. 72r $-111^{r}$ ein Bericht über den Sacco di Roma, zusammengesetzt aus bekannten und unbekannten Quellen.

MS 18690. Briefe von Cardona, de Leyva und Nájera, 1512-1522.

MS 18697. Briefe von Nájera, 1522-1523.

MS 18730, Nr. 16. Anonymer Augenzeugenbericht über den Sacco di Roma.

MS 20210. Briefe von Caracciolo und Prospero Colonna, 1521-1527.

MS 20212. Briefe von Guasto und de Leyva, 1512-1527.

MS 20213. Briefe von Nájera, 1521-1527.

MS 20476. Auf fol. 188r - 236V "Noticias de las hazanas de Antonio de Leyva in Italia." Juan Paez de Castro zugeschrieben.

\section{Madrid, Real Academia de la Historia:}

Archivo Lope de Soria 176. Brief von Oranges, Feb. 1530.

Archivo Lope de Soria 197 und 198. Briefe der Regierung in Siena, 1530.

Colección de Don Luis de Salazar y Castro. A/21. Briefe der kaiserlichen Beamten, Diplomaten und Militärs in Italien, Juli - Dez. 1521. A/22. Forts., Jan. - Feb. 1522. A/23. 
Forts., März -Apr. 1522. A/24. Forts., Mai - Juni 1522. A/25. Forts., Juli - Aug. 1522. A/26. Forts., Sept. - Dez. 1522. A/27. Forts., Jan. - Apr. 1523. A/28. Forts., Mai Aug. 1523. A/29. Forts., Sept. - Dez. 1523. A/30. Forts., Jan. - März 1524. A/31. Forts., Apr. - Juli 1524. A/32. Forts., Aug. - Nov. 1524. A/33. Dez. 1523 - Dez. 1524. A/34. Forts., Jan. - Juni 1525. A/35. Forts., Juli - Sept. 1525. A/36. Forts., Okt. - Dez. 1525, und einige von 1523. A/37. Forts., Jan. - Juni 1526. A/38. Forts., Juli - Sept. 1526. A/39. Forts., Okt. - Dez. 1526, und einige von Mai - Sept. 1526. A/40. Forts., Jan. - Juni 1527. A/41. Forts., Juli - Dez. 1527. A/42. Forts., Jan. - Juli 1528. A/43. Forts., Juli - Dez. 1528. A/44. Forts., Jan. - Dez. 1529. A/45. Kopien von verschiedenen Briefen, 1521-1539.

\section{Mailand, Archivio dell'amministrazione delle II. PP. A. B.:}

Comuni 182. Akten des Prozesses um die von spanischen Soldaten angerichteten Schäden und die Kontributionen im Haus von Andrea Sormani und Dionisio Sesto in den Jahren 1526 und 1527.

\section{Mailand, Archivio Civico:}

Dicasteri, Busta 221. Akten des Tribunale della Provvisione, 1524-1531.

Famiglie, Cart. 1629. Mailänder Zählung von 1524.

Materie 11, 6. Alloggi militari, parte b: Atti diversi 1443-1643. Befehle von de Leyva und Belgioioso, die Kontributionen betreffend, Okt. 1529.

Registri di lettere ducali. Bd. 19. In Mailand ausgerufene Dekrete, 1524-1537. Bd. 20. Forts., 1526-1537.

\section{Mailand, Archivio di Stato:}

Sforzesco, Cart. 136. Brief eines römischen Kollegiums an Nájera, Jan. 1527.

Sforzesco, Cart. 137. Briefe von Scipione Atellaro an Francesco Sforza, Mai - Juni 1527.

Sforzesco, Cart. 1359. Briefe an Francesco Sforza, Nov. - Dez. 1526. Cart. 1360. Forts., Jan. - März 1527. Cart. 1361. Forts., Apr. - Mai 1527.

Sforzesco, Cart. 1375. Briefe aus Lodi an Francesco Sforza, 1527.

Sforzesco, Cart. 1386. Briefe aus Pavia an Francesco Sforza, 1526.

Sforzesco, Cart. 1394. Briefe aus Tortona an Francesco Sforza, 1526.

Sforzesco, Cart. 1423. Schutzbrief von Guasto, Juni 1526.

Sforzesco, Cart. 1424. Briefe aus Mailand, Jan. 1527 - Aug. 1528.

Sforzesco, Cart. 1504. In Mailand ausgerufene Dekrete, 1525. Cart. 1505. Forts., 1526.

Cart. 1506. Forts., 1527 und 1528. Cart. 1507. Forts., 1529.

Sforzesco, Cart. 1582. Briefe an die Kanzlei von Francesco Sforza in Cremona.

Autografi, Cart. 195. Briefe von Guasto, Jan. 1527.

Autografi, Cart. 196. Briefe von de Leyva, Apr. 1527.

Autografi, Cart. 230. Liste der Inhaftierten im Kastell von Mailand, Jan. 1527.

Censo 1520. Mailänder Zählung von 1524.

Popolazione, Cart. 88 bis. Totenbuch der Stadt Mailand für 1526.

Sanità, busta 38. Gesundheitspolitische Maßnahmen, 1522-1534. 


\section{Prato, Archivio di Stato:}

Buonamici 2, Fasc. 18. Namensliste mit den Empfängern von Entschädigungszahlungen aus dem Erlös verkaufter Kirchengüter.

Ceppi 96. Eingänge und Ausgänge des Ceppo Nuovo für das Jahr 1501. Auf fol. $26^{\mathrm{r}}$, 87V und $88^{\mathrm{r}}$ drei Briefentwürfe eines Soldaten.

Ceppi 728. Enthält ein Heft mit Zeichnungen und Kritzeleien von Soldaten, überwiegend in spanischer Sprache.

Ceppi 1906. Auf fol. 264r Bericht über die Plünderung von Prato.

Comune 2549. Auf fol. $1^{\mathrm{r}}-53^{\mathrm{r}}$ eine Liste mit Einwohnern aus Stadt und Contado von Pistoia mit detaillierten Informationen über die von diesen aufgekaufte Beute aus Prato; fol. $55^{r}-197^{r}$ Erklärungen der Einwohner aus Prato über Lösegelder; fol. 198 ${ }^{r}-205^{r}$ eine Liste wie die aus Pistoia für das Vikariat Firenzuola.

\section{Prato, Biblioteca Roncioniana:}

MS 72. Chronik von Prato von Alessandro Guardini.

MS 378. Abschrift des Berichts von Jacopo Modesti und einige Schriftstücke, die Legation der Prateser zu Papst Leo X. betreffend.

MS 759. Memoriale von Giuliano di Francesco de Michele Guizzelmi von 1488 bis 1519.

\section{Rom, Archivio Segreto Vaticano:}

AA. Arm. I-XVIII 6522. Briefe von Botschaftern und Militärs an die Kurie, 1525-1532.

Pio 53 und 54. Briefe an die Kurie, 1526-1527.

\section{Rom, Archivio di Stato:}

Miscellanea Corvisieri, Busta 1, Fasc. 3. Schutzbrief von de la Motte, Sept. 1527.

Miscellanea Corvisieri, Busta 1, Fasc. 32. Vertrag zwischen Gundisalvo de Salazar und Johannes Andracinus über das Lösegeld des letzteren, Mai 1527.

Miscellanea Corvisieri, Busta 1, Fasc. 36. Lösegeld einiger im Pantheon gefangener Römer.

Miscellanea Corvisieri, Busta 12, Fasc. 255. Berichte des ferraresischen Botschafters Naselli aus Rom an den Herzog, Jun. - Dez. 1527.

Monasterio di SS. Silvestro e Martino, Busta 8: Notizie varie 1522-1539.

Sforza-Cesarini, parte I, 17, Nr. 40. Vertrag zwischen Camillo Colonna und Ostilio Savelli über das Lösegeld von Savelli, Jun. 1527.

\section{Rom, Archivio Storico Capitolino:}

Camera Capitolina, Cred. I, Bd. 16. Dekrete des Rates, 1530-1533.

Cardelli, Div. I, Bd. 146. Schutzbrief von Urbina, Aug. 1527. 


\section{Rom, Biblioteca Angelica:}

MS 1002. Zusammenstellung verschiedener Berichte und Quellen zum Sacco di Roma, die zum großen Teil in Edition vorliegen.

\section{Rom, Biblioteca Vaticana:}

MS Barb. Lat. 2799. Tagebuch von Biagio da Cesena.

MS Ottob. Lat. 2137. Tagebuch von Cornelius da Fine.

MS Urb. Lat. 850. Sammlung von Berichten zum Sacco di Roma.

MS Urb. Lat. 1677. Sammlung von Berichten zum Sacco di Roma.

MS Vat. Lat. 4104. Epistolar eines Fulvius Ursinus. Auf fol. 79-80 ein Brief von Antonio Tebaldeo an Angelo Colotio, Nov. 1527.

MS Vat. Lat. 7933. Chronik des Klosters S. Cosimato in Mica Aurea.

\section{Simancas, Archivo General:}

Estado 1172. Briefe von Antonio de Leyva, 1528-1529.

\section{Wien, Haus-, Hof und Staatsarchiv:}

Registratur Karls V., Belgien PA 66. Briefe der kaiserlichen Beamten, Diplomaten und Militärs in Italien in unregelmäßiger Folge.

Registratur Karls V., Belgien PA 67. Forts.

\section{Quelleneditionen}

Albèri, Eugenio (HrsG.): Relazioni degli ambasciatori Veneti al Senato. Serie 2. Florenz 1839-1846.

Alberini, Marcello: Ricordi. In: Domenico Orano (Hrsg.): Il Sacco di Roma del 1527. Studi e documenti, Bd. 1. Rom 1901.

AMMIRATI, SCIPIONE: Istorie fiorentine. Hrsg. v. Luciano Scarabelli. Bd. 7. Turin 1853.

ANONYM: Copia d'una letra del successo et gran crudeltade fatta drento di Roma che non fu in Hierusalem o in Troia così grande. Gedruckter Brief eines Sekretärs des venezianischen Botschafters in Rom vom 20. Mai 1527 aus Civitavecchia, ohne Datum und Erscheinungsort. Das hier verwendete Exemplar befindet sich in Brescia, Biblioteca Queriniana, C. I. 15.

ANONYM: Relación de los sucesos de las armas de España en Italia en los años de 1511 y 1512, con la jornada de Ravenna. In: Colecciòn de documentos inéditos para la historia de España 79 (1882). S. 233-298.

ArCo, CARlo DE (HrSG.): Notizie di Isabella Estense, moglie a Francesco Gonzaga. In: Archivio Storico Italiano, App. 11 (1844). S. 203-326. 
Armellini, M. (HrSG.): Un documento del sacco di Roma nel 1527. In: Cronachetta mensuale di Archeologia e di scienze naturali. Jg. 25, Bd. 12 (1890). S. 179-187.

BAEÇA, GASPAR DE (HRSG.): Vida del famoso caballero Don Hugo de Moncada. Colección de documentos inéditos para la historia de España 24 (1854).

BAlan, PIETRO (HrSG.): Monumenta saeculi XVI. Bd. 1: Clementis VII. epistolae per Sadoletum scriptae quibus accedunt variorum ad papam et ad alios epistolae. Önipons 1885.

BAnChI DetTo DE' LANCEllotti, ToMmasinO DE': Cronaca Modenese. Parma 1862-1884. 12 Bde. Bd. 1-8 hrsg. v. C. Borghi. Bd. 9-12 hrsg. v. T. Lodi.

Bellay, Guillaume DU: Brief an Admiral Chabot. Hrsg. v. Léon Dorez. In: Mélanges d'archéologie et d'histoire. École Française de Rome. Jg. 16, Fasc. 5. (1896). S. 410414.

Belli, PIERINO: De Re militari \& Bello tractatus divisus in partes XI. Venedig 1563. Neudruck mit Einleitung v. Arrigo Cavalieri und englischer Übersetzung v. Herbert C. Nutting. The Classics of International Law 18. Washington 1936.

Beltrami, LuCA (HrsG.): Documenti relativi al castello di Milano negli anni 1513 e 1526. Mailand 1904.

Bembo, PIETRO: Opere in volgare. Hrsg. v. Mario Marti. Florenz 1961.

BerettA, RinAldo: Gian Giacomo de' Medici in Brianza (1527-1531). In: Archivio Storico Lombardo 43 (1916). S. 53-120.

Bernardi, GioACChino (HrSG.): L'assedio di Milano del 1526 dappresso una corrispondenza inedita di Francesco Guicciardini, commissario generale del papa nell'esercito dei collegati. In: Archivio Storico Lombardo 23 (1896). S. 245-354.

Berthier, JoAchim Joseph (HrSG.): Chroniques du monastère de San Sisto et de San Domenico e Sisto à Rome écrites par trois religieuses du même monastère et traduites par un religieux dominicain. Levanto 1919.

Bertolotti, A. (HrsG.): Memorie coeve sul sacco di Roma (aus einem Register des Konvents von S. Agostino). In: Archivio storico, artistico, archeologico e letterario della città e provincia di Roma 3 (1878). S. 212.

BertolotTI, A. (HRSG.): Note sincrone sui papi della metà del secolo XV a quella del XVI e sul sacco di Roma del 1527. In: Archivio storico, artistico, archeologico e letterario della città e provincia di Roma. Jg. 7, Bd. 4 (1881). S. 241-255.

Biblioteca Apostolica Vaticana (HrsG.): Roma al tempo di Giulio III. La pianta di Roma di Leonardo Bufalini del 1551, riprodotta dall'esemplare esistente nella Biblioteca Vaticana. Eingeleitet v. Francesco Ehrle. Città del Vaticano o. J.

Bicci, UBALDO/COMBO, GIOVANNI: Notizia storica della famiglia Boccapaduli nobile romana. Rom 1761.

BOCCHINERI, ANDREA: Ricordi. Hrsg. v. Cesare Guasti. In: Miscellanea pratese di cose inedite o rare antiche e moderne 8 (1872). S. 7-16.

Bonardi, Antonio (Hrsg.): L'assedio e la battaglia di Pavia. Diario inedito. Pavia 1895. Auch in: Memorie e Documenti per la Storia di Pavia e suo Principato. Jg. 1 (18941895).

BorgheSI, S./BANCHI, E. L. (HRSG.): Nuovi documenti per la storia dell'arte senese. Siena 1898.

Bortolan, Domenico (HrSG.): Cronicha che comenza dell'anno 1400. Vicenza 1889.

BRAmi DA Colle, SimONE: Bericht über die Plünderung von Prato 1512. In: Documenti del Sacco dato a Prato dagli Spagnoli nel 1512. Hrsg. v. Atto Vannucci. Archivio Storico Italiano, Bd. 1 (1842). 
Brewer, J. S. (HrSG.): Letters and papers, foreign and domestic, of the reign of Henry VIII. preserved in the public record office, the British Museum and elsewhere in England. Bd. 4, Teilbd. 2. London 1872.

Brugazzi, Giovanni Stefano: Vicende di Lodi dal 1528 al 1542. Hrsg. v. Andrea Timolati. In: Archivio Storico Lombardo 2 (1875). S. 381-401.

Burigozzo, Giovanni Marco: Cronaca di Milano dall'anno 1500 sino al 1544. Hrsg. v. Cesare Cantù. In: Archivio Storico Italiano, Bd. 3 (1842). S. 419-552.

CAldogno, Pietro Angelo di (Hrsg.): Alcune lettere scritte nei secoli XVI - XVII non più stampate. Venedig 1835.

CAnetTa, Carlo: I bagni di Bormio. In: Archivio Storico Lombardo 9 (1882). S. $722-$ 726.

CAPElla, Galeazzo: Beschreibung und Geschicht deß Meylandischen kriegß / der vom ein und zwentzigsten biß in das dryssigest fast by zechen Jar lang geweret hat / inn welcher schynbarlich ursach und ursprung / wie der Krieg entstanden / mit was anschlegen der selbig angehept / fürgenommen / verhandlet / und wie yedes geendet habe / erlütret wirt. Übers. v. Wenzelslaus Lincken. Bern 1539.

CAPPONI, GINO (HRSG.): Documenti di storia italiana dall'anno 1522 al 1530 che fanno seguito ai pubblicati da Giuseppe Molini nel 1836-37. In: Archivio Storico Italiano, App. 9 (1844). S. 389-485.

Cavalletti-Rondinini, G. (HrsG.): Nuovi documenti sul sacco di Roma del MDXXVII. Rom 1884. Auch in: Studi e documenti di storia e diritto 5 (1884). S. 221-246.

CAve, Jean: Bellum Romanum. Hrsg. v. Léon Dorez. In: Mélanges d'archéologie et d'histoire. École Française de Rome. Jg. 16, Fasc. 5. Rom 1896. S. 355-407.

Cellini, Benvenuto: La vita. Hrsg. v. Giulio Davico Bonini. Turin 1973.

Cerezeda, Martín García: Tratado de las campañas y otros acontecimientos de los ejércitos del emperador Carlos V en Italia, Francia, Austria, Berbería y Grecia, desde 1521 hasta 1545. Hrsg. v. der Sociedad de bibliófilos españoles. Bd. 1. Madrid 1873.

Ceruti, Antonio (HrsG): Diarii Udinesi dall'anno 1508 al 1541 di Leonardo e Gregorio Amaseo e Gio. Antonio Azio. Monumenti Storici pubblicati dalla R. Deputazione Veneta di Storia Patria, Bd. 11. Serie 3: Cronache e Diarii. Bd. 2. Venedig 1884.

COMUNE Di Roma (HRSG.): Regesti di bandi, editti, notificazioni e provvedimenti diversi relativi alla città di Roma ed allo Stato Pontifico. Bd. 1 (1234-1605). Rom 1920.

Contile, LuCA: La Historia de fatti di Cesare Maggi da Napoli, dove si contengono tutte le Guerre successe nel suo tempo in Lombardia \& in altre parti d'Italia et fuor d'Italia. Mailand 1565.

CorAzZINI, GiUSEPPE OdOARdo (HrsG.): Ricordanze di Bartolomeo Masi calderaio fiorentino dal 1478 al 1526. Florenz 1906.

Corvisieri, Alessandro (Hrsg.): Documenti inediti sul sacco di Roma nel MDXXVII. Rom 1873.

Droysen, GustaV (HrSG.): Zeitgenössische Berichte über die Eroberung der Stadt Rom 1527. Materialien zur neueren Geschichte. Halle 1881.

EgGer, Hermann (HrSG.): Römische Veduten. Handzeichnungen aus dem XV. - XVIII. Jahrhundert. Bd. 1 Wien und Leipzig 1911, Bd. 2 Wien 1931.

Falletti, Pio Carlo (Hrsg.): Assedio di Firenze. Contributo. Parte II: Documenti. Palermo 1885.

FRONSPERGER, LIENHART: Fünff Bücher von Kriegß Regiment und Ordnung / wie sich ein yeder kriegßmann inn seinem Ampt und bevelch halten soll. Frankfurt 1555.

Gasparoni, Benvenuto (HrsG.): Arti e lettere. Bd. 2. Rom 1865. 
GASSLER, FrANZ (HRSG.): Schilderungen aus Urschriften unserer Voreltern. Innsbruck 1789.

GATTINARA, GIOVANNI BARTOLOMEO: Lettera di ragguaglio di ciò che successe nel sacco di Roma, scritta da un offiziale dell'esercito di Borbone a Carlo V. In: Carlo Milanesi (Hrsg.): Il sacco di Roma del MDXXVII. Narrazioni di contemporanei. Florenz 1867. S. 493-530.

Gavardo, ARrivaBene: Copia d'una letra del successo et gran crudeltade fatta drento di Roma che non fu in Hierusalem o in Troia così grande. Hrsg. v. A. R. In: Archivio Storico Lombardo 4 (1877).

GAYANGOS, PASCUAL DE (HRSG.): Calendar of letters, despatches, and state papers, relating to the negociations between England and Spain, preserved in the archives at Simancas and elsewhere. Bd. 3, Teilbd. 1. Henry VIII. 1525-1526. London 1873. Bd. 3, Teilbd. 2. Henry VIII. 1527-1529. London 1877. Bd. 4. Henry VIII. 1529-1530.

Giovio, PaOlo: Istorie del suo tempo. Übers. v. Ludovico Domenichi. 2 Bde. Venedig 1555.

Giovio, PaOlo: Lettere. Hrsg. v. Guido Ferrero. Bd. 1 (1514-1544). Rom 1956.

Giovio, PAOLO: Le vite del Gran Capitano e del Marchese di Pescara. Übers. von Ludovico Domenichi. Hrsg. v. Costantino Panigada. Scrittori d'Italia 133. Bari 1931.

Giovio, PAOlo: Le vite di Leon Decimo et d'Adriano VI. summi pontifici, et del Cardinal Pompeo Colonna. Übers. v. Ludovico Domenichi. Florenz 1551.

GiRALDi CINTHIO, GiovanNi BATTISTA: Hecatommithi, overo cento novelle, nelle quali non solo s'impara, \& si esercita il vero parlar Toscano; ma ancora vengono rappresentate, come in vaghissima Scena, \& in lucidissimo Spechio, le varie maniere del viver $\mathrm{Hu}-$ mano. Venedig 1608.

GiUlini, ALESSANDRO: Un frammento di cronaca milanese. In: Archivio Storico Lombardo 42 (1915). S. 731-735.

GiUstiniani, Agostino: Castiagatissimi annali con la loro copiosa Tavola della Eccelsa \& Illustrissima Republica di Genoa. Genua 1537.

Gregorovius, FerdinAND (HrSG.): Ein deutscher Bericht über die Eroberung Roms. In: Sitzungsberichte der philosophisch-philologischen und historischen Classe der königlich bayerischen Akademie der Wissenschaften zu München. 1877, Heft 4. S. 329-397.

Gregorovius, Ferdinand (HrSG.): Das Römische Staatsarchiv. In: Historische Zeitschrift 36 (1876). S. 141-173.

Grollier, CÉSAIRE: Historia expugnatae et direptae urbis Romae per exercitum Caroli V. Imp. die VI. Maii M. D. XXVII. Clemente VII. Pontifice. Paris 1637.

Grumello, Antonio: Cronaca di Antonio Grumello pavese dal MCCCCLXVII al MDXXIX. Hrsg. v. Giuseppe Müller. Mailand 1856.

GuALDERONiCO, T.: Gli orrori del saccheggio di Roma l'anno 1527 descritti da un cittadino romano di quel tempo. Hrsg. v. M. Armellini. In: Cronachetta mensuale di scienze naturali e d'Archeologia. Jg. 20, Fasc. 6 (1886). S. 91-94.

Guerrini, PaOlo (HrSG): Documenti bresciani riguardanti il sacco di Roma del 1527. In: Rivista di scienze storiche, Jg. 1, Fasc. 8. Aug. 1904.

Guasti, Cesare (Hrsg.): Il sacco di Prato e il ritorno dei Medici a Firenze nel MDXII. Scelta di curiosità letterarie inedite o rare dal secolo XIII al XVII. Dispensa 177: Narrazioni in verso e in prosa. Dispensa 178: Documenti per la massima parte inediti. Bologna 1880.

Guerin-DAlle Mese, JeAnnine (HrsG.): Una cronaca vicentina del Cinquecento. Vicenza 1983. 
GuiCCIARDINI, FranCESCO: Opere inedite. Bd. 9: La prigionia di Clemente VII, la caduta della Repubblica Fiorentina e la legazione di Bologna. Carteggio dal 1527 al 1534. Hrsg. v. Piero und Luigi Guicciardini. Florenz 1866.

Guicciardini, Francesco: Storia d'Italia. Hrsg. v. Alessandro Gherardi. 4 Bde. Florenz 1919.

GuICCIARDINI, LUIGI: Il sacco di Roma. In: Il sacco di Roma del MDXXVII. Narrazioni di contemporanei. Hrsg. v. Carlo Milanesi. Florenz 1867. S. 1-244.

Hagen, A. (HRSG.): Die Eroberung Roms im Jahre 1527. Eine Beschreibung in der BelerPlatnerschen Chronik von Königsberg. In: Neue Preußische Provinzial-Blätter 8 (1849). S. 147-157 u. 179-191.

Heros, Martin de los: Historia del conde Pedro Navarro, general de infantería, marina é ingeniero, en los reinados de Fernando y Isabel, y de doña Juana y su hijo don Carlos. Colección de documentos inéditos para la historia de España 25 (1854).

HormAYER (HRSG.): Carl V. und seine Helden. In: Archiv für Geographie, Historie, Staatsund Kriegskunst. Wien 1812. Verschiedene Editionen in Fortsetzung.

HÜlsen, Christian/Egger, Hermann (HrsG.): Die römischen Skizzenbücher von Marten van Heemskerck im Königlichen Kupferstichkabinett zu Berlin. 2 Bde. Berlin 19131916.

JoPPI, VinCENZO (HRSG.): Diario del campo tedesco nella guerra veneta dal 1512 al 1516 di un contemporaneo. In: Archivio Veneto. Teil 1: Bd. 34 (1887). S. 133-152. Teil 2: Bd. 35 (1888). S. 83-116.

Lalanne, Ludovic (HrsG.): Euvres complètes de Pierre de Bourdeille, seigneur de Brantôme, publiées d'après les manuscrits avec variantes et fragments inédits pour la société de l'histoire de France. Bd. 1. Paris 1864.

LANDUCCI, LUCA: Diario fiorentino dal 1450 al 1516 continuato da un anonimo fino al 1542. Hrsg. v. Iodoco del Badia. Florenz 1883.

LANZ, KARL (HRSG.): Correspondenz des Kaisers Karl V. Aus dem königlichen Archiv und der Bibliothèque de Bourgogne zu Brüssel. Bd. 1. Leipzig 1844.

LeE, Egmont (HrsG.): Descriptio Urbis. The Roman Census of 1527. Rom 1985.

Livi, Ridolfo (HRSG.): Cronachetta pratese del Cinquecento. In: Archivio Storico Pratese 2 (1919). S. 181-185.

Luzio, Alessandro (HrsG.): Fabrizio Maramaldo. Nuovi documenti. Ancona 1883.

LUZIO, ALESSANDRO: Isabella d'Este e il sacco di Roma. Mailand 1908.

MACHIAVELLI, NiCCOLÒ: L'arte della guerra. Mailand 1928.

MAGALDI, V./FABRIS, R. (HRSG.): Notizie sui salari e sui prezzi di alcune derrate alimentari e prodotti industriali nelle città di Milano, Venezia, Genova, Firenze, Pisa, Mantova, Lucca e Forlì nei secoli XIII al XVIII. In: Annali di statistica. Serie 2a, Bd. 3 (1878). S. 5-106.

MANTESE, G. (HRSG.): La guerra di Cambrai a Marostica e nel Vicentino negli anni 15101512, secondo nuovi documenti ed una cronaca inedita del notaio Paolo Bellodo. In: Archivio Veneto, Serie 5, Bd. 78 (1966). S. 5-54.

MARChesini, G. B. (HrSG.): La lega di Cambray e le spese di guerra di un comune della Riviera Benacense. In: Archivio Veneto. Jg. 5 (1875). S. 126-154.

MAYERHOFER, JoHANNES (HrSG.): Zwei Briefe aus Rom aus dem Jahre 1527. Ein Beitrag zur Geschichte des "Sacco di Roma". In: Historisches Jahrbuch 12 (1891). S. 747756.

MazIO, PAOLO: Storia della guerra fra Clemente VII e gli imperiali e documenti inediti in proposito. In: Il Saggiatore Romano 10-11 (1844). Teil 1: S. 305-316. Teil 2: S. 337347. 
Milanesi, Carlo (Hrsg.): Il Sacco di Roma del MDXXVII. Narrazioni di contemporanei. Florenz 1867.

MocENIGO, ANDREA: La guerra di Cambrai, fatta a' tempi nostri in Italia tra gli illustrissimi signori venetiani con tutti i prencipi di Christianita. Venedig 1562.

ModeSTI, JACOPO: Bericht über die Plünderung von Prato 1512. In: Documenti del Sacco dato a Prato dagli Spagnoli nel 1512. Hrsg. v. Atto Vannucci. Archivio Storico Italiano, Bd. 1 (1842).

MolinI, GIUSEPPE (HRSG.): Documenti di storia italiana copiati su gli originali autentici e per lo più autografi esistenti in Parigi. 2 Bde. Florenz 1836-1837.

Morone, Gerolamo: Ricordi inediti di Gerolamo Morone, gran Cancelliere dell'ultimo duca di Milano sul decennio dal 1520 al 1530. Pubblicati dal C. Tullio Dandolo. Milano 1859.

MÜLleR, GIUSEPPE (HRSG.): Documenti che concernono la vita pubblica di Girolamo Morone. Miscellanea di Storia Italiana. Bd. 3. Turin 1865.

OMONT, H. (HRSG.): Les suites du sac de Rome par les impériaux et la campagne de Lautrec en Italie. Journal d'un scrittore de la pénitencerie apostolique (Décembre 1527 Avril 1528). In: Mélanges d'archéologie et d'histoire. École Française de Rome. Jg. 16, Fasc. 1-2. (1896). S. 13-61.

OZNAYA, JUAN DE: Historia de la guerra de Lombardia, batalla de Pavia y prisión del rey Francisco de Francia. In: Colección de documentos inéditos para la historia de España 38 (1861). S. 289-403.

PACHECO Y DE LeYva, ENRIQUe (HrSG.): La política española en Italia. Correspondencia de Don Fernando Marín, abad de Nájera, con Carlos I. Bd. 1 (1521-1524). Madrid 1919.

Palazzo, Bartolomeo: Diario. In: Paolo Guerrini (Hrsg.): Le cronache bresciane inedite dei secoli XV-XIX. Bd. 1. Brescia 1922. S. 256-386.

PASSERO, GIUliano: Storie in forma di Giornali. Hrsg. v. Vincenzo Maria Altobelli. Neapel 1785.

Pierrugues, Antoine Dominique (Hrsg.): Giornali del Principe d'Oranges nelle guerre d'Italia dal 1526 al 1530. Florenz 1897.

PorTO, Luigi DA: Lettere storiche di Luigi da Porto vicentino dall'anno 1509 al 1528. Hrsg. v. Bartolomeo Bressan. Florenz 1857.

Reiffenberg, Frédéric Auguste Ferdinand Thomas de (HrsG.): Coppie des nouvelles que le josne Montrichart a apporté de Rome anno 1527. In: Bulletin de l'académie royale de Bruxelles. Bd. 10, Fasc. 11 (1843). S. 476-488.

REISSNER, ADAM: Historia Herrn Georgen unnd Herrn Casparn von Frundsberg, Vatters und Sons / beyder Herrn zu Mündelheym / etc. Keyserlicher Oberster Feldt Herrn. Frankfurt 1572.

RoBert, Ulysse: Philibert de Chalon, prince d'Orange. Lettres et documents. Boletín de la Real Academia de la Historia 39 (1901).

RoDOCANACHI, E.: La première Renaissance. Rome au temps de Jules II et de Léon X. La cour pontificale, les artistes et les gens de lettres, la ville et le peuple, le sac de Rome en 1527. Paris 1912.

Rodriguez ViLla, ANTONio: Italia desde la batalla de Pavia hasta el saco de Roma. Madrid 1885.

RodRigueZ ViLla, ANTONIO: Memorias para la historia del asalto y saqueo de Roma en 1527 por el ejército imperial formadas con documentos originales, cifrados e ineditos en su mayor parte. Madrid 1875. 
RonChetTI, GiUSEPPE: Memorie istoriche della città e chiesa di Bergamo dal principio del V. secolo di nostra Salute sino all'anno MCCCCCXXVIII. Bd. 7. Bergamo 1839.

Rossi, OtTavio: Monumenta Brixiana; seu civitatis Brixiae antiquitates. In: Thesaurus antiquitatum et historiarum Italiae. Bd. 4, Teilbd. 1. Hrsg. v. Johannes Graevius u. Petrus Burmann. Leiden 1722.

Ruscelli, Gerolamo (HrsG.): Lettere di principi, le quali ò si scrivono da principi, ò à principi, ò ragionan di principi. Bd. 1 Venedig 1570. Bd. 2 Venedig 1575. Bd. 3 Venedig 1577.

SAlOMONI, ANGIOlo (HrSG.): Memorie storico-diplomatiche degli Ambasciatori, Incaricati d'affari, Corrispondenti, e Delegati, che la città di Milano inviò a diversi suoi principi dal 1500 al 1796. Mailand 1806.

Saluzzo di Castellar, Giovanni Andrea: Memoriale. Hrsg. v. V. Promis. Miscellanea di Storia Italiana 8. Turin 1869.

Santa Cruz, Alonso De: Crónica del Emperador Carlos V. Hrsg. v. Antonio Blázqueu y Delgado-Aguilera y Ricardo Beltrán y Rózpide. 3 Bde. Madrid 1920-22.

SANTORO, CATERINA (HRSG): Contributi alla storia dell'amministrazione sforzesca. In: Archivio Storico Lombardo, N. S. 4 (1939). S. 27-114.

SANTORO DA CASERTA, LEONARDO: Dei successi del sacco di Roma e guerra del regno di Napoli sotto Lotrech. Hrsg. v. Scipione Volpicella. Neapel 1858.

SAnsi, Achille (HrSG.): Saggio di documenti storici tratti dall'archivio del comune di Spoleto. Fuligno 1861.

SAnUto, Marino: Diarii. 58 Bde. Hrsg. v. Federico Stefani, Guglielmo Berchet, Nicolò Barozzi u. a. Venedig 1879-1903.

SASSI, ROMUALDO (HRSG.): Il sacco di Roma del 1527 negli atti d'un notaio contemporaneo. In: Atti e memorie della Reale deputazione di storia patria per le Marche. Serie 4, Bd. 4, Fasc. 1 (1527). S. 299-300.

SCACCIA SCARAFONI, CAMILlo (HRSG.): Un documento ignoto relativo al sacco di Roma. In: La Bibliofilia 40 (1938). S. 46-53.

SCHERTLIN VON BURTENBACH, SEBASTIAN: Lebensbeschreibung des berühmten Ritters Sebastian Schärtlins von Burtenbach. Aus dessen eigenen und GeschlechtsNachrichten vollständig herausgegeben und mit Anmerkungen und Beylagen versehen. Hrsg. v. Christoph Sigmund von Holzschuher. Frankfurt und Leipzig 1777.

Schulte, Aloys: Die Fugger in Rom 1495-1523. Mit Studien zur Geschichte des kirchlichen Finanzwesens jener Zeit. Bd. 1: Darstellung. Bd. 2: Dokumente. Leipzig 1904.

SegARIZZI, ARNALDo (HRSG.): Relazioni degli ambasciatori veneti al Senato. Bd. 2: Milano - Urbino. Bari 1913.

Segre, Arturo (Hrsg.): Documenti di storia sabauda dal 1510 al 1536 preceduti da una introduzione. Turin 1902.

Sinibaldi dA Montelupo, RAFFAello di BARTOlomeO: Autobiografie. Hrsg. v. Giovanni Gaye. In: Carteggio inedito d'artisti dei secoli XIV, XV, XVI. Bd. 3 (1501-1672). Florenz 1840. S. 581-594.

SPElta, ANTONIO MARIA: Historia delle vite di tutti i vescovi, che dall'anno di nostra salute VL fino al M.D.IIIC. successivamente ressero la chiesa dell'antichissima, \& Regal Città di Pavia. Pavia 1597.

TRIVUlzio, SCARAMUCCIA: Copia d'una del cardinale di Como a uno suo segretario, data a Civitavecchia alli 24 di Maggio 1527. In: Carlo Milanesi (Hrsg.): Il sacco di Roma del MDXXVII. Narrazioni di contemporanei. Florenz 1867. S. 471-490. 
Ughi, GiUliano: Cronica di Firenze o compendio delle cose di Firenze dall'anno MDI al MDXLVI. Hrsg. v. Francesco Frediani. In: Archivio Storico Italiano, Appendice 23. (Bd. 7) Florenz 1849. S. 97-274.

UlloA, FrANCESCO: Vita del valorosissimo e gran capitano Don Ferrante Gonzaga, principe di Molfetta, \&c. Venedig 1563.

VAleriano, PIERIO: La infelicità dei letterati. Hrsg. v. Cornelio Tollio. Mailand 1829.

Vallabio, Bernardino: Cronichetta. Hrsg. v. Paolo Guerrini. In: Fonti per la storia bresciana 3. Le cronache bresciane inedite dei secoli XV-XIX. Bd. 2. Brescia 1927. S. 169-195.

VAlles, Pedro: Historia del Fortissimo, y prudentissimo Capitan Don Hernando de Avalos Marques de Pescara, con los hechos memorables de otros siete excelentissimos Capitanes del Emperador Don Carlos V. Rey de España, que fueron en su tiempo, es a saber, el Prospero Coluna, el Duque de Borbon, Don Carlos Lanoy, Don Hugo de Moncada, Philiberto Principe de Orange, Antonio de Leyva, y el Marques del Guasto. Antwerpen 1558.

Vannucci, Atto (Hrsg.): Documenti del Sacco dato a Prato dagli Spagnoli nel 1512. In: Archivio Storico Italiano, Bd. 1 (1842).

VARChI, Benedetto: Storia Fiorentina. Hrsg. v. Gaetano Milanesi. 3 Bde. Florenz 185758.

VASARI, GIORgIO: Le vite dei più eccellenti pittori, scultori, e architetti. Eingeleitet von Maurizio Marini. Rom 1991.

Verri, MARTINO: Relazione delle cose successe in Pavia dal MDXXIV al MDXXVIII. Hrsg. v. Giuseppe Müller. In: Raccolta di cronisti e documenti storici lombardi inediti. Bd. 2. Mailand 1857.

VetTORI, FrAnCESCO: Sommario della storia d'Italia dal 1511 al 1527. Hrsg. v. Alfred v. Reumont. In: Archivio Storico Italiano, App. 22 (1849). S. 287-387.

VICTORIA, FRANCISCO DE: De Indis recenter inventis et de iure belli Hispanorum in Barbaros relectiones. Vorlesungen über die kürzlich entdeckten Inder und das Recht der Spanier zum Kriege gegen die Barbaren. 1539. Hrsg. u. übers. v. Walter Schätzel. Tübingen 1952.

Vitelli, Vitello: Lettere di diversi illustrissimi signori, et repubbliche scritte all' Illustrissimo Signore il Signor Vitello Vitelli. Anonymer Hrsg. Florenz 1551.

Zagata, PIER (HrsG.): Cronica della città di Verona colla continuazione di Jacopo Rizzoni, ampliata e supplicata da Giambattista Biancolini. 3 Bde. Verona 1745-49.

\section{Darstellungen:}

AdAmi, VitTORIO: Milano e gli alloggi militari. Mailand 1928. Auch in: Città di Milano 11 (1927).

Agresti, Domenico Guglielmo Di: Aspetti di vita pratese del Cinquecento. Collana Ricciana, Fonti 7. Florenz 1976.

AlEAti, GiUSEPPE: La popolazione di Pavia durante il dominio spagnolo. Mailand 1957.

AndennA, Giancarlo U. A. (HrSGg.): Comuni e signorie nell'Italia settentrionale: la Lombardia. Bd. 6 von: Storia d'Italia. Hrsg. v. Giuseppe Galasso. Turin 1998.

Avalle, CARlo: Storia di Alessandria dall'origine ai nostri giorni. Bd. 3. Turin 1854.

BALAN, PIETRO: Clemente VII e l'Italia dei suoi tempi. Mailand 1887. 
Ballesteros-Gaibrois, Manuel: Ramón de Cardona. Colaborador del Rey Catolico en Italia. Madrid 1953.

BANCA PoPOlARE Di Lodi (HRSG.): Lodi. La storia dalle origini al 1945. 3 Bde. Lodi 1989.

BANDini, ANGElo MARIA: Il Bibbiena o sia il ministro di stato delineato nella vita del cardinale Bernardo Dovizi da Bibbiena. Livorno 1758.

Bardi, Alessandro: Carlo V e l'assedio di Firenze. In: Archivio Storico Italiano. Serie 5, Bd. 11 (1893). S. 1-85.

BARBIERI, GINO: Economia e politica nel ducato di Milano 1386-1535. Mailand 1938. Pubblicazioni dell'Università Cattolica del Sacro Cuore. Serie terza: Scienze sociali. Bd. 18.

BARBIERI, GINO: I redditi dei Milanesi all'inizio della dominazione spagnuola. In: Rivista internazionale di Scienze Sociali (1937). S. 759-781.

BARDINI, MARCO: Borbone occiso. Studi sulle tradizioni storiografiche del sacco di Roma del 1527. Pisa 1991.

BARTHOLD, F. W.: George von Frundsberg oder das deutsche Kriegshandwerk zur Zeit der Reformation. Hamburg 1833.

BARtolini, DARIO: Notizie storico-statistiche sui prezzi e salari. In: Annali di statistica. Serie 2a, Bd. 1 (1878). S. 194-204.

Baumann, ReInHARD: Georg von Frundsberg, Vater der Landsknechte, Feldhauptmann von Tirol. München 1991.

BAUMANN, REINHARD: Landsknechte. Ihre Geschichte und Kultur vom späten Mittelalter bis zum Dreißigjährigen Krieg. München 1994.

BAUMANN, REINHARD: Das Söldnerwesen im 16. Jahrhundert im bayerischen und süddeutschen Beispiel. Eine gesellschaftsgeschichtliche Untersuchung. München 1978.

Baumgarten, HermanN: Geschichte Karls V. Bd. 2. Stuttgart 1888.

BELlERMANN, ChristiAn: Erinnerungen aus Südeuropa. Geschichtliche, topographische und literarische Mittheilungen aus Italien, dem südlichen Frankreich, Spanien und Portugal. Berlin 1851.

BelOCH, KarL Julius: Bevölkerungsgeschichte Italiens. Bd. 2: Die Bevölkerung des Kirchenstaates, Toskanas und der Herzogtümer am Po. Bd. 3: Die Bevölkerung der Republik Venedig, des Herzogtums Mailand, Piemonts, Genuas, Corsicas und Sardiniens. Die Gesamtbevölkerung Italiens. Berlin 1961.

Belotti, Bortolo: Storia di Bergamo e dei Bergamaschi. 3 Bde. Mailand 1940.

Beltrami, LuCA: Il castello di Milano sotto il dominio dei Visconti e degli Sforza. MCCCLXVIII - MDXXXV. Mailand 1894.

Benvenuti, MAtteo: Come facevasi guistizia nello stato di Milano dall'anno 1471 al 1763. In: Archivio Storico Italiano, Serie 4, Bd. 9 (1882). S. 442-482.

Besta, BEATRICE: La popolazione di Milano nel periodo della dominazione Spagnola. In: Atti del congresso internazionale per gli studi sulla popolazione. (Roma, 7-10 settembre 1931). Hrsg. v. Corrado Gini. Bd. 1. Rom 1933.

BINDI, ENRICO: I Pistoiesi alla difesa di Prato nel sacco del 1512. In: Calendario pratese. Memorie e studi di cose patrie. 5. Jahrgang 1850. S. 43-52.

BLASIIS, GIUSEPPE DE': Fabrizio Maramaldo e i suoi antenati. In: Archivio storico per le provincie napoletane. Bd. 2 (1877). Bd. 3. (1878).

Blastenbrei, Peter: Die Einwanderung nach Rom nach dem Sacco von 1527. Ein altes Problem und eine (mögliche) neue Lösung. In: Quellen und Forschungen aus italienischen Archiven und Bibliotheken 72 (1992). S. 204-229.

BlENDINGER, FRIEDRICH: Sebastian Schertlin von Burtenbach. In: Lebensbilder aus dem bayerischen Schwaben. Bd. 2. München 1953. S. 198-226. 
BonetTi, CARlo: Cremona durante le guerre di predominio straniero (1499-1526). Biblioteca Storica Cremonese 9. Cremona 1939.

BRANDI, KARL: Kaiser Karl V. Werden und Schicksal einer Persönlichkeit und eines Weltreiches. Bd. 1. München 1937.

BuchOltZ, Franz-BernhaRD VON: Geschichte der Regierung Ferdinand des Ersten. Bd. 3. Wien 1832.

BurgiÈre, ANDRÉ: La démographie. In: Faire de l'histoire. Hrsg. v. Jacques Le Goff und Pierre Nora. 3 Bde. Paris 1974. Bd. 2. S. 74-104.

Burschel, PETER: Söldner im Nordwestdeutschland des 16. und 17. Jahrhunderts. Sozialgeschichtliche Studien. Veröffentlichungen des Max-Planck-Instituts für Geschichte 113. Göttingen 1994.

CADENAS Y Vicent, Vicente DE: El saco de Roma de 1527 por el ejército de Carlos V. Madrid 1974.

CAdenas y Vicent, Vicente De: El saco de Prato, la primera reposición de los Medicis en Florencia y la presencia de España en el Milanesado. Madrid 1982.

CÁnovas del CASTILlo, AnTONIO: Del asalto y saco de Roma por los españoles. Epístola dirigida al excmo. Señor D. Serafin Estévanez Calderon. Madrid 1858.

CANTÙ, Cesare: Storia della città e diocesi di Como. 2 Bde. Como1899-1900.

CAPPElletti, GiUsepPe: Storia di Padova dalla sua origine sino al presente. 2 Bde. Padua 1875.

CAPPONI, GINO: Storia della Repubblica di Firenze. Bd. 2. Florenz 1875.

CARANDE Y TOVAR, RAMÓN: Carlos V y sus banqueros. Bd. 3: Los caminos del oro y de la plata. Barcelona 1990.

CARTwright, Julia: Isabella d'Este, Marchioness of Mantua, 1474-1539. A Study of the Renaissance. 2 Bde. London 1904.

CAsali, Luigi/Galandra, Marco: Pavia nelle vicende militari d'Italia dalla fine del secolo XV e la battaglia del 24 Febbraio 1525. In: Storia di Pavia. Bd. 3: Dal libero comune alla fine del principato indipendente 1024-1535; Teilbd. 2: La battaglia di Pavia del 24 Febbraio 1525 nella storia, nella letteratura e nell'arte, Università e cultura. Hrsg. v. d. Banca del Monte di Lombardia. Pavia 1990.

CASONI, FILIPPO: Annali della Repubblica di Genova del secolo decimosesto. Genua 1708.

CAVRIOlO, Elia: Dell'istorie della città di Brescia libri XIV con diverse aggiunte di altri autori. Venedig 1744.

CAZZAmini Mussi, Francesco: Milano durante la dominazione spagnola (1525-1706). Mailand 1947.

Chabod, Federico: Lo stato e la vita religiosa a Milando nell'epoca di Carlo V. Turin 1971.

Chastel, ANDrÉ: The sack of Rome. Princeton 1983.

Ciaconio, Alfonso: Vitae et res gestae Pontificum Romanorum et S. R. E. Cardinalium ab initio nascentis Ecclesiae usque ad Clementem IX. P. O. M. Bd. 3. Rom 1677.

Cipolla, CARlo Maria: Per la storia della popolazione lombarda nel secolo XVI. In: Studi in onore di Gino Luzzatto. Bd. 4. Mailand 1950. S. 144-155.

Cipolla, CARlo Maria: Storia delle signorie italiane dal 1313 al 1530. Mailand 1881.

ClonARD, CONDE DE: Historia orgánica de las armas de infantería y caballería españolas, desde la creación del ejercito permanente hasta el día. Bd. 3. Madrid 1853.

CORRADI, ALFONSO: Annali delle epidemie occorse in Italia dalle prime memorie fino al 1850 compilati con varie note e dichiarazioni. Memorie della società medicochirurgica di Bologna seguito agli opuscoli da essa pubblicati. Bd 6, Fasc. 3-10. Bologna 1865-1895. 
CORVISIER, ANDRÉ: Armées et sociétés en Europe de 1494 à 1789. Vendôme 1976.

Creighton, Mandell: A History of the Papacy During the Period of the Reformation. Bd. 5: The German Revolt 1517-1527. London 1894.

Crespi, AtTilio Luigi: Del Senato di Milano. Ricerche intorno alla costituzione dello stato di Milano al tempo della dominazione spagnuola. Mailand 1898.

Croce, Benedetto: La Spagna nella vita italiana durante la Rinascenza. Bari 1917.

DELBRÜCK, HANS: Geschichte der Kriegskunst im Rahmen der politischen Geschichte. 7 Bde. Berlin 1920-1936. Bd. 4: Neuzeit (1920).

Delumeau, Jean: Rome au XVIe siècle. Paris 1975.

Dennistoun, James: Memoirs of the Dukes of Urbino, illustrating the Arms, Arts, and Literature of Italy, from 1440 to 1630 . London 1851. 3 Bde.

DURRER, ROBERT: Die Schweizergarde in Rom und die Schweizer in päpstlichen Diensten. Luzern 1927.

ERLER, ADALBERT: Der Loskauf Gefangener. Ein Rechtsproblem seit drei Jahrtausenden. Berlin 1978.

EROLI, GiOVANNI: Il sacco de' Borboni. In: Miscellanea storica narnese 1 (1858). S. 9-45.

EsCH, ARNOLD: Mit Schweizer Söldnern auf dem Weg nach Italien. Das Erlebnis der Mailänderkriege 1510-1515 nach bernischen Akten. In: Quellen und Forschungen aus italienischen Archiven und Bibliotheken 70 (1985). S. 348-440.

ESCH, ARNOLD: Überlieferungs-Chance und Überlieferungs-Zufall als methodisches Problem des Historikers. In: Historische Zeitschrift 240 (1985). S. 529-570.

FANFANI, AMINTORE: La rivoluzione dei prezzi a Milano nel XVI e XVII secolo. In: Contributi del laboratorio di statistica. Serie 3. Mailand 1934. S. 211-236.

FANFANI, AMINTORE: Storia del lavoro in Italia. Bd. 3: Dalla fine del secolo XV agli inizi del XVIII. Mailand 1959.

FERNÁNDEZ ÁlvareZ, MANUEL: El siglo XVI. Economía, Sociedad, Instituciones. Bd. 19 von: Historia de España. Hrsg. v. José María Jover Zamora. Madrid 1989.

FERRARIO, GIUSEPPE: Statistica medica di Milano dal secolo XV fino ai nostri giorni. Bd. 2. Mailand 1840.

FIEDLER, SIEGFRIED: Kriegswesen und Kriegführung im Zeitalter der Landsknechte. Abt. 1, Bd. 2 von: Heerwesen der Neuzeit. Hrsg. v. Georg Ortenburg. Koblenz 1985.

FIRPO, MASSIMO: Il sacco di Roma del 1527 tra profezia, propaganda politica e riforma religiosa. Cagliari 1990.

FIUMI, ENRICO: Demografia, movimento urbanistico e classi sociali in Prato dall'età comunale ai tempi moderni. Florenz 1968.

FORMENTINI, MARCO: La dominazione spagnola in Lombardia. Mailand 1881.

FORMENTINI, MARCO: Il ducato di Milano. Studi storici documentati. Mailand 1877.

FURET, FrAnÇOIS: Le quantitatif en histoire. In: Faire de l'histoire. Hrsg. v. Jacques Le Goff und Pierre Nora. 3 Bde. Paris 1974. Bd. 1. S. 42-61.

GHILINI, GiRolamo: Annali di Alessandria, overo le cose accadute in essa città, nel suo, e circonvicino territorio dall'anno dell'origine sua sino al M.DC.LIX. Mailand 1666.

GIODA, CARLO: Girolamo Morone e i suoi tempi. Turin, Rom, Mailand, Florenz 1887.

GORI, VitTORIO: Il sacco di Prato. Collana storica pratese 2. Prato 1972.

Gosellini, Giuliano: Vita di Don Ferrando Gonzaga, principe di Molfetta. Collezione di ottimi scrittori italiani in supplemento ai classici milanesi. Bd. 16. Pisa 1821.

Gouwens, KENNETH: Remembering the Renaissance. Humanist Narratives of the Sack of Rome. Brill's Studies in Intellectual History 85. Leiden 1998.

Gregorovius, Ferdinand: Storia della città di Roma nel Medio Evo. 6 Bde. Rom 1901.

GuAITOLI, GIANFRANCO: L'occupazione spagnola di Carpi (1523-1527). Carpi 1998. 
Gulik, Wilhelm van/Eubel, KonRAD: Hierarchia Catholica medii et recentioris aevi sive summum pontificorum, S. R. E. Cardinalium, ecclesiarum antistitum series. Bd. 3. Münster 1923.

Hale, John R.: Armies, Navies and the Art of War. In: The New Cambridge Modern History. Bd. 2: The Reformation 1520-1559. Hrsg. v. G. R. Elton. Cambridge 1990. S. 540-569.

Hale, John R.: War and Public Opinion in Renaissance Italy. In: E. F. Jacob (Hrsg.): Italian Renaissance Studies. London 1960. S. 94-122.

Hale, JoHn R.: War and Society in Renaissance Europe. London 1985.

Halkin, LÉOn E./DAnSAert, Georges: Charles de Lannoy, Vice-Roi de Naples. Brüssel 1934.

Helm, Johann GeORG: Die Rechtsstellung der Bevölkerung im Kriege in ihrer geschichtlichen Entwicklung. Ein Beitrag zur Geschichte des Völkerrechts. Frankfurt 1957.

HerliHy, DAVID: Medieval and Renaissance Pistoia. The Social History of an Italian Town 1200-1430. London 1967.

Herrera, Antonio DE: Commentarios de los hechos de los Españoles, Franceses, y Venecianos en Italia, y de otras Republicas, Potentados, Principes, y Capitanes famosos Italianos, desde el año de 1281. hasta el de 1559. Madrid 1624.

HoOK, JUDITH: The Sack of Rome. London 1972.

INGHIRAMI, FRANCESCO: Storia della Toscana compilata ed in sette epoche distribuita. Bd. 9. Epoca 5. Dall'anno 1115 al 1530 dopo G. Cr. Florenz 1843.

Koenigsberger, H. G.: The Empire of Charles V in Europe. In: The New Cambridge Modern History. Bd. 2: The Reformation 1520-1559. Hrsg. v. G. R. Elton. Cambridge 1990. S. 339-376.

LANCIANI, RODOLFO: Storia degli scavi di Roma e notizie intorno le collezioni romane di antichità. Bd. 1 (1000-1530). Rom 1902.

LEBEY, ANDRÉ: Le connetable de Bourbon. Paris 1904.

LENZI, MARIA LudOVICA: Il sacco di Roma del 1527. Florenz 1978.

LENZI, MARIA LUDOVICA: La pace strega. Guerra e società in Italia dal XIII al XVI secolo. Montepulciano 1988.

LENZI, MARIA LudOVICA: L'Italia e l'Europa nella prima metà del Cinquecento. In: Storia della società italiana. Bd. 9: I secoli del primato italiano: il Cinquecento. Hrsg. v. Gianfranco Berardi u. a. Mailand 1989.

LEVA, GIUSEPPE DE: Storia documentata di Carlo V in correlazione all'Italia. Bd. 2. Venedig 1864.

Magenta, CARLO: I Visconti e gli Sforza nel castello di Pavia e loro attinenze con la certosa e la storia cittadina. Bd. 1: Testo. Bd. 2: Documenti. Mailand 1883.

MARIMONTI, GIUSEPPE: Memorie storiche della città di Monza. Monza 1841.

MAZZEI, FRANCESCO: Il sacco di Roma. Mailand 1986.

Merriman, Roger Bigelow: The Rise of the Spanish Empire in the Old World and the New. Bd. 3. New York 1925.

Mignet, M.: Rivalité de François Ier et de Charles-Quint. Bd. 2. Paris 1875.

Mittermaier, KarL: Machiavelli. Moral und Politik zu Beginn der Neuzeit. Gernsbach 1990.

MoISÈ, FILIPPO: Storia dei dominii stranieri in Italia dalla caduta dell'Impero Romano in occidente fino ai nostri giorni. Bd. 4. Florenz 1843.

Möller, Hans-Michael: Das Regiment der Landsknechte. Untersuchung zu Verfassung, Recht und Selbstverständnis in deutschen Söldnerheeren des 16. Jahrhunderts. Wiesbaden 1976. 
Muletti, Delfino: Memorie storico-diplomatiche appartenenti alla città ed ai marchesi di Saluzzo. Bd. 6. Saluzzo 1836.

NaGL, Franz/LANG, AlOIS: Mitteilungen aus dem Archiv des deutschen Nationalhospizes S. Maria dell'Anima in Rom. Suppl. 12 von: Römische Quartalschrift für christliche Alterthumskunde und für Kirchengeschichte. Rom 1899.

OCHRANE, ERIC (HRSG.): Longman History of Italy. Darin Bd. 3: Italy in the age of the Renaissance 1380-1530. Hrsg. v. Denis Hay u. John Law. New York 1989. Bd. 4: Italy 1530-1630. Hrsg. v. Julius Kirshner. New York 1988.

OdORICI, FEDERICO: Storie bresciane dai primi tempi sino all' età nostra. 11 Bde. Brescia 1853-1865. Bd. 9. (1860).

OMAn, Charles: A History of the Art of War in the Sixteenth Century. London 1937.

Orano, Domenico: Il Sacco di Roma del 1527. Studi e documenti. Bd. 1. Rom 1901.

PASERO, CARlo: Francia, Spagna, Impero a Brescia 1509-1516. Commentari dell'Ateneo di Brescia 156, Suppl. 1. Brescia 1958.

PASTOR, Ludwig VON: Geschichte der Päpste seit dem Ausgang des Mittelalters. Bd. 4: Geschichte der Päpste im Zeitalter der Renaissance und der Glaubensspaltung von der Wahl Leos X. bis zum Tode Klemens' VII. (1513-1534). Teilbd. 2: Adrian VI. und Klemens VII. Freiburg 1907.

PAMPAlONI, Guido: Prato nella Repubblica Fiorentina. Secolo XIV-XVI. In: Storia di Prato. Hrsg. v. d. Cassa di Risparmio di Prato. Prato 1980.

PARTNER, PETER: Renaissance Rome 1500-1559. A Portrait of a Society. Berkeley 1976.

PAVOlo, Claudio: Tre villaggi del contado di Vicenza. Indagine demografica per una storia sociale della popolazione veneta nei primi secoli dell'età moderna. In: Lisiera. Immagini, documenti e problemi per la storia e cultura di una comunità veneta. Strutture - congiunte - episodi. Hrsg. v. Claudio Pavolo. Bd. 2. Vicenza 1981. S. 8751035.

PeCCHIAI, PIO: Roma nel Cinquecento. Bologna 1948.

Petronio, Ugo: Il senato di Milano. Istituzioni giuridiche ed esercizio del potere nel ducato di Milano da Carlo V a Giuseppe II. Varese 1972.

PiCATOSTE, FeliPE: Estudios sobre la grandeza y decadencia de España. Los españoles en Italia. 2 Bde. Madrid 1887.

PICCA, PAOlO: Il Sacco di Roma del 1527. Profezie, previsioni, prodigi. In: Nuova Antologia. Rivista di lettere, scienze ed arti. Jg. 64, Fasc. 1379 (1929).

PinetTI, ANGElo: Dalla lega di Cambrai alla pace di Noyon (1508-1516). Cronistoria martinenghese da documenti inediti. Bergamo 1916.

PitTS, Vincent J.: The Man Who Sacked Rome. Charles de Bourbon, Constable of France (1490-1527). New York 1993.

Poggiali, Cristoforo: Memorie storiche di Piacenza. Bd. 8. Piacenza 1760.

PUDDU, RAFFAELE: Il soldato gentiluomo. Autoritratto di una società guerriera: la Spagna del Cinquecento. Bologna 1982.

Putelli, Romolo: Intorno al castello di Breno. Storia di Valcamonica, Lago d'Iseo e vicinanze. Breno 1915.

QUATREFAGES, RENÉ: La Revolución militar moderna. El crisol español. Madrid 1996.

RAVIOLI, CAMILlO: Le guerre dei sette anni sotto Clemente VII, assalto, presa e sacco di Roma, l'assedio e la perdita di Firenze dall'anno MDXXIII al MDXXXI sui documenti ufficiali. In: Archivio della Società romana di storia patria 6 (1883).

REDLICH, FRITZ: Der Marketender. In: Vierteljahresschrift für Wirtschafts- und Sozialgeschichte 41 (1954). S. 227-252. 
REDLICH, FRITZ: De praeda militari. Looting and booty 1500-1815. Beiheft 39 der Vierteljahresschrift für Sozial- und Wirtschaftsgeschichte. Wiesbaden 1956.

REINHARD, MARCEL R./ARMENGAUD, ANDRÉ: Histoire générale de la population mondiale. Paris 1961.

RENAZZI, FILIPPO MARIA: Storia dell'università degli studi di Roma, detta comunemente la Sapienza che contiene anche un saggio storico della letteratura romana dal principio del secolo XIII sino al declinare del secolo XVIII. Bd. 2. Rom 1804.

REumONT, AlfRED von: Geschichte der Stadt Rom. Bd. 3, Teilbd. 2. Berlin 1870.

RoBert, UlysSE: Philibert de Chalon, prince d'Oranges, vice-roi de Naples, (18 mars 1502 - 3 août 1530). Paris 1902.

Romano, Ruggiero/Tenenti, Alberto: Die Grundlegung der modernen Welt. Spätmittelalter, Renaissance, Reformation. Frankfurt 1994.

RoSMINI, CARLO DE': Dell'istoria di Milano. 4 Bde. Mailand 1820.

Rovelli, GiUsePPE: Storia di Como. Bd. 3. Como 1802.

RÜSTOW, W.: Geschichte der Infanterie. Bd. 1. Bis auf den Anfang des Siebenzehnten Jahrhunderts. Gotha 1857.

SALVIOLI, GIUSEPPE: Nuovi studii sulla politica e le vicende dell' esercito imperiale in Italia nel 1526-27 e sul sacco di Roma da documenti inediti dell' Archivio di Stato di Modena. In: Archivio Veneto 9. (1879). S. 1-34.

SANDOVAl, PRUdencio DE: Vida y hechos del emperador Carlos Quinto max. fortissimo Rey de España, y de las Indias, Islas, y Tierrafirme del mar Oceano. Bd. 1 (15001528). Valladolid 1604. Bd. 2 (1528-1557). Valladolid 1606.

SANTORO, CATERINA: Aspetti dell'amministrazione finanzaria del comune di Milano dal XIV al XVIII secolo. Mailand 1963.

SANTORO, CATERINA: Gli Sforza. Mailand 1968.

SCHMIDLIN, JOSEPH: Geschichte der deutschen Nationalkirche in Rom S. Maria dell' Anima. Freiburg 1906.

SCHÖNHERR, DAVID: Der Krieg Kaiser Maximilians I. mit Venedig 1509. Wien 1879.

SCHUlZ, HANS: Deutsche Zeitungen über den Sacco di Roma von 1527. In: Zeitschrift für Bücherfreunde. Jg. 3, Bd. 1 (1899). S. 21-24.

Schulz, Hans: Der Sacco di Roma. Karls V. Truppen in Rom 1527-1528. Halle 1894.

SÉDILlOT, RENÉ: Toutes les monnaies du monde. Paris 1955.

SForza Benvenuti, Francesco: Storia di Crema. 2 Bde. Mailand 1859-1860.

SiTONIS, JOHANNES DE: Elucubratio de antiquis, et modernis in insubria monetis. In: De monetis Italiae variorum illustrium virorum dissertationes. Hrsg. v. Philippus Argelatus. Bd. 2. Mailand 1750. S. 1-38.

SolgER, E.: Der Landsknechtsobrist Konrat von Bemelberg der kleine Hess. Nördlingen 1870.

SOLLEDER, FRIDOLIN: Reichsverbote fremden Kriegsdienstes, fremder Werbung und Rüstung unter Maximilian I. In: Zeitschrift für bayerische Landesgeschichte 18 (1955). S. 315-351.

Stolz, Oтто: Zum Verbot des Kriegsdienstes für fremde Mächte in Deutschland im sechzehnten Jahrhundert. In: Elsass-lothringisches Jahrbuch 21 (1943). S. 188-213.

STUMPO, ENRICO: Le forme del Governo cittadino. In: Elena Fasano Guarini (Hrsg.): Un microcosmo in movimento (1494-1815). Prato 1986. Seinerseits Bd. 2 von: Prato. Storia di una città. Hrsg. v. Fernand Braudel.

SuAREZ De Alarcon, ANTONIO: Comentarios de los hechos del señor Alarcon, marques de la Valle Siciliana, y de Renda, y de las guerras en que se hallò por espacio de cinquenta y ocho años. Madrid 1665. 
SUPERTI-FuRGA, ISABELlA: Dal dominio straniero all'età napoleonica. In: Storia di Monza e della Brianza. Hrsg. v. Alfredo Bosisio und Giulio Vismara. Bd. 2: Le vicende politiche dal dominio straniero all'Italia unita. Mailand 1978.

TAYLOR, F. L.: The Art of War in Italy 1494-1529. London 1993.

TORRE, GIUSEPPE DEL: Venezia e la Terraferma dopo la guerra di Cambrai (1515-1530). Vicenza 1986.

Treccani Degli Alfieri, Giovanni, U. A. (Hrsgg.): Storia di Brescia. Bd. 2: La dominazione veneta (1426-1575). Brescia 1963.

Treccani Degli Alfieri, Giovanni, U. A. (HrsgG.): Storia di Milano. Bd. 8: Tra Francia e Spagna (1500-1535). Mailand 1957.

Ulmann, H.: Aus deutschen Feldlagern während der Liga von Cambrai. In: Deutsche Zeitschrift für Geschichtswissenschaft 2 (1889). S. 346-380.

VAQUERO PIÑERO, MANUEL: La renta y las casas. El patrimonio inmobiliario de Santiago de los Españoles de Roma entre los siglos XV y XVII. Rom 1999.

VARESE, CARLO: Storia della Repubblica di Genova, dalla sua origine sino al 1814. Bd. 4. Genua 1836.

VERri, PIETRO: Storia di Milano. 2 Bde. Mailand 1834-1835.

VIDARI, GiovanNI: Frammenti storici dell'Agro Ticinese. 2 Bde. Pavia 1886.

Vigo, Giovanni: Real Wages of the Working Class in Italy: Building Workers' Wages (14th to 18th Century). In: Journal of European Economic History 3 (1974). S. 378399.

VIRGILI, A.: Dopo la battaglia di Pavia. In: Archivio Storico Italiano, Serie 5, Bd. 6. (1890).

VIRGILI, A.: Otto giorni avanti alla battaglia di Pavia. In: Archivio Storico Italiano, Serie 5, Bd. 4 (1889).

VisConti, Alessandro: Storia di Milano. Mailand 1952.

Wette, Wolfram: Militärgeschichte von unten. Die Perspektive des "kleinen Mannes". In: Der Krieg des kleinen Mannes. Eine Militärgeschichte von unten. Hrsg. v. Wolfram Wette. München 1999.

WIEBE, GeORG: Zur Geschichte der Preisrevolution des XVI. und XVII. Jahrhunderts. Leipzig 1895.

Wilson, Charles/PARKer, GeOfFrey: An Introduction to the Sources of European Economic History 1500-1800. Bd. 1: Western Europe. London 1977.

WoEHLKens, ERICH: Pest und Ruhr im 16. und 17. Jahrhundert. Hannover 1954.

ZANelli, Agostino: La devozione di Brescia a Venezia e il principio della sua decadenza nel secolo XVI. In: Archivio Storico Lombardo 39 (1912). S. 23-100.

ZANETti, DANTE E.: A Milano nel 1524. I sospetti del Gentilino. In: Fatti e idee di storia economica nei secoli XII-XX. Festschrift für Franco Borlandi. Hrsg. v. Carlo M. Cipolla, Domenico Demarco und Federigo Melis. Bologna 1977.

ZANETTI, DANTE E.: La morte a Milano nei secoli XVI-XVIII. Appunti per una ricerca. In: Rivista Storica Italiana. Jg. 88, Fasc. 4 (1976). S. 804-851.

Zanetti, Dante E.: Problemi alimentari di una economia preindustriale. Cereali a Pavia dal 1398 al 1700. Turin 1964.

ZANETTI, Polibio: L'assedio di Padova dell'anno 1509 in correlazione alla guerra combattuta nel Veneto dal maggio all'ottobre. Venedig 1891. 
Anhang I: Durchlaufende Nummerierung der Befragten in Konkordanz zur Nummerierung der Blätter des Manuskripts ASP 2549.

\begin{tabular}{|c|c|}
\hline Nr. & fol. \\
\hline $1-5$ & $1^{\mathrm{r}}$ \\
\hline $6-10$ & $1^{\mathrm{V}}$ \\
\hline $11-15$ & $2^{\mathrm{r}}$ \\
\hline $16-19$ & $2^{\mathrm{V}}$ \\
\hline $20-27$ & $3^{\mathrm{r}}$ \\
\hline $28-31$ & $3^{\mathrm{V}}$ \\
\hline $32-37$ & $4^{\mathrm{r}}$ \\
\hline $38-43$ & $4^{\mathrm{V}}$ \\
\hline $44-48$ & $5^{\mathrm{r}}$ \\
\hline $49-54$ & $5^{\mathrm{V}}$ \\
\hline $55-59$ & $6^{\mathrm{r}}$ \\
\hline $60-64$ & $6^{\mathrm{V}}$ \\
\hline $65-73$ & $7^{\mathrm{r}}$ \\
\hline $74-78$ & $7^{\mathrm{V}}$ \\
\hline $79-84$ & $8^{\mathrm{r}}$ \\
\hline $85-92$ & $8^{\mathrm{V}}$ \\
\hline $93-97$ & $9^{\mathrm{r}}$ \\
\hline $98-101$ & $9^{\mathrm{V}}$ \\
\hline $102-103$ & $10^{\mathrm{r}}$ \\
\hline $104-105$ & $10^{\mathrm{V}}$ \\
\hline $106-111$ & $11^{\mathrm{r}}$ \\
\hline $112-118$ & $11^{\mathrm{V}}$ \\
\hline $119-120$ & $12^{\mathrm{r}}$ \\
\hline $121-123$ & $12^{\mathrm{V}}$ \\
\hline $124-129$ & $13^{\mathrm{r}}$ \\
\hline $130-136$ & $13^{\mathrm{V}}$ \\
\hline $137-142$ & $14^{\mathrm{r}}$ \\
\hline 143 & $14^{\mathrm{V}}$ \\
\hline $144-149$ & $15^{\mathrm{r}}$ \\
\hline $150-157$ & $15^{\mathrm{V}}$ \\
\hline $158-163$ & $16^{\mathrm{r}}$ \\
\hline $164-169$ & $16^{\mathrm{V}}$ \\
\hline $170-174$ & $17^{\mathrm{r}}$ \\
\hline $175-180$ & $17^{\mathrm{V}}$ \\
\hline $181-186$ & $18^{\mathrm{r}}$ \\
\hline & \\
\hline
\end{tabular}

\begin{tabular}{|c|c|}
\hline Nr. & fol. \\
\hline $187-194$ & $18^{\mathrm{V}}$ \\
\hline $195-199$ & $19^{\mathrm{r}}$ \\
\hline $200-205$ & $19^{\mathrm{V}}$ \\
\hline $206-212$ & $20^{\mathrm{r}}$ \\
\hline $213-220$ & $20^{\mathrm{V}}$ \\
\hline $221-227$ & $21^{\mathrm{r}}$ \\
\hline $228-234$ & $21^{\mathrm{V}}$ \\
\hline $235-240$ & $22^{\mathrm{r}}$ \\
\hline $241-244$ & $22^{\mathrm{V}}$ \\
\hline $245-249$ & $23^{\mathrm{r}}$ \\
\hline $250-254$ & $23^{\mathrm{V}}$ \\
\hline $255-260$ & $24^{\mathrm{r}}$ \\
\hline $261-264$ & $24^{\mathrm{V}}$ \\
\hline $265-271$ & $25^{\mathrm{r}}$ \\
\hline $272-277$ & $25^{\mathrm{V}}$ \\
\hline $278-285$ & $26^{\mathrm{r}}$ \\
\hline $286-289$ & $26^{\mathrm{V}}$ \\
\hline $290-294$ & $27^{\mathrm{r}}$ \\
\hline $295-301$ & $27^{\mathrm{V}}$ \\
\hline $302-308$ & $28^{\mathrm{r}}$ \\
\hline $309-314$ & $28^{\mathrm{V}}$ \\
\hline $315-319$ & $29^{\mathrm{r}}$ \\
\hline $320-326$ & $29^{\mathrm{V}}$ \\
\hline $327-332$ & $30^{\mathrm{r}}$ \\
\hline $333-339$ & $30^{\mathrm{V}}$ \\
\hline $340-345$ & $31^{\mathrm{r}}$ \\
\hline $346-352$ & $31^{\mathrm{V}}$ \\
\hline $353-360$ & $32^{\mathrm{r}}$ \\
\hline $361-367$ & $32^{\mathrm{V}}$ \\
\hline $368-370$ & $33^{\mathrm{r}}$ \\
\hline $371-373$ & $33^{\mathrm{V}}$ \\
\hline $374-379$ & $34^{\mathrm{r}}$ \\
\hline $380-382$ & $34^{\mathrm{V}}$ \\
\hline $383-387$ & $35^{\mathrm{r}}$ \\
\hline $388-394$ & $35^{\mathrm{V}}$ \\
\hline & \\
\hline
\end{tabular}

\begin{tabular}{|c|c|}
\hline Nr. & fol. \\
\hline 395 & $36^{\mathrm{r}}$ \\
\hline $396-398$ & $36^{\mathrm{V}}$ \\
\hline $399-403$ & $37^{\mathrm{r}}$ \\
\hline $404-407$ & $37^{\mathrm{V}}$ \\
\hline $408-415$ & $38^{\mathrm{r}}$ \\
\hline $416-422$ & $38^{\mathrm{V}}$ \\
\hline $423-430$ & $39^{\mathrm{r}}$ \\
\hline $431-433$ & $39^{\mathrm{V}}$ \\
\hline $434-438$ & $40^{\mathrm{r}}$ \\
\hline $439-442$ & $40^{\mathrm{V}}$ \\
\hline $443-448$ & $41^{\mathrm{r}}$ \\
\hline $449-452$ & $41^{\mathrm{V}}$ \\
\hline $453-455$ & $42^{\mathrm{r}}$ \\
\hline $456-459$ & $42^{\mathrm{V}}$ \\
\hline $460-468$ & $43^{\mathrm{r}}$ \\
\hline $469-474$ & $43^{\mathrm{V}}$ \\
\hline $475-479$ & $44^{\mathrm{r}}$ \\
\hline $480-486$ & $44^{\mathrm{V}}$ \\
\hline $487-489$ & $45^{\mathrm{r}}$ \\
\hline $490-495$ & $45^{\mathrm{V}}$ \\
\hline $496-502$ & $46^{\mathrm{r}}$ \\
\hline $503-508$ & $46^{\mathrm{V}}$ \\
\hline $509-516$ & $47^{\mathrm{r}}$ \\
\hline $517-524$ & $47^{\mathrm{V}}$ \\
\hline $525-530$ & $48^{\mathrm{r}}$ \\
\hline $531-533$ & $48^{\mathrm{V}}$ \\
\hline $534-538$ & $49^{\mathrm{r}}$ \\
\hline $539-540$ & $49^{\mathrm{V}}$ \\
\hline $541-547$ & $50^{\mathrm{r}}$ \\
\hline $548-554$ & $50^{\mathrm{V}}$ \\
\hline $555-558$ & $51^{\mathrm{r}}$ \\
\hline $559-565$ & $51^{\mathrm{v}}$ \\
\hline $566-570$ & $52^{\mathrm{r}}$ \\
\hline $571-575$ & $52^{\mathrm{V}}$ \\
\hline $576-578$ & $53^{\mathrm{r}}$ \\
\hline
\end{tabular}




\section{Anhang II: Kurzbiografien der wichtigsten Beteiligten}

Alarcon, Hernando De: (* 1466 Palomares de Huete, $\uparrow 1540$ Castelnovo) War schon bei der Eroberung von Granada 1492 dabei und ging mit Gonzalo de Córdoba nach Neapel. Nach einem Zwischenspiel in Nordafrika zog er mit Cardona 1511 nach Norditalien und geriet 1512 bei Ravenna in Gefangenschaft. Nach der Schlacht von Pavia brachte er den französischen König als Gefangenen nach Spanien und machte auch die anschließenden Feldzüge in Italien mit. Nach der Eroberung von Tunis 1536 wurde er Vizekönig von Sizilien.

ANHALT, Rudolf Von: $(* 1466, \uparrow 1510$ Verona) Studierte vermutlich in Mainz und begab sich unmittelbar darauf an den Hof Maximilians von Österreich. 1486 war er bei dessen Krönung zum römischen König in Aachen dabei und von da an als Diplomat und Feldherr in den Diensten Maximilians in ganz Europa unterwegs. 1510 führte er die kaiserliche Abteilung im Krieg der Liga von Cambrai.

Belgioioso, LUdovico BARBiAnO Di: $(* 1488, \uparrow 1530)$ Nahm auf der Seite der Franzosen am Krieg der Liga von Cambrai Teil. Nach der Schlacht von Melegnano ging er nach Frankreich, war nach dem Ausbruch des Krieges 1521 zunächst beim Feldzug in den Pyrenäen dabei, dann in Italien. Nach der Schlacht von Pavia war er wieder in Frankreich zu finden, die Bedrohung seiner Besitzungen in der Lombardei aber ließen ihn den Abschied beantragen. Als dieser abgelehnt wurde, setzte er sich unter dem Vorwand einer Duellforderung nach Italien ab und bot seine Dienste zunächst vergeblich Venedig an. 1527 wechselte er zu den Spaniern, geriet bei der Eroberung von Pavia durch die Franzosen in Gefangenschaft, war aber im folgenden Jahr schon wieder im Einsatz. 1529 war er Berater des Kaisers bei den Verhandlungen von Bologna.

BemelberG, KonRAD von: $(* 1494, \uparrow 1567$ Schelkingen) Gewann im Krieg des Schwäbischen Bundes Frundsbergs Vertrauen und wurde nach Teilnahme am Krieg in Italien 1526 sein Stellvertreter und, nach dessen Schlaganfall auf dem Zug nach Rom, Generalhauptmann der Landsknechte. 1529 führte er die Deutschen bei der Belagerung von Florenz, 1531 gegen die Türken in Ungarn. 1537 findet man ihn in den Niederlanden, 1544 auf dem Zug gegen Frankreich, 1546 auf kaiserlicher Seite im Schmalkaldischen Krieg und 1551 wieder in den Niederlanden.

Bonnivet, Guillaume Gouffier, Seigneur DE: $(* 1488, \uparrow 1525$ vor Pavia) Tat sich zuerst 1507 bei der französischen Strafexpedition nach Genua hervor. Nach der Schlacht von Melegnano im Jahr 1515 wurde er Admiral von Frankreich. 1519 findet man ihn auf Gesandtschaftsreisen nach England und Deutschland, wo er vergeblich die Wahl von Franz I. zum Kaiser betrieb. 1521 bekämpfte er zunächst die Spanier in den Pyrenäen, wurde dann 1523 an der Spitze eines Heeres nach Italien geschickt, wo ihm eine Reihe von militärischen Misserfolgen beschieden war. In der Schlacht von Pavia kam er ums Leben.

Bourbon, Charles de: $(*$ 1490, $† 1527$ vor Rom $)$ War schon 1507 bei der französischen Strafexpedition gegen Genua und 1509 bei Agnadello dabei. 1514 wurde er zum Connetable von Frankreich und 1516 zum Gouverneur von Mailand ernannt. Ab 1521 begann eine Kampagne bei Hof gegen ihn, in deren Verlauf man ihm sein Kommando entzog. Nachdem die Güter seiner Frau nach deren Tod 1523 der Krone zugeschlagen worden waren, wechselte er in die Dienste des Kaisers und nahm auf dessen Seite 
am Krieg in Italien und am Zug in die Provence Teil. Nach der Schlacht von Pavia und einem Aufenthalt in Spanien wurde er 1526 erneut Gouverneur von Mailand, diesmal für den Kaiser, und Generalhauptmann von dessen Heer in Italien. Beim Sturm auf Rom kam er durch den legendären Arkebusenschuss ums Leben.

BRAUnSCHWEIG-LÜNEBURG-WOLFENbÜTTEL, HeINRICH, HERZOG VON: $(* 1489$ * $† 1568)$ Trat 1514 die Nachfolge seines Vaters an. Nach seiner Niederlage in der Hildesheimer Stiftsfehde 1519 erlangte er die Gunst von Karl V. Nach Teilnahme am Bauernkrieg führte er 1528 ein eigenes Heer nach Italien, das sich allerdings schon nach wenigen Monaten durch massenhafte Desertion der Landsknechte auflöste, ohne erwähnenswerte Leistungen vollbracht zu haben. Als entschlossener Gegner der Reformation wurde er 1542 aus seinem Land vertrieben, geriet 1545 beim Versuch der Rückkehr in Gefangenschaft und musste bis zur Niederlage des Schmalkaldischen Bundes im Jahr 1547 warten, um sein Land wieder in Besitz nehmen zu können.

Caracciolo, Marino: (* 1469 Neapel, † 1538 Mailand) Befand sich seit 1484 im Gefolge von Kardinal Ascanio Sforza. Bis 1505 war er mit diesem auf zahlreichen Reisen unterwegs und verbrachte unter anderem zwei Jahre - von 1500 bis 1502 - in französischer Gefangenschaft. 1513 wurde er zum Botschafter des Herzogs von Mailand beim Papst ernannt, und 1518 zum päpstlichen Nuntius beim Kaiser. Er folgte dem Hof Karls V. in den folgenden Jahren nach Flandern und Spanien; 1524 wurde er dessen Botschafter beim Herzog von Mailand. Nach einigen Legationsreisen nach Venedig wurde er zusammen mit Antonio de Leyva Gouverneur von Mailand und 1530 wiederum Botschafter des Kaisers beim wieder eingesetzten Herzog Francesco Sforza. Der Kaiser erwirkte 1535 seine Ernennung zum Kardinal, 1536 wurde er ein weiteres Mal Gouverneur von Mailand in der Nachfolge des verstorbenen de Leyva.

Cardona, RAMón FOLCH DE: (* Bellpuig, † 1522 Neapel) War mit Gonzalo de Córdoba auf den Feldzügen in Neapel dabei, anschließend im Seekrieg gegen Berber und Türken. 1507 wurde er Vizekönig von Sizilien und zwei Jahre später Vizekönig von Neapel. Ab 1511 war er Oberbefehlshaber des spanischen Heeres auf den Feldzügen in Norditalien. Nach seiner Rückkehr nach Neapel im Jahr 1515 widmete er sich bis zu seinem Tod den dortigen Staatsgeschäften.

Colonna, Pompeo: (* 1479 Rom, † 1532 Neapel) Wurde 1501 von Papst Alexander VI. enteignet und so ins Lager der Spanier getrieben. Er nahm zunächst im Gefolge von Gonzalo de Córdoba an den Feldzügen in Neapel Teil. Sein Onkel Prospero drängte ihn zur kirchlichen Karriere, diese wurde immer wieder von der Teilnahme an militärischen Aktionen unterbrochen. 1516 erhielt er die Kardinalswürde und wurde trotz seiner Gegnerschaft zur Wahl von Clemens VII. im Jahr 1524 Vizekanzler. 1526 kam es zum Bruch mit dem Papst und zur Teilnahme am Krieg gegen diesen auf der Seite des Kaisers. 1527 erfolgte die Aussöhnung im besetzten Rom. 1528 war er im Krieg um das Königreich Neapel dabei und wurde später Stellvertreter von Philibert von Oranges während dessen Abwesenheit bei der Belagerung von Florenz.

Colonna, Prospero: $(* \sim 1460$ Lavinio, $\uparrow 1523$ Mailand) War bereits 1484 als Soldat in den Diensten von Papst Innozenz VIII. 1495 befand er sich für kurze Zeit im Gefolge von Karl VIII. von Frankreich, fiel aber noch vor dessen Rückzug aus Italien von ihm ab. Er machte die Feldzüge von Gonzalo de Córdoba in Neapel mit und stieß nach der Niederlage von Ravenna im Jahr 1512 zum Heer von Car- 
dona. 1521 bekam er das Oberkommando über das kaiserliche Heer und hatte entscheidenden Anteil an den militärischen Erfolgen der nächsten beiden Jahre.

FRUNDSBERG, GEORG VON: (* 1473 Mindelheim, † 1528 Mindelheim) Nahm 1499 am Reichskrieg gegen die Schweiz Teil und kam unmittelbar darauf mit einem kaiserlichen Kontingent zur Unterstützung des Herzogs von Mailand nach Italien. Nach einem Aufenthalt in den Niederlanden kämpfte er ab 1509 mit einer kurzen Unterbrechung erneut in Italien für das Reich. Die folgenden Jahre führten ihn in den Krieg gegen Herzog Ulrich von Württemberg und anschließend in die Picardie. Ab 1522 war er dann wieder in Italien und nahm an den Schlachten von La Bicocca und Pavia Teil. Im Bauernkrieg 1525 war er vor allem als Vermittler tätig und führte im folgenden Jahr erneut ein Heer nach Italien. Bei einer Revolte der Landsknechte auf dem Weg nach Rom erlitt er vor Aufregung einen Schlaganfall und blieb gelähmt in Ferrara zurück. 1528 kehrte er schwer krank nach Hause zurück und starb unmittelbar darauf.

Gattinara, Giovanni Bartolomeo di: $(* \sim 1480$ Vercelli, $\uparrow 1544$ Vercelli) Tauchte 1519 am Hof des Kaisers als Berater auf, nachdem sein Verwandter Mercurino ein Jahr zuvor dort Großkanzler geworden war. 1522 kam er im Gefolge des Vizekönigs Lannoy nach Neapel. Nach mehreren Legationsreisen nach Rom und einem Aufenthalt in Spanien wurde er 1526 mit Bourbon als Kommisar des Heeres erneut nach Italien geschickt. Bei den Verhandlungen mit dem Papst im besetzten Rom war er eine der Ausschlag gebenden Persönlichkeiten. Unmittelbar darauf wurde er zum Gouverneur von Parma und Piacenza ernannt, konnte die Städte aber nicht für den Kaiser in Besitz nehmen und begab sich nach Genua, wo er durch einen Angriff der Franzosen zur Flucht gezwungen wurde. Nach dem Ende des Krieges war er kurz als Berater im Herzogtum Mailand tätig. Von 1530 bis 1532 weilte er in Deutschland und war danach bis zu seinem Tod Berater des Herzogs von Savoyen.

GonZaga, Ferrante: $(* 1507, \dagger 1557)$ War 1527 auf dem Zug nach Rom und auf den anschließenden Feldzügen in Neapel dabei. 1530 wurde er nach dem Tod von Oranges Kommandant des Belagerungsheeres vor Florenz. Nach der Expedition nach Tunis 1535 wurde er zum Vizekönig von Sizilien ernannt. Im folgenden Jahr nahm er am Zug in die Provence Teil. Nach einem Aufenthalt in Deutschland führte er für seinen minderjährigen Neffen die Staatsgeschäfte in Mantua. 1544 führte er das kaiserliche Heer nach Frankreich und trat zwei Jahre später die Nachfolge von Guasto als Gouverneur in Mailand an. Wegen anschließender Misserfolge wurde 1554 ein Verfahren gegen ihn eingeleitet, in dessen Folge er durch Alvaro de Toledo ersetzt wurde. Kurz vor dem Tod des Kaisers söhnte er sich mit diesem aus und nahm am Feldzug Philipps II. gegen Frankreich Teil, auf dem er starb.

Guasto, Alfonso D'Avalos, Markgraf von: (* 1502 Ischia, † 1546 Vigevano) Auch Vasto genannt. War als Cousin von Pescara mit diesem in der Schlacht von La Bicocca und auf dem Zug in die Provence dabei. 1525 wurde er Generalhauptmann der spanischen Infanterie. Auf dem Zug nach Rom verließ er das Heer auf Grund von religiösen Skrupeln, stieß aber später wieder dazu. In der Seeschlacht von Capo d'Orso im Golf von Salerno geriet er 1528 in Gefangenschaft, nahm aber im folgenden Jahr schon wieder am Krieg gegen Florenz Teil. 1535 kommandierte er die Expedition gegen Tunis und war 1536 einer der Protagonisten auf dem Zug in die Provence. 1538 wurde er nach dem Tod von Caracciolo Gouverneur in Mailand, fiel aber auf Grund zahlreicher Beschwerden in Ungnade und starb, bevor er sich rechtfertigen konnte. 
LANNOY, Charles de: (* 1487 Valenciennes, $† 1527$ Gaeta) Wurde zusammen mit Karl V. erzogen und war mit diesem befreundet. 1521 wurde er Gouverneur von Tournai und im Jahr darauf als Nachfolger Cardona Vizekönig von Neapel. Er beteiligte sich an den Kriegen in der Lombardei und begleitete Franz I. in die Gefangenschaft nach Spanien. Nach seiner Rückkehr führte er den Krieg gegen den Papst mit dem neapolitischen Heer zusammen mit den Truppen der Colonna fort und traf mit einiger Verspätung 1527 in Rom ein, wo er an der Epidemie erkrankte, die sein Leben kurz darauf beendete.

LAUTReC, Odet DE FoIX, SEIGNEUR DE: († 1528 vor Neapel) 1511 kam er zum ersten Mal mit Ludwig XII. nach Italien und nahm im folgenden Jahr an der Schlacht von Ravenna und 1515 an der von Melegnano Teil. 1516 wurde er Oberbefehlshaber des französischen Heeres in Italien. Nach der vergeblichen Verteidigung der Lombardei 1521 kämpfte er zunächst in den Pyrenäen gegen Spanien und war erst 1525 zur Schlacht von Pavia wieder in Italien. 1527 wurde er mit der Führung eines neuen Zuges nach Italien beauftragt, nach einigen Erfolgen in der Lombardei wurde sein Heer jedoch bei der Belagerung von Neapel von einer Epidemie dezimiert, die auch ihn nicht aussparte.

Leyva, Antonio DE: (* 1480, † 1536 Aix-en-Provence) Nahm an den Feldzügen von Gonzalo de Córdoba in Neapel Teil und war unter Ramón de Cardona ab 1511 Hauptmann. Zwischen Oktober 1524 und Februar 1525 machte er sich einen Namen als Verteidiger von Pavia gegen die Franzosen. Nach Bourbons Abzug wurde er 1527 Gouverneur von Mailand und Oberbefehlshaber des Besatzungsheeres in der Lombardei. Nach dem Ende der Besatzung nahm er 1532 an der Verteidigung von Wien gegen die Türken und 1535 an der Expedition nach Tunis Teil. Er starb 1536 auf dem Zug in die Provence.

LODRON, LUDWIG VON: (* 1484 Lodron, $† 1538$ Esseg) Nahm schon in den Diensten von Kaiser Maximilian I. an den Kriegen in Italien Teil. 1525 kämpfte er zusammen mit seinem Schwager Frundsberg in der Schlacht von Pavia. Nachdem in Italien Frieden eingekehrt war, kämpfte er seit 1532 im Krieg gegen die Türken, in dem er 1538 in Slawonien in Gefangenschaft geriet und hingerichtet wurde.

Maramaldo, Fabrizio: $(* \sim 1495, \dagger \sim 1555)$ Tauchte nach $1521 \mathrm{im}$ Gefolge von Prospero Colonna in der Lombardei auf, wo er an allen Feldzügen Teil nahm. Mit seinen vor allem in Kalabrien rekrutierten Kompanien terrorisierte er die Bevölkerung dermaßen, dass sein Name zum Begriff für rücksichtslos marodierende Soldateska wurde. Nach dem Abzug aus Rom folgte er dem Heer nach Neapel, wo er zwischenzeitlich unschuldig des Verrats angeklagt wurde. Im Krieg gegen Florenz war er ebenso dabei wie bei der Verteidigung von Wien gegen die Türken und der Expedition nach Tunis. In den folgenden Jahren verliert sich seine Spur.

NÁJERA, FERNANdo de MARín, ABT VON: († 1527 Rom) War von 1507 bis 1511 Abt von Santa Maria la Real in der Nachfolge seines Onkels Pablo Martinez de Uruñuela in Nájera. Danach weilte er unter anderem in Rom. 1521 wurde er zum Generalkommissar des kaiserlichen Heeres ernannt, ein Posten, den er bis zu seinem Tod an der Epidemie im eroberten Rom innehatte.

NAvarro, Pedro: $(* \sim 1460$ Garde, $† 1528$ Neapel $)$ Brach schon als Heranwachsender mit genuesischen Kaufleuten aus Abenteuerlust nach Italien auf und nahm dort an verschiedenen Kriegen Teil, wo er erste Erfahrungen im Umgang mit Minen sammelte. Danach war er einige Jahre lang mit der Piratenbekämpfung im Mittelmeer beschäftigt und begab sich nach einer Verletzung in die Dienste von Golnzalo de Córdoba, wo er sich den Ruf als größter Belagerungsexperte seiner Zeit erwarb. Nach Aufenthalten in Spanien und Nordafrika traf er 1512 wieder in Italien bei Cardonas Heer ein. In der Schlacht 
von Ravenna geriet er in Gefangenschaft, wurde nach Frankreich gebracht und wechselte dort in den Dienst des französischen Königs. 1522 fiel er in Genua den Spaniern in die Hände und blieb bis zum Frieden von Madrid im Jahr 1526 in Gefangenschaft. Schon im folgenden Jahr war er wieder mit Lautrec auf dem Weg nach Italien, geriet aber 1528 nach dem Untergang des französischen Heeres auf dem Rückzug von Neapel erneut in Gefangenschaft, wo er unmittelbar darauf starb.

MonCAdA, Hugo DE: $(* \sim 1460, \uparrow 1528$ Capo d'Orso $)$ War bereits 1496 auf dem Zug gegen Frankreich im Roussillon dabei und dann mit Gonzalo de Córdoba in Neapel. 1521 nahm er an der Belagerung von Tournai Teil und wurde 1522 Vizekönig von Sizilien. Auf dem Zug in die Provence geriet er 1524 in französische Gefangenschaft und wurde 1526 nach dem Frieden von Madrid wieder freigelassen. Er zog zunächst mit Bourbon nach Mailand und kommandierte anschließend die neapolitanische Armee im Krieg gegen den Papst. Nach dem Tod von Lannoy wurde er 1527 Vizekönig von Neapel und kam 1528 in der Seeschlacht von Capo d'Orso im Golf von Salerno ums Leben.

Morone, Gerolamo: (* 1470 Mailand, $\uparrow 1529$ bei Florenz) War ab 1499 in den Diensten der Franzosen in Mailand und für diese auf zahlreichen Gesandtschaftsreisen unterwegs. 1509 erfolgte seine Ernennung zum Gouverneur des von den Franzosen besetzten Brescia. 1512 wechselte er in den Dienst des von den Schweizern in Mailand eingesetzten Marionettenherzogs Massimiliano Sforza. Nach der erneuten Besetzung Mailands durch die Franzosen wurden seine Dienste zunächst weder von diesen, noch vom Kaiser in Anspruch genommen. 1521 wurde er dann Gouverneur von Mailand für den noch abwesenden Francesco Sforza. 1525 knüpfte er Verhandlungen mit den Gegnern des Kaisers an und wurde verhaftet, nachdem er versucht hatte, Pescara in eine Verschwörung hineinzuziehen. 1527 erfolgte seine Freilassung und Rehabilitierung gegen ein hohes Lösegeld. Er folgte dem kaiserlichen Heer nach Rom, Neapel und vor Florenz und wurde dessen Generalkommissar in der Nachfolge des verstorbenen Nájera.

Oranges, Philibert de Chalon, Prinz von: (* 1502 Nozeroi, † 1530 Gavinana) Kündigte Franz I. schon 1520 wegen Lehnsstreitigkeiten die Treue auf und verlor seine Besitzungen in Frankreich. 1521 hatte er bereits ein hohes Kommando in spanischen Diensten im Krieg gegen Frankreich in den Pyrenäen. 1523 fiel er bei der Überfahrt nach Italien den Gegnern des Kaisers in die Hände und blieb bis zum Frieden von Madrid im Jahr 1526 in Bourges in Gefangenschaft. Anfang 1527 stieß er zu Bourbon und wurde nach dessen Tod beim Sturm auf Rom nach anfänglichem Sträuben Generalhauptmann des Heeres, das er 1528 bei der Verteidigung von Neapel und der anschließenden Rückeroberung des Königreiches führte. Nach dem Tod von Moncada wurde er zum Vizekönig von Neapel ernannt und führte das Heer 1529 bei der Belagerung von Florenz. Wenige Monate vor dem Fall der Stadt kam er in einem Gefecht bei Gavinana ums Leben.

Pescara, Fernando Francesco d'AValos, Markgraf von: (* 1489 Neapel, $† 1525$ Mailand) Nahm mit Gonzalo de Córdoba an den Feldzügen in Neapel und später mit Cardona in Norditalien Teil, wo er 1512 in der Schlacht von Ravenna in Gefangenschaft geriet. Nach seiner Freilassung war er schon 1513 wieder beim Heer und wurde 1516 zum Generalhauptmann der spanischen Infanterie ernannt. 1523 bekam er nach dem Tod von Prospero Colonna das Kommando über das gesamte Heer, führte 1524 den Zug in die Provence an und hatte 1525 das Kommando bei der Schlacht von Pavia. Das An- 
gebot von Gerolamo Morone, sich einer neu zu formenden Liga gegen den Kaiser anzuschließen, nahm er zum Schein an, ließ Morone verhaften und das Heer in Mailand einrücken, wo er kurz darauf starb.

SCHERTLIN VON BURTENBACH, SEBASTIAN: ( * 1496 Schorndorf, $†$ 1577) Kämpfte 1519 gegen Herzog U1rich von Württemberg, 1521 gegen Frankreich und 1522 gegen die Türken. 1524 zog er auf eigene Faust nach Italien und nahm am Zug in die Provence und an der Schlacht von Pavia Teil. 1525 findet man ihn im Bauernkrieg und 1526 schon wieder in Italien, wo er mit Bourbon nach Rom zog und anschließend am Krieg in Neapel Teil nahm. 1529 kehrte er kurz nach Hause zurück, war aber schon im selben Jahr wieder am Krieg gegen die Türken beteiligt und gehörte auch 1532 zu den Verteidigern von Wien. Auf Grund seiner Aktivitäten für den Schmalkaldischen Bund musste er 1547 in die Schweiz fliehen, aus der er 1550 wegen diplomatischer Verwicklungen mit dem Kaiser ausgewiesen wurde. Nach einigen Jahren in französischen Diensten erwirkte er 1553 eine Amnestie beim Kaiser, die ihm die Rückkehr nach Deutschland und ein ruhiges Leben auf seinen Besitzungen ermöglichte.

Sforza, Francesco II, Herzog von MAIlAnd: (* 1495 Mailand, † 1535 Mailand) Verbrachte die Zeit der französischen Herrschaft in Mailand im Exil in Deutschland und wurde erst 1521 vom Kaiser als Herzog von Mailand eingesetzt, wo er im folgenden Jahr eintraf. Nach der Teilnahme am Krieg auf der Seite des Kaisers näherte er sich den Franzosen an und wurde im November 1525 von den Spaniern im Kastell von Mailand eingeschlossen. Im Juli 1526 musste er schließlich kapitulieren und kämpfte in den folgenden Jahren auf der Seite der Gegner des Kaisers, gestützt auf die von diesen besetzten Randgebiete seines Staates. 1529 erfolgte die Aussöhnung mit dem Kaiser und 1530 sein erneuter Einzug als Herzog in Mailand. Sein kinderloser Tod hatte die Einziehung des Herzogtums Mailand als erledigtes Reichslehen zur Folge.

URBINA, JUAN DE: $(* \sim 1590$ Álava, $† 1530$ Hispelo) Kämpfte zunächst in Afrika und kam dann mit Cardona nach Norditalien. Auch im folgenden Krieg war er ab 1521 wieder in Italien dabei. Schon bald war er wegen seiner Tollkühnheit bekannt, die ihn 1530 beim Sturm auf Hispelo im Krieg um Florenz das Leben kostete.

Urbino, Francesco Maria della Rovere, Herzog von: $(*$ 1490, † 1538) Übernahm 1507 die Regierung im Herzogtum Urbino. Unter seinem Onkel Julius II. war er Generalhauptmann der päpstlichen Heere im Krieg der Liga von Cambrai, fiel aber unter Leo X. in Ungnade und wurde von diesem in einen Krieg um das Herzogtum hineingezogen. Nachdem er sich als Herzog von Urbino behauptet hatte, stand er von 1523 bis 1525 in venezianischen Diensten und wurde nach dem Abschluss der Liga von Cambrai 1526 Generalhauptmann des Heeres der Liga. Seine Passivität vor allem angesichts des kaiserlichen Zuges auf Rom 1527 wurde ihm oft zum Vorwurf gemacht und mit seinem lebenslangen Hass auf die Medici begründet. Im Krieg gegen die Türken starb er 1538 so plötzlich, dass viele vermuteten, er sei vergiftet worden. 


\section{Anhang III: Karten}

Die folgenden Karten geben sozusagen eine grafische Quintessenz der militärischen Ereignisgeschichte des untersuchten Zeitraums. Die genaue Wiedergabe der Kriegszüge ist nicht immer ganz unproblematisch, da die Heere sich im Verlauf des Krieges immer weiter aufspalteten und einzelne Abteilungen oft weit im Land verstreut unterwegs waren, vor allem wenn die militärischen Aktivitäten ruhten. Die Karten dienen daher vor allem dazu, den in der Arbeit gewonnenen Erkenntnissen einen anschaulichen und übersichtlichen Hintergrund hinzuzufügen, da die Ausführungen zur Beschreibung der den Krieg begleitenden Phänomene immer wieder parallel auf Informationen von allen Kriegsschauplätzen zurückgreifen, so dass die chronologische und geografische Ordnung sich auflöst.

\section{Zeichenerklärung:}

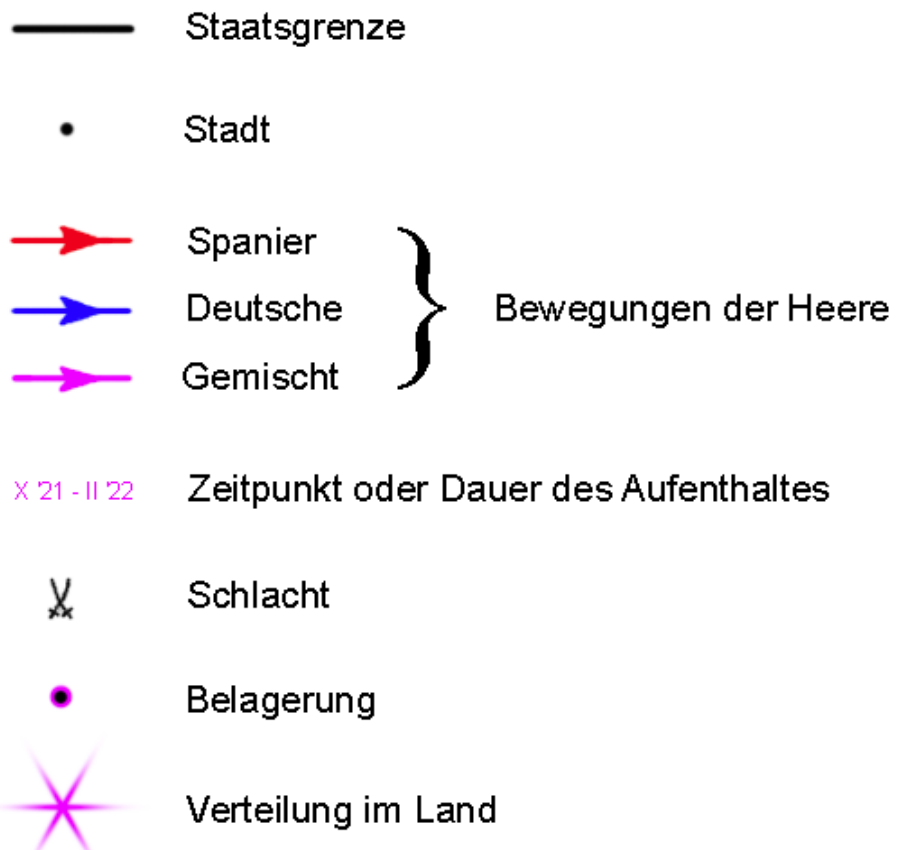


November 1511 - November 1512

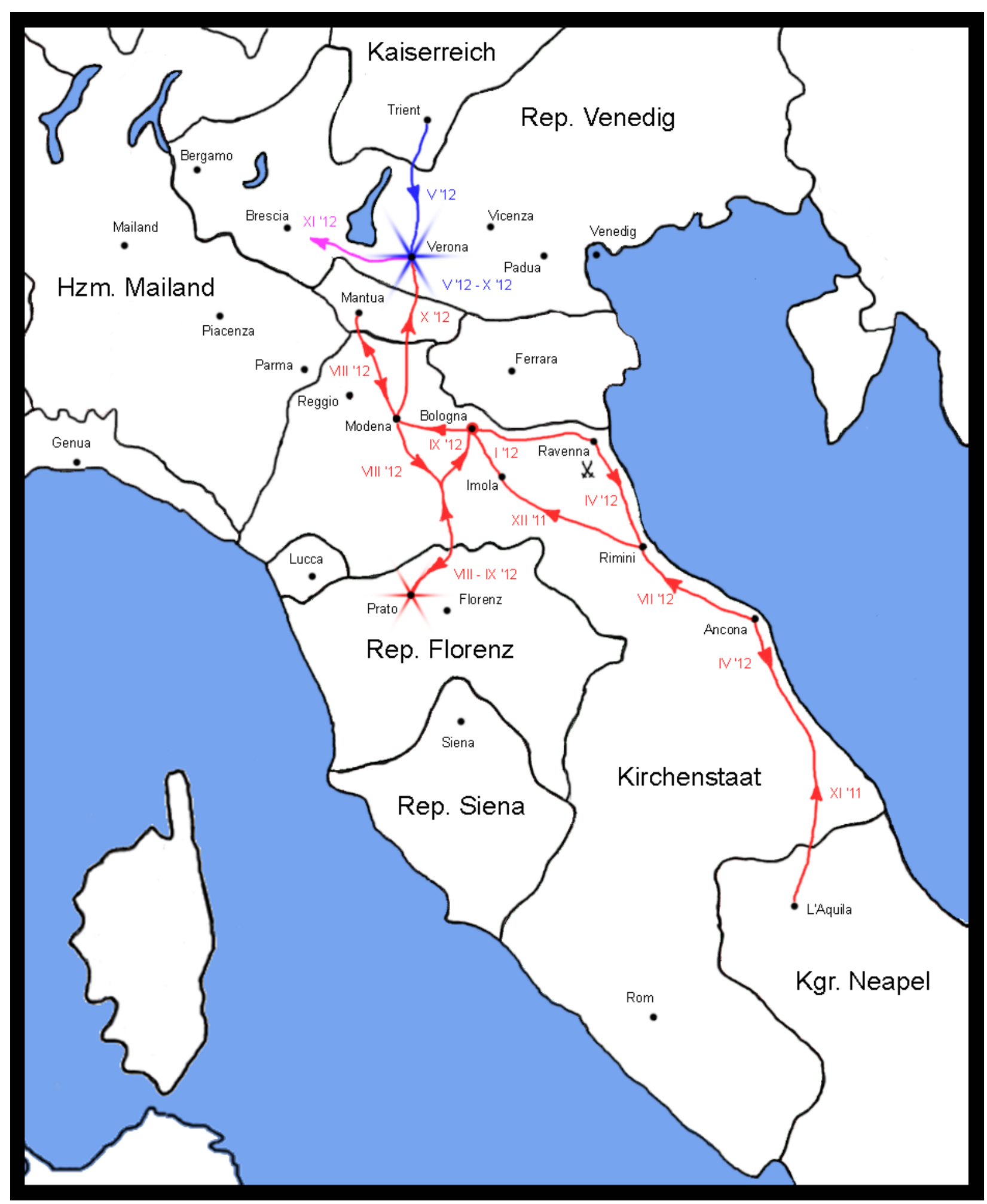


November 1512 - Oktober 1513

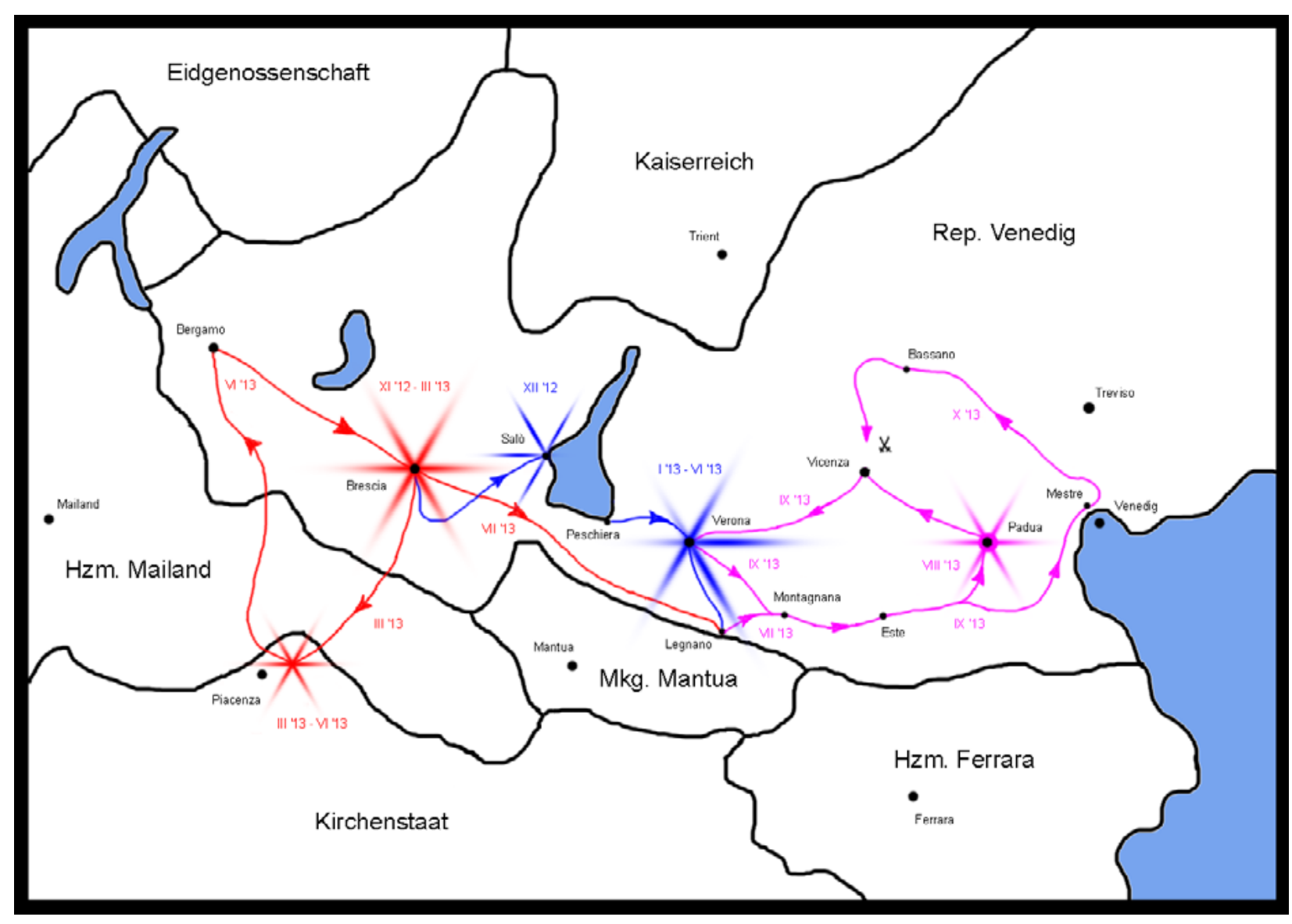


Oktober 1513 - Mai 1515

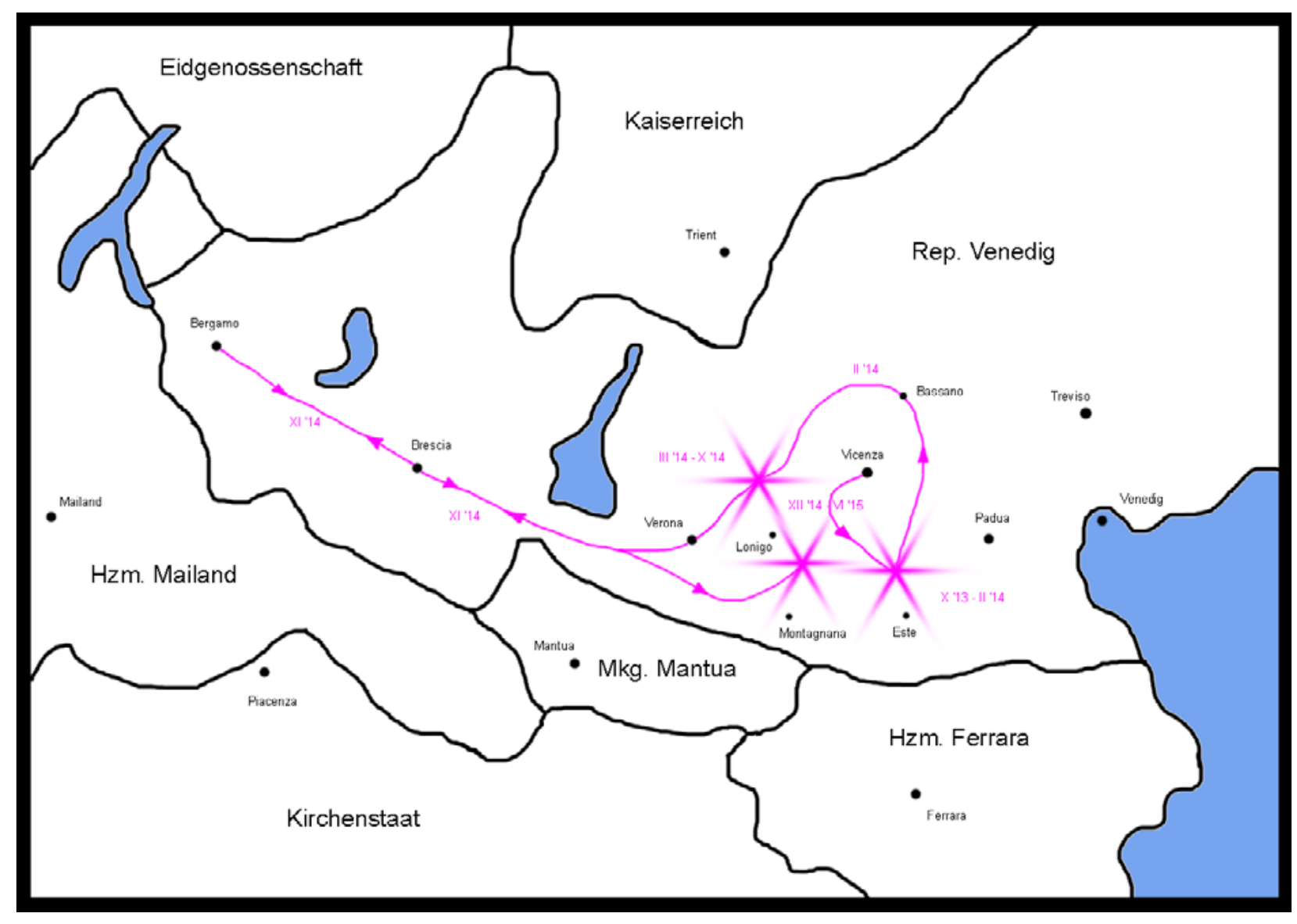


Juni 1521 - Dezember 1522

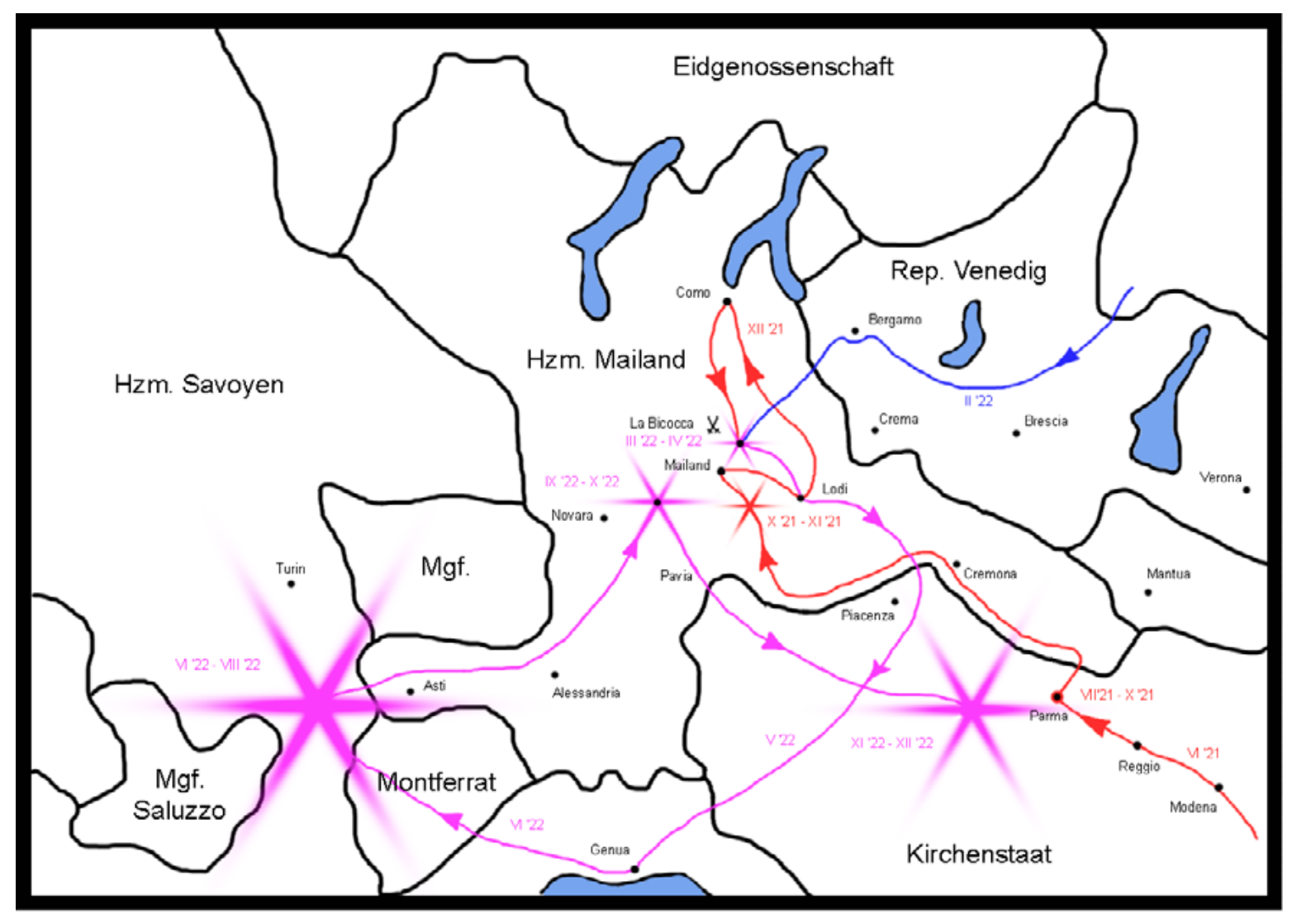


Januar 1523 - Mai 1524

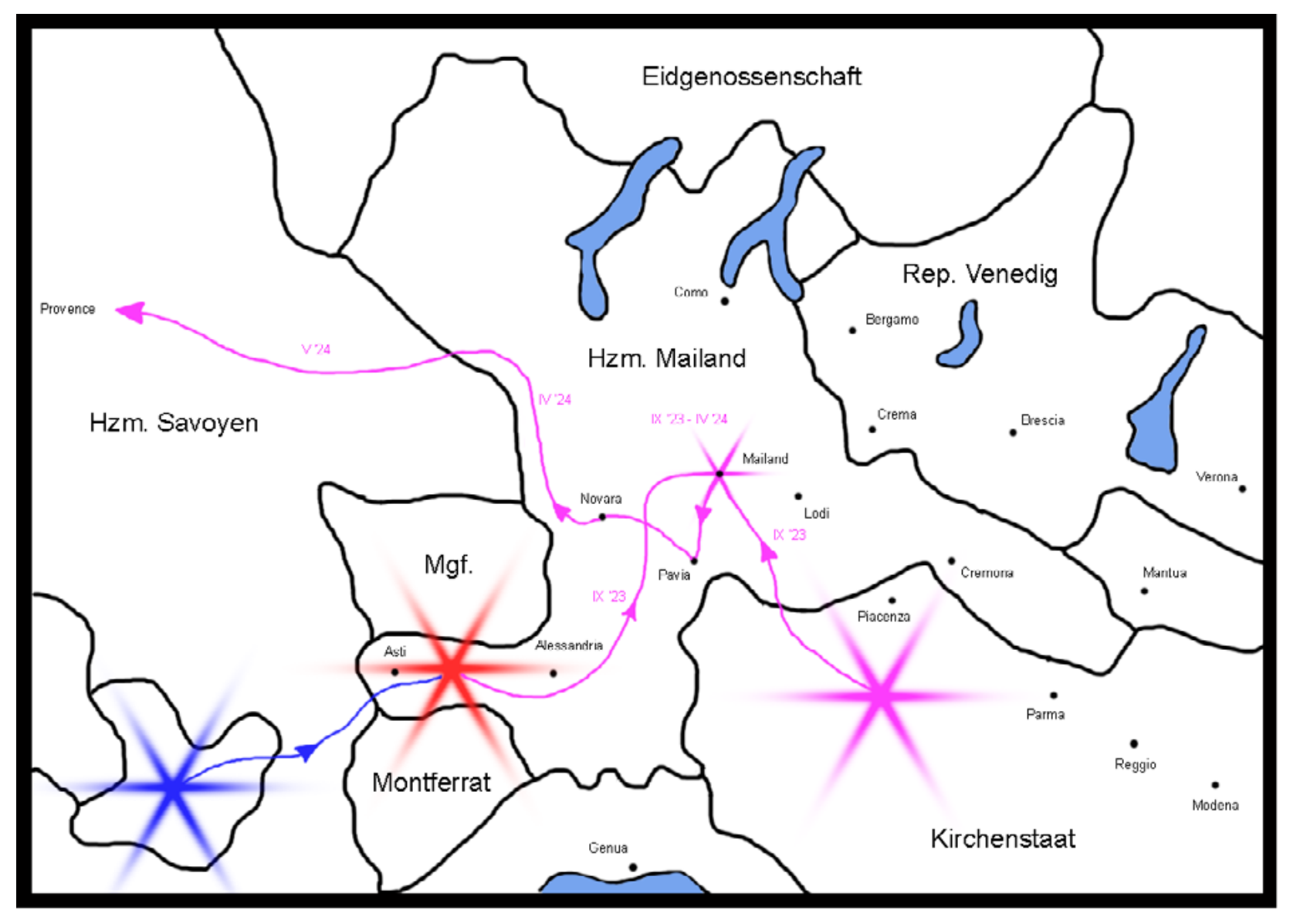


Oktober 1524 - November 1526

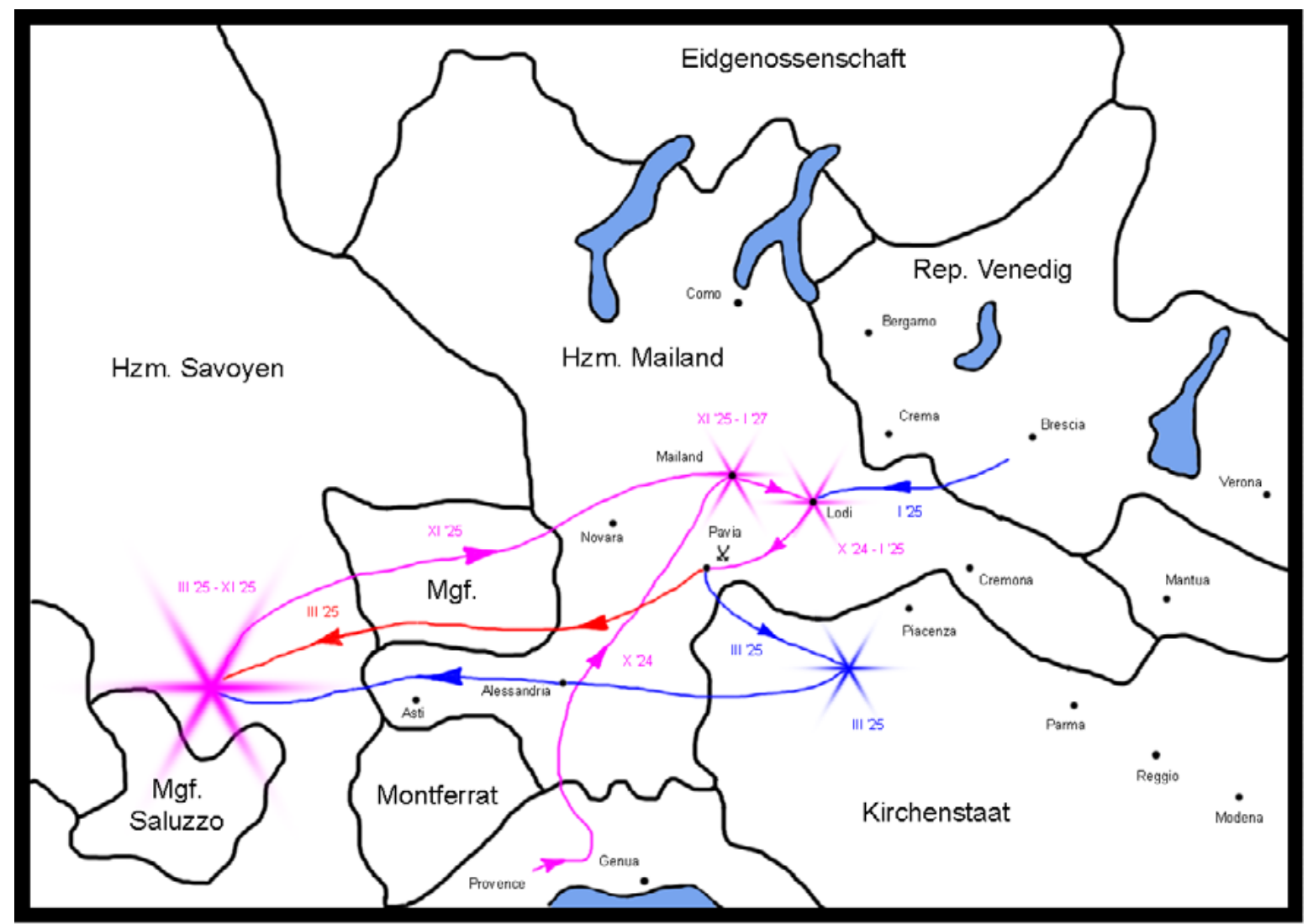


November 1526 - Februar 1528

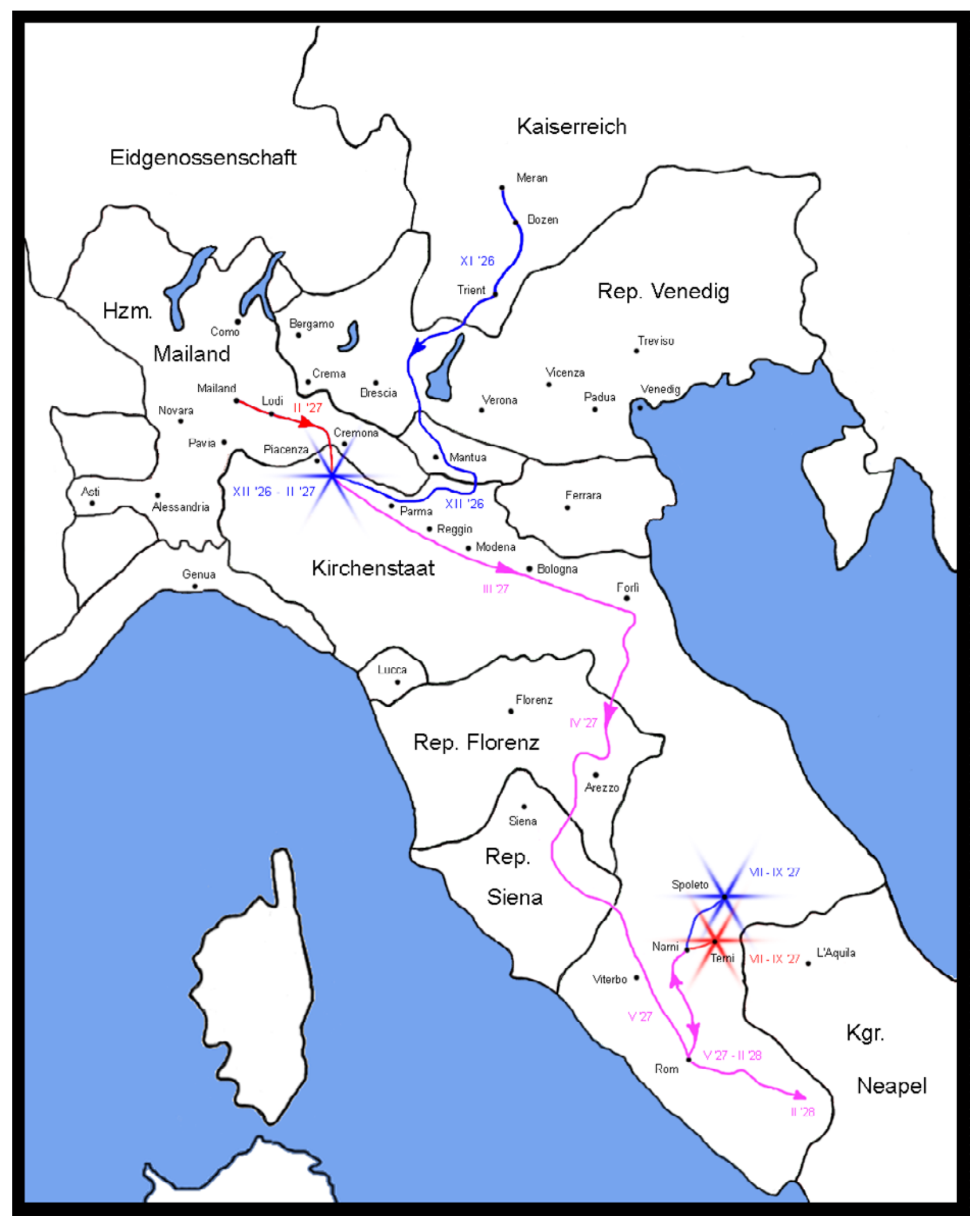


Februar 1528 - Dezember 1529

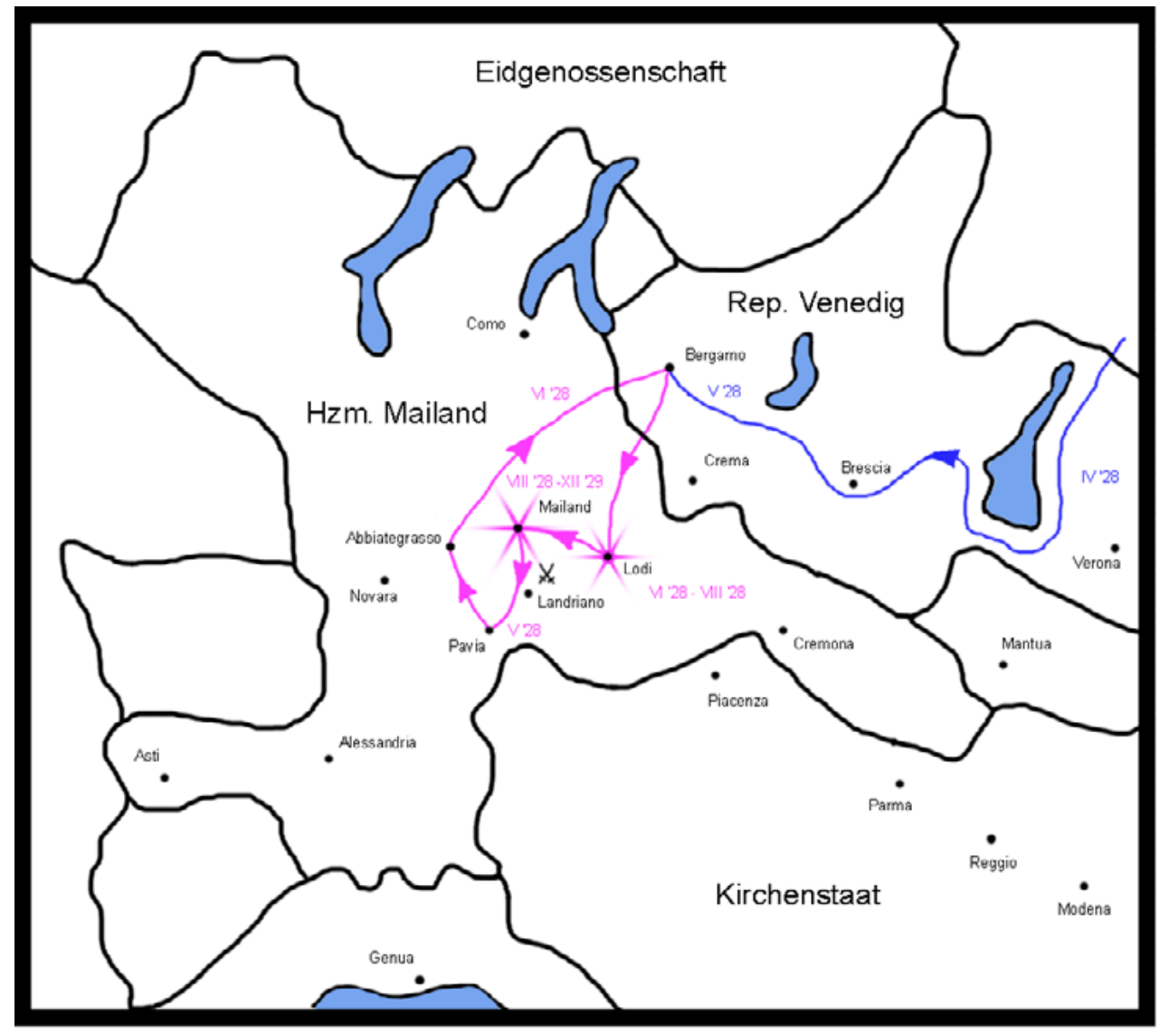

